U.S. Department of Energy and Nuclear Regulatory Commission - Advanced Fuel Cycle Research and Development Seminar Series

Fiscal Years 2007 and 2008

Nuclear Engineering Division 


\section{About Argonne National Laboratory}

Argonne is a U.S. Department of Energy laboratory managed by UChicago Argonne, LLC under contract DE-AC02-06CH11357. The Laboratory's main facility is outside Chicago, at 9700 South Cass Avenue, Argonne, Illinois 60439. For information about Argonne and its pioneering science and technology programs, see www.anl.gov.

\section{DOCUMENT AVAILABILITY}

Online Access: U.S. Department of Energy (DOE) reports produced after 1991 and a growing number of pre-1991 documents are available free via DOE's SciTech Connect (http://www.osti.gov/scitech/)

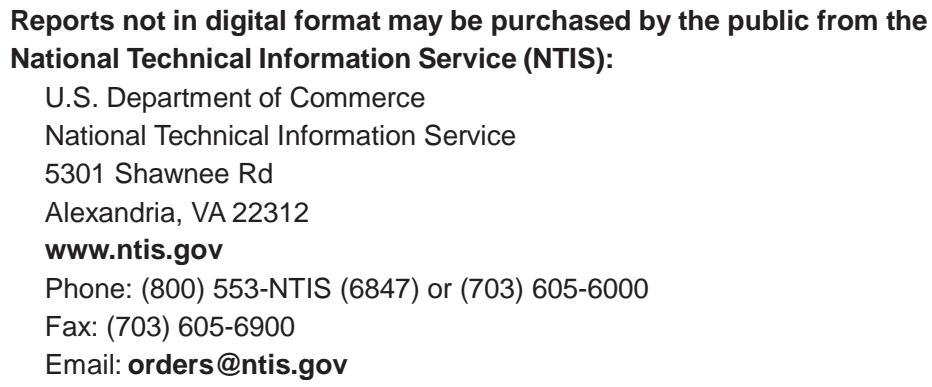

Reports not in digital format are available to DOE and DOE contractors from the Office of Scientific and Technical Information (OSTI):

U.S. Department of Energy

Office of Scientific and Technical Information

P.O. Box 62

Oak Ridge, TN 37831-0062

www.osti.gov

Phone: (865) 576-8401

Fax: (865) 576-5728

Email: reports@osti.gov

\section{Disclaimer}

This report was prepared as an account of work sponsored by an agency of the United States Government. Neither the United States Government nor any agency thereof, nor UChicago Argonne, LLC, nor any of their employees or officers, makes any warranty, express or implied, or assumes any legal liability or responsibility for the accuracy, completeness, or usefulness of any information, apparatus, product, or process disclosed, or represents that its use would not infringe privately owned rights. Reference herein to any specific commercial product, process, or service by trade name, trademark, manufacturer, or otherwise, does not necessarily constitute or imply its endorsement, recommendation, or favoring by the United States Government or any agency thereof. The views and opinions of document authors expressed herein do not necessarily state or reflect those of the United States Government or any agency thereof, Argonne National Laboratory, or UChicago Argonne, LLC. 
ANL-AFCl-238

\section{U.S. Department of Energy and Nuclear Regulatory Commission - Advanced Fuel Cycle Research and Development Seminar Series}

Fiscal Years 2007 and 2008

Compiled by

Christopher Grandy

Nuclear Engineering Division

Argonne National Laboratory

August 2008 


\section{Overview}

In fiscal year 2007, the Advanced Burner Reactor project initiated an educational seminar series for the Department of Energy (DOE) and Nuclear Regulatory Commission (NRC) personnel on various aspects of fast reactor fuel cycle closure technologies. This important work was initiated to inform DOE and NRC personnel on initial details of sodium-cooled fast reactor, separations, waste form, and safeguard technologies being considered for the Advanced Fuel Cycle Research and Development program, and to learn the important lesson from the licensing process for the Clinch River Breeder Reactor Plant that educating the NRC staff early in the regulatory process is very important and critical to a project success.

The following was the initial list of proposed training seminars from which DOE and NRC personnel could make a selection:

1. Overview and Sodium Technology Background

a. Introduction to LMR Technology; LMR experience, designs, performance, operational issues, safety issues, US and international, status. US R\&D program and experience.

b. Sodium technology, chemistry, thermal-hydraulic performance, corrosion of steel, oxidation.

2. Physics and Thermal-Hydraulics Performance

a. Fast reactor physics performance; breeding, burning, mass loadings/inventory, coolant void worth, and reactivity coefficients.

b. Fast reactor thermal-hydraulic performance; temperatures, heat fluxes, forced convection, natural circulation, etc.

3. Fuel Performance Experience

a. Fuel performance - general; metal and oxide

b. Fuel irradiation experience and results; EBR-II, FFTF

c. TREAT testing results for metal and oxide fuel

d. Fabrication \& standards history/current capabilities

4. Structures, Systems, and Components \#1

a. Major sodium component technology; pumps, heat exchangers, vessels, refueling systems design and performance, etc.

b. Structural materials for SFR technology and their performance

c. I\&C, fire protection, sodium leak detection, etc.

d. Prior and current operating experience (availability?)

5. Structures, Systems, and Components \#2

a. Control and protection systems designs and performance

b. Containment systems designs and performance

c. Seismic isolation systems and reactor applications

d. Prior and current operating experience (availability?)

6. Safety Issues \#1

a. Safety issues; DBA, BDBA, severe accident historically (coolant void, recriticality, FCI), passive safety

b. Safety analysis past results (FFTF, CRBRP, SAFR, PRISM) 
c. Safety analysis methods; reactor, structural, coolant aerosols, containment

7. Safety Issues \#2

a. Licensing issues in FFTF, CRBRP, SAFR, PRISM. International experience in perspective, high profile issues in Phenix, SuperPhenix, MONJU, BN-350, EBR-1, FERMI explained and lessons learned.

b. Inherent passive safety characteristics of sodium fast reactor systems (with respect to loss of flow without scram, etc.). Inherent reactivity shutdown, natural circulation decay heat removal

c. Safety testing results, EBR-II shutdown heat removal test, FFTF unprotected loss of flow (Gas Expansion Modules); TREAT

8. Codes, Modeling, Analyses

a. Computer Codes Used for Transient and Accident Analyses of Liquid Metal Reactors

b. Mechanistic Source Term Modeling for Liquid Metal Reactors

c. General - status of other codes, modeling, analyses; need for updating or new applications; access to data and codes, etc.

9. Licensing Strategy/Framework

a. DOE - Applicant/Licensee

- Relationship

- Responsibilities

- Contractual Requirements

b. Applicability of DOE Orders

c. NRC Regulatory Requirements

- Technical Requirements

- Material, SSC Specifications

- Safety Program

- QA Program

- Fuel Technical Criteria and Qualification

d. Recycle/Fabrication/Reactor Operations/Safety/Quality Interactions

10. Nuclear Fuel Separations Processes

a. Introduction to nuclear fuel separations and chemical processes

b. Aqueous separations processes for spent nuclear fuel treatment

- PUREX and its modifications

- UREX+ family of processes

c. Electro-chemical processing of spent nuclear fuel

d. International and domestic experience in processing of spent nuclear fuel

11. Advanced Modeling and Simulation - Overview

a. GNEP approach to advanced modeling and simulation

b. Modeling and Simulation Campaign

c. Status of FY07 work on modeling and simulation

d. Future directions in advanced modeling and simulation

12. Reactor - Advanced Modeling and Simulation

a. Advanced Modeling and Simulation $-\mathrm{T} / \mathrm{H}$ 
b. Advanced Modeling and Simulation - Structural

c. Reactor code framework

d. Neutronics modeling

13. Advanced fuel cycle safeguards:

a. Introduction and current technical basis

b. Reprocessing

c. Fuel Fabrication

d. Fast Reactor

For each of the advanced fuel cycle technologies the current state of the art in safeguards approach and technical means is discussed, followed by challenges presented by AFCI/GNEP (both physics based and rule based).

Presentation would provide a) fundamentals of technology (current and needed) and b) areas where NRC would need to address shortcomings from laboratory technical perspective (including DOE perspective).

The balance between technical content and safeguards approaches can be tailored to their needs and interest.

14. Waste Forms

a. Integrated Waste Management Strategy

b. Candidate Waste/Storage Forms from Aqueous Processing

c. Candidate Waste/Storage Forms from Electrochemical Processing

d. Current Work in Technology Development

e. Long-Term S\&T Plan and Role of Modeling and Simulation

Given the above list of seminar topics, DOE and NRC personnel selected a number of seminars that were presented to both DOE and NRC personnel in Fiscal Years 2007 and 2008. The topics and dates of the presentations are given in Table $1^{1}$.

1 The dates shown in this table are the dates the presentations were given to NRC personnel. In general, the presentations were given to DOE personnel the day prior to the NRC seminar date. 
Table 1 - FY2007 - 2008 DOE/NRC AFCRD Seminars

\begin{tabular}{|c|c|c|c|}
\hline Tag\# & Topic & Presenter & Date \\
\hline 1 & $\begin{array}{l}\text { Introduction to Fast Reactor } \\
\text { Technology - An Overview }{ }^{2}\end{array}$ & $\begin{array}{l}\text { Chris Grandy } \\
\text { James Cahalan }\end{array}$ & March 21, 2007 \\
\hline 2 & Sodium as a Fast Reactor Coolant & Thomas Fanning & May 3, 2007 \\
\hline 3 & $\begin{array}{l}\text { Fast Reactor Physics and Core } \\
\text { Design }\end{array}$ & Robert Hill & May 3, 2007 \\
\hline 4 & $\begin{array}{l}\text { Sodium Fast Reactor - Safety } \\
\text { Issues \#1 }\end{array}$ & Jim Cahalan & June 21, 2007 \\
\hline 5 & $\begin{array}{l}\text { Sodium Fast Reactor - Safety } \\
\text { Issues \#2 }\end{array}$ & Jim Cahalan & October 31, 2007 \\
\hline 6 & $\begin{array}{l}\text { SFR Fuel Performance and } \\
\text { Approach to Qualification }\end{array}$ & $\begin{array}{l}\text { Steven Hayes and } \\
\text { Douglas Porter }\end{array}$ & November 28, 2007 \\
\hline 7 & Spent Nuclear Fuel Reprocessing & Terry Todd & March 25, 2008 \\
\hline 8 & UREX+ Process Overview & Candido Pereira & March 26, 2008 \\
\hline 9 & $\begin{array}{l}\text { Electrochemical Processing of } \\
\text { Spent Nuclear Fuel }\end{array}$ & Michael Goff & March 26, 2008 \\
\hline 10 & $\begin{array}{l}\text { Overview of Systems Analysis } \\
\text { and Waste Form Campaigns }\end{array}$ & Kathryn McCarthy & April 23, 2008 \\
\hline 11 & $\begin{array}{l}\text { Waste Treatment Baseline and } \\
\text { Integrated Waste Management } \\
\text { Strategy }\end{array}$ & Dirk Gombert & April 23, 2008 \\
\hline 12 & $\begin{array}{l}\text { GNEP Waste Form Technology } \\
\text { Development }\end{array}$ & John Vienna & April 23, 2008 \\
\hline 13 & Advanced Fuel Cycle Safeguards & Michael Miller & June 10, 2008 \\
\hline
\end{tabular}

2 This presentation was removed from this report to aid in the publication clearance process. 


\section{Acknowledgement}

The participants would like to thank the U.S. Department of Energy's Global Nuclear Energy Partnership's Advanced Fuel Cycle Research and Development program for sponsoring and supporting this important work. Specifically, the seminars were hosted and sponsored by the Federal Project Director, Fast Reactors and his staff for which we are truly grateful.

In addition, we would like to thank the hard work and dedication of all the presenters who spent evenings and weekends preparing their presentation materials for this seminar series. All of the presentations were very well received by all participants. 


\section{Argonne NATIONAL LABORATORY}

... for a brighter future

i. UChicago Argonne $_{\text {uc }}$

\section{Sodium as a Fast Reactor Coolant}

Presented by

Thomas H. Fanning Nuclear Engineering Division

U.S. Department of Energy U.S. Nuclear Regulatory Commission Topical Seminar Series on Sodium Fast Reactors

May 3, 2007 


\section{Background}

- Unless new sources of energy are found, the development of nuclear power will necessarily depend on fast reactors.

- Fast reactors are not a new technology.

- Fast reactors have achieved well over 300 reactor-years of operation.

- To support effective actinide management (as envisioned by GNEP) a fast reactor must have a compact core with a minimum of materials which absorb or moderate fast neutrons. This places a significant heat transfer requirement on the coolant.

- The choice of coolant determines the main design approaches and the technical and economic characteristics of a nuclear power plant.

- Historically, this requirement has been met by the use of sodium in nearly all fast reactors constructed and operated.

- The Generation IV International Forum (GIF) identified three fast reactor concepts for potential future development: SFR, LFR, and GFR. 


\section{Objectives}

- Identify important differences between sodium and other fast reactor coolants (lead/LBE and helium) and why sodium is preferred.

- Characterize the nature of sodium interactions with air and water.

- Understand how differences between sodium and water result in broad design differences between a sodium-cooled fast reactor (SFR) and a light-water reactor. 


\section{Topics to be Covered}

- Historical Perspective on Reactor Coolants

- Coolants that have been used in the past

- Coolants for future fast reactors: sodium, lead, helium

- Comparison of Sodium with other Fast Reactor Coolant Options

- Thermophysical properties

- Material properties

- Neutronic properties

- Safety

- Cost

- Other issues

- Sodium Reactivity with Air and Water

- Impact of Coolant on SFR and LWR Differences

- Operating Pressure

- Thermal Margins

- Plant Design

- Summary 


\section{Historical Perspective on Reactor Coolants}




\section{Historical Perspective on Reactor Coolants}

- In the 1950s and 1960s, scientists and engineers considered (and in many cases built) nearly everything imaginable at the time:

- Water (light, heavy)

- Liquid-metal (NaK, sodium, lithium, mercury, rubidium, lead, bismuth, lead-bismuth, gallium, tin, etc. and numerous other alloys)

- Gas (air, argon, carbon dioxide, helium, hydrogen, nitrogen)

- Fluid Fuel (aqueous: $\mathrm{UO}_{2} /$ phosphoric acid, $\mathrm{U}\left(\mathrm{SO}_{4}\right)_{2}, \mathrm{UO}_{2} \mathrm{SO}_{4} / \mathrm{ThO}_{2}$; molten salt: $\mathrm{NaF}_{-} \mathrm{BeF}_{2}-\mathrm{UF}_{4}$, LiF-BeF${ }_{2}-\mathrm{ZrF}_{4}-\mathrm{UF}_{4} / \mathrm{FLiBe}$; liquid metal: U-Bi)

- Organic (polyphenyls/terphenyls, kerosene, Santowax)

- Combinations of coolant and moderator were also studied:

- Sodium-cooled, graphite moderated (SRE, Hallam)

- Organic-cooled, heavy water moderated (Whiteshell 1, ESSOR) 


\section{Historical Perspective on Fast Reactors}

- Data from IAEA Fast Reactor Database. Does not include submarine (S1G/S2G) or space reactors (SNAP).

- More recent fast reactors under construction:

- CEFR (China) 2008 $25 \mathrm{MW}_{\mathrm{e}}$

- PFBR (India) 2010 $500 \mathrm{MW}_{\mathrm{e}}$

- BN-800 (Russia)

- China has an ambitious vision to deploy $200 \mathrm{GWe}$ of sodium-cooled fast breeder reactors by 2050 (12\% of projected capacity).

\begin{tabular}{|c|c|c|c|}
\hline Facility & Country & $\begin{array}{c}\text { First } \\
\text { Critical }\end{array}$ & Coolant \\
\hline Clementine & USA & 1946 & Mercury \\
\hline EBR-I & USA & 1951 & NaK \\
\hline BR-2 & Russia & 1956 & Mercury \\
\hline BR-5/BR-10 & Russia & 1958 & Sodium \\
\hline DFR & UK & 1959 & $\mathrm{NaK}$ \\
\hline Fermi & USA & 1963 & Sodium \\
\hline EBR-II & USA & 1963 & Sodium \\
\hline Rapsodie & France & 1967 & Sodium \\
\hline BOR-60 & Russia & 1968 & Sodium \\
\hline SEFOR & USA & 1969 & Sodium \\
\hline KNK-II & Germany & 1972 & Sodium \\
\hline$B N-350$ & Kazakhstan & 1972 & Sodium \\
\hline Phenix & France & 1973 & Sodium \\
\hline PFR & UK & 1974 & Sodium \\
\hline FFTF & USA & 1980 & Sodium \\
\hline BN-600 & Russia & 1980 & Sodium \\
\hline JOYO & Japan & 1982 & Sodium \\
\hline FBTR & India & 1985 & Sodium \\
\hline Super-Phenix & France & 1985 & Sodium \\
\hline MONJU & Japan & 1995 & Sodium \\
\hline
\end{tabular}




\section{Historical Perspective on Sodium}

- Liquid metals in general have received the most attention for fast reactor applications because of their high thermal conductivity, indifference to radiation, and useful temperature range at low pressure.

Liquid-Metals Handbook, NAVEXOS-P-733, US Atomic Energy Commission, US Navy, US Government Printing Office, Washington DC, June 1952. (Revised in 1954)

- Sodium received so much additional attention, that a supplement to the Liquid-Metals Handbook was published in 1955

Liquid-Metals Handbook: Sodium-NaK

Supplement, USAEC Report TID-5277,

US Atomic Energy Commission, US Navy,

US Government Printing Office, Washington

DC, July 1955.

- Numerous additional reports and monographs have been published since. More recently, during the IFR program:

J. K. Fink and L. Leibowitz, "A Consistent

Assessment of the Thermophysical Properties of

Sodium," High Temperature and Materials Science, 1996.

\section{LIQUID-METALS HANDBOOK}

SODIUM-NaK SUPPLEMENT

TID 5277

-

1 JULY 1955

ATOMIC ENERGY COMMISSION • DEPARTMENT OF THE NAVY WASHINGTON, D.C. 


\section{Historical Perspective on LBE}

- In the U.S., use of lead/LBE was dismissed early mainly due to high pumping power requirements.

- A program for studying compatibility of lead, bismuth, and their alloys with structural materials existed at BNL between 1950 and 1962 as part of the Liquid Metal Fuel Reactor program.

- Focus was on development/testing of a natural U-Bi liquid metal fuel.

- An in-pile liquid-metal fuel loop was constructed and tested in the 1950s

- Recent interest in lead and LBE developed as part of their application to accelerator-driven systems as target/coolant materials.

- The only LBE-cooled reactors are those developed for the Soviet Project 705 (Alfa-class) submarines

- Modified November-class (Project 645) commissioned in 1963 to test reactors intended for Alfa-class submarines.

- Initial prototype (Project 661/Papa Class) commissioned in 1969.

- Production started in 1974, with first commissioning in 1977. Production ended in 1983 with seven vessels. 


\section{Historical Perspective on LBE (continued)}

- Two different reactor designs were used in the Alfa-class submarines: OK-550 and BM-40A.

- Significant effort invested to solve the problem of LBE corrosion.

- Detailed information on the results of Russian LBE testing is difficult to find in the literature.

- First vessel was decommissioned in 1987, with four more by 1992. At least one vessel

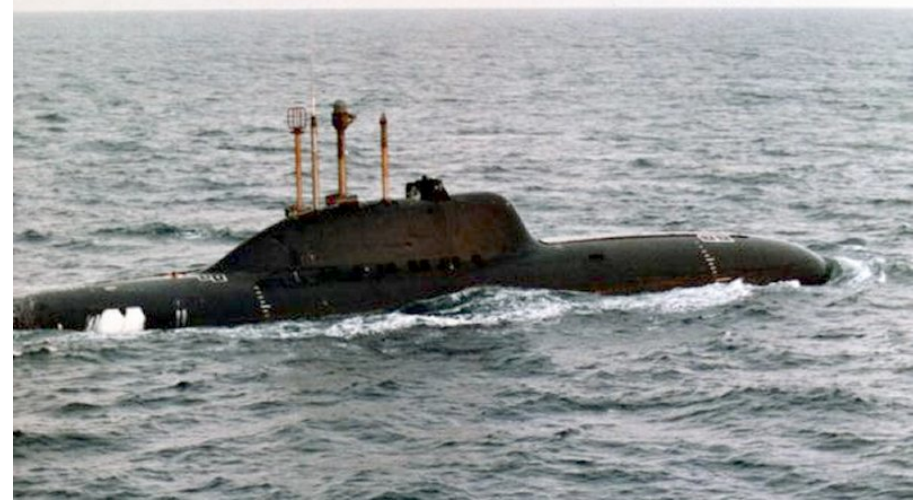

Project 705 Alfa-class Submarine was refitted with a VM-4 PWR and used for training.

- Reactors were single-use designs with HEU and a long core lifetime (up to 15 years)

- Coastal facilities were constructed to provide superheated steam during shutdown and maintenance to keep the LBE molten. These proved to be unreliable and completely broke down in the 1980s.

- Reactors were kept running even while in harbor, and significant maintenance became impossible.

- Reactor failures and coolant leaks led to a number of fatalities. 


\section{Historical Perspective on Helium}

- No gas-cooled fast reactors have ever been constructed

- GA led efforts to develop a gas-cooled fast breeder reactor in the 1970 s.

- Most early gas-cooled reactors were $\mathrm{CO}_{2}$ cooled, graphite moderated, natural uranium reactors developed primarily for plutonium production (mainly in UK and France)

- Vast majority of currently-operating gas-cooled reactors use $\mathrm{CO}_{2}$ for coolant (UK: 14 AGR, 8 Magnox)

n Helium-cooled thermal power reactors (using enriched uranium) include:

- USA: Peach Bottom 1 (1967 - 1974),

Fort St. Vrain $(1974 / 9$ - 1989)

- UK: Dragon (1966 - 1976)

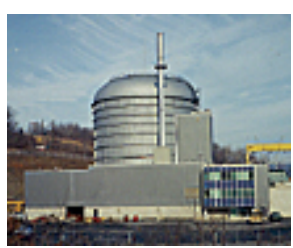

Peach Bottom

- Germany: AVR/Jülich (1967 - 1988)

THTR-300 (1985 - 1988)

- Japan: HTTR (1998/2002 - Present)

- China: HTR-10 (2000/3 - Present)
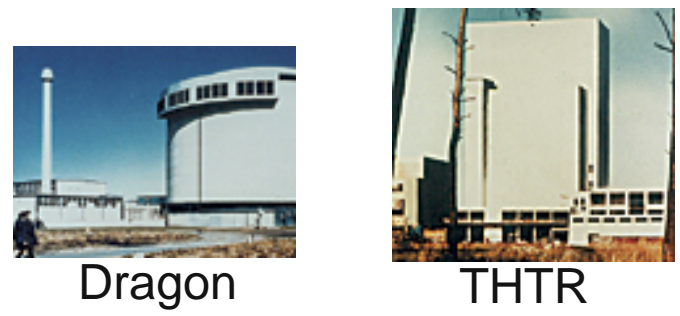


\section{Properties of Fast Reactor Coolants: Sodium, Lead/LBE, and Helium}




\section{Coolant Criteria}

- Thermophysical Properties:

- Excellent heat transfer

- Low vapor pressure

- High boiling point

- Low melting point

- Material Properties:

- Thermal stability

- Radiation stability

- Material compatibility

- Neutronic Properties:

- Low neutron absorption

- Minimal induced radioactivity

- Negligible moderation

- Support Passive Safety
Cost:

- Initial inventory

- Make up inventory

- Low pumping power

- Hazards:

- Non-toxic

- Non-reactive 


\section{Thermophysical Properties for Fast Reactor Coolants}

\begin{tabular}{lllll}
\hline & $\mathrm{Na}$ & $\mathrm{Pb}$ & $\mathrm{LBE}$ & $\mathrm{He}$ \\
\hline Atomic Weight & 22.997 & 207.21 & 208 & 4 \\
Melting Point $\left({ }^{\circ} \mathrm{C}\right)$ & 97.8 & 327.4 & 123.5 & $\mathrm{n} / \mathrm{a}$ \\
Boiling Point $\left({ }^{\circ} \mathrm{C}\right)$ & 892 & 1737 & 1670 & -267 \\
Density $\left(\mathrm{kg} / \mathrm{m}^{3}\right)$ & 880 & 10500 & 10300 & 0.178 \\
Specific Heat $(\mathbf{J} / \mathbf{k g}-\mathrm{K})$ & 1300 & 160 & 146 & 5200 \\
Heat Capacity (MJ/m $\left.{ }^{3}-\mathrm{K}\right)$ & 1.14 & 1.68 & 1.50 & 0.0009 \\
Thermal Conductivity & 76 & 16 & 11 & 0.152 \\
(W/m-K) & & & & 0.238 \\
Viscosity (cP) & 0.34 & $2.0-2.5$ & 1.7 & 0.018 \\
& & & & 0.031 \\
\hline
\end{tabular}

Values at STP. Italic $=$ Evaluated at $\sim 300^{\circ} \mathrm{C}$ 


\section{Thermophysical Properties}

- Despite very different densities and specific heat, sodium and LBE have similar volumetric heat capacities.

- Similar volumetric flow rates

- For identical flow geometries, similar flow velocity. But LBE will have a significantly higher pressure drop and pumping requirements.

- LBE will develop slightly higher natural circulation velocity, but at the expense of somewhat higher cladding temperatures.

- Relatively low thermal conductivity of LBE (combined with low flow velocity) affects heat transfer from cladding to coolant.

- Specific heat of helium is high, but density is very low. Requires a high pressure system $(\sim 85 \mathrm{~atm})$ and high coolant velocity $(\sim 100 \mathrm{~m} / \mathrm{s})$. Introduces risk of flow-induced vibrations.

- Low thermal conductivity of helium results in poor heat transfer even at high coolant velocity. Cladding surfaces can be roughened to improve heat transfer (4x), but it is still 8-9x lower than for sodium. 


\section{Material Properties}

- Sodium, LBE, helium have excellent thermal and radiation stability.

- Compatibility of coolants with available structural, heat exchanger, and pump materials is a key criteria for selection.

- Helium is chemically inert, but low molecular weight leads to diffusive losses at seals and valves. Impurities (especially moisture) can lead to corrosion.

- Liquid metals may selectively deplete constituents from, and impurities may chemically react with, structural materials

- Chemistry control will be required for all coolants.

- Standards for sodium:

- ASTM C 1051-85: "Standard Specification for Sodium as a Coolant For Liquid Metal-Cooled Reactors" (withdrawn in 2000).

- ASTM C 997-83: "Standard Test Methods for Chemical and Instrumental Analysis of Nuclear-Grade Sodium and Cover Gas" (withdrawn in 1999). 


\section{Material Properties (Sodium)}

- Primary issue with sodium is its chemical reactivity in air and water.

- Sodium is inherently compatible with stainless steels, requiring no special corrosion protection measures

- Oxygen preferentially reacts with sodium, forming $\mathrm{Na}_{2} \mathrm{O}$.

- Oxygen impurity can readily be maintained well below 10 ppm using a cold trap.

- No difference between high-purity sodium and helium when comparing strain-rate and creep-rupture data for austenitic steels. No indication of liquid metal embrittlement.

- Based on long-term corrosion testing in BR-10, "the operating service life of sodium equipment in fast reactors can be increased to $60 \mathrm{yr}$ and longer."

- Fuel-coolant interactions are benign for metallic fuel.

- Many fission products are soluble in sodium and can be filtered out in the cold trap.

- Database for sodium compatibility is extensive, with information available in the open literature. 


\section{Material Properties (LBE)}

- Prior to 1998, material database relied mainly on anecdotal information from Russian sources.

- Solubility of steels in LBE is generally higher than in lead (due to Bi). Solubility of $\mathrm{Ni}$ is of particular concern $\left(\mathrm{Ni}-37000 \mathrm{ppm}\right.$ at $\left.600^{\circ} \mathrm{C}\right)$.

- Russian approach is to maintain a protective oxide layer on structural components (particularly cladding) and minimize coolant flow velocities.

- Applicable to ferritic-martensitic steels.

- Above $550^{\circ} \mathrm{C}$, oxide layer can become thick and unstable

- Oxygen control is a dynamic equilibrium: thickness of oxide layer stabilizes, but structural (cladding) weight loss continues.

- Coolant velocity and high shear stress (viscosity) results in erosion.

- Oxide layer impacts heat transfer from cladding to coolant.

- Oxide control:

\begin{tabular}{l|l|c} 
Dissolution & Protective Oxide Layer & PbO Sludge \\
\hline $\mathrm{Fe}_{3} \mathrm{O}_{4}, \mathrm{FeCr}_{2} \mathrm{O}_{4}$ & $\mathrm{PbO}$ & Oxygen in LBE
\end{tabular}




\section{Oxide Control in LBE Systems}

- Oxygen is controlled by constant addition (e.g. flow over PbO "balls") and subtraction (e.g. bubbling hydrogen gas in a helium carrier to form water).

- Problems with oxygen control:

- Non-homogeneous oxygen distribution in real systems results in nonuniform coatings. Crevice corrosion and dissolution of occlusions can occur.

- Magnetite $\left(\mathrm{Fe}_{3} \mathrm{O}_{4}\right)$ undergoes a phase transformation at $570^{\circ} \mathrm{C}$.

- Newer solution is to prefer $\mathrm{SiO}_{2}$ and $\mathrm{Al}_{2} \mathrm{O}_{3}$ based oxide layers.

- Oxide layer forms at lower oxygen concentrations.

- No phase transformation.

- EP-823 (Russian steel similar to HT-9 but with higher Si content).

- Silicon degrades mechanical properties (ductility) and reduces irradiation performance.

- Some interest in oxide dispersion strengthened (ODS) steels. Irradiation performance and cost are not well known. 


\section{Neutronic Characteristics}

- Sodium, Lead, LBE, and Helium are all suitable for fast reactor applications

- Sodium and LBE both introduce a small amount of parasitic absorption.

- Reduced neutron leakage in an LBE system allows for a higher coolant volume fraction.

- Helium is transparent to neutrons, and the relatively low density leads to negligible moderation, but this leads to a higher neutron leakage fraction. 


\section{Sensitivity of Neutron Flux to Varying Parameters}

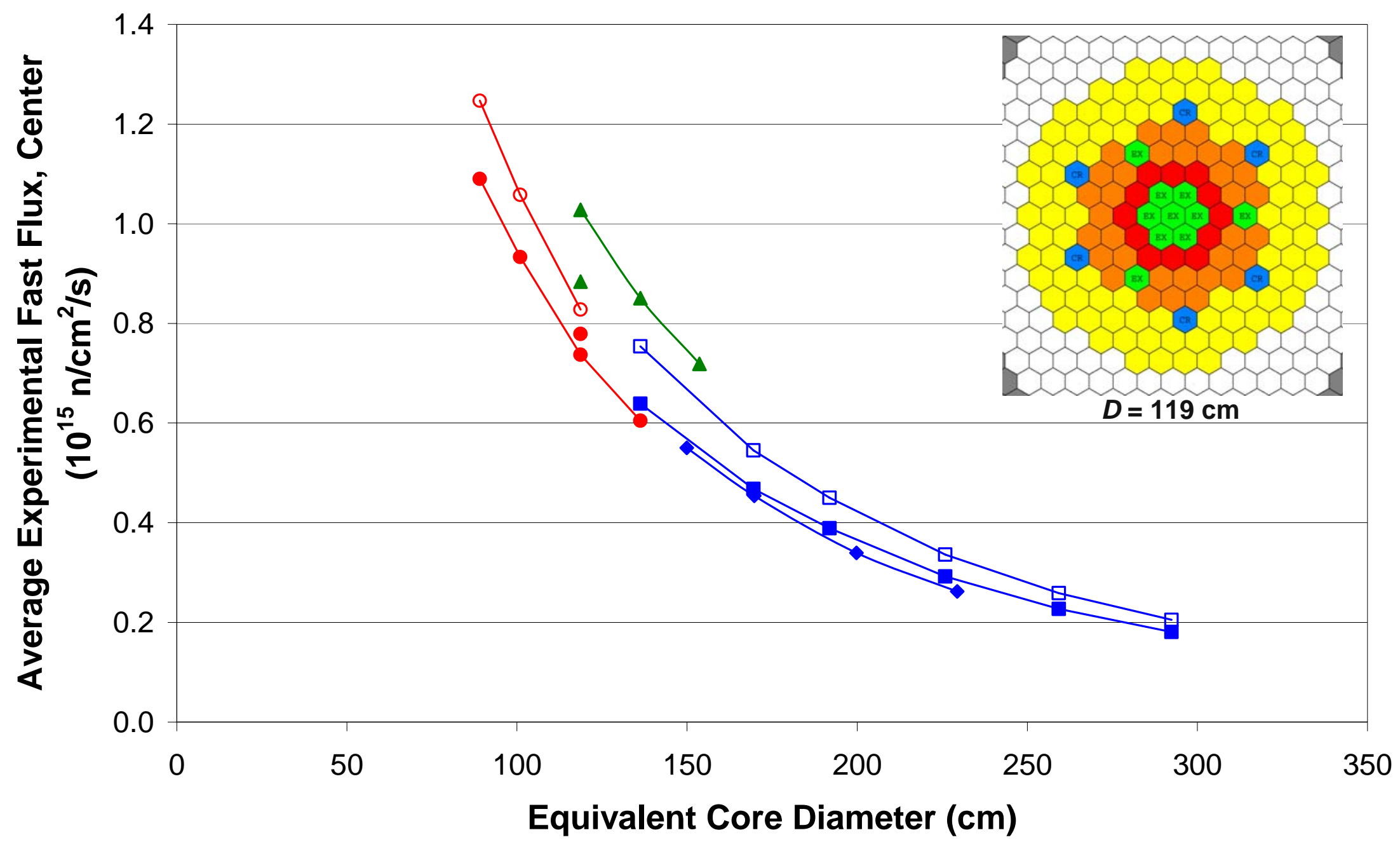

$\rightarrow-\mathrm{He}$, Standard $(\mathrm{U}) \rightarrow \mathrm{He}$, Standard $(\mathrm{Pu}) \rightarrow \mathrm{He}$, Compact $(\mathrm{U}) \rightarrow \mathrm{LBE}, 61-\mathrm{Pin}(\mathrm{U})$

$\rightarrow$ Na, 91-Pin (U) $\quad \mathrm{Na}, 61-\mathrm{Pin}(\mathrm{U}) \quad \rightarrow \mathrm{Na}$, 91-Pin (Pu) $\quad$ LBE, 91-Pin (U) 


\section{Sensitivity of Enrichment to Varying Parameters}

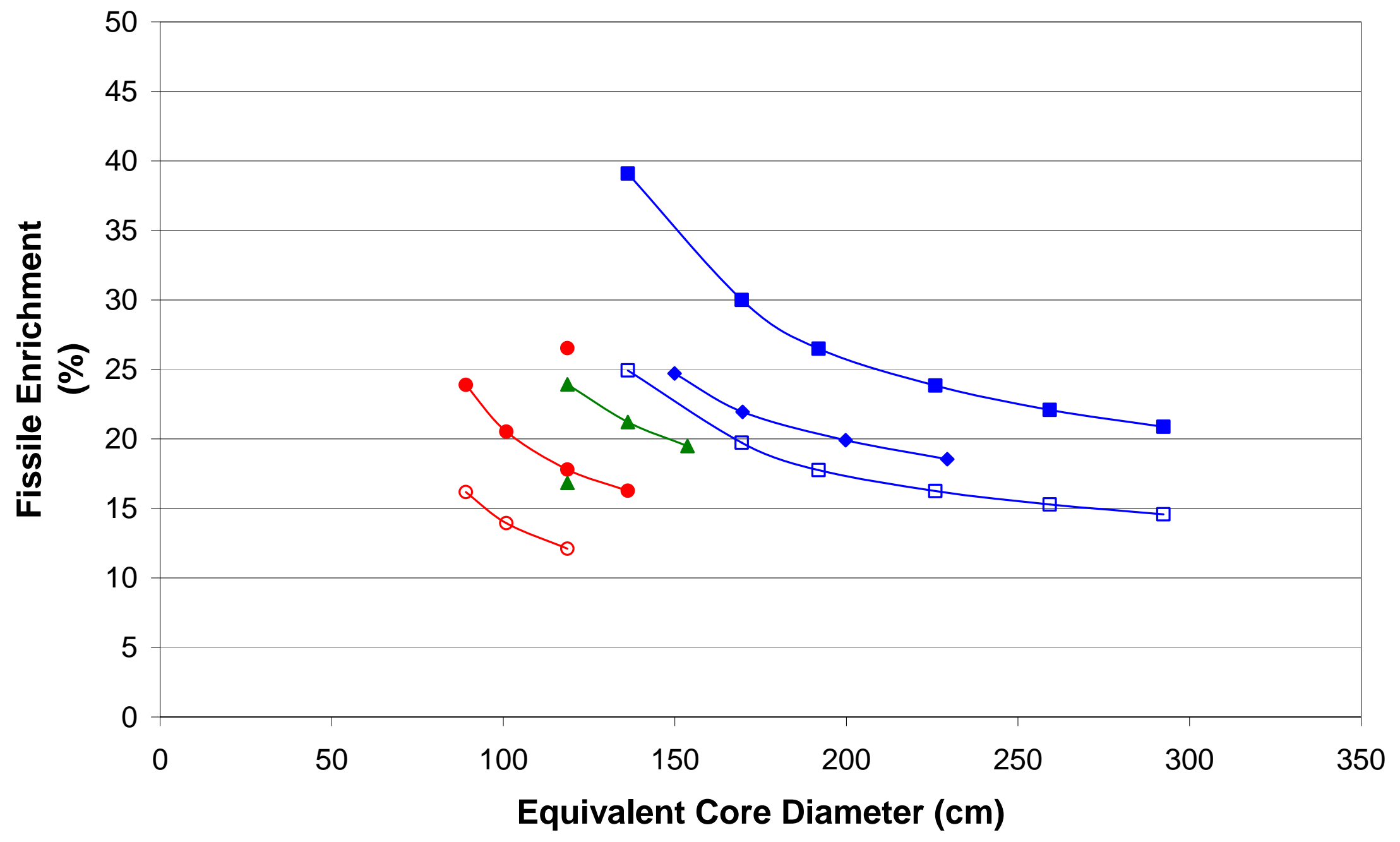

$\rightarrow-\mathrm{He}$, Standard $(\mathrm{U}) \rightarrow \mathrm{He}$, Standard $(\mathrm{Pu}) \rightarrow \mathrm{He}$, Compact $(\mathrm{U}) \rightarrow-\mathrm{LBE}, 61-\mathrm{Pin}(\mathrm{U})$

$\rightarrow-\mathrm{Na}, 91-\mathrm{Pin}(\mathrm{U}) \quad \bullet \mathrm{Na}, 61-\mathrm{Pin}(\mathrm{U}) \quad \rightarrow \mathrm{Na}, 91-\mathrm{Pin}(\mathrm{Pu}) \quad \Delta \mathrm{LBE}, 91-\mathrm{Pin}(\mathrm{U})$ 


\section{Scaling to Higher Power}

When comparing sodium and LBE designs with identical geometries, LBE:

- Requires a slightly lower enrichment

- Can produce a higher fast flux

- Results in a lower fissile inventory.

- Use of identical geometries does not account for optimization based on individual coolant properties

- $250 \mathrm{MW}_{\text {th }}$ options for sodium and LBE were evaluated to assess more realistic core designs.

- Additional constraint on fissile uranium enrichment: < 20\% U-235 (LEU)

- Coolant velocity limit $(2 \mathrm{~m} / \mathrm{s})$ imposed on LBE to limit erosion.

- Core designs were adjusted to achieve similar experimental flux levels.
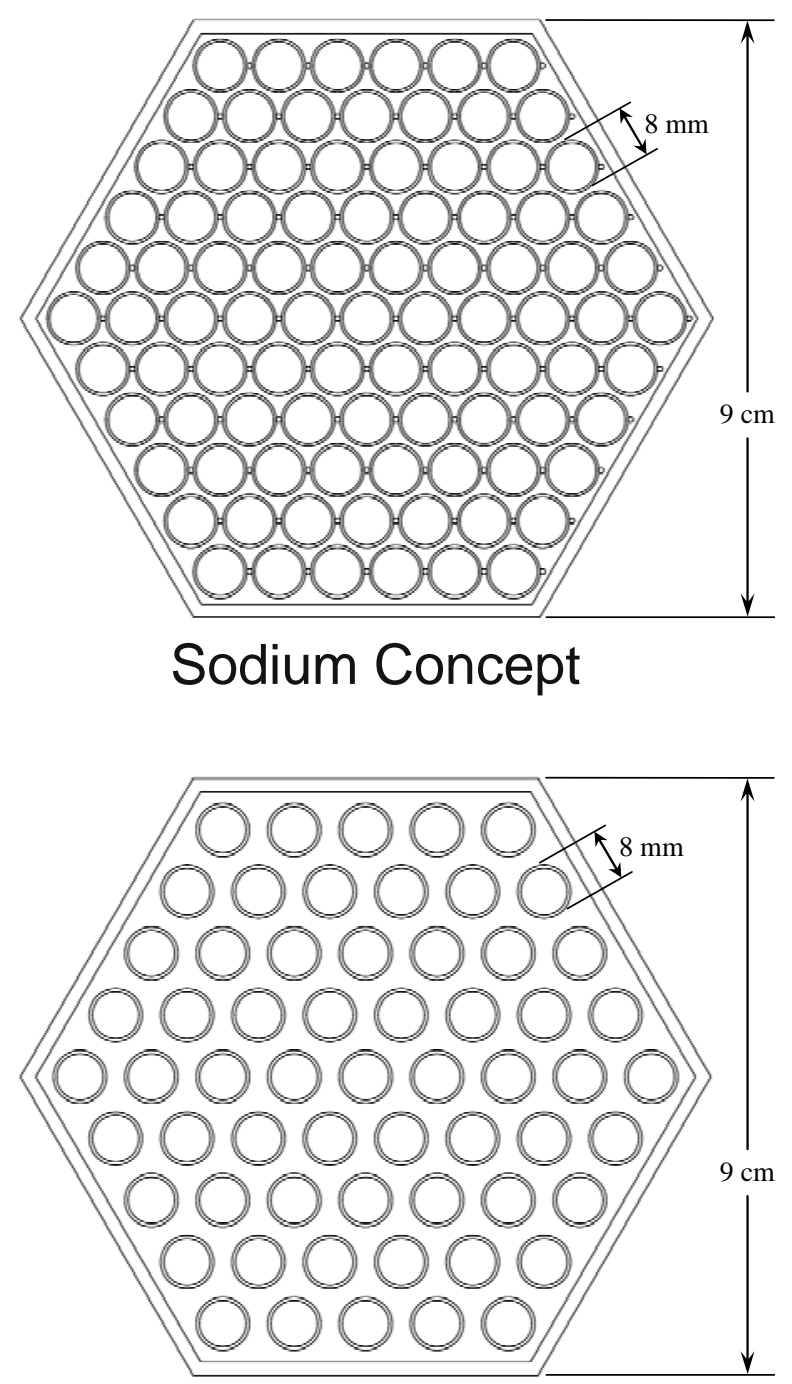

LBE Concept 


\section{Scaling to Higher Power}

- Sodium coolant results in a smaller core with higher power density, lower enrichment, fewer driver assemblies, and lower heavy metal inventory

\begin{tabular}{lcc}
\hline & Sodium & LBE \\
\hline Thermal Power (MW) & 250 & 250 \\
Coolant Velocity (m/s) & 8.3 & 2.0 \\
Average Experimental Fast Flux & 1.83 & 1.79 \\
$\left(\mathbf{1 0}^{15} \mathbf{n} / \mathbf{c m}^{2} / \mathbf{s}\right)$ & & \\
Number of Driver Assemblies & 135 & 237 \\
Pins per Assembly & 91 & 61 \\
Equivalent Core Diameter (cm) & 119 & 154 \\
Active Height (cm) & 100 & 100 \\
Fissile Enrichment (\%) & 18.3 & 20.0 \\
Heavy Metal Inventory (kgHM) & $\mathbf{5 1 3 8}$ & $\mathbf{5 7 1 6}$ \\
\hline
\end{tabular}

- Sodium case still has room for further optimization 


\section{Coolant Activation}

- Coolant activation results in radioactive isotopes circulating through the primary loop.

- Helium yields no activation products unless impurities are present.

- Sodium: ${ }^{23} \mathrm{Na}(\mathrm{n}, \gamma)^{24} \mathrm{~N}\left(\mathrm{t}_{1 / 2}=15\right.$ hours $)$

- LBE: ${ }^{209} \mathrm{Bi}(\mathrm{n}, \gamma){ }^{210} \mathrm{Bi},{ }^{210} \mathrm{Bi} \rightarrow{ }^{210} \mathrm{Po}\left(\mathrm{t}_{1 / 2}=138\right.$ days $)$

- Operationally, this requires shielding for primary components.

- Po-210 represents a significant biological hazard, requiring a leakproof system.

- $\mathrm{PbPo}(\mathrm{s})+\mathrm{H}_{2} \mathrm{O}=\mathrm{PbO}+\mathrm{H}_{2} \mathrm{Po}(\mathrm{g}) \quad$ (volatile alpha-emitting aerosol)

- Estimates of cool-down time to meet the IAEA "exemption" criteria (to be freely used for other industrial purposes):

- Sodium (pure): $\sim 7$ years

- Sodium (with impurities): 50-100 years

- LBE: 100,000 years

- Experience exists for processing large quantities of primary sodium coolant for disposal (EBR-II). 


\section{Passive Safety (Liquid Metals)}

- Heat capacity and high thermal conductivity of liquid-metal coolants provides large thermal inertia against system heating during loss-offlow accidents.

- Combined with favorable reactivity feedback (core design/fuel choice) sufficient cooling is available to support passive shutdown.

- Full-power unprotected loss of flow and loss of heat sink accidents demonstrated in EBR-II in 1986. Similar tests (at 50\% power) demonstrated passive response in FFTF

- Response of lead/LBE systems to seismic events will pose design challenges.

- For medium-sized plant, one can expect primary coolant alone to weigh $\sim 10,000$ metric tons.

- Structural design of primary system becomes a significant challenge. 


\section{Passive Safety (Demonstrated in EBR-II in 1986)}

Unprotected (no scram) Loss of Flow (ULOF) results in brief temperature rise which is terminated by negative reactivity feedback effects

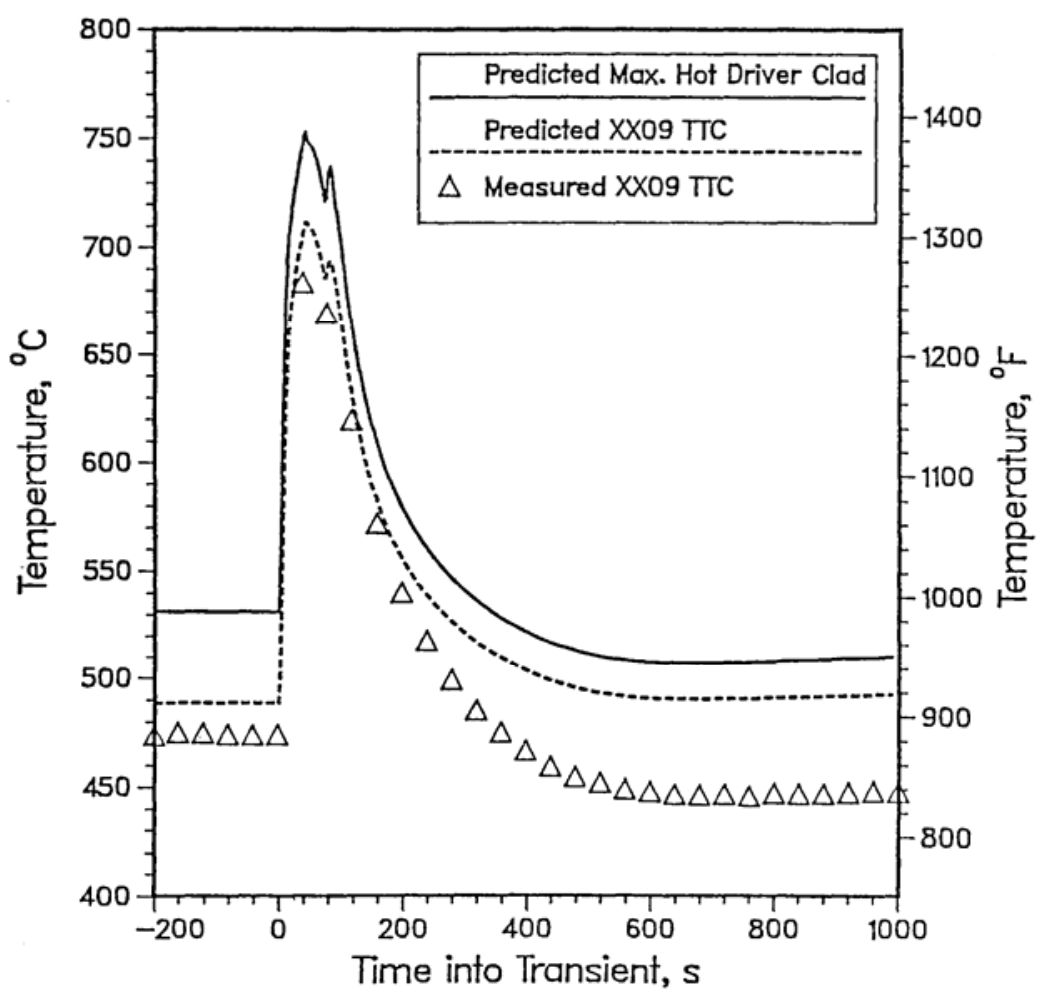

Unprotected Loss of Heat Sink (ULOHS) causes increase in inlet temperature which introduces negative reactivity feedback effects.

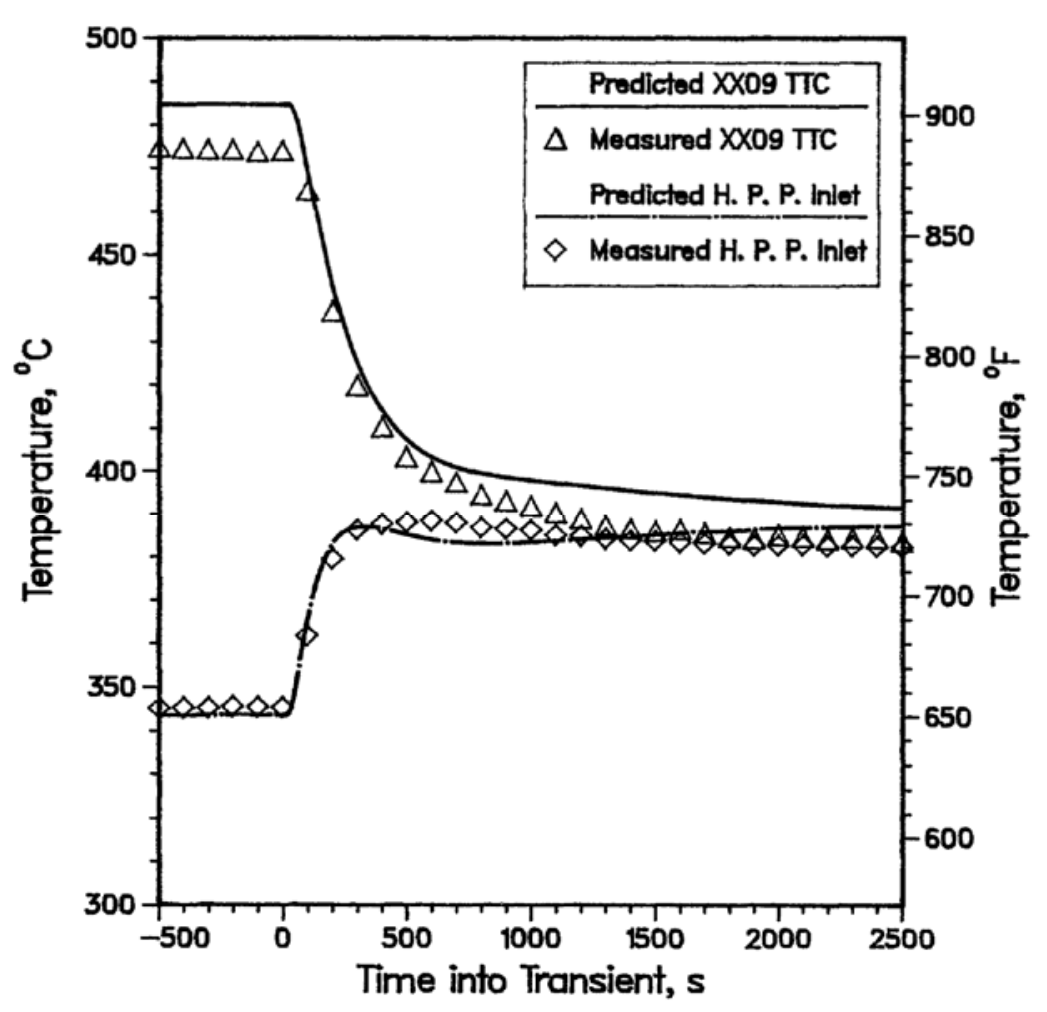




\section{Passive Safety (Helium-Cooled Fast Reactor)}

- In gas-cooled thermal reactors, graphite moderator provides a large heat capacity against excessive temperature rises. Not present in a fast reactor.

- Low thermal conductivity of helium coolant minimizes thermal shock during transients.

- Thermal transients do not propagate to structural materials rapidly. Heat is deposited in the fuel.

- Despite minimal thermal shock, power-to-flow mismatches may be a significant safety concern for gas-cooled fast reactors.

- GFR relies on secondary vessel/containment to limit pressure loss.

- May be able to support decay heat removal, but not full-power transients.

- Adequate decay heat removal may not be possible under loss of pressure scenarios. 


\section{Coolant Cost}

\section{Direct cost}

- Sodium: On a volume basis, it is generally the cheapest of all metals, and is among the most abundant elements in the earth's crust. 2006 price from DuPont (reactor grade/Niapure ${ }^{\mathrm{TM}}$ ) is $\$ 1.58 / \mathrm{lb}\left(\$ 3400 / \mathrm{m}^{3}\right)$.

- Lead: 2005 USGS, 43 - 61 \$/lb $\left(\$ 15,000 / \mathrm{m}^{3}\right)$.

- Bismuth: U.S. ceased domestic production in 1997 and is highly dependent on imports. By the end of 2005, USGS-tracked price had increased to $>\$ 4 /$ pound $\left(\$ 86,000 / \mathrm{m}^{3}\right)$.

- The Helium Privatization Act of 1996 mandates the price of helium. In 2005 , Government price was $1.965 \$ / \mathrm{m}^{3}$. Private prices ranged from 2.42 to $2.63 \$ / \mathrm{m}^{3}$. At $85 \mathrm{~atm}$, this is roughly $\$ 220 / \mathrm{m}^{3}$.

\section{- Indirect costs}

- Coolant chemistry/purification, inventory makeup (helium).

- Pumping requirements.

- Core and primary system size.

- Component lifetime.

- Passive safety and safety-related systems. 


\section{Other Considerations}

- Component Technology R\&D

- Regardless of coolant, component testing will be required.

- 50+ years of sodium component development, testing, and operation.

- Fuel handling

- Opaqueness of sodium and lead/LBE affects fuel handling.

- Need to maintain pressure boundary with helium also affects fuel handling.

- Must be able to remove residual coolant from spent fuel or test assemblies.

- Significant experience exists for "washing" sodium from spent fuel with steam or moist air.

- Removing LBE from spent fuel may require an acidic "brew" or boiling in glycerin. Sodium may be used, but it will also remove surface oxides. 


\section{Sodium as a Fast Reactor Coolant}

- Thermophysical and thermal-hydraulic properties of sodium are superior to lead or helium.

- Smaller core with higher power density, lower enrichment, and lower heavy metal inventory. Demonstrated passive safety performance.

- Use of sodium codified in ASTM standards.

- Extensive testing of coolants lead to nearly all (land-based) fast reactors constructed during the last 50 years using sodium as the primary coolant.

- Current fast reactor construction projects use sodium as the primary coolant.

- LBE-cooled reactors limited to Russian Alfa-class submarine experience.

- No He-cooled (or gas-cooled) fast reactors.
Thermophysical Properties:

Excellent Heat Transfer

Low Vapor Pressure

High Boiling Point

Low Melting Point

Material Properties:

Thermal Stability

Radiation Stability

Material Compatibility

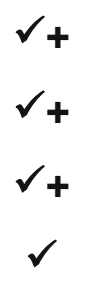

$\checkmark$

$\checkmark+$

$\checkmark+$

$\checkmark+$

Neutronic Properties:

Low Neutron Absorption

Minimal Activation

Negligible Moderation

Supports Passive Safety

Cost:

Initial Inventory

Make-Up Inventory

Low Pumping Power

Hazards:

Sodium reacts with air and water (next) 


\section{Sodium Reactivity with Air and Water}




\section{Sodium Reactivity with Air}

- Burning reaction is characterized by a zone of small (few $\mathrm{cm}$ ) flames at the sodium-air interface, formation of $\mathrm{Na}_{2} \mathrm{O}$ on the surface, and vigorous emission of oxide fumes.

- Sodium reaction with air is slow and causes relatively low heat release

- Sodium has a high latent heat of vaporization and high boiling temperature.

- This results in a low evaporation rate during combustion.

- Gasoline will burn approximately 4 times faster than sodium

- Sodium-air heat of reaction is one-fourth that of burning gasoline.

- Energy released during sodium burning is approximately a factor of 15 lower than in the case of gasoline.

- In one series of tests, temperature 1 meter above a 1 square meter pool of burning sodium was less than $100^{\circ} \mathrm{C}$.

- For gasoline, the flame zone extended as high as 4 meters and the average temperature 2 meters above the pool exceeded $600^{\circ} \mathrm{C}$. 


\section{Sodium Reactivity with Air}

- Sodium aerosols ( $\mathrm{NaO}$ and $\mathrm{Na}_{2} \mathrm{O}$ ) react with air (including water vapor and $\mathrm{CO}_{2}$ ) to produce $\mathrm{NaOH}$, and $\mathrm{Na}_{2} \mathrm{CO}_{3}$.

- Production of $\mathrm{NaOH}$ takes a few seconds after particle formation.

- $\mathrm{Na}_{2} \mathrm{CO}_{3}$ formation can take several minutes.

- Aerosols deposit on the floor, walls, and ceiling.

- Aerosol particles can cause equipment damage (electrical and instrumentation)

- Highly toxic

- Sodium leaks can be detected through gas sampling techniques

- Ability for detection means leaks can be readily identified. 


\section{Sodium Leaks}

- Most sodium leaks have been small and were the result of design and/or fabrication deficiencies.

E.g. leak from the secondary cold trap at the Fast Breeder Test Reactor:

- During initial commissioning, preheating of the cold trap led to overpressurization of the NaK "jacket" due to inadequate expansion space.

- 2.5 liters of NaK leaked through a spark-plug type high-level probe.

- A 20 liter expansion "pot" was added to the argon supply line to prevent overpressurization.

- Of the 27 leaks at BN-600, the main causes have been identified as

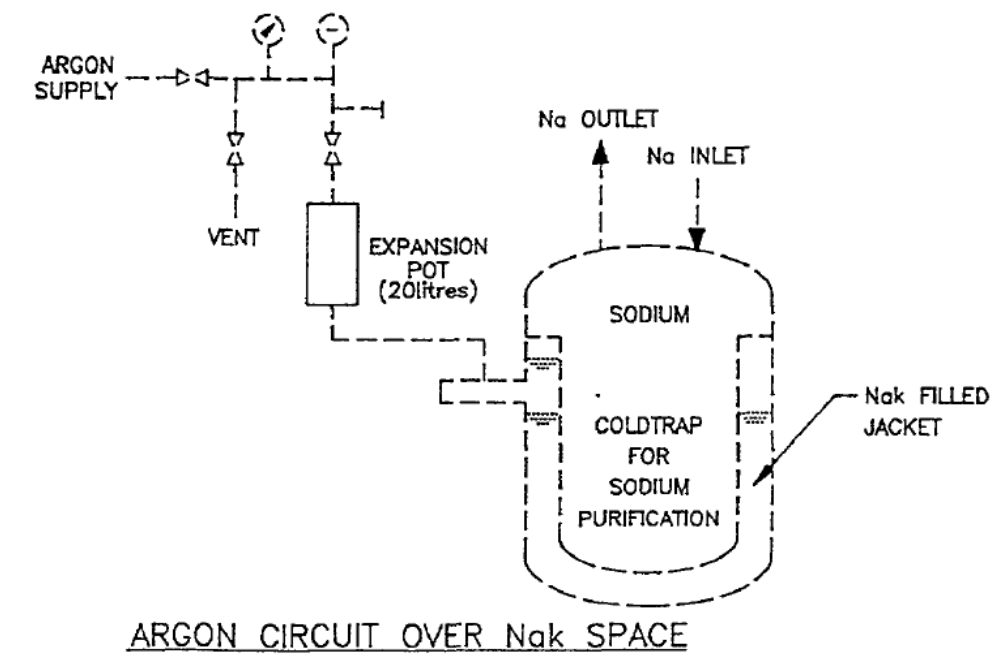

Source: Figure 5 from R.P. Kapoor, et al., "Unusual Occurrences in Fast Breeder Test Reactor," Unusual Occurrences During LMFR Operation, IAEA-TECDOC-1180, October 2000. Used with permission.

- Inadequate valve design.

- Insufficient thermal compensation and manufacturing faults.

- Loss of leak-tightness in sodium reception from tanker cars.

- Causes for leaks are known. 


\section{Significant Sodium Leaks *}

BN-600

- 1981: Flange joint failure in SG valve seal $(300 \mathrm{~kg})$

- 1990: Manufacturing defect in SG drain pipeline $(600 \mathrm{~kg}$ )

- 1993: Thermal expansion induced failure in primary sodium purification system $(1000 \mathrm{~kg}, \sim 10 \mathrm{Ci})$

- 1994: Staff error, pipeline cutting before sodium was frozen $(650 \mathrm{~kg})$

Monju (8 ${ }^{\text {th }}$ December, 1995$)$ secondary sodium leak $(\sim 640 \mathrm{~kg})$

- 19:47 - Off-scale sodium temperature alarm at IHX outlet, followed by fire alarm, and sodium leak alarm

- 20:00 - Reactor power-down begins

- 21:20 - Reactor manually tripped due to observation of increased fumes

- 22:55 - Began draining secondary sodium circuit

- 00:15 - Draining operations completed

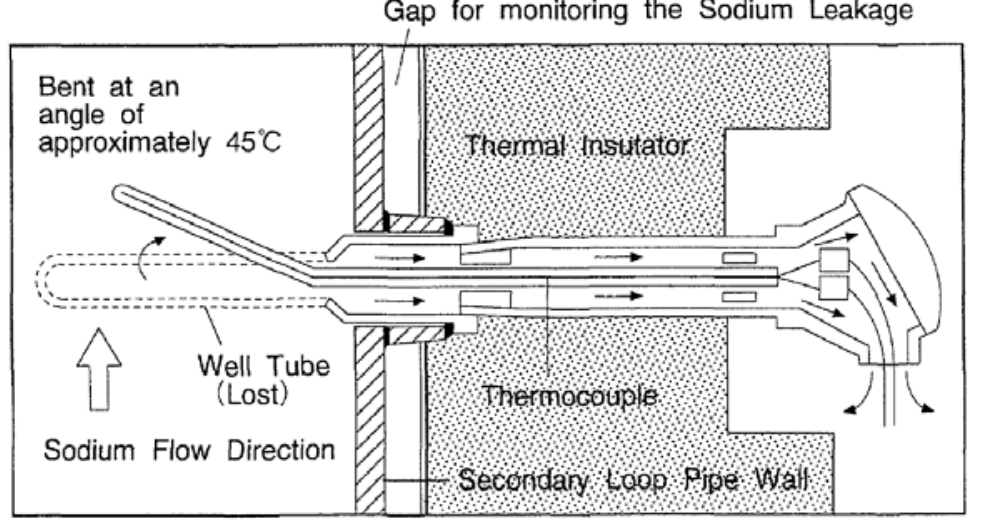

Source: Figure 4 from A. Miyakawa,et al., "Sodium Leakage Experience at the Prototype FBR Monju, Unusual Occurrences During LMFR Operation, IAEA-TECDOC-1180, October 2000. Used with permission
Union

- No adverse effects were reported for operating personnel or surrounding environment 


\section{Consequences of the Sodium Leak at Monju}

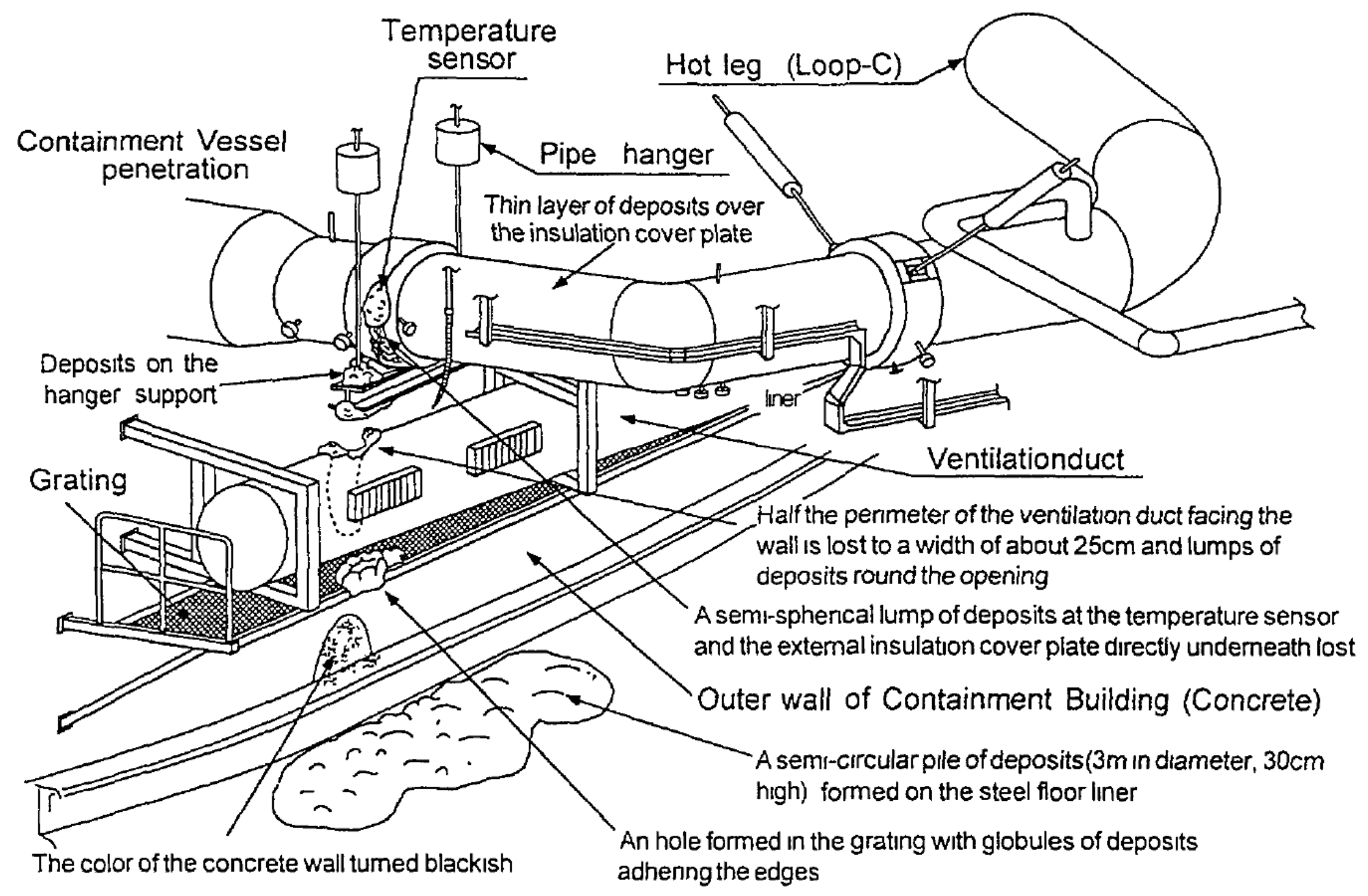

Source: Figure 2 from A. Miyakawa,et al., "Sodium Leakage Experience at the Prototype FBR Monju," Unusual Occurrences During LMFR Operation, IAEA-TECDOC-1180, October 2000. Used with permission. 


\section{Sodium Reactivity with Water}

- Sodium-water chemical interactions take place in two stages.

- In the first stage, the reaction proceeds at a high rate with release of gaseous hydrogen:

$$
\mathrm{Na}+\mathrm{H}_{2} \mathrm{O}=\mathrm{NaOH}+1 / 2 \mathrm{H}_{2}+140 \mathrm{~kJ} / \text { mole }
$$

- In the second stage, chemical interaction takes place between the products of the first stage and excess sodium:

$2 \mathrm{Na}+\mathrm{NaOH}=\mathrm{Na}_{2} \mathrm{O}+\mathrm{NaH}$

$\mathrm{Na}+1 / 2 \mathrm{H}_{2}=\mathrm{NaH}$

- Hydrogen detection plays a key role in leak detection

- Diffusion method uses a metal membrane permeable to hydrogen.

- E.g. diffusion of hydrogen through a nickel membrane into a vacuum cavity coupled to a magnetic discharge pump.

- Capable of detecting 10 - 30 gram water leak into 100 tons of secondary sodium.

- Acoustic detection techniques are also being developed. 


\section{Sodium Reactivity with Water}

- Potential for sodium/water interactions requires separation of steam cycle from primary system: an intermediate sodium loop is used.

- Lack of fabrication experience in early sodium/water steam generators resulted in a number of large and small water leaks into the sodium.

- 33 gas-space leaks in PFR SGs were all associated with cracking of the tube-to-tubeplate welds due to lack of post-weld heat treatment.

- Large ingress of water does not lead to catastrophic consequences. (One incident at BN-350 leaked 800 $\mathrm{kg}$ of water into secondary sodium.)

- Components remained repairable.

- Steam generators can be designed to minimize the impact of leaks on the operation of the plant as a whole.

- Minimize weld joints and prevent flow-induced vibrations

- Proper selection of tube materials, thickness, spacing

- Use of expansion volumes, rupture disks

- Accommodate leak detection 


\section{EBR-II Steam Generator Experience}

- No tube leaks occurred during the $\mathbf{3 0}$ years of operation of EBR-II.

- No sodium leaks occurred at the tube-to-sodium tube sheet welds.

- One water/steam leak occurred at the tube-to-steam tube sheet.

- Steam leaked into the space between the two tube sheets.

- This weld was repaired (only one tube-to-tube sheet weld was involved) and the unit was returned to service.

- Repaired unit operated satisfactorily for the life of the plant.

- The EBR-II objective was achieved: sodium and water never came in contact during the operating lifetime of the plant.

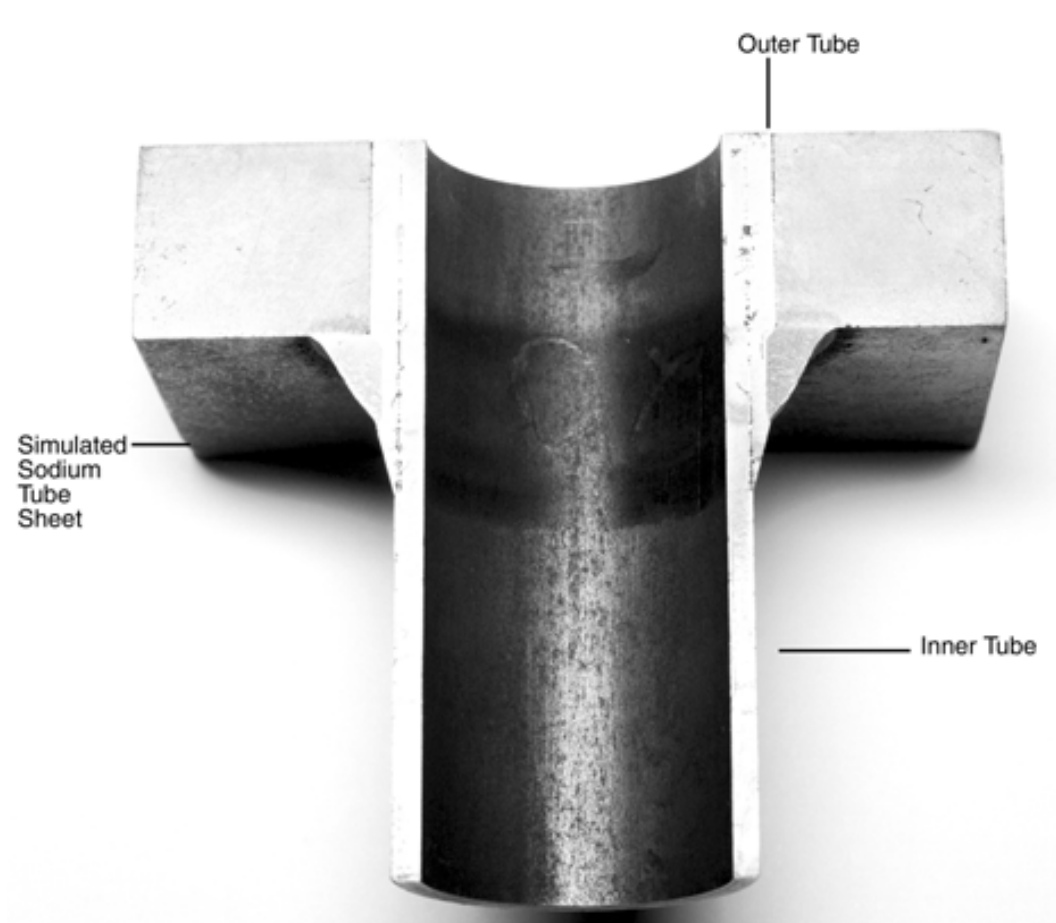




\section{Impact of Coolant on SFR and LWR Differences}




\section{Coolant Choice Affects Design Differences}

- The choice of sodium has broad consequences in reactor design

- Absence of high pressure in the primary system

- Higher operating temperatures with significant thermal margins

- More compact fuel assembly designs

- Incorporation of an intermediate loop

- Different arrangements for fuel handling 


\section{Selected Properties of Sodium and Water}

\begin{tabular}{|c|c|c|}
\hline & Sodium & Water \\
\hline Atomic Weight & 22.997 & 18 \\
\hline Optical Properties & Opaque & Transparent \\
\hline Melting Point $\left({ }^{\circ} \mathrm{C}\right)$ & 97.8 & 0 \\
\hline Boiling Point $\left({ }^{\circ} \mathrm{C}\right)$ & 892 & 100 \\
\hline Density $\left(\mathrm{kg} / \mathrm{m}^{3}\right)$ & 880 & 713 \\
\hline Specific Heat (J/kg-K) & 1300 & 5600 \\
\hline Heat Capacity $\left(\mathrm{MJ} / \mathrm{m}^{3}-\mathrm{K}\right)$ & 1.14 & 4.00 \\
\hline Thermal Conductivity (W/m-K) & 76 & 0.54 \\
\hline Viscosity (cP) & 0.34 & $\begin{array}{l}0.1 \\
(\sim 1)\end{array}$ \\
\hline
\end{tabular}

Values at STP. Italic $=$ Evaluated at $\sim 300^{\circ} \mathrm{C}$ (and 2000 psi for water $)$ 


\section{Sodium Allows Operation at Low System Pressure}

- While PWRs operate at system pressures in excess of 2000 psi, the inert cover gas in a sodium-cooled fast reactor is near atmospheric pressure.

- This difference impacts several design features:

- Vessel Thickness: PWR $\sim 10$ inches, SFR $\sim 1$ inch

- No need for pressurization of SFR fuel pins.

- Low system pressure offers advantages in terms of safety:

- Minimal pressure loading on the coolant boundary.

- In a high-pressure system, coolant pipe breaks are a concern.

- In a low-pressure system, coolant leaks are unlikely to propagate to a large-scale failure.

- No need for high-pressure injection cooling. 


\section{Sodium Provides a Large Margin to Coolant Boiling}

\begin{tabular}{lcc}
\hline & PWR $(2200$ psi) & SFR \\
\hline Inlet Temperature $\left({ }^{\circ} \mathrm{C}\right)$ & 300 & 355 \\
Core $\Delta \mathrm{T}\left({ }^{\circ} \mathrm{C}\right)$ & 30 & 155 \\
Outlet Temperature $\left({ }^{\circ} \mathrm{C}\right)$ & 330 & 510 \\
Boiling Temperature $\left({ }^{\circ} \mathrm{C}\right)$ & 345 & $>892$ \\
Margin to Boiling $\left({ }^{\circ} \mathrm{C}\right)$ & 15 & $>380$ \\
\hline
\end{tabular}

- Some nucleate boiling in a PWR is desirable, and the margin to boiling does not represent a real limit. Instead, the limit is defined by the departure from nucleate boiling, which can result in cladding burnout.

- Boiling in an SFR significantly impairs heat transfer and must be avoided. 


\section{Sodium Possesses High Thermal Conductivity}

- In sodium, the thickness of the thermal boundary layer is significantly larger than the thickness of the hydrodynamic boundary layer.

- Heat transfer coefficient for sodium is independent of viscosity (which is temperature dependent)

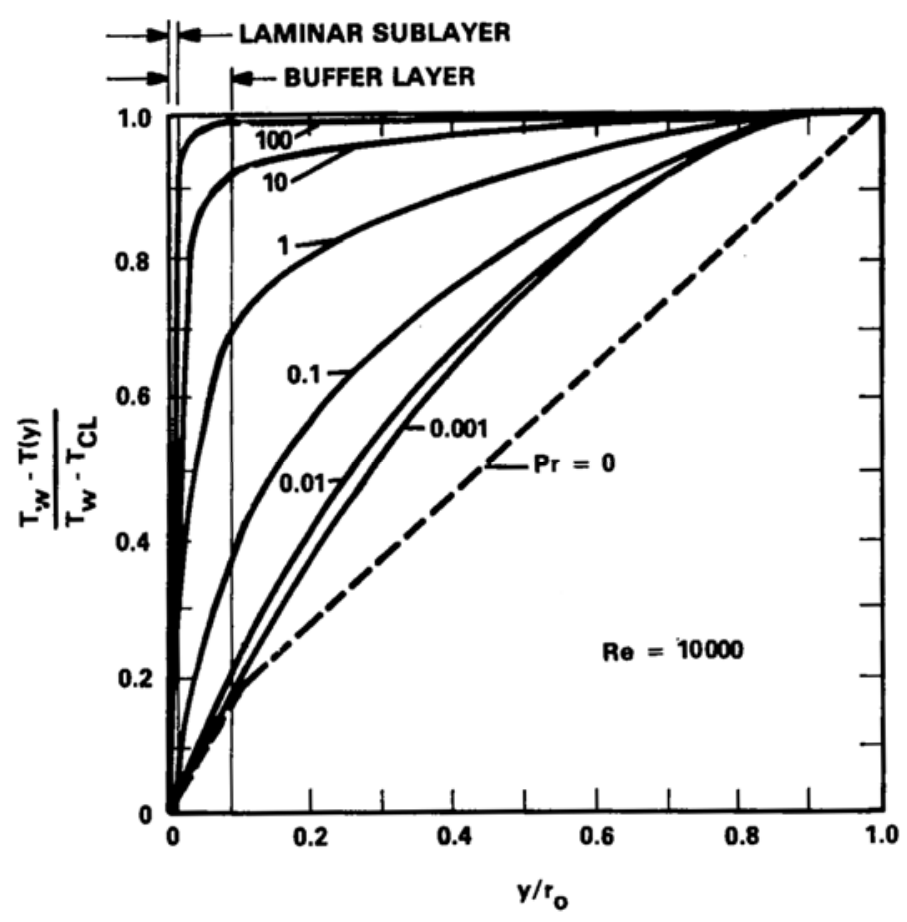

Source: Figure 9-15 (upper right) and Figure 9-16 (above) from A. E. Waltar and A. B. Reynolds, Fast Breeder Reactors, Pergamon Press, New York, 1981. Used with permission.

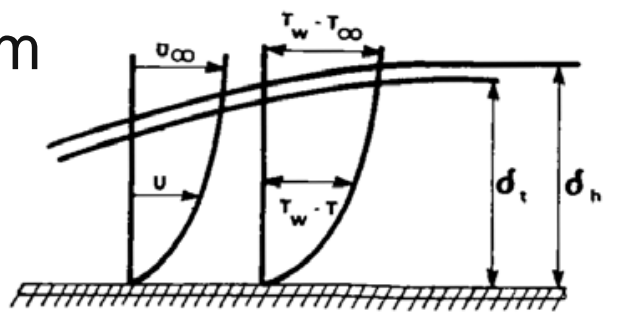

(a) ORDINARY FLUID

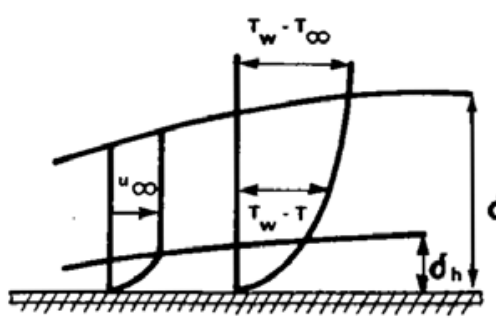

(b) LLUID METAL

FIGURE 9-15. Comparison of thermal $\left(\delta_{t}\right)$ and hydrodynamic $\left(\delta_{h}\right)$ boundary layers for ordinary fluids vs liquid metals.

- In turbulent flow, there is a high resistance to heat transfer in the laminar and buffer sublayers for ordinary fluids $(\operatorname{Pr} \sim 1)$.

- Critical heat flux determines minimum pin diameter.

- Moderator-to-fuel ratio impacts core size.

- For sodium $(\operatorname{Pr}<0.01)$ resistance to heat transfer is distributed throughout the flow channel.

- No thermal limit on pin diameter. 


\section{Thermal Hydraulics and Neutronics Affect Assembly Design}

00000000000000000 00000000000000000 00000000000000000 00000000000000000 00000000000000000 00000000000000000 $0000000000000000021.5 \mathrm{~cm}$ 00000000000000000 00000000000000000 00000000000000000 00000000000000000 00000000000000000 00000000000000000 00000000000000000 00000000000000000 00000000000000000 00000000000000000 ?

Typical PWR Assembly (289 pin locations) Pin Diameter $=9.4 \mathrm{~mm}$ Pin Pitch $=12.5 \mathrm{~mm}$
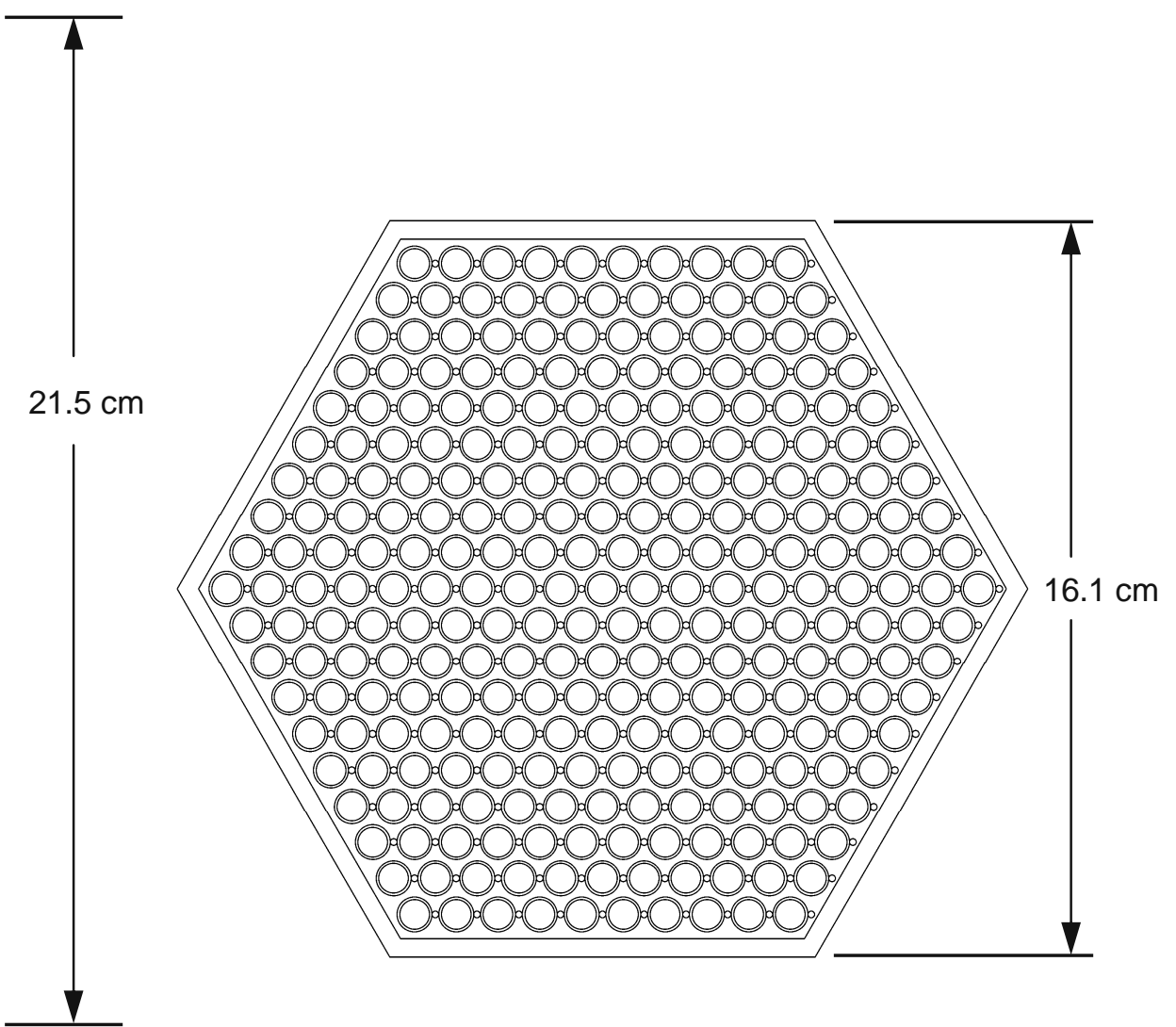

"Typical" SFR Assembly (271 pins) Pin Diameter $=7.4 \mathrm{~mm}$ Pin Pitch $=8.9 \mathrm{~mm}$ 


\section{Sodium Coolant Needs an Intermediate Coolant Loop}

- Because of coolant activation, the potential for sodium/water interactions between high-pressure steam and a low-pressure sodium loop, an intermediate coolant loop is used.

- This leads to two fundamental design choices: Pool vs. Loop

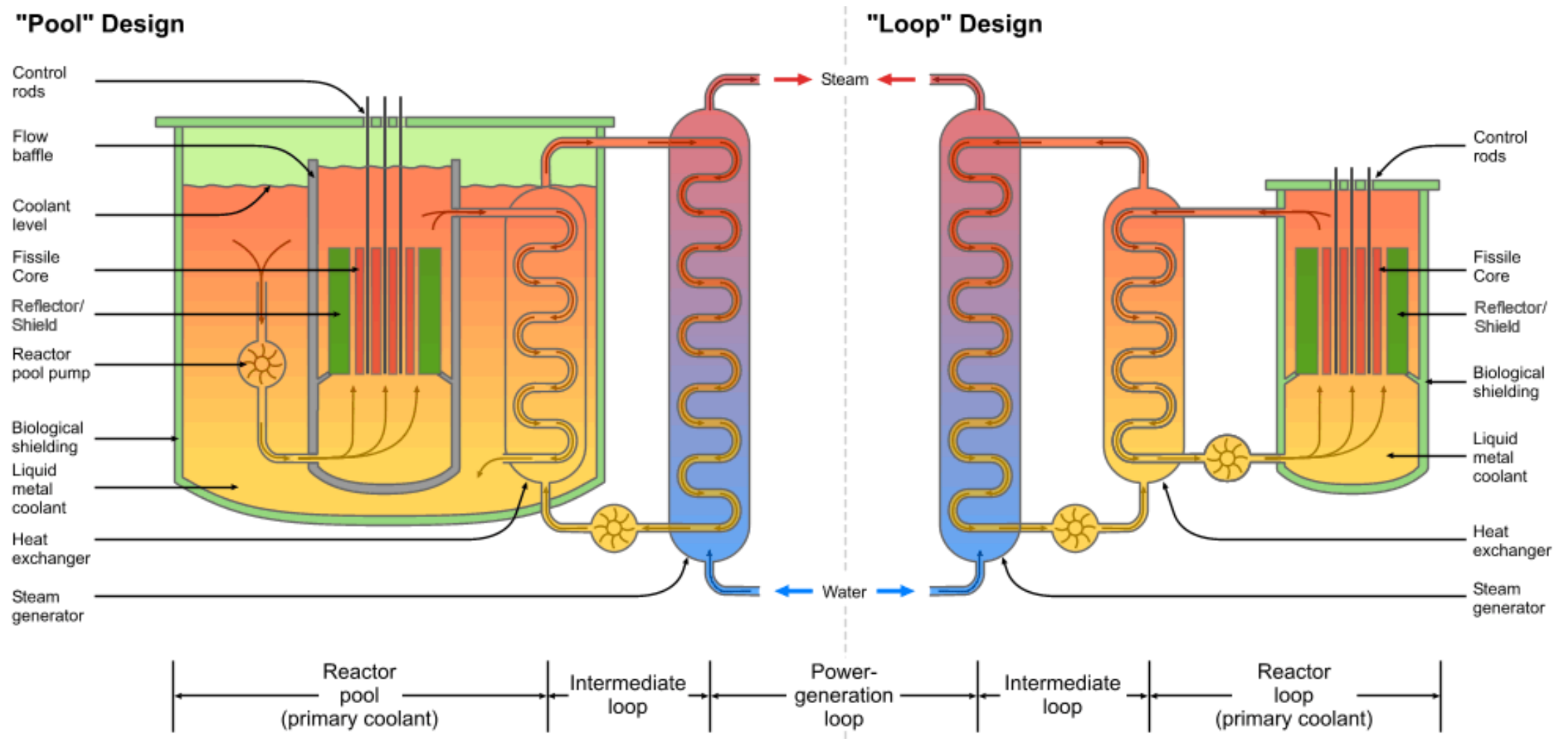




\section{Opaqueness of Sodium}

- The opaqueness of sodium has never been an issue for the safe operation of sodium fast reactors.

- Fuel handling requires careful tracking and positioning since visual inspections cannot be made under sodium.

- Dimensional gauging: A probe (or the fuel handling mechanism) can be used to identify and measure predefined index points to check the integrity of reactor internal structures

- Under-sodium viewing (USV):

- Ultrasonic imaging technique

- Developed as early as the late 1960s

- Can suffer from specular reflection effects

- Presently limited to a research area. Not essential for operation.

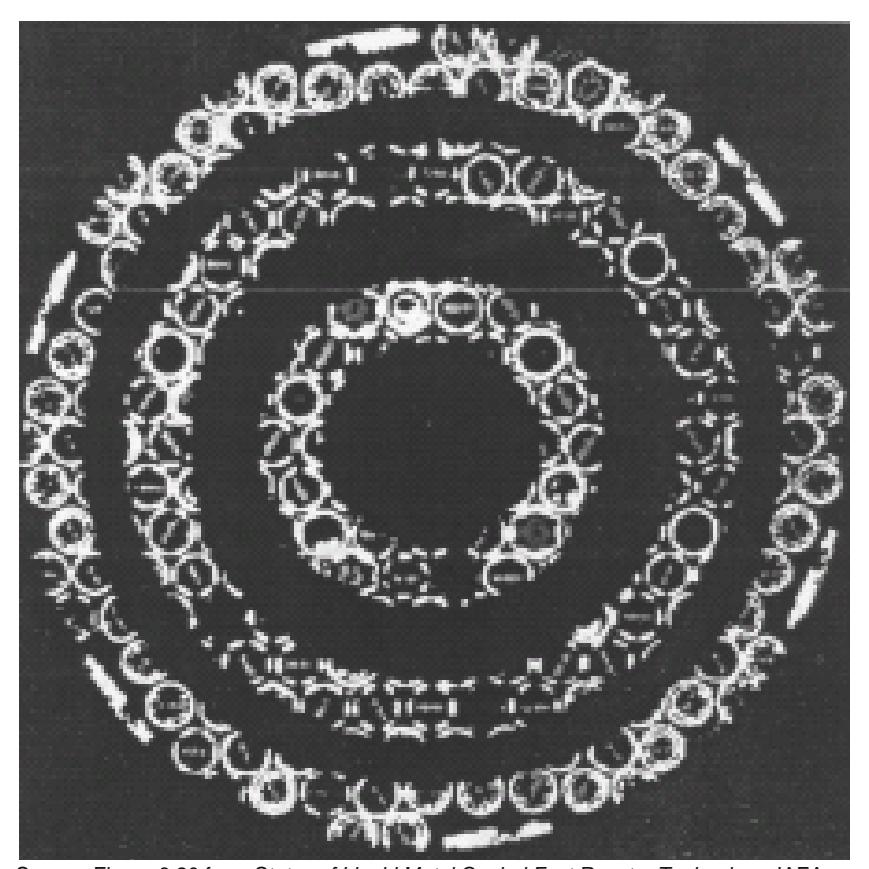

Source: Figure 6.20 from Status of Liquid Metal Cooled Fast Reactor Technology, IAEATECDOC-1083, April 1999. Used with permission.

USV Images from PFR 


\section{Summary}

Extensive testing of a wide variety of coolants in the 1950s and 1960s.

- Nearly all fast reactors constructed have used sodium coolant.

- 50+ years of sodium component development, testing, and operation.

- Current fast reactor construction projects also use sodium.

- Very limited experience with LBE coolant, and no experience with lead or helium-cooled fast reactors.

- Thermophysical and thermal-hydraulic properties of sodium are superior to lead or helium.

- Smaller core with higher power density, lower enrichment, and lower heavy metal inventory.

- Use of sodium codified in ASTM standards.

- Issues of sodium reactivity must be addressed through proper component design, fabrication, and testing.

- There are important differences in reactor design introduced by the use of sodium.

- Low system pressure, high thermal conductivity, large safety margins.

- Demonstrated capability for passive shutdown and decay heat removal. 


\section{Argonne LABORATORY}

... for a brighter future

\section{Fast Reactor Physics and Core Design}

NRC Topical Seminar on Sodium Fast Reactors Two White Flint, Rockville, MD May 3, 2007

Robert N. Hill

Department Head - Nuclear Systems Analysis Nuclear Engineering Division Argonne National Laboratory 


\section{Outline}

- Fast Reactor Physics

- Contrast LWR physics and different fast reactor types

- Important phenomena and modeling/data challenges

- Impact on fuel cycle performance

- Brief overview of existing methods and codes

- Sodium-cooled Fast Reactor (SFR) Core Design

- Contrast to LWR design parameters

- Typical reactor configuration

- Typical reactor performance

- SFR Reactivity Coefficients

- Identification of physics for each feedback

- Brief discussion of safety implications 


\section{Comparison of LWR and SFR Spectra}

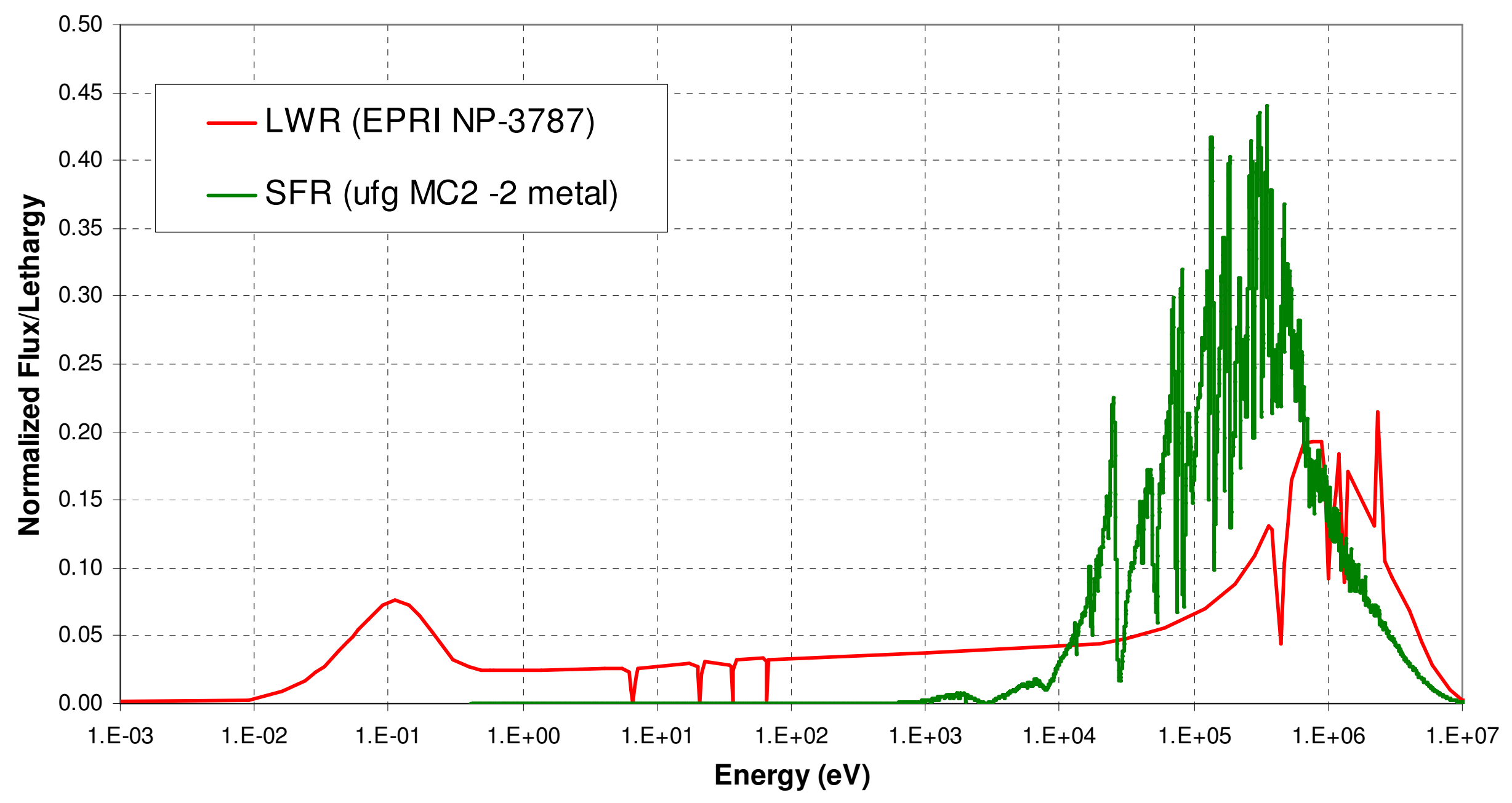

- In LWR, most fissions occur in the $0.1 \mathrm{eV}$ thermal "peak"

- In SFR, moderation is avoided - no thermal neutrons 


\section{Neutron Moderation Comparison}

- Significant elastic scattering of the neutrons in both spectra

- In FRs, neutron moderation is avoided by using high $A$ materials

- Sodium is most moderating

- In LWRs, neutrons are moderated primarily by hydrogen

- Oxygen in water and fuel also

\begin{tabular}{|l|c|c|c|}
\hline & $\sigma_{\mathrm{s}}$ (barn) & N (\#/barn $\cdot \mathrm{cm})$ & $\xi \Sigma_{\mathrm{s}}\left(\mathrm{cm}^{-1}\right)$ \\
\hline $\mathrm{TRU}$ & 4.0 & $3.2 \mathrm{E}-03$ & $1.1 \mathrm{E}-04$ \\
\hline $\mathrm{U}$ & 5.6 & $5.6 \mathrm{E}-03$ & $2.7 \mathrm{E}-04$ \\
\hline $\mathrm{Zr}$ & 8.1 & $2.6 \mathrm{E}-03$ & $4.6 \mathrm{E}-04$ \\
\hline $\mathrm{Fe}$ & 3.4 & $1.9 \mathrm{E}-02$ & $2.3 \mathrm{E}-03$ \\
\hline $\mathrm{Na}$ & 3.8 & $8.2 \mathrm{E}-03$ & $2.7 \mathrm{E}-03$ \\
\hline $\mathrm{H}$ & 11.9 & $2.9 \mathrm{E}-02$ & $3.5 \mathrm{E}-01$ \\
\hline
\end{tabular}
slows down the neutrons

- Slowing-down power in FR is $\sim 1 \%$ that observed for typical LWR

- Thus, neutrons are either absorbed or leak from the reactor before they can reach thermal energies 


\section{Comparison of Fast Reactor Spectra}

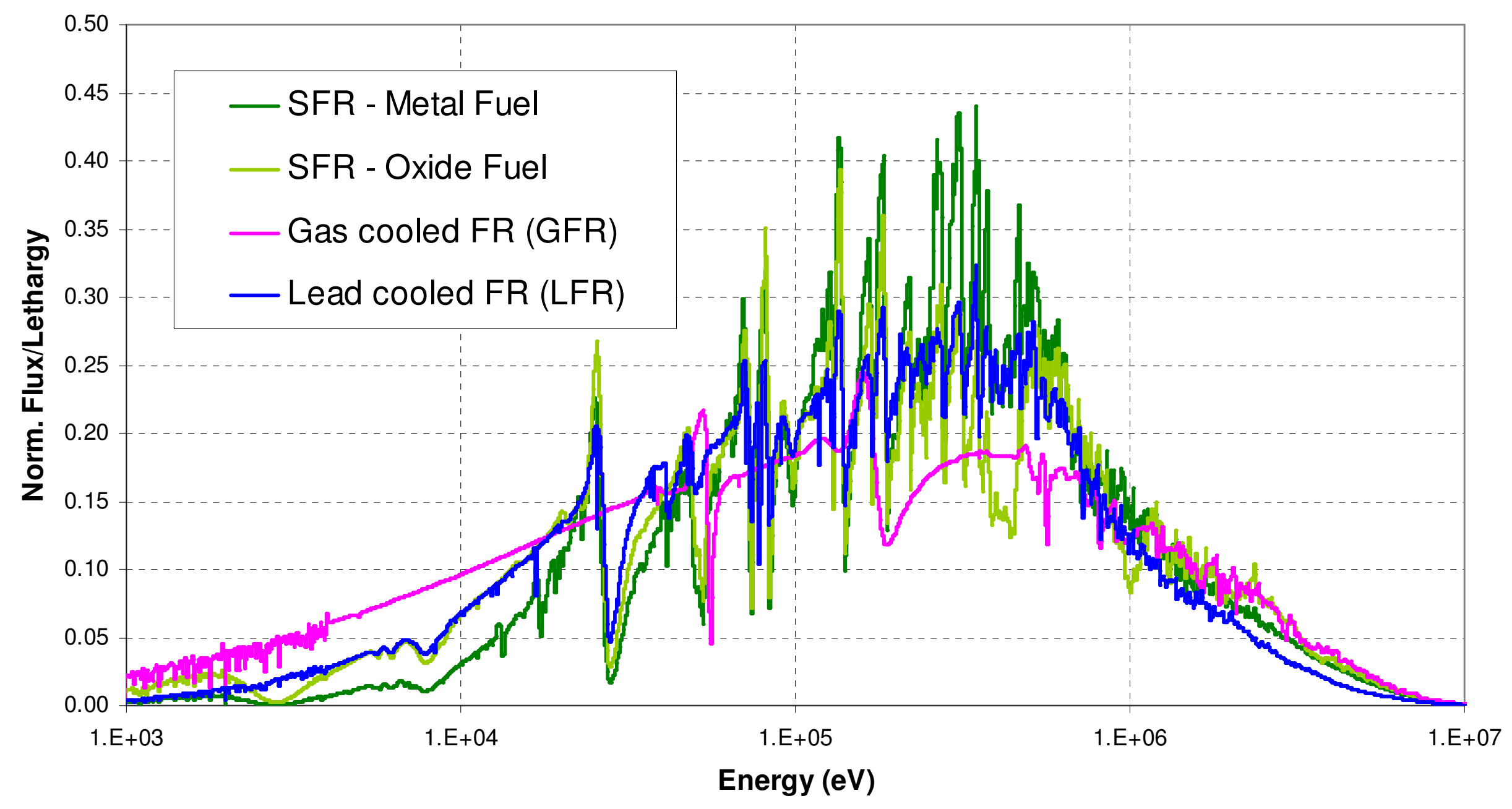

- Also, spectral differences between fast reactor concepts

- At high energy (>1 MeV) lead is effective inelastic scattering material

- Low energy tail caused by moderating materials (next viewgraph) 


\section{Fast Reactor Moderating Materials}

- Lead has highest scattering of the neutrons, but little moderation

- Oxide fuel in SFR leads to a significant moderation effect resonances also observed

- LFR designs also utilize nitride or oxide fuel forms

- In modern GFR designs, $\mathrm{SiC}$ matrix for fuel is utilized, with most moderation of the FR cases

\begin{tabular}{|l|c|c|c|}
\hline & $\sigma_{\mathrm{s}}$ (barn) & $\mathrm{N}$ (\#/barn.cm) & $\xi \Sigma_{\mathrm{s}}\left(\mathrm{cm}^{-1}\right)$ \\
\hline $\mathrm{TRU}$ & 4.0 & $3.2 \mathrm{E}-03$ & $1.1 \mathrm{E}-04$ \\
\hline $\mathrm{U}$ & 5.6 & $5.6 \mathrm{E}-03$ & $2.7 \mathrm{E}-04$ \\
\hline $\mathrm{Zr}$ & 8.1 & $2.6 \mathrm{E}-03$ & $4.6 \mathrm{E}-04$ \\
\hline $\mathrm{Fe}$ & 3.4 & $1.9 \mathrm{E}-02$ & $2.3 \mathrm{E}-03$ \\
\hline $\mathrm{Na}$ & 3.8 & $8.2 \mathrm{E}-03$ & $2.7 \mathrm{E}-03$ \\
\hline $\mathrm{O}$ & 3.6 & $1.4 \mathrm{E}-02$ & $5.8 \mathrm{E}-03$ \\
\hline $\mathrm{Pb}$ & 8.6 & $1.6 \mathrm{E}-03$ & $1.3 \mathrm{E}-04$ \\
\hline $\mathrm{C}$ & 3.9 & $1.6 \mathrm{E}-02$ & $1.0 \mathrm{E}-02$ \\
\hline $\mathrm{He}$ & 1.7 & $3.1 \mathrm{E}-04$ & $2.3 \mathrm{E}-04$ \\
\hline
\end{tabular}

- Net result is that the SFR-metal has the hardest neutron spectrum

- SFR-oxide and LFR similar with slightly more moderation

- GFR (with silicon-carbide matrix) has significant low energy tail 


\section{Spectral Variation of Neutron Cross Sections}

Pu-239

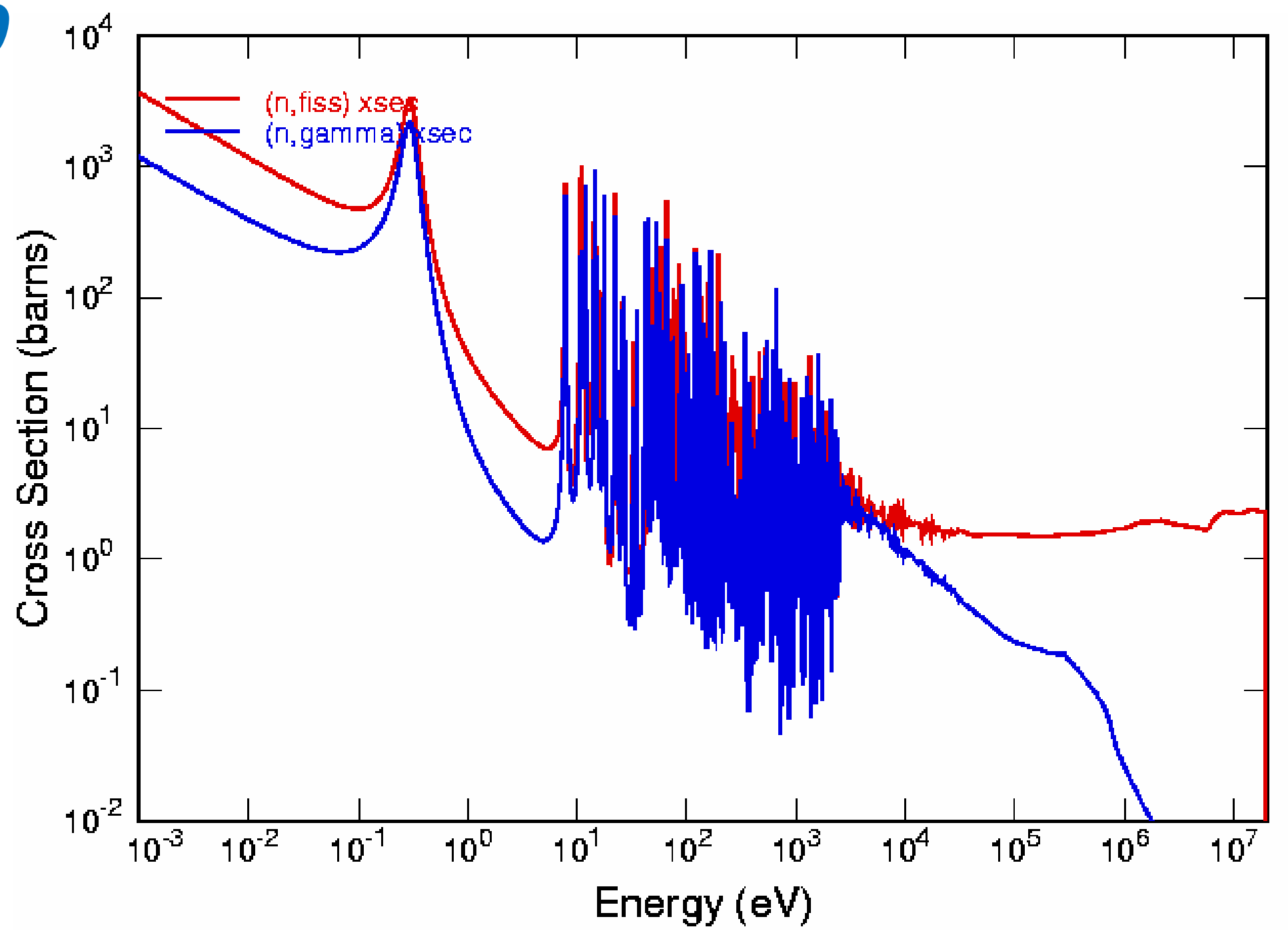

- Fission and capture cross section $>100 \mathrm{X}$ higher in thermal range

- Sharp decrease in capture cross section at high energy 


\section{Spectral Variation of Neutron Cross Sections}

$U-238$

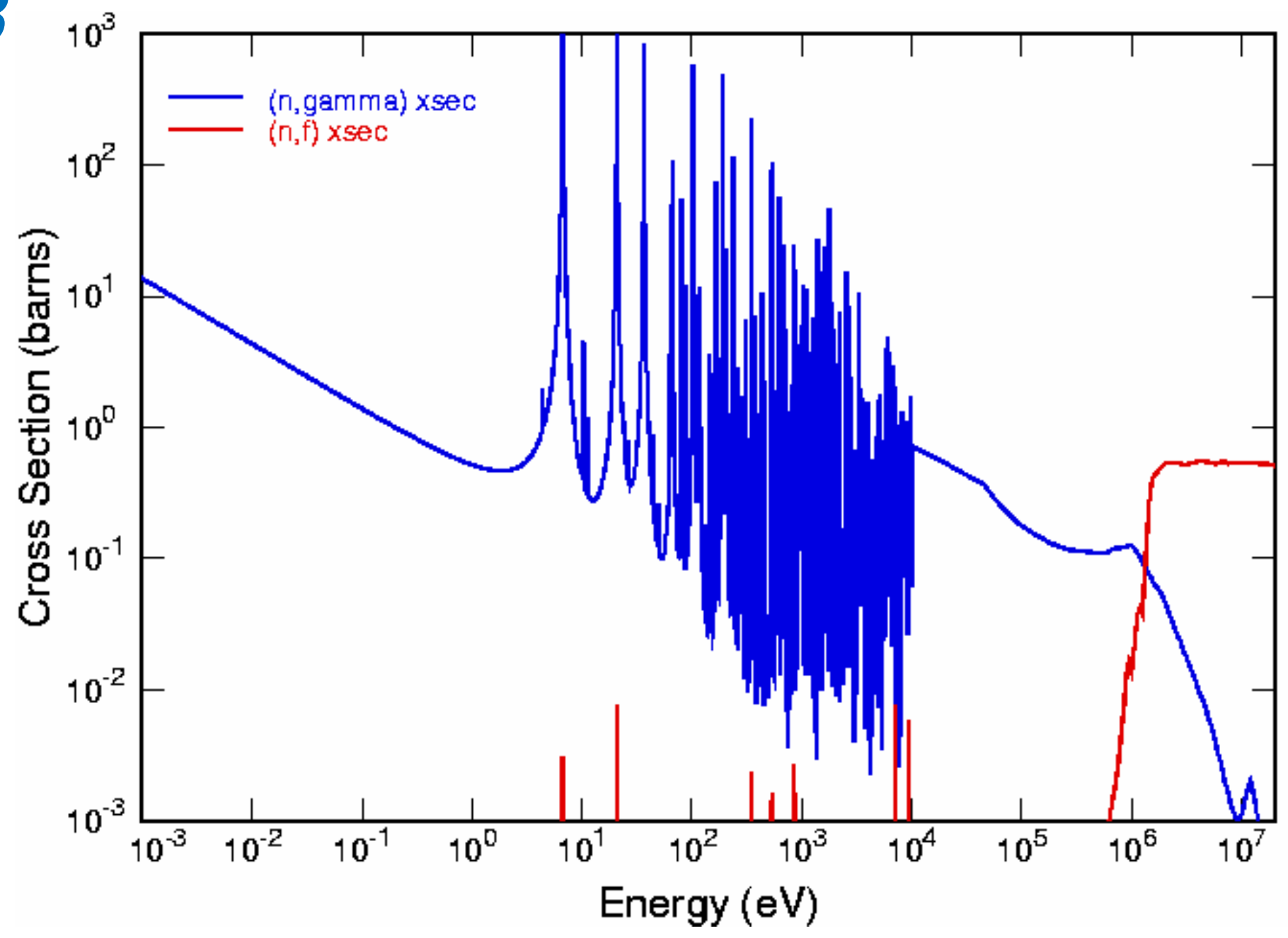

- Much smaller thermal increase in capture ( 10X)

- Unresolved resonance range begins at $\sim 10 \mathrm{keV}$

- Threshold fission at $\sim \mathrm{MeV}$ 


\section{Spectral Variation of Neutron Cross Sections}

Fe and $\mathrm{Na}_{10^{2}}$

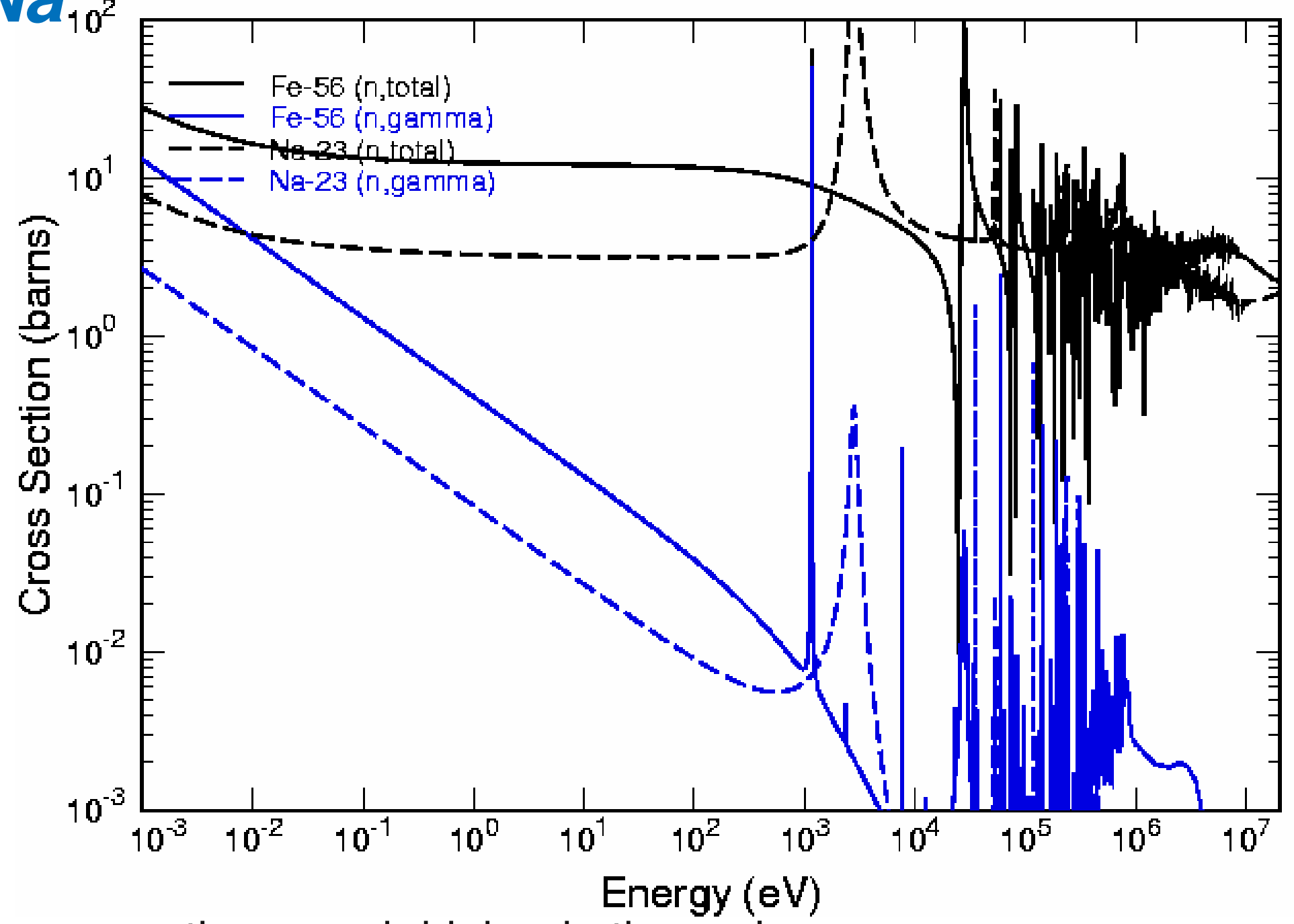

- Capture cross sections much higher in thermal range

- Significant scattering resonance structure throughout fast range 


\section{Implications of Fast Spectrum Physics}

- Combination of increased fission/absorption and increased number of neutrons/fission yields more excess neutrons from Pu-239

- Enables "breeding" of fissile material

- In a fast spectrum, U-238 capture is more prominent

- Higher enrichment (TRU/HM) is required (next viewgraph)

- Enhances internal conversion

- Reduced parasitic capture and improved neutron balance

- Allows the use of conventional stainless steel structures

- Slow loss of reactivity with burnup

- Less fission product capture and more internal conversion

- The lower absorption cross section of all materials leads to a much longer neutron diffusion length (10-20 cm, as compared to $2 \mathrm{~cm}$ in LWR)

- Neutron leakage is increased (>20\% in typical designs)

- Reflector effects are more important

- Heterogeneity effects are relatively unimportant 
Impact of Energy Spectrum

on Enrichment and Depletion Behavior

\begin{tabular}{|l|c|c|c|c|c|c|}
\hline \multirow{2}{*}{ Reaction } & \multicolumn{3}{|c|}{ Thermal Concepts } & \multicolumn{3}{c|}{ Fast Concepts } \\
\cline { 2 - 7 } & PWR & VHTR & SCWR & SFR & LFR & GFR \\
\hline U238c & 0.91 & $\mathbf{4 . 8 0}$ & 0.95 & 0.20 & 0.26 & 0.32 \\
\hline Pu239f & 89.2 & 164.5 & 138.8 & 1.65 & 1.69 & 1.90 \\
\hline P239f/U238c & 97.7 & 34.3 & 146.6 & $\mathbf{8 . 1 4}$ & $\mathbf{6 . 5 9}$ & $\mathbf{6 . 0 0}$ \\
\hline Fe & 0.4 & & & $\mathbf{0 . 0 0 7}$ & & \\
\hline Fission Prod. & 90 & & & $\mathbf{0 . 2}$ & & \\
\hline
\end{tabular}

- Generation-IV fast systems have similar characteristics

- One-group XS are significantly reduced in fast system

- However, U-238 capture is much more prominent (low P239f/U238c)

- A much higher enrichment is required to achieve criticality

- The parasitic capture cross section of fission products and conventional structures is much higher in a thermal spectrum (next viewgraph) 


\section{Neutron Balance}

\begin{tabular}{|l|l|c|c|c|}
\hline \multirow{2}{*}{} & \multirow{2}{*}{ PWR } & \multicolumn{2}{|c|}{ SFR } \\
\cline { 3 - 5 } \multicolumn{2}{|c|}{} & & CR=1.0 & CR=0.5 \\
\hline \multirow{2}{*}{ U-235 or TRU enrichment, \% } & $\mathbf{4 . 2}$ & $\mathbf{1 3 . 9}$ & $\mathbf{3 3 . 3}$ \\
\hline \multirow{3}{*}{ Source } & fission & $100.0 \%$ & $99.8 \%$ & $99.9 \%$ \\
\cline { 2 - 5 } & (n,2n) & & $0.2 \%$ & $0.1 \%$ \\
\hline \multirow{5}{*}{ Loss } & leakage & $3.5 \%$ & $22.9 \%$ & $\mathbf{2 8 . 7 \%}$ \\
& radial & $3.0 \%$ & $12.3 \%$ & $16.6 \%$ \\
& axial & $0.4 \%$ & $10.6 \%$ & $12.1 \%$ \\
\cline { 2 - 5 } & absorption & $96.5 \%$ & $77.1 \%$ & $71.3 \%$ \\
& fuel & $76.7 \%$ & $71.8 \%$ & $62.2 \%$ \\
& (U-238 capture) & $(27.2 \%)$ & $(31.6 \%)$ & $(17.1 \%)$ \\
& coolant & $3.4 \%$ & $0.1 \%$ & $0.1 \%$ \\
& structure & $0.6 \%$ & $3.7 \%$ & $3.7 \%$ \\
& fission product & $6.8 \%$ & $1.5 \%$ & $2.4 \%$ \\
& control & $9.0 \%$ & $0.0 \%$ & $2.9 \%$ \\
\hline
\end{tabular}

- Conversion ratio defined as ratio of TRU production/TRU destruction - Slightly different than traditional breeding ration with fissile focus 


\section{Impact of Energy Spectrum on Fuel Cycle (Transmutation) Performance}

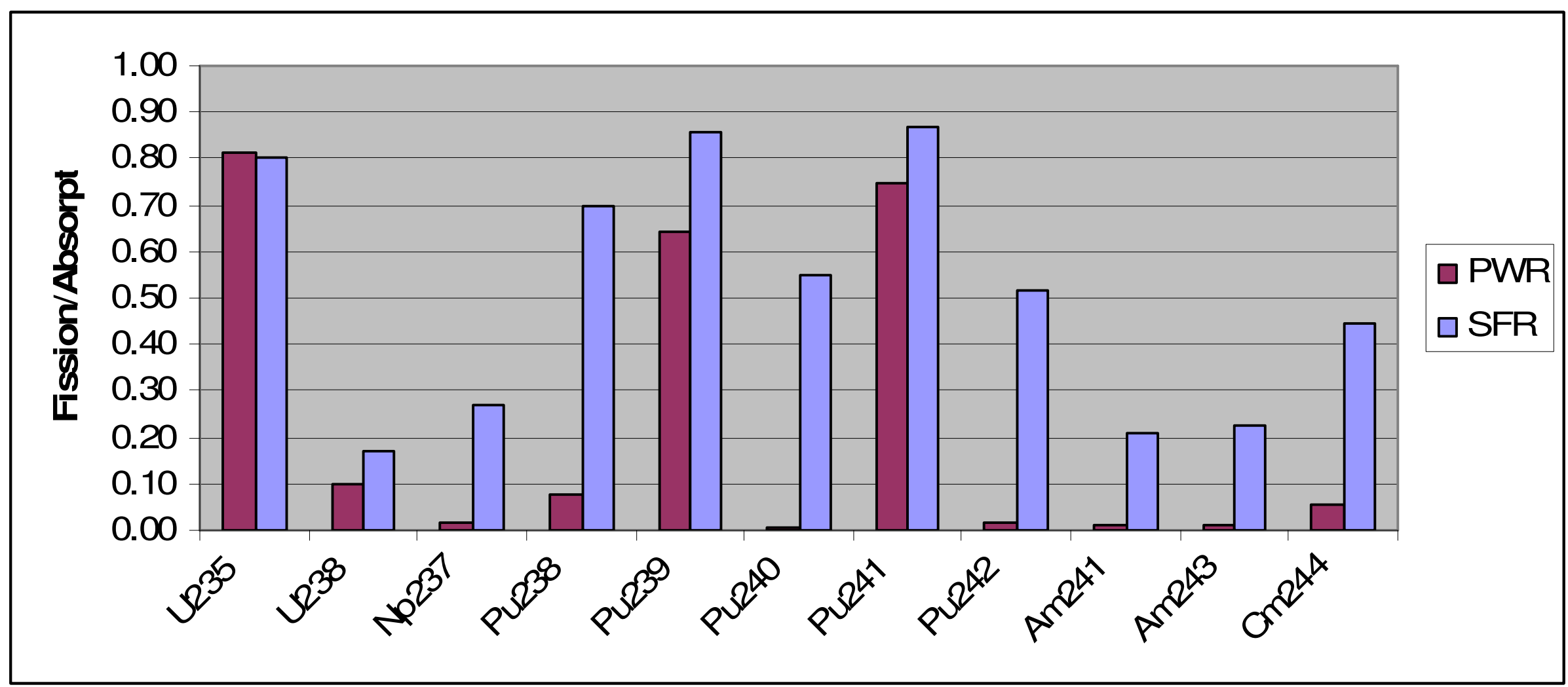

- Fissile isotopes are likely to fission in both thermal/fast spectrum

- Fission fraction is higher in fast spectrum

- Significant (up to 50\%) fission of fertile isotopes in fast spectrum

Net result is more excess neutrons and less higher actinide generation in FR 
Spectral Comparison of Isotopic D-factors

\begin{tabular}{|l|ccc|ccc|}
\hline \multirow{2}{*}{ Isotope } & \multicolumn{3}{|c|}{ Thermal Concepts } & \multicolumn{3}{c|}{ Fast Concepts } \\
\cline { 2 - 7 } & PWR & VHTR & SCWR & SFR & LFR & GFR \\
\hline U-235 & 0.65 & 0.53 & 0.70 & 1.04 & 0.92 & 0.84 \\
\hline U-238 & 0.02 & -0.26 & -0.01 & 0.89 & 0.71 & 0.62 \\
\hline Np-237 & -0.96 & -1.11 & -1.03 & 0.88 & 0.65 & 0.51 \\
\hline Pu-239 & 0.83 & 0.72 & 0.80 & 1.71 & 1.59 & 1.45 \\
\hline Pu-240 & -0.04 & -0.12 & -0.09 & 1.28 & 1.04 & 0.94 \\
\hline Pu-241 & 0.95 & 0.88 & 0.90 & 1.42 & 1.29 & 1.27 \\
\hline
\end{tabular}

D-factor measures the neutron balance to completely fission a given isotope - Positive value indicates excess neutrons are generated

- Fast systems have favorable neutron balance for all TRU isotopes

- Thermal reactor only for the fissile isotopes

- Thus, fast systems can efficiently convert U-238 and consume the actinides, while a fissile source is require to sustain the thermal conversion 


\section{Equilibrium Composition in Fast and Thermal Spectra}

\begin{tabular}{|c|c|c|c|}
\hline Isotope & $\begin{array}{c}\text { Once- } \\
\text { Through }\end{array}$ & $\begin{array}{c}\text { Fast } \\
\text { U-238 }\end{array}$ & $\begin{array}{c}\text { Thermal } \\
\text { U-238 }\end{array}$ \\
\hline Np237 & 0.048 & 0.008 & 0.002 \\
\hline Pu238 & 0.024 & 0.014 & 0.046 \\
\hline Pu239 & 0.476 & 0.666 & 0.388 \\
\hline Pu240 & 0.225 & 0.243 & 0.197 \\
\hline Pu241 & 0.106 & 0.021 & 0.111 \\
\hline Pu242 & 0.066 & 0.018 & 0.085 \\
\hline Am241 & 0.034 & 0.021 & 0.019 \\
\hline Am242m & 0.000 & 0.001 & 0.001 \\
\hline Am243 & 0.015 & 0.005 & 0.033 \\
\hline Cm242 & 0.000 & 0.000 & 0.002 \\
\hline Cm244 & 0.005 & 0.002 & 0.055 \\
\hline Cm245 & 0.000 & 0.000 & 0.018 \\
\hline Cm246 & 0 & 0.000 & 0.031 \\
\hline Cm247 & 0 & 0.000 & 0.004 \\
\hline Cm248 & 0 & 0.000 & 0.006 \\
\hline
\end{tabular}

Equilibrium higher actinide content much lower in fast spectrum system

- Generation of Pu-241 (key waste decay chain) is suppressed

- However, if starting from once-through LWR composition (e.g., burner reactor) the higher actinide content will be higher than the U-238 equilibrium 


\section{Fuel Cycle Implications}

The physics distinctions facilitate different fuel cycle strategies

- Thermal reactors are typically configured for once-through (open) fuel cycle

- They can operate on low enriched uranium (LEU)

- They require an external fissile feed (neutron balance)

- Higher actinides must be managed to allow recycle

- Separation of higher elements - still a disposal issue

- Extended cooling time for curium decay

- Fast reactors are typically intended for closed fuel cycle with uranium conversion and resource extension

- Higher actinide generation is suppressed

- Neutron balance is favorable for recycled TRU

- No external fissile material is required

- Can enhance U-238 conversion for traditional breeding

- Can limit U-238 conversion for burning 


\section{Computational Methods}

- Many of the assumptions employed in traditional LWR methods do not apply

- Lack of a 1/E type spectrum as a basis for the calculation of resonance absorption

- $E \varphi(E)$ strongly decreases with decreasing energy in FR

- Up-scattering resulting from the thermal motion of the scattering nuclei may be neglected

- Inelastic, $(\mathrm{n}, 2 \mathrm{n})$, anisotropic scatterings are of great importance

- Long mean free path implies global coupling

- Local reactivity effects impact entire core

- The energy range where neutrons induce fission and the energy range where the fission neutrons appear strongly overlap

- Other physics consideration have high priority in FR methods

- Detailed energy modeling for resonance structure (core/reflector)

- Transport and anisotropy effects more important at high energy

- In general, a distinct set of physics analysis and core design tools with tailored assumptions was developed for fast reactor analysis 


\section{Comparison of LWR and SFR Spectra}

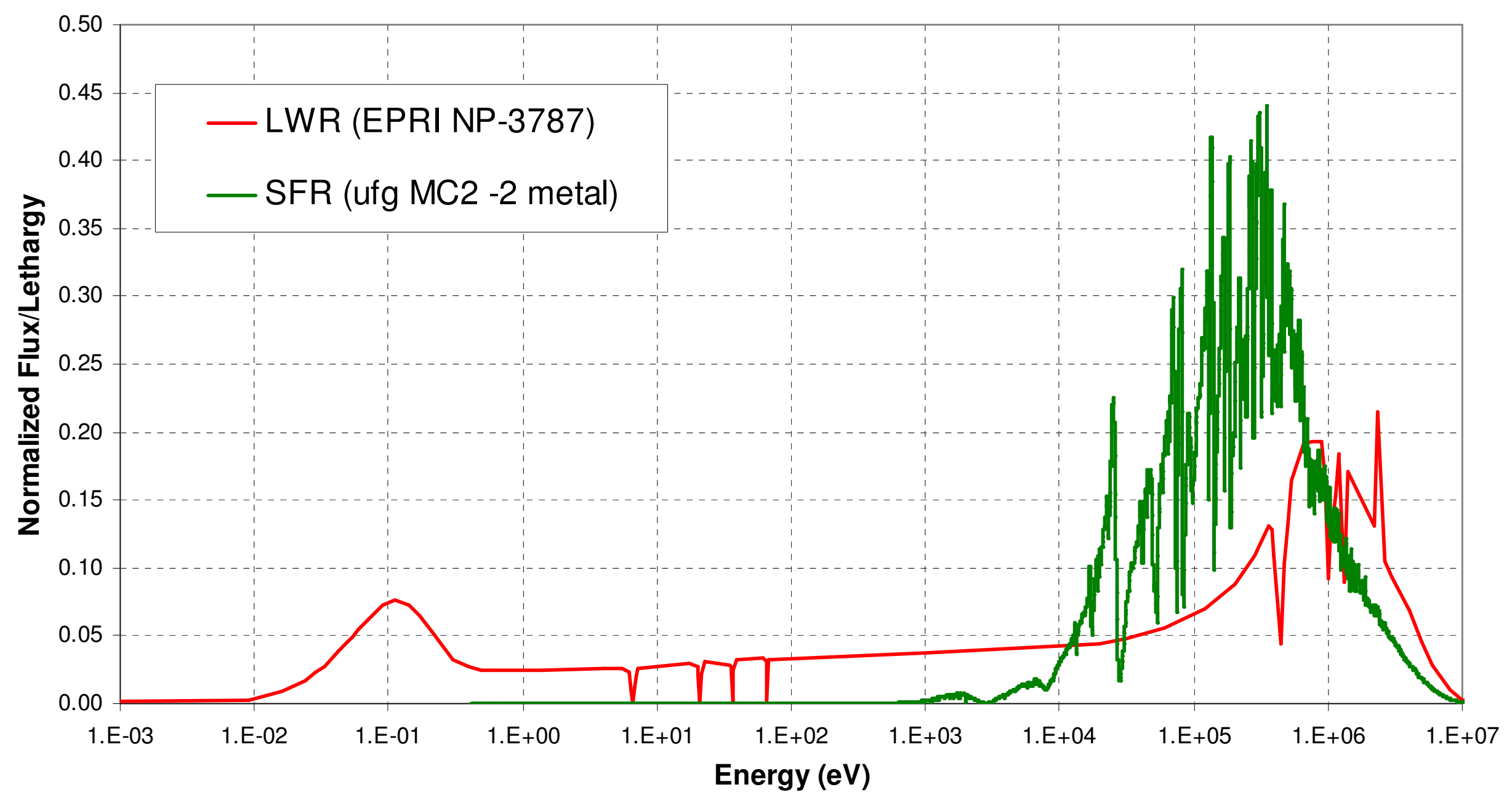

- In LWR, most fissions occur in the $0.1 \mathrm{eV}$ thermal "peak"

- In SFR, moderation is avoided - no thermal neutrons 


\section{Existing Sodium-Cooled Fast Reactor Code Suite}

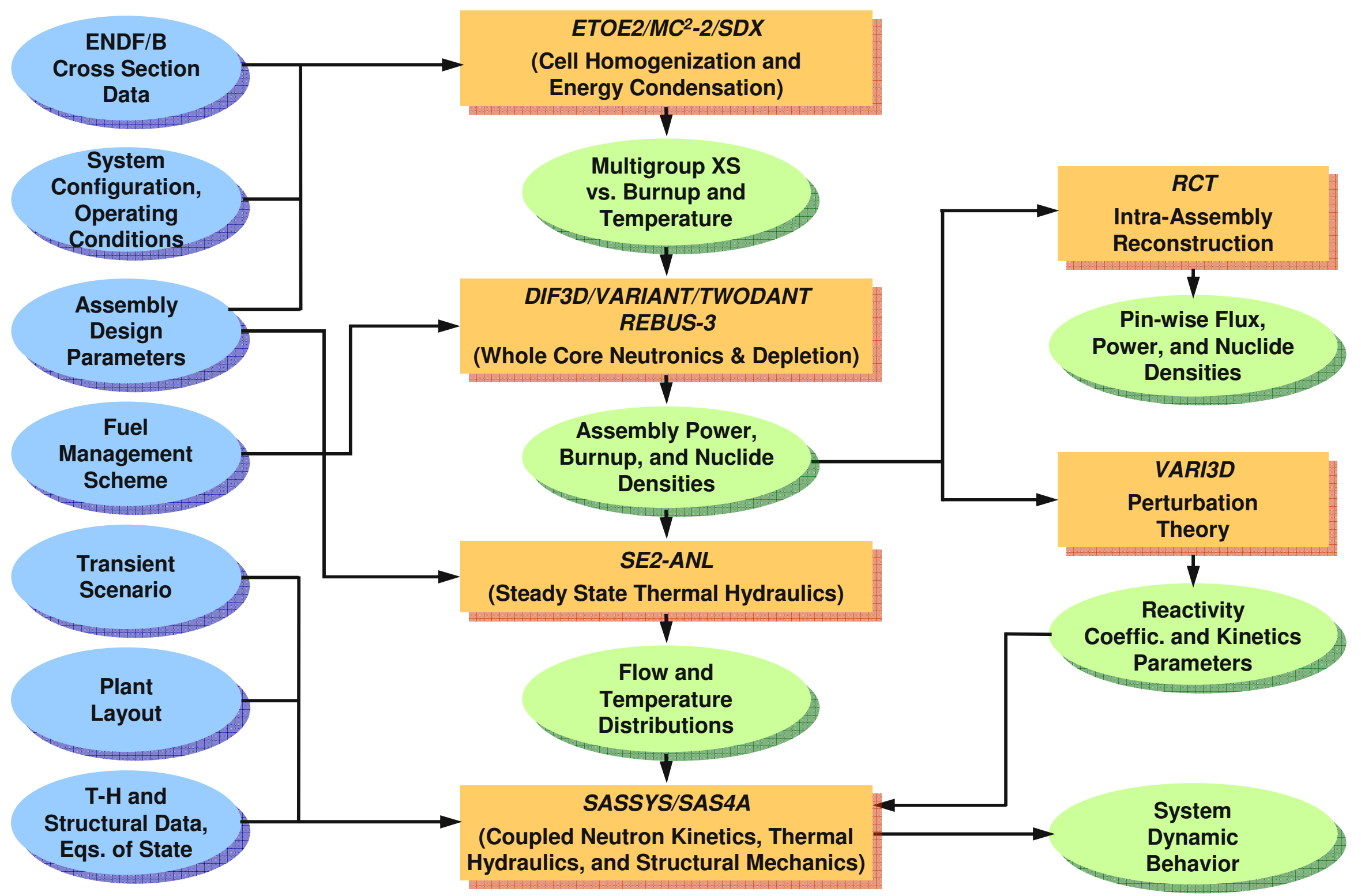




\section{Typical Neutronics Analysis Techniques}

- Design calculations typically performed using 33 energy groups

- Cross sections self-shielded at ultrafine group ( 2000+) level

- Spatial collapse to form regional broad group cross sections

- Design calculations utilize nodal diffusion method

- Nodal transport techniques also available

- Continuous energy Monte Carlo for benchmarking

- Advanced transport methods (generalized geometry and many energy groups) being developed in GNEP advanced simulation campaign

- Depletion calculations include extensive external cycle modeling

- Several axial depletion regions within assembly (pin-wise for processing)

- Conventional FR fuel management does not shuffle fuel

- Current tools are adequate to begin the design process

- Extensive critical experiment and reactor operation database exists

- Validation and capabilities have evolved in parallel

- Formal and comprehensive documentation needs to be done

- This activity should support evaluation of advanced methods 


\section{Typical Design Specifications of LWR and SFR}

\begin{tabular}{|c|c|c|c|c|}
\hline & & & PWR & SFR \\
\hline \multirow{2}{*}{ General } & \multicolumn{2}{|c|}{ Specific power (kWt/kgHM) } & 786 (U-235) & 556 (Pu fissile) \\
\hline & \multicolumn{2}{|c|}{ Power density $\left(\mathrm{MWt} / \mathrm{m}^{3}\right)$} & 102 & 300 \\
\hline \multirow{5}{*}{ Fuel } & \multicolumn{2}{|c|}{ Rod outer diameter (mm) } & 9.5 & 7.9 \\
\hline & \multicolumn{2}{|c|}{ Clad thickness (mm) } & 0.57 & 0.36 \\
\hline & \multicolumn{2}{|c|}{ Rod pitch-to-diameter ratio } & 1.33 & 1.15 \\
\hline & \multicolumn{2}{|c|}{ Enrichment (\%) } & $\sim 4.0$ & $\sim 20 \mathrm{Pu} /(\mathrm{Pu}+\mathrm{U})$ \\
\hline & \multicolumn{2}{|c|}{ Average burnup (MWd/kg) } & 40 & 100 \\
\hline \multirow{9}{*}{$\begin{array}{l}\text { Thermal } \\
\text { Hydraulic }\end{array}$} & \multirow{4}{*}{ Coolant } & pressure (MPa) & 15.5 & 0.1 \\
\hline & & inlet temp. $\left({ }^{\circ} \mathrm{C}\right)$ & 293 & 332 \\
\hline & & outlet temp. $\left({ }^{\circ} \mathrm{C}\right)$ & 329 & 499 \\
\hline & & reactor $\Delta \mathrm{p}(\mathrm{MPa})$ & 0.345 & 0.827 \\
\hline & \multirow{2}{*}{$\begin{array}{l}\text { Rod surface } \\
\text { heat flux }\end{array}$} & average $\left(\mathrm{MW} / \mathrm{m}^{2}\right)$ & 0.584 & 1.1 \\
\hline & & maximum $\left(\mathrm{MW} / \mathrm{m}^{2}\right)$ & 1.46 & 1.8 \\
\hline & \multicolumn{2}{|c|}{ Average linear heat rate $(\mathrm{kW} / \mathrm{m})$} & 17.5 & 27.1 \\
\hline & \multirow{2}{*}{ Steam } & pressure (MPa) & 7.58 & 15.2 \\
\hline & & temperature $\left({ }^{\circ} \mathrm{C}\right)$ & 296 & 455 \\
\hline \multirow{2}{*}{ Control } & \multicolumn{2}{|l|}{ Control Rods } & $0.07(10.8 \$)$ & Primary/Secondary $(10 \$ / 3 \$)$ \\
\hline & \multicolumn{2}{|c|}{ Chemical Shim } & $0.25(38.5 \$)$ & \\
\hline
\end{tabular}




\section{Sodium-Cooled Fast Reactor Primary Vessel and Fuel Assembly}

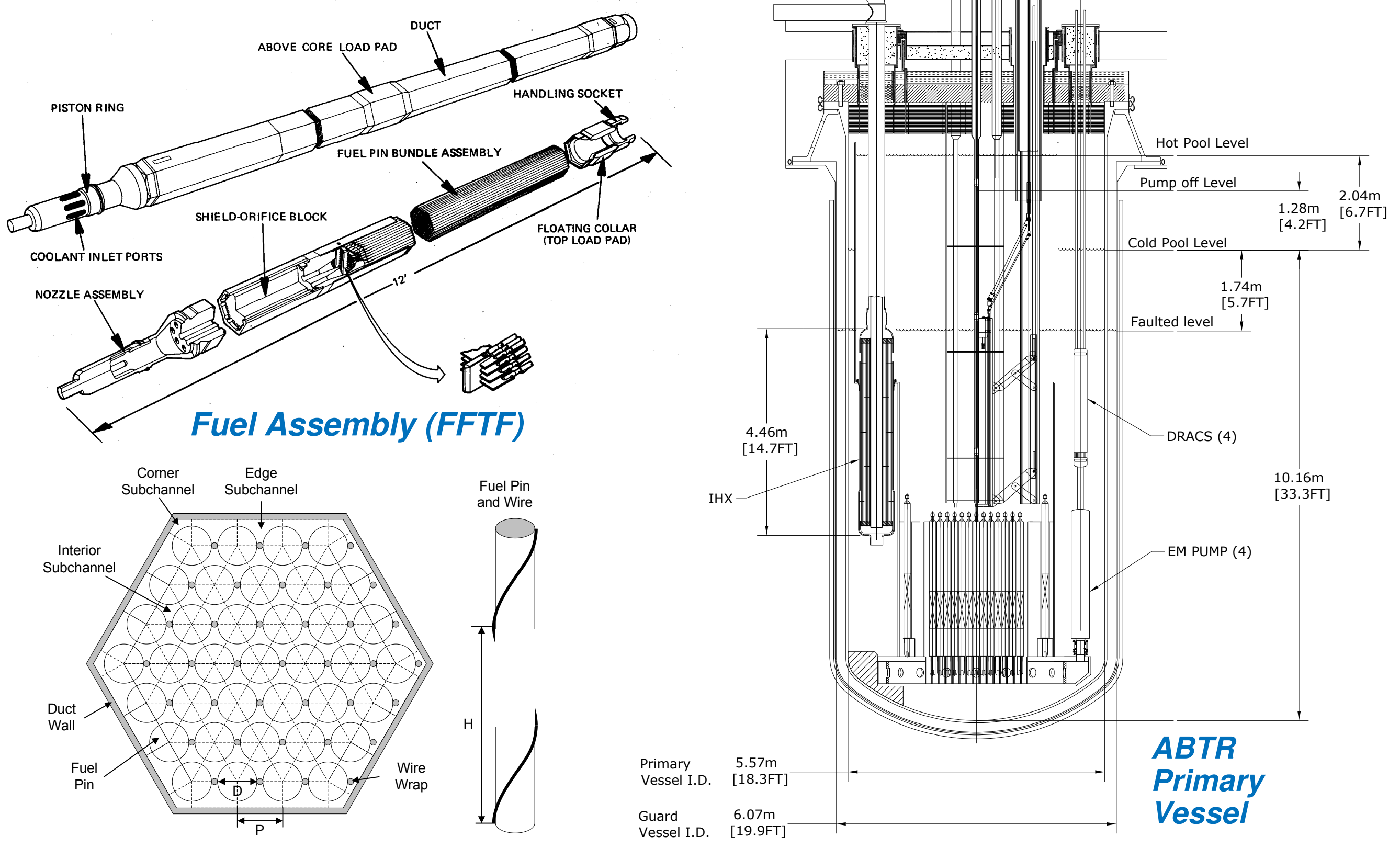

\section{Argonne}




\section{Typical Core Design Volume Fractions}

\begin{tabular}{|c|c|c|c|c|c|}
\hline \multirow{2}{*}{ Material } & \multirow{2}{*}{ PWR } & \multicolumn{2}{|c|}{ SFR } & \multirow{2}{*}{ LFR } & \multirow{2}{*}{ GFR } \\
\cline { 3 - 4 } & & CR=1.0 & CR=0.5 & & \\
\hline Fuel & 30 & 40 & 30 & 34 & 30 \\
\hline Coolant & 59 & 35 & 44 & 55 & 57 \\
\hline Structure & 11 & 25 & 26 & 11 & 13 \\
\hline
\end{tabular}

- For conventional fast reactor, fuel volume fraction (VF) maximized

- Tightly packed pin lattice

- High volume fraction blankets to introduce additional U-238

- For burner design, TRU production reduced by lower fuel VF

- Smaller pins to yield increased coolant VF

- For LFR, higher coolant VF is required to reduce coolant velocity

- Needed for oxygen control to prevent cladding erosion

- For GFR, higher coolant VF is required because of inferior heat transfer

- Trade-off between pumping power and neutronic performance 


\section{Early Fast Reactors and Fuel Forms}

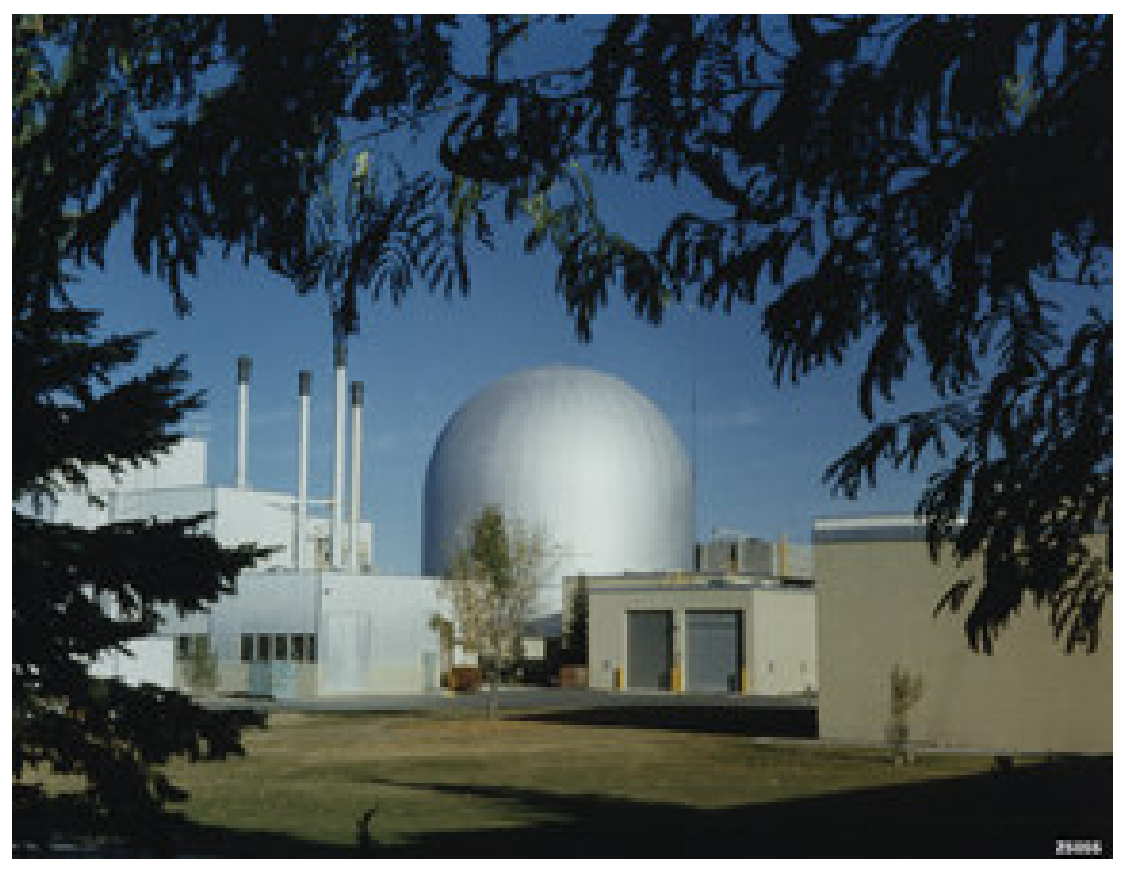

Original choice was high density metal fuel (for breeding)

- First usable nuclear electricityEBR-I in 1951

- EBR-II (1963), Fermi (1963), DFR (UK, 1959) all used metal fuel

- Early designs experienced severely limited fuel burnup because of fuel swelling (U-10Mo burnup of $3 \mathrm{GWd} / \mathrm{MT}$ for Fermi)

U.S. and international programs switched to oxide fuel in the late 1960s

- Low swelling and successful Navy oxide fuel experience $\rightarrow$ high burnup

- Fast Flux Test Facility (400 MWt) operated with oxide from 1980 to 1992

- EBR-II (20 MWe) continued metal fuel development from 1963 to 1994

- Solved burnup limitation by allowing adequate space for fuel swelling

- Demonstrated peak burnup comparable to oxide fuel (200 GWd/MT) 


\begin{tabular}{|c|c|c|c|c|}
\hline $\begin{array}{l}\text { Fast Reactor Fuel Type } \\
\text { Fresh Fuel Properties }\end{array}$ & $\begin{array}{c}\text { Metal } \\
\text { U-20Pu-10Zr }\end{array}$ & $\begin{array}{c}\text { Oxide } \\
\mathrm{UO}_{2}-\mathbf{2 0 P u O}\end{array}$ & $\begin{array}{c}\text { Nitride } \\
\text { UN-20PuN }\end{array}$ & $\begin{array}{l}\text { Carbide } \\
\text { UC-20PuC }\end{array}$ \\
\hline Heavy Metal Density, $\mathrm{g} / \mathrm{cm}^{3}$ & 14.1 & $\underline{9.3}$ & 13.1 & 12.4 \\
\hline Melting Temperature, ${ }^{\circ} \mathrm{K}$ & $\underline{1350}$ & 3000 & $3035^{*}$ & 2575 \\
\hline Thermal Conductivity, $\mathrm{W} / \mathrm{cm}-{ }^{\circ} \mathrm{K}$ & 0.16 & $\underline{0.023}$ & 0.26 & 0.20 \\
\hline $\begin{array}{l}\text { Operating Centerline Temperature } \\
\text { at } 40 \mathrm{~kW} / \mathrm{m},{ }^{\circ} \mathrm{K} \text {, and }\left(\mathrm{T} / \mathrm{T}_{\text {melt }}\right)\end{array}$ & $\begin{array}{l}1060 \\
(0.8)\end{array}$ & $\begin{array}{l}2360 \\
(0.8)\end{array}$ & $\begin{array}{l}1000 \\
(\mathbf{0 . 3}) \\
\end{array}$ & $\begin{array}{l}1030 \\
(0.4) \\
\end{array}$ \\
\hline Fuel-Cladding Solidus, ${ }^{\circ} \mathrm{K}$ & $\underline{1000}$ & 1675 & 1400 & 1390 \\
\hline Thermal Expansion, $1 /{ }^{\circ} \mathrm{K}$ & $17 \mathrm{E}-6$ & $12 \mathrm{E}-6$ & $10 \mathrm{E}-6$ & $12 \mathrm{E}-6$ \\
\hline Heat Capacity, $\mathrm{J} / \mathrm{g}^{\circ} \mathrm{K}$ & 0.17 & 0.34 & 0.26 & 0.26 \\
\hline Reactor Experience, Country & US, UK & $\begin{array}{l}\text { RUS, FR, JAP } \\
\text { US, UK }\end{array}$ & & IND \\
\hline Research \& Testing, Country & $\begin{array}{l}\text { US, JAP, ROK, } \\
\text { CHI }\end{array}$ & $\begin{array}{l}\text { RUS, FR, JAP, } \\
\text { US, CHI }\end{array}$ & US, RUS, JAP & IND \\
\hline
\end{tabular}




\section{Conventional 1000 MWt SuperPRISM (Metal Core)}
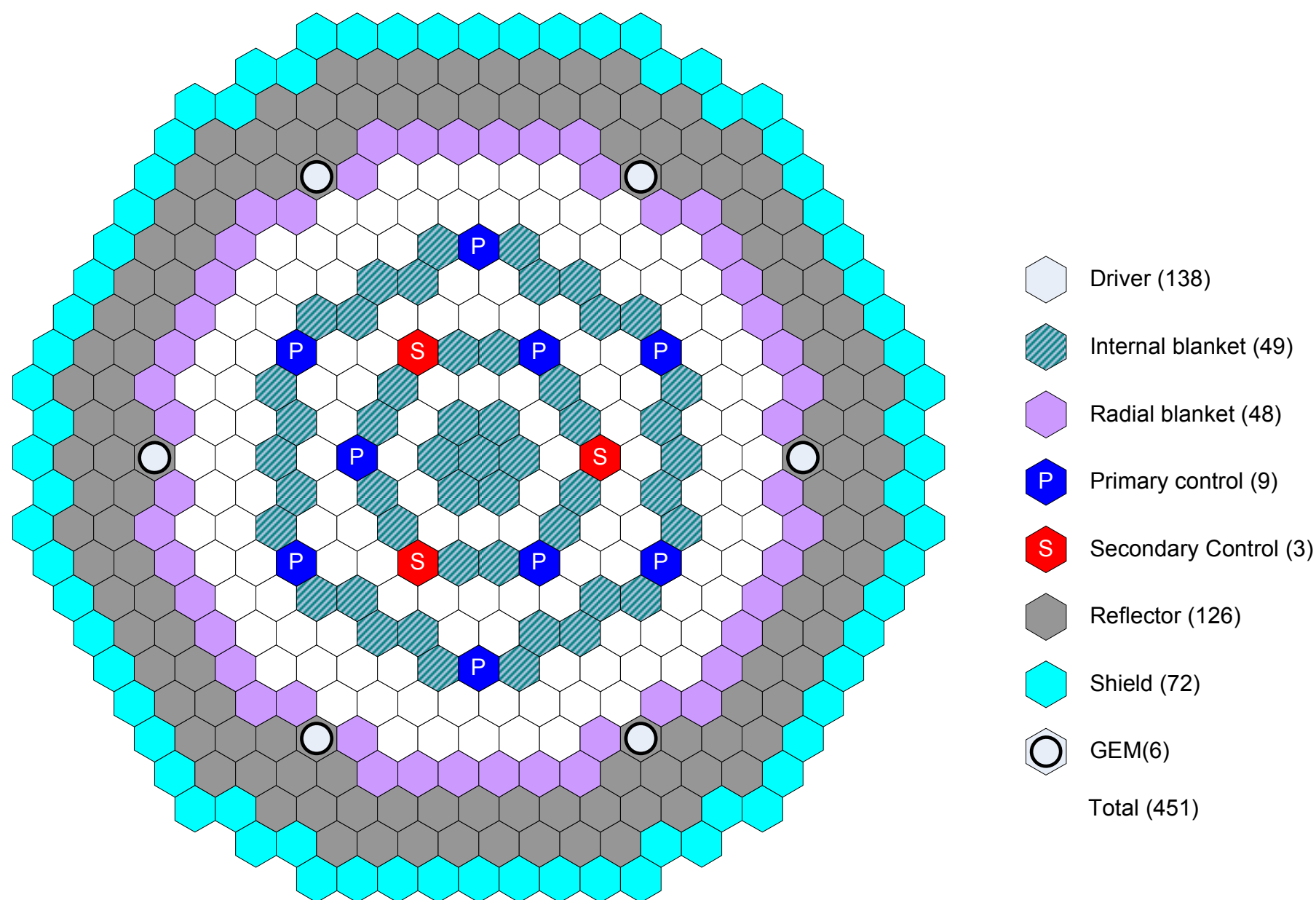

- Internal and external blankets allocated

- Result in conversion ratio of $\sim 1$

- Only 12 control rod locations with very low burnup reactivity losses

- Blanket, two row reflector, and boron carbide for radial shielding 


\section{Burner 1000 MWt Preliminary ABR Burner Design}

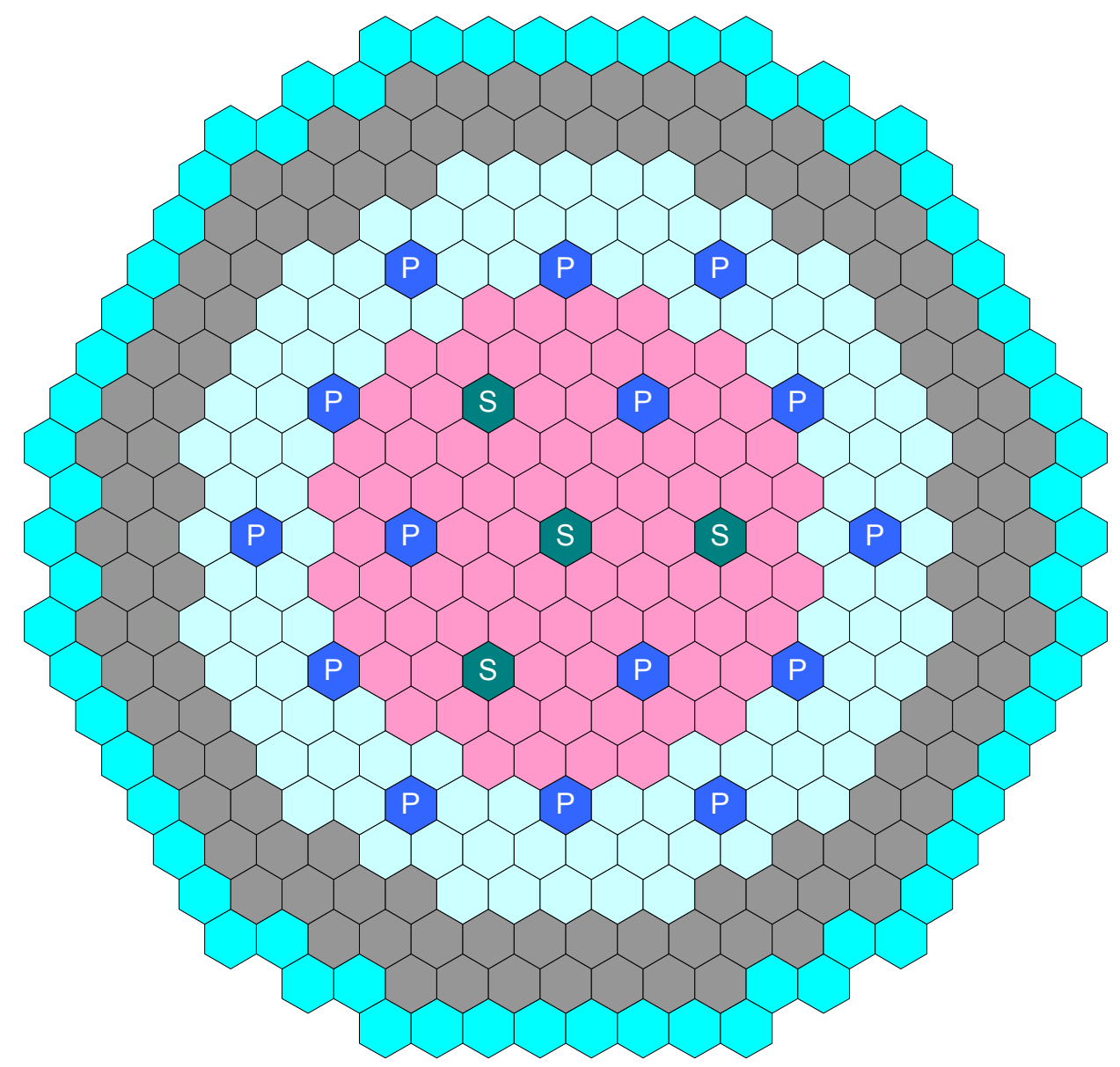

Inner core (78)

Outer core (102)

Reflector (114)

Primary control (15)

Secondary control (4)

Shield (66)

Total (379)

- Two enrichment zones to reduce radial power peaking

- No blankets allocated for conversion ratio $<1$

- Additional (20) control rod locations for burnup reactivity losses

- Similar radial shield configuration 
Core Performance and Mass Flow

\begin{tabular}{|c|c|c|c|c|c|c|}
\hline & \multicolumn{2}{|c|}{ SPRISM - Metal } & \multirow{2}{*}{$\begin{array}{c}1000 \mathrm{MWt} \\
\mathrm{ABR}\end{array}$} & \multirow{2}{*}{$\begin{array}{l}840 \mathrm{MWt} \\
\text { LCFR }\end{array}$} & \multirow{2}{*}{$\begin{array}{c}3500 \mathrm{MWt} \\
\text { US-Eur }\end{array}$} \\
\hline & & Breakeven & Breeder & & & \\
\hline \multicolumn{2}{|c|}{ Cycle length, month } & 23 & 23 & 12 & 6 & 12 \\
\hline \multicolumn{2}{|c|}{ Number of batches } & 4 & 4 & 4 & 6 & 3 \\
\hline \multicolumn{2}{|c|}{ Average TRU enrichment, \% } & $\sim 11$ & $\sim 9$ & 21.9 & $\sim 50$ & 14 \\
\hline \multicolumn{2}{|c|}{ Fissile/TRU conversion ratio } & $1.05 /-$ & $1.22 /-$ & $0.84 / 0.73$ & $-/ 0.25$ & $1.13 /-$ \\
\hline \multicolumn{2}{|c|}{$\mathrm{HM} / \mathrm{TRU}$ inventory at $\mathrm{BOC}, \mathrm{MT}$} & $26.1 / 3.1$ & $36.3 / 3.2$ & $13.2 / 2.9$ & $4.6 / 2.25$ & $59.5 / 5.9$ \\
\hline \multicolumn{2}{|c|}{ Average/peak burnup, $\mathrm{MWd} / \mathrm{kg}$} & $106 / 149$ & $103 / 145$ & $93 / 138$ & $177 / 321$ & $80 / 114$ \\
\hline \multicolumn{2}{|c|}{ Peak Fast Fluence, $10^{23} \mathrm{n} / \mathrm{cm}^{2}$} & 3.9 & 3.9 & 4.0 & 4.0 & 3.1 \\
\hline \multicolumn{2}{|c|}{ Burnup reactivity swing $(\% \Delta \mathrm{k})$} & 0.12 & -0.31 & 3.5 & 4.3 & -0.62 \\
\hline \multicolumn{2}{|c|}{ Average linear power, $\mathrm{kW} / \mathrm{m}$} & 18.9 & 18.3 & 23.3 & & \\
\hline \multicolumn{2}{|c|}{ Peak linear power, kW/m } & 30.4 & 29.8 & 37.2 & 45.4 & 45.4 \\
\hline \multirow{4}{*}{$\begin{array}{l}\text { Mass flow } \\
\text { (kg/year) }\end{array}$} & Uranium & & & -255.8 & -75 & -1216 \\
\hline & Fissile $\mathrm{Pu}$ & 19.3 & 69.9 & -44.0 & & 124 \\
\hline & MA & & & -6.5 & & \\
\hline & TRU & 33.6 & 84.6 & -81.9 & -193 & 158 \\
\hline
\end{tabular}




\section{Burner Design Challenges}

- Radial blanket typically replaced by reflector

- Many criticals (BFS-62, MUSE-4) exhibit problems in accurate prediction of reaction rates in the immediate reflector region

- Spectral and directional transitions are hard to model

- Important for shielding and bowing (safety) considerations

- High leakage configurations also challenge design methods

- Transport effects are magnified

- Key reactivity coefficients (e.g., void worth) impacted

- Current GNEP strategy keeps the grouped TRUs together

- Minor actinides present in fresh fuel

- If low conversion ratio, the TRU enrichment could be high

- However, plutonium remains the dominant fission source (fission contributions on next viewgraph)

- For dedicated minor actinide burners (or targets), uncertainty of the basic MA cross section data becomes important 
Isotopic Fission Fractions

\begin{tabular}{|l|c|c|c|}
\hline & \multirow{2}{*}{ PWR } & \multicolumn{2}{|c|}{ SFR } \\
\cline { 3 - 4 } & & CR=1.0 & CR=0.5 \\
\cline { 3 - 4 } & & $\mathbf{1 3 . 9}$ & $\mathbf{3 3 . 3}$ \\
\hline U-235 or TRU enrichment, \% & $\mathbf{4 . 2}$ & $0.2 \%$ & $0.2 \%$ \\
\hline U-235 & $59.8 \%$ & $15.7 \%$ & $8.3 \%$ \\
\hline U-238 & $6.2 \%$ & $0.2 \%$ & $0.6 \%$ \\
\hline Np-237 & & $0.8 \%$ & $3.4 \%$ \\
\hline Pu-238 & & $70.7 \%$ & $57.0 \%$ \\
\hline Pu-239 & $29.8 \%$ & $6.7 \%$ & $11.4 \%$ \\
\hline Pu-240 & & $4.5 \%$ & $11.9 \%$ \\
\hline Pu-241 & $4.0 \%$ & $0.4 \%$ & $2.5 \%$ \\
\hline Pu-242 & & $0.3 \%$ & $0.8 \%$ \\
\hline Am241 & & $0.2 \%$ & $0.6 \%$ \\
\hline Am-242m & & $0.1 \%$ & $0.7 \%$ \\
\hline Am-243 & & $0.1 \%$ & $0.9 \%$ \\
\hline Cm-244 & & $0.1 \%$ & $1.2 \%$ \\
\hline Cm-245 & & & \\
\hline
\end{tabular}




\section{Assembly Power (MW) of 1000 MWt ABR - Startup Core}

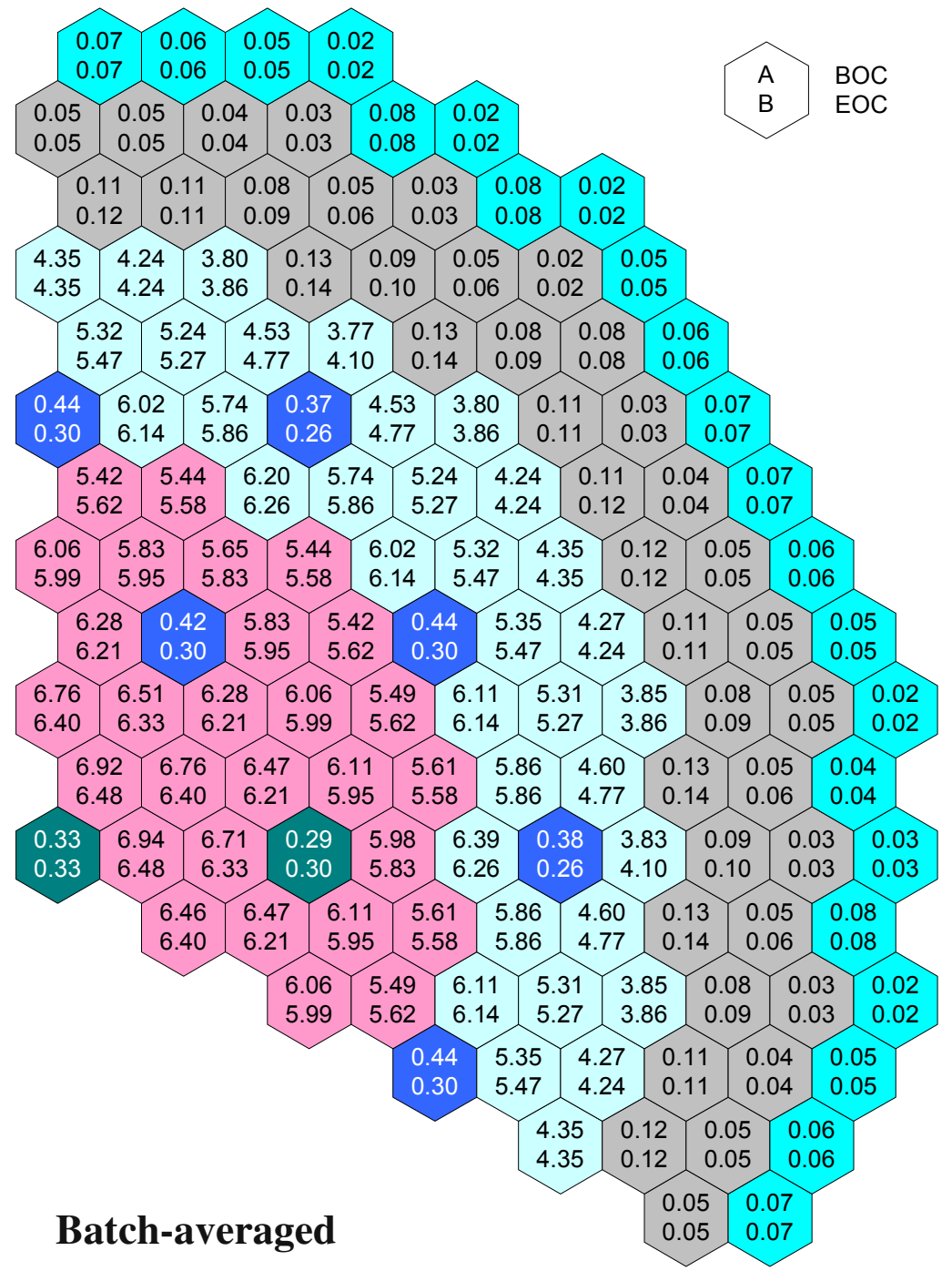

Assembly Power

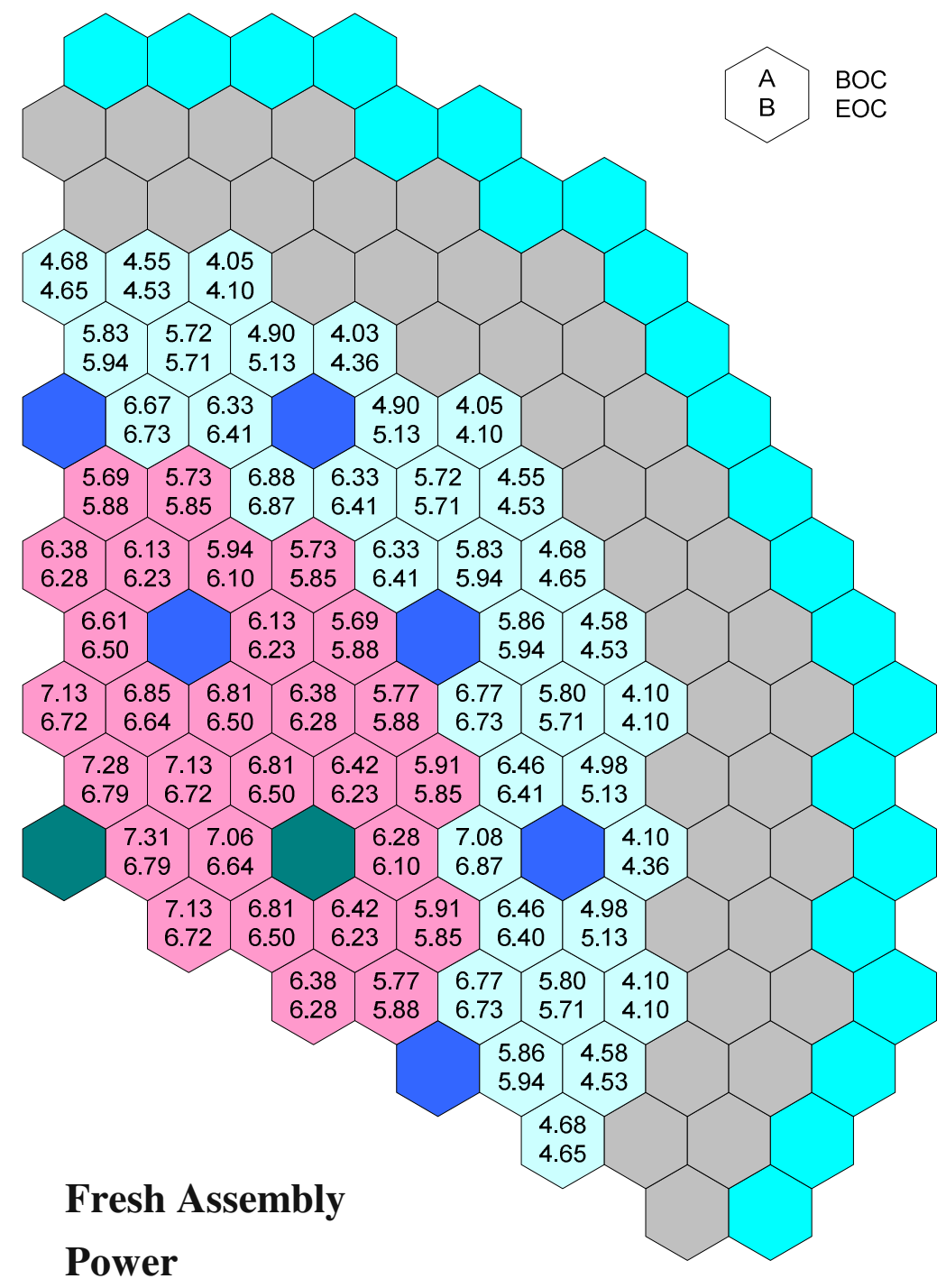

Power

Power peaking factor $(\mathrm{BOC} / \mathrm{EOC})=1.43 / 1.39$ 


\section{Power Profiles of 1000 MWt ABR - Startup Core}
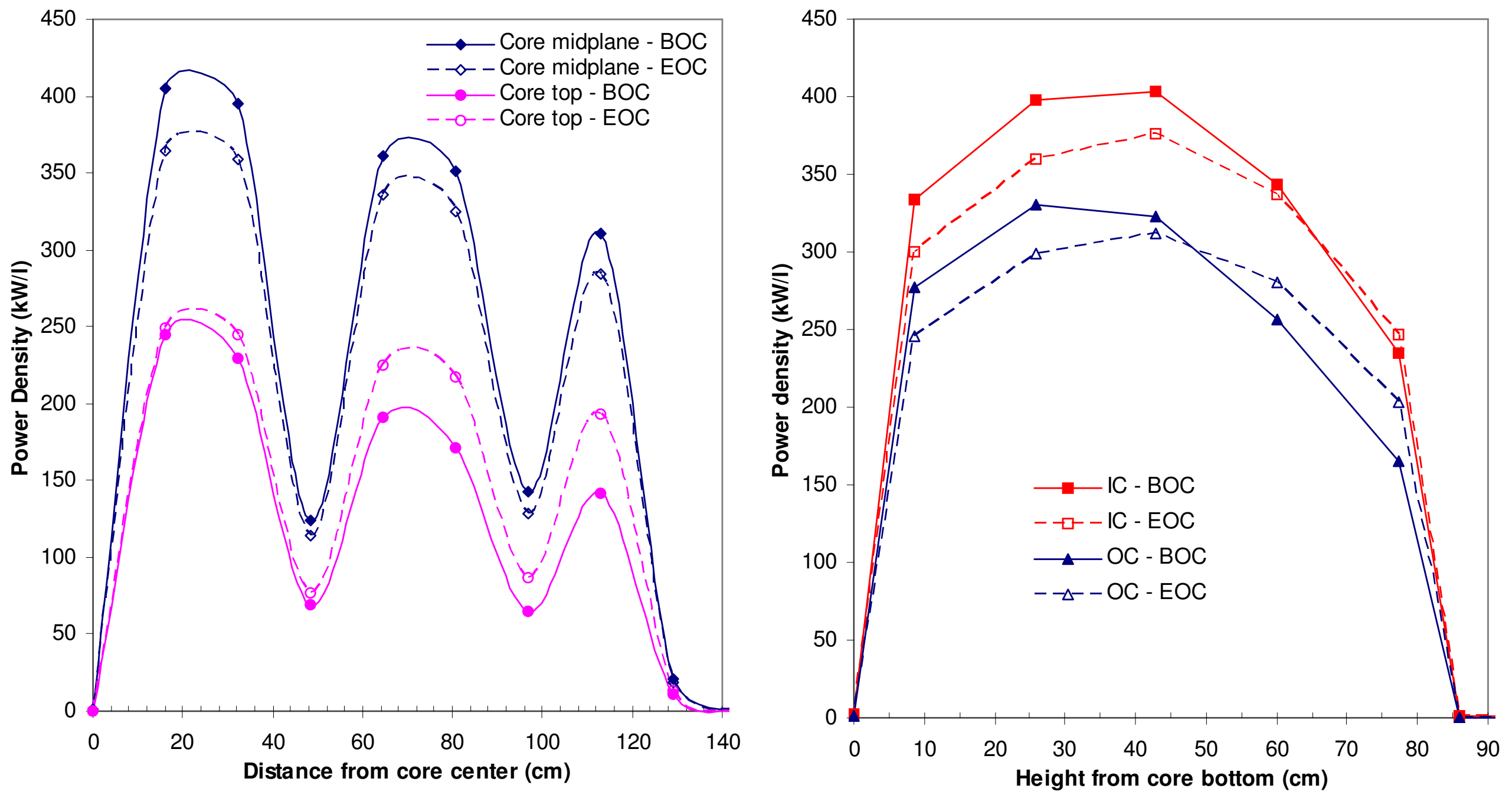

Bottom skewed axial distribution (control assembly tip position at $\mathrm{BOC}=57 \mathrm{~cm}$ )

Axial power peaking factor at $B O C / E O C=1.20 / 1.16$ 


\section{Control Assembly}

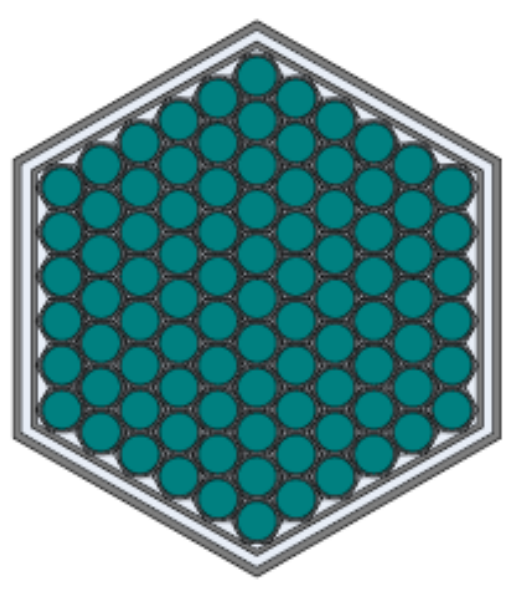

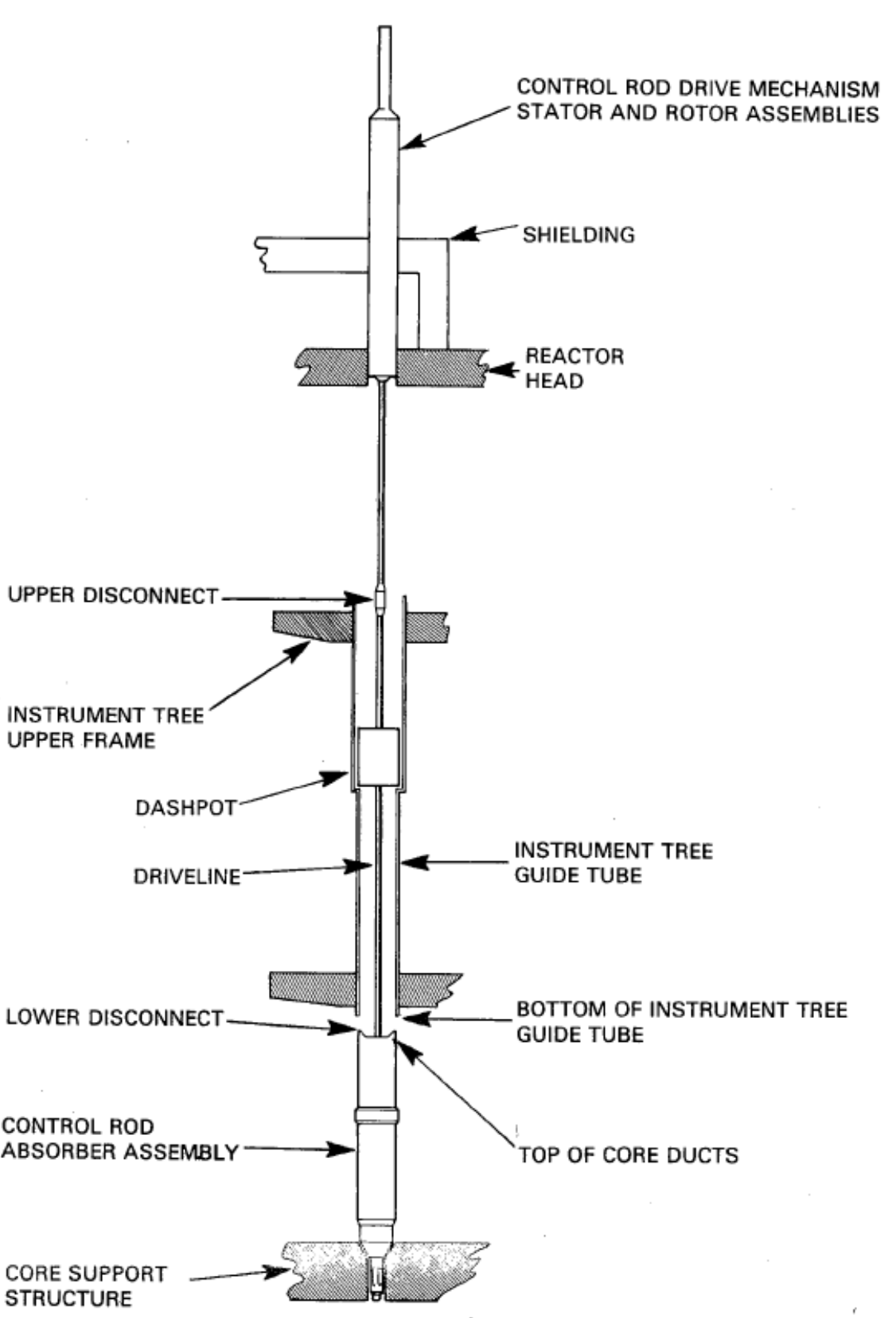




\section{Control System Requirements}

- Typical design utilizes ducted bundle of absorber pins within the coolant duct

- Sufficient reactivity worth to bring reactor

- From any operating condition

- Overpower condition

- Reactivity fault

- To cold sub-critical at refueling temperature

- With most reactive control assembly stuck at full power operating condition

- Hold down excess reactivity for fuel cycle

- Fuel burnup

- Axial growth of metal fuel

- Accommodate reactivity uncertainties

- Criticality and fissile loading

- Temperature defect, burnup reactivity, and fuel growth 


\section{Control Requirement and Shutdown Margin (\$) of Primary System}

\begin{tabular}{|l|r|r|r|r|}
\hline & $\begin{array}{c}1000 \mathrm{MWe} \\
\text { LMFBR a) }\end{array}$ & $\begin{array}{c}975 \mathrm{MWt} \\
\text { CRBRP b) }\end{array}$ & $\begin{array}{c}840 \mathrm{MWt} \\
\text { ALMR/95 }\end{array}$ & $\begin{array}{c}1000 \mathrm{MWt} \\
\text { ABR }\end{array}$ \\
\hline Number of control assemblies & 13 & 15 & 10 & 15 \\
\hline Total worth & 20.0 & 31.8 & 20.0 & 39.5 \\
\hline Worth of 1 stuck rod & 3.0 & 2.8 & 2.3 & 4.3 \\
\hline Reactivity worth available & 17.0 & 29.0 & 17.7 & 35.2 \\
\hline Control requirement & 12.0 & 26.5 & 12.7 & 17.9 \\
\hline - Temperature defect & 2.4 & 3.2 & 1.1 & 1.4 \\
\hline - Burnup reactivity loss & 5.0 & 18.2 & 7.2 & 10.4 \\
\hline - Fuel axial growth & & & 0.5 & 1.2 \\
\hline - Overpower margin & 0.3 & 0.2 & 0.1 & 0.1 \\
\hline - Reactivity fault & 3.0 & 2.8 & & 0.7 \\
\hline - Uncertainties & 1.3 & 2.1 & 2.0 & 2.3 \\
\hline - Other margin c) & & & 1.8 & 1.8 \\
\hline Shutdown margin & 5.0 & 2.5 & 5.0 & 17.3 \\
\hline
\end{tabular}
a) GEFR-00392 (1978)
b) Early homogeneous design (1974)
c) ALMR/95 requires additional margins such as ATWS reactivity and fast runback margin 


\section{Requirements of Secondary System}

- Sufficient reactivity worth to shutdown reactor

- From any operating condition

- Including reactivity fault of one primary control assembly

- To hot standby condition

- With most reactive control assembly stuck at full power operating condition

- Not necessary to duplicate primary system capability

- Hold down excess reactivity for fuel cycle

- Reactivity uncertainties 


\section{Control Requirement and Shutdown Margin (\$) of Secondary System}

\begin{tabular}{|l|r|r|r|c|}
\hline & $\begin{array}{c}1000 \mathrm{MWe} \\
\text { LMFBR a) }\end{array}$ & $\begin{array}{c}975 \mathrm{MWt} \\
\text { CRBRP b) }\end{array}$ & $\begin{array}{c}840 \mathrm{MWt} \\
\text { ALMR/95 }\end{array}$ & $\begin{array}{c}1000 \mathrm{MWt} \\
\text { ABR }\end{array}$ \\
\hline Number of control assemblies & 6 & 4 & 3 & 4 \\
\hline Total worth & 8.0 & 8.4 & 9.4 & 9.5 \\
\hline Worth of 1 stuck rod & 2.5 & 2.0 & 3.7 & 2.6 \\
\hline Reactivity worth available & 5.5 & 6.4 & 5.7 & 6.9 \\
\hline Control requirement & 5.0 & 6.3 & 1.7 & 1.9 \\
\hline - Temperature defect & 1.6 & 2.4 & 1.1 & 1.4 \\
\hline - Overpower margin & 0.3 & 0.2 & 0.3 & 0.2 \\
\hline - Temp defect uncertainty & & 0.9 & 0.3 & 0.3 \\
\hline - Reactivity fault or others & 3.1 & 2.8 & & \\
\hline Shutdown margin & 0.5 & 0.1 & 4.0 & 5.0 \\
\hline
\end{tabular}

a) GEFR-00392 (1978)

b) Early homogeneous design (1974) 


\section{Reactivity Feedback Coefficients}

- The reactivity coefficients further define the physics of system

- Kinetics parameters

- Response to a variety of perturbations

- Feedback coefficients are computed for a specific design (geometric and material) configuration

- Typically evaluated for BOEC and EOEC composition

- Typical set of whole-core reactivity coefficients

- Computed with perturbation theory for spatial distributions

- Delayed neutron fraction and prompt lifetime

- Sodium density coefficient and void worth

- Fuel and structural Doppler coefficient

- Fuel and structural worth distributions

- Computed by eigenvalue difference $(\Delta \mathrm{k} / \mathrm{k})$

- Uniform axial expansion

- Uniform radial expansion

- Control rod driveline expansion 


\section{Whole-Core Reactivity Coefficients for Different Powers}

\begin{tabular}{|l|c|c|c|c|}
\hline & unit & $\begin{array}{c}250 \mathrm{MWt} \\
\text { ABTR }\end{array}$ & $\begin{array}{c}1000 \mathrm{MWt} \\
\text { ABR }\end{array}$ & $\begin{array}{c}3500 \mathrm{MWt} \\
\text { US-Europe }\end{array}$ \\
\hline Effective delayed neutron fraction & & 0.0033 & 0.00334 & 0.0035 \\
\hline Prompt neutron lifetime & $\mathrm{Ms}$ & 0.33 & 0.38 & 0.32 \\
\hline Radial expansion coefficient & $\Phi /{ }^{\circ} \mathrm{C}$ & -0.43 & -0.38 & -0.21 \\
\hline Axial expansion coefficient & $\Phi /{ }^{\circ} \mathrm{C}$ & -0.05 & -0.05 & -0.07 \\
\hline Sodium density coefficient & $\Phi /{ }^{\circ} \mathrm{C}$ & 0.03 & 0.13 & 0.18 \\
\hline Doppler coefficient & $\Phi /{ }^{\circ} \mathrm{C}$ & -0.10 & -0.13 & -0.13 \\
\hline Sodium void worth & $\$$ & 1.10 & 4.93 & $7.29^{*}(4.98)$ \\
\hline Sodium voided Doppler coefficient & $\Phi /{ }^{\circ} \mathrm{C}$ & -0.07 & -0.09 & -0.09 \\
\hline
\end{tabular}

- Power coefficient is quite negative

- More negative at smaller size because of radial expansion coefficient

- Sodium density coefficient also more positive at larger size

- Physics underlying each component will be explained

- Void worth will be addressed separately 


\section{Delayed Neutron Fraction}

- Hummel and Okrent - Reactivity Coefficients in Large Fast Power Reactors, ANS, 1970 is a good reference for underlying physics

- Delayed neutron fraction dominated by key fission isotopes

- Low $(0.2 \%)$ for Pu-239

- High (1.5\%) for U-238

- Between 0.3-0.5\% for higher plutonium isotopes

- Particularly low $(<0.2 \%)$ for minor actinides

net result is $0.3-0.4 \%$ for conventional compositions

- Slightly lower for burner designs (next viewgraph)

- Much higher for U-235 enriched systems

- Delayed neutron fraction for U-235 is $\sim 0.67 \%$

- Delayed neutron fraction is an indicator of sensitivity

- At low values, response to small changes in the reactivity is magnified and power can change more quickly

- Feedback effects can be favorable or not depending on the transient 


\section{Low Conversion Ratio Fast Reactor Analyses}

Fast reactors with closed fuel cycle can effectively manage TRU

- Can be configured as modest breeders ( $C R \geq 1)$ to moderate burners $(C R \geq 0.5)$ with conventional technology

- Low conversion ratio designs $(C R<0.5)$ have been investigated for transmutation applications in AFCl

- High enrichment fuels are required ( 50\% TRU/HM for $\mathrm{CR}=0.25)$

- Non-uranium fuel would be needed to achieve $\mathrm{CR}=0$

\begin{tabular}{|c|c|c|c|}
\hline Conversion Ratio & $\begin{array}{c}\text { TRU/HM } \\
\text { Enrichment }\end{array}$ & $\begin{array}{c}\text { Equilibrium } \\
\text { Fraction of FR }\end{array}$ & $\begin{array}{c}\text { Delayed } \\
\text { Neutron Fraction }\end{array}$ \\
\hline 1.1 & $11 \%$ & $100 \%$ & 0.0034 \\
\hline 0.75 & $20 \%$ & $51 \%$ & 0.0033 \\
\hline 0.5 & $30 \%$ & $34 \%$ & 0.0031 \\
\hline 0.25 & $50 \%$ & $26 \%$ & 0.0028 \\
\hline 0.0 & $100 \%$ & $21 \%$ & 0.0020 \\
\hline
\end{tabular}




\section{Geometric Expansion Coefficients}

Whole-core coefficients are computed by eigenvalue difference for a small change in each dimension

- Radial expansion - uniform expansion of grid plate by $1 \%$

- Reduction of fuel/structure densities by $1 \%$

- This allows more axial leakage in particular

- Axial expansion - uniform expansion of fuel by $1 \%$

- Reduction of fuel density by $1 \%$

- Allows more radial leakage

- Also, effectively inserts the control rods which remain stationary

- In some cases, fuel assumed bound to clad for axial expansion

- These feedbacks are very important for fast reactor transient behavior

- Tied to different material temperatures (grid plate, fuel)

- Thus, timing will be different 


\section{Neutron Balances of Radial and Axial Expansions}

\begin{tabular}{|l|c|c|c|c|c|}
\hline & Base Case & \multicolumn{2}{|c|}{ Radial Expansion } & \multicolumn{2}{c|}{ Axial Expansion } \\
\cline { 2 - 6 } & balance & balance & $\Delta \rho(\%)$ & balance & $\Delta \rho(\%)$ \\
\hline Fission source & 100.00 & 100.00 & & 100.00 & \\
\hline$(\mathrm{n}, 2 \mathrm{n})$ source & 0.18 & 0.18 & & 0.18 & \\
\hline Absorption & 68.89 & 68.93 & -0.04 & 68.93 & -0.05 \\
\hline Leakage & 31.54 & 32.16 & -0.63 & 31.61 & -0.07 \\
\hline Radial & 17.49 & 17.72 & -0.23 & 17.59 & -0.10 \\
\hline Axial & 14.05 & 14.45 & -0.40 & 14.02 & 0.03 \\
\hline Sum & & & -0.67 & & -0.12 \\
\hline
\end{tabular}

$\square$ To first order, radial expansion is an axial leakage effect, and

$\square$ Axial expansion is a radial leakage effect

$\square$ Because the height is the short dimension (more axial than radial leakage), the radial expansion coefficient is more negative

$\square$ Absorption effect arises from control rod absorption increases 


\section{Coolant Density Coefficient}

Coolant density coefficient computed by first-order perturbation theory to evaluate small density (temperature variation) impacts

- Spectral effect

- Reduced moderation as sodium density decreases

- In fast regime, this is a positive reactivity effect

- From Pu-239 excess neutrons and threshold fission effects

- Leakage effect

- Sodium density decrease allows more neutron leakage

- This is a negative reactivity effect in the peripheral regions

- Capture effect

- Sodium density decrease results in less sodium capture

- This is a relatively minor effect

Void worth is evaluated using exact perturbation theory to account for shift in flux distribution and change in cross sections for voided condition

- In general, $10 \%$ more positive than the first-order density worth 


\section{Sodium Void Worth by Components (\$)}

\begin{tabular}{|c|c|c|c|c|c|}
\hline & & Capture & Spectral & Leakage & Total \\
\hline $\begin{array}{c}\text { 1000 MWt ABR } \\
\text { (startup metal core) }\end{array}$ & BOC & 0.5 & 9.1 & -5.2 & 4.4 \\
\cline { 2 - 6 } & EOC & 0.5 & 9.9 & -5.5 & 4.9 \\
\hline $\begin{array}{c}250 \text { MWt ABTR } \\
\text { (startup metal core) }\end{array}$ & BOC & 0.4 & 6.4 & -5.8 & 1.0 \\
\cline { 2 - 6 } & EOC & 0.4 & 6.6 & -5.8 & 1.1 \\
\hline
\end{tabular}

- Flowing sodium completely voided in ALL active and above-core regions

void worth tends to increase with core size

- However, difficult to conceive transient situations that reach boiling

- Low pressure system

$->300^{\circ} \mathrm{C}$ margin to boiling

- Other feedbacks are negative (see next viewgraphs)

- Extensive report on void worth reduction - Khalil and Hill, NSE, 109 (1995) 
Response to a ULOF in Large 3500 MWt SFR using Metal Fuel

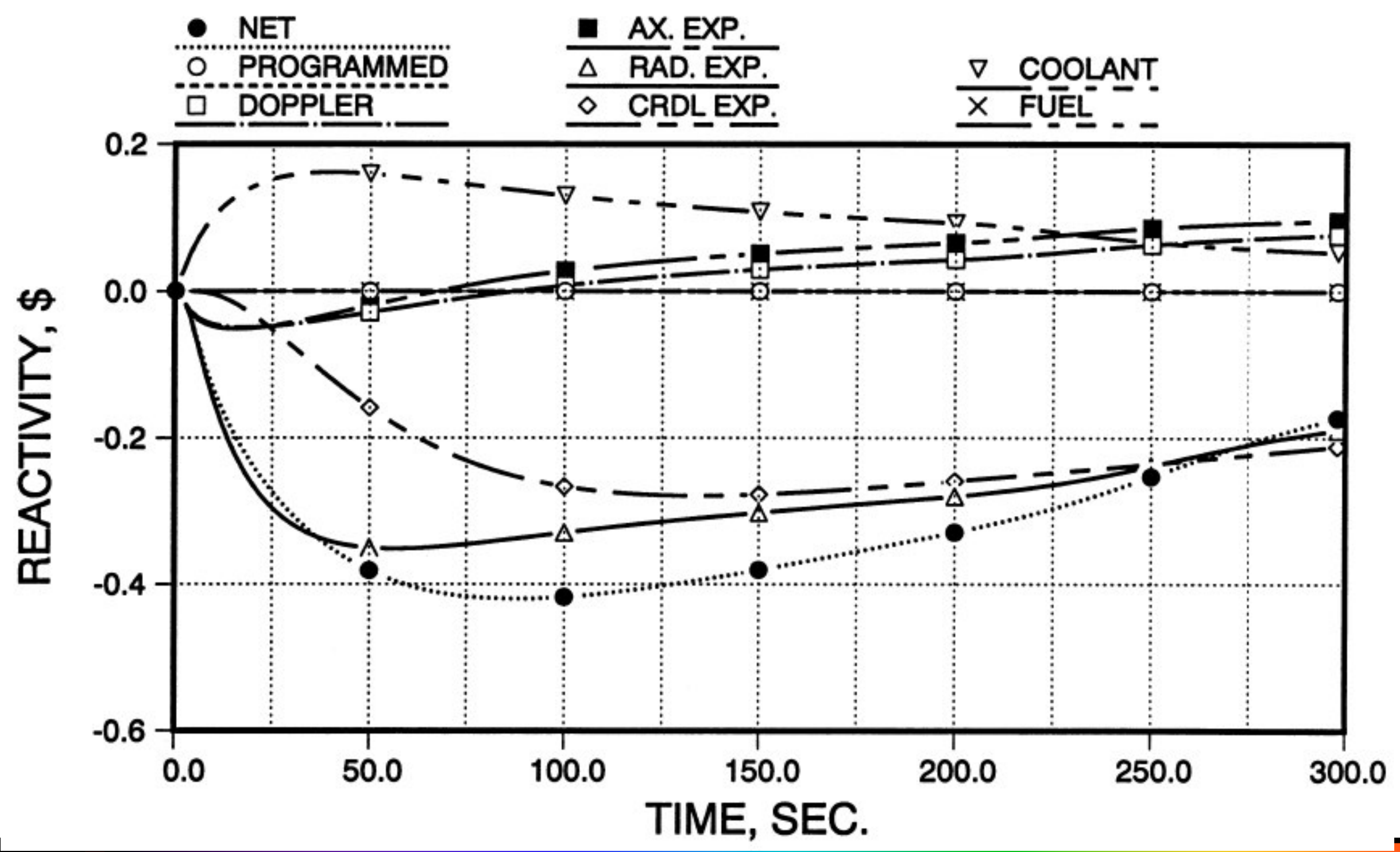


Response to a ULOF in Large $3500 \mathrm{MWt}$ SFR using Metal Fuel

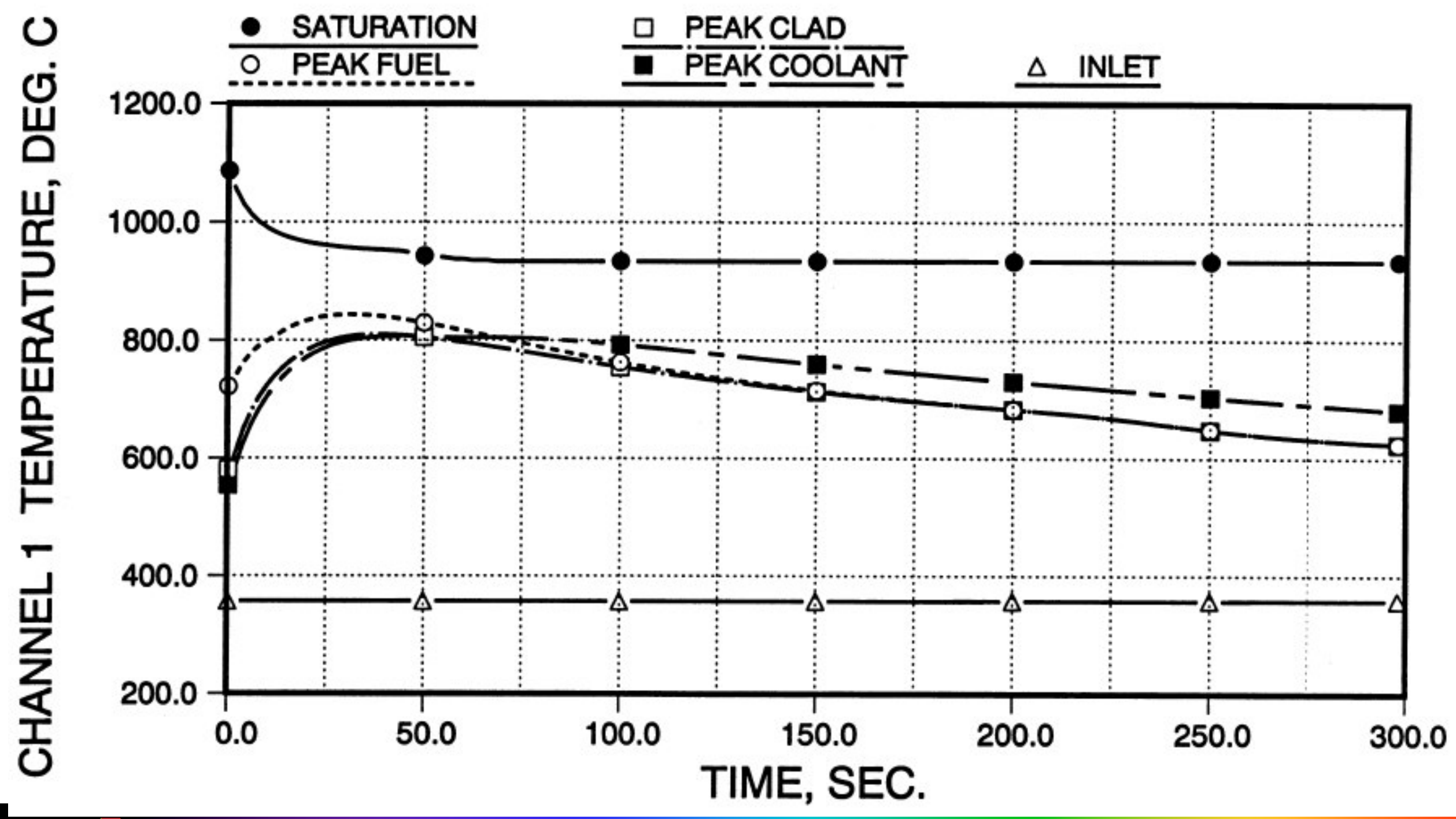




\section{Doppler Coefficient}

- Doppler coefficient arises primarily from U-238 resonance broadening

- Enhanced by high U-238 content

- Reduced Doppler for high enrichment burner concepts

- Self-shielding effect more pronounced at low energies (keV range)

- Doppler enhance by spectral softening

- Voided Doppler is smaller from spectral shift

- Temperature dependence in fast spectrum is different than LWR

- Doppler range from $1 / \mathrm{T}^{1 / 2}$ for large to $1 / \mathrm{T}^{3 / 2}$ for small resonances

- For typical FR, an approximate 1/T dependence observed

- There is also a structural Doppler reactivity effect ( $1 / 3$ fuel Doppler)

- However, tied to temperature of steel, not fuel (different timing)

- Doppler feedback is not helpful in all transients

- For example, when trying to cool the fuel to shutdown condition (e.g., ULOF), it is a positive feedback

- Conversely prompt negative feedback in UTOP trasnsient 


\section{Passive Safety Behavior}

- Inherent safety trends and general criteria are explained in Wade and Fujita, Trends versus Reactor Size of Passive Reactivity Shutdown and Control Performance, Nuclear Science and Engineering, 103 (1989).

Brief synopsis by Cahalan at last topical seminar

- The fast reactor reactivity balance can be written as follows:

$$
\delta \rho=[P(t)-1] A+[P(t) / F(t)-1] B+\left[\delta T_{\text {in }}(t)\right] C+\delta \rho_{\text {external }}
$$

where $P(t)=$ normalized reactor power

$$
F(t)=\text { normalized core coolant flow }
$$

$\delta T_{\text {in }}(t)=$ change in coolant temperature at the core inlet

$\delta \rho_{\text {external }}=$ externally applied change in reactivity (control rods, etc.)

- the relative importance of each of these terms is determined by the grouped reactivity feedback parameters, A, B, and C 


\section{Reactivity Feedback Coefficients}

- The reactivity feedback coefficients that form the three parameters $A, B$, and $C$ are associated with the reactor core, and depend on fuel type, fuel volume fraction, coolant volume fraction, etc.,

$$
\begin{aligned}
& A=\alpha_{\text {Doppler }} \Delta T_{F C}(t=0) \\
& B=\left[\alpha_{\text {Doppler }}+\alpha_{\text {NaCoolant }}+a_{\text {AxialExp. }}+a_{1} \alpha_{\text {RadialExp }}+a_{2} \alpha_{\text {ControlRod }}\right] \Delta T_{C}(t=0) / 2 \\
& C=\left[\alpha_{\text {Doppler }}+\alpha_{\text {NaCoolant }}+\alpha_{\text {AxialExp. }}+b_{1} \alpha_{\text {RadialExp }}+b_{2} \alpha_{\text {ControlRod }}\right] \\
& \text { where } \alpha_{\text {Doppler }} \quad=\text { Doppler coefficient } \\
& \alpha_{\text {NaCoolant }}=\text { Sodium coolant density coefficient } \\
& \alpha_{\text {AxialExp. }}=\text { Fuel axial expansion coefficient } \\
& \alpha_{\text {RadialExp }}=\text { Core radial expansion coefficient } \\
& \alpha_{\text {ControlRod }}=\text { Control rod driveline expansion coefficient } \\
& \Delta T_{F C}(t=0)=\text { Steady-state temperature difference, fuel to coolant } \\
& \Delta T_{C}(t=0)=\text { Steady-state coolant temperature rise, inlet to outlet } \\
& a_{1}, a_{2}, b_{1}, b_{2}=\text { geometric parameters }
\end{aligned}
$$




\section{Passive Safety Criteria}

Criteria established for acceptable asymptotic core outlet temperatures for possible unprotected accident scenarios

- $\mathrm{A} / \mathrm{B}<1$ for passive control of pump and BOP-induced accident scenarios

- $1<\mathrm{C} \Delta \mathrm{T}_{\mathrm{c}} / \mathrm{B}<2$ for LOF, pump overspeed and chilled inlet

- $\delta \rho_{\mathrm{TOP}} / \mathrm{B}<1$ for TOP performance

- Comparison of the whole-core reactivity coefficients to these criteria gives and indicated that the concept has favorable passive safety features

- Detailed safety analyses required to confirm performance and margins 


\section{Summary and Conclusions}

- Fast reactor physics are quite different from thermal reactor behavior

- Better neutron balance (flexible actinide management)

- Higher enrichment is required to compensate U-238 capture

- Neutron leakage is increased

- Typical fast reactor core designs were reviewed

- Traditional blanketed breeder, moderate burner with no blanket, low conversion ratio option (high fuel enrichment) configurations

- Reactor performance, high power density, burnup, fluence

- Reactivity compensation and control rod requirements

- Reactivity coefficients were discussed

- Expansion coefficients prominent because of high leakage

- Positive sodium density (and void) coefficient

- Overall favorable passive performance for complete set of feedbacks 


\section{Sodium Fast Reactor}

\section{Argonne LABORATORY}

... for a brighter future

Safety \#1

DOE/HQ June 20, 2007

NRC/White Flint June 21, 2007

(Rev. 1, October, 2008)

Presented by: Jim Cahalan 


\section{Notice}

- This presentation has been revised to remove citations to and information from Applied Technology documents. 


\section{FFTF References}

- Fast Flux Test Facility Preliminary Safety Analysis Report, Vols. 1 and 2, September, 1970.

- C. P. Cabell, A Summary Description of the Fast Flux Test Facility, HEDL-400, December, 1980.

D. E. Simpson, FFTF Design for Safety, Proc. Fast Reactor Safety Meeting, CONF740401-P2, pp. 1041-1060, American Nuclear Society, Beverly Hills, California, April 2-4, 1974.

D. E. Simpson, Resolution of Key Safety-Related Issues in FFTF Regulatory Review, Proc. Intl. Mtg. Fast Reactor Safety and Related Physics, CONF-761001, Vol. II, pp.400-410, American Nuclear Society, Chicago, Illinois, October 5-8, 1976.

- A. R. Schade and D. E. Simpson, FFTF Regulatory Review for Operating Authorization, Proc. Intl. Mtg. Fast Reactor Safety Technology, Vol. 5, pp. 24252430, American Nuclear Society, Seattle, Washington, August 19-23, 1979.

- Safety Evaluation Report by the Office of Nuclear Reactor Regulation, USNRC, for the Fast Flux Test Facility, USNRC Report NUREG-0358, August, 1978.

Supplement No. 1, May, 1979. 


\section{CRBRP References}

- Clinch River Breeder Reactor Plant Preliminary Safety Analysis Report, Project Management Corporation. Vols. 1 - 27. (Updated through amendment 77, May, 1983)

- 1974 Technical Progress Report, Clinch River Breeder Reactor Project.

- L. E. Strawbridge, Safety Related Criteria and Design Features in the Clinch River Breeder Reactor Plant, Proc. Fast Reactor Safety Meeting, CONF-740401-P1, pp. 7292, American Nuclear Society, Beverly Hills, California, April 2-4, 1974.

- R. J. Slember, Safety-Related Design Considerations for the Clinch River Breeder Reactor Plant, Proc. Intl. Mtg. Fast Reactor Safety and Related Physics, CONF761001, Vol. I, pp. 112-125, American Nuclear Society, Chicago, Illinois, October 5-8, 1976.

L. E. Strawbridge and G. H. Clare, Exclusion of Core Disruptive Accidents from the Design Basis Accident Envelope in CRBRP, Proc. Intl. Mtg. Fast Reactor Safety, Vol. 1, pp.317-327, American Nuclear Society, Knoxville, Tennessee, April 21-25, 1985.

J. G. Giitter and M. W. Akhtar, An Assessment of the Clinch River Breeder Reactor Core and Containment Response to Core Disruptive Accidents, Proceedings of the International Meeting on Fast Reactor Safety, Knoxville, Tennessee, American Nuclear Society, CONF-850410, pp. 463-470, April 21-25, 1985.

- Safety Evaluation Report Related to the Construction of the Clinch River Breeder Reactor Plant, USNRC Report NUREG-0968, Vols. 1 and 2, March, 1983. 


\section{SAFR and PRISM References}

- Preapplication Safety Evaluation Report for the Sodium Advanced Fast Reactor (SAFR) Liquid-Metal Reactor, USNRC Report NUREG-1369, December, 1991.

- Preapplication Safety Evaluation Report for the Power Reactor Innovative Small Module (PRISM) Reactor, USNRC Report NUREG-1368, February, 1994.

- P. M. Magee, U.S. ALMR Licensing Status, Proc. Intl. Topical Mtg. Advanced Reactor Safety, pp. 1011-1017, American Nuclear Society, Pittsburg, Pennsylvania, April 17-21, 1994. 
- H. Hummel and D. Okrent, Reactivity Coefficients in Large Fast Power Reactors, American Nuclear Society, 1970.

- Hans K. Fauske, The Role of Core-Disruptive Accidents in Design and Licensing of LMFBRs, Nuclear Safety, Vol. 17, No. 5, pp. 550567, September-October, 1976.

A. E. Waltar and A. B. Reynolds, Fast Breeder Reactors, Pergamon Press, 1981.

10CFR50 Appendix A, General Design Criteria for Nuclear Power Plants

- DOE O 5480.30, Nuclear Reactor Safety Design Criteria

aNSI/ANS-54.1-1989, General Safety Design Criteria for a Liquid Metal Reactor Nuclear Power Plant 
- Safety Issues \#1 (Today)

- Safety issues; DBA, BDBA, severe accident historically (coolant void, recriticality, $\mathrm{FCl}$ ), passive safety

- Safety analysis past results (FFTF, CRBRP, SAFR, PRISM)

- Safety analysis methods; reactor, structural, coolant aerosols, containment

- Safety Issues \#2 (Future)

- Licensing issues in FFTF, CRBRP, SAFR, PRISM. International experience in perspective, high profile issues in Phenix, SuperPhenix, MONJU, BN-350, EBR-1, FERMI explained and lessons learned.

- Inherent passive safety characteristics of sodium fast reactor systems (wrt loss of flow without scram, etc.). Inherent reactivity shutdown, natural circulation decay heat removal

- Safety testing results, EBR-II SHRT, FFTF ULOF (GEMS); TREAT 


\section{Basic Safety Objectives}

- Protect public health and safety

- Reduce the risk from releases of radioactivity to acceptable levels

- Comply with regulatory requirements and provide additional margin

- Protect plant worker health and safety

- Provide a safe working environment and reduce risk of injury

- Comply with regulatory requirements and promote worker protection

- Protect the environment

- Provide a design that complies with all federal, state, and local requirements

- Build, operate, and decommission the plant in a way that preserves environmental quality

- Protect the plant investment

- Provide plant designs, equipment, and operating/maintenance practices to preserve investor equity and return reward

- Maintain product quality and reliability 


\section{Radiation Protection Mechanisms}

- Barriers

- Contain radioactive materials and prevent human exposure or release to the environment

- Distance

- Provide spatial margins to reduce the intensity of radiation exposure

- Time

- Isolate radioactive material until it has decayed to a stable or less harmful state 


\section{Safety by Design}

- By design, the plant and all its systems are configured and constructed in a manner that assures safe, stable, and reliable operation while preserving protection mechanisms

- Engineered safety systems are provided to prevent development of conditions that can defeat the basic radiation protection mechanisms, and to mitigate the consequences of equipment failure or inappropriate operator actions

- Inherent protection margins (No operator action or equipment activation needed) can be provided by selection of materials and arrangement of components

- The design principle of defense in depth is applied for important safety-related functions

- Containment

- Reactor shutdown

- Residual heat removal 


\section{Defense in Depth}

- Plant functions that are important to preservation of safety protection mechanisms are designed according to the defense in depth principle, which provides multiple layers of safety assurance

- Level 1: Provide a conservative design with large safety margins that can be constructed and operated normally without challenges to safety limits

- Level 2: Provide additional design features that protect against a single, unlikely fault ( once in the plant lifetime). (Limited damage, minor repair).

- Level 3: Provide additional design features that protect against a single, extremely unlikely fault (not expected in the plant lifetime). (Extensive damage, major repair)

- Foreseen events at Levels 1, 2, and 3 are within the plant safety design basis, and the most demanding events are usually identified as Design Basis Accidents (DBAs) 


\section{Defense in Depth Safety Design Features}

- For key safety functions (maintain barriers, keep radioactivity at a distance, and provide time for recovery)

- Multiple, diverse, and independent structures, systems, or components, each of which is capable of achieving the defined safety function

- Redundancy, diversity, and independence assure that not all safety function can be lost due to a single failure

- Safety grade systems, components, and systems are designed and maintained to criteria that assure their reliable operation

- Quality assurance, inspection, testing, repair, ...

- Seismic, electrical supply, ... 


\section{Safety Design Features}

- Containment of radioactive material by multiple physical barriers

- Fuel cladding

- Primary coolant system boundary

- Containment structure

- Reactor shutdown by multiple reactor control and protection systems

- Primary scram system for startup, shutdown, reactor power changes, and power distribution management

- Secondary scram system, always available for activation

- Residual heat removal by multiple heat transport paths and systems

- Normal heat removal system (SG, condenser)

- Dedicated shutdown heat removal systems (HXs, forced or natural circulation, from primary or secondary coolant, through vessel wall) 


\section{Sodium Fast Reactor Characteristics}

- Fast spectrum, compact core design ( 400 MW FFTF example)

- High power density ( 400 kW/liter, PWR $100 \mathrm{kw} / \mathrm{liter})$

- High coolant velocity $(\sim 20 \mathrm{ft} / \mathrm{sec})$

- High linear pin power ( 8 kW/ft, PWR $5 \mathrm{~kW} / \mathrm{ft})$, short core height ( $\sim 3 \mathrm{ft}$, PWR $12 \mathrm{ft}$ )

- Small fuel pins ( 0.23 in OD, PWR 0.37 in) on a tight triangular pitch (P/D 1.2, PWR $\sim 1.5 \mathrm{sq}$ ) grouped in hexagonal ducted fuel assemblies

- Oxide (FFTF) or metallic (EBR-II) fuel with a high fissile content ( 20\%, PWR $\sim 3 \%$ )

- Core coolant rise $\sim 300^{\circ} \mathrm{F}$ (PWR $\sim 63^{\circ} \mathrm{F}$ ), outlet $\sim 980^{\circ} \mathrm{F}$ (PWR $620^{\circ} \mathrm{F}$ ) (Na NBP $\sim 1638^{\circ} \mathrm{F}$ )

\section{- Low pressure ( atmospheric) coolant}

- Large temperature margin to boiling ( $4 \mathrm{X}$ Power/Flow Ratio in typical reactor designs for flow transients at core outlet pressure)

- Pool (EBR-II) or loop (FFTF) primary system design, with backup guard vessel and piping to assure core cooling if the primary vessel leaks

- Intermediate heat exchanger isolates radioactive sodium within containment, transfers heat to second sodium loop which transports heat to steam generator (or for FFTF, air dump heat exchangers) outside containment 


\section{Fast Flux Test Facility (FFTF) Chronology}

Conceptual design studies 1966-1969

口 PAR submitted by HEDL in September 1970

- Initial construction authorization in September 1971; full construction authorization in March 1972

ACRS letter in May 1973

- FSAR submitted by HEDL in December 1975

- Construction complete/Na fill 1978

Criticality February 1980, full power October 1980

- Research operations April 1982 to April 1992

- DOE Shutdown order December 1993 


\section{FFTF Design}

- Mission: Provide a prototypic LMFBR operating environment for testing and development of fuels, materials, and components

- Secondary: Develop design and construction experience

- $400 \mathrm{MWt}$, MOX fuel (22\% and $27 \% \mathrm{Pu})$, three loop primary system, three intermediate sodium loops to air dump heat exchangers

- Reactor core: 73 fuel assemblies, 9 control assemblies, 9 test assemblies

Coolant inlet $680^{\circ} \mathrm{F}\left(360^{\circ} \mathrm{C}\right)$, outlet $980^{\circ} \mathrm{F}\left(527^{\circ} \mathrm{C}\right)$

10psi steel containment

- Two independent reactor shutdown systems (both by moveable rods)

Natural convection decay heat removal through three independent loops

- Pony motors on primary and secondary pumps

- Core physics and structural design for inherent negative power and temperature reactivity feedbacks 
FFTF Site - Hanford, Washington

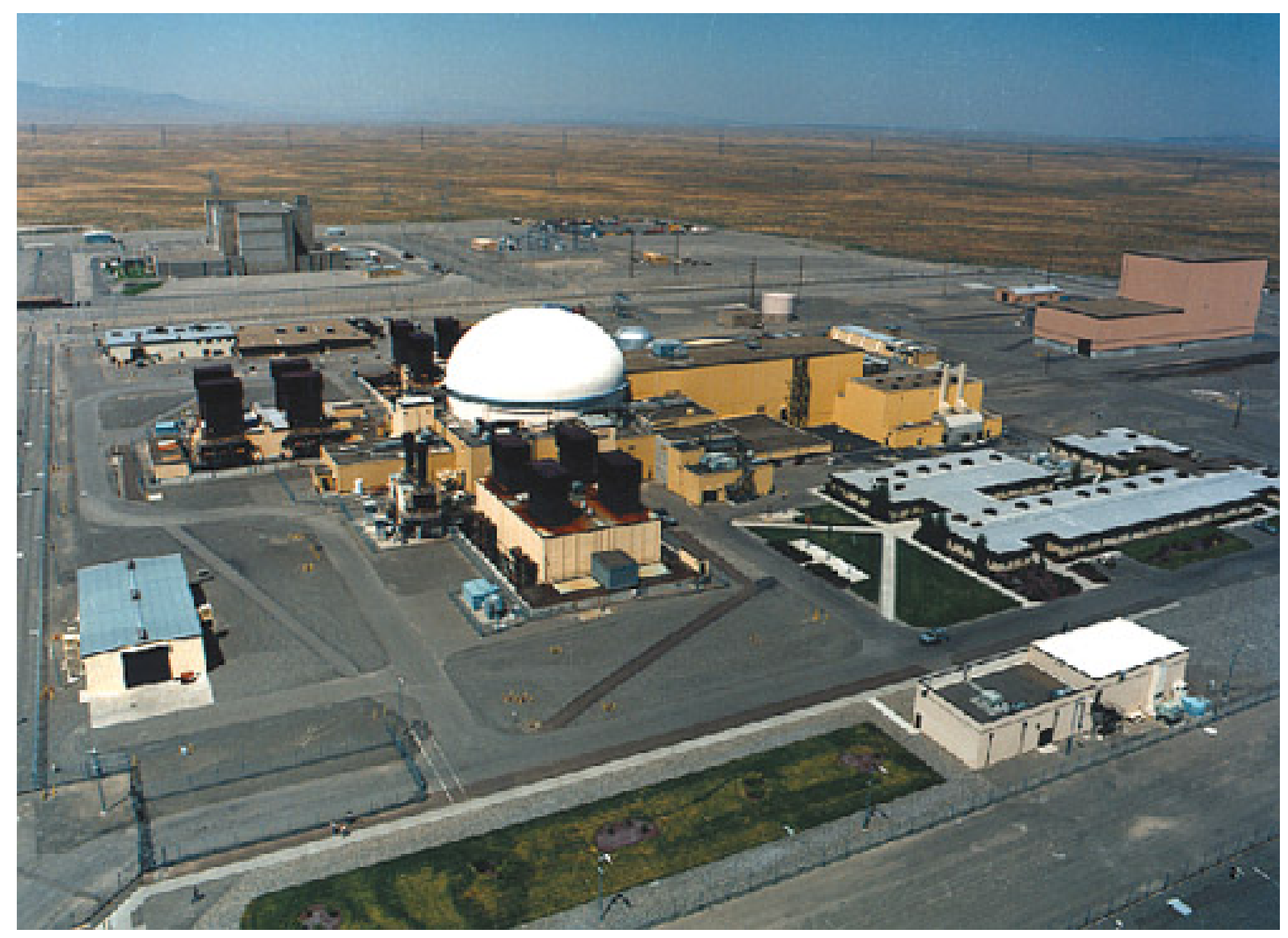




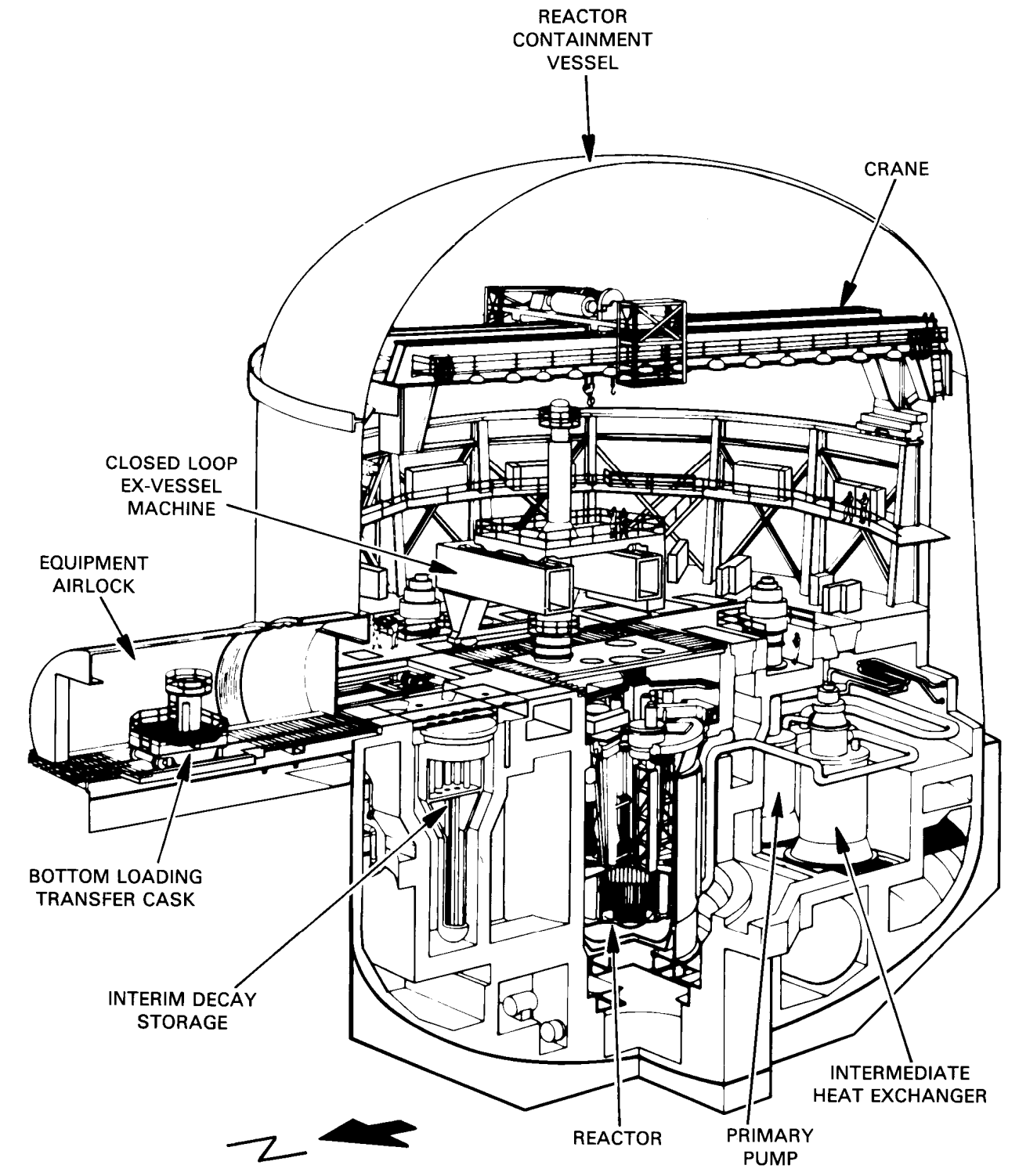




\section{FFTF Loop-Type Primary and Secondary Systems}

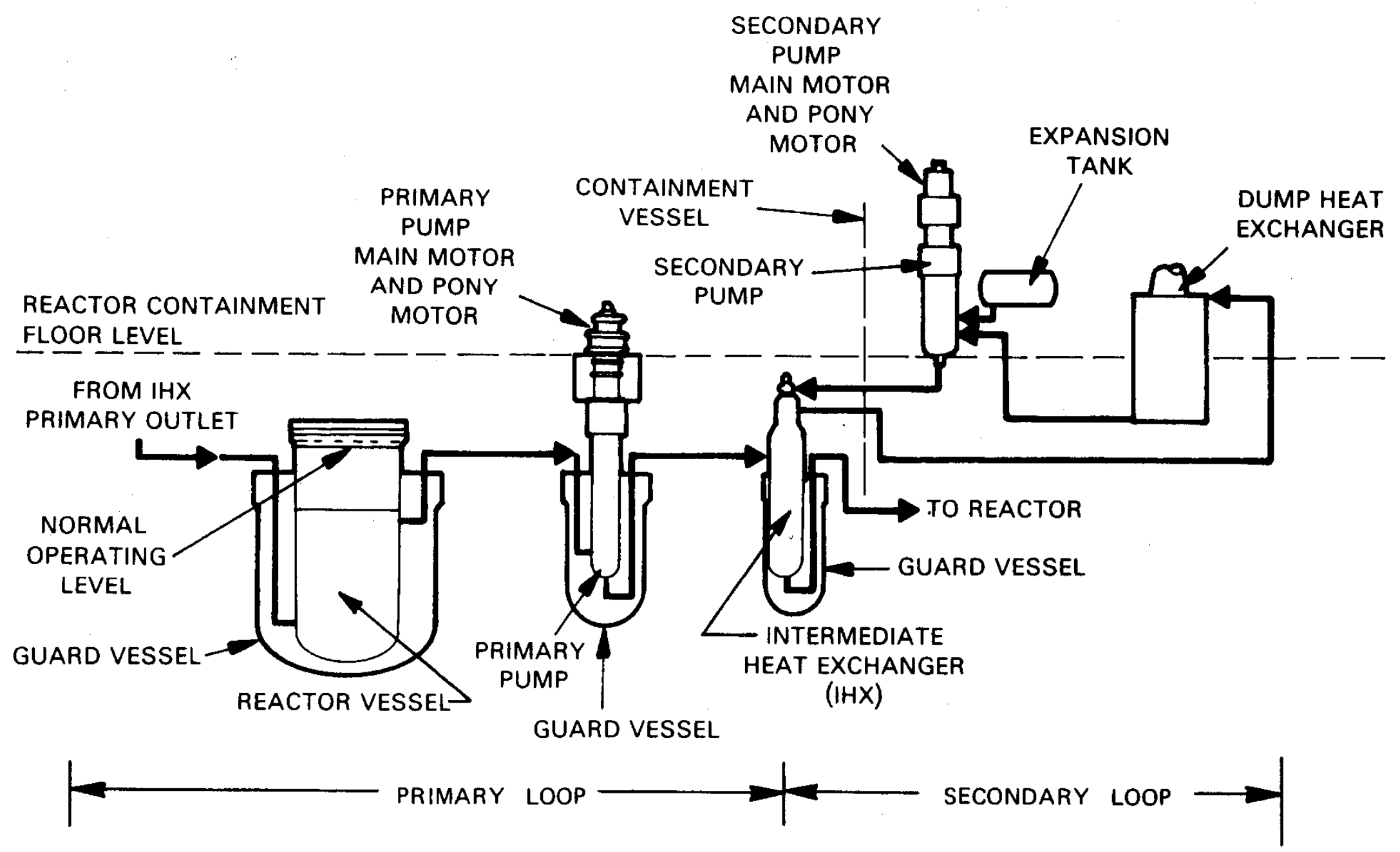




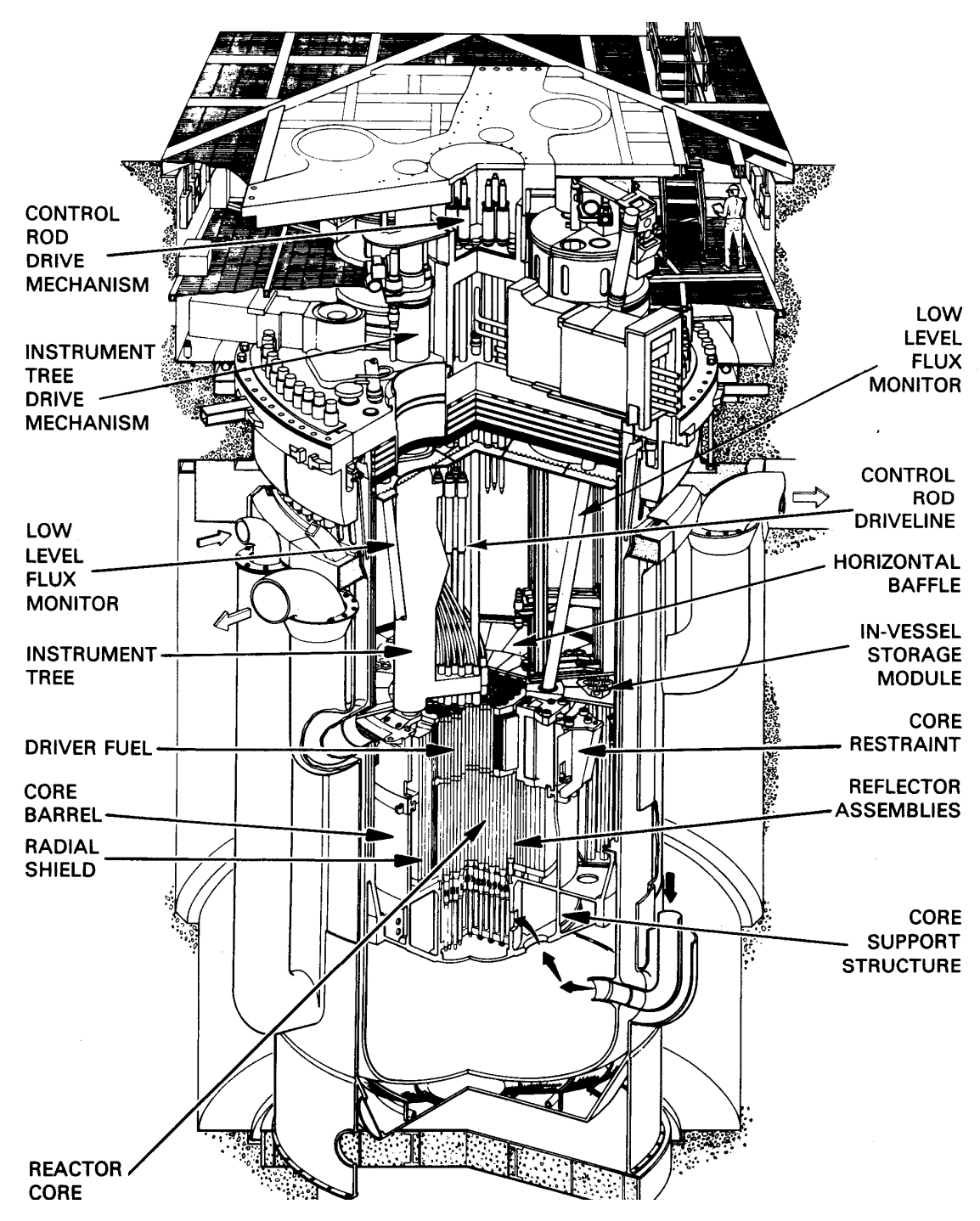


FFTF Construction View

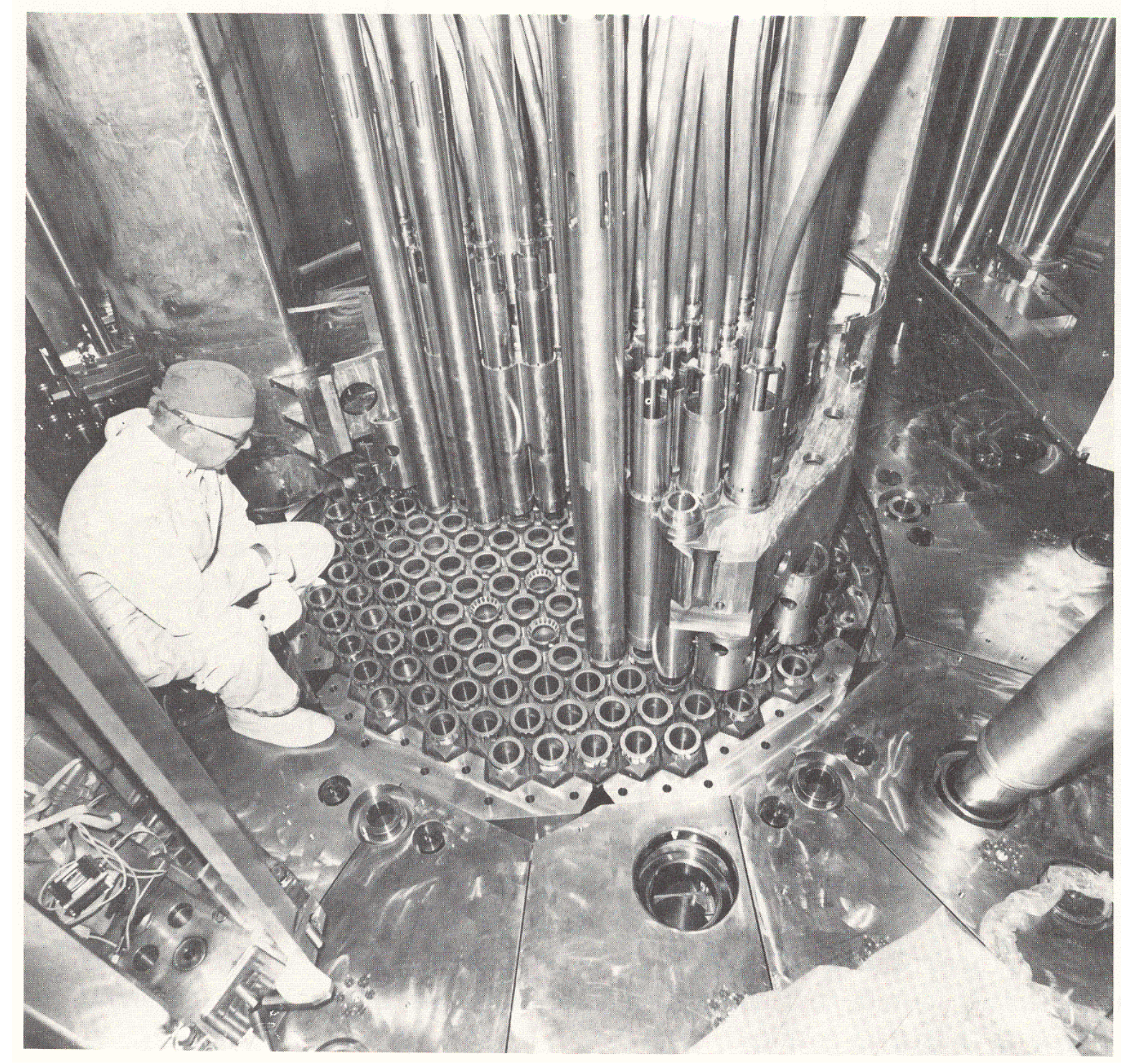

- Simulated core assemblies

- Two of three instrument trees in place 


\section{FFTF Driver Fuel Pin}

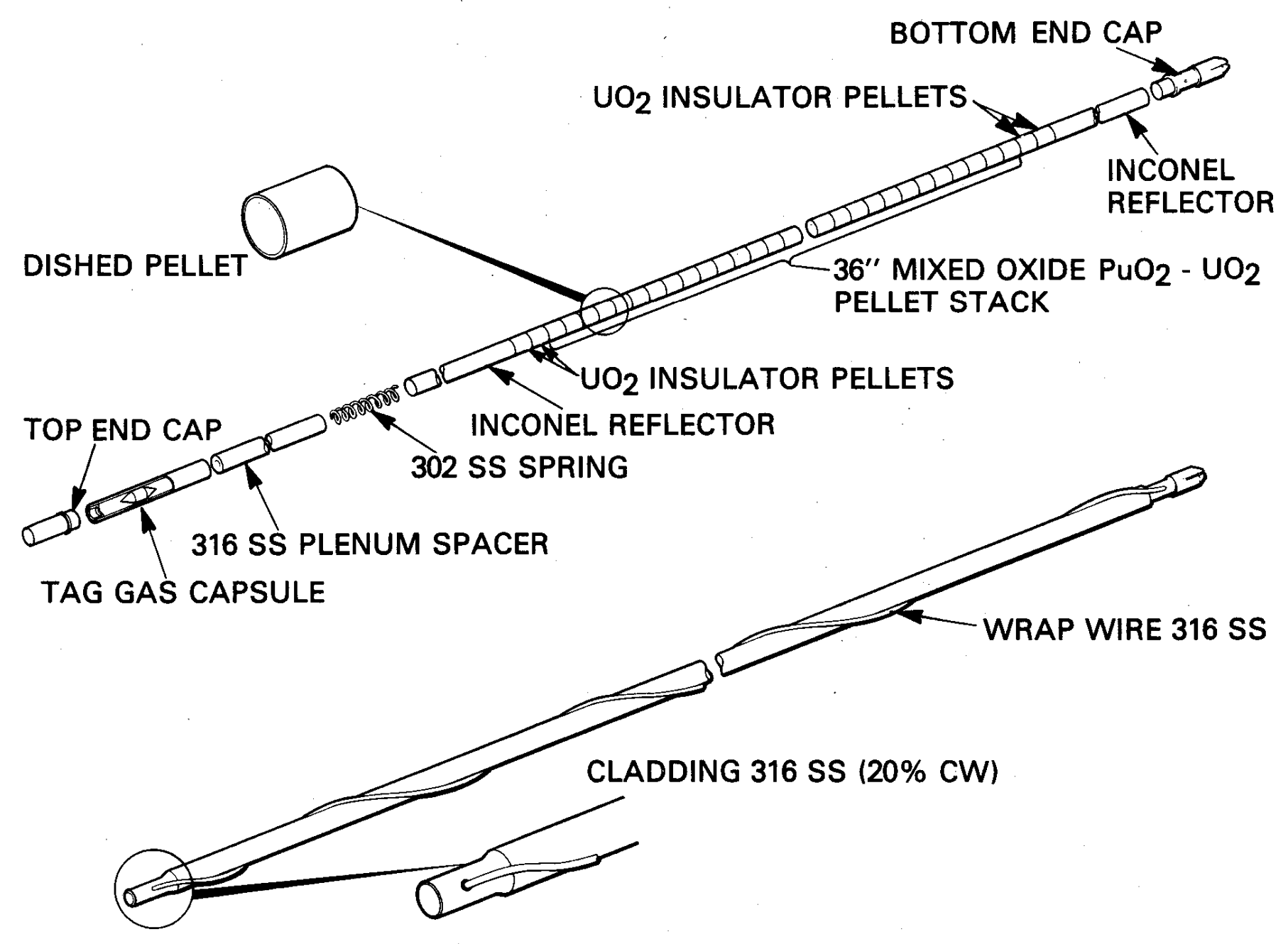




\section{FFTF Driver Fuel Assembly}

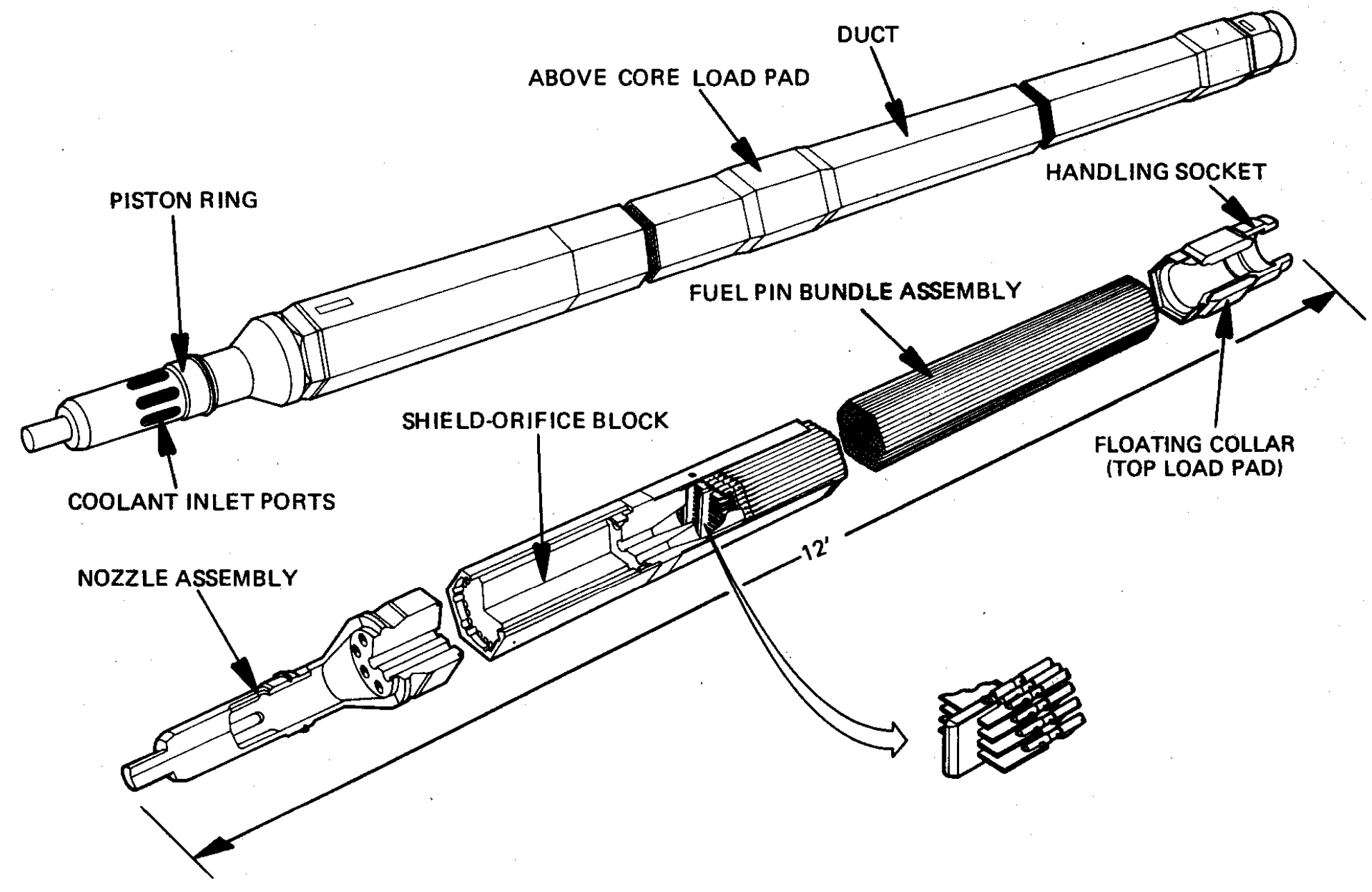




\section{FFTF Core Layout}

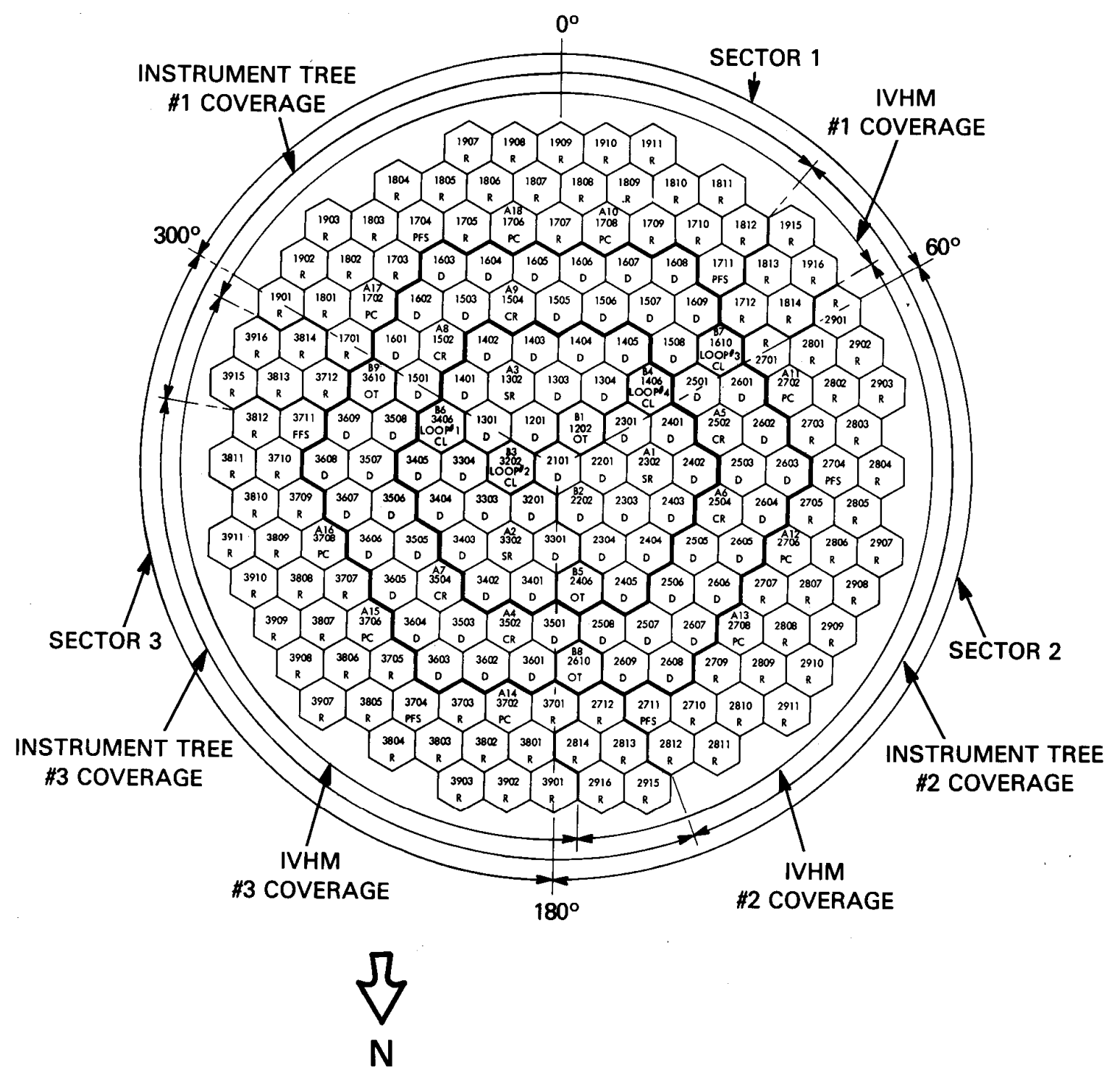




\section{Clinch River Breeder Reactor Plant (CRBRP) Chronology}

- June 1970. U.S. Congress enacts Public Law 91-273 authorizing AEC to design, construct, and operate an LMFBR demonstration plant.

- January 1972. Joint proposal by Commonwealth Edison and TVA accepted.

- March 1972. Two not-for-profit organizations established. Project Management Corporation (PMC) for project management, and Breeder Reactor Corporation (BRC) for utility industry liaison.

- November 1972. Westinghouse-Advanced Reactor Division (W-ARD) selected as lead reactor manufacturer, Burns and Roe (B\&R) as A/E.

- February 1973. Initial work authorization. Al and GE added to team.

- January 1974. AEC/W-ARD contract signed.

- PSAR submitted April 1975 (Updated through Rev. 77 May 1983)

- Licensing suspended: commercial reprocessing banned March 1977

- Licensing resumed September 1981

- NRC Safety Evaluation Report (NUREG-0968) March 1983, ACRS letter

- Funding stopped October 1983 


\section{CRBRP Design}

- Mission: Demonstrate the safe and reliable operation of an LMFBR in a utility environment. Demonstrate LMFBR economics, and the transition from technology development to commercial operation

- $975 \mathrm{MWt}, 380 \mathrm{MWe}$ (gross), MOX fuel (22\% and 32\% Pu), three loop primary system, three intermediate sodium loops to steam generators

- Reactor core: 198 fuel assemblies (108 inner/90 outer), 19 control assemblies (15 primary/4 secondary), 150 radial blanket assemblies

- Coolant inlet $730^{\circ} \mathrm{F}\left(388^{\circ} \mathrm{C}\right)$, outlet $95^{\circ} \mathrm{F}\left(535^{\circ} \mathrm{C}\right)$

10psi steel containment

- Two independent reactor shutdown systems (both by moveable rods)

- Decay heat removal through three independent loops

- Pony motors on primary and secondary pumps

- Auxiliary decay heat removal through water side of SG

- Direct decay heat removal system independent of HTS loops

- Core physics and structural design for inherent negative power and temperature reactivity feedbacks 
Clinch River Breeder Reactor Plant (CRBRP)

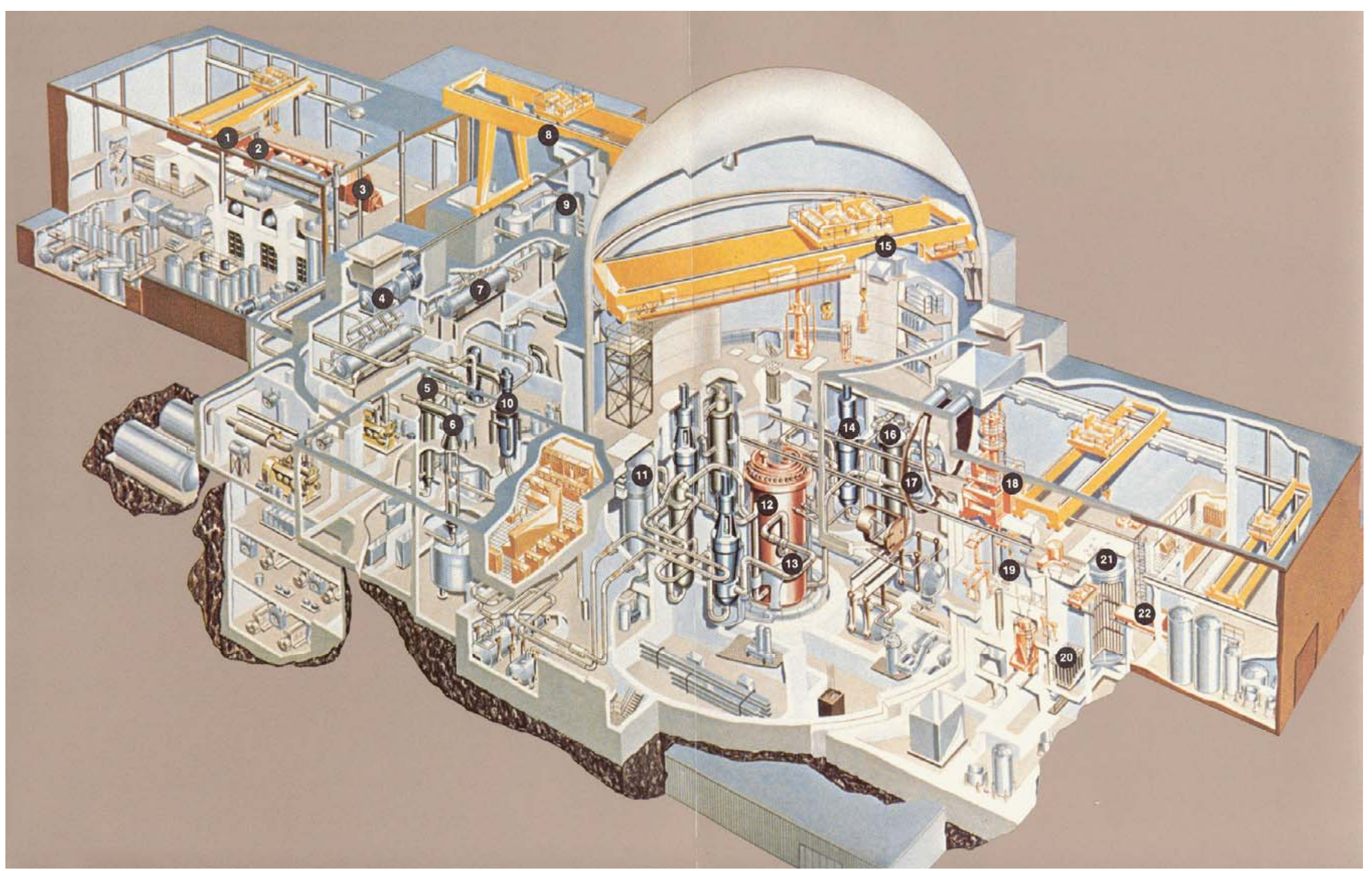

\section{Argonne}




\section{SAFR and PRISM Background and Chronology}

- Beginning in the early/mid 1980's, DOE funded conceptual design studies for modular advanced liquid metal reactor plants

- At Rockwell International, the Sodium Advanced Fast Reactor (SAFR)

- At General Electric, the Power Reactor - Inherently Safe Module (PRISM)

- Preliminary Safety Information Documents for SAFR and PRISM were submitted to NRC in November, 1986

- The initial SAFR and PRISM concepts focused on innovative design approaches for economics and safety

- Design simplification based on passive safety performance

- DOE subsequently (ca 1988?) selected the PRISM concept for continued development in the Advanced Liquid Metal Reactor (ALMR) program

- NRC issued pre-application SERs for SAFR (1991) and PRISM (1994)

- DOE support for PRISM design studies ceased with the cancellation of the ALMR program in 1994 


\section{SAFR Design}

- Multiple (4) power units per site co-located with a spent fuel processing facility

- $900 \mathrm{MWt}$ reactor, U-Pu-Zr metallic fuel, pool type primary system, two intermediate loops

- 60 year plant life

- Reactor core: $\mathbf{9 6}$ driver fuel assemblies, $\mathbf{4 6}$ internal and $\mathbf{4 8}$ radial blanket assemblies, 6 control assemblies, 3 safety assemblies

- Coolant outlet $950^{\circ} \mathrm{F}\left(510^{\circ} \mathrm{C}\right)$, inlet $675^{\circ} \mathrm{F}\left(357^{\circ} \mathrm{C}\right)$

- Inherent response for emergency reactor shutdown

- Inherent reactivity feedbacks in temperature and flow transients

- Self-Actuated Shutdown System (SASS); thermally-activated magnetic latch release

- Two natural circulation decay heat removal systems

- Direct heat removal from hot sodium pool (DRACS)

- Ambient air cooling of guard vessel (RACS)

- Compact containment building design 


\section{PRISM Design}

- Multiple power modules (6) co-located with a spent fuel reprocessing facility (Module reactor size grew as the concept evolved, to $840 \mathrm{MWt}$ in 1995. The SER looks at the $471 \mathrm{MWt}$ design)

- $840 \mathrm{MWt}$, U-Pu-Zr metallic fuel, pool-type primary system, two intermediate loops

- Reactor core (burner): 192 fuel assemblies, 10 control assemblies, 3 safety assemblies

- Coolant outlet $930^{\circ} \mathrm{F}\left(500^{\circ} \mathrm{C}\right)$, inlet $680^{\circ} \mathrm{F}\left(360^{\circ} \mathrm{C}\right)$

- One safety grade automatic reactor protection system, with a manually operated safety grade ultimate shutdown system ( 3 safety rods)

- Inherent accommodation of ATWS transients without core melt, significant reactivity addition, or large radiological release

- Shutdown cooling by turbine bypass with emergency removal systems

- Air cooling system (ACS) on the steam generator shell

- Primary sodium auxiliary cooling system (PSACS); reqs. valve action

- Reactor vessel air cooling system (RVACS)

- Compact containment shell design 
- Low pressure, chemically reactive coolant

- For pool-type design, all radioactive sodium contained within reactor vessel, with secondary guard vessel for leak protection

- For loop-type design, guard vessels and double piping; equipment in steel-lined, inerted cells within containment

- Guard vessels and double pipes fulfill ECCS role for core coverage

- Reactor shutdown and residual heat removal requirements

- Diverse, redundant, independent, safety grade systems

- Potential for natural circulation designs due to large thermal heat capacity of coolant systems for time margin, excellent sodium heat transfer and buoyancy properties for natural convection

- Containment loading mechanism for design basis

- Low pressure coolant, leak-before-break

- Sodium oxidation with air; heating, aerosol generation, pressurization 
- Low pressure, liquid metal boiling

- Only relevant for beyond design basis power, flow, or heat removal accident sequences

- Flow regime: low pressure and high heat flux leads to rapid vapor formation, large vapor bubbles that fill the hexcan radially and move upwards due to buoyancy or forced liquid flow

- Vapor bubbles condense in unheated, above-core region

- Moving vapor bubbles leave behind a relative thick liquid film ( $15 \%$ of original vol. frac.); sodium wets stainless steel at high temperature

- Liquid film absorbs heat from cladding, and evaporates; can also be stripped by high vapor velocities

- High two-phase pressure drop with boiling can stop assembly liquid flow (parallel flow system)

- Boiling can remove low power $(<1 \%$ ?), but higher heat fluxes lead to coolant voiding, followed by cladding dryout, temperature increase, and cladding failure

Coolant voiding may introduce significant positive reactivity, depending on the core design 
Sodium Boiling Model Features (SAS4A)

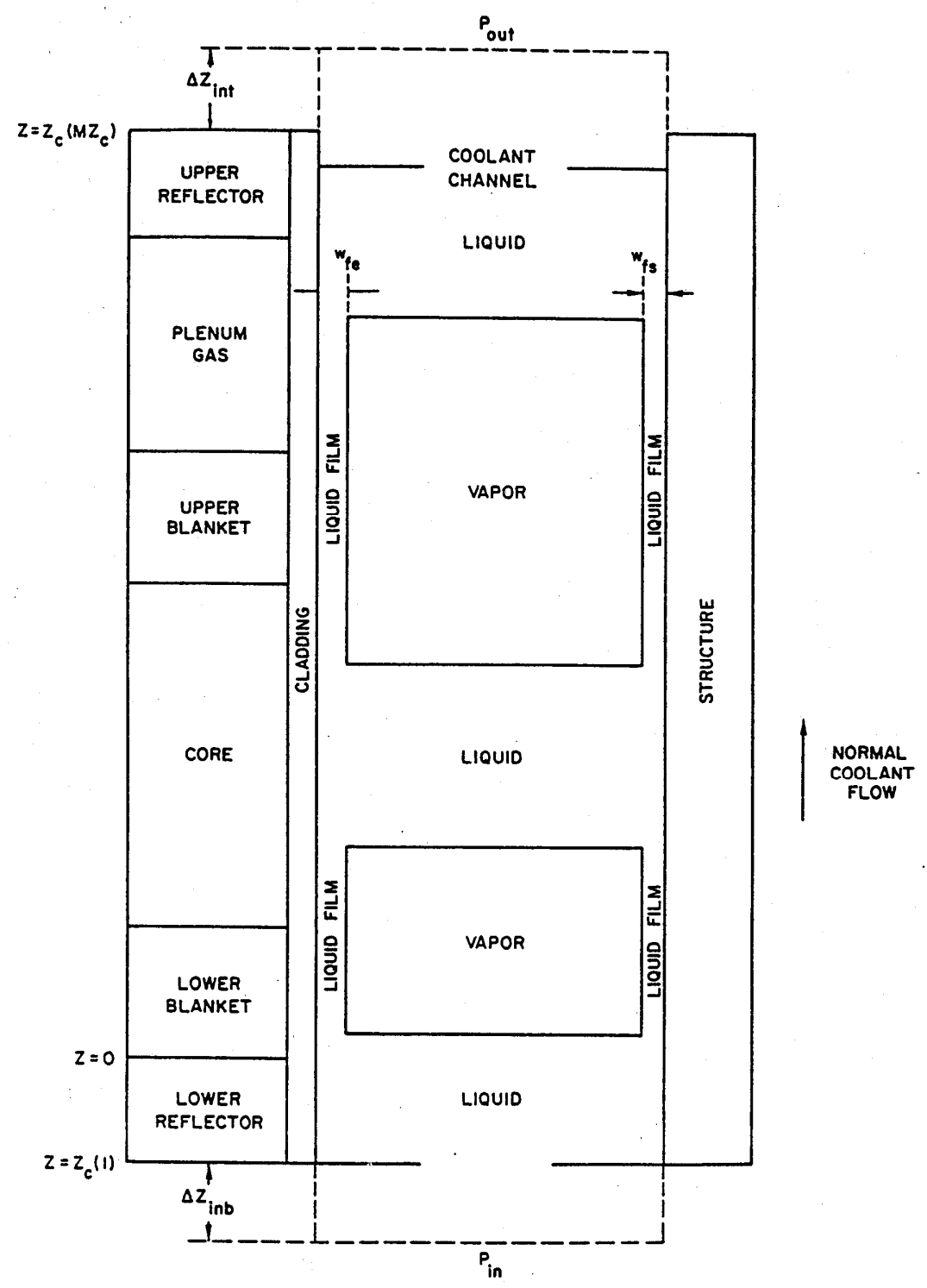


Special Safety Considerations for SFRs -- 3

- Fuel melting and relocation

- Only relevant for beyond design basis power, flow, or heat removal accident sequences (Unprotected $=$ Without reactor scram)

- Without cooling, cladding failure and fuel melting will occur rapidly, within seconds for full power levels

- Modes of cladding and fuel melting and relocation depend on reactor power and coolant flow conditions, and type of fuel (oxide or metal)

- Unprotected transient overpower accident (UTOP)

- Unprotected loss-of-flow accident (ULOF)

- Unprotected loss-of-heat-sink accident (ULOHS)

Fuel compaction in a fast reactor will introduce significant positive reactivity

- Fast reactors have a fuel inventory of several/many critical masses, depending on design

- The reactivity state of the reactor is sensitive to small (thermal expansion) fuel relocations

- Gross fuel motion in accidents can yield energetic power excursions 


\section{Special Safety Considerations for SFRs -- 4}

\section{- UTOP Accident Sequence}

- External reactivity insertion (i.e. control rod withdrawal) without scram; time scale depends on insertion rate

- Reactor power increases with full coolant flow; inherent reactivity feedback mechanisms may limit power increase

- At around 4X normal power, cladding will rupture locally, and molten fuel will discharge through the cladding failure

- ULOF Accident Sequence

- Coolant flow coastdown without scram; time scale depends on coastdown rate

- Outlet coolant temperature rises with flow coastdown; inherent reactivity feedback mechanisms may reduce power

- At around 4X Power/Flow, coolant boils, and voiding leads to loss of fuel cooling and reactivity increase

- As fuel and coolant temperatures increase, melting and relocation will occur 
- ULOHS Accident Sequence

- Loss of heat removal (e.g. SG feedwater) propagates a temperature increase through the coolant systems that eventually results in a reactor inlet temperature increase (pumps still running); slow time scale (minutes) due to large coolant systems heat capacity

- Coolant temperature increases with inlet temperature rise; inherent reactivity feedbacks may reduce reactor power

- As coolant temperature increases to boiling, bubbles formed are sweep out of the core by pump head, until local boiling pressure drop increase overcomes pump (parallel flow system)

- Coolant void formation can lead to fuel heating and melting

- Fuel relocation implications

- Initially compactive motion will yield positive reactivity; dispersive motion will yield negative reactivity

- Extended ex-core fuel motion will yield large shutdown reactivity

- If the fuel is coolable, relocation will cease

- If sufficient fuel collects ex-core, recriticality may occur 


\section{Initiating Phase Fuel Relocation Model Features (SAS4A)}

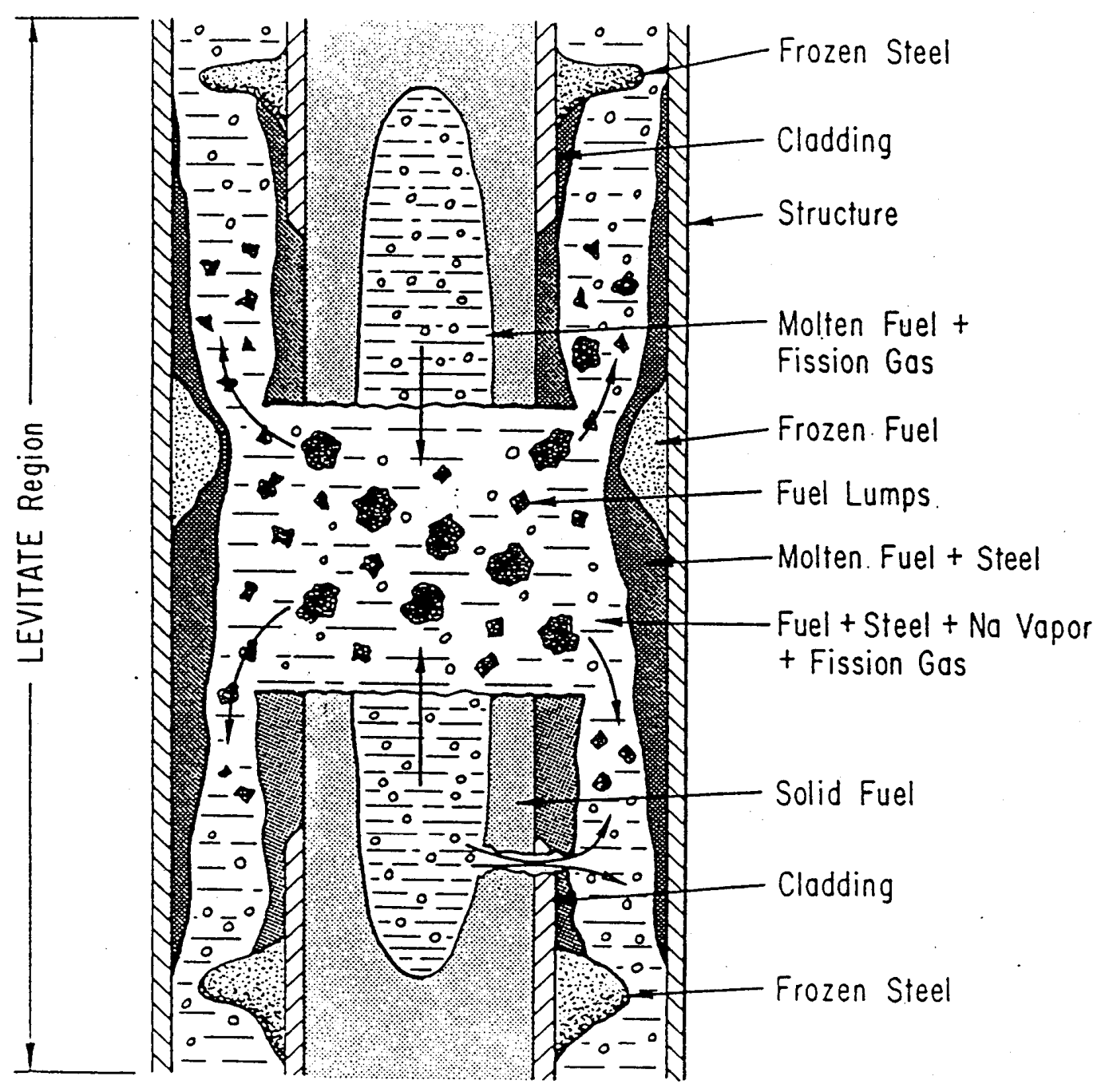


After the FFTF and CRBRP era, continued R\&D identified the potential for SFR design options that provide inherent reactivity feedback mechanisms to reduce fission power and natural circulation cooling options to remove heat in ULOF, ULOHS, and UTOP accident sequences

- Metallic fuel; high thermal conductivity, lower operating temperature, less 'stored' reactivity to overcome for power reduction to decay heat

- Sodium coolant natural circulation decay heat removal

EBR-II tests of ULOF and ULOHS accident sequences from $100 \%$ power and flow initial conditions demonstrated inherent protection potential with metallic fuel and sodium coolant

FFTF ULOF tests from $\mathbf{5 0 \%}$ power with GEMS

EBR-II and FFTF test results covered in future presentation

- SAFR and PRISM designs incorporated inherent protection design features to eliminate coolant boiling, cladding failures, and fuel melting in ULOF, UTOP, and ULOHS accident sequences 


\section{Regulatory Reviews for Safety Design Assurance}

- Sodium fast reactors have design features to prevent severe accident progression, and to mitigate the consequences of extremely unlikely accidents

- Safety by design, Defense in Depth

- Reactor scram, shutdown heat removal, containment

- Past regulatory reviews of SFR projects

- FFTF: SAR, SER, ACRS letter

- CRBRP: SAR, SER, "met CP requirements"

- SAFR: PSID, Pre-application SER

- PRISM: PSID, Pre-application SER

- Safety review basis provided by the SAR

- Design development and safety review proceeds from the General Design Criteria 


\section{General Design Criteria - 1}

10CFR50 Appendix A lists criteria in six areas for an LWR

- Overall Requirements (1 through 5)

- Protection by Multiple Fission Product Barriers (10 through 19)

- Protection and Reactivity Control Systems (20 through 29)

- Fluid Systems (30 through 46)

- Reactor Containment (50 through 57)

- Fuel and Radioactivity Control (60 through 64)

ANS 54.1 lists criteria in the same areas for a liquid metal-cooled reactor (LMR)

- Some criteria deleted/added/changed compared to 10CFR50 because of generic design differences

- DOE $0 \mathbf{5 4 8 0 . 3 0}$ lists safety design criteria for a DOE reactor

- Criteria written to apply to all DOE reactors

- Cross comparison of individual criteria provided in Appendix A 


\section{General Design Criteria - 2}

- LMR Design Characteristics (compared to LWR)

- Low pressure coolant; "leak before break"; reduces DBA focus on pipe break and loss-of-coolant; eliminates ECCS requirement by supplying secondary guard pipes and vessels to maintain core coverage in the event of leaks

- Loop vs. Pool arrangement

- Chemically reactive reactor coolant; adds requirement for leakage detection and multiple barriers to mitigate consequences; cell liners and inert cell atmosphere for loop-type primary system; fire suppression systems; steam generator instrumentation and pressure relief

- Sodium heating to prevent freezing

- Enhanced potential for natural circulation residual heat removal

- Enhanced potential for inherent protection against reactivity and cooling faults 


\section{General Design Criteria - 3}

- Top level safety requirements for an LMR are the same as for an LWR

- Diverse, independent, redundant reactor shutdown systems

- Normally, two safety-grade reactivity shutdown systems; independent instrumentation and power supplies

- Role for inherent reactivity feedback protection?

- Diverse, independent, redundant residual heat removal systems

- Normally, two safety-grade decay heat removal systems; independent instrumentation and power supplies

- For diversity and reliability, one of the systems may be a natural circulation system

- Multiple barriers for release of radioactivity

- Fuel cladding, primary coolant boundary, containment building

- Role for reduced volume containment, or alternative confinement system? 
- Domestic and international experience has demonstrated the feasibility of successful LMR licensing

- Design flexibility provided by sodium coolant properties in normal operation

- Potential severe accident safety issues associated with positive coolant voiding reactivity or core melt scenarios have been successfully treated as beyond-design-basis phenomena

- Severe accident probability reduced through conservative design, large safety margins, and adherence to defense-in-depth design philosophy

- Analysis of severe accidents with "best estimate" (not conservative) modeling assumptions to provide measure of thermal and structural margins beyond the design basis; significant resources applied 


\section{General Design Criteria - 5}

च Is there a design basis role for LMR inherent safety characteristics?

- With sodium cooling, reactor thermal safety margins are already large

- Emphasis of self-protection design features can utilize natural safety margins to provide enhanced reactivity feedback and reactor cooling mechanisms to further reduce the probability of severe accidents for faulted initiators

- Enhanced natural circulation decay heat removal at high temperatures

- Inherent protection in under-cooling (loss-of-coolant-flow or loss-of-heat-sink) or over-power (reactivity insertion) accidents without scram 
- SAR Chapter 15 Accident Analysis Example: Clinch River Breeder Reactor Plant (CRBRP) Safety Design Approach and Design Basis Accident (DBA) Classification

- Design Level 1: Normal Operation. Prevention of accidents by intrinsic features of design, construction, and operation, including quality assurance, redundancy, testability, and maintainability.

- Design Level 2. Anticipated Faults and Unlikely Faults. Provide design features to protect against errors or malfunctions.

- Design Level 3. Extremely Unlikely Faults. Provide extra protection in the design basis to assure public safety for events not expected to occur in the life of the plant.

- In Chapter 15, accident sequences classified as "Anticipated", "Unlikely", or "Extremely Unlikely" are defined and analyzed as design basis events

- Accident analysis techniques include consideration of uncertainties 
Chapter 15 Accident Analysis (cont.)

- The CRBRP DBAs are listed in Appendix B. 17 Anticipated Events, 21 Unlikely Events, 23 Extremely Unlikely Events

- The events are design specific

- Classification of events taken from RDT Standard C-16-1

- Anticipated: Faulted event that may occur once or more in the plant life, no damage, return to operation after fault correction

- Unlikely: Faulted event not individually expected during the plant life, but one or more events in whole category may occur in the plant life, some damage requiring repair for return to operation

- Extremely unlikely: Faulted event with such a low probability that no events in the whole category are expected in the plant life, damage sufficient preclude resumption of operation but no loss of safety function 


\section{Safety Documentation for Licensing - 3}

- DBA acceptance criteria are established for affected systems, structures, and components

- Criteria based on performance requirement for a class of events, usually expressed as a limiting temperature or mechanical limit

- For some structures and components, may use ASME Code

- CRBRP acceptance criteria example for fuel pins

- Basis:

- maintain cladding integrity in Anticipated and Unlikely faults

- maintain coolable geometry in Extremely Unlikely faults

- limiting criteria based on enveloping thermal/mechanical analysis

- Anticipated fault: no fuel melting and cladding temperature $<1500^{\circ} \mathrm{F}$

- Fuel melting $\sim 4800^{\circ} \mathrm{F}$ (MOX fuel)

- Cladding melting $\sim 2500^{\circ} \mathrm{F}$ (316 SS)

- Unlikely fault: no fuel melting and cladding temperature $<1600^{\circ} \mathrm{F}$

- Extremely unlikely fault: no cladding melting or coolant boiling

- Coolant boiling $\sim 1800^{\circ} \mathrm{F}$ (Reactor outlet pressure) 


\section{Safety Documentation for Licensing - 4}

- In the SAR Chapter 15 presentation, it is demonstrated that the selected set of design basis accidents result in reactor and plant design compliance with the acceptance criteria

- In a successful regulatory review, both applicant and regulatory agree that the set of DBAs envelope and characterize the satisfactory performance of the safety design, in compliance with the general design criteria and applicable regulations 


\section{Beyond Design Basis -- Core Disruption Accidents}

- The role of core disruption accidents in licensing was addressed by Fauske, 1976, during the CRBRP regulatory review

- The consensus view (industry, regulator, and R\&D) was that core disruption accidents (CDAs) should be considered and analyzed in the design review and licensing process, but that their probability of occurrence should (and must) be reduced to a level that justifies exclusion from the design basis.

- Consequence assessment should be made on a best-estimate basis using 'realistic' data and methods rather than arbitrarily conservative assumptions.

- In earlier analyses for FFTF (See Appendix A of the FFTF FSAR) the case had been made for a 'conservative upper bound HCDA case'

- Consequence assessment was used to estimate barrier challenge, containment performance, and radiological consequences

- For CRBRP, beyond design basis structural and thermal margins were assessed in relation to calculated accident energetics 
- Documented in FSAR Appendix A

- Analyzed bounding UTOP and ULOF accident sequences for estimation of consequences and demonstration of the ability of the containment to provide protection of public health and safety

- UTOP initiators: $0.03 \$ / \mathrm{s}$ (max. by design) to $0.5 \$ / \mathrm{s}$ without scram

- ULOF initiators: complete loss of primary pumping without scram

- Initiating phase accident analyses tracked with detailed modeling to the point of initial fuel melting and dispersal

- Reactor power reduction, but for the ULOF sequence, the reactor state may not be coolable, leading to further melting and transition to whole core melting

- Whole core disruption phase analyzed with scoping tools to assess modes and rates of fuel relocation, assessment of associated reactivity transients, and resulting energy deposited in the fuel 
- Work-energy analysis to assess conversion of fuel energy to pressure loading of reactor structures

- Mechanical consequences assessment to determine damage to structures and reactor vessel

- Post-accident heat removal assessment to scope final core debris stability and coolability

- Radiological assessment to scope radioactivity release

- Conclusions

- Neither the UTOP nor the ULOF lead to significant public risk

- UTOP: Initial cladding failures, fuel sweep-out and dispersal, remainder of core is coolable in place, fuel within intact reactor vessel

- ULOF: Whole core disruption and dispersal, moderate pressure transient causes minor coolant (" $300 \mathrm{lbs")} \mathrm{and} \mathrm{fuel} \mathrm{("<1 \% ")} \mathrm{loss} \mathrm{from}$ vessel, containment structure remains intact ( $0.1 \%$ per day leak rate)

- 30 day dose at site boundary is $>100 \mathrm{X}$ below guidelines for reactor siting 


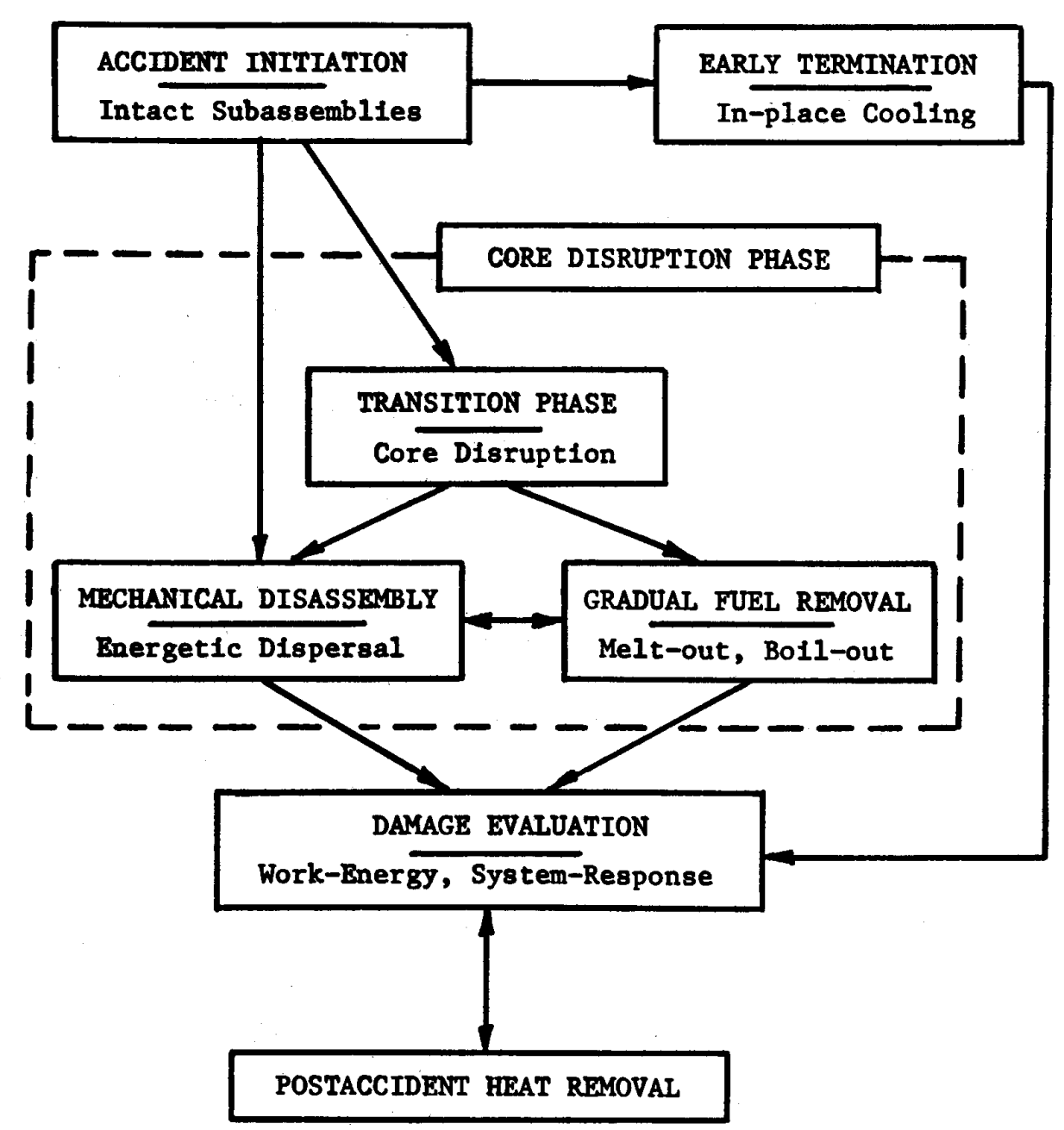


- Initially document in PSAR Appendix D

- PSAR Appendix D was deleted in Amendment 24, July 1976

- Core Disruption Accidents were excluded from the design basis, see papers by Strawbridge and Slember

- The limiting design basis accident for containment challenge was PSAR 15.6.1.1 Primary Sodium In-Containment Storage Tank Failure During Maintenance (See Appendix B)

- However, the subject of core disruptive accidents and their consequences were extensively analyzed and discussed by the project and NRC. (At one point, the CDA issue determined the critical path for the licensing schedule)

- NRC discussion in SER Appendix A

- Project Reports:

- CRBR-3, Hypothetical Core Disruptive Accident Consideration in CRBRP, Volumes 1 and 2, Revision 4, 1982 
CRBRP Core Disruption Accident Analyses --2

- Extensive analyses were performed by General Electric (using Argonne codes and data) and by Argonne Natl. Lab. 
- Compared to FFTF, the issue in CRBRP was the larger core size (975 MWt vs $400 \mathrm{MWt}$ ), and the implications for energetics

- 2.5X initial core power in the same diameter reactor vessel

- $\sim 3.5 \$$ coolant void worth compared to $\sim 0$ in FFTF

- The role of the larger coolant void reactivity worth altered the ULOF scenario

- In FFTF, coolant boiling and voiding had little reactivity effect, so initial fuel disruption occurred at near nominal power in a 'dry' core

- In CRBRP, coolant boiling and voiding introduced positive reactivity and raised the power level, so cladding failure and initial fuel disruption occurred at elevated power $\left(\sim 10 \mathrm{X} \mathrm{P}_{\mathrm{o}}\right)$ in a core with significant liquid sodium (and corresponding reactivity) still present

- CDA attention was focused on the ULOF and the potential for initiating phase energetics

Attention on the CDA issue was emphasized by the role of CRBRP as a prototype demonstration design 


\section{Fauske (1976) Illustration of Work Energy Estimates}

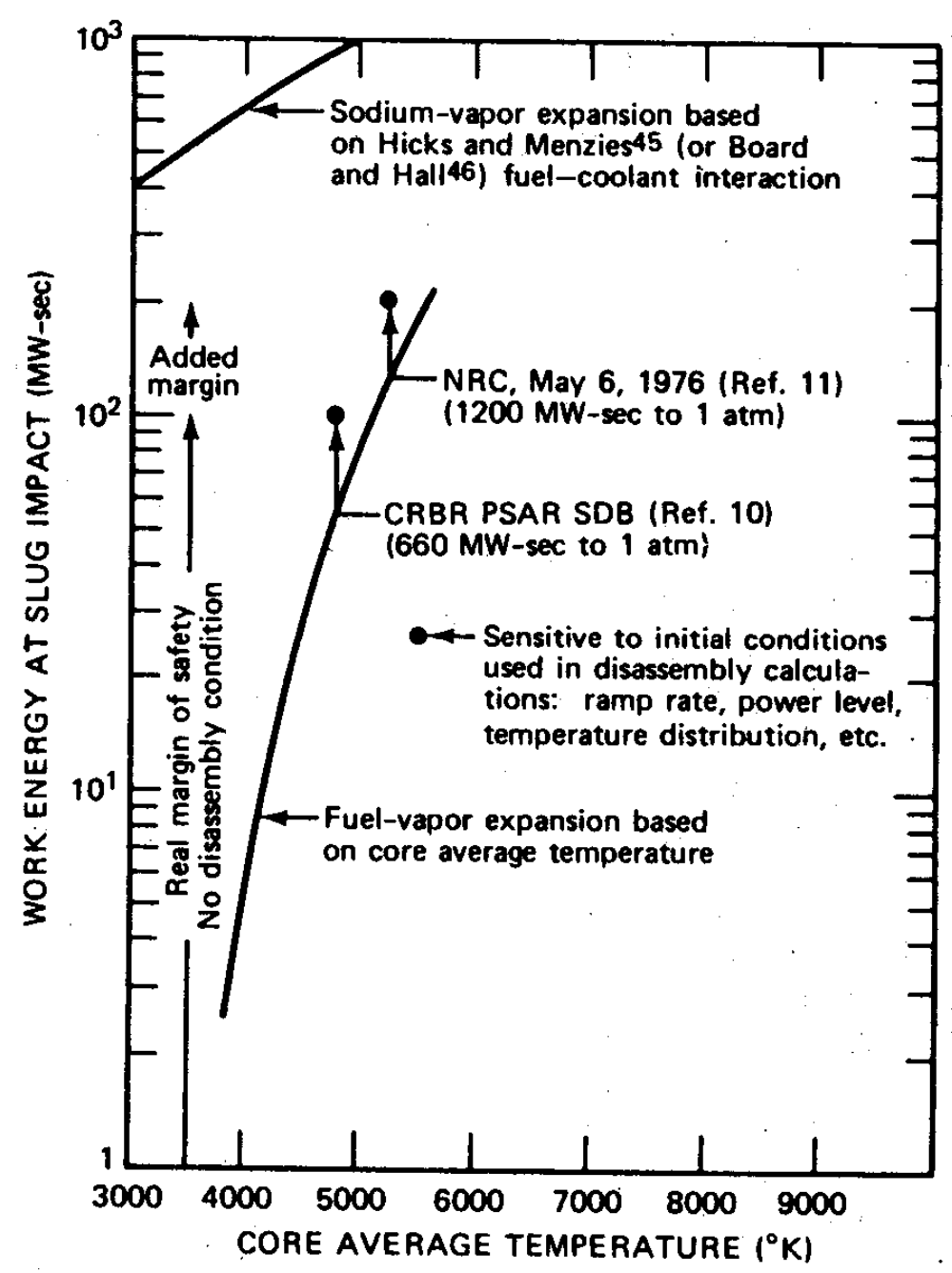




\section{Example CRBRP ULOF Analysis Results}

- Nominal base case results for best-estimate phenomenological assumptions (similar to FFTF analysis assumptions) yields a nonenergetic initiating phase

- Peak power $\sim 12 X P_{o}$, peak reactivity $\sim 0.8 \beta$

- Bounding case results

- Neglect of reactivity feedback from axial thermal expansion

- "Pessimistic" modeling assumptions for initial fuel dispersal

- "Pessimistic" modeling of cladding failure and subsequent fuel motion in low power fuel that fails late into unvoided or partially voided coolant channels ('Fuel-coolant interaction' or 'LOF-drivenTOP')

- Peak power $\sim 2750 X P_{o}$, peak reactivity $\sim 1.06 \beta$, peak fuel temperature $\sim 6000 \mathrm{~K}$, average core fuel temperature $\sim 4480 \mathrm{~K}$, isentropic fuel expansion work energy $\sim 680 \mathrm{MJ}$ (CRBRP structural margin design basis $\sim 661 \mathrm{MJ}$ ) 


\section{Resolution of CRBRP CDA Issues for Licensing}

- See 1985 papers by Strawbridge and Giitter, and NUREG-0968 Appendix A Section A.6

- NRC approved the project position on CDA energetics

- Contingent on changes to the fuel pin design, the rotating plugs design, and analysis and testing results for cell liner performance

- NRC sponsored independent analyses at LANL

- Concluded that containment would not be challenged by missiles or spray fires, and radiological consequences would depend on the beyond-design-basis containment thermal margins to deal with sodium spills and hydrogen burns. NRC concluded that the design could adequately deal with such challenges, and that the risk from a CDA in CRBRP was not significantly different from the risks from typical LWRs. 
- By mission, the SAFR and PRISM conceptual designs were developed under a mandate for innovation, modularity, and reduced costs

- This mission prompted new approaches to interpretation of the General Design Criteria and the Defense-in-Depth principle

- Reliance on inherent mechanism in place of active systems for reactor shutdown and residual heat removal

- With large initial (fuel and coolant) safety margins and very reliable inherent safety mechanisms, the probability of CDAs was dramatically reduced, and containment designs were adjusted accordingly

- The SAFR and PRISM projects engaged NRC and a dialog on begun. However, the designs did not reach full maturity, and the projects terminated with issues unresolved

- See the SAFR and PRISM SERs, and the GE paper by Pat Magee 
- The SAFR and PRISM PSIDs present the designer proposals for the GDCs, and the SERs document the NRC responses

- Mostly in agreement, with some divergences

- The SAFR and PRISM projects supplied only minimal DBA analyses, because of the immaturity of the designs.

- Designs were evolving, in part due to additional mission requirements and in part due to interactions with NRC

- Considerable emphasis was placed on passive safety accommodation of the ULOF, UTOP, and ULOHS accident sequences while maintaining substantial margins to prevent CDA progression and severe accident consequences

- The combination sodium cooling, a pool-type primary system, and metallic fuel provides the potential for self protection mechanisms to prevent severe accident consequences 
- Pool-Type primary system

- All primary coolant confined to a single vessel with no external piping. Eliminates pipe break (leak) accident scenario (with appropriate redundancy in pump-to-inlet plenum connection)

- Sodium coolant

- Low operating pressure eliminates pipe or vessel rupture possibility

- With oxygen control, no corrosion of steel structural material

- Superior heat removal properties due to high thermal conductivity, volumetric heat capacity, and thermal expansion for buoyancy (natural convection)

Metallic fuel

- High thermal conductivity, low operating temperature, low invested cold-to-hot reactivity to compensate for shutdown

- Hard spectrum and high density promotes low burnup reactivity swings, minimizing control rod worths and external reactivity 


\section{Reactivity Swing for Power Reduction}

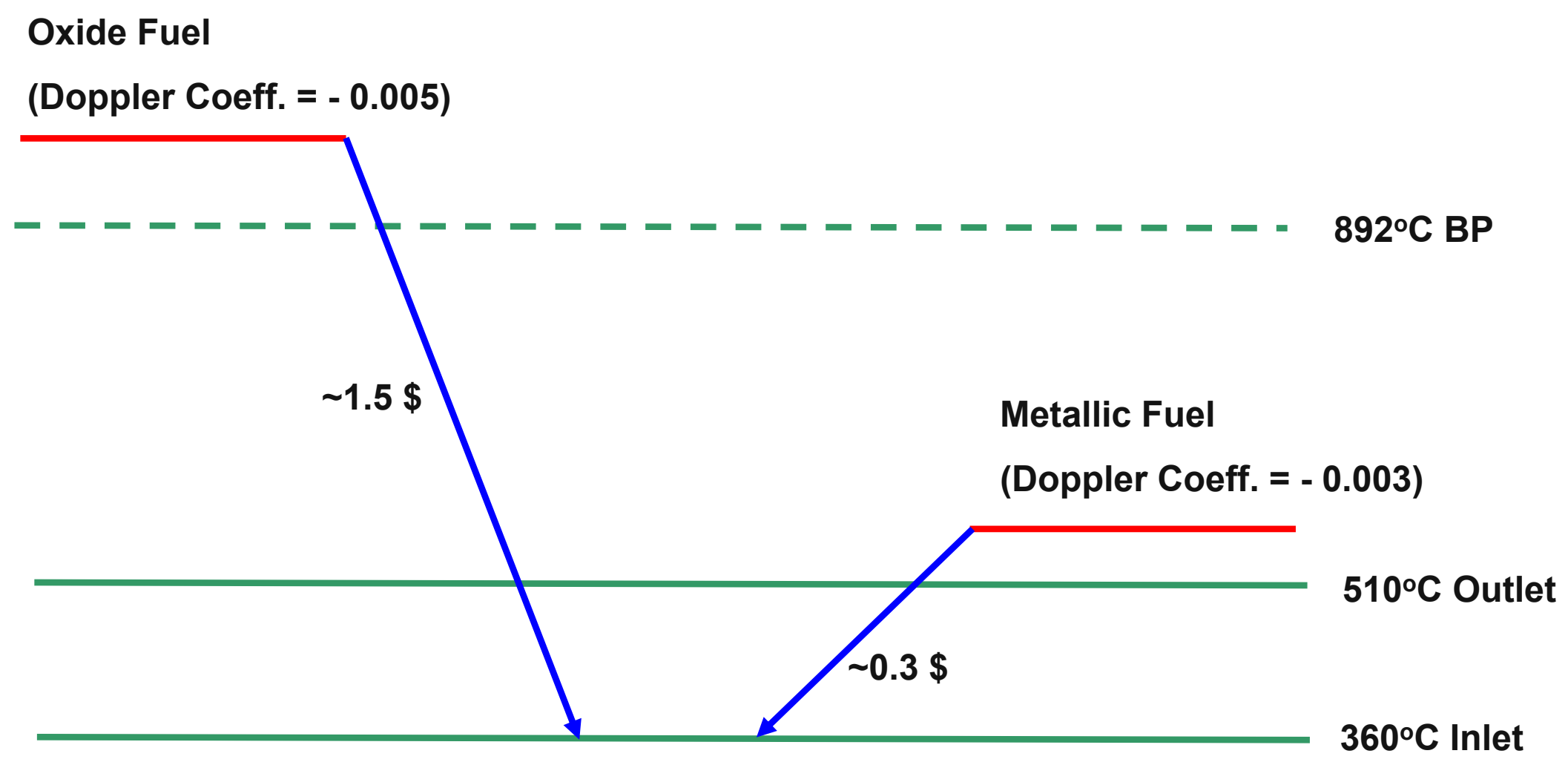




\section{Small Fast Reactor ULOF Power and Flow}

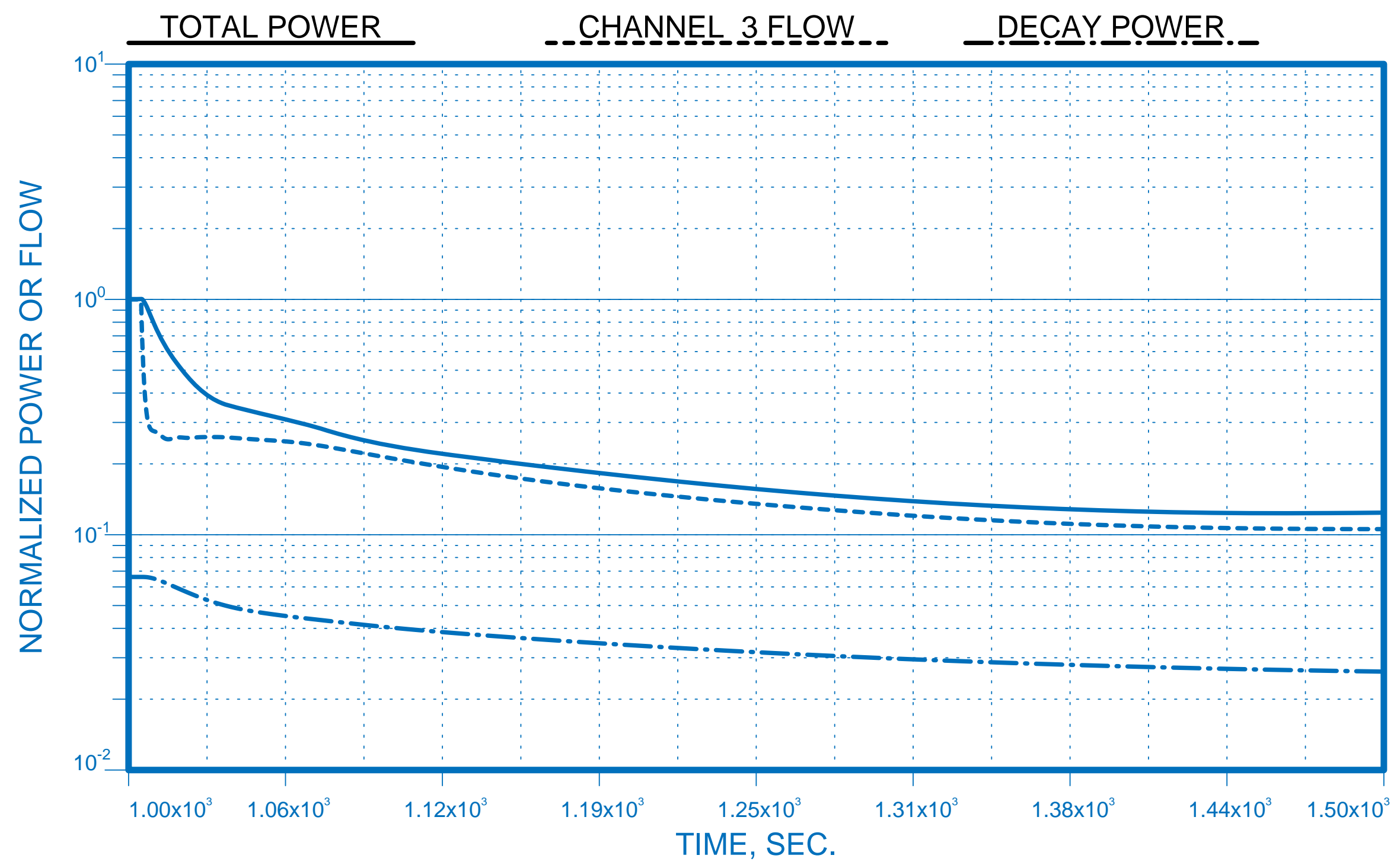




\section{Small Fast Reactor ULOF Reactivities}

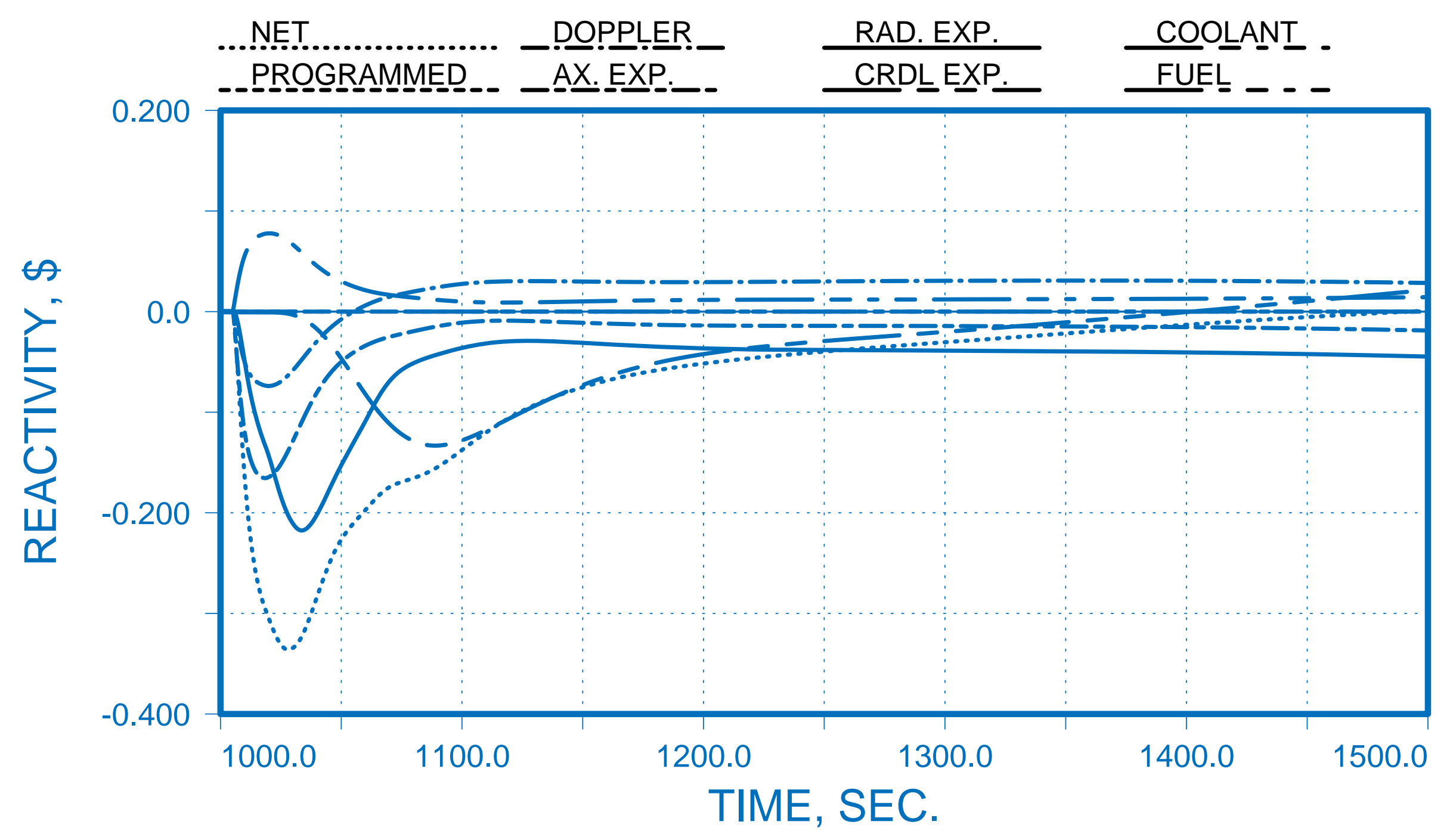

\section{Argonne}




\section{Small Fast Reactor ULOF Temperatures}

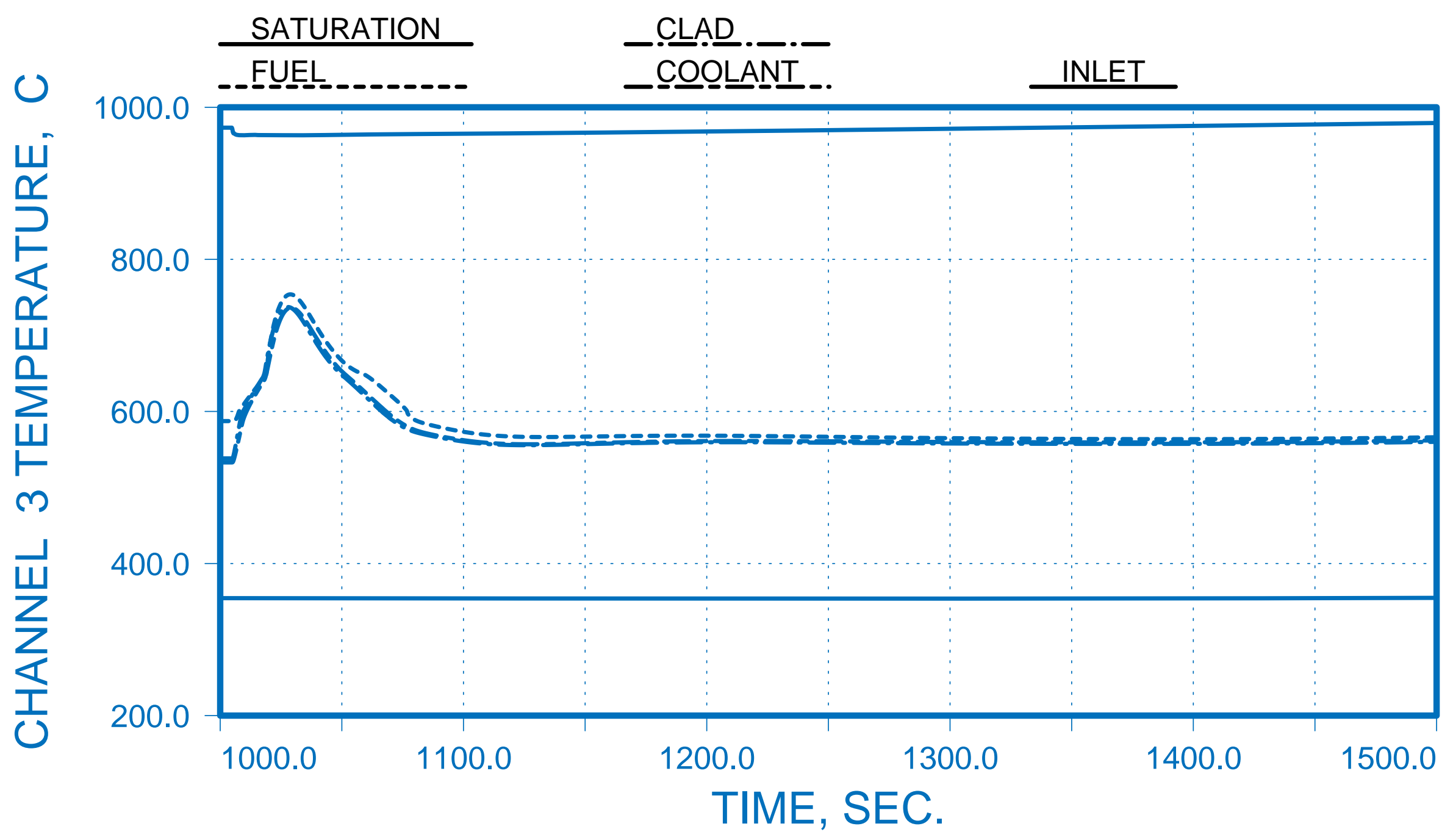


- A sodium-cooled, pool-type, metallic fuelled reactor design can be configured to survive all ULOF, UTOP, and ULOHS accident initiators with substantial margin to coolant boiling, cladding failure, or fuel melting

- In FFTF and CRBRP, these initiators lead to core disruption and the potential for energetics and containment challenge

- In SAFR, PRISM, and similar designs, unprotected accident initiators result in reduced accident consequences, short of coolant boiling and fuel disruption

- Progression to severe accident consequences requires assumption of very low probability initiators (triple fault?)

- Assessment of severe accident consequences may best be carried out within the PRA framework, not necessarily related to a deterministic accident sequence 
- See paper by Fauske (1976) for LMFBR models and codes

- FFTF and early CRBRP core disruption analysis was performed with the SAS3A (SAS3D) computer code at Argonne

- HEDL used the MELT code for UTOP analysis (ULOF at ANL)

- The SAS4A code was developed at Argonne with modeling appropriate for initiating phase core disruption analysis of higher void worth core designs

- Mainly one-dimension modeling appropriate until melting of hexcans

- The SIMMER code development began at about the same time at LANL for analysis of the 'transition' phase of the core disruptive accident; whole-core two dimensional model

- The VENUS code had been developed earlier at ANL for analysis of the disassembly phase

- The SASSYS-1 code was developed later for whole-plant analysis

- Focus today on Argonne SAS4A and SASSYS-1 codes 


\section{SAS4A/SASSYS-1 Computer Code Background}

Developed at ANL for transient analysis of liquid metal reactor core disruption and systems analysis

- Originally developed to support CRBRP licensing

- Safety margin assessment in design basis accidents (DBA) and anticipated transients without scram (ATWS); SASSYS-1

- Consequence assessment in severe accidents; SAS4A

- Development continued during the Integral Fast Reactor (IFR) program (metallic fuel)

Heavy liquid metal coolant options added during the Advanced Accelerator Applications (AAA) program

- Water versions developed in NPR and international programs

Modeling validated by applications to testing data from TREAT, EBR-II, and FFTF

- World-wide standard code for LMR safety analysis; Germany, Japan, France, Italy, Russia; additional validation with CABRI test data 


\section{SAS4A/SASSYS-1 Modeling Features}

- Single and multiple pin subassembly thermal hydraulics; multiple subassemblies for whole-core simulation

- Two-dimensional pin heat transfer

- Single and two-phase coolant dynamics (coolant boiling, fission gas release upon pin failure)

- Liquid metal coolants: $\mathrm{Na}, \mathrm{NaK}, \mathrm{Pb}, \mathrm{Pb}-\mathrm{Bi}$

- Oxide and metallic fuel and cladding mechanics

- Reactor point and spatial kinetics with reactivity feedbacks; nodal diffusion and nodal transport options

- Primary and intermediate coolant systems thermal hydraulics with components (pumps, pipes, plena, valves, heat exchangers, steam generators)

- Steam power cycle with components (turbine, condenser, pumps, heaters, steam generators)

Reactor and plant control systems 
- SAS4A: Simulation of initiating phase CDA

- Developed for higher-void-worth core applications (CRBRP); fuel disruption at above nominal power levels

- Modeling validated with TREAT test data

- Exported to Japan, France, and Germany; validation with CABRI test data

- SAS4A Fuel Disruption Models

- Single-pin, multiple channel thermal hydraulics core model

- DEFORM-4 (oxide) fuel pin mechanics model

- Multiple slug/bubble coolant boiling model

- CLAP cladding melting and relocation model

- PLUTO2 fuel/coolant interaction model

- LEVITATE fuel pin disruption model 


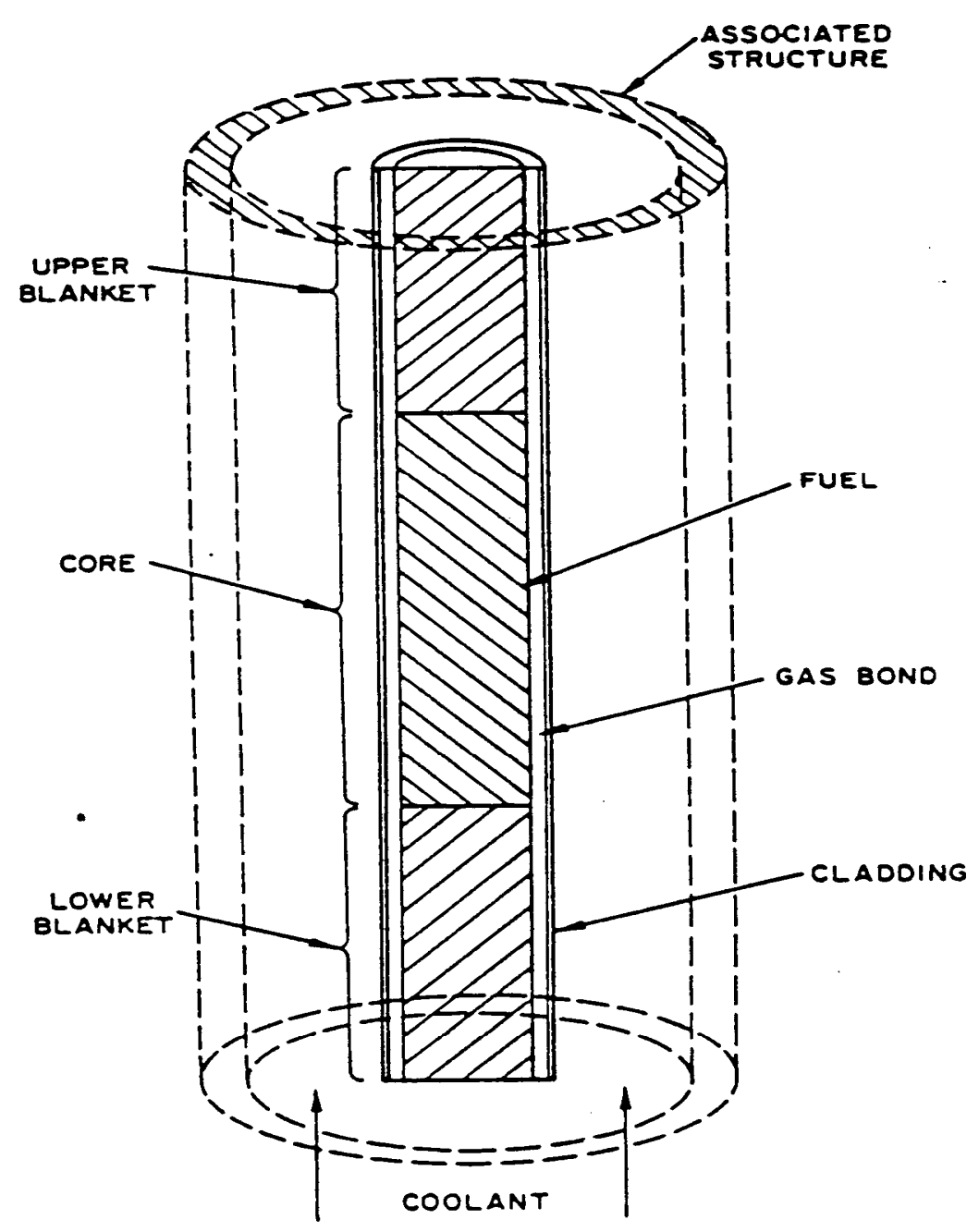


SAS4A/SASSYS-1 Single-Pin Channel Model
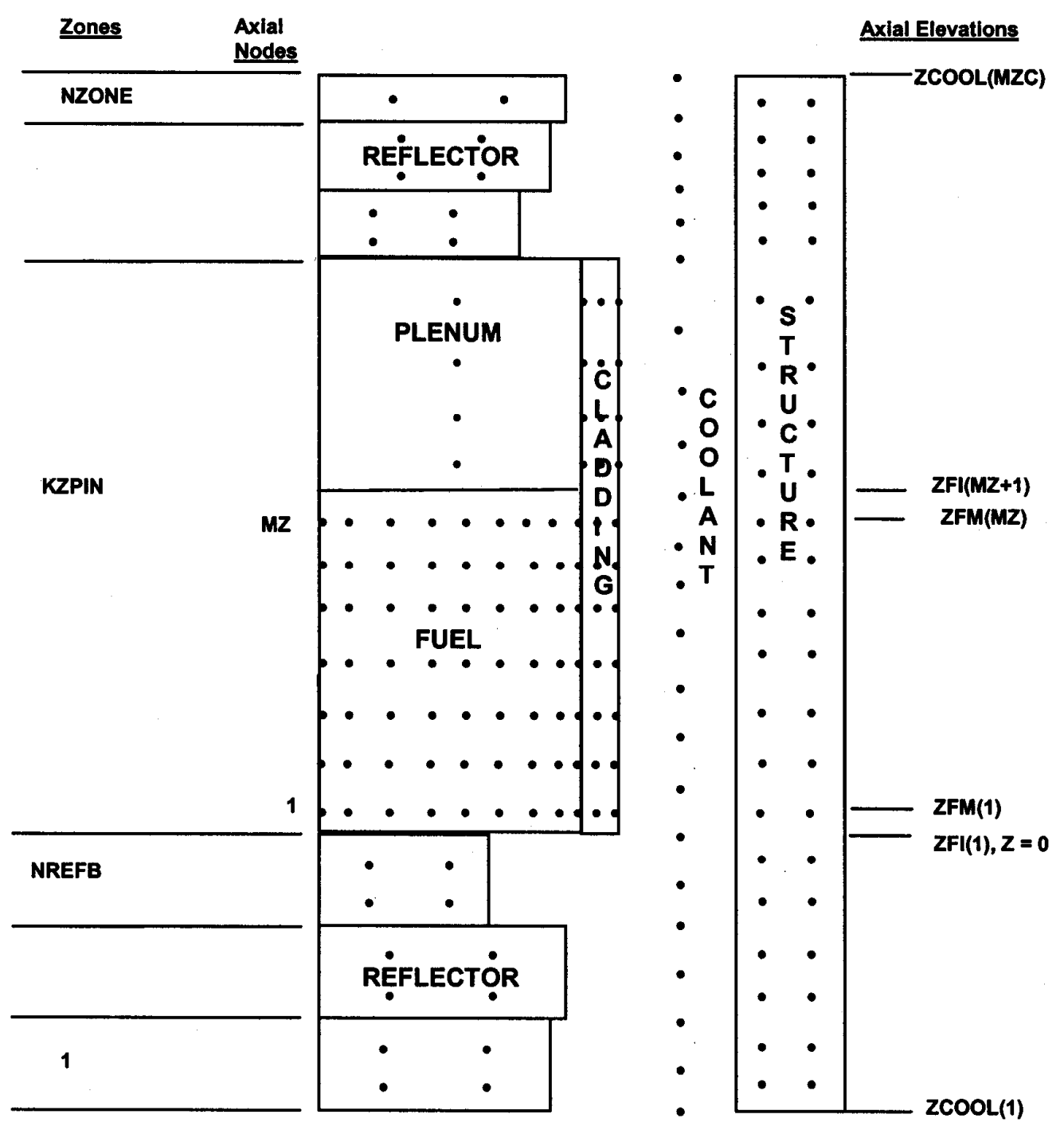


\section{SAS4A Fuel Pin Heat Transfer Model}

- One-dimensional, radial heat transfer at many axial locations

- Radial conduction through the fuel and cladding; conduction and radiation across the fuel/cladding gap

- Convective boundary condition to the axially flowing coolant from the cladding and the structure

- Initial, steady state conditions for the coolant mass flow and the axially-dependent channel power

- Steady state channel pressure drop in all channels adjusted to match the peak channel pressure drop with addition of a channeldependent inlet orifice coefficient

- Transient channel flows computed from time-dependent inlet-tooutlet plena pressure drop 


\section{Channel Radial Heat Transfer Mesh}

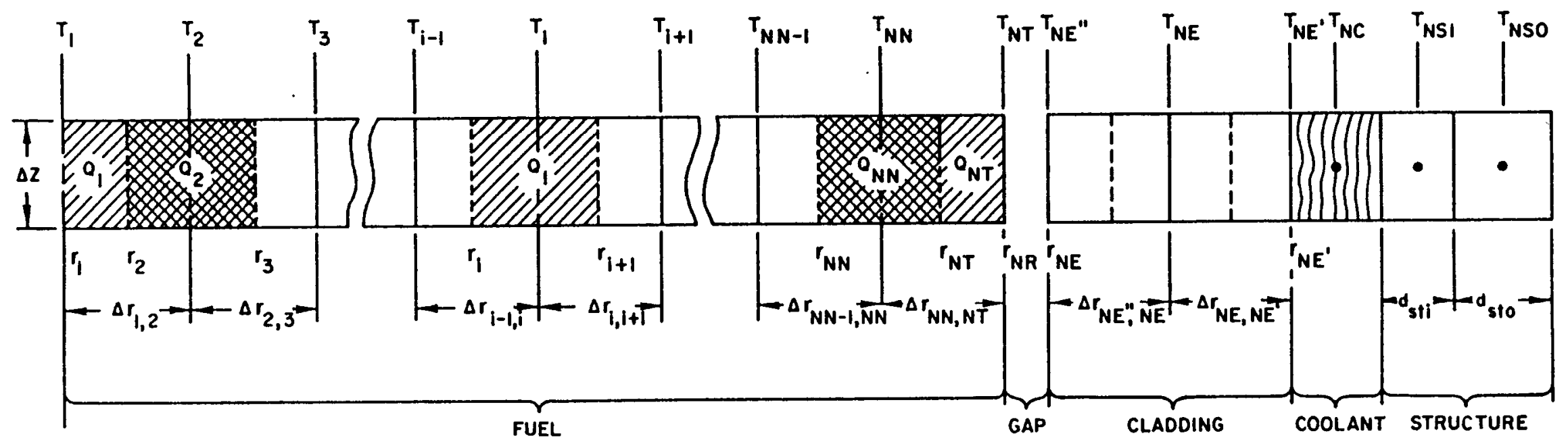




\section{DEFORM-4 Model}

- Mechanistic simulation of oxide fuel and stainless steel cladding behavior during irradiation and in a transient

- Porosity migration, grain growth, fission gas release, fuel cracking with crack healing, fission-gas-induced swelling, irradiationinduced steel swelling, gas plenum pressurization, fuel-cladding gap conductance

- Fuel and cladding mechanical behavior, thermal expansion, molten fission gas release and pressurization, cladding failure

- Original ANL model was modified at FZK (Germany) to be more applicable to European reactor materials and designs 


\section{DEFORM-4 Fuel/Cladding Deformation Model}
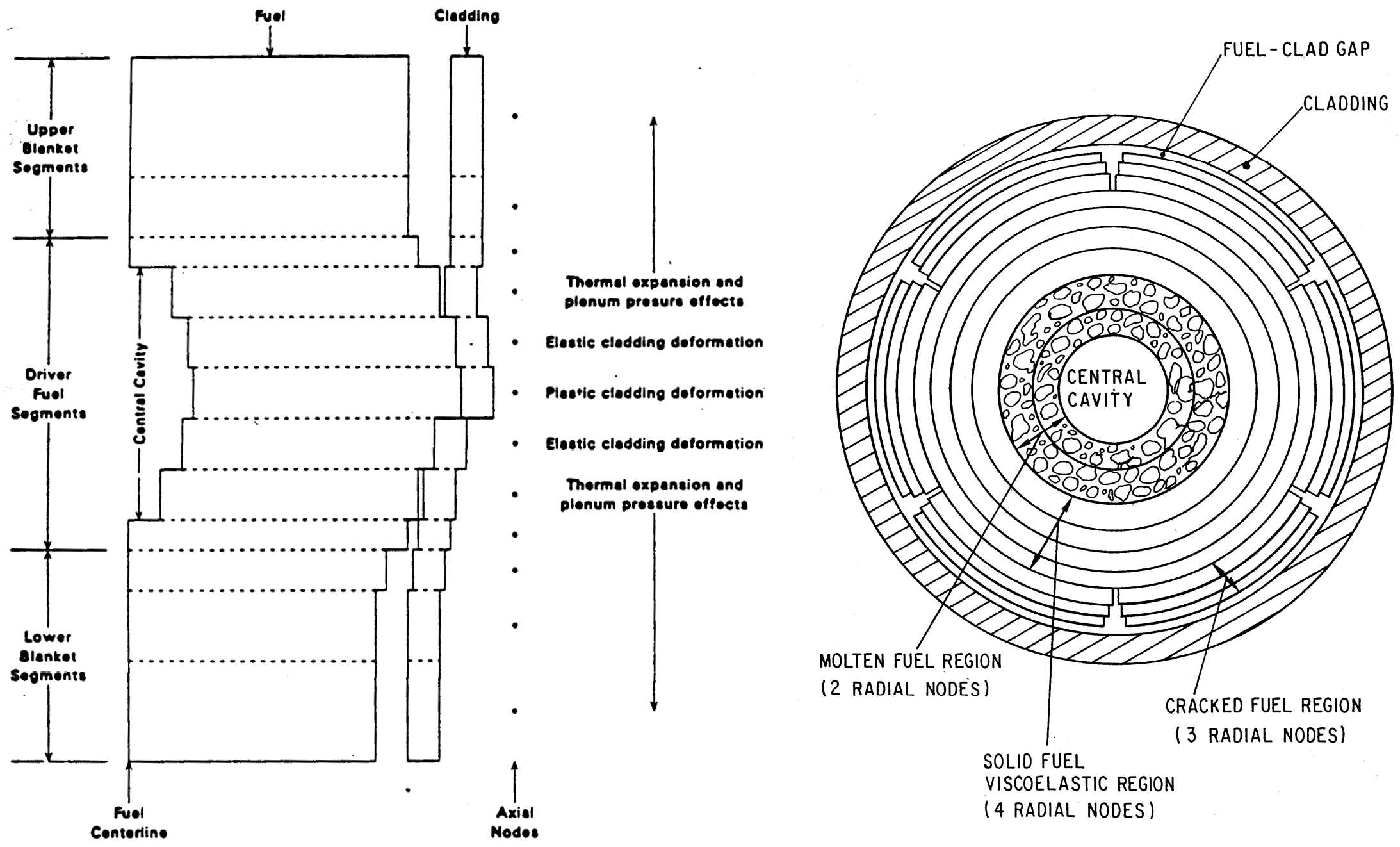
- Single and two-phase sodium coolant flow in pin bundles

- Low-pressure liquid sodium boiling: multiple slug/bubble flow regime

- Cladding wetting: liquid sodium film on cladding and hexcan wall

- Simulates bubble initiation and growth, bubble motion, void formation, film evaporation and stripping, liquid flow reversal and chugging

- Loss of heat removal and reactivity effect of voiding

- Model validated by analysis of laboratory and reactor tests (e.g. R5 TREAT) 
SAS4A Sodium Boiling Model

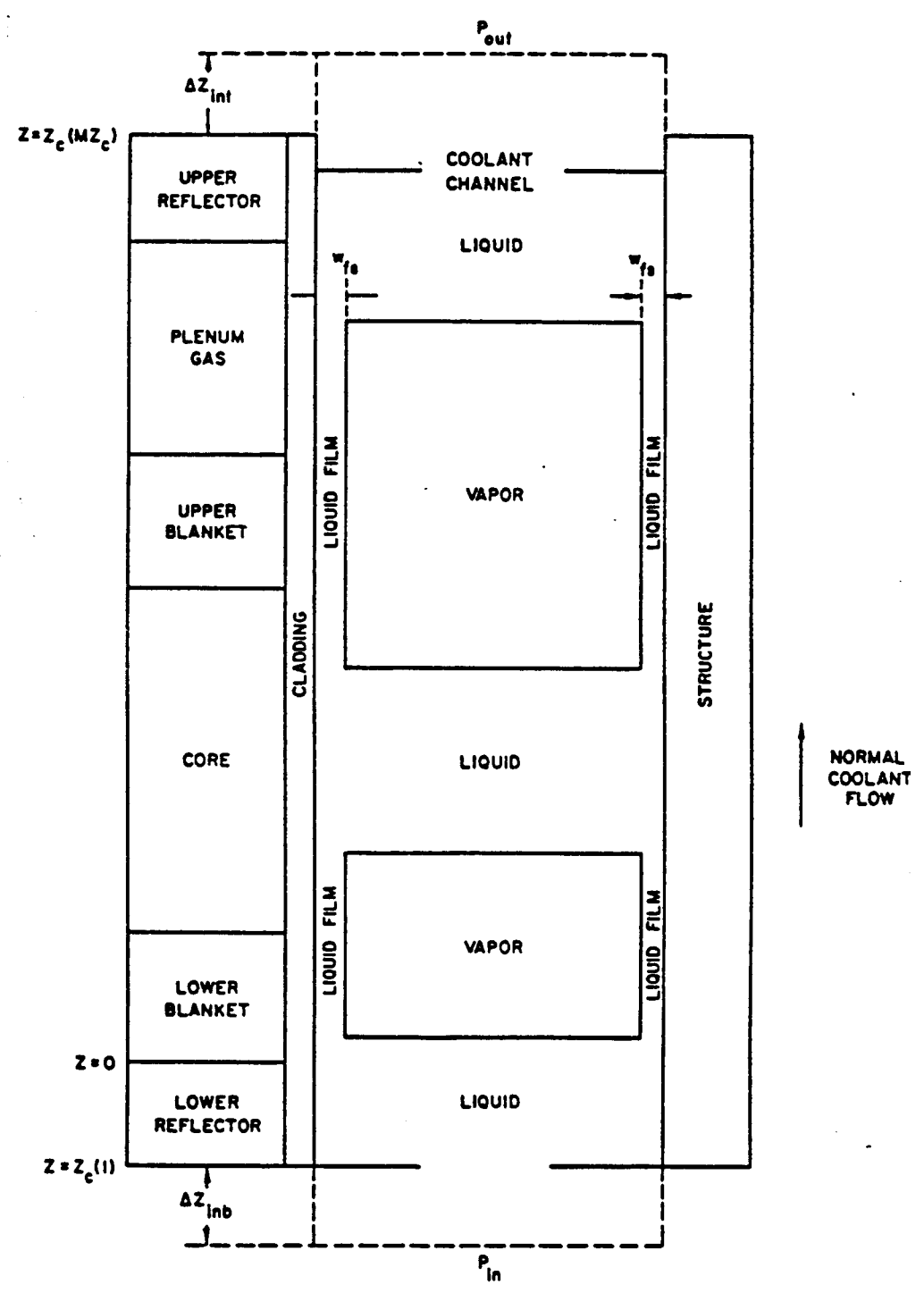


- Cladding melting and relocation following dryout of sodium film

- Motion due to coolant vapor flow (pressure gradient and shear forces) and gravity

- Molten cladding freezing and blockage formation

- Heat capacity loss with cladding motion

- Reactivity effect of steel removal from core 
CLAP Model

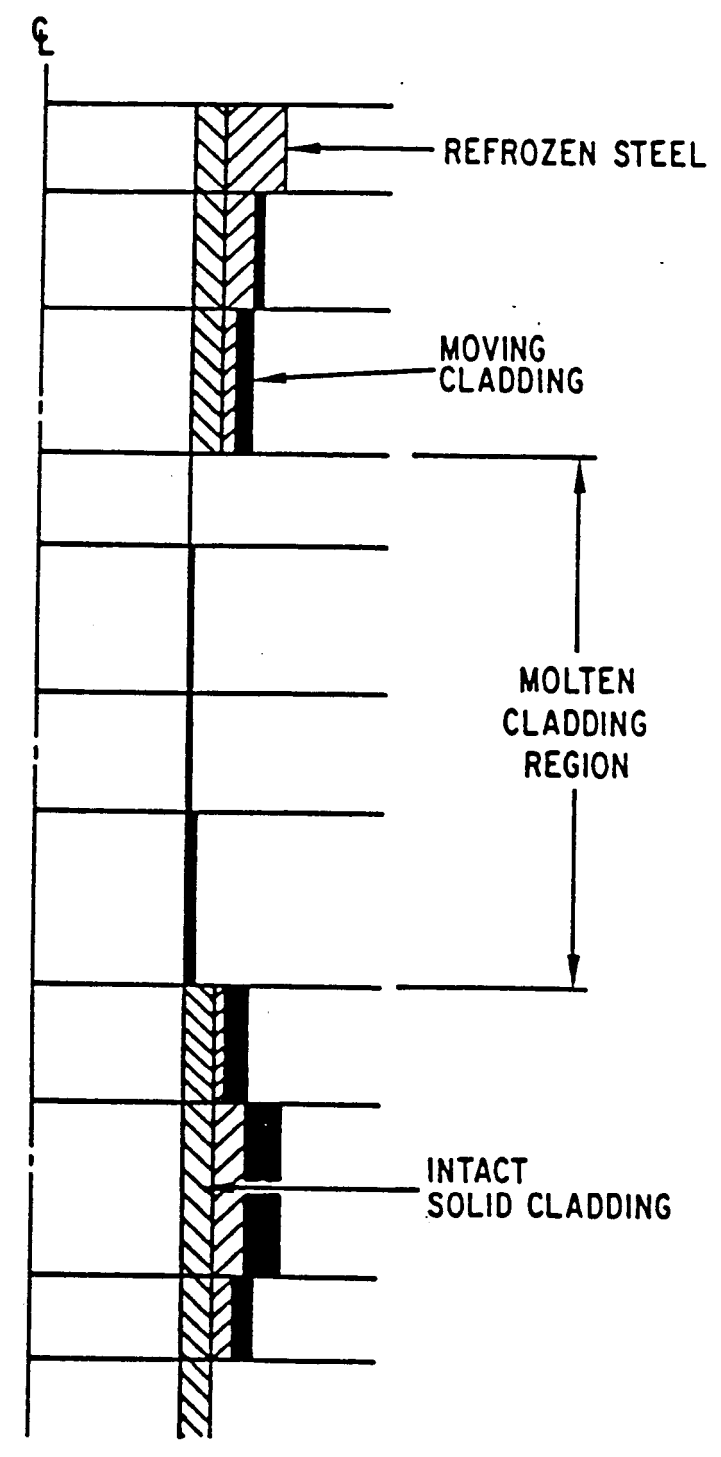




\section{PLUTO-2 Fuel Coolant Interaction Model}

Model for fuel motion following cladding failure with flowing liquid coolant

Fuel (in- and ex-pin), fission gas, and coolant dynamics following cladding failure in a channel with flowing liquid sodium

- Detailed material dynamics (two-fluid) with particulate of continuous flow regimes

Fuel freezing and plate-out

- Cladding rip elongation

Model validated by comparison to TREAT tests

- Modifications performed by JNC for CABRI test analysis 


\section{PLUTO-2 Modeling}

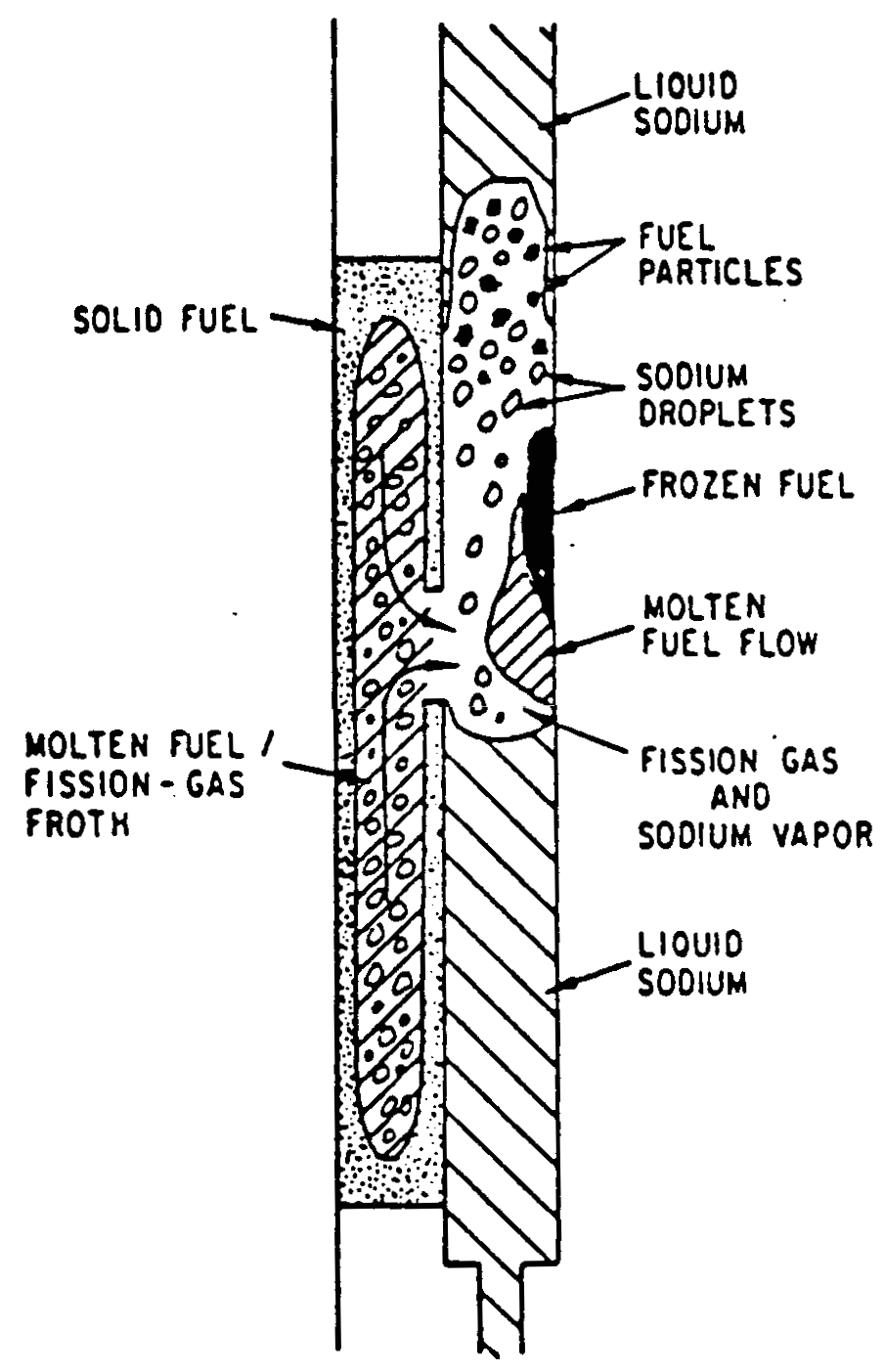




\section{LEVITATE Fuel Pin Disruption Model}

- Model for fuel pin disruption in voided coolant channels

- Fuel (in- and ex-pin), fission gas, cladding, and coolant vapor dynamics following cladding failure and disruption in a channel voided of coolant

Detailed material dynamics (two-fluid) with multiple flow regimes

- Solid fuel fragmentation ("chunk" formation) and relocation

- Molten fuel ejection and freezing

Modifications performed by JNC for CABRI test analysis 


\section{LEVITATE Modeling}

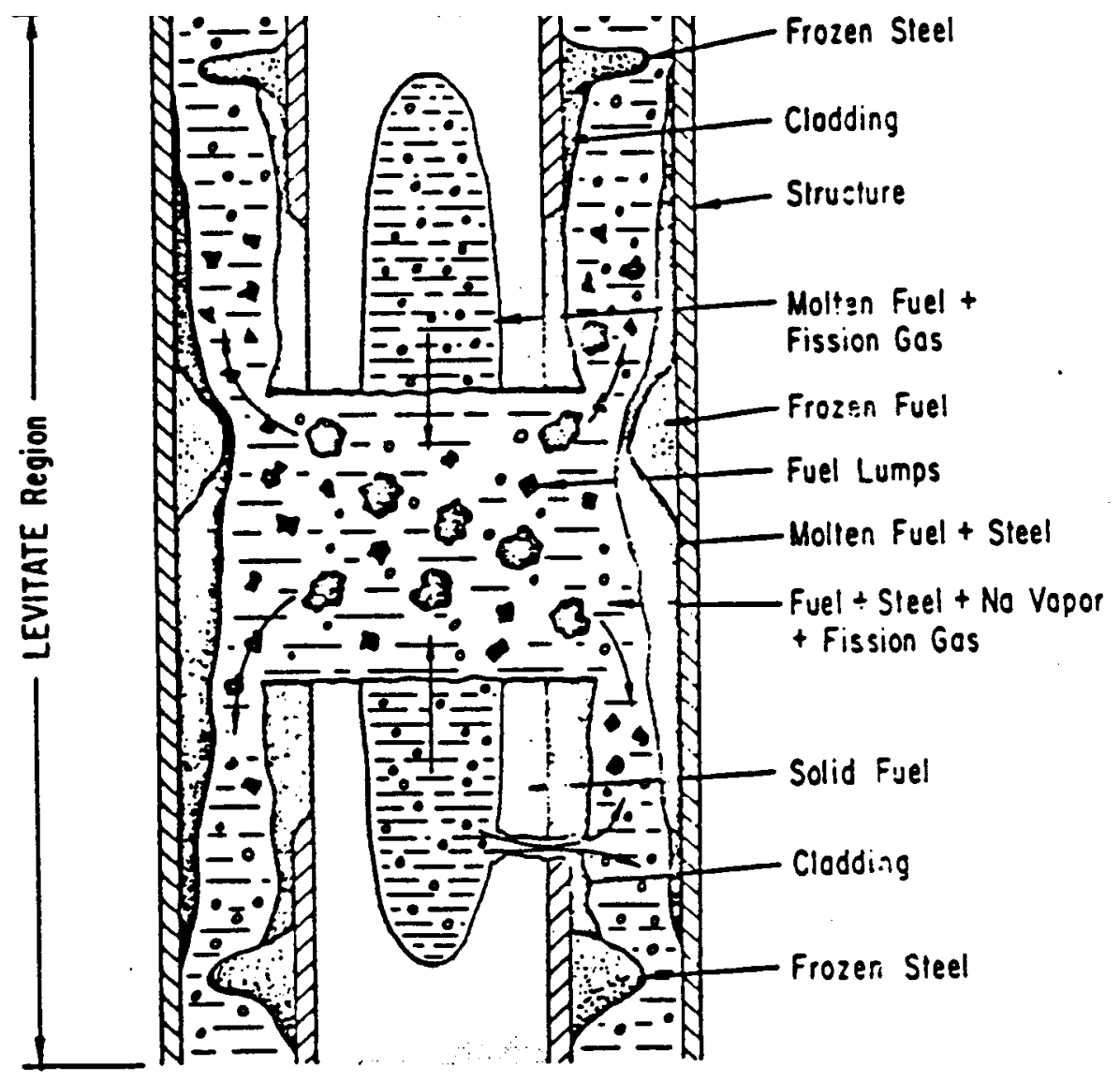


- SASSYS-1 modeling was originally developed for analysis of shutdown heat removal transients

- Reactor and heat transport systems models for design basis and accident analysis

- Scope of analysis soon grew to cover the steam generators and balance-of-plant, and the control systems

- During the ANL Integral Fast Reactor program (1984-94) metallic fuel modeling was added, and SASSYS-1 was used to analyze ATWS events to assess passive safety performance

- Extensive applications to EBR-II Shutdown Heat Removal Tests and FFTF Inherent Safety Tests (circa 1986)

- EBR-II real time simulator

- Concept evaluations in the IFR program, support to SAFR and PRISM 
- SASSYS-1 models include

- Multiple-pin subassembly model

- PRIMAR-4 coolant systems model

- DEFORM-5 metallic fuel cladding failure model

- SSCOMP metallic fuel properties model

- FPIN-2 metallic fuel pin behavior model 
Steady-state and transient calculation of fuel, cladding, coolant, and structure temperatures and coolant flow rates

- Basic model applicable to sodium, lead, lead-bismuth, helium, and water coolants given appropriate constituent data

- Triangular pitch/hexagonal geometry or square pitch/square geometry.

With or without subassembly wrapper can

- Coolant flow parallel to pins and between sub-channels driven by pressure differences and flow sweeping due to wire wrap

- Forced convection and buoyancy-driven natural circulation

- Solve mass, energy, and momentum equations for coolant

- Constitutive relations for cross-sub-channel mass flow and energy flow (turbulent mixing and thermal conduction)

- Solve conduction energy equation in fuel, cladding, and structure 


\section{SASSYS-1 Multiple-Pin Subassembly Model}

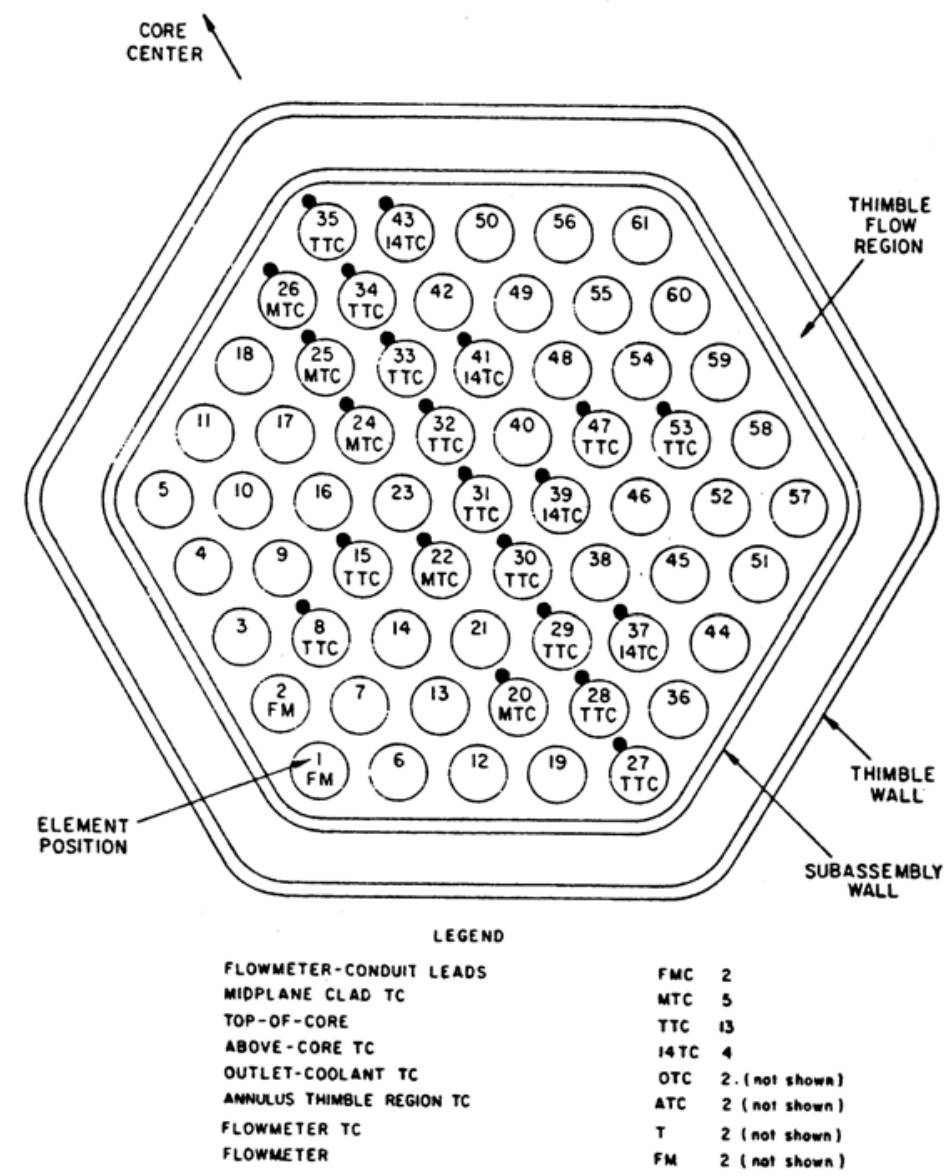

EBR-II XX09 Instrumented Subassembly

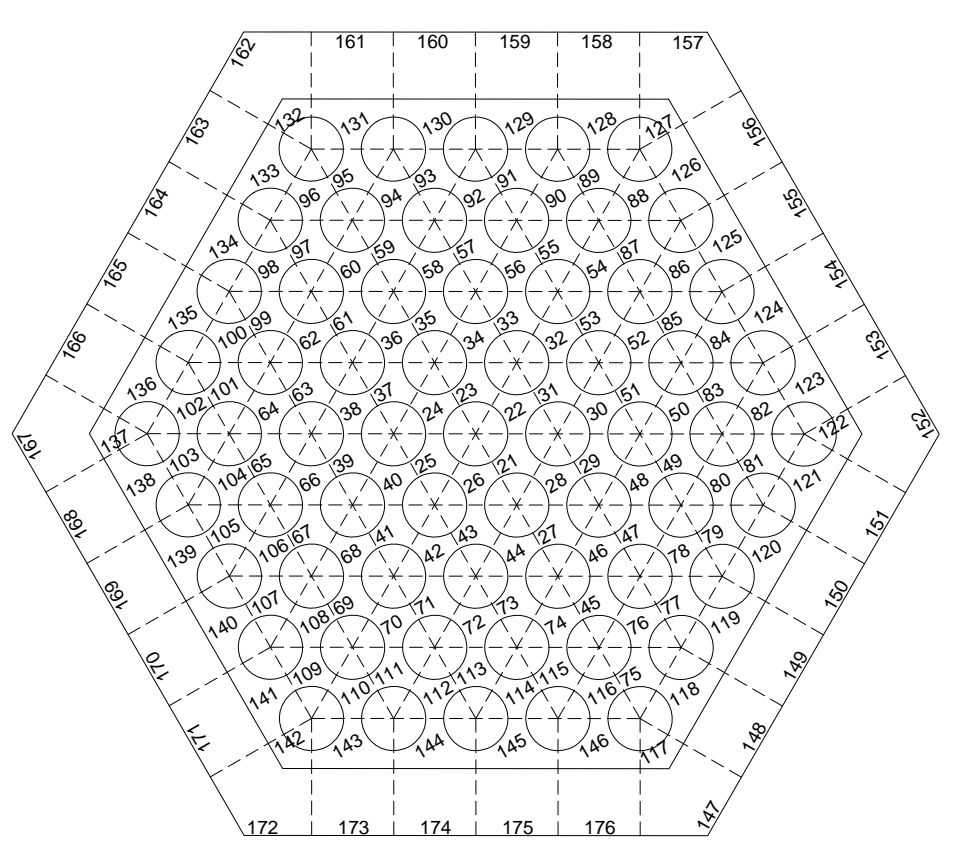

SASSYS-1 Model of XX09 
SASSYS-1 Multiple-Pin Subassembly Coolant Temperature Results
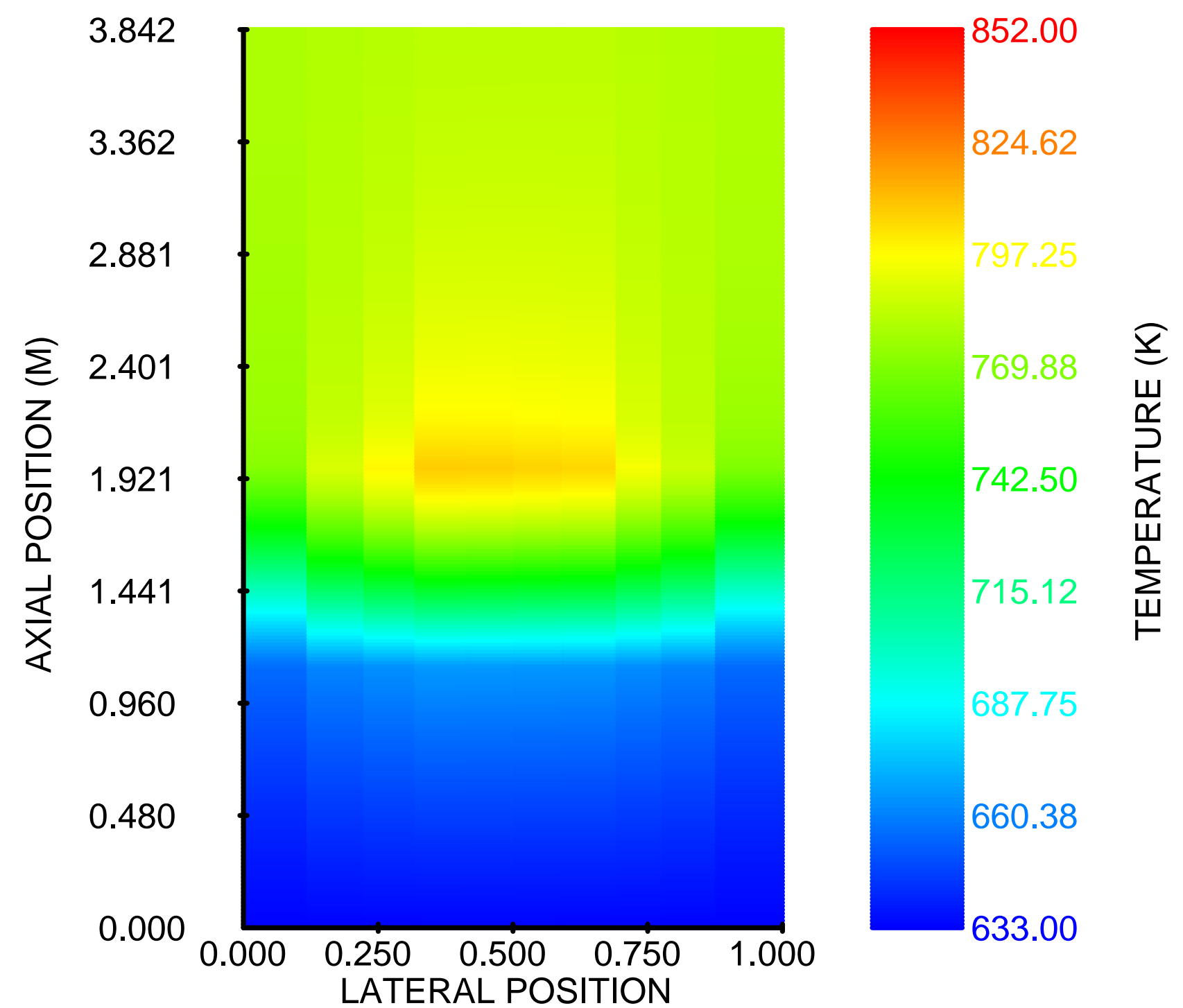


\section{PRIMAR-4 Model}

Thermal and hydraulic model for primary and intermediate sodium coolant loops

- General arrangement of volumes connected by segments

Volumes are perfectly mixed, compressible liquid with or without cover gas

- Flow segments divided into elements for hydraulics simulation and into temperature groups for heat transfer

- Special models for pumps, valves, heat exchangers, steam generators

Explicit core by-pass channels for control, blanket, and reflector assemblies

- Component-to-component heat transfer

Explicit decay heat removal simulation: DRACS, RVACS, etc.

Annular flow elements for IHX bypass flow 


\section{PRIMAR-4 Model of a Small Pool-Type Reactor}

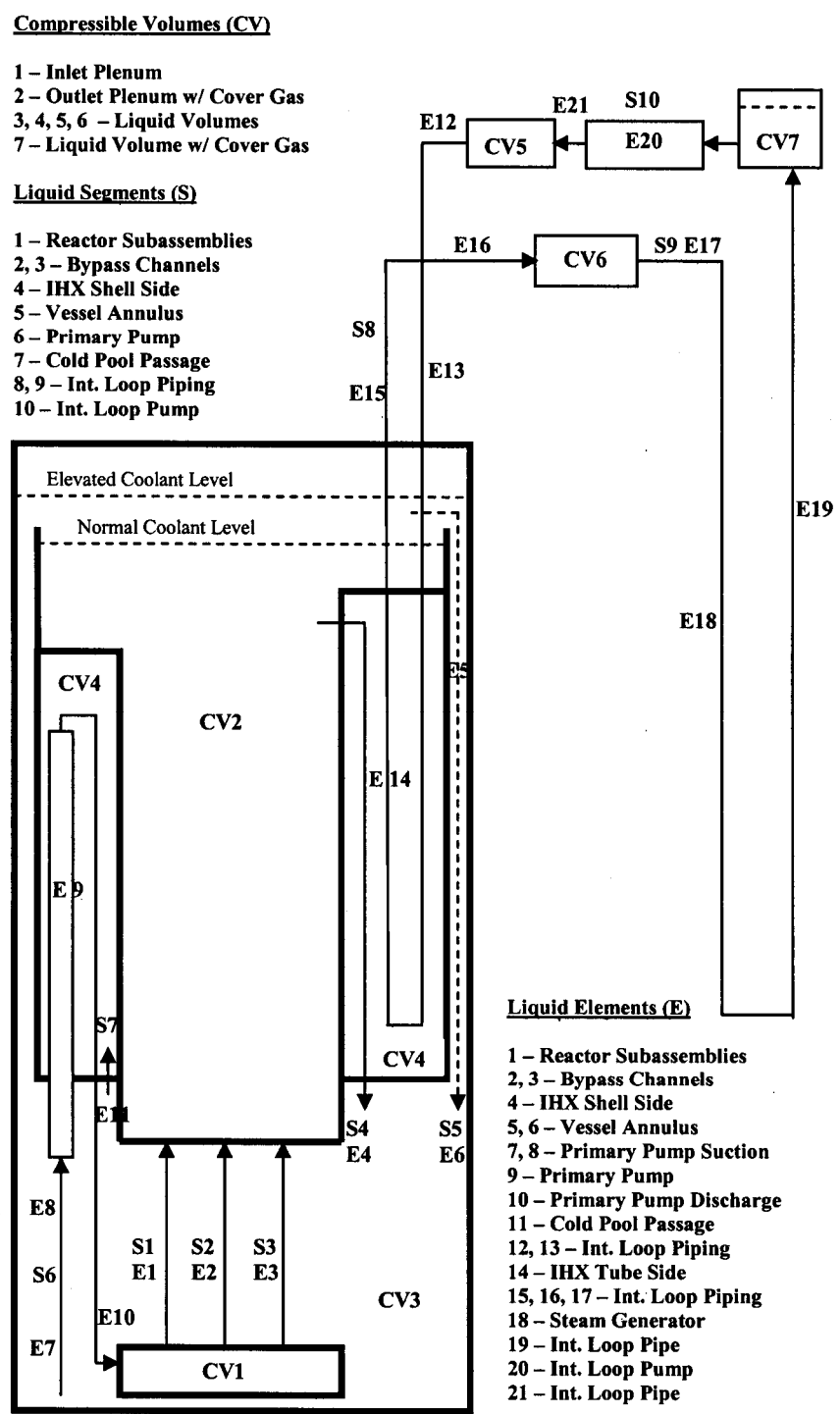




\section{DEFORM-5 Metallic Fuel Cladding Failure Model}

- For stainless steel clad metallic fuel pins, predicts

- Margins to cladding failure in DBA and BDBA transients

- Cladding failure time and location in severe accident transients

Simulates transient cladding mechanical response taking into account

- Fuel and cladding temperatures

- Fission gas pressure loading

- Eutectic thinning of cladding at fuel/cladding interface

Failure prediction based on plastic cladding strain and strain rate

- Cladding damage based on evaluated life fraction correlation used in FPIN-M

- Calculated cladding failure predictions show excellent agreement with TREAT test data 
- Correlation of Integral Fast Reactor (IFR) program metallic fuel properties database

- Enthalpy, specific heat, density, thermal expansion, and thermal conductivity for binary (U-Zr) and ternary (U-Pu-Zr) metallic fuel

- Burnup/porosity corrections and uncertainties for thermal conductivity

- Automated data interpolation among experimental data for composition corrections

- Integrated implementation in SASSYS-1 fuel heat transfer and constituent models as an alternative to oxide correlations and table input for properties

- Basis for integration of future metallic fuels data and phenomenological models 


\section{FPIN-2 Metallic Fuel Pin Behavior Model}

- Validated model for fuel pin fuel and cladding mechanical behavior developed by John Kramer and Tom Hughes

- Integrated with SASSYS-1 by Tanju Sofu

- Driven by SASSYS-1 calculated fuel and cladding temperatures

- Models elastic, plastic, thermal, and swelling phenomena

- Rigorous mechanical model based on force-displacement formulation

- Equilibrium equations derived from equations for virtual work

- Implicit finite element solution method using linear shape functions

- Additional metallic fuel models for fission gas generation and release, molten cavity formation, gas plenum, fuel-cladding eutectic formation

- Cladding rupture predicted using a life fraction formulation based on measured data stress-strain data 


\section{In closing...}

- Liquid sodium was initially selected as the coolant for fast reactors on the basis of 1) low pumping power requirement, 2) high volumetric heat capacity, and 3) high thermal conductivity.

- Other favorable properties include low neutron absorption and very good compatibility (negligible corrosion) with structural materials

- Many reactor years $(\sim 300)$ of experience in the US and internationally have demonstrated the effectiveness of the liquid metal fast reactor concept for electricity generation and fuel production, as originally conceived by Fermi, Szilard, and Wigner

- The US reactor development program has also demonstrated that liquid metal cooling contributes to excellent inherent safety reactor performance, through

- Natural circulation decay heat removal

- Passive reactor power reduction in beyond-design-basis accidents

- Based on several decades of liquid metal fast reactor research and development, the concept has achieved the level of technical maturity necessary for commercial deployment 


\section{Appendix A}

General Design Criteria Cross-Reference between 10CFR50 Appendix A, ANSI/ANS 54.1, and DOE Order 5480.30 


\section{Appendix A GDC Comparison - 1}

\begin{tabular}{|l|c|c|c|}
\hline \multicolumn{1}{|c|}{ Criterion/Requirement } & 10CFR50, App. A & ANSI/ANS 54.1 & DOE 5480.30 \\
\hline I. Overall Requirements & & & \\
\hline Single Failure & & & 8.c.1 \\
\hline Quality Standards and Records & GDC 1 & 3.1.1 & 8.c.2 \\
\hline Design Bases for Protection Against Natural Phenomena & GDC 2 & 3.1.2 & 8.c.3 \\
\hline Fire Protection & GDC 3 & 3.1.3 & 8.c.4 \\
\hline Protection Against Sodium and NaK Reactions & & 3.1.4 & 8.c.5, 8.c.10 \\
\hline Environmental and Dynamics Effects Design Bases & GDC 4 & 3.1.5 & 8.c.6 \\
\hline Sharing of Structures, Systems, and Components & GDC 5 & 3.1.6 & 8.c.7 \\
\hline Sodium Heating Systems & & 3.1.7 & 8.c.9 \\
\hline Siting & & & 8.c.11 \\
\hline Human Factors Engineering & & & 8.c.13 \\
\hline Safeguards and Security & & & 8.c.15 \\
\hline Reactor Decontamination and Decommissioning & & & 8.c.16 \\
\hline Support Systems & & & \\
\hline Non-Safety Class Structures, Systems, and Components & & & \\
\hline
\end{tabular}




\section{Appendix A GDC Comparison - 2}

\begin{tabular}{|l|c|c|c|}
\hline \multicolumn{1}{|c|}{ Criterion/Requirement } & $\begin{array}{c}\text { 10CFR50, App. } \\
\text { A }\end{array}$ & $\begin{array}{c}\text { ANSI/ANS } \\
54.1\end{array}$ & DOE 5480.30 \\
\hline $\begin{array}{l}\text { II. Protection by Multiple Fission Product } \\
\text { Barriers }\end{array}$ & & & \\
\hline Reactor Design & GDC 10 & 3.2 .1 & 8.d.3.a \\
\hline Reactor Inherent Protection & GDC 11 & 3.2 .2 & 8.d.3.b \\
\hline Suppression of Reactor Power Oscillations & GDC 12 & 3.2 .3 & 8.d.3.c \\
\hline Instrumentation and Control & GDC 13 & 3.2 .4 & 8.d.5.a \\
\hline Reactor Coolant Pressure Boundary & GDC 14 & 3.2 .5 & 8.d.1.a \\
\hline Reactor Coolant System Design & GDC 15 & 3.2 .6 & 8.d.6.a \\
\hline Containment Design & GDC 16 & 3.2 .7 & 8.c.8 \\
\hline Electric Power Systems & GDC 17 & 3.2 .8 & 8.d.2.a \\
\hline Inspection and Testing of Electric Power Systems & GDC 18 & 3.2 .9 & 8.d.2.b \\
\hline Control Room & GDC 19 & 3.2 .10 & 8.d.5.e \\
\hline Remote Shutdown & & & 8.d.5.f \\
\hline $\begin{array}{l}\text { Heating, Ventilation, and Air Conditioning (HVAC) } \\
\text { Systems }\end{array}$ & & & 8.d.7.a,b.c \\
\hline
\end{tabular}




\section{Appendix A GDC Comparison - 3}

\begin{tabular}{|l|c|c|c|}
\hline \multicolumn{1}{|c|}{ Criterion/Requirement } & $\begin{array}{c}\text { 10CFR50, App. } \\
\text { A }\end{array}$ & $\begin{array}{c}\text { ANSI/ANS } \\
54.1\end{array}$ & $\begin{array}{c}\text { DOE } \\
5480.30\end{array}$ \\
\hline III. Protection and Reactivity Control Systems & & & \\
\hline Protection System Functions & GDC 20 & 3.3 .1 & 8.d.4.a \\
\hline Protection System Reliability and Testing & GDC 21 & 3.3 .2 & 8.d.4.a \\
\hline Protection System Independence & GDC 22 & 3.3 .3 & 8.d.4.b \\
\hline Protection System Failure Modes & GDC 23 & 3.3.4 & 8.d.4.c \\
\hline Separation of Protection and Control Systems & GDC 24 & 3.3.5 & 8.d.4.d \\
\hline $\begin{array}{l}\text { Protection System Requirements for Reactivity } \\
\text { Control Malfunctions }\end{array}$ & GDC 25 & 3.3 .6 & 8.d.4.e \\
\hline Reactivity Control System Redundancy and Capability & GDC 26 & 3.3.7 & 8.d.5.b \\
\hline Combined Reactivity Control Systems Capability & GDC 27 & 3.3.8 & 8.d.5.c \\
\hline Reactivity Limits & GDC 28 & 3.3 .9 & 8.d.5.d \\
\hline $\begin{array}{l}\text { Protection Against Anticipated Operational } \\
\text { Occurrences }\end{array}$ & GDC 29 & 3.3 .10 & 8.d.4.f \\
\hline
\end{tabular}




\section{Appendix A GDC Comparison - 4}

\begin{tabular}{|l|c|c|c|}
\hline \multicolumn{1}{|c|}{ Criterion/Requirement } & $\begin{array}{c}\text { 10CFR50, } \\
\text { App. A }\end{array}$ & $\begin{array}{c}\text { ANSI/ANS } \\
54.1\end{array}$ & $\begin{array}{c}\text { DOE } \\
5480.30\end{array}$ \\
\hline IV. Fluid Systems & & & \\
\hline Assurance of Adequate Reactor Coolant Inventory & & 3.4 .1 & \\
\hline Quality of Reactor Coolant Pressure Boundary & GDC 30 & 3.4 .2 & 8.d.1.b \\
\hline $\begin{array}{l}\text { Fracture Prevention of Reactor Coolant Pressure } \\
\text { Boundary }\end{array}$ & GDC 31 & 3.4 .13 & 8.d.1.c \\
\hline Inspection of Reactor Coolant Pressure Boundary & GDC 32 & 3.4 .3 & 8.d.1.d \\
\hline Reactor Coolant Makeup & GDC 33 & & 8.d.6.c \\
\hline $\begin{array}{l}\text { Reactor and Intermediate Coolant and Cover Gas Purity } \\
\text { Control }\end{array}$ & & 3.4 .4 & \\
\hline Intermediate Coolant System & & 3.4 .5 & 3.4 .6 \\
\hline $\begin{array}{l}\text { Inspection and Surveillance of Intermediate Coolant } \\
\text { Boundary }\end{array}$ & GDC 34 & 3.4 .7 & 8.d.6.b \\
\hline Residual Heat Removal & GDC 35 & & 8.d.6.d \\
\hline Emergency Core Cooling & GDC 36 & 3.4 .8 & 8.d.6.d \\
\hline Inspection of Emergency Core Cooling System & GDC 37 & 3.4 .9 & 8.d.6.d \\
\hline Testing of Emergency Core Cooling System & & 8.c.8 \\
\hline Containment Heat Removal & & & \\
\hline
\end{tabular}




\section{Appendix A GDC Comparison - 5}

\begin{tabular}{|l|c|c|c|}
\hline \multicolumn{1}{|c|}{ Criterion/Requirement } & $\begin{array}{c}\text { 10CFR50, } \\
\text { App. A }\end{array}$ & $\begin{array}{c}\text { ANSI/ANS } \\
54.1\end{array}$ & $\begin{array}{c}\text { DOE } \\
5480.30\end{array}$ \\
\hline IV. Fluid Systems (cont.) & & & \\
\hline Inspection of Containment Heat Removal System & GDC 39 & & 8.c.8 \\
\hline Testing of Containment Heat Removal System & GDC 40 & & 8.c.8 \\
\hline Containment Atmosphere Cleanup & GDC 41 & 3.5.11 & 8.c.8 \\
\hline $\begin{array}{l}\text { Inspection of Containment Atmosphere Cleanup } \\
\text { Systems }\end{array}$ & GDC 42 & 3.5.12 & 8.c.8 \\
\hline Testing of Containment Atmosphere Cleanup Systems & GDC 43 & 3.5.13 & 8.c.8 \\
\hline Cooling Water & GDC 44 & 3.4.10 & 8.d.6.e \\
\hline Inspection of Cooling Water System & GDC 45 & 3.4.11 & 8.d.6.e \\
\hline Testing of Cooling Water System & GDC 46 & 3.4.12 & 8.d.6.e \\
\hline
\end{tabular}




\section{Appendix A GDC Comparison - 6}

\begin{tabular}{|c|c|c|c|}
\hline Criterion/Requirement & $\begin{array}{c}\text { 10CFR50, } \\
\text { App. A }\end{array}$ & $\begin{array}{c}\text { ANSI/ANS } \\
54.1\end{array}$ & $\begin{array}{c}\text { DOE } \\
5480.30\end{array}$ \\
\hline \multicolumn{4}{|l|}{ V. Reactor Containment } \\
\hline Containment Design Basis & GDC 50 & 3.5.1, 3.5.2, 3.5.3 & 8.c.8 \\
\hline Fracture Prevention of Containment Pressure Boundary & GDC 51 & 3.5.4 & 8.c. 8 \\
\hline Capability for Containment Leakage Rate Testing & GDC 52 & 3.5.5 & 8.c. 8 \\
\hline Provisions for Containment Testing and Inspection & GDC 53 & 3.5.6 & 8.c.8 \\
\hline Piping Systems Penetrating Containment & GDC 54 & 3.5.7 & 8.c.8 \\
\hline Reactor Coolant Pressure Boundary Penetrating Containment & GDC 55 & 3.5.8 & 8.c.8 \\
\hline Primary Containment Isolation & GDC 56 & 3.5 .9 & 8.c. 8 \\
\hline Closed System Isolation Valves & GDC 57 & 3.5.10 & 8.c.8 \\
\hline \multicolumn{4}{|l|}{ VI. Fuel and Radioactivity Control } \\
\hline Control of Releases of Radioactive Materials to the Environment & GDC 60 & 3.6.1 & 8.c.12.a, 8.c.14 \\
\hline Fuel Storage and Handling and Radioactivity Control & GDC 61 & 3.6 .2 & 8.d.8.a, 8.d.8.d \\
\hline Prevention of Criticality in Fuel Storage and Handling & GDC 62 & 3.6 .3 & 8.d.8.b \\
\hline Monitoring Fuel and Waste Storage & GDC 63 & 3.6.4 & 8.d.8.c \\
\hline Monitoring Radioactivity Releases & GDC 64 & 3.6.5 & 8.c.12.b, 8.c.14 \\
\hline
\end{tabular}




\section{Appendix B \\ Listing of Design Basis Accidents for \\ The Clinch River Breeder Reactor Plant \\ PSAR Chapter 15}


PSAR Section

15.2.1.1

15.2.1.2

15.2.1.3

15.2.1.4

15.2.1.5

15.3.1.1

15.3.1.2

15.3.1.3

15.3.1.4

15.3.1.5

15.3.1.6

15.3.1.7

15.7.1.1

15.7.1.2

15.7.1.3

15.7.1.4

15.7.1.5

\section{Anticipated Events}

Control Assembly Withdrawal at Startup

Control Assembly Withdrawal at Full Power

Seismic Reactivity Insertion (OBE)

Small Reactivity Insertions Inadvertent Drop of a Single Control Rod at Full Power Loss of Off-Site Electrical Power

Spurious Primary Pump Trip

Spurious Intermediate Pump Trip Inadvertent Closure of One Evaporator or Superheater Module Isolation Valve Turbine Trip

Loss of Normal Feedwater Inadvertent Actuation of the Sodium/Water Reaction Pressure Relief System Loss of One D.C. System

Loss of Instrument or Valve Air System

IHX Leak

Off-Normal Cover Gas Pressure In PHTS

Off-Normal Cover Gas Pressure In IHTS 
PSAR Section

15.2.2.1

15.2.2.2

15.2.2.3

15.3.2.1

15.3.2.2

15.3.2.3

15.3.2.4

15.5.2.1

15.5.2.2

15.5.2.3

15.5.2.4

15.5.2.5

15.7.2.1

15.7.2.2

15.7.2.3

15.7.2.4

15.7.2.5

15.7.2.6

15.7.2.7

15.7.2.8

15.7.2.9

\section{Unlikely Events}

Loss of Hydraulic Holddown

Sudden Core Radial Movement

Maloperation of Reactor Plant Controller

Single Primary Pump Seizure

Single Intermediate Loop Pump Seizure

Small Water to Sodium Leaks In Steam Generator Tubes

Failure of Steam Bypass System

Fuel Assembly Dropped During Refueling

Attempt to Insert a Fuel Assembly Into an Occupied Position

Single Fuel Assembly Cladding Failure In Fuel Handling System

Cover Gas Release During Refueling

Heaviest Crane Load Impacts Reactor Closure Head

Inadvertent Release of Oil Through the Pump Seal (PHTS)

Inadvertent Release of Oil Through the Pump Seal (IHTS)

Generator Breaker Failure to Open at Turbine Trip

Rupture in the RAPS Cold Box

Liquid Radwaste System Failure

Failure In the EVST NaK System

Leakage from Sodium Cold Traps

Rupture In RAPS Noble Gas Storage Vessel Cell

Rupture in the CAPS Cold Box 


\section{Appendix B CRBRP PSAR Table 15.1.3-2 Accident Events - 3}

\section{PSAR Section}

15.2.3.1

15.2.3.2

15.2.3.3

15.2.3.4

15.2.3.5

15.3.3.1

15.3.3.2

15.3.3.3

15.3.3.4

15.3.3.5

15.5.3.1

15.6.1.1

15.6.1.2

15.6.1.3

15.6.1.4

15.6.1.5

15.7.3.1

15.7.3.2

15.7.3.3

15.7.3.4

15.7.3.5

15.7.3.6

15.7.3.7

\section{Extremely Unlikely Events}

Cold Sodium Insertion

Gas Bubble Passage Through Core, Radial Blanket and Control Assembly

Core, Radial Blanket, and Control Rod Movement Due to Safe Shutdown

Earthquake

Control Assembly Withdrawal at Startup - Maximum Mechanical Speed

Control Assembly Withdrawal at Power - Maximum Mechanical Speed

Steam or Feed Line Pipe Break

Loss of Normal Shutdown Cooling System

Large Sodium/Water Reactions

Primary Heat Transport System Pipe Leak

Intermediate Heat Transport System Pipe Leak

Collision of EVTM with Control Rod Drive Mechanisms

Primary Sodium In-Containment Storage Tank Failure During Maintenance

Failure of the Ex-Vessel Storage Tank Sodium Cooling System During Operation

Failure of Ex-Containment Primary Sodium Storage Tank

Primary Heat Transport System Piping Leaks

Intermediate Heat Transport System Piping Leak

Leak In a Core Component Pot

Spent Fuel Shipping Cask Drop from Maximum Possible Height

Maximum Possible Conventional Fires, Flood or Storms or Minimum River Level

Failure of Plug Seals and Annuli

Fuel Rod Leakage Combined with IHX and Steam Generator Leakage

Sodium Interaction with Chilled Water

Sodium-Water Reduction In Large Component Cleaning Vessel 


\section{Sodium Fast Reactor}

\section{Argonne LABORATORY}

... for a brighter future

Safety \#2

DOE/HQ October 31, 2007

NRC/White Flint November 1, 2007

(Rev. 1, October, 2008)

Presented by: Jim Cahalan 


\section{Notice}

- This presentation has been revised to remove citations to and information from Applied Technology documents. 


\section{FFTF References}

- Fast Flux Test Facility Preliminary Safety Analysis Report, Vols. 1 and 2, September, 1970.

- C. P. Cabell, A Summary Description of the Fast Flux Test Facility, HEDL-400, December, 1980.

- D. E. Simpson, FFTF Design for Safety, Proc. Fast Reactor Safety Meeting, CONF-740401-P2, pp. 1041-1060, American Nuclear Society, Beverly Hills, California, April 2-4, 1974.

- D. E. Simpson, Resolution of Key Safety-Related Issues in FFTF Regulatory Review, Proc. Intl. Mtg. Fast Reactor Safety and Related Physics, CONF-761001, Vol. II, pp.400-410, American Nuclear Society, Chicago, Illinois, October 5-8, 1976.

- A. R. Schade and D. E. Simpson, FFTF Regulatory Review for Operating Authorization, Proc. Intl. Mtg. Fast Reactor Safety Technology, Vol. 5, pp. 2425-2430, American Nuclear Society, Seattle, Washington, August 19-23, 1979.

- Safety Evaluation Report by the Office of Nuclear Reactor Regulation, USNRC, for the Fast Flux Test Facility, USNRC Report NUREG-0358, August, 1978. Supplement No. 1, May, 1979. 


\section{CRBRP References}

- Clinch River Breeder Reactor Plant Preliminary Safety Analysis Report, Project Management Corporation. Vols. 1 - 27. (Updated through amendment 77, May, 1983)

- 1974 Technical Progress Report, Clinch River Breeder Reactor Project.

- L. E. Strawbridge, Safety Related Criteria and Design Features in the Clinch River Breeder Reactor Plant, Proc. Fast Reactor Safety Meeting, CONF-740401-P1, pp. $72-$ 92, American Nuclear Society, Beverly Hills, California, April 2-4, 1974.

- R. J. Slember, Safety-Related Design Considerations for the Clinch River Breeder Reactor Plant, Proc. Intl. Mtg. Fast Reactor Safety and Related Physics, CONF761001, Vol. I, pp. 112-125, American Nuclear Society, Chicago, Illinois, October 5-8, 1976.

- L. E. Strawbridge and G. H. Clare, Exclusion of Core Disruptive Accidents from the Design Basis Accident Envelope in CRBRP, Proc. Intl. Mtg. Fast Reactor Safety, Vol. 1, pp.317-327, American Nuclear Society, Knoxville, Tennessee, April 21-25, 1985.

J. G. Giitter and M. W. Akhtar, An Assessment of the Clinch River Breeder Reactor Core and Containment Response to Core Disruptive Accidents, Proceedings of the International Meeting on Fast Reactor Safety, Knoxville, Tennessee, American Nuclear Society, CONF-850410, pp. 463-470, April 21-25, 1985.

- Safety Evaluation Report Related to the Construction of the Clinch River Breeder Reactor Plant, USNRC Report NUREG-0968, Vols. 1 and 2, March, 1983. 


\section{SAFR and PRISM References}

- Preapplication Safety Evaluation Report for the Sodium Advanced Fast Reactor (SAFR) Liquid-Metal Reactor, USNRC Report NUREG-1369, December, 1991.

- Preapplication Safety Evaluation Report for the Power Reactor Innovative Small Module (PRISM) Reactor, USNRC Report NUREG-1368, February, 1994.

- P. M. Magee, U.S. ALMR Licensing Status, Proc. Intl. Topical Mtg. Advanced Reactor Safety, pp. 1011-1017, American Nuclear Society, Pittsburg, Pennsylvania, April 17-21, 1994. 


\section{EBR-I, Fermi References}

- F. W. Thalgott et al, Stability Studies on EBR-I, Proc. Second U.N. Intl. Conf. on Peaceful Uses of Atomic Energy, Geneva, September 1-13, 1958, P/1845, Vol. 12, pp. 242-266, United Nations, New York, 1958.

- R. O. Brittan, Analysis of the EBR-I Core Meltdown, Proc. Second U.N. Intl. Conf. on Peaceful Uses of Atomic Energy, Geneva, September 1-13, 1958, P/2156, Vol. 12, pp. 267-272, United Nations, New York, 1958.

- Technical Information and Hazards Summary Report, Enrico Fermi Atomic Power Plant, Power Reactor Development Company, Detroit, Michigan, June, 1961.

W. J. McCarthy and W. H. Jens, A Review of the Fermi Reactor Fuel Damage Incident and a Preliminary Assessment of Its Significance to the Design and Operation of Sodium Cooled Fast Reactors, Proc. Intl. Conf. on the Safety of Fast Reactors, Aix-en-Provence, September 19-22, 1967, pp. Va-1-1 Va-1-23, Commissariat a l'Energie Atomique, 1967 


\section{BN-350, Phenix References}

- Soviet Power Reactors-1970, Report of the United States of America Nuclear Power Reactor Delegation Visit to the Union of Soviet Socialist Republics, June 15-July 1, 1970, USAEC Report WASH-1175, August, 1970.

- R. Balent, Interim Progress Report on BN-350 Steam Generators, Atomics International, Tranmitted by letter, S. W. Ahrends, ERDA, August 5, 1975.

- J. Sauvage, Phenix, 30 Years of History: The Heart of a Reactor, http://www.iaea.org/inisnkm/nkm/aws/fnss/phenix/book/indlex. html 
- Status of Liquid Metal Cooled Fast Reactor Technology, IAEA-TECDOC1083, IAEA, Vienna, April, 1999.

- L. Rahmani, et al, SPX Significant Events and Whether It Would Have Happened on EFR, Proc. Tech. Committee Meeting on Unusual Occurances during LMFR Operation, 9-13 November, 1998, IAEATECDOC-1180, IAEA, Vienna, October, 2000.

- The Creys-Malville Power Plant, Brochure, NERSA/Electricite de France, 1985.

- Monju Web site: http://www.jaea.go.jp/04/monju/EnglishSite/index.html

- A. Miyakawa, et al, Sodium Leakage Experience at the Prototype FBR Monju, Proc. Tech. Committee Meeting on Unusual Occurances during LMFR Operation, 9-13 November, 1998, IAEA-TECDOC-1180, IAEA, Vienna, October, 2000. 


\section{EBR-II. FFTF References}

- Stanley H. Fistedis, Ed., The Experimental Breeder Reactor-II Inherent Safety Demonstration, Nucl. Eng. Des., Vol. 101, No. 1. (Special Issue), 1987.

- F. E. Dunn, et al, Whole Core Sub-Channel Analysis Verification with the EBR-II SHRT-17 Test, Paper 6364, Proceedings of ICAPP '06, Reno, NV USA, June 4-8, 2006.

- T. M. Burke, et al, Results of the 1986 Inherent Safety Tests, $\underline{\text { Trans. Am., }}$ Nucl. Soc., 54, p. 249, 1987.

- B. J. Knutson, et al, Fast Flux Test Facility Passive Safety Reactivity Feedback Measurements, Proceedings International Topical Meeting on Safety of Next Generation Power Reactors, Seattle, WA, May 1-5, 1988. 


\section{General References}

H. Hummel and D. Okrent, Reactivity Coefficients in Large Fast Power Reactors, American Nuclear Society, 1970.

- Hans K. Fauske, The Role of Core-Disruptive Accidents in Design and Licensing of LMFBRs, Nuclear Safety, Vol. 17, No. 5, pp. 550567, September-October, 1976.

A. E. Waltar and A. B. Reynolds, Fast Breeder Reactors, Pergamon Press, 1981.

- Fast Reactor Database, 2006 Update, IAEA-TECDOC-1531, IAEA, Vienna, December, 1996. See also http://www-frdb.iaea.org

- 10CFR50 Appendix A, General Design Criteria for Nuclear Power Plants

DOE O 5480.30, Nuclear Reactor Safety Design Criteria

ANSI/ANS-54.1-1989, General Safety Design Criteria for a Liquid Metal Reactor Nuclear Power Plant 
- Safety Issues \#1 (Last Time)

- Safety issues; DBA, BDBA, severe accident historically (coolant void, recriticality, $\mathrm{FCl}$ ), passive safety

- Safety analysis past results (FFTF, CRBRP, SAFR, PRISM)

- Safety analysis methods; reactor, structural, coolant aerosols, containment

Safety Issues \#2 (Today)

- Licensing issues in FFTF, CRBRP, SAFR, PRISM.

- Domestic and international experience in perspective, high profile events in EBR-1, FERMI, BN-350, Phenix, SuperPhenix, and MONJU explained and lessons learned.

- Safety testing results, EBR-II SHRT, FFTF ULOF (GEMS)

- Inherent passive safety characteristics of sodium fast reactor systems (wrt loss of flow without scram, etc.). Inherent reactivity shutdown, natural circulation decay heat removal 


\section{Licensing issues in FFTF, CRBRP, SAFR, PRISM}




\section{FFTF Chronology}

- Conceptual design studies 1966-1969

- PSAR submitted by HEDL in September 1970

- Initial construction authorization in September 1971; full construction authorization in March 1972

- ACRS letter in May 1973

- FSAR submitted by HEDL in December 1975

- Construction complete/Na fill 1978

- Criticality February 1980, full power October 1980

- Research operations April 1982 to April 1992

- DOE Shutdown order December 1993 


\section{FFTF Design}

- Mission: Provide a prototypic LMFBR operating environment for testing and development of fuels, materials, and components

- Secondary: Develop design and construction experience

- $400 \mathrm{MWt}$, MOX fuel ( $22 \%$ and $27 \% \mathrm{Pu})$, three loop primary system, three intermediate sodium loops to air dump heat exchangers

- Reactor core: 73 fuel assemblies, 9 control assemblies, 9 test assemblies

- Coolant inlet $680^{\circ} \mathrm{F}\left(360^{\circ} \mathrm{C}\right)$, outlet $980^{\circ} \mathrm{F}\left(527^{\circ} \mathrm{C}\right)$

- 10psi steel containment

- Two independent reactor shutdown systems (both by moveable rods)

- Forced and natural convection decay heat removal through three independent loops

- Pony motors on primary and secondary pumps

- Core physics and structural design for inherent negative power and temperature reactivity feedbacks 
FFTF Site - Hanford, Washington

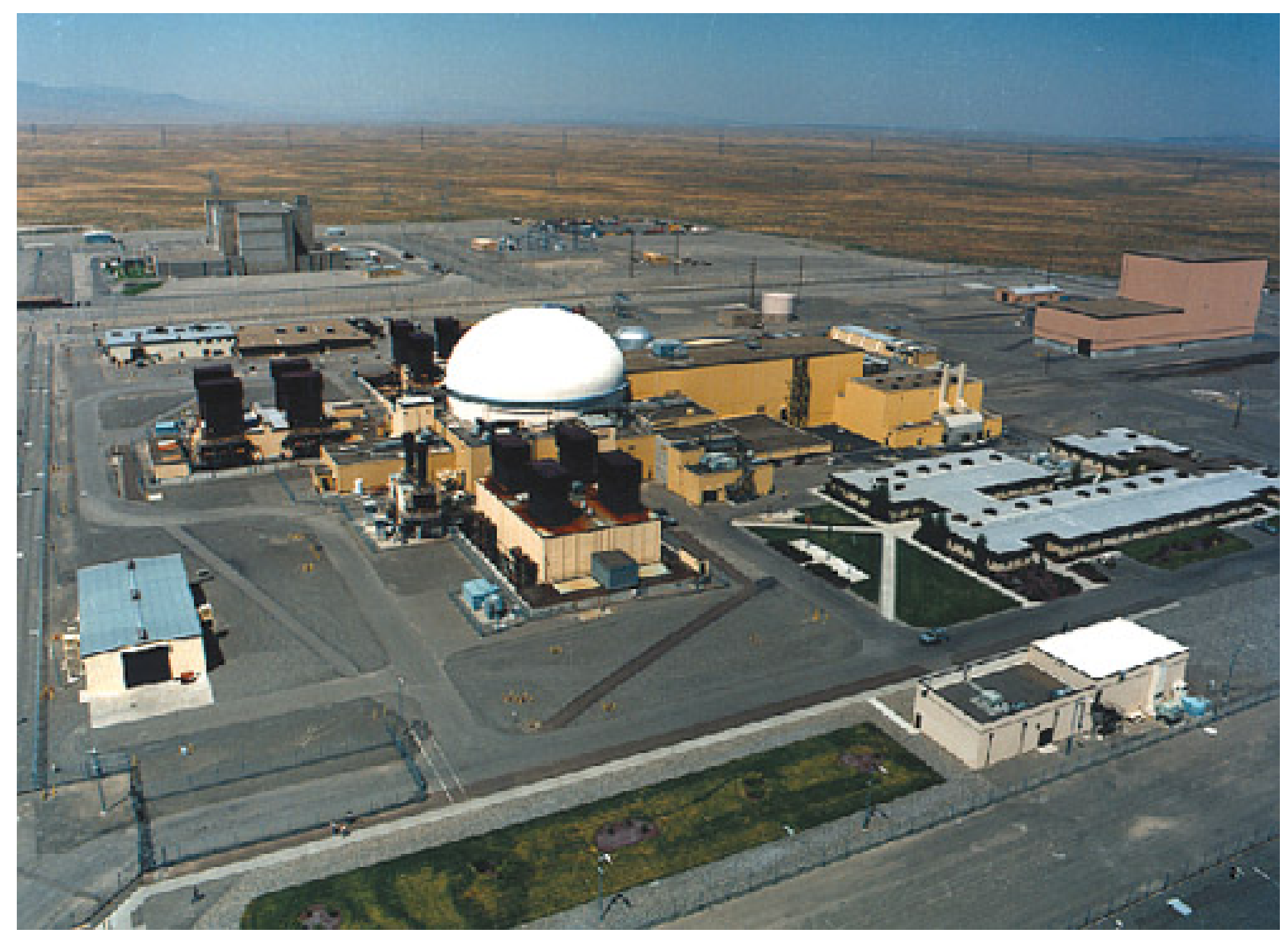




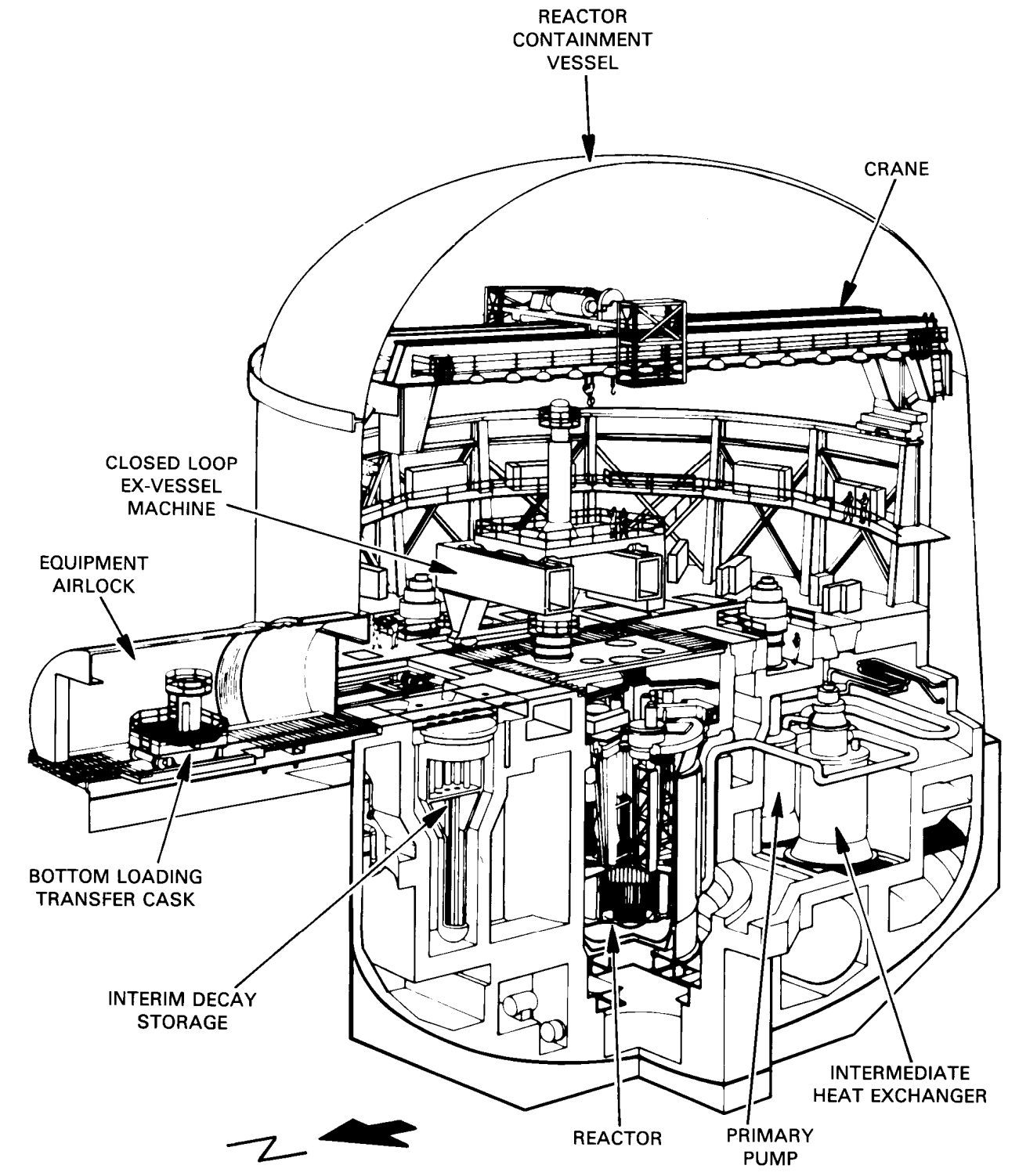




\section{FFTF Loop-Type Primary and Secondary Systems}

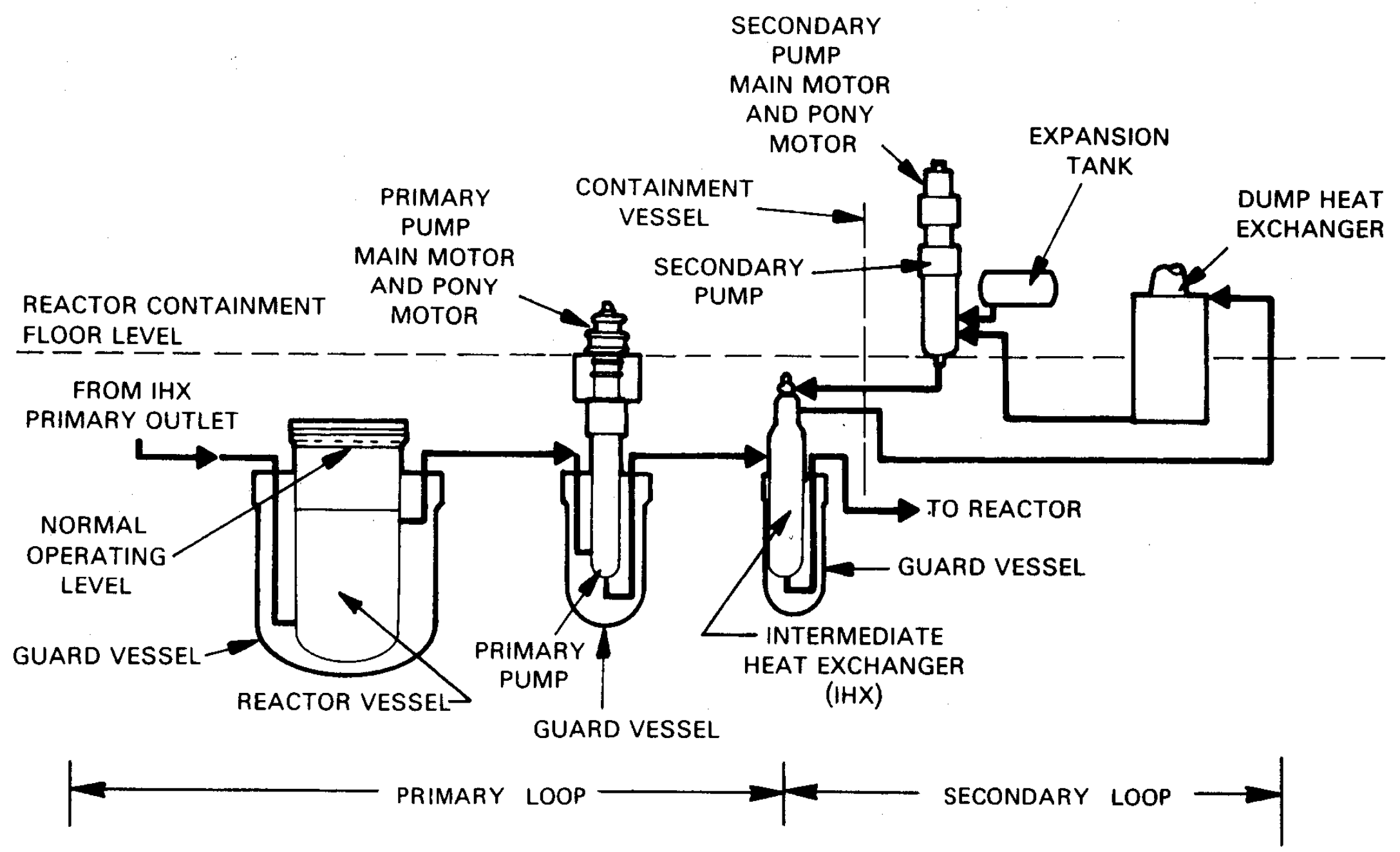




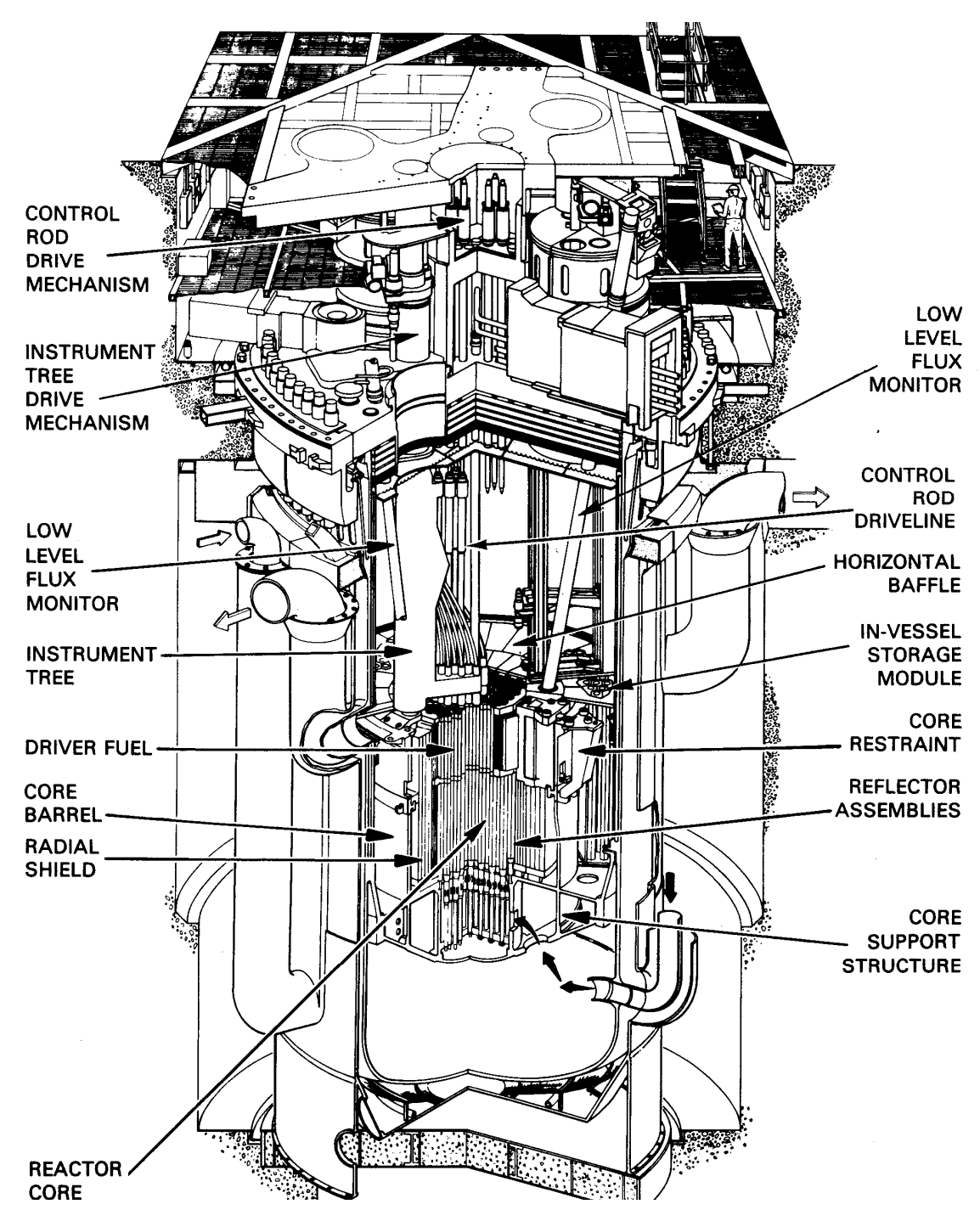




\section{FFTF Regulatory Review -- 1}

- As an AEC project, FFTF did not require licensing as for commercial LWR plants, but technical review by NRC was required

- The depth and detail of the NRC review was similar to full licensing

- Construction and operation permission; ACRS letters

- Site selection in 1968; site evaluation report prepared in 1969 and submitted for review in July 1970 (See "Chronology"). PSAR Sept. 1970. First meeting with NRC staff Nov. 1970, first ACRS meeting Dec. 1970

- Site issues: seismic $(0.25 \mathrm{~g})$ and tornado (150 $\mathrm{mph}$ rotation)

- Studies and analyses submitted to NRC and ACRS for review

- Hypothetical Core Disruptive Accidents (HCDA) received the greatest regulatory attention and review emphasis

- Basis for evaluation of containment margins (10CFR100 offsite dose)

- Project position: HCDA was not a design basis (150 MW-s margin evaluation basis)

- NRC requested further study; response by HEDL and ANL 


\section{FFTF Regulatory Review -- 2}

- A major part of the LMFBR safety base program was oriented to support FFTF regulatory review

- At HEDL

- Transient Overpower (TOP) accident analysis (MELT computer code)

- TOP fuel testing (TREAT)

at ANL

- Loss-of-Flow (LOF) accident analysis (SAS3A computer code)

- LOF fuel testing (TREAT)

- Post-accident Heat Removal (PAHR) analyses and experiments

- Structural dynamics analysis and testing

- Fuel Element Failure Propagation (FEFP) studies and experiments

- Coolant dynamics analyses and experiments

- Fuel dynamics analyses and experiments (OPERA)

- High temperature materials properties

- Fuel coolant interactions ( $\mathrm{FCl}$ ) analyses and experiments (OPERA) 


\section{FFTF Regulatory Review -- 3}

- LMFBR safety base program activities also performed at ORNL, Al, GE, and W-ARD

- Activities coordinated under HEDL technical direction

- ANL provided direct support to FFTF licensing

- Preparation of technical reports of analyses, experiments, and tests for use as FSAR support documents

- Participation in meetings with NRC staff and ACRS

- Regulatory review for construction nominally concluded with the May 1973 ACRS letter, but open issues continued to receive attention

- HCDA energetics

- Design fallbacks, including sealing the reactor head compartment and ex-vessel core melt retention

- Piping integrity; provision for pipe break mediation design, and surveillance and in-service inspection

- Natural convection cooling and emergency power 


\section{FFTF Regulatory Review -- 4}

- Through 1976, HEDL and ANL continued to meet with NRC staff and ACRS

- ANL supplied technical support for resolution of the HCDA energetics and core melt retention issues

- In 1974, NRC concurred with the ANL assessment that HCDA energetics would not exceed FFTF capability. Also, NRC concurred that sealing of the head compartment would not significantly improve containment margins

- In 1975, NRC recommended that construction could be completed without addition of an ex-vessel core catcher

- The FFTF FSAR was issued in March, 1976, followed by an NRC staff review

- The NRC staff review continued, and the Final Safety Evaluation Report was issued in August 1978. The SER stated that the major unresolved issues were natural convection verification, control room habitability, piping integrity, and containment margins

- Natural convection verification testing was performed during start-up 


\section{FFTF Regulatory Review -- 5}

- A safety-grade system to provide control room isolation upon detection of unacceptable levels of sodium aerosols or radioactivity was added

- The piping integrity and containment margin issues were resolved without design changes by additional analyses and information submittals to NRC

- ACRS concurred with NRC findings in a November 1978 letter

- Coolant filling was accomplished in 1979, and fuel loading began

- First criticality was in February 1980, and power operation began in October 1980 


\section{Clinch River Breeder Reactor Plant (CRBRP) Chronology}

- June 1970. U.S. Congress enacts Public Law 91-273 authorizing AEC to design, construct, and operate an LMFBR demonstration plant.

- January 1972. Joint proposal by Commonwealth Edison and TVA accepted.

- March 1972. Two not-for-profit organizations established. Project Management Corporation (PMC) for project management, and Breeder Reactor Corporation (BRC) for utility industry liaison.

- November 1972. Westinghouse-Advanced Reactor Division (W-ARD) selected as lead reactor manufacturer, Burns and Roe (B\&R) as A/E.

- February 1973. Initial work authorization. Al and GE added to team.

- January 1974. AEC/W-ARD contract signed.

- PSAR submitted April 1975 (Updated through Rev. 77 May 1983)

- Licensing suspended: commercial reprocessing banned March 1977

- Licensing resumed September 1981

- NRC Safety Evaluation Report (NUREG-0968) March 1983, ACRS letter

- Funding stopped October 1983 


\section{CRBRP Design}

- Mission: Demonstrate the safe and reliable operation of an LMFBR in a utility environment. Demonstrate LMFBR economics, and the transition from technology development to commercial operation

- 975 MWt, 380 MWe (gross), MOX fuel (19\% and 27\% Pu), three loop primary system, three intermediate sodium loops to steam generators

- Reactor core: 198 fuel assemblies (108 inner/90 outer), 19 control assemblies (15 primary/4 secondary), 150 radial blanket assemblies

- Coolant inlet $730^{\circ} \mathrm{F}\left(388^{\circ} \mathrm{C}\right)$, outlet $95^{\circ} \mathrm{F}\left(535^{\circ} \mathrm{C}\right)$

- 10psi steel containment

- Two independent reactor shutdown systems (both by moveable rods)

- Decay heat removal through three independent loops

- Pony motors on primary and secondary pumps

- Auxiliary decay heat removal through water side of SG

- Direct decay heat removal system independent of HTS loops

- Core physics and structural design for inherent negative power and temperature reactivity feedbacks 
Clinch River Breeder Reactor Plant (CRBRP)

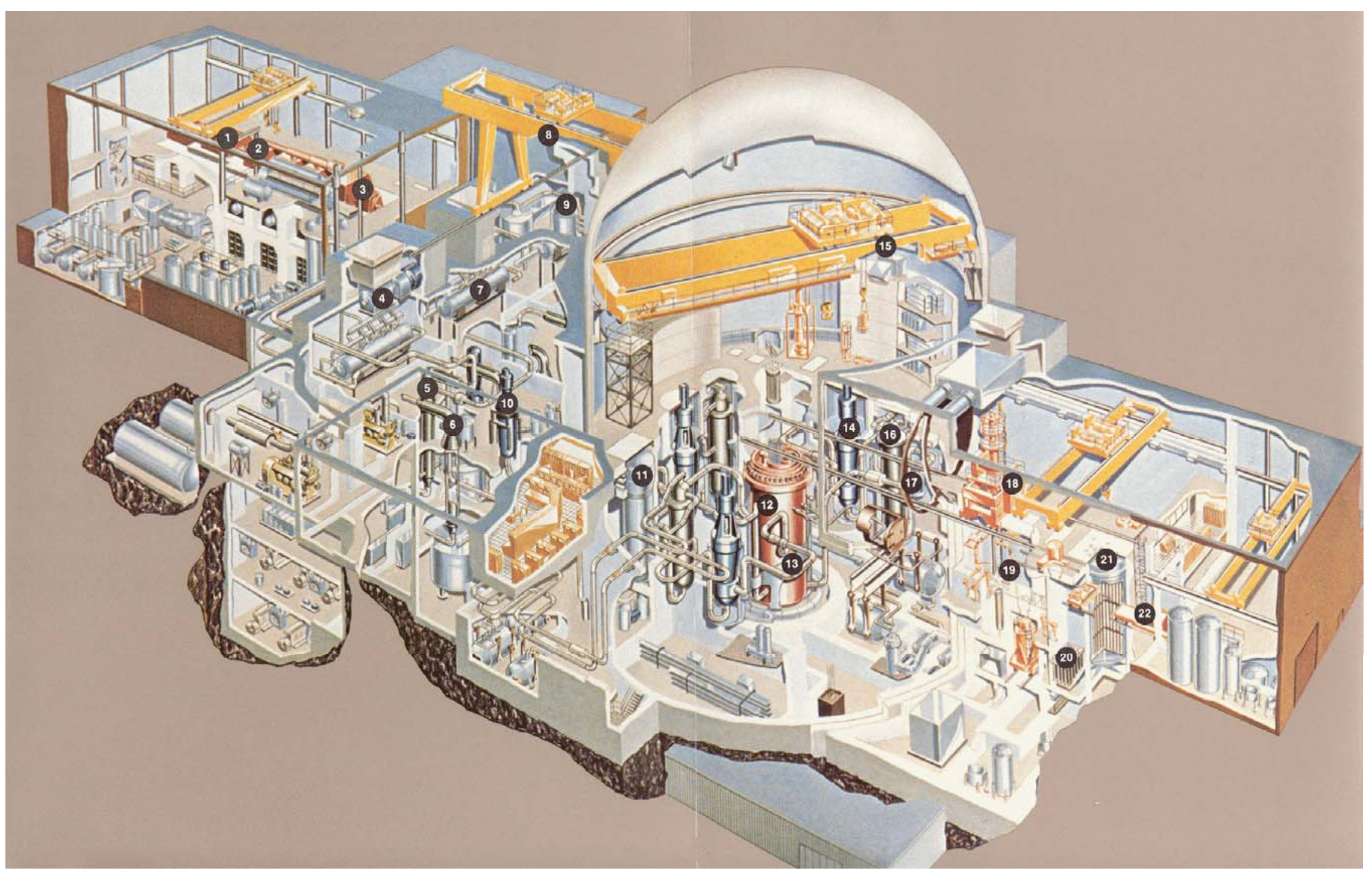

\section{Argonne}


- CRBRP was licensed as a commercial power reactor by NRC

- Project suspended in accord with the Presidential order in 1977

- Licensing activities continued to obtain the equivalent to a construction permit in 1983

- Site selection in 1972, environmental report early 1975, PSAR April 1975

- Site issues: seismic ( $0.18 \mathrm{~g})$ and tornado (290 $\mathrm{mph}$ rotation)

- Consistent with other TVA sites

- As for FFTF, HCDAs received much regulatory review attention

- Early agreement (1976) between NRC and the project that HCDAs would not be a design basis for containment

- However, the role of severe accidents and characterization of their consequences dominated the attention of the interveners, the regulators, and the project

- Licensing, and treatment of severe accidents, set the critical path for construction 


\section{CRBRP Regulatory Review -- 2}

- PSAR preparation was the responsibility of W-ARD

- General design criteria

- Preliminary design

- Design basis event (DBE) analyses for PSAR Ch. 15

- The LMFBR base program, and particularly ANL provided significant resources to address design and licensing issues

- TREAT fuel testing; basic phenomenological test measurements and prototypic TOP and LOF transient tests

- LOF and TOP accident analyses (SAS3D computer code)

- Coolant and structural dynamics tests and analyses

- Post-accident heat removal analyses

- ANL provided direct support to CRBRP licensing

- Preparation of technical reports of analyses, experiments, and tests for use as PSAR support documents

- Participation in meetings with NRC staff and ACRS 


\section{CRBRP Regulatory Review -- 3}

- HCDA issues compared to FFTF

- Bigger reactor (975 MWt vs $400 \mathrm{MWt}$ ), more fuel

- Positive coolant void reactivity worth $(\sim 3 \$$ vs $\sim 0 \$)$

- LOF sequence bounded energetics as in FFTF, but because of the positive coolant void worth, cladding failures and fuel melting occurred at higher power than in FFTF $\left(\sim 10 \mathrm{P}_{\mathrm{o}}\right.$ vs $\left.\sim 1 \mathrm{P}_{\mathrm{o}}\right)$

- Higher power LOF caused other phenomena in accident sequences that raised energy releases in analyses

- CRBRP structural limits (vessel head bolt strength) corresponded to an accident energy release of $661 \mathrm{MW}$-s: project structural margin beyond the design basis (SMBDB)

- NRC (LANL) performed independent analyses: $1200 \mathrm{MW}-\mathrm{s}$ 


\section{CRBRP Regulatory Review -- 4}

- Ultimately,

- The ASLB ruled against intervenor's contention that HCDAs should be a design basis

- NRC staff stated: "It is our current position that the probability of core melt and disruptive accidents can and must be reduced to a sufficiently low level to justify their exclusion from the design basis accident spectrum."

- CRBRP project, with ANL support, built a technical case to justify exclusion

- CRBRP met licensing requirements for construction without inclusion of HCDAs in the design basis 
- Beginning in the early/mid 1980's, DOE funded conceptual design studies for modular advanced liquid metal reactor plants

- At Rockwell International, the Sodium Advanced Fast Reactor (SAFR)

- At General Electric, the Power Reactor - Inherently Safe Module (PRISM)

- Preliminary Safety Information Documents for SAFR and PRISM were submitted to NRC in November, 1986

- The initial SAFR and PRISM concepts focused on innovative design approaches for economics and safety

- Design simplification based on passive safety performance

- DOE subsequently (ca 1988?) selected the PRISM concept for continued development in the Advanced Liquid Metal Reactor (ALMR) program

- NRC issued pre-application SERs for SAFR (1991) and PRISM (1994)

- DOE support for PRISM design studies ceased with the cancellation of the ALMR program in 1994 


\section{Rockwell International SAFR Design}

- Multiple (4) power units per site co-located with a spent fuel processing facility

- $900 \mathrm{MWt}$ reactor, U-Pu-Zr metallic fuel, pool type primary system, two intermediate loops

60 year plant life

- Reactor core: 96 driver fuel assemblies, 46 internal and 48 radial blanket assemblies, 6 control assemblies, 3 safety assemblies

- Coolant outlet $950^{\circ} \mathrm{F}\left(510^{\circ} \mathrm{C}\right)$, inlet $675^{\circ} \mathrm{F}\left(357^{\circ} \mathrm{C}\right)$

- Inherent response for emergency reactor shutdown

- Inherent reactivity feedbacks in temperature and flow transients

- Self-Actuated Shutdown System (SASS); thermally-activated magnetic latch release

- Two natural circulation decay heat removal systems

- Direct heat removal from hot sodium pool (DRACS)

- Ambient air cooling of guard vessel (RACS)

- Compact containment building design 


\section{General Electric PRISM Design}

- Multiple power modules (6) co-located with a spent fuel reprocessing facility (Module reactor size grew as the concept evolved, to $840 \mathrm{MWt}$ in 1995. The SER looks at the 471 MWt design)

- $840 \mathrm{MWt}$, U-Pu-Zr metallic fuel, pool-type primary system, two intermediate loops

- Reactor core (burner): 192 fuel assemblies, 10 control assemblies, 3 safety assemblies

- Coolant outlet $930^{\circ} \mathrm{F}\left(500^{\circ} \mathrm{C}\right)$, inlet $680^{\circ} \mathrm{F}\left(360^{\circ} \mathrm{C}\right)$

- One safety grade automatic reactor protection system, with a manually operated safety grade ultimate shutdown system (3 safety rods)

- Inherent accommodation of ATWS transients without core melt, significant reactivity addition, or large radiological release

- Shutdown cooling by turbine bypass with emergency removal systems

- Air cooling system (ACS) on the steam generator shell

- Primary sodium auxiliary cooling system (PSACS); reqs. valve action

- Reactor vessel air cooling system (RVACS)

- Compact containment shell design 


\section{SAFR/PRISM Safety Design/Licensing}

- By the time (mid 1980's) SAFR and PRISM were being designed, technical understanding of severe accident progression had advanced to a point that reactor designs could be specified to greatly reduce the consequences of accident initiators that led to severe accident conditions (coolant boiling, fuel melting, cladding failure) for FFTF and CRBRP designs

- Beyond design basis, double fault accidents with failure of the automatic scram system; loss of coolant flow, reactivity addition, or loss of normal heat rejection

- Full scope, integral testing in EBR-II and FFTF (ca 1986) provided confirmation of design features performance that limited accident consequences to elevated temperatures short of coolant boiling or fuel melting, with margins

- Inherent, passive reactor response provided by designs with negative reactivity feedbacks to reduce power and with natural circulation cooling to remove heat

n For SAFR and PRISM, the FFTF and CRBRP severe accident initiators cause elevated coolant temperatures that trigger inherent protection 


\section{Safety Design and Licensing Implications}

- The double fault accident sequences that led to core disruption in FFTF and CRBRP were considered as challenges to containment margins

- The same initiators in current sodium fast reactor designs do not produce conditions that approach containment margins

- Fuel cladding, reactor vessel, and containment building integrity are maintained

- These performance characteristics were reflected in the SAFR and PRISM designs, which included simplifications of shutdown, cooling, and containment features

- To achieve core melt conditions in modern liquid metal reactor designs, it is necessary to assume accident initiators with very low probability

- For example, "triple" fault initiators or extremely large earthquakes

- Proper characterization of such initiators requires probabilistic analysis and a risk-based assessment

- Passive safety mechanisms effectively increase containment margins and public safety 
- FFTF and CRBRP experiences demonstrate that a liquid sodium-cooled reactor plant can be licensed

- FFTF underwent NRC review, and CRBRP construction was approved

- Requires interpretation of 10CFR50 App. A in view of low pressure, chemically active liquid metal coolant, compliance with intent, and possibly additional criteria to cover physical characteristics not considered in the LWR criteria

- Compliance with defense-in-depth principles in design specifications

Effective management of the licensing process can be achieved

- Recognition by both applicant and regulator of each other's responsibilities

- Focus on top-level goals and actions necessary to fulfill both regulatory and project requirements 
- Innovative SAFR and PRISM safety design features promise increased margins to beyond-design-basis safety limits, high reliability safety systems, and safety design simplification

- Reliance on inherent mechanisms for power and reactivity control and natural circulation heat removal

- Early recognition of potential issues of significance and establishment of a framework for resolution

- Example: Passive reactivity feedbacks and natural circulation heat removal. Proof of reliability by test?

- Example: Severe accident prevention and consequence mitigation. Risk informed assessment?

- Others

- Begin technical interactions at the earliest possible opportunity 
- EBR-I Power Excursion

- Fermi-1 Fuel Assembly Inlet Blockage

BN-350 Steam Generator Leak

- Phenix Reactivity Anomaly

- SuperPhenix

- Monju Sodium Leak 


\section{Experimental Breeder Reactor-1 (EBR-I)}

- Experimental Breeder Reactor-I (EBR-I) was built at the National Reactor Testing Station in Idaho to demonstrate fuel breeding

- From 1951 to 1963, EBR-I was operated with four core designs to demonstrate breeding and to develop an understanding of liquid metal fast reactor performance

- Pu breeding demonstrated by February, 1952

- Testing platform for reactor physics, fluid dynamics, and power generation

- $1.4 \mathrm{MWt}$, generated $200 \mathrm{~kW}$ of electricity for NRTS

- NaK cooled, U-235 ( $94 \%$ enriched) metal fuel in stainless steel cladding

- 217 pin locations on a triangular 0.494 in. pitch; 0.384 in. fuel OD; 0.448 in. cladding OD; 8.5 in. core height

$-227^{\circ} \mathrm{C}$ inlet, $316^{\circ} \mathrm{C}$ outlet, 20 psig

- Mk I and II cores used top support, above-core shield plates, and a bottom tube plate to position fuel pins

- Mk III (and IV) core used hexagonal tubes and wire wraps for fuel pin positioning

- Mk IV core used Pu fuel (1962) 


\section{EBR-I Reactor}

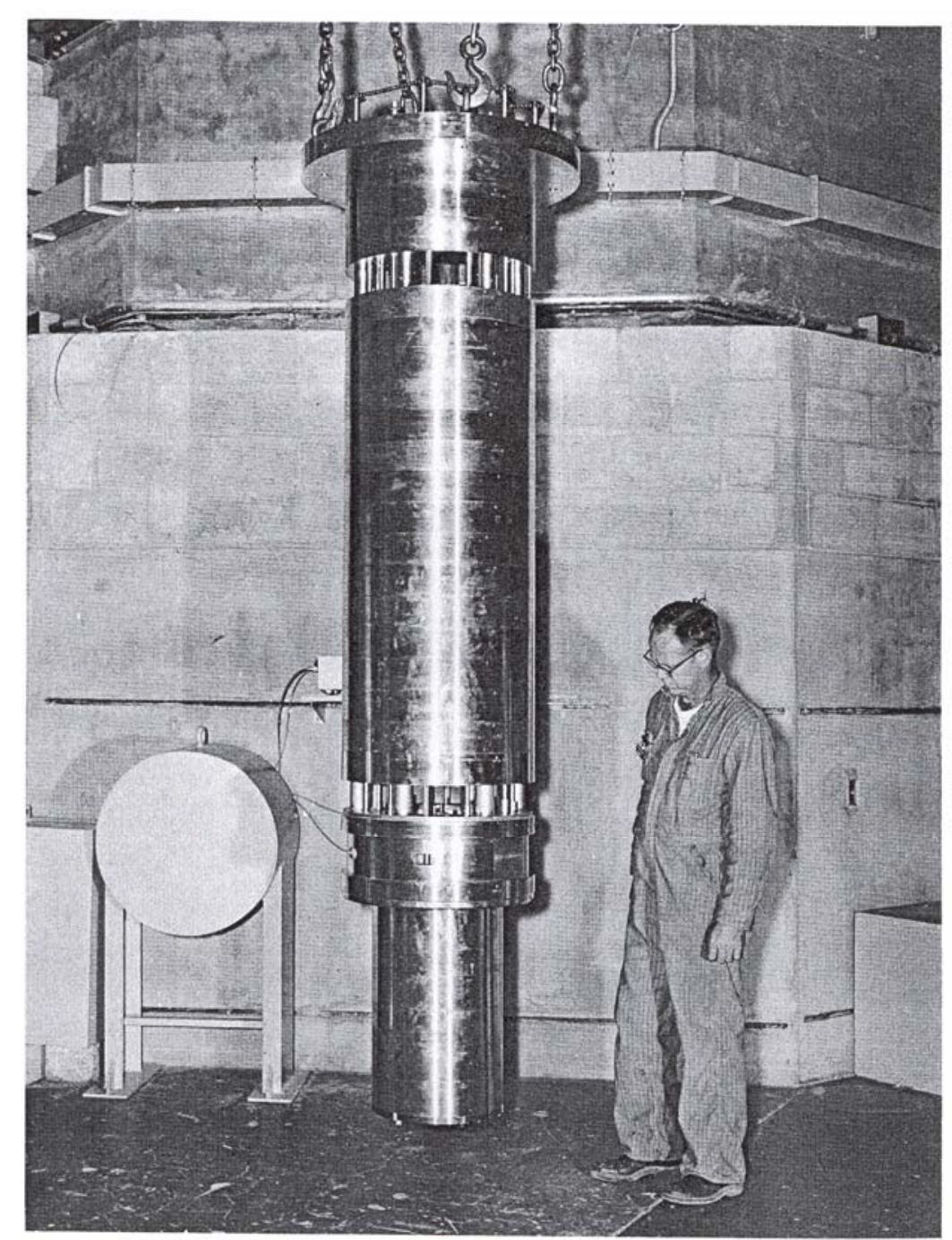

(Reactor Shield in Background)

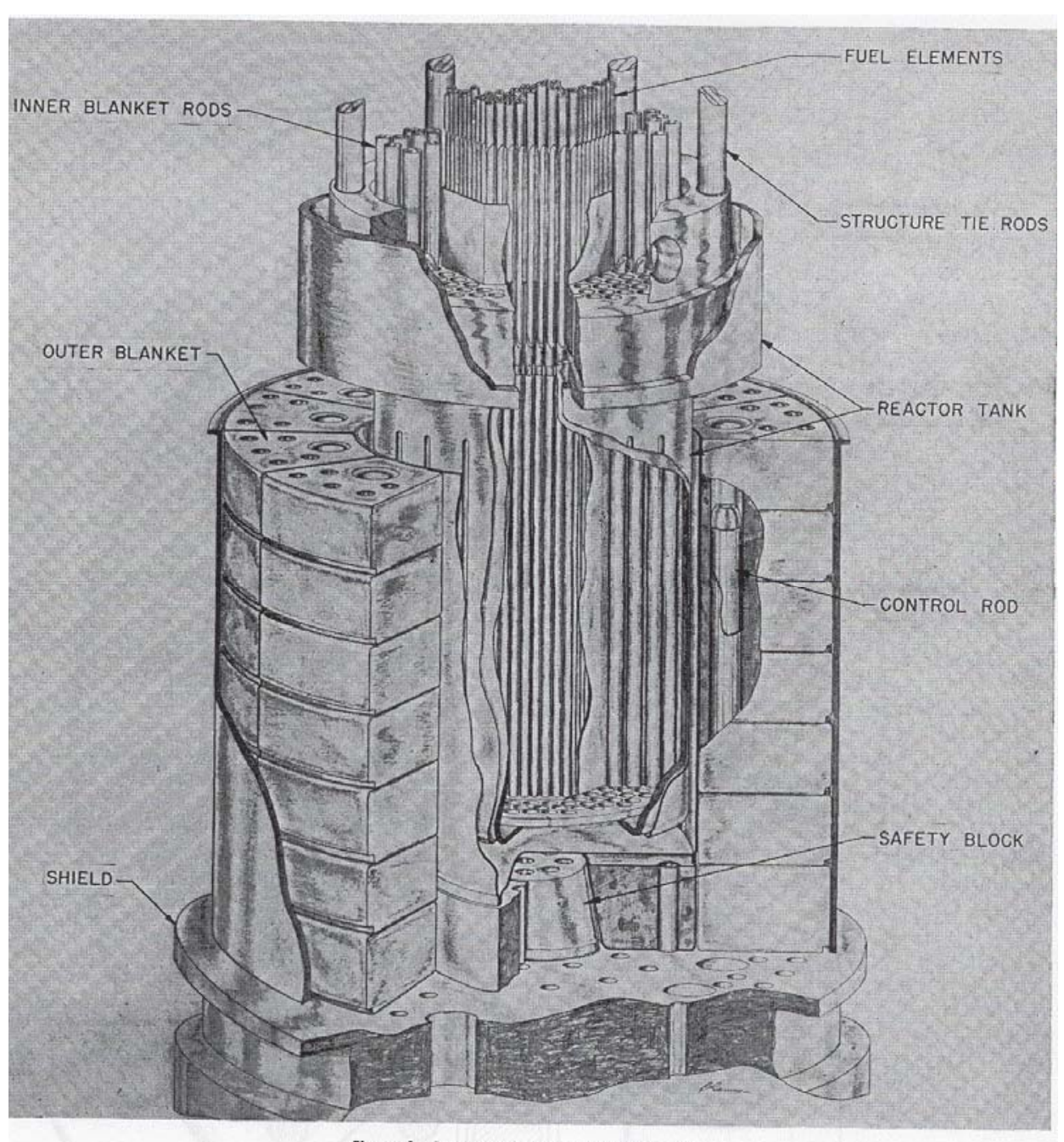

Figure 1. Cut-away showing EBR construction

EBR-I Core Mk I and II

\section{Argonne}




\section{EBR-I Mk I and II Above-Core Shield Plate}

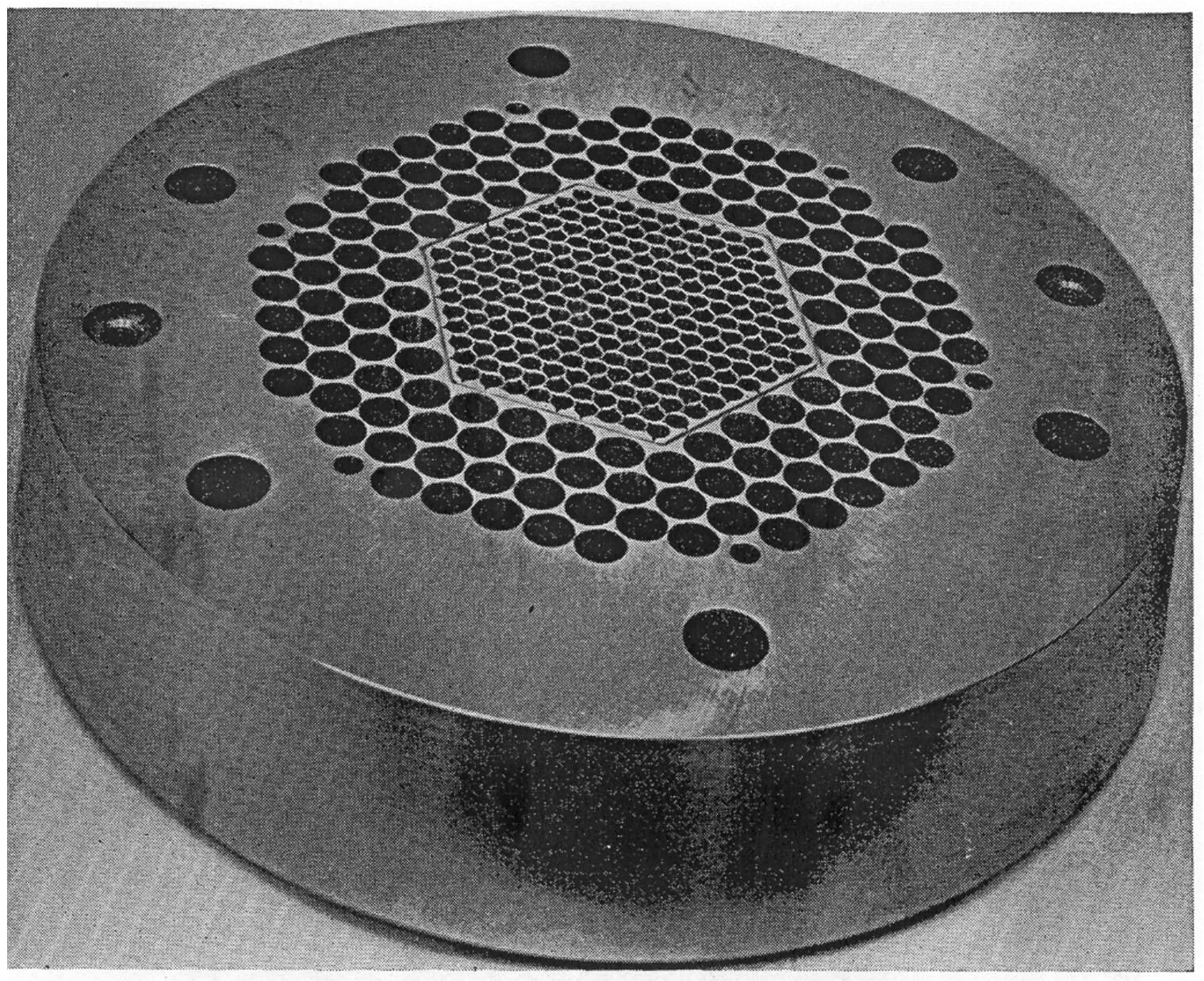

Fuel element holes 0.460 in. OD (Cladding 0.448 in. OD)

Figure 2a. Stainless steel holding plate for core fuel elements and inner blanket rods 


\section{EBR-I Accident}

- The Mk II core loading was found to have a prompt positive power coefficient, especially for very low power/very low flow conditions

- In November, 1955, during a test to investigate the prompt positive component of the power coefficient, an unanticipated power excursion resulted in fuel melting.

- Repeat of a previous test, with additional instrumentation

- $60 \mathrm{~s}$ initial period from $50 \mathrm{~W}$, no coolant flow

- Excursion during $500 \mathrm{~s}$ to $<1 \mathrm{~s}$ period, $\sim 10 \mathrm{MW}$ (est.)

- Scram by control rods failed to terminate the excursion; manual scram by blanket (reflector) drop

- After the test, radiation alarms upon flow restart

- Subsequent investigations identified fuel rod bowing as the source of the positive reactivity feedback

- Inward pin bending in the core due to radial power profile and insufficient radial support to prevent compaction

- Core was replaced and operation continued through 1963

- Mk III and IV cores used wire wraps and hex tubes for radial support 


\section{EBR-I Mk III Core Loading}

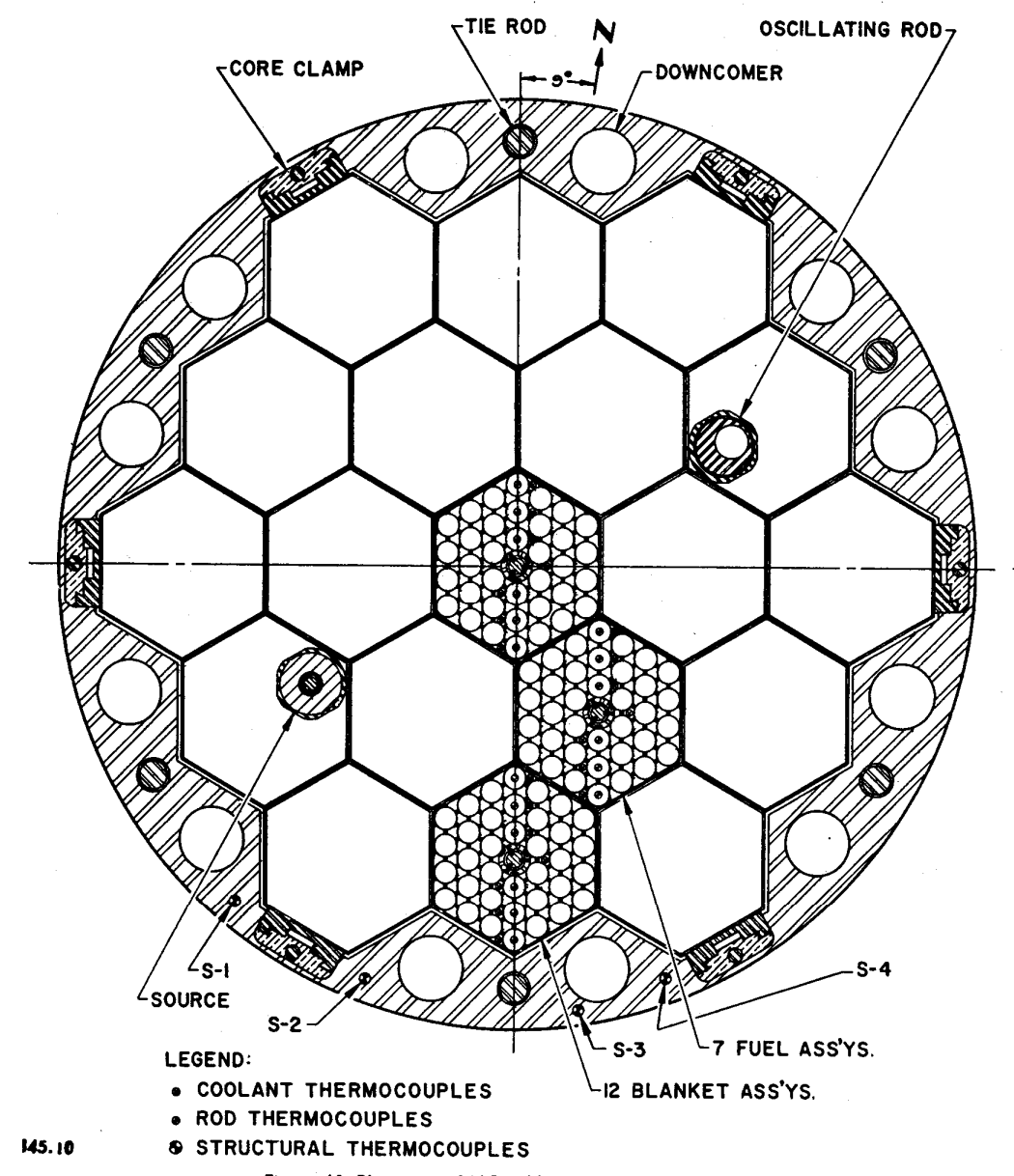

Figure 10. Plan view of EBR-I, Mark III at core centerline
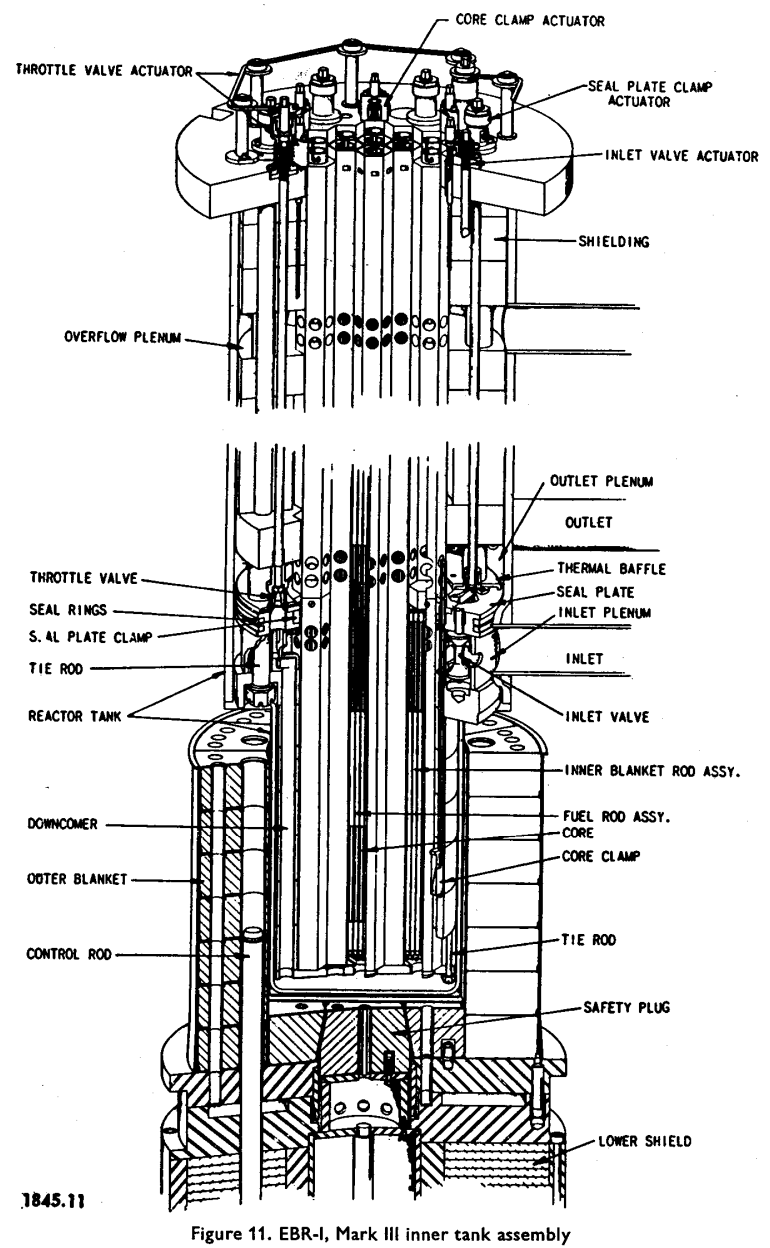

Elevation View

\section{Plan View at Midplane}




\section{EBR-I Accident - Lesson Learned}

- The EBR-I core melt accident demonstrated the sensitivity of compact fast reactors to small changes in core fuel density

- Sensitivity magnified in a very small, high enrichment core like EBR-I

- Subsequent fuel assembly designs have used wire wraps and hexcans in the U.S. (grids in Europe) to provide control of fuel geometry

- Must be sufficiently 'loose' to accommodate thermal expansion and swelling, but 'tight' enough to provide support and positioning

- Trend to bottom support of fuel pins and free axial expansion upward within the hexcan

- Hexcans are usually supported at the bottom in the core grid plate, and constrained radially in a manner to accommodate hexcan swelling and creep

- Early designs used 'free bowing' concept (EBR-II) to give room for withdrawal in refueling; accommodation of steel swelling

- Later designs (FFTF) used a 'limited free bow' design to manage hexcan bending to assure a negative power coefficient 
200 MWt power station located on the western shore of Lake Erie south of Detroit

- Designed by Atomic Power Development Associates (APDA) and constructed by Power Reactor Development Co. (PRDC) for Detroit Edison

- Critical August 1963, first power August 1966

- Sodium cooled, $288^{\circ} \mathrm{C}$ inlet, $427^{\circ} \mathrm{C}$ outlet, 120 psia

- Metal fuel, Zr cladding 0.158 in. OD, 31 in. height, square pin pitch

- Subassembly flow blockage and fuel melting accident during power ascension on October 5, 1966

- Metal fuel core removed and replaced with oxide core; full power 1969

- Operation ceased in 1972 


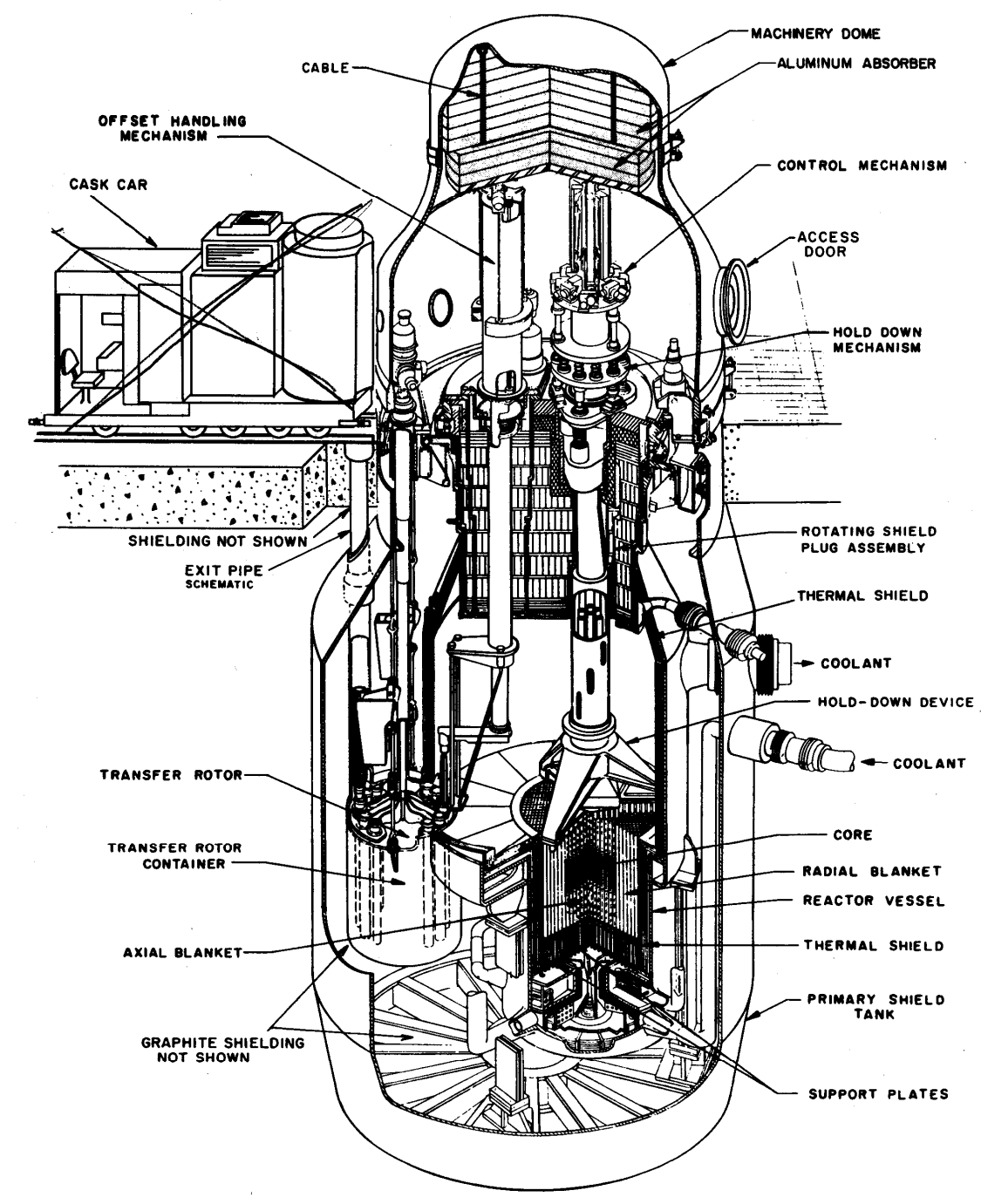

PERSPECTIVE VIEW OF REACTOR 
Fermi-1 Reactor Vessel

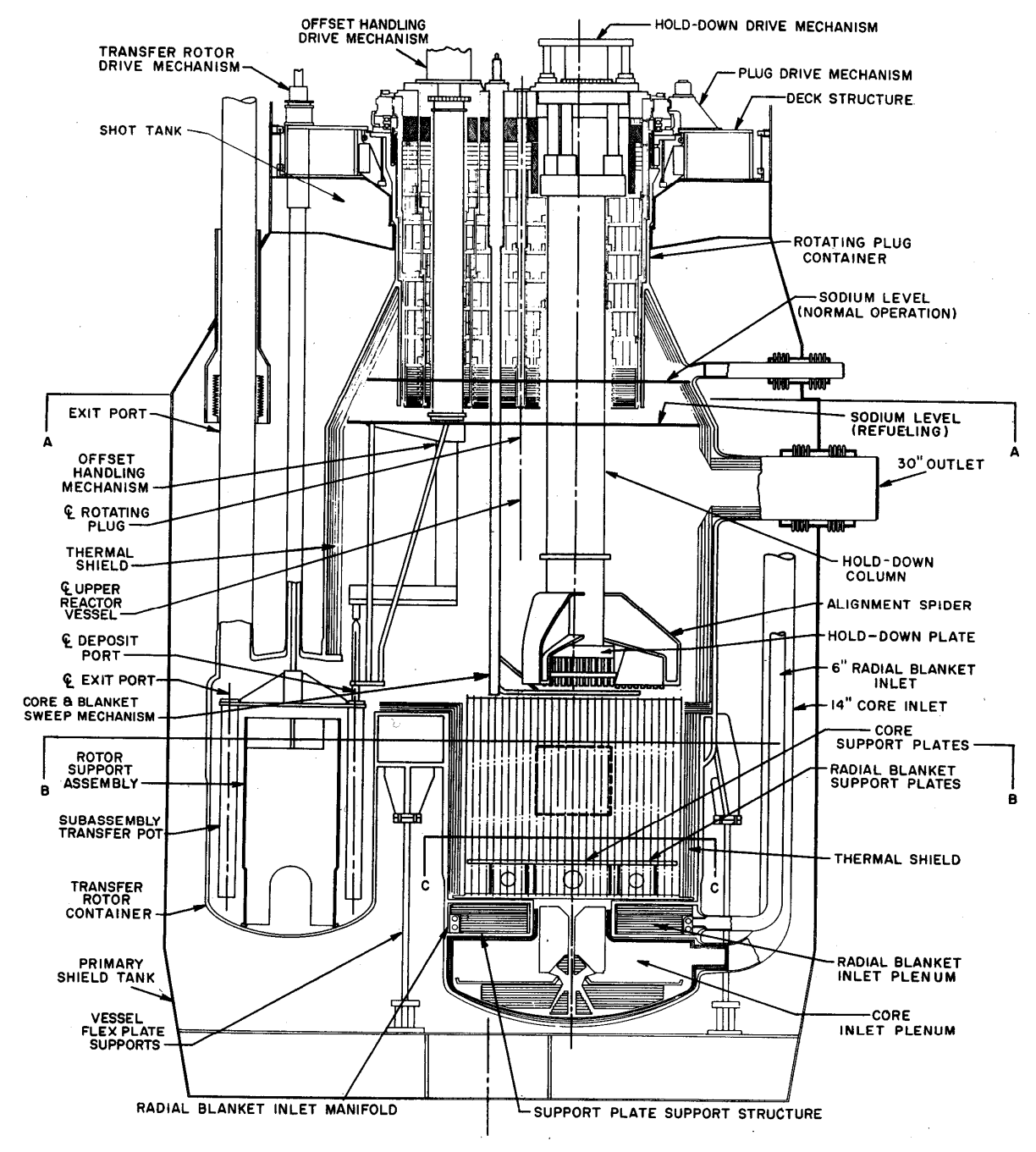

REACTOR VESSEL (ELEVATION)

\section{Argonne}




\section{Fermi-1 Core Inlet Plenum and Melt-Down Section}

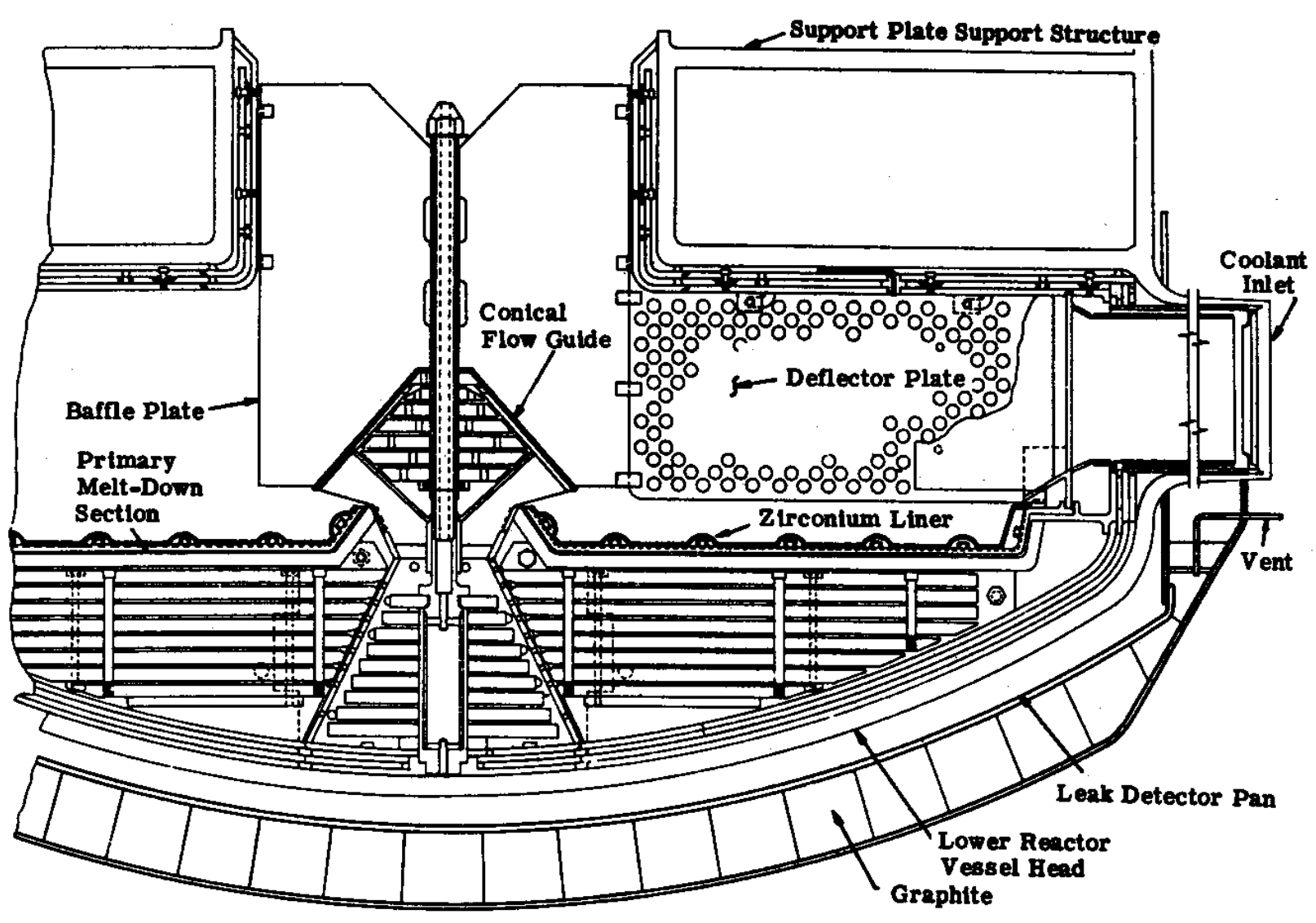

FG. 7 MELT-DOWN SECTON IN LOWER REACTOR VESSEL 


\section{Fermi-1 Fuel Assembly}

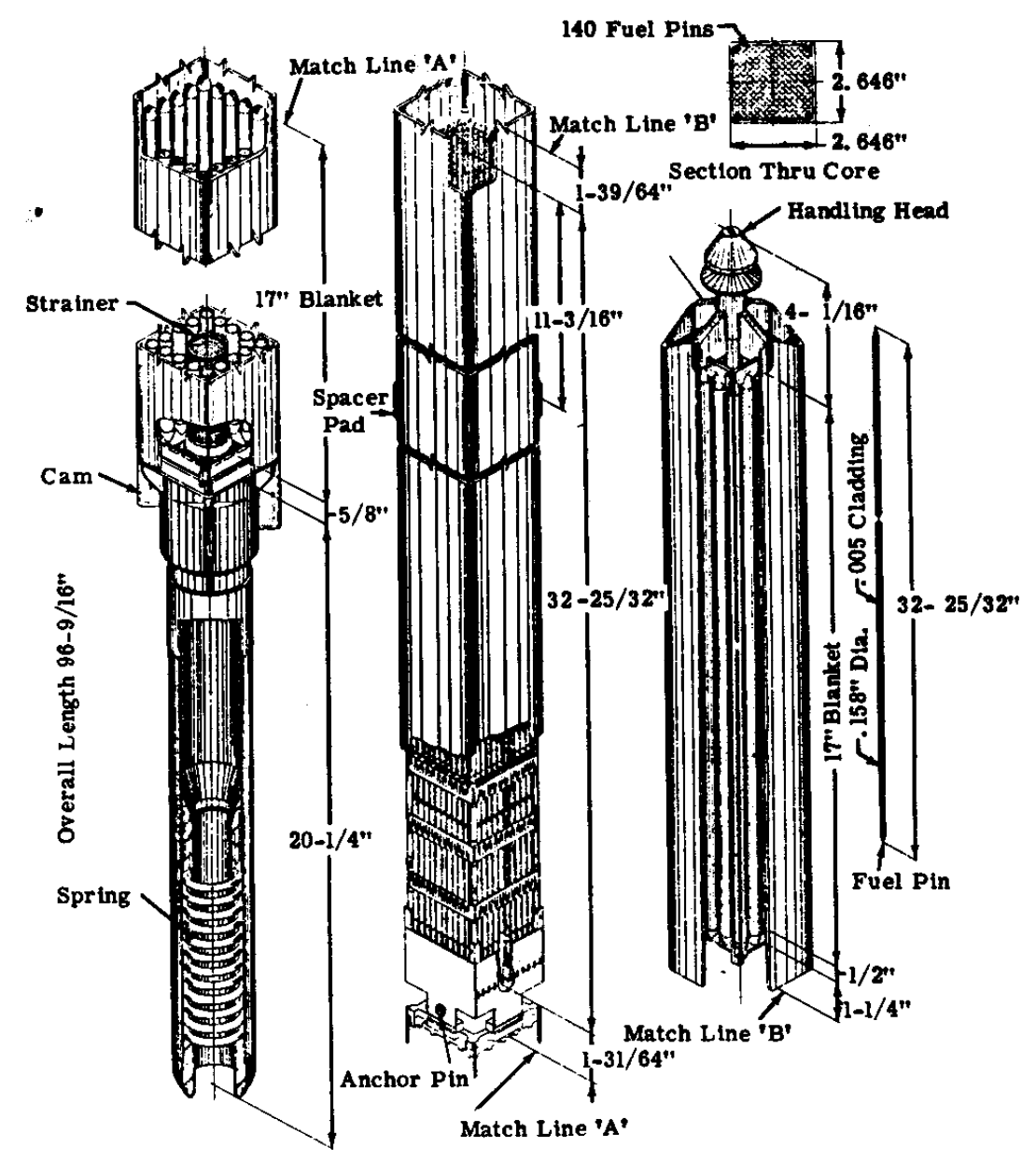




\section{Fermi-1 Fuel Melting Accident}

- Prior to October 5, high fuel assembly outlet thermocouple readings had been observed during low power operations

- Assemblies with abnormal temperature readings were relocated to positions under different thermocouples

- The location(s) of the high temperature readings changed on each start-up, but not in correlation with the assembly movements

- On Oct. 5 during a power ascension at $34 \mathrm{MWt}$, building radiation alarms sounded, indicating fuel damage

- The reactor had previously operated at $100 \mathrm{MWt}$ without problems

- Subsequent investigations revealed fuel melting in two adjacent assemblies

- Another adjacent assembly was bent, with no internal damage

- A 'foreign object' was found in the inlet plenum, which later proved to be a crumpled $Z$ r plate from the melt-down section liner

- The loose Zr plate had apparently been swept by flowing coolant to cover (partially or completely) the inlet nozzle of various assemblies during the multiple start-ups 


\section{Fermi-1 Fuel Melting Accident - Lessons Learned}

- Assembly inlet nozzle designs since Fermi-1 have included multiple coolant inlet passages so that complete external blockages are 'impossible' by design

- Considerable research and testing of both external and internal blockages have been performed to understand and quantify the damage mechanisms and limits

- In the U.S., the assembly blockage scenario (external and internal) has been addressed in the assembly design (inlet flow diversity), in the inlet plenum design (coolant flow distribution and assurance of assembly supply), in the instrumentation design (detection by multiple thermocouples, delayed neutron detectors, gas tags), and in fuel handling equipment design (casks)

- Internationally, in some countries the fuel assembly blockage scenario has become a design basis accident 


\section{$B N-350$}

$750 \mathrm{MWt}$ power station located on the eastern shore ( $\sim 2 \mathrm{mi}$. inland) of the Caspian Sea near Aktau (Shevchenko), Kazakhstan

- 130 MWe, 150 MWt desalination

- Critical 1972, Power (partial) 1973, Shutdown 1994

- Power level during early operation (1973-1975) limited (350-550 MWt) by leaks in the steam generator evaporator tubes

- Plant designed for 5 of $\mathbf{6}$ loop operation (One loop spare)

- In each loop; two evaporators with bayonet tubes and two superheaters with U-tubes

- 816 bayonet tubes in each evaporator, $33 \mathrm{~mm}$ OD x $3 \mathrm{~mm}$ thick (originally 32x2) with a welded end cap and a $16 \mathrm{~mm} \times 1.4 \mathrm{~mm}$ internal downcomer tube

- In start-up tests, found leaks at the tube-sheet welds and the end cap welds

- In operation, eight evaporator leaks through 1975 involving all but one of the loops (Loop No. 4 never had a leak)

- Three major leaks with extensive damage 


\section{BN-350 Plant Layout}

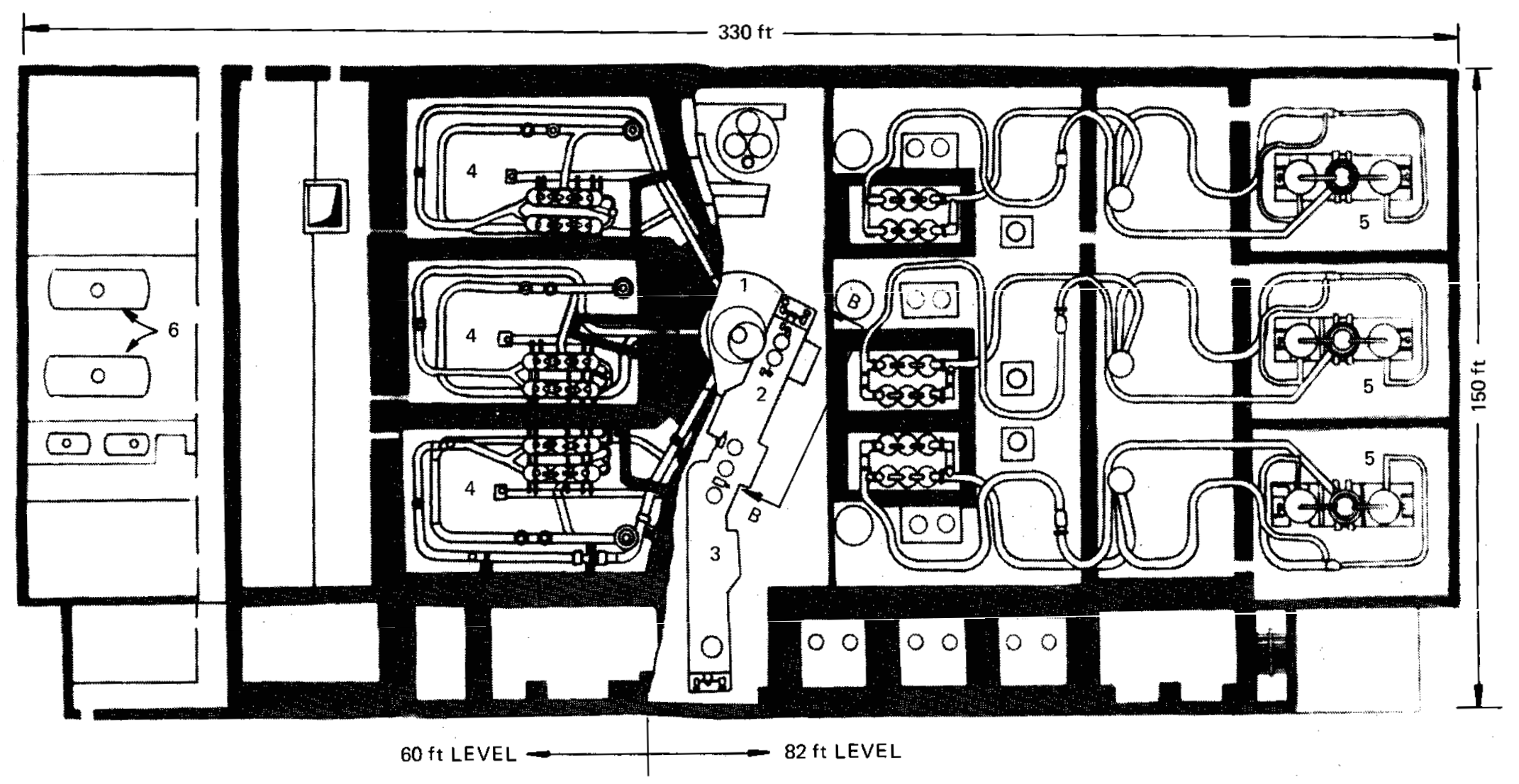

Fig. A.3.3. Plan View of BN-350, Reactor Building Only. Symmetrical layout-3 loops to the right of the reactor; 3 to the left of the reactor. 1-Reactor; 2-Refueling cell; 3-Wash cell; 4-Three of 6 IHX compartments, 2 shells in each compartment; 5-Three of 6 steam generator compartments; 6 -Secondary dump tanks. For B-B see Fig. A.3.17. 


\section{BN-350 Flow Diagram}

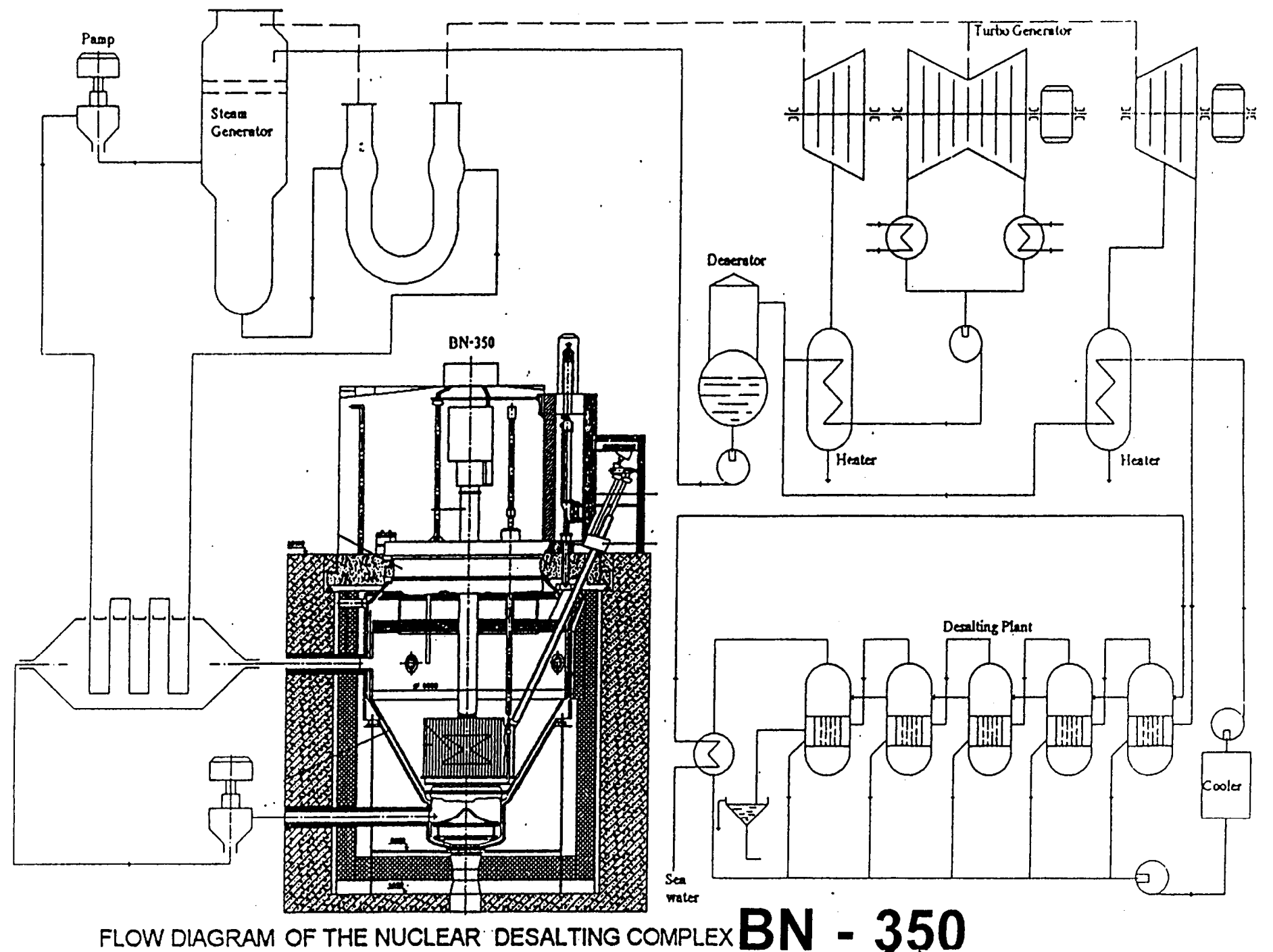

\section{Argonne}




\section{BN-350 Coolant Loop (1 of 6)}

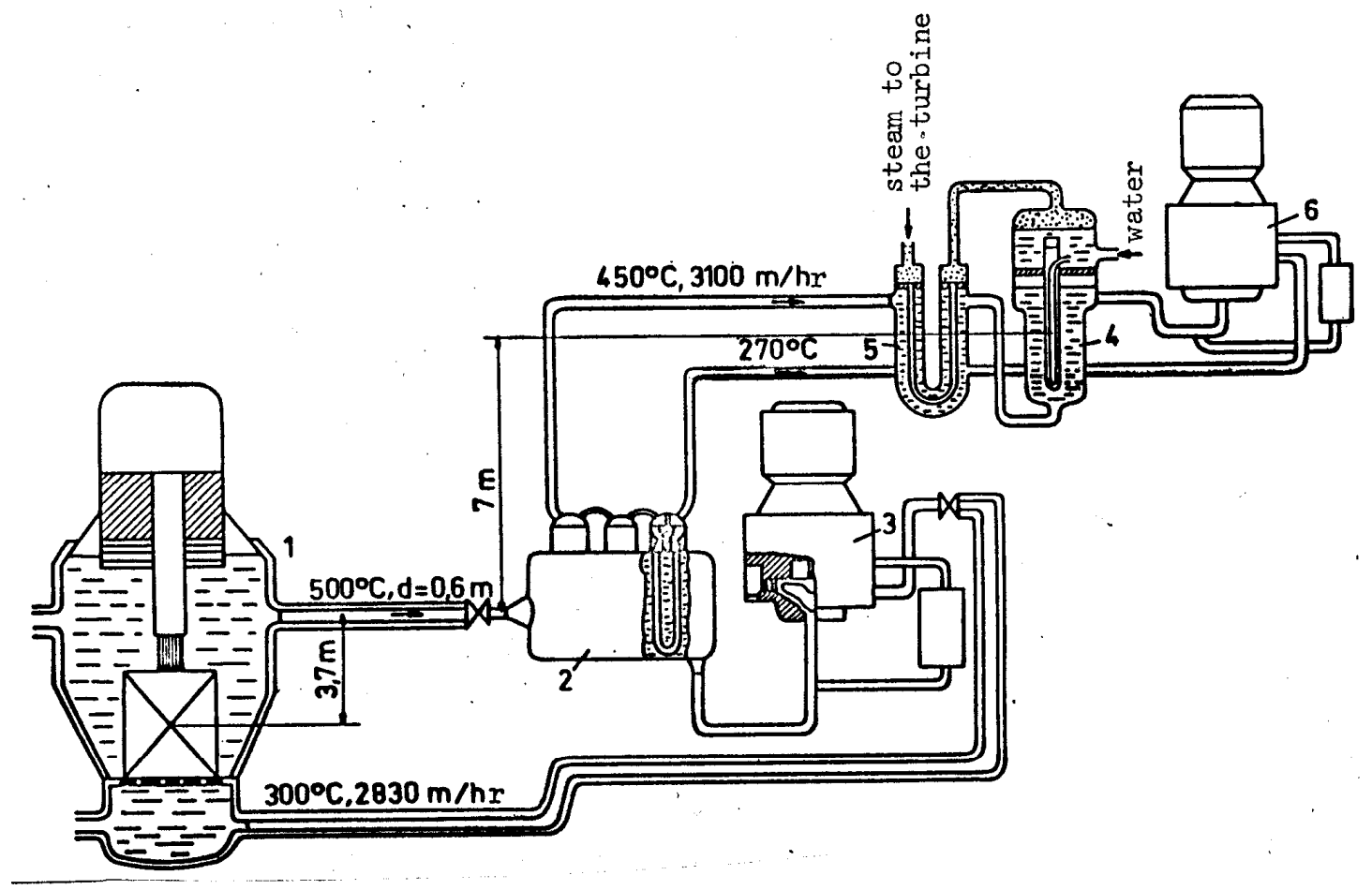

$$
\begin{aligned}
& 1 \text { - Reactor } \\
& 2 \text { - Exchanger } \\
& 3 \text { - Primary Pump } \\
& 4 \text { - Boiler } \\
& 5 \text { - Steam Superheat } \\
& 6 \text { - Secondary Pump }
\end{aligned}
$$

Fig. 1. Schematic diagram of a cooling loop of the energy-production system of BN350.

\section{Argonne}




\section{BN-350 Steam Generator and Evaporator Tube}

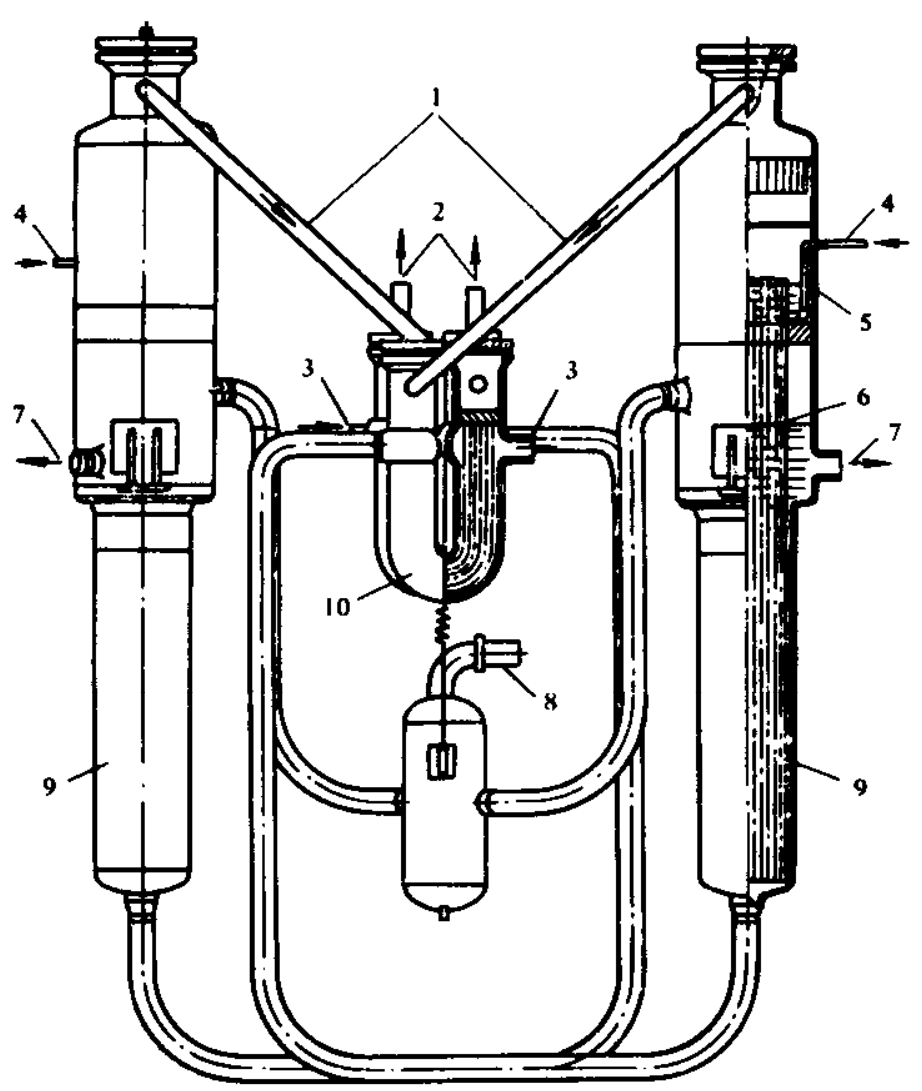

Fig. A.3.23. BN-350 Steam Generator. 1-Saturated steam inlets, 2-Superheated steam, 3,7-Sodium inlet and outlet, 4-Feedwater inlet, 5-Water level, 6-Sodium level, 8-Burst diaphragm, 9-Evaporator, 10-Superheater.

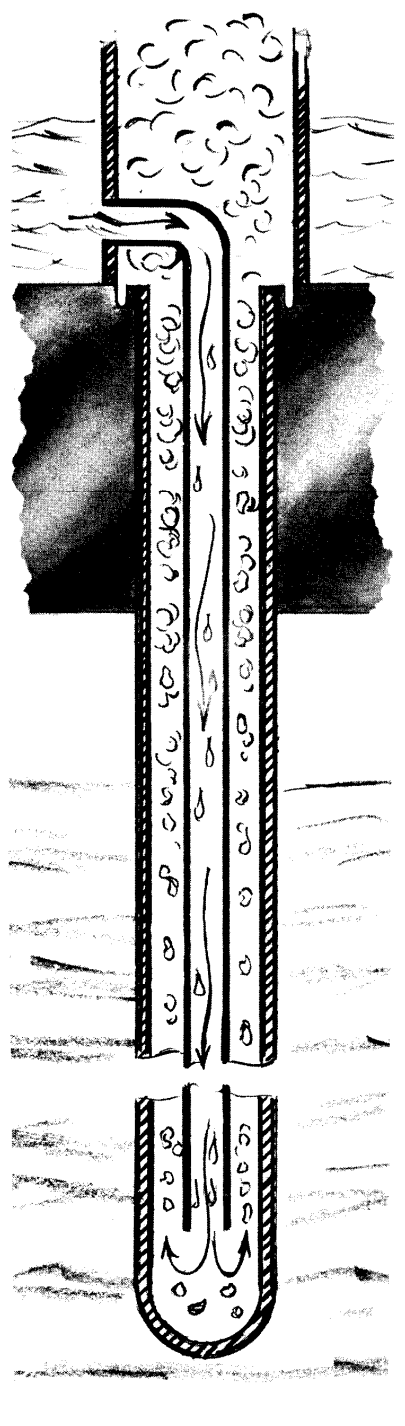

BN-350 bayonet steam generator

\section{Argonne}




\section{BN-350 Steam Generator Evaporator Experience}

- Through 1974, two major leaks and three smaller leaks

- Initiated from end cap welds; micro-cracks in end cap weld seam zone, attributed to mechanical deformation at end cap manufacture

- In 1974, decision to re-tube all evaporators except Loop No. 4

- By February 1975, three of five loops had been re-tubed

- After 7 days of operation, one of the evaporators in the most recently re-tubed loop failed (No. 5), leading to the most significant leak (Balent report)

- 120 tubes failed, $800 \mathrm{~kg}$ water leak

- This steam generator was dismantled and replaced with a Czechoslovakian steam generator

- It is claimed that safety systems (rupture disk and blowdown) prevented destruction of the evaporator vessels for the three large leaks (i.e. no sodium leaks)

- 1975 US delegation visit (Balent) report speculated that the reaction products stayed within the vessel shell, and this aggravated tube failure propagation

- After re-tubing, some leaks still occurred, but emphasis on sodium and feedwater quality control, early leak detection, and remediation (tube plugging) resulted in stable plant operation at design power levels 


\section{BN-350 Steam Generator Failures - Lessons Learned}

- Soviet steam generator technology experience prompted needs for

- Improved steam generator component manufacturing techniques; tube drawing/forging and welding

- Design for failure prevention; sodium and feedwater quality control

- Design provision for tube failure;

- Detection; quick recognition and action to prevent propagation

- Containment; blow-down relief to control intermediate sodium system pressure

- Remediation; plugging of leaking tubes

U.S. and Western technology contrast

- EBR-II evaporator/superheater experience 


\section{Phenix}

- 563 MWt, 250 MWe power station located near Marcoule, France

- Criticality 1973, full power 1974

a $85 \mathrm{~cm}$ core height, $430 \mathrm{~cm}$ subassembly height

- 217 wire-wrapped pins per subassembly

- Number of subassemblies: 55 inner core, 48 outer core, 90 radial blanket, 1317 reflector and shield

- Free-Standing (Free-Flowering) Core Restraint

- Accommodation of thermal/mechanical/irradiation effects for refueling

- Four rapid, large, negative reactivity excursions triggered automatic scrams due to power reduction: 6 August '89, 24 August '89, 14 September '89, and 9 September 1990

- Intensive investigations failed to provide identification of the cause(s)

- Operations twice interrupted and then resumed following testing, installation of additional instrumentation, and analyses of events 


\section{Phenix Site}

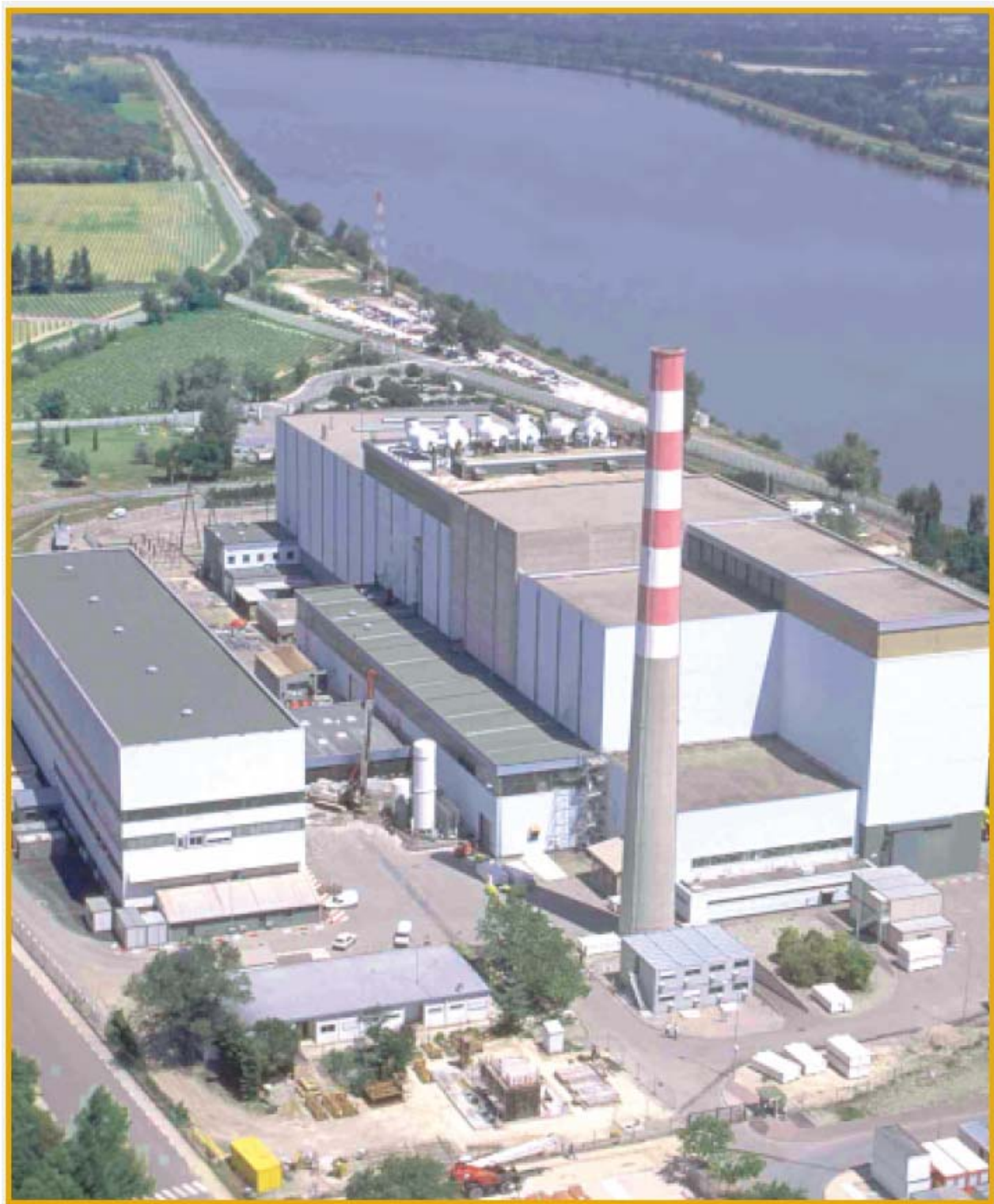

\section{Argonne}




\section{Phenix Reactor Building}

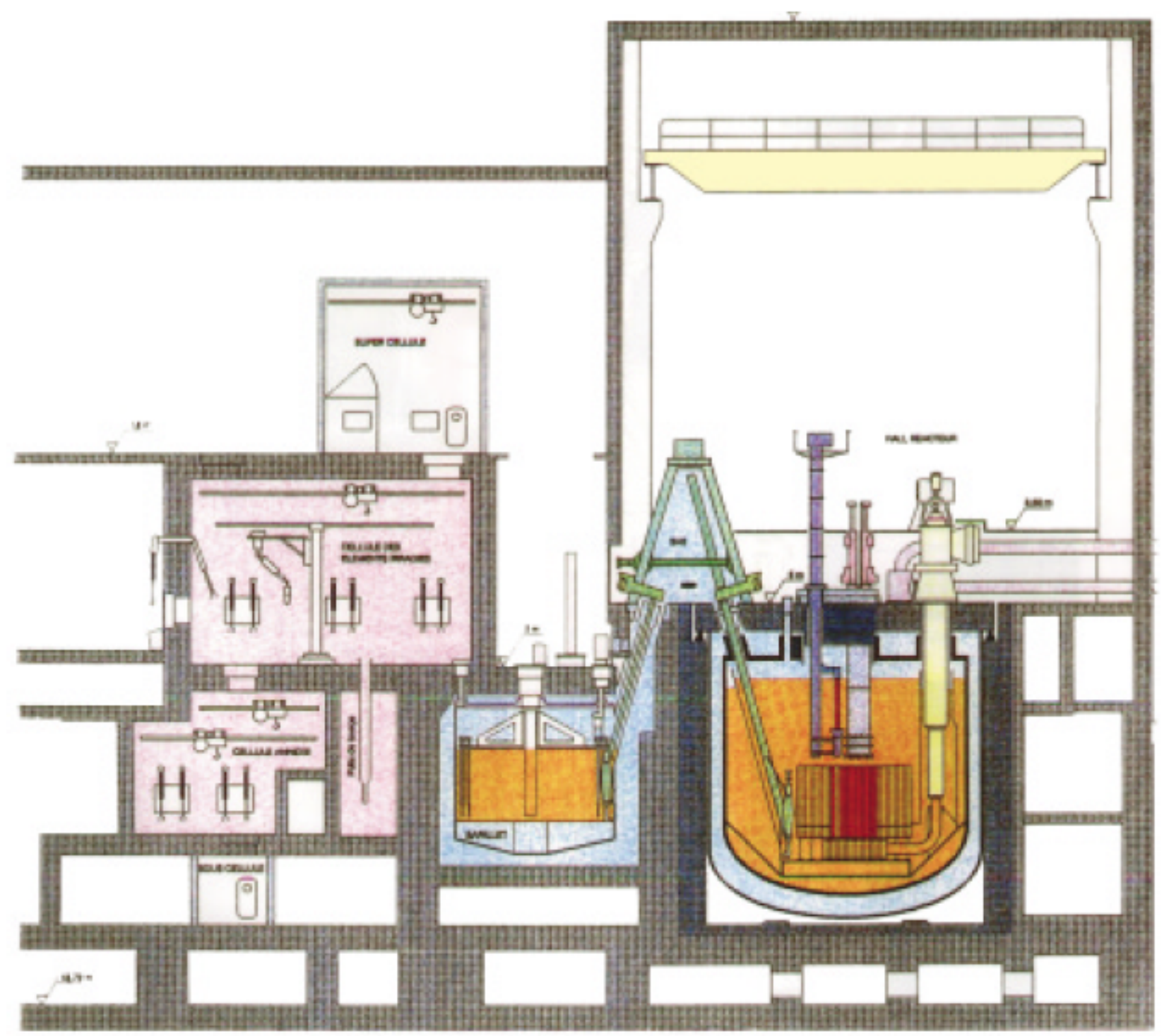


Phenix Pool-Type Primary System

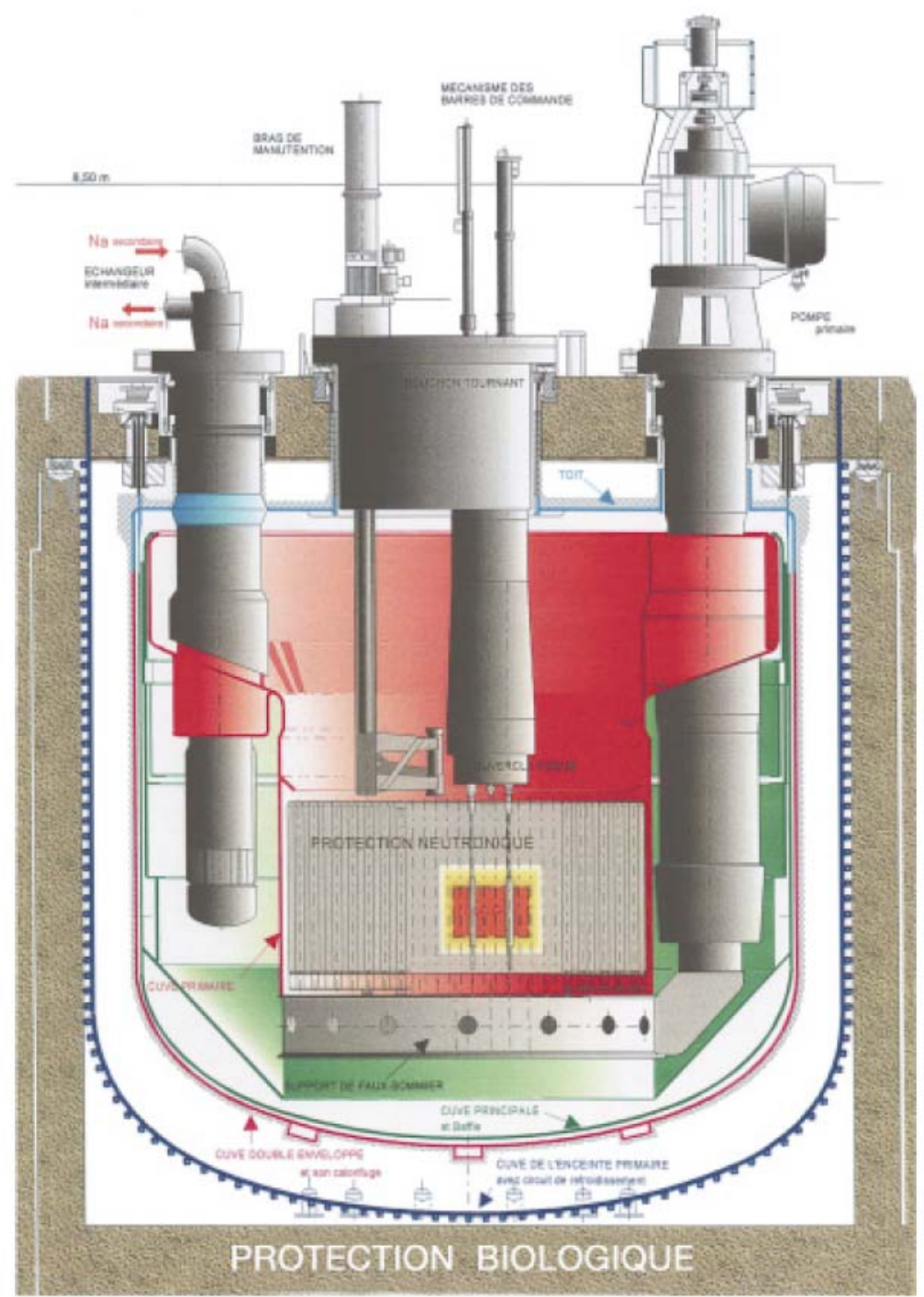




\section{Phenix Reactor Core}

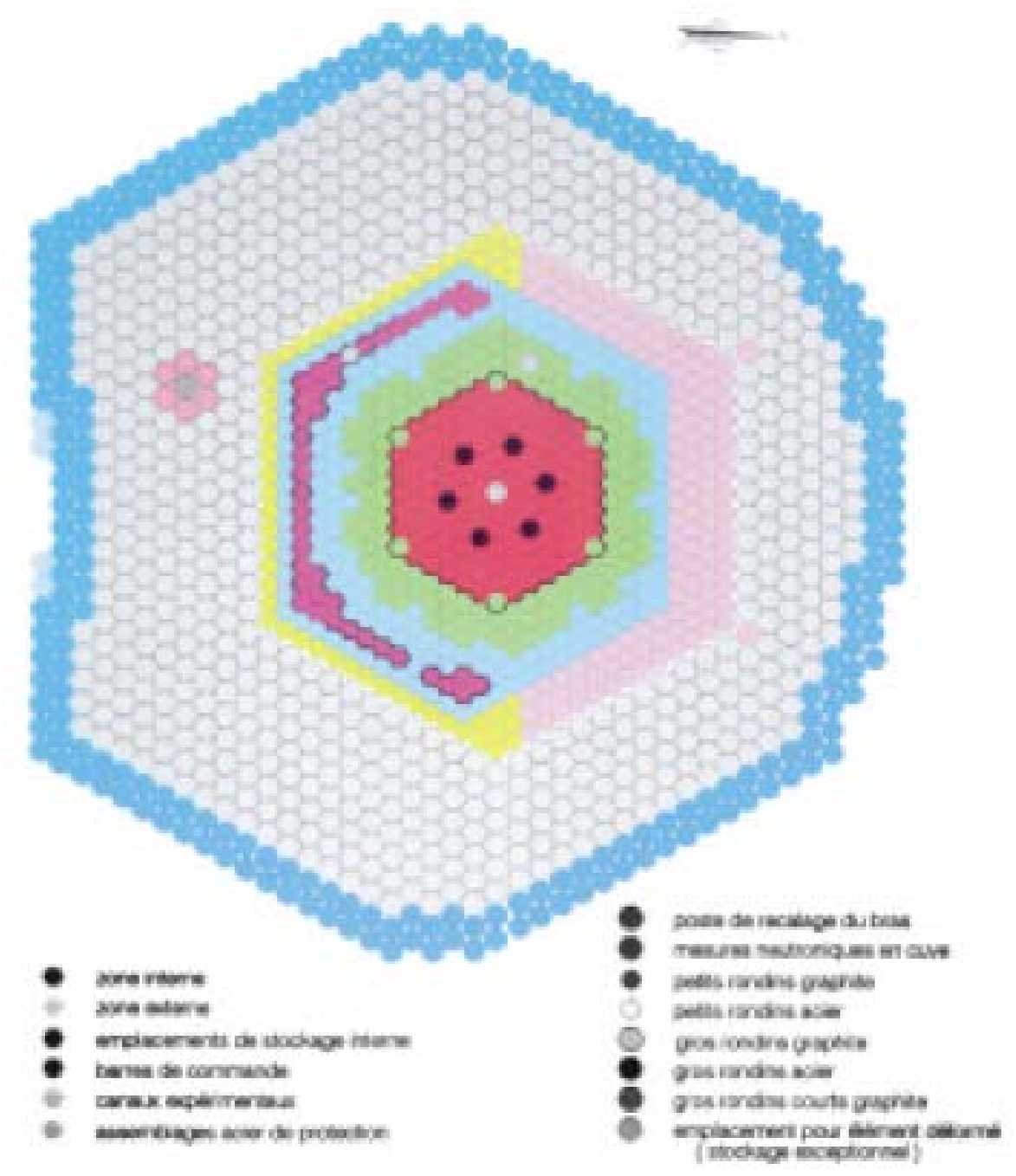

IMPLANTATION GENERALE DANS LE COEUR 
Phenix Negative Reactivity Transients, P (Mwt) vs t (ms)

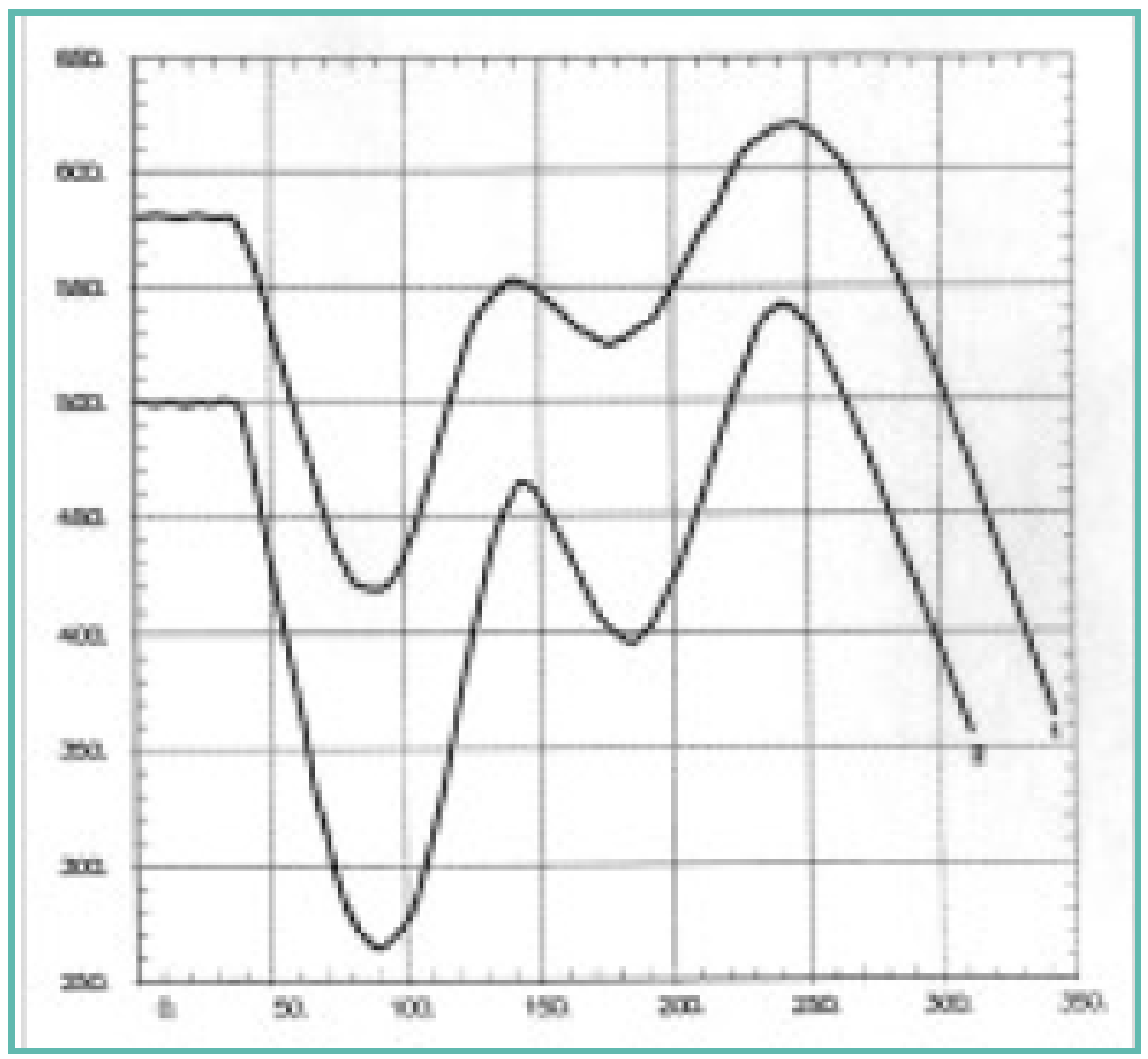

1 - Sept. 14, 1989, 2 - Sept. 9, 1990 


\section{Phenix Reactivity Excursions - 1}

- After the first two events (August '89), the cause was attributed to 'interference' in operation of the plant control system instrumentation, which had been modified just prior to 1989 , but no specific fault was found

- After the third event (September '89), the cause was attributed to passage of a gas bubble through the core periphery (negative reactivity) due to plugging of inlet plenum vents designed to prevent gas build-up. After a shutdown, maintenance, and analyses, the reactor was restarted in December '89

- Two cycles later, the fourth event (September '90) invalidated the gas bubble hypothesis

- Reactor operation ceased and an intensive investigation was begun

- A panel of experts was convened to consider all possible causes

- Reactor and plant tests and repairs were performed

- By the end of '91, the root cause had not been identified, but the 'strong presumption' was (rapid) radial expansion of the subassemblies 


\section{Phenix Reactivity Excursions - 2}

- Through 1992, analyses and testing with installation of special reactor surveillance equipment continued

- Focus on causal phenomena: coolant voiding, control rods motions, and core movements

- Given the amplitude and speed of the events, only core movements could cause the observed behavior

Modeling and simulations were performed, but no one specific scenario or cause was identified

- Final explanation: Outward (radial) expansion of the subassembly lattice, followed by a return

- Ultimately, consensus that operations could be safety resumed

- No further events to date

- Lesson learned? My opinion: Avoid free flowering core restraint design. 


\section{Super Phenix (Creys-Malville)}

- 2990 MWt, 1242 MWe power station located 50 KM east of Lyon, France

- Criticality 1985, full power 1986

- $1 \mathrm{~m}$ core height, $5.4 \mathrm{~m}$ subassembly height

- 271 wire-wrapped pins per subassembly

- Number of subassemblies: 193 inner core, 171 outer core, 234 radial blanket, 1288 reflector and shield

- On March 8, 1987, a leak in the fuel storage tank was detected

- Leaking sodium was contained by the storage tank guard vessel

- Stored fuel (new fuel, one partly irradiated subassembly, and dummy subassemblies used for pre-startup testing) were unloaded and the tank was drained.

- Investigations began to determine the location of the leak (Sept. '87)

- It was ultimately concluded that the tank could not be repaired, and alternative fuel handling equipment and procedures were adopted

- The expense associated with this and other events led to closure of the plant in 1998 (Down 2 yrs for technical, $4 \frac{1 / 2}{y r s}$ for 'administrative') 
Super Phenix Plant Site

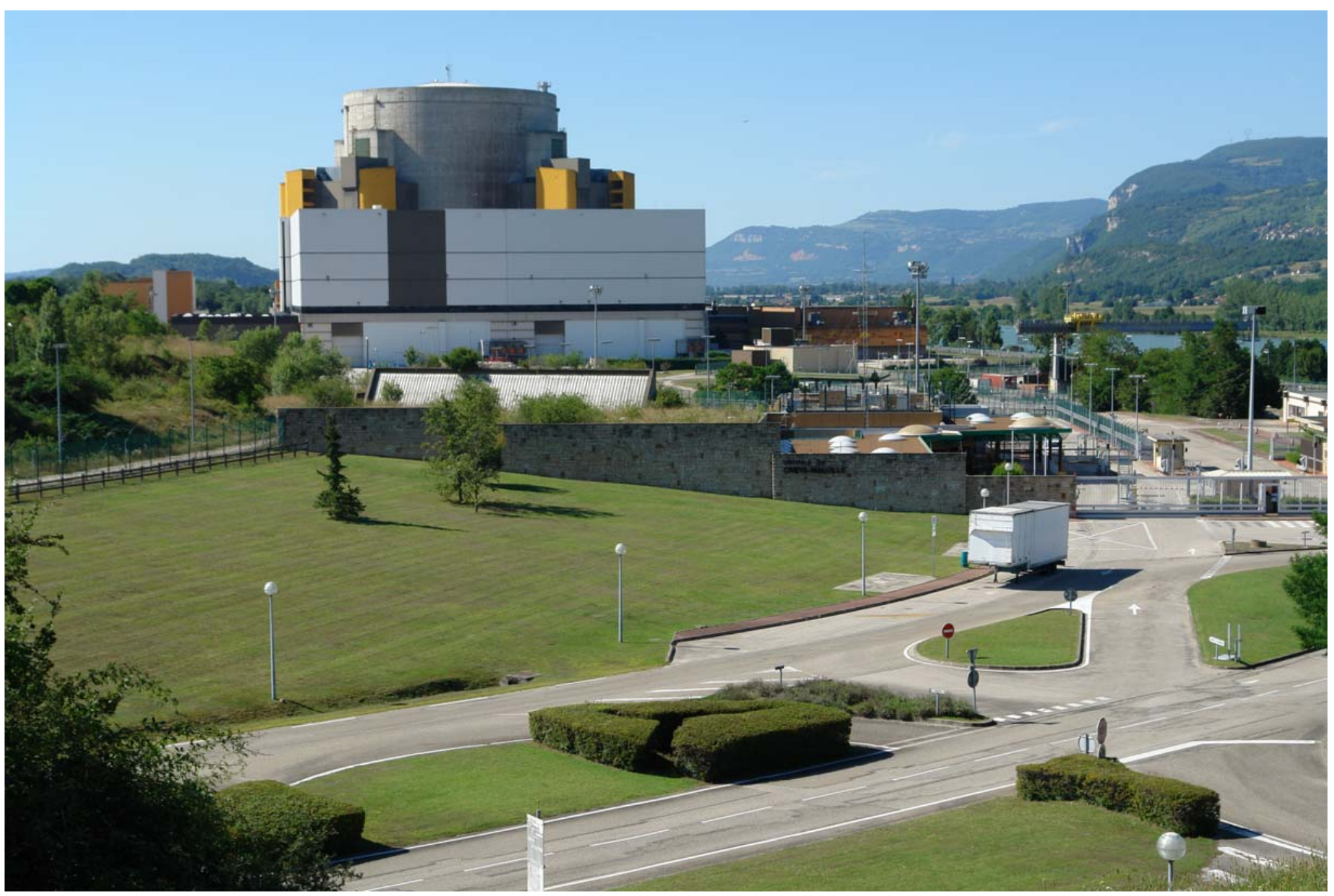




\section{Super Phenix Plant Coolant Flow Diagram}

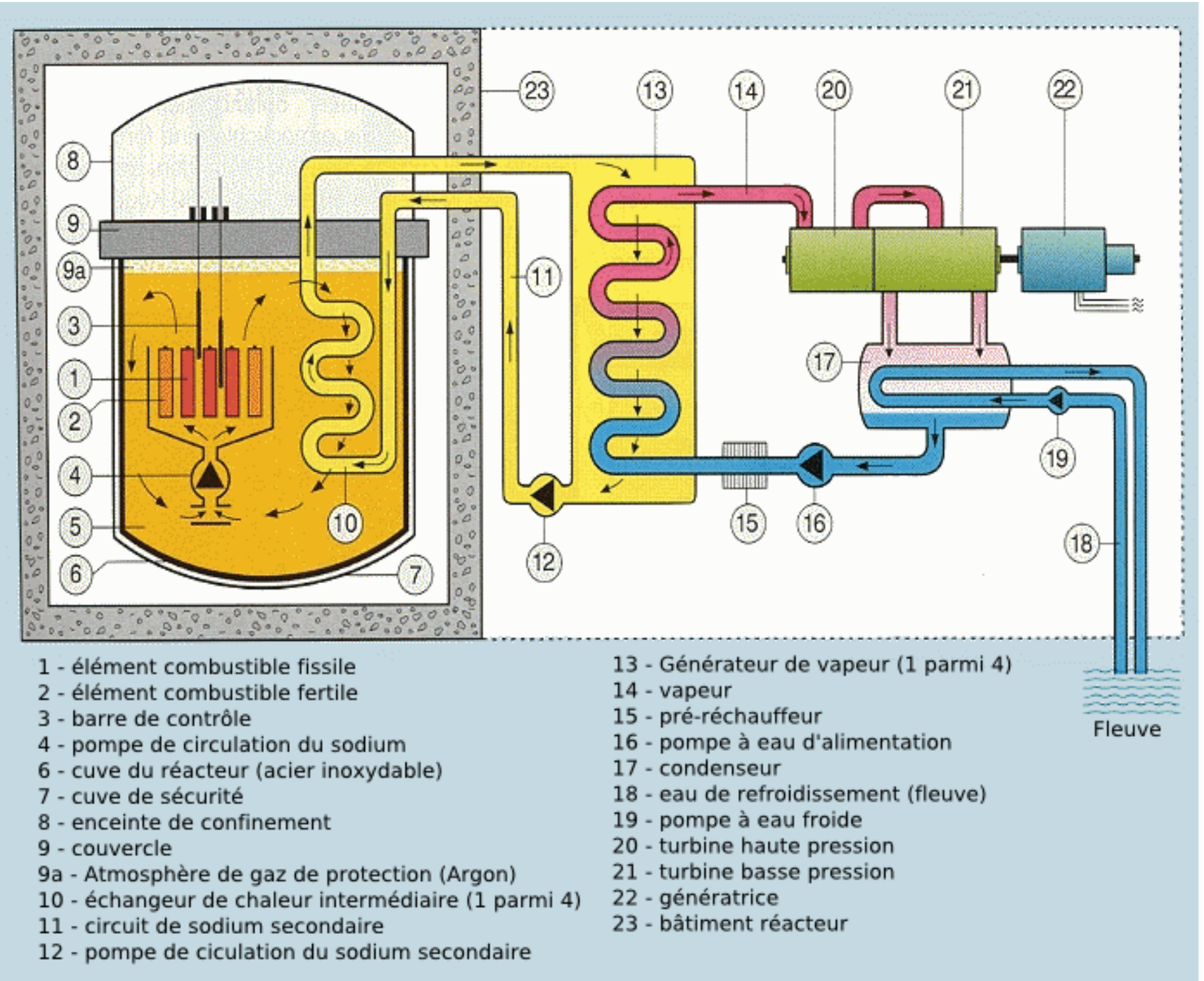




\section{Super Phenix Plant Plan View}

\section{plan view}

section at 22.50 level

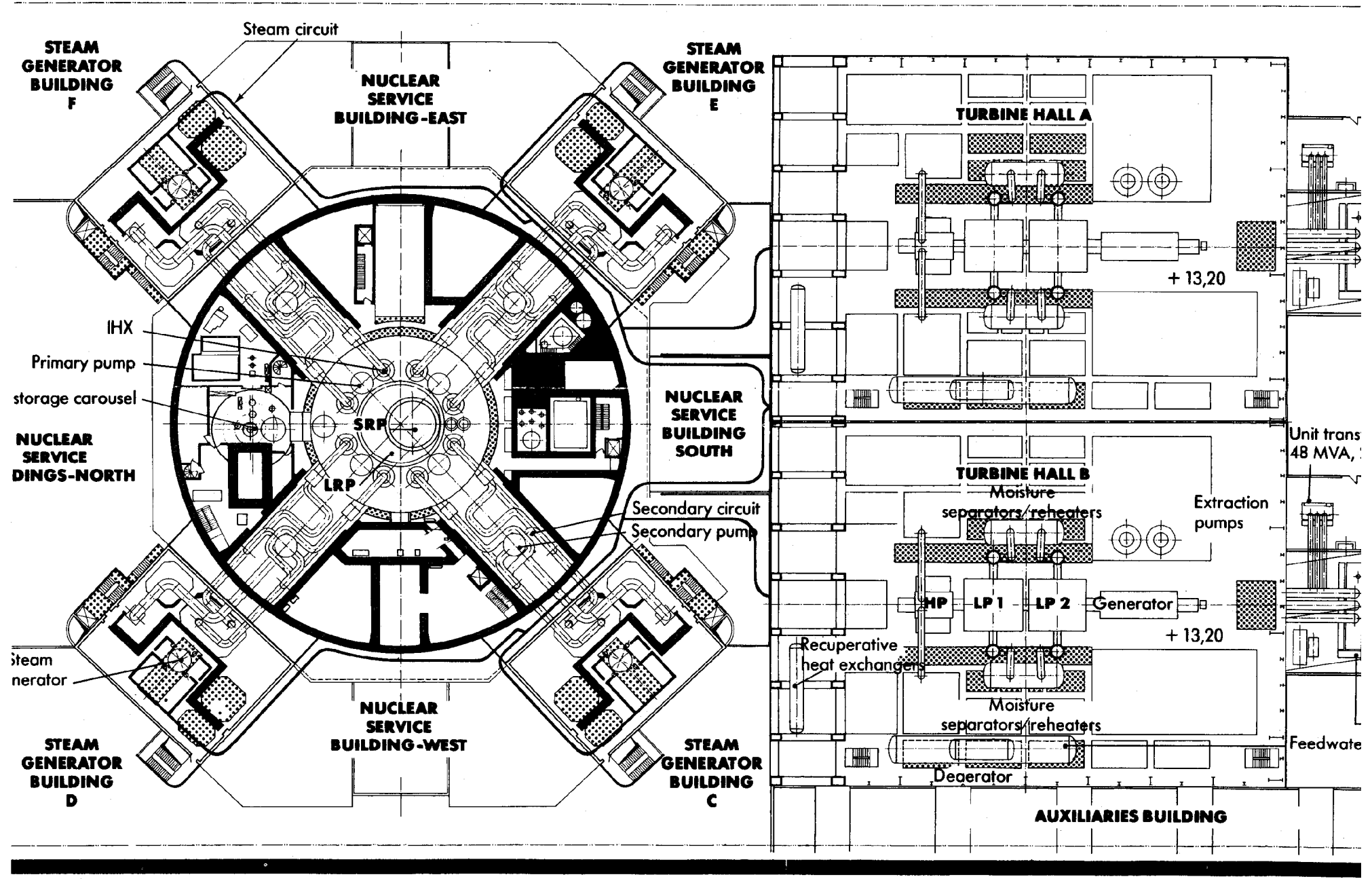

\section{Argonne}




\section{Super Phenix Plant Elevation View}

\section{longitudinal cross section}

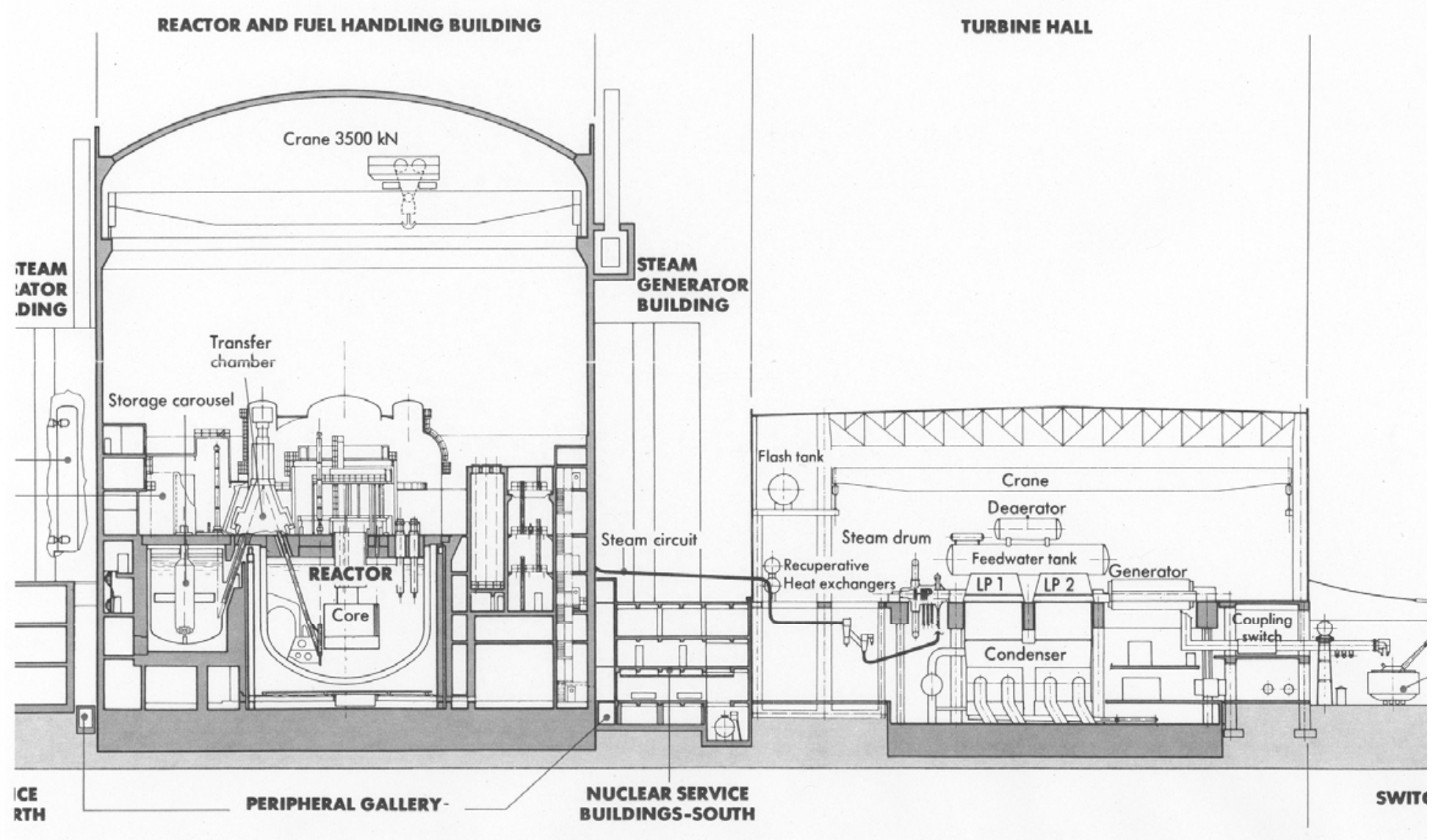




\section{Fuel Storage Tank Detail}

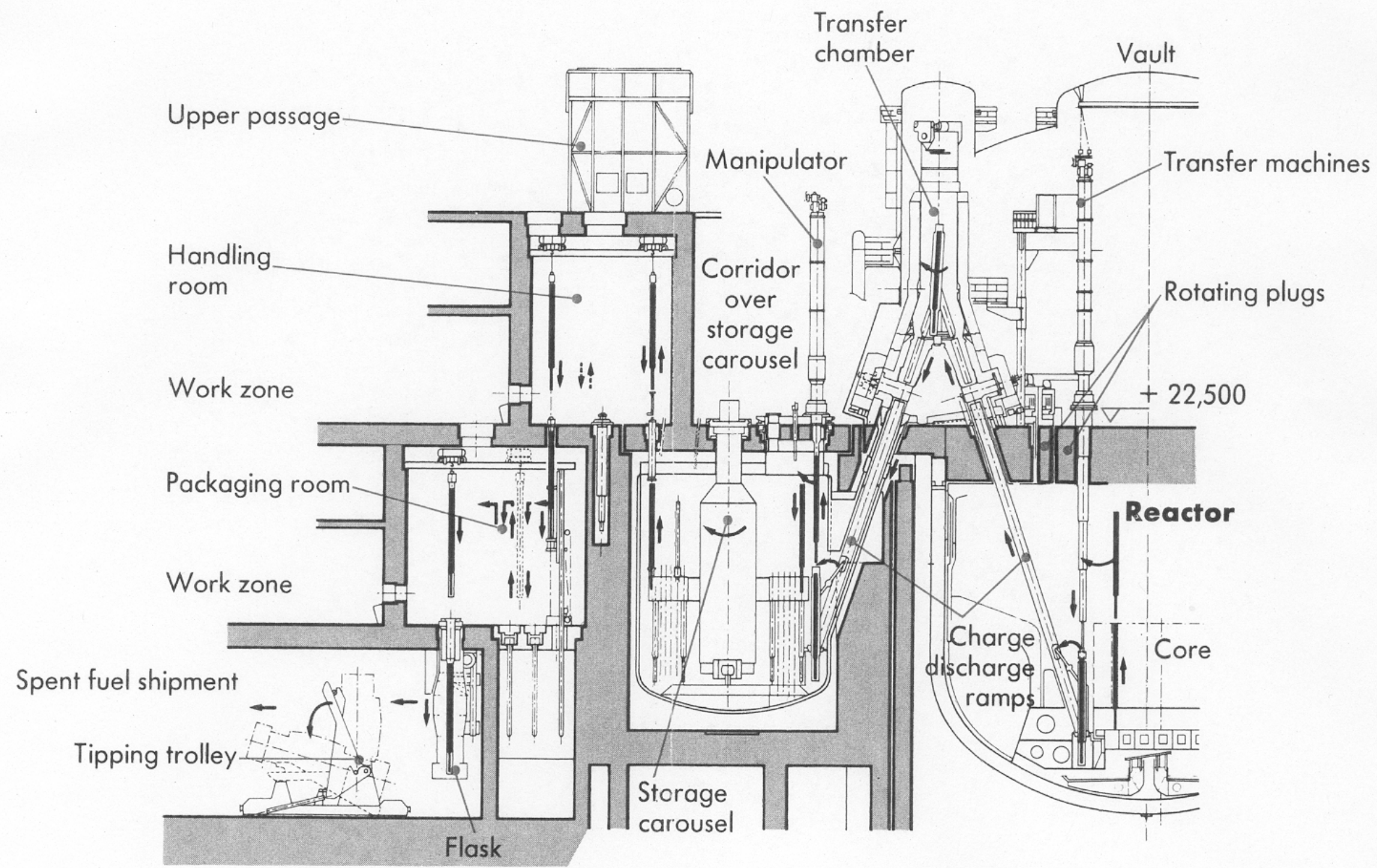




\section{Fuel Storage Tank During Construction}

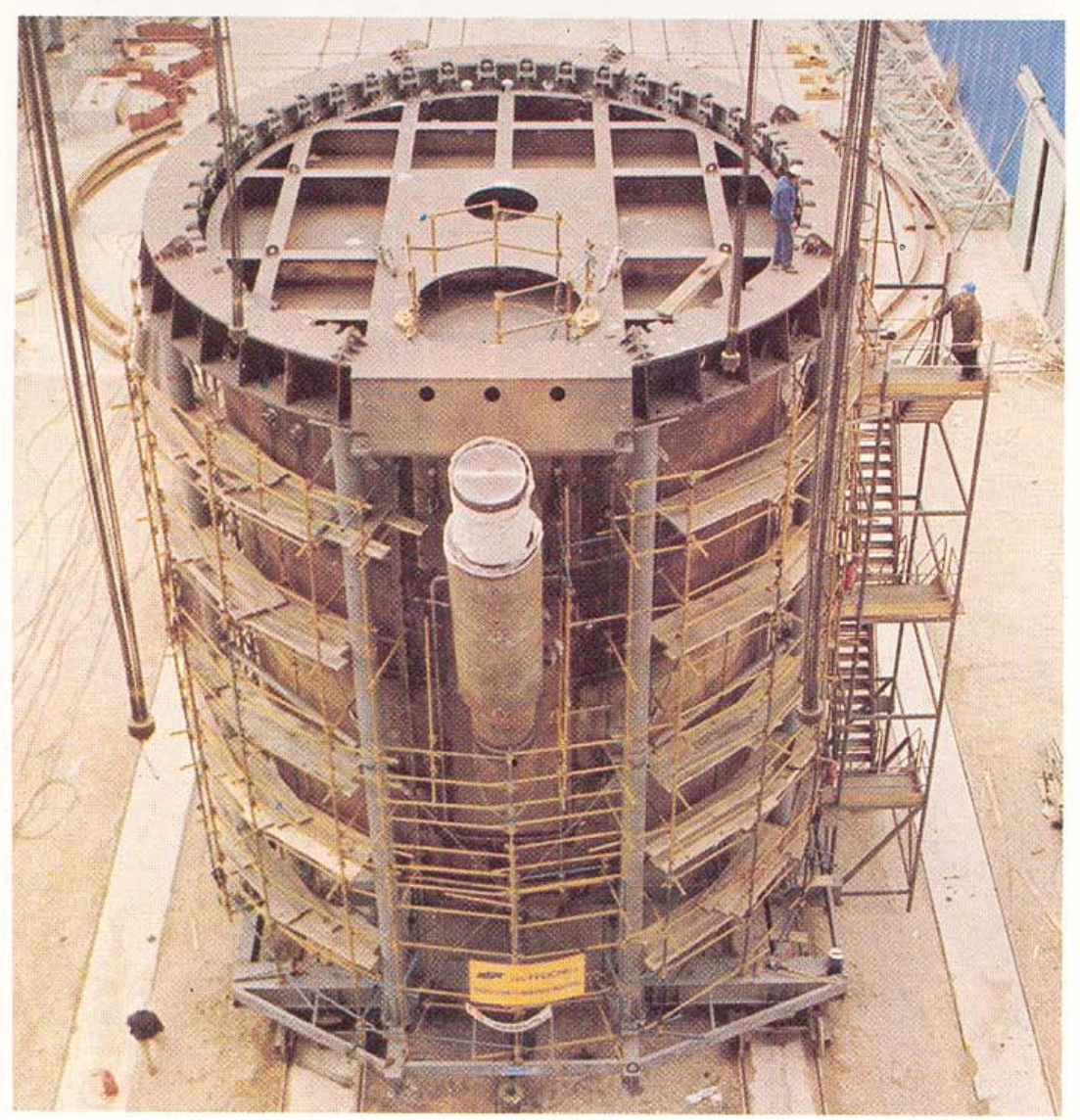

April 26th, 1980: Storage drum being placed in the reactor building.

This photo has been taken from the sloping handling ramp. The criss-cross girdering of the vessel roofs can be seen and the system for connecting this roof to the hoop anchored in the main structure: 42 slings fixed to the roof flanges and the hoop supports. 


\section{Inside the Fuel Storage Tank During Fabrication}

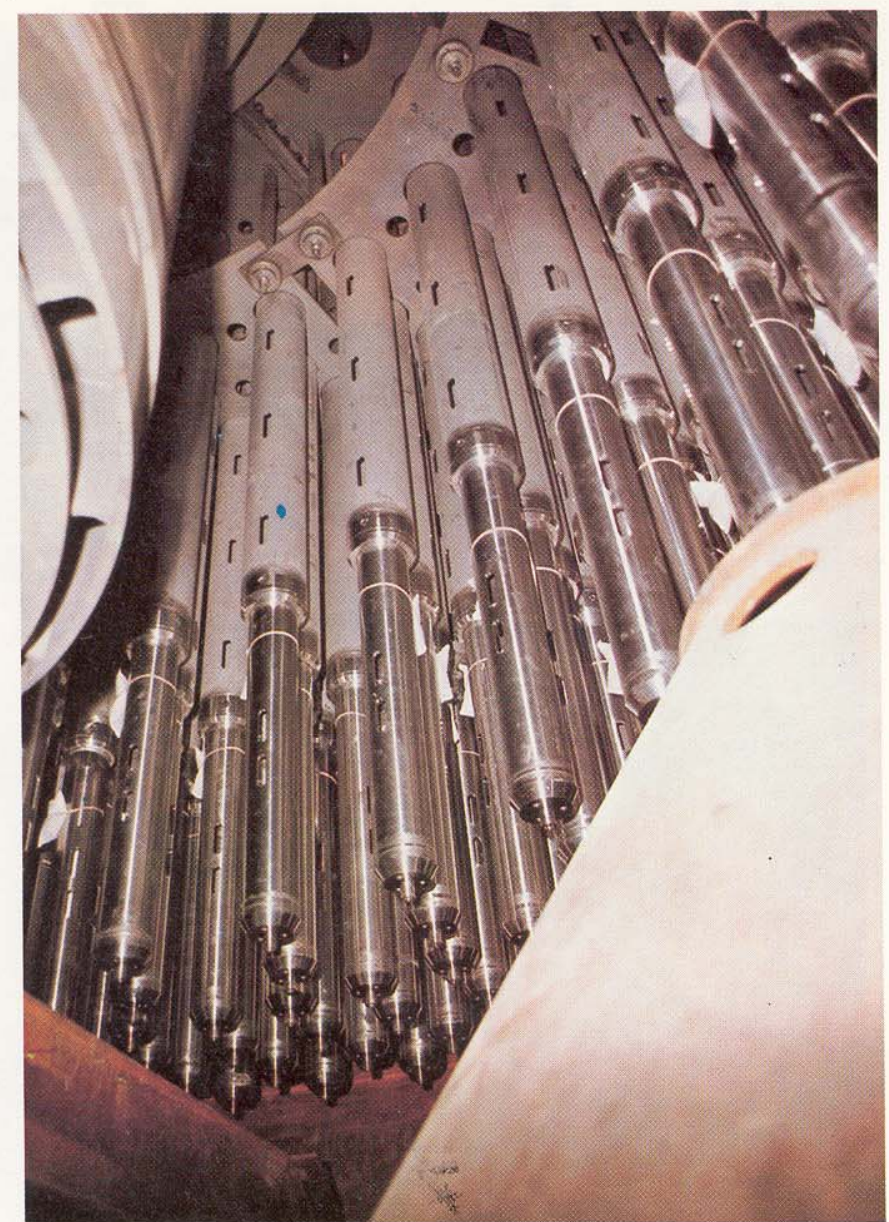

Creys-Malville: Inside the lower part of the storage drum.

Penetrating the diagrid bottom plate are the lower parts of the thimbles into which the fuel elements will be placed. Note the holes for the circulation of sodium.

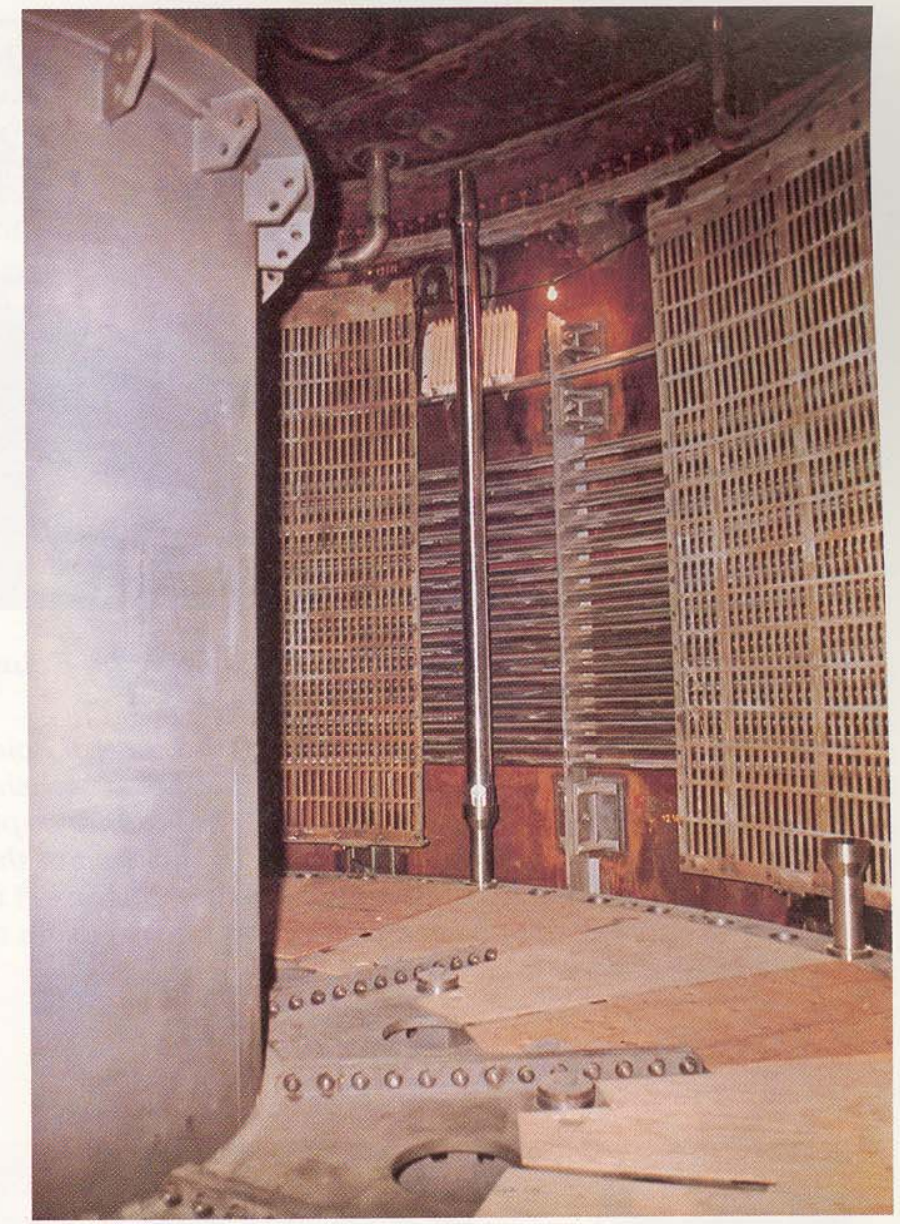

Creys-Malville: Storage drum during assembly viewed from the inside.

Left: the axis of the diagrid carousel. Its upper plate is covered with hardboard sheets to facilitate movement during assembly. Right: note the cooling system tubes (sodium-sodium exchange) behind their protective grids. 


\section{Fuel Storage Tank Leak Location}

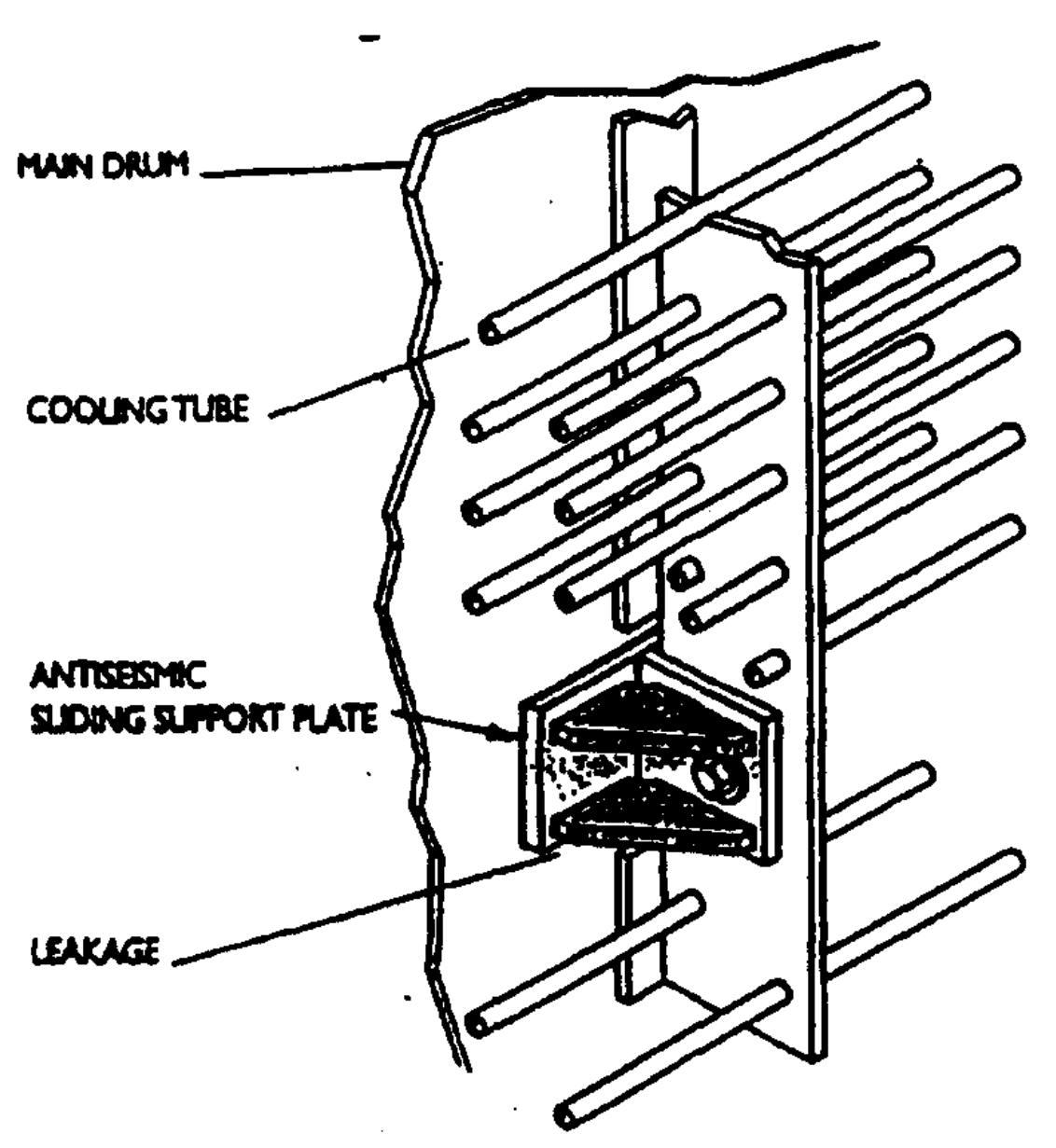

F1G. 2.21. Super-phenix fuel storage drum leak localization. 


\section{Super Phenix Fuel Storage Tank Leak}

- Leak caused by a horizontal crack $\sim 60 \mathrm{~cm}$ long on the lower welding bead of a cooling system support plate

- Investigation showed cracks at other locations as well; other support plates and tank wall weld beads

- The "most probable scenario" causing the crack was identified as "the nature of the drum steel (ferritic 15 D3) and the simultaneous presence of three factors: the existence of start (sic) sites (micro-cracking) in zones of high hardness, residual stresses close to the elastic limit of the material, and lastly, the contributions of hydrogen which allowed the brittling phenomena to occur."

- It is customary to use austenitic stainless steel in contact with liquid sodium at high temperatures (reactor vessels and pipes)

- Lesson learned: Select the correct material for high temperature sodium service 


\section{MONJU}

$714 \mathrm{MWt}, 280 \mathrm{MWe}$ power station located $12 \mathrm{~km}$ NE of Tsuruga, Japan

- Criticality 1994, full power 1995

- $93 \mathrm{~cm}$ core height, $420 \mathrm{~cm}$ subassembly height

169 wire-wrapped pins per subassembly

- Number of subassemblies: 108 inner core, 90 outer core, 172 radial blanket, 324 reflector and shield

- On December 8, 1995; sodium leak detected in the room housing the "C" secondary loop (non-radioactive sodium) during operation at $43 \%$ power

- High temperature at the IHX outlet and smoke alarm at 19:47

- Reactor shutdown begun at 20:00, manual trip at 21:20

- C loop draining at 22:55, complete at 00:15

- Inspection confirmed sodium leak at thermocouple well; $\sim 1 \mathrm{~m}^{3}$ mound of $\mathrm{Na}_{2} \mathrm{O}$ on the steel floor, aerosol on the walls and floor

- Leak caused by failure of a thermocouple well

- Clean-up and repairs were made, but restart was delayed by legal actions, court decisions, appeals, safety reviews, etc.

- Restart scheduled for 2008 


\section{MONJU Site}

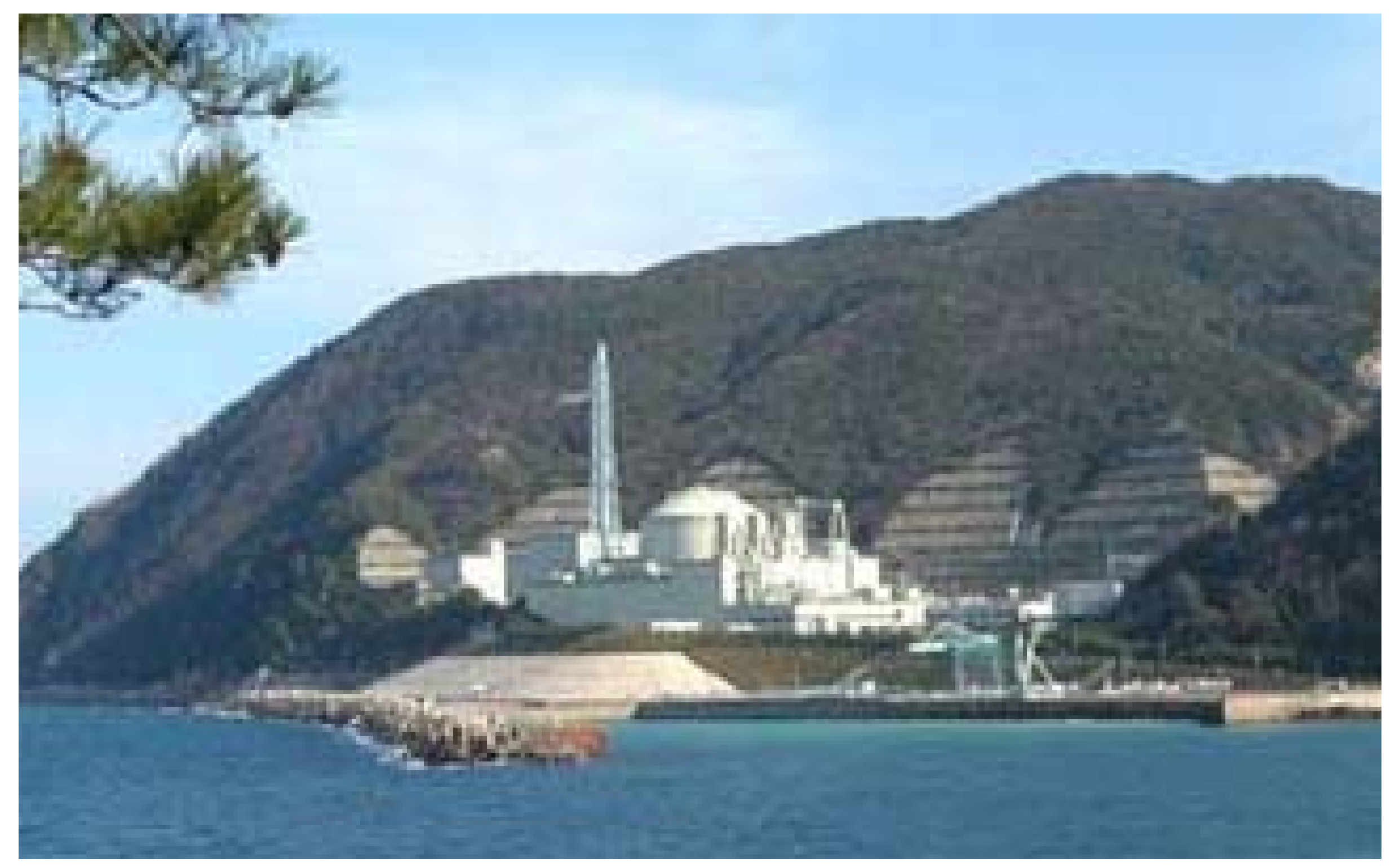

\section{Argonne}




\section{MONJU Flow Diagram}

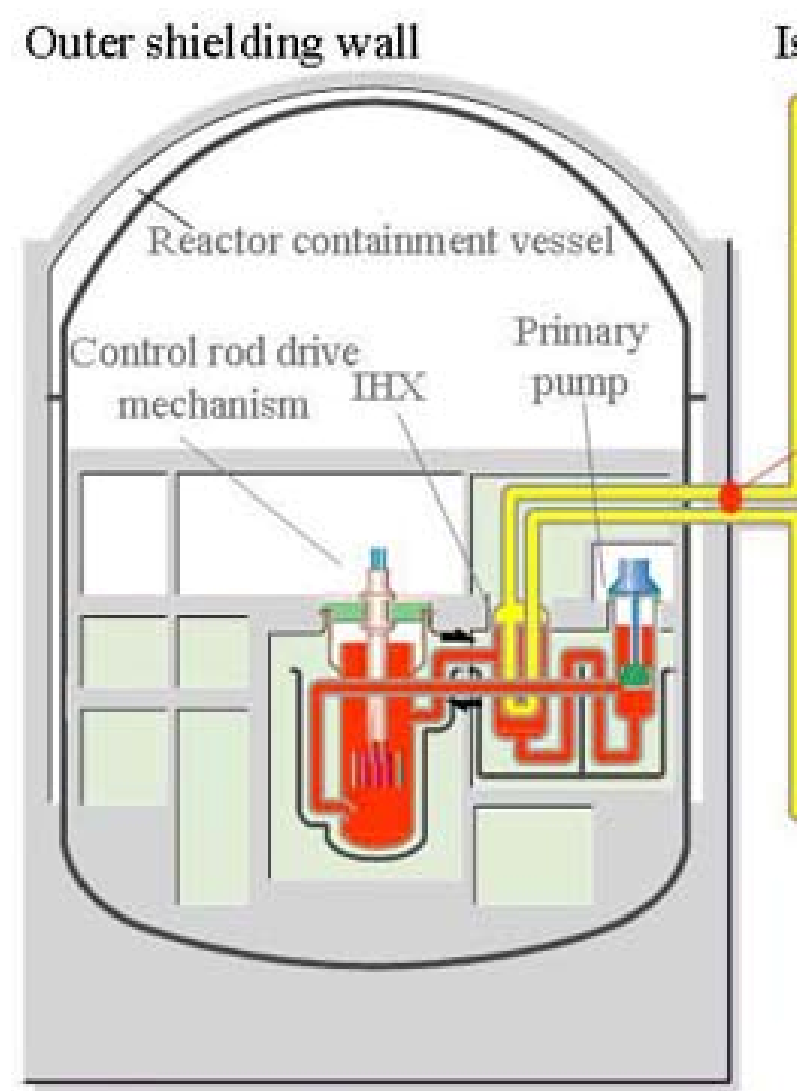

Primary cooling system (Sodium)
Isolation valve

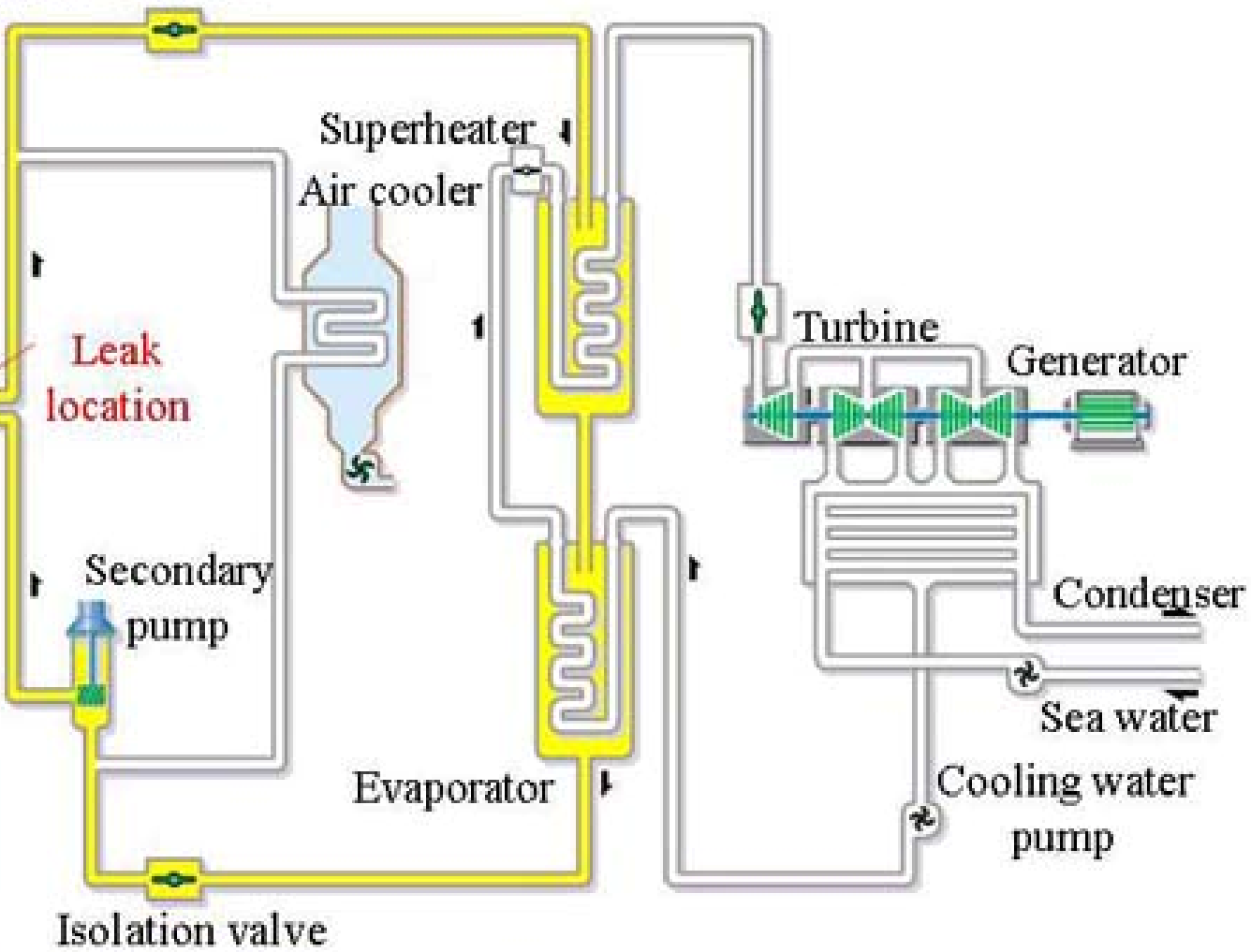

Secondary cooling system (Sodium)
Water \& steam system 


\section{MONJU Reactor Vessel and Core}

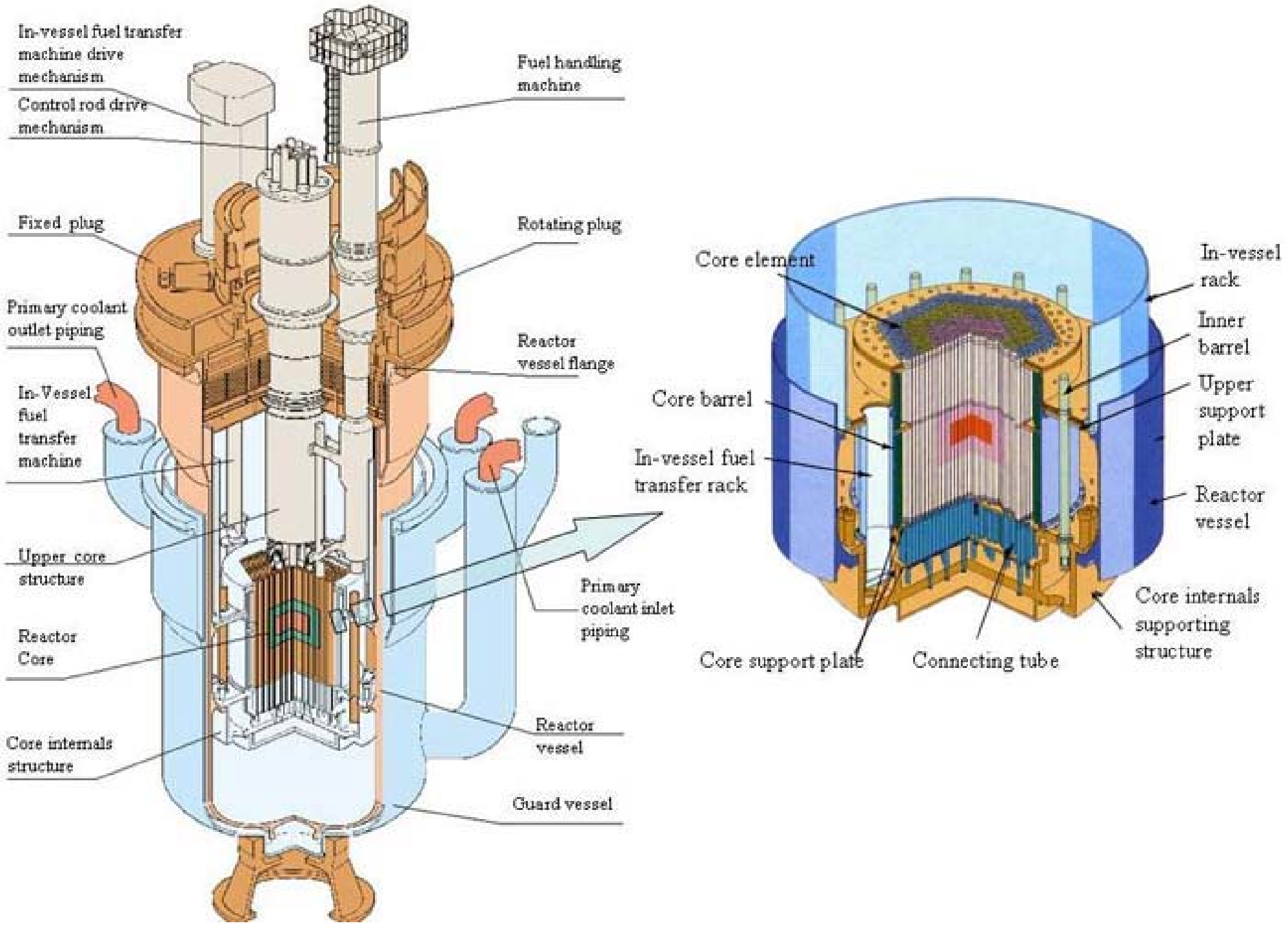


MONJU Coolant Systems

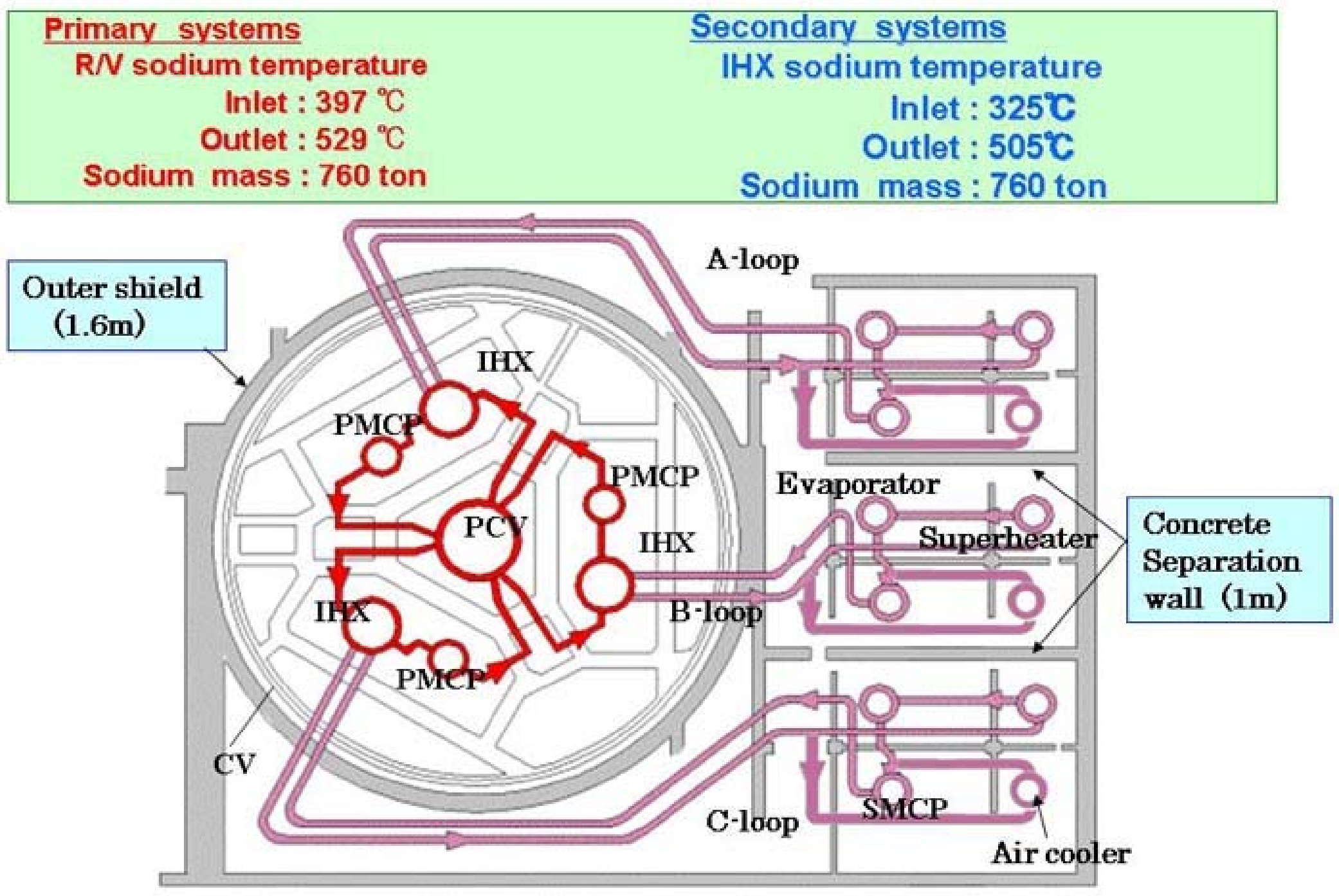




\section{MONJU Secondary Sodium Leak Location on C Loop}

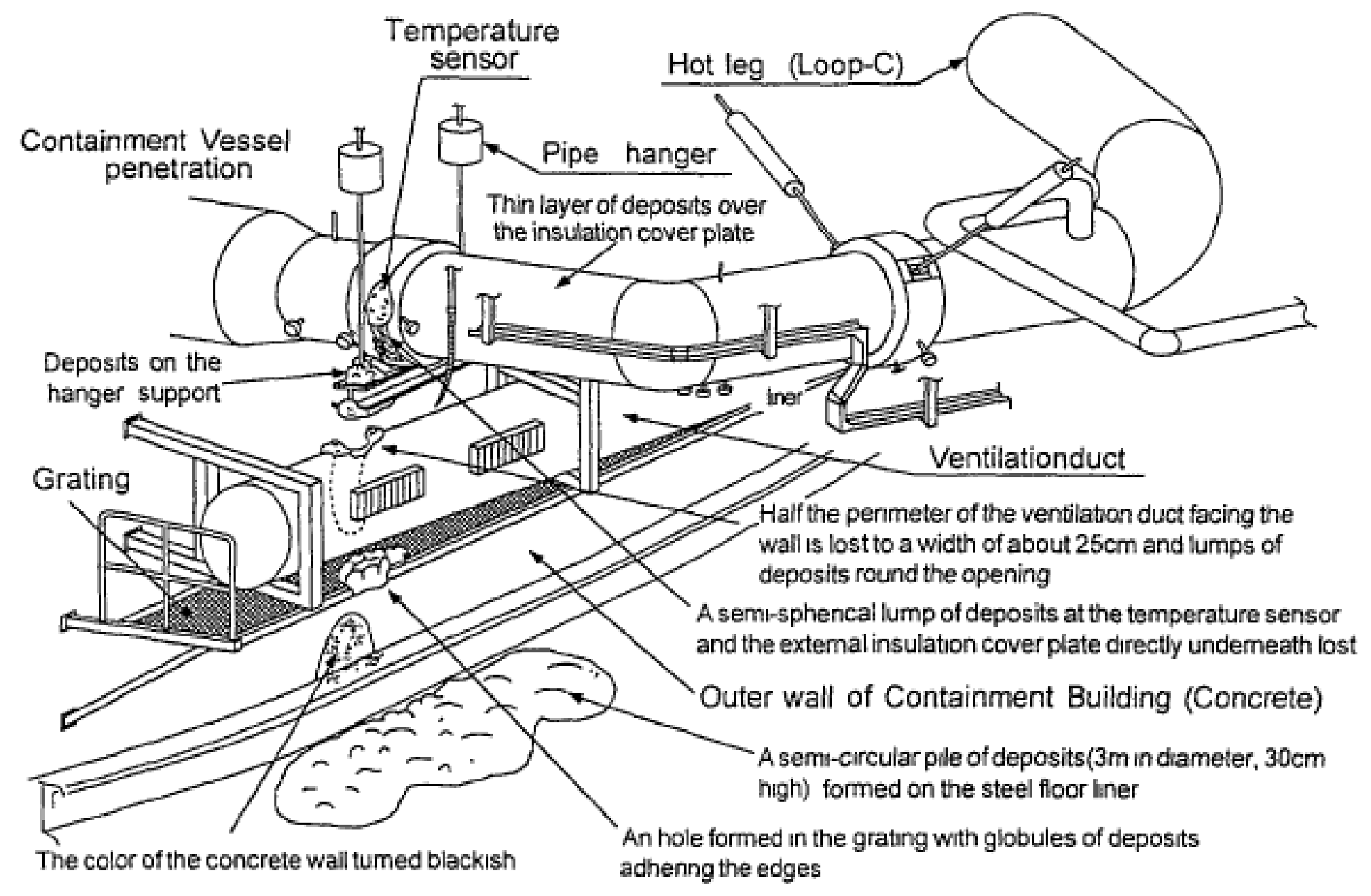

Fig. 2. Sketch of the affected area. 


\section{Original Secondary Circuit Thermocouple}

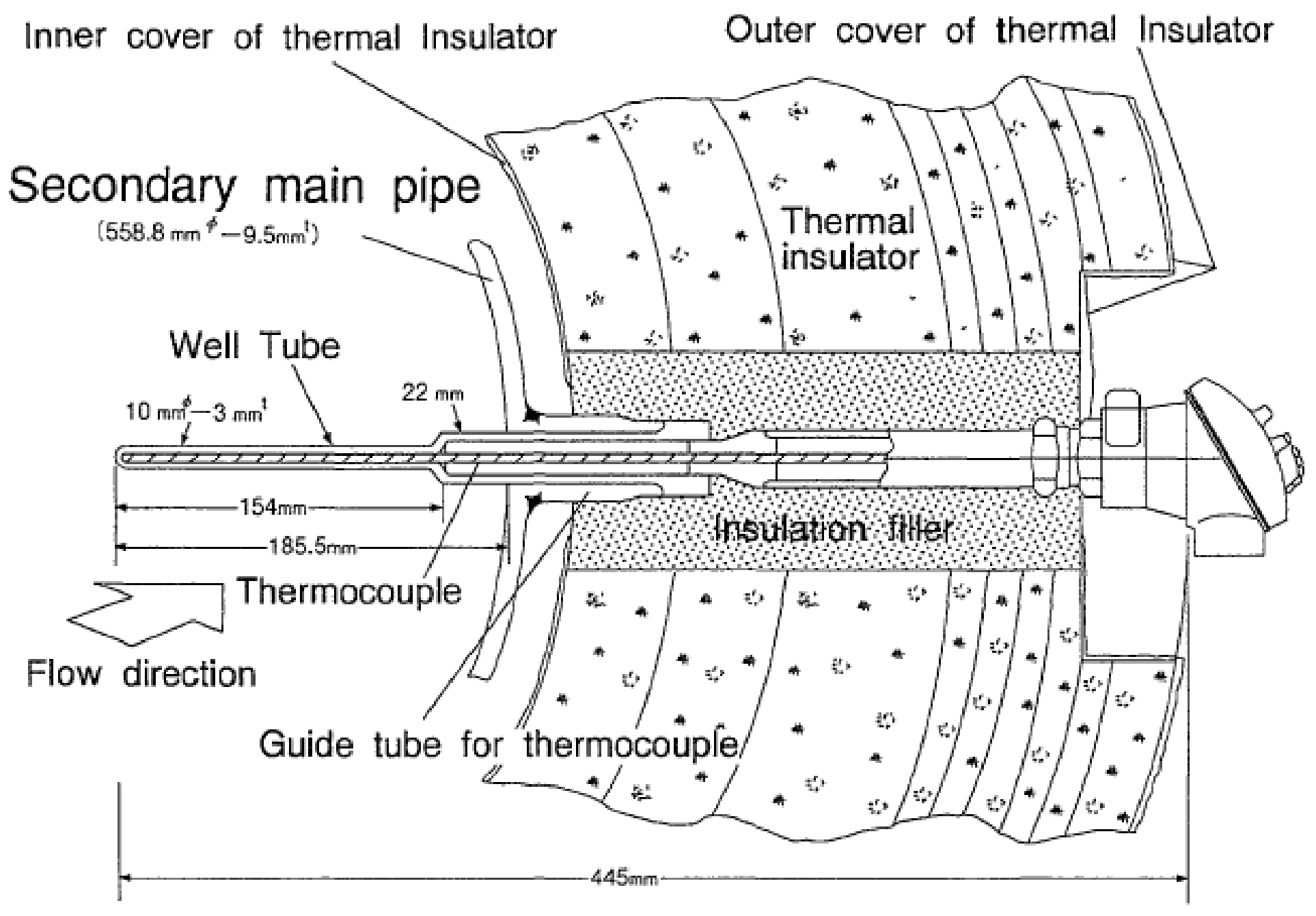

Fig. 3. The thermocouple well of the secondary circuit. 


\section{Damaged Secondary Circuit Thermocouple}

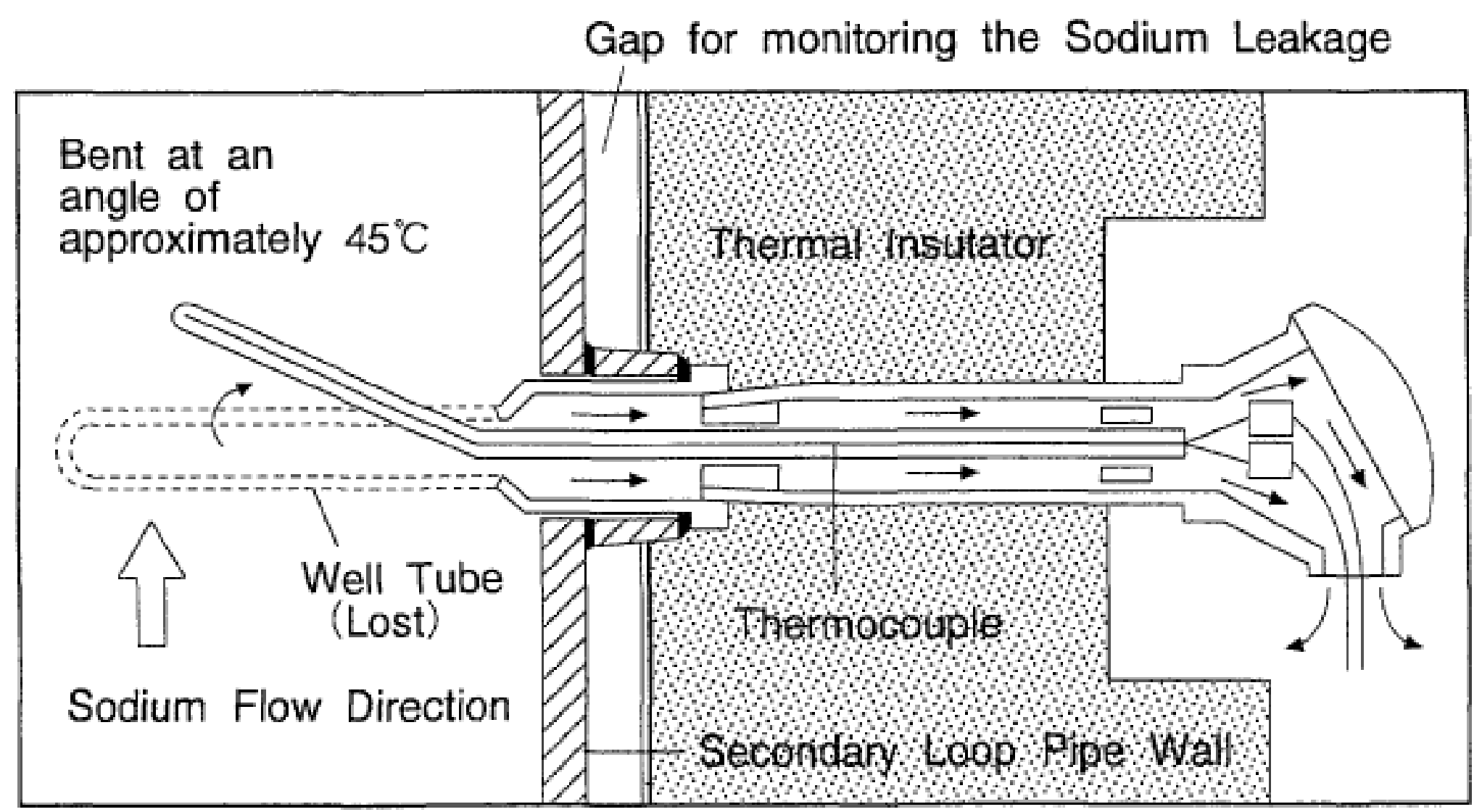

Fig. 4. The sodium leak flow path. 


\section{MONJU Thermocouple Sodium Leak}

n Video: http://www.mext-monju.jp/takuhai/video/monju02.wmv

- Video (6 min., in Japanese) shows post-leak consequences, clean up activities, repairs and remediation measures

- Thermocouple well tip failed due to flow-induced cycle fatigue

- All thermocouples in the secondary loop were replaced 


\section{Thermocouples Replaced on Secondary Circuit}

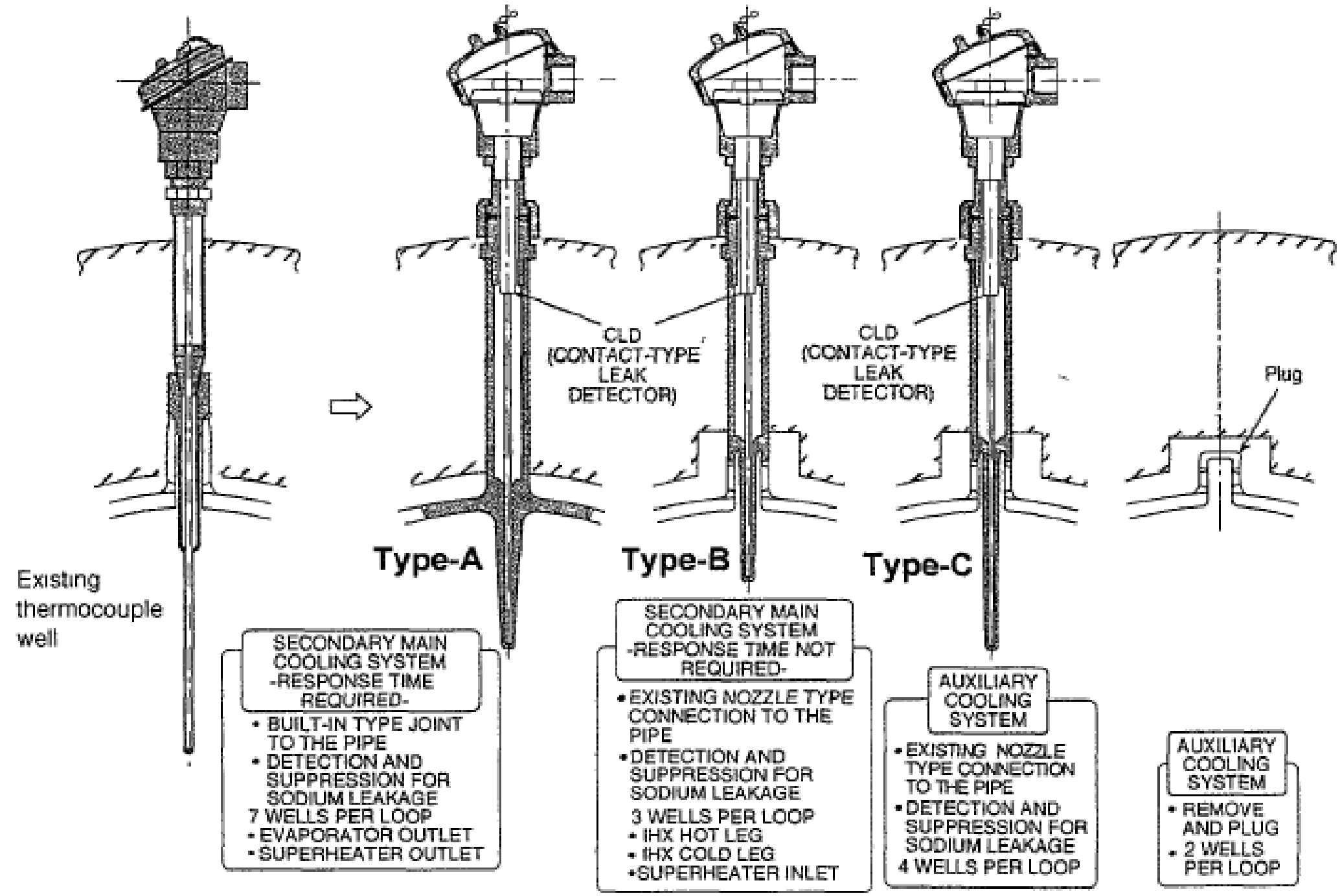

Fig. 7 Modified destgn concepts for the thermocouple wells on the secondary cooling system. 


\section{Countermeasures against Sodium Leakage}

- Replacement of Secondary Thermocouple wells

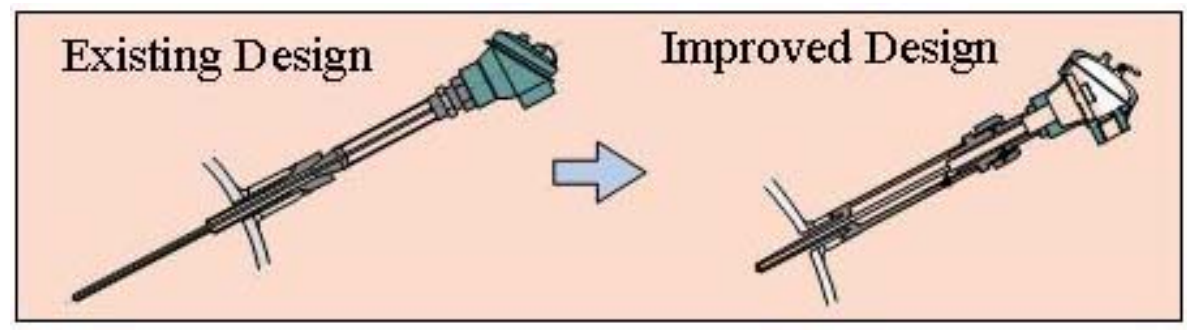

- Leakage Control by Metallic Gasket Type Seal and Welded Seal

- Leakage Detection

- Prevention of Flow-induced Vibration

- Improvement of Facilities

- Improvement of Drain System, Reduction of Drain Time

- Integral Sodium Leakage Monitoring System

- Subdivision of Building / Nitrogen Gas Extinguisher System 
Improvement of Drain System, Reduction of Drain Time

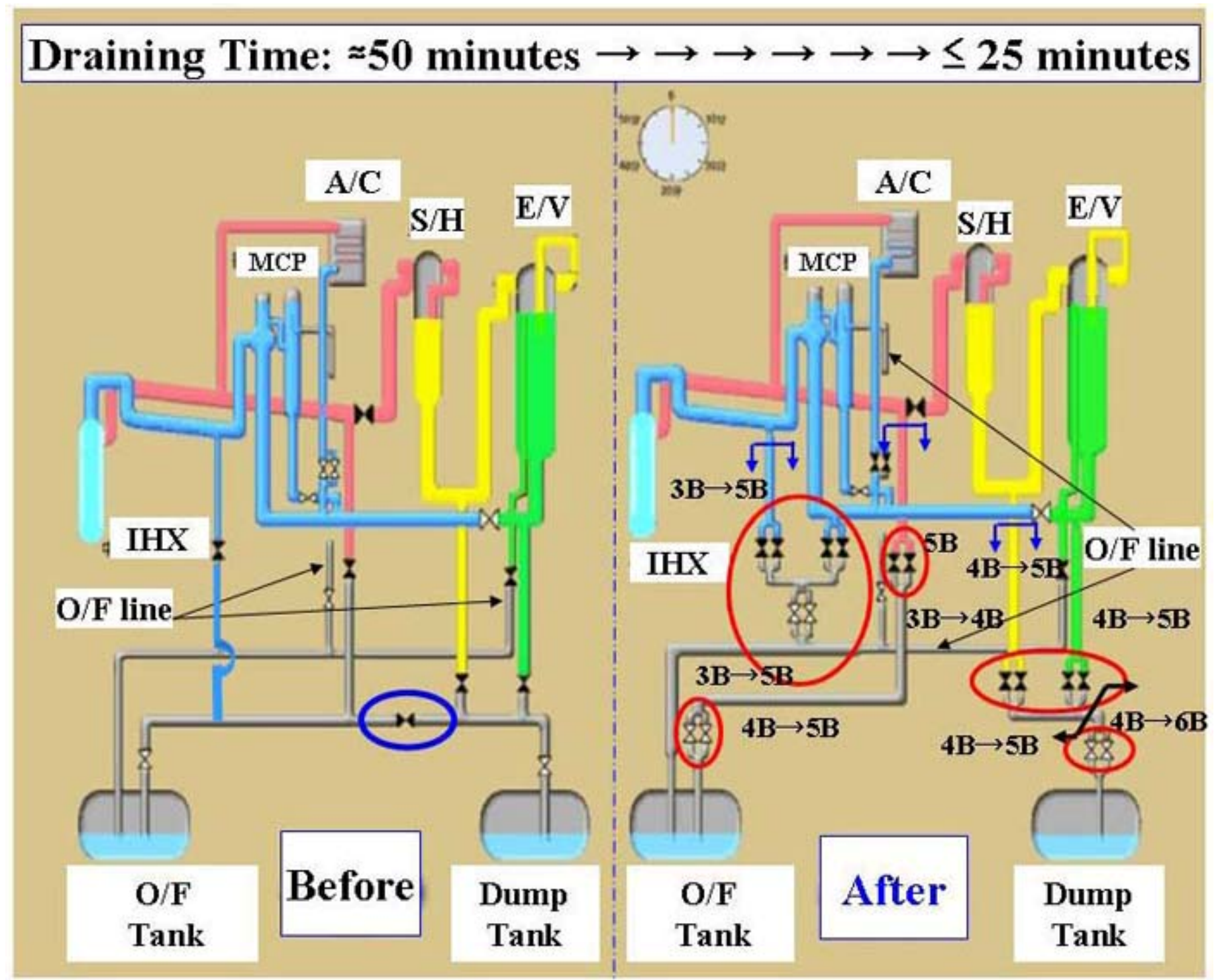




\section{Integrated Sodium Leakage Monitoring System}

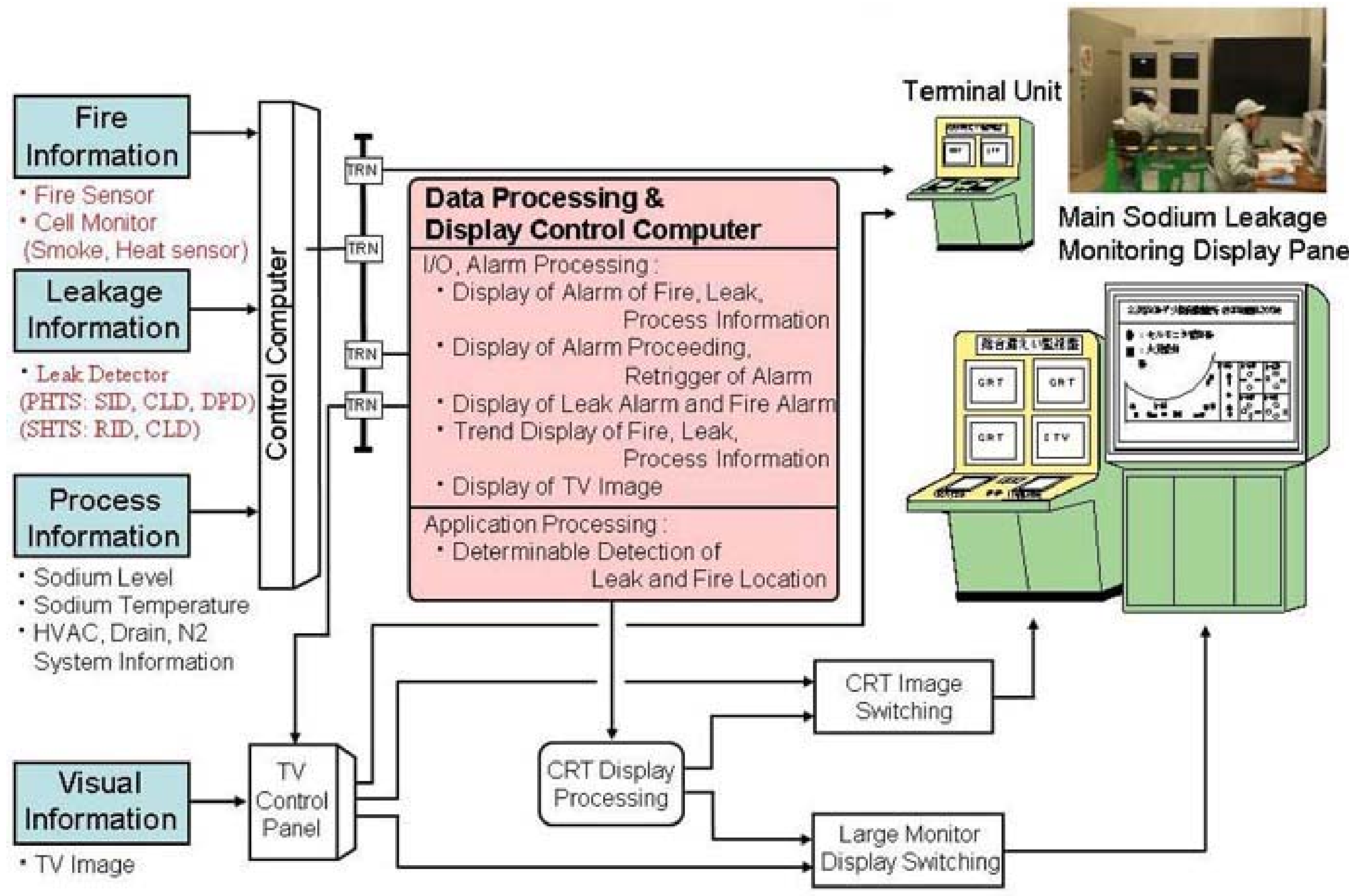




\section{Installation of Nitrogen Gas Injection System}

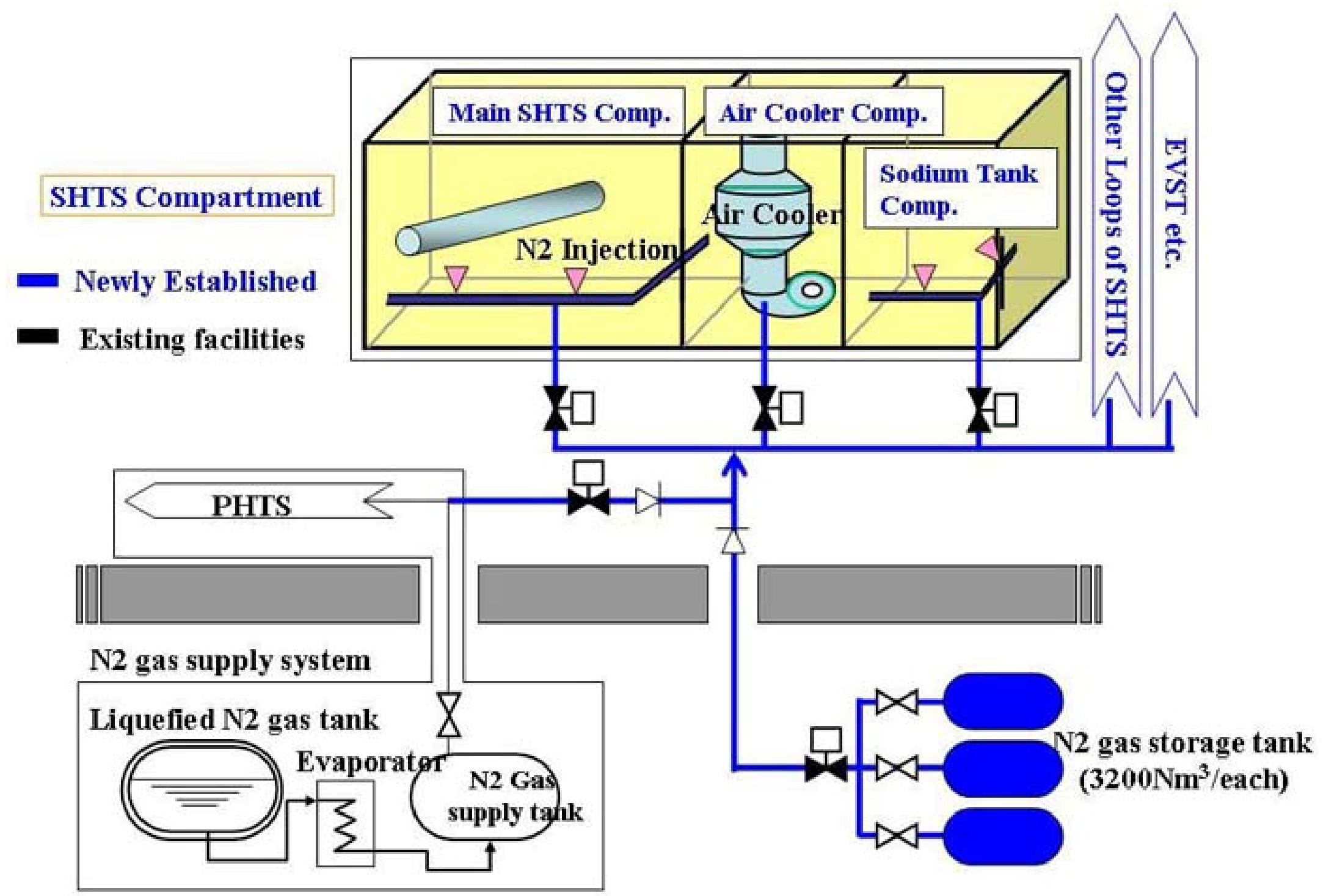




\section{MONJU Sodium Leak and Lessons Learned}

- Event had no radiological consequences, no injuries, no environmental harm

- Post-event information management, legal action, license review

- Technical lessons

- Faulty thermocouple well design; inadequate prototype testing, lack of backup leak prevention

- Some experts question need for pipe penetrations 


\section{Safety Testing Results}

n EBR-II Shutdown Heat Removal Tests

- FFTF Inherent Safety Tests: Unprotected Loss-Of-Flow with GEMS 


\section{EBR-II Shutdown Heat Removal Test (SHRT) Program}

- Thermal-hydraulic testing at EBR-II began to support safe and reliable operation of EBR-II, but evolved to become a broader program to support design and performance assessment for advanced liquid metal reactors

- Early testing (1974) focused on steady-state fission and decay heat removal by natural circulation, and pioneered the use of specially instrumented fuel subassembly (XX07) for flow and temperature measurements

- Subsequent tests examined the transition from forced to natural circulation with updated instrumentation (XX08), from a variety of initial conditions

- Ex: Primary and secondary pump trips with scram from hot standby

- Smooth, benign transitions to natural circulation

- The SHRT program employed new instrumentation (XX09) and extended the test matrix to transients from full power, with and without scram

- Culmination: Full scale demonstrations of passive reactor shutdown and natural circulation shutdown heat removal for loss-of-flow and loss-of-heat-sink transients (1986) 


\section{EBR-II Design Overview}

- $62.5 \mathrm{MWt}, 20 \mathrm{MWe}$ power station located at Argonne National LaboratoryWest, Idaho

- Initial mission: Demonstrate fuel breeding and closed cycle operation with reprocessing of metallic fuel

- Following mission fulfillment, shift to irradiation testing of advanced fuels

Dry critical 1961, wet critical 1963, full power 1964, shutdown 1994

- Sodium cooled, $371^{\circ} \mathrm{C}$ inlet, $473^{\circ} \mathrm{C}$ outlet, $47 \mathrm{psig}$

Fuel pins 0.17 in. OD, 13.5 in. core height; metal fuel in SS cladding

- First fuel processed in Fuel Cycle Facility in September 1964; recycled fuel irradiation in April 1965

- Mission oriented to irradiation testing in 1969; supporting FFTF and CRBRP oxide fuel testing and development

- Integral Fast Reactor (IFR) program began in mid 1980's

- Testing and demonstration of high burnup metallic fuels

- Shutdown Heat Removal Test series 1984-86; natural circulation decay heat removal and passive shutdown in ATWS events (unprotected loss-of-flow and loss-of-heat-sink) 
EBR-II Site at Argonne-West

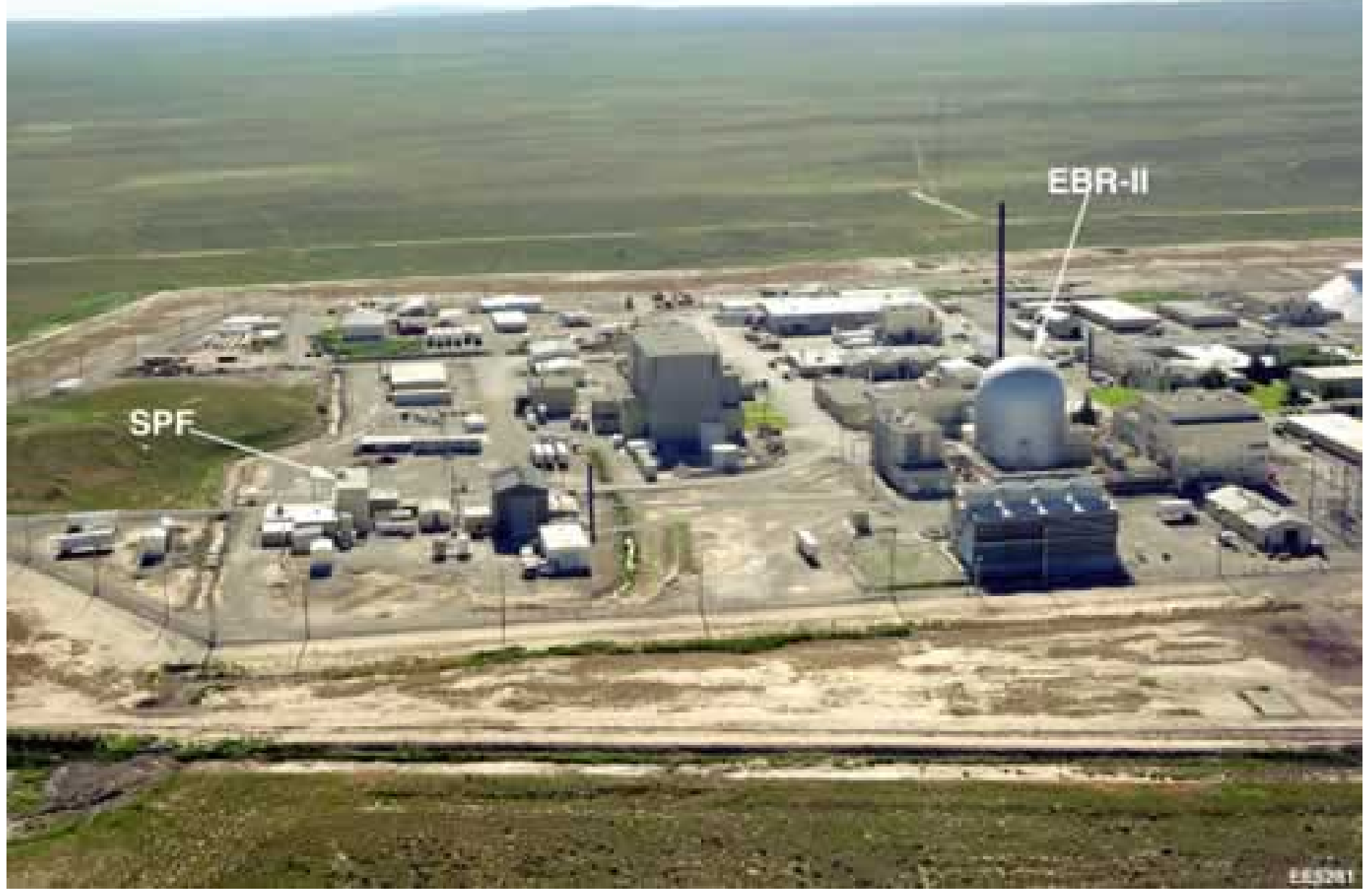

\section{Argonne}




\section{EBR-II Site at Argonne-West}

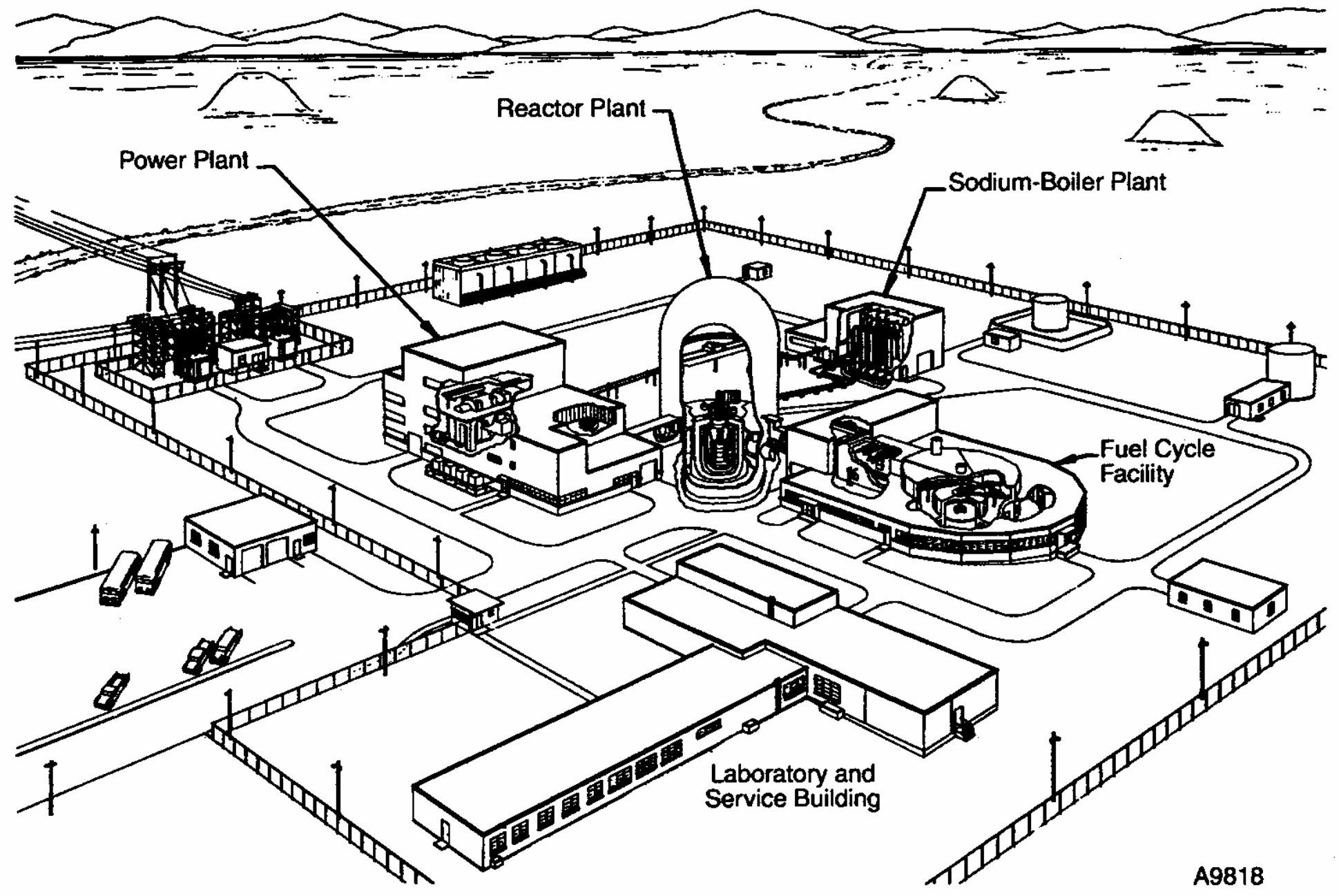




\section{EBR-II Coolant and Power Conversion Systems}

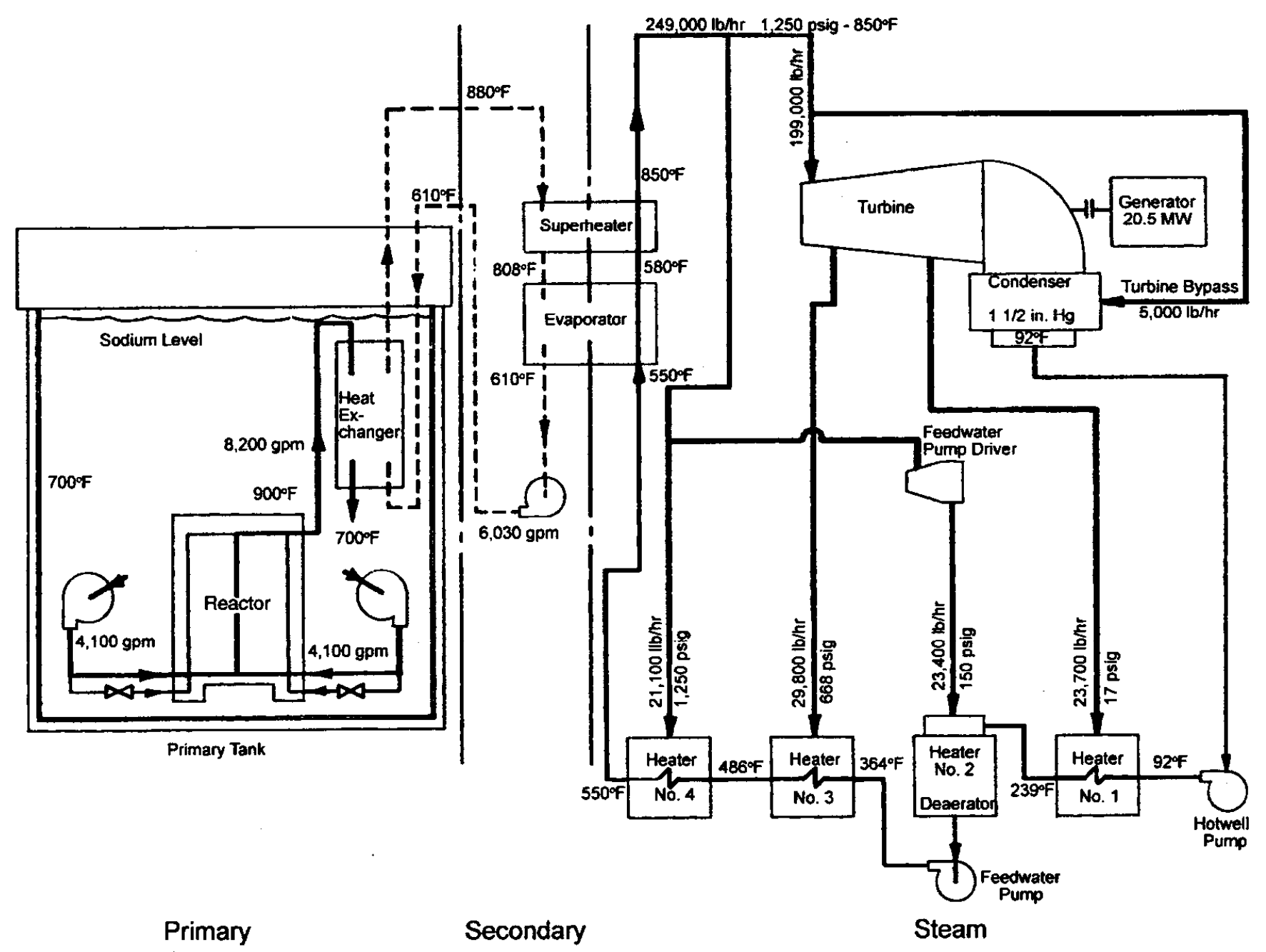




\section{EBR-II Pool-Type Primary System}

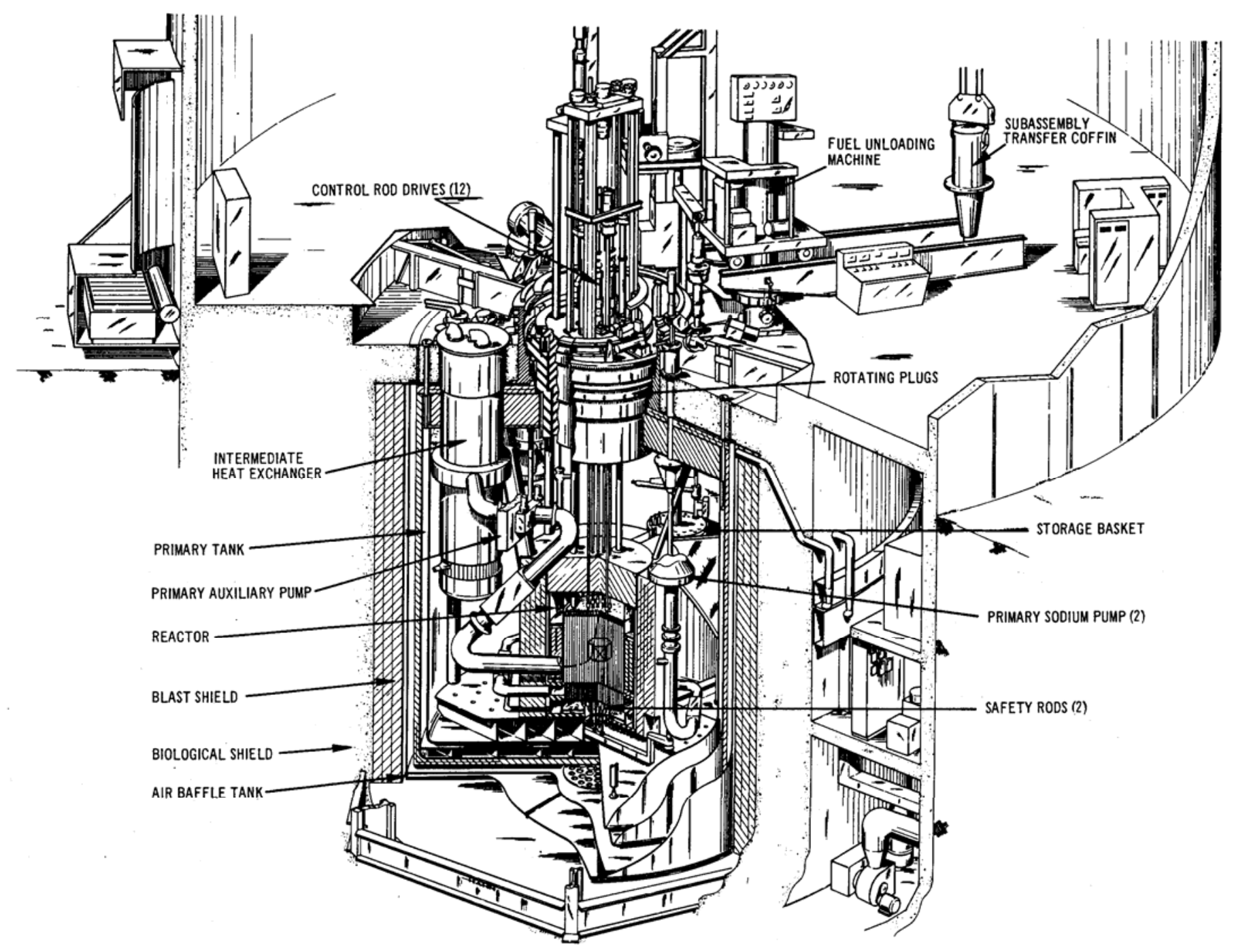




\section{EBR-II Reactor Tank}

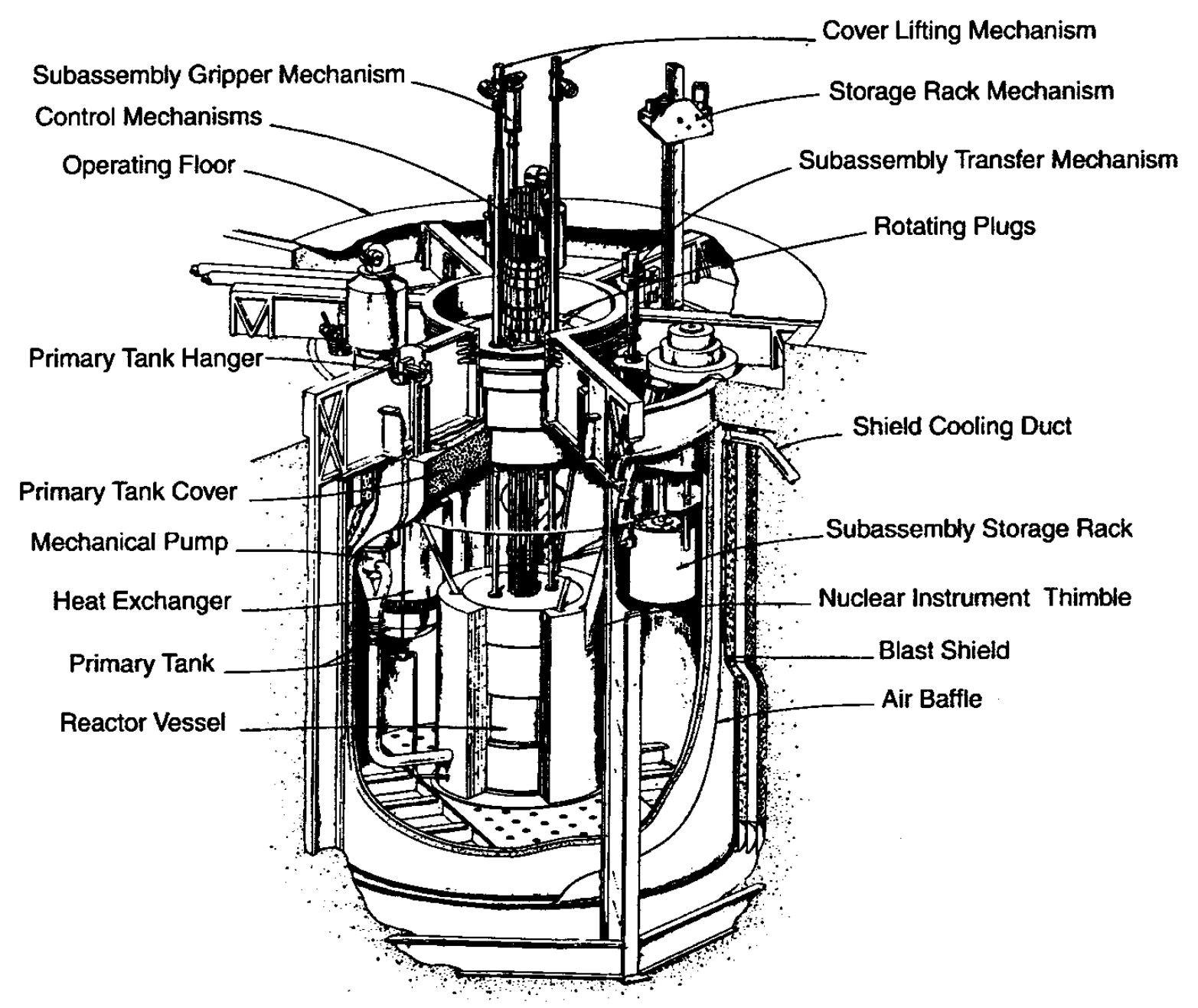




\section{EBR-II Reactor Vessel Assembly}

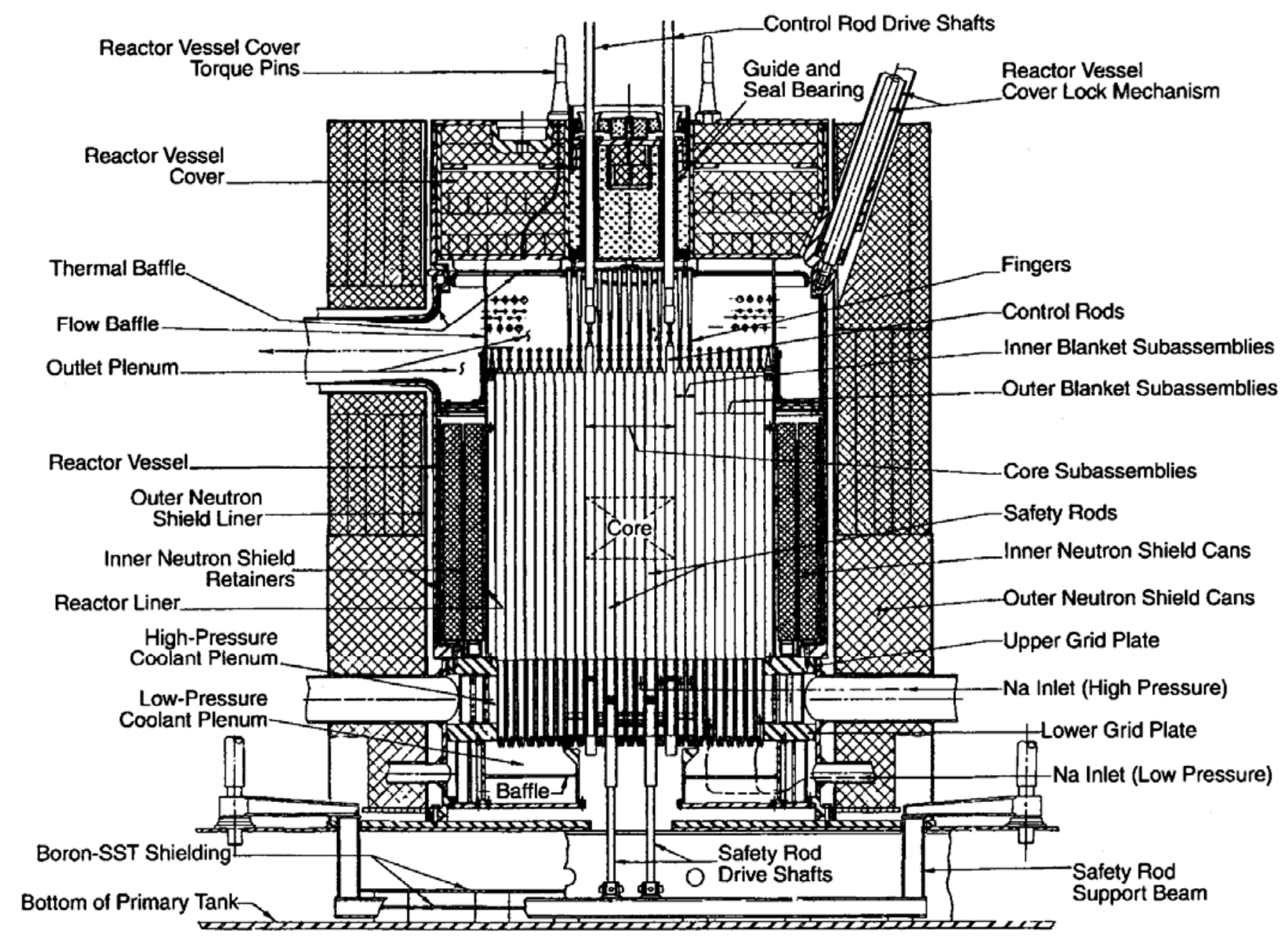




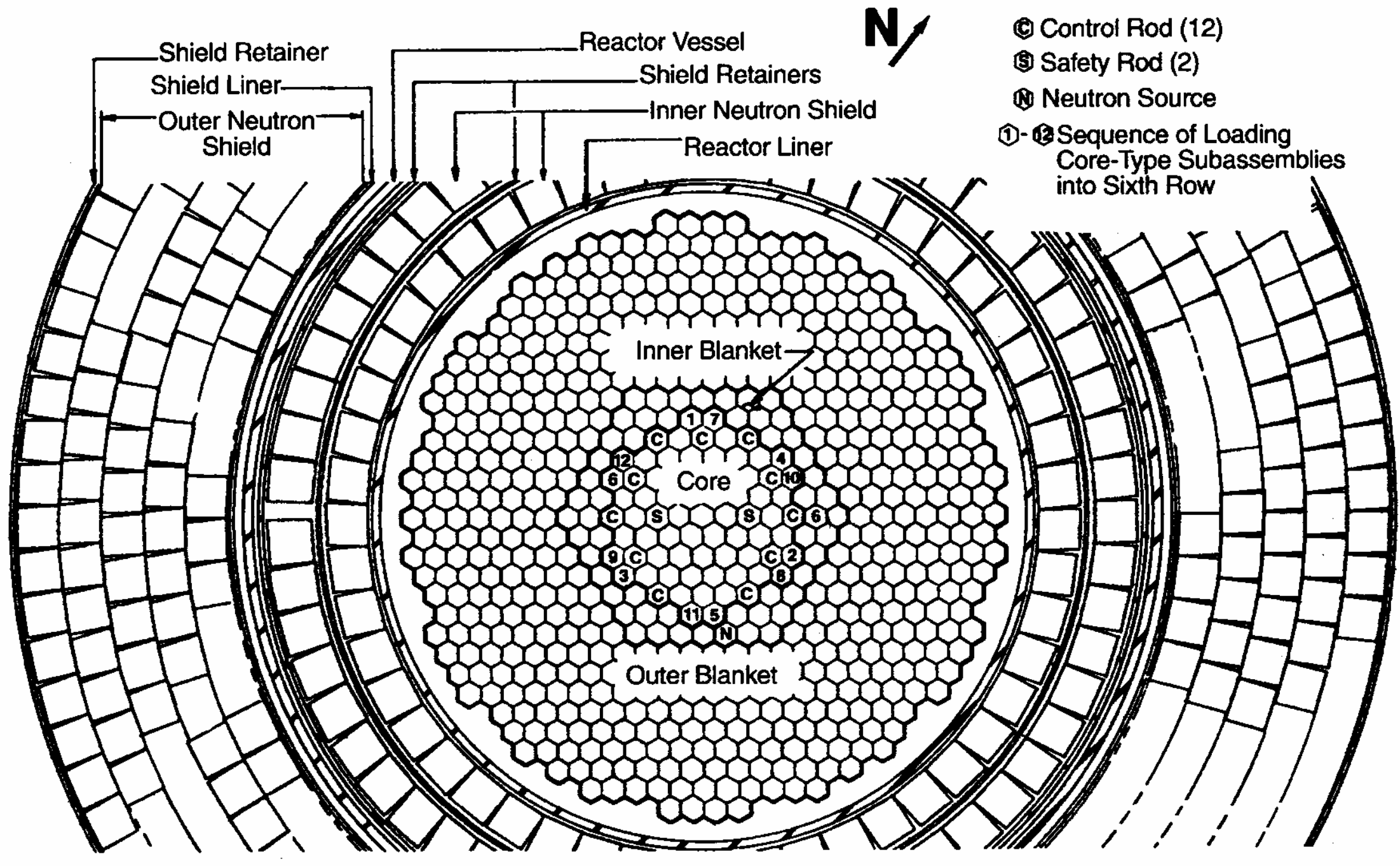




\section{EBR-II Shutdown Heat Removal Tests (SHRT) (1984-1986)}

- A series of tests, originally intended to qualify EBR-II for continued operation, that evolved into an experimental program supporting the safety and design of advanced liquid metal reactors

- Testing ranged from demonstration of natural circulation decay heat removal to whole-plant simulation of unprotected (without scram) loss-offlow (ULOF) and loss-of-heat-sink (ULOHS) accident from full power and flow

- Test results provided data for validation of computer codes used in design and safety analysis of advanced LMRs

- Instrumented subassembly XX09, equipped with calibrated thermocouples and flow meters, provided real-time measurements of coolant temperatures and flow rates during the tests

- The ULOF and ULOHS tests demonstrated the ability of a pool-type, metalfueled LMR to provide self-protection in beyond-design-basis accidents 


\section{XX09 Instrumented Subassembly and Subchannel Model}
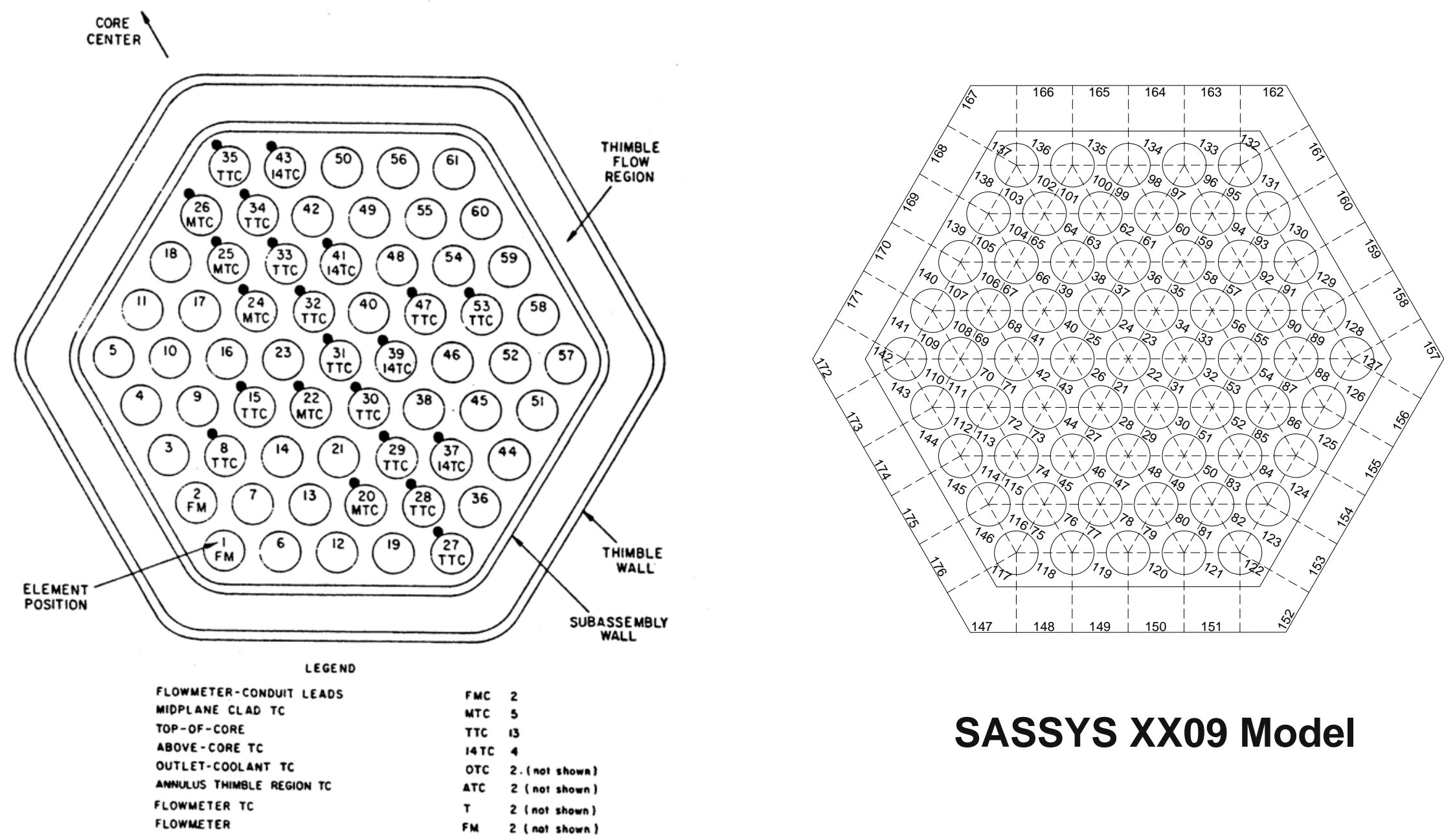

SASSYS XX09 Model

\section{XX09 Thermocouples}




\section{EBR-II Primary Heat Transport System SASSYS Model}

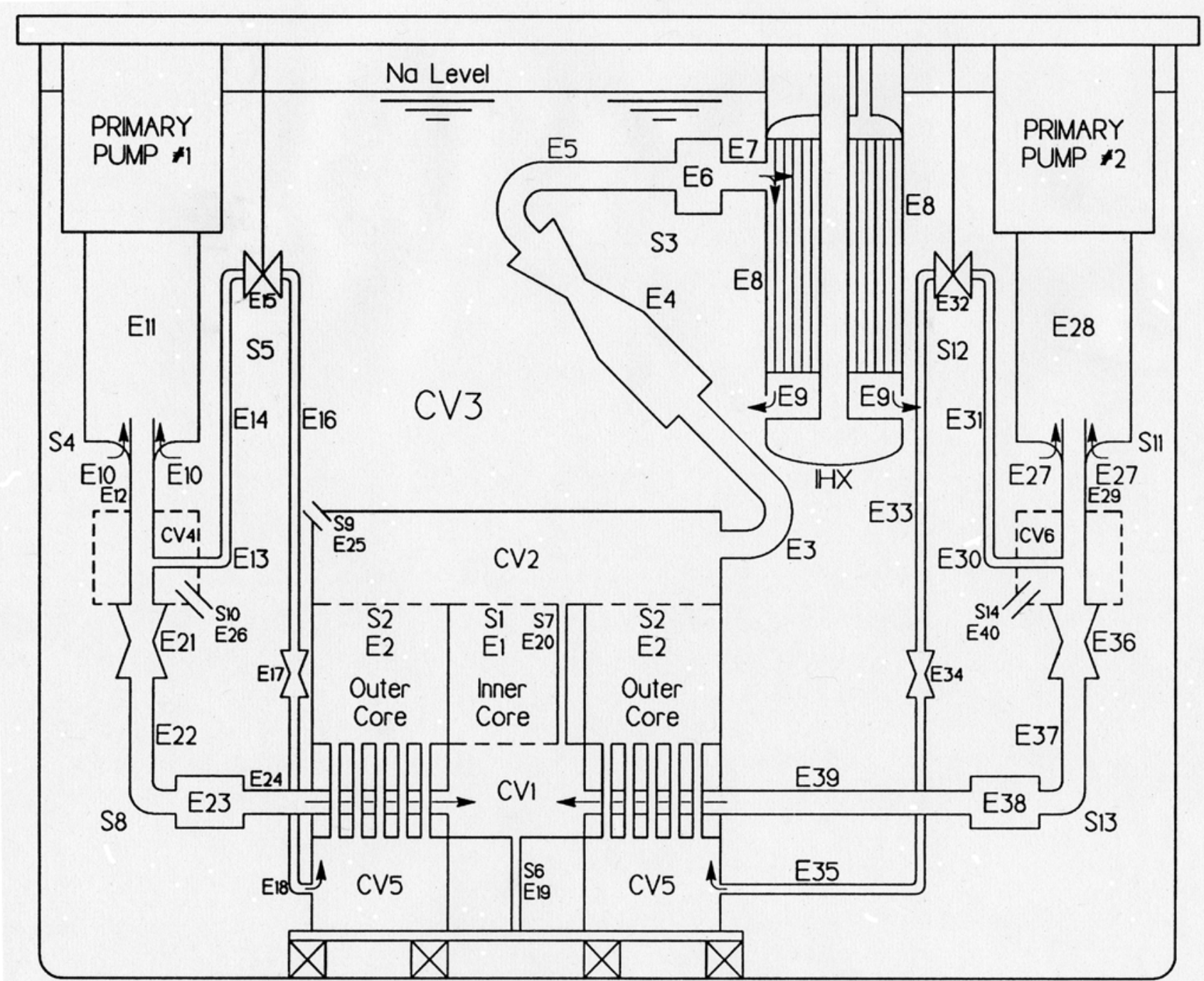


EBR-II Intermediate Heat Transport System SASSYS Model

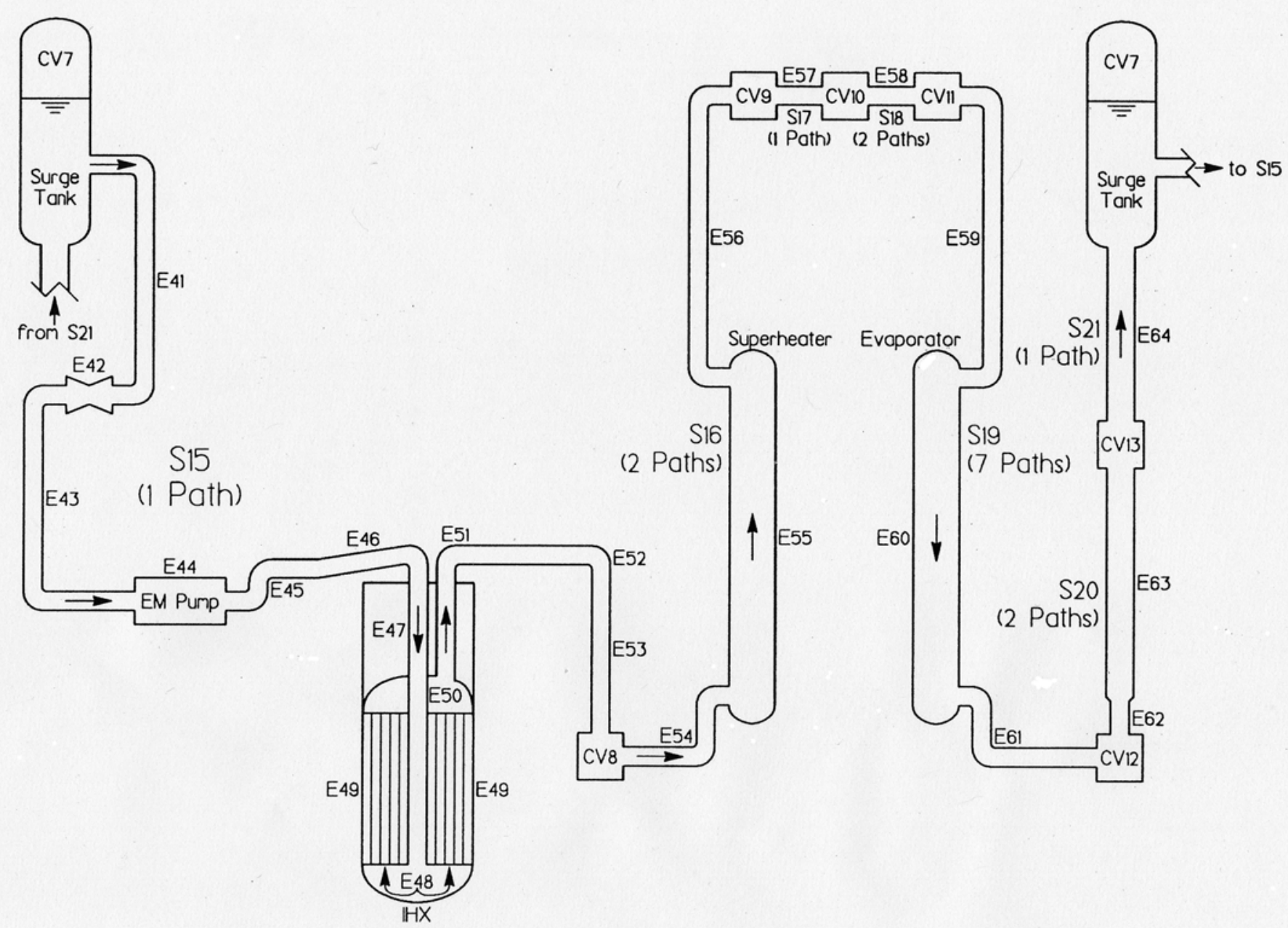




\section{EBR-II SHRT-17 Protected Loss-of-Flow XX09 Results SASSYS Calculation - 2006}
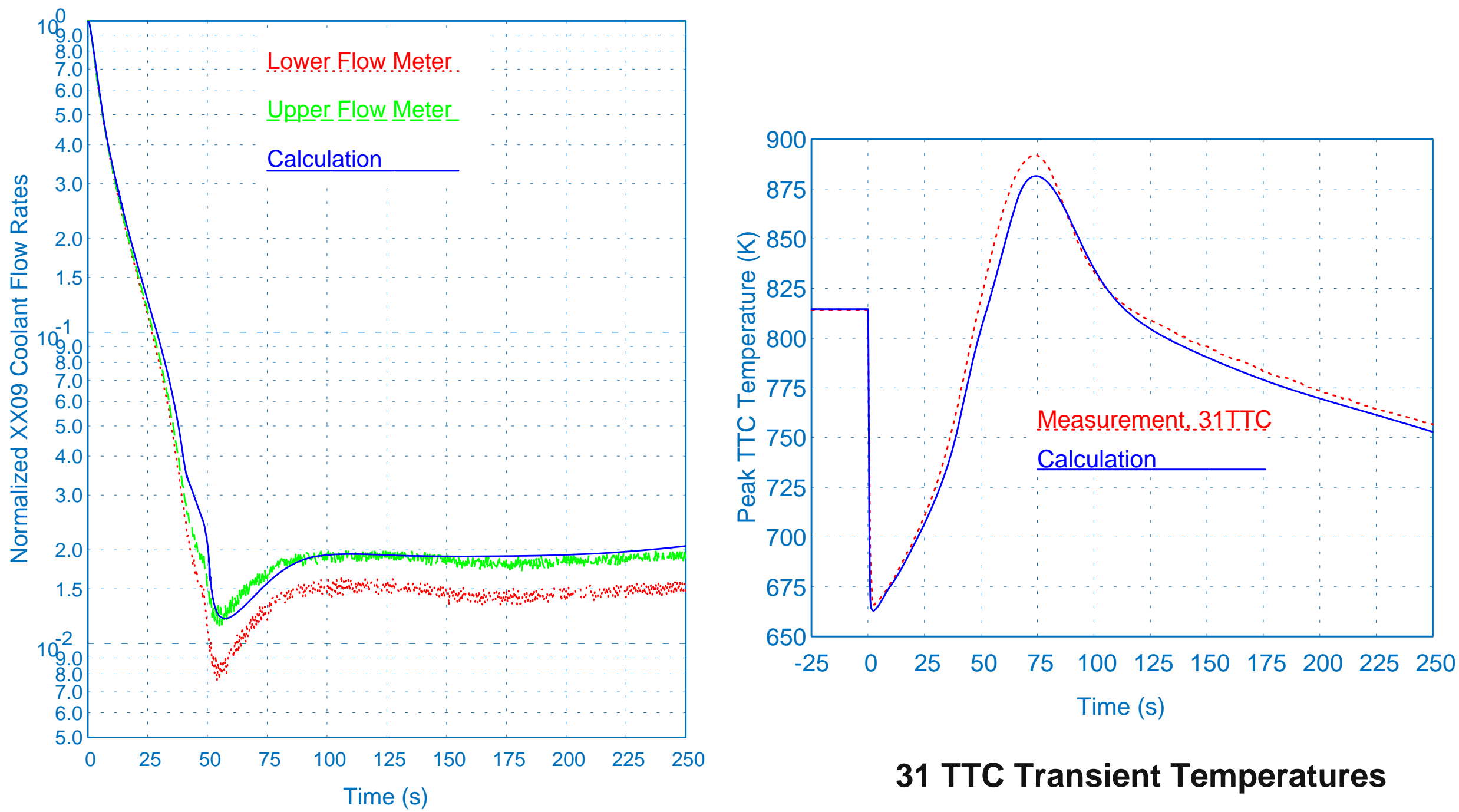

31 TTC Transient Temperatures

XX09 Transient Coolant Flow 
EBR-II SHRT 39 Unprotected Loss of Flow Sequence Results - 1 NATDEMO/HOTCHAN Calculation - 1986

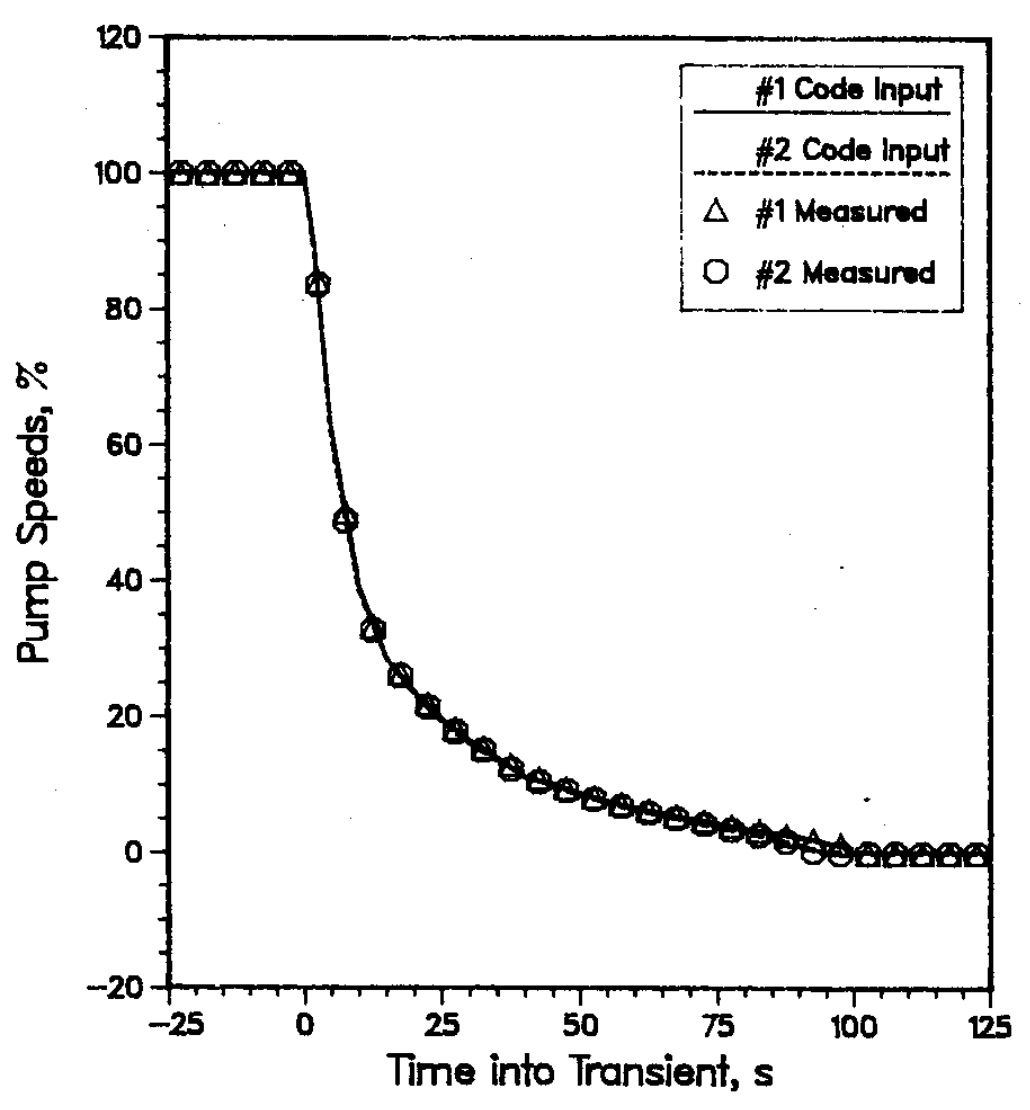

Pump coastdown without scram...

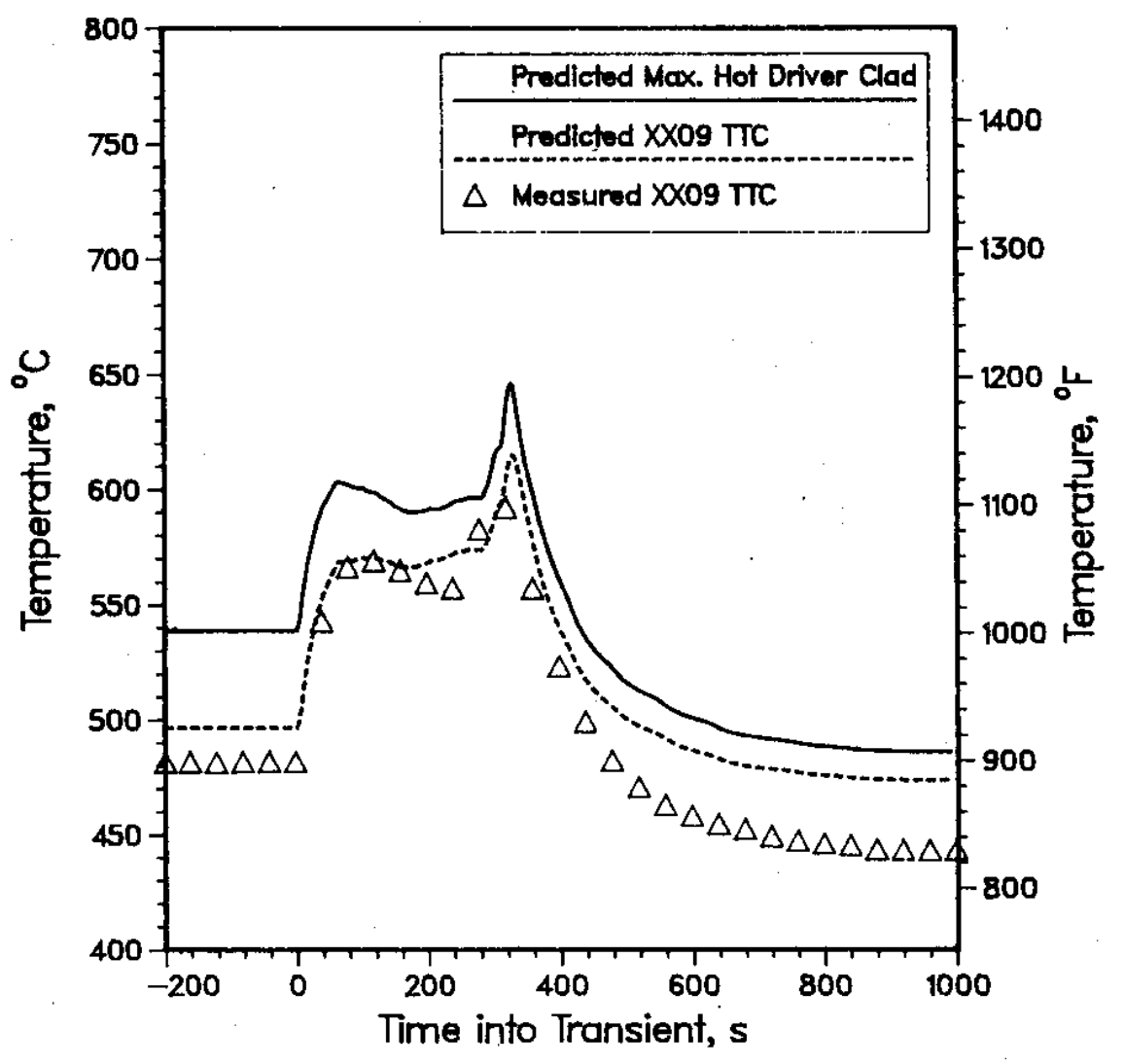

causes transient temperature rise... 
EBR-II SHRT 39 Unprotected Loss of Flow Sequence Results - 2 NATDEMO/HOTCHAN Calculation - 1986

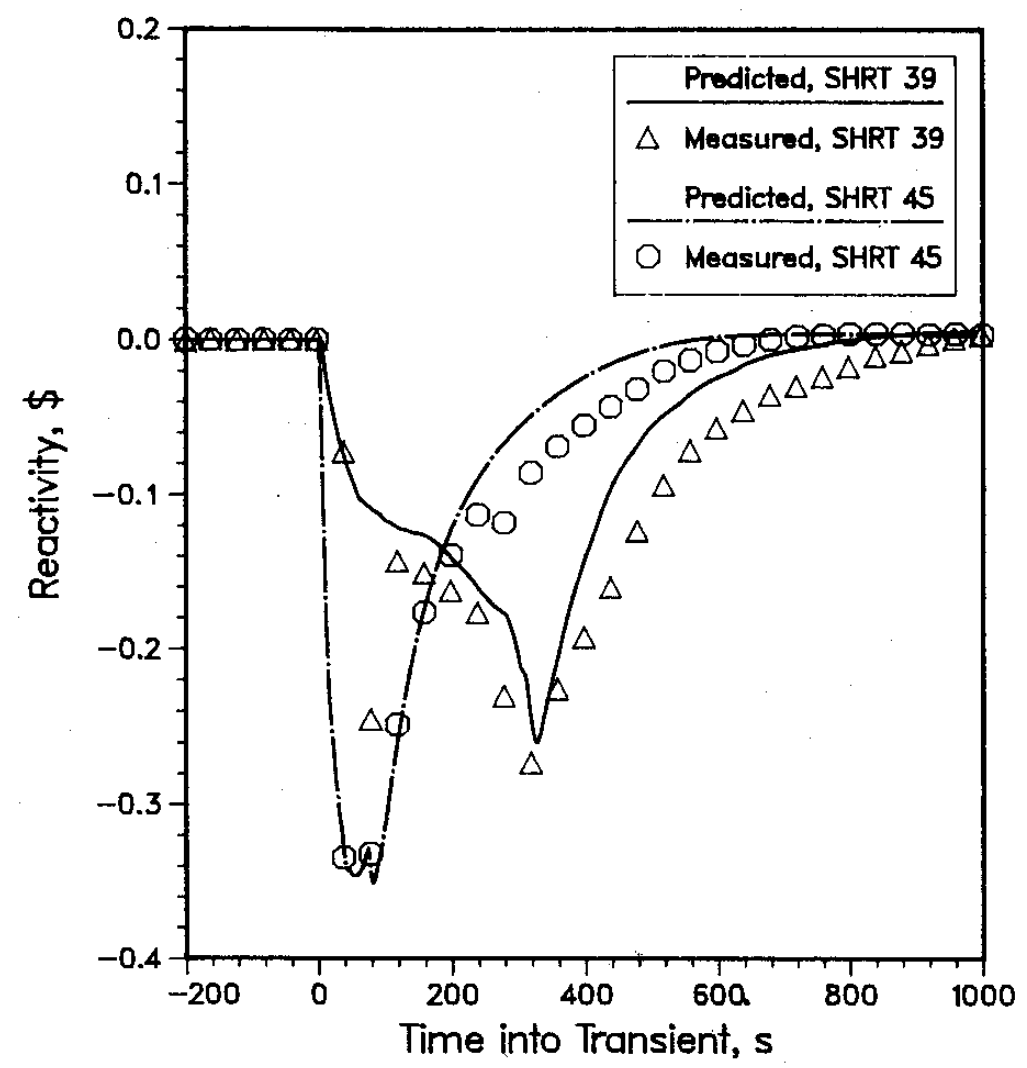

introducing negative reactivity...

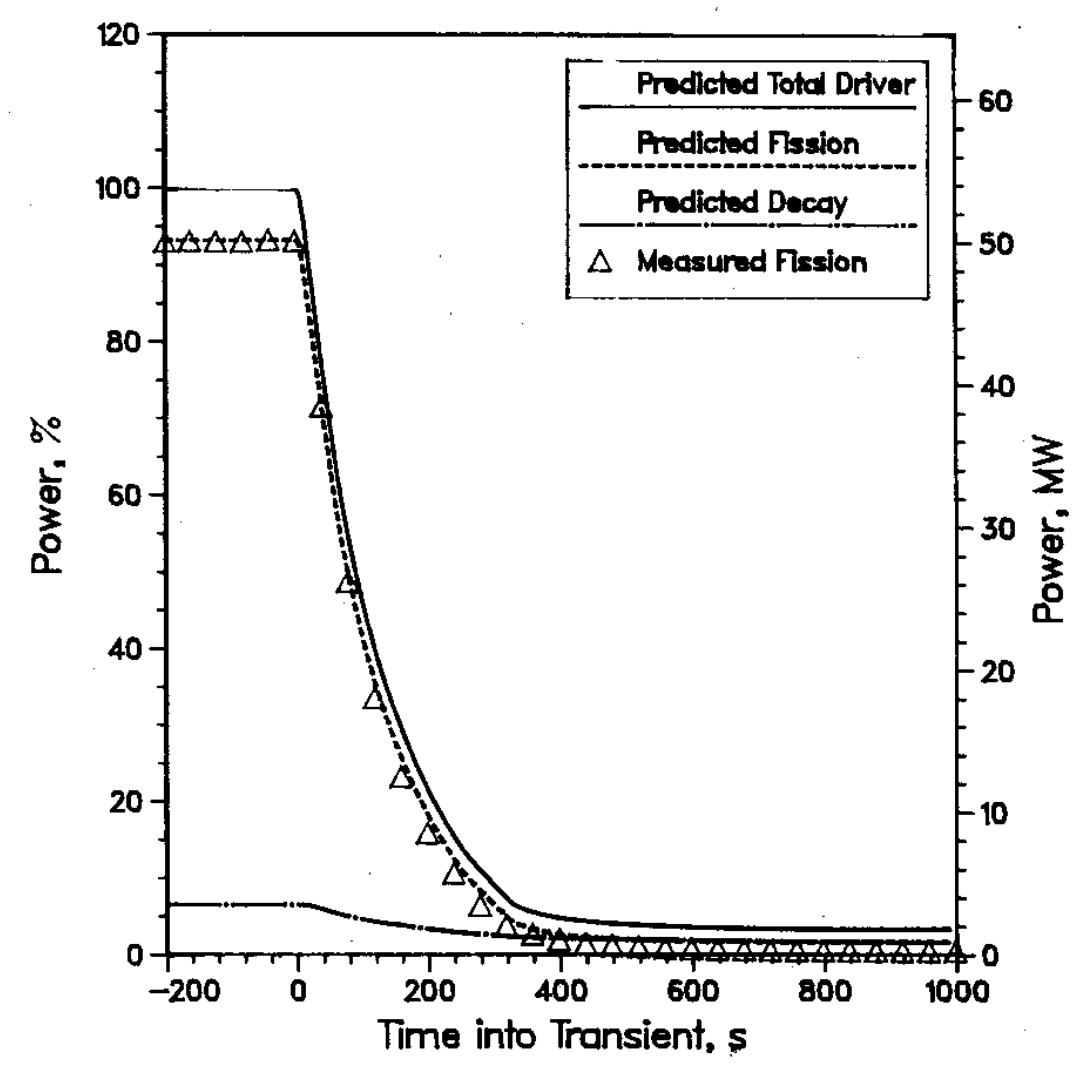

reducing reactor power to decay heat. 


\section{EBR-II Unprotected Loss of Heat Sink Sequence Results - 1 NATDEMO/HOTCHAN Calculation - 1986}

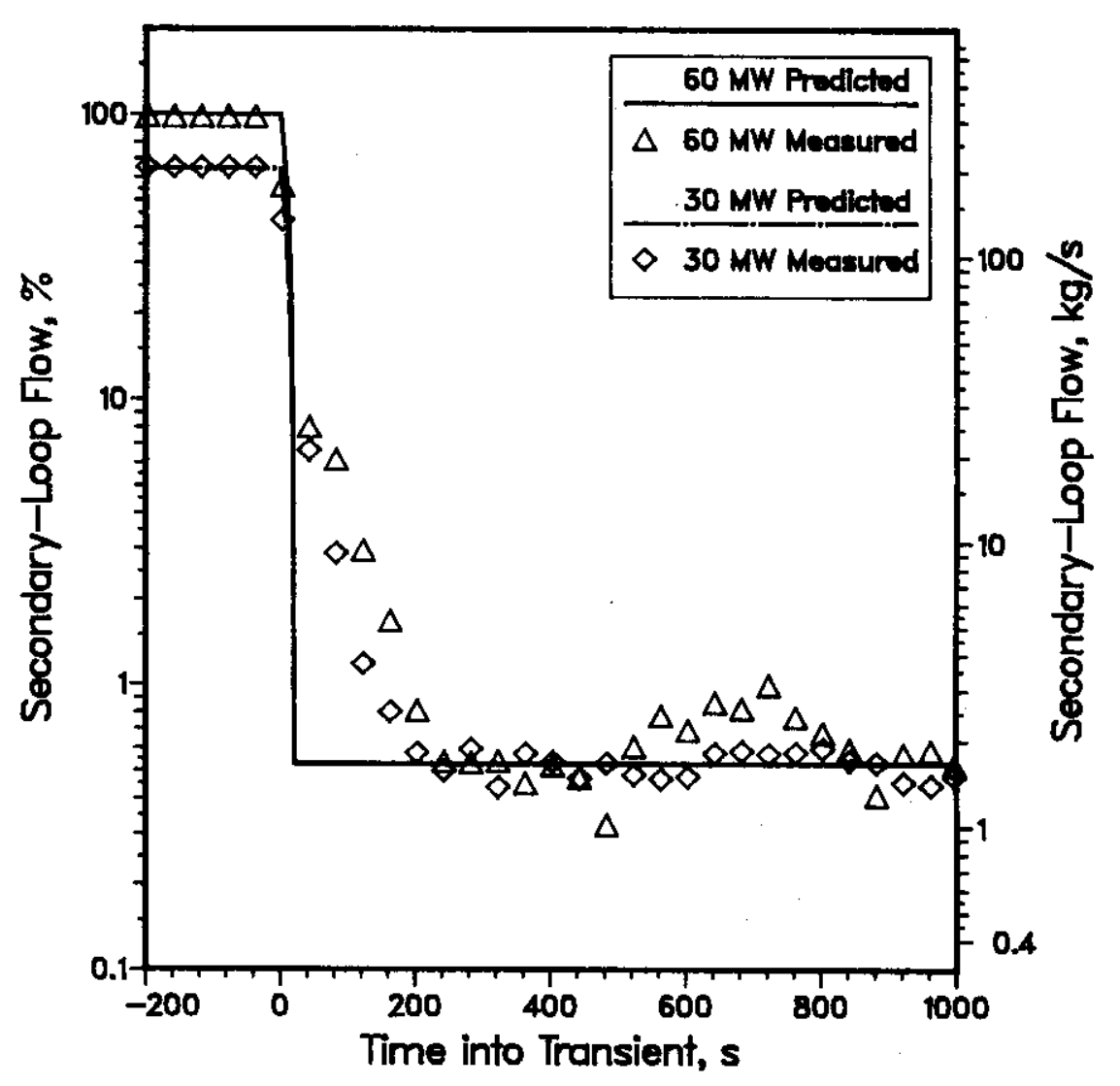

Secondary pump trip without scram...

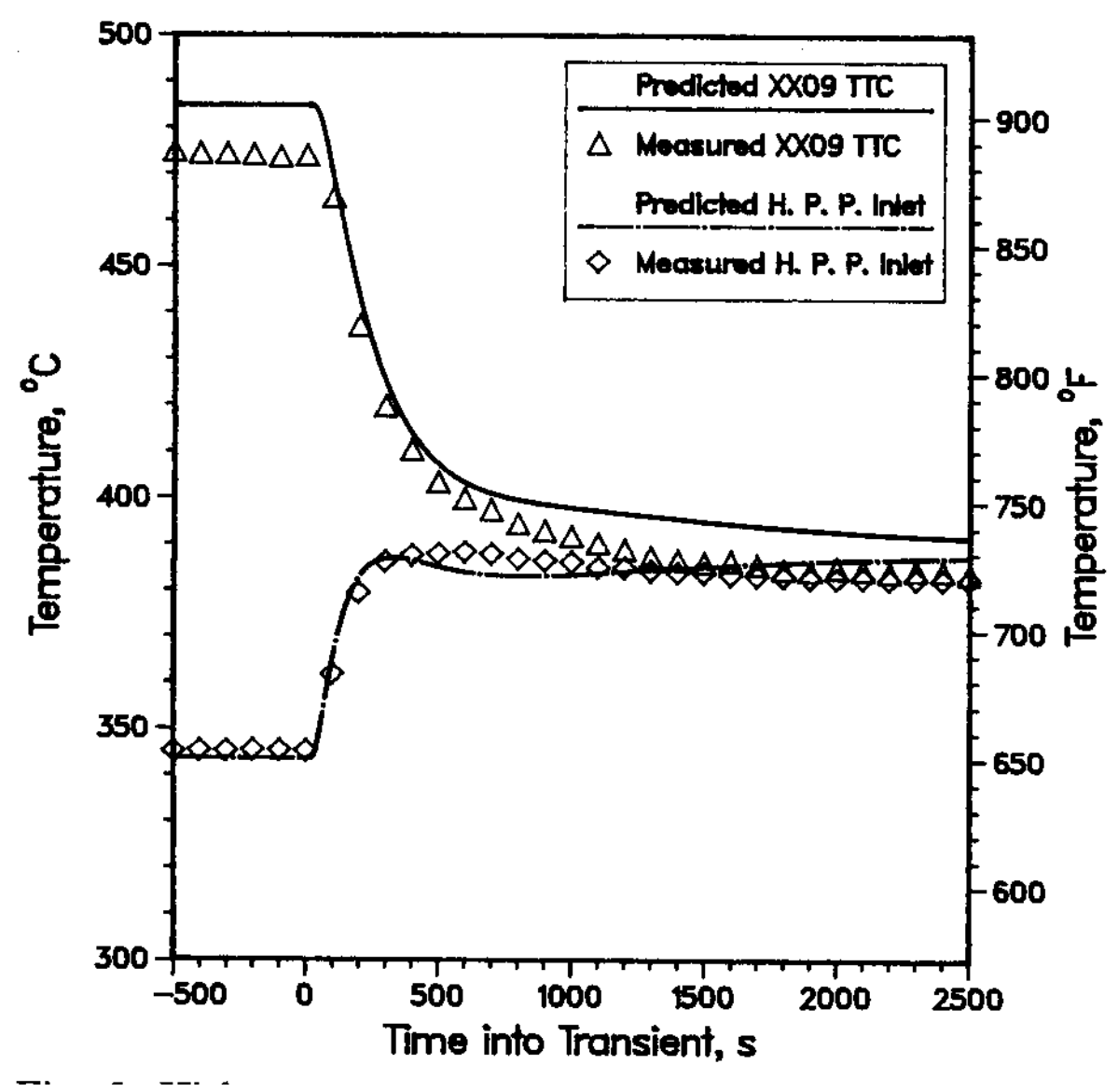

causes transient inlet temperature rise... 


\section{EBR-II Unprotected Loss of Heat Sink Sequence Results - 1 NATDEMO/HOTCHAN Calculation - 1986}

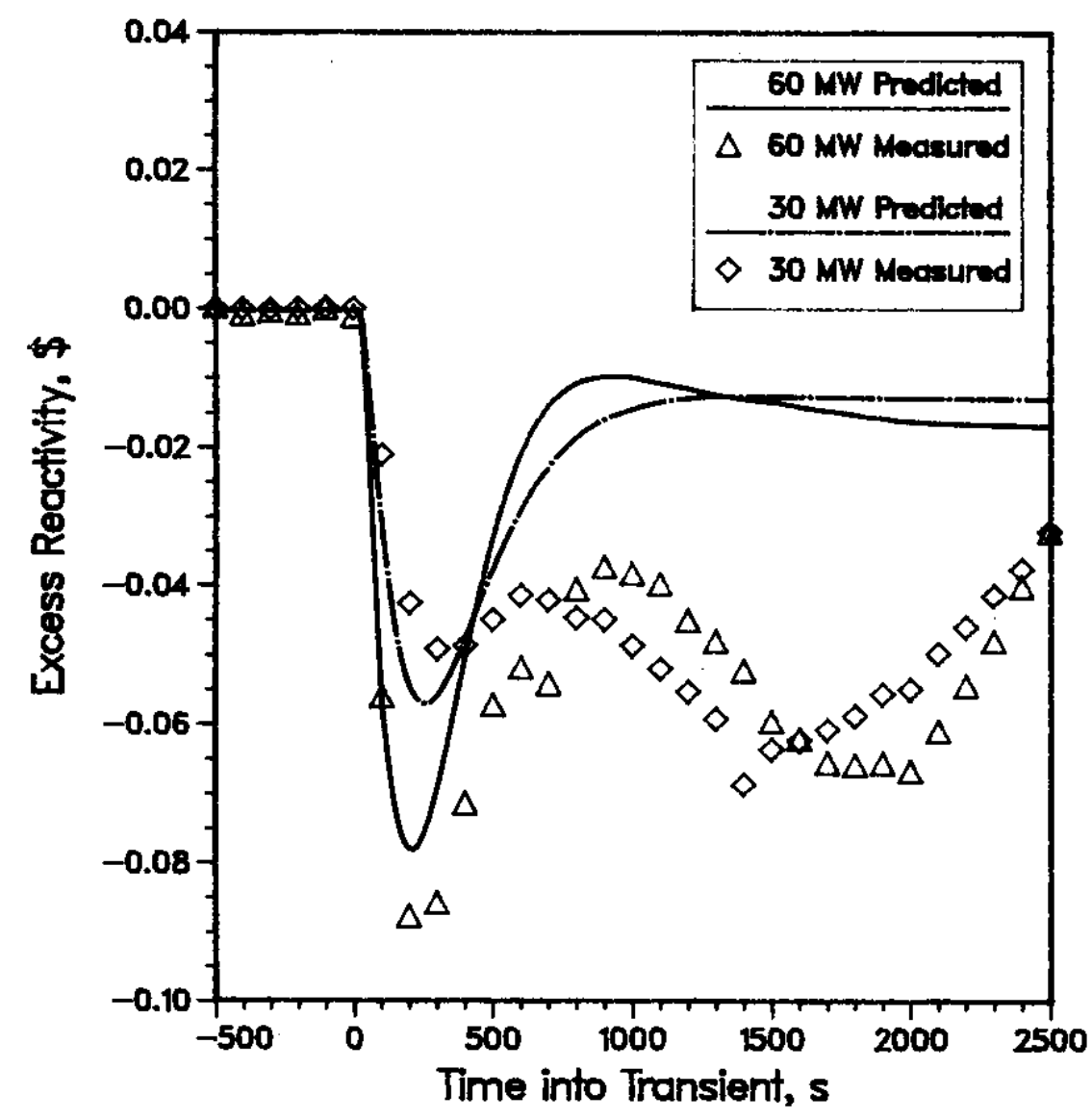

introducing negative reactivity...

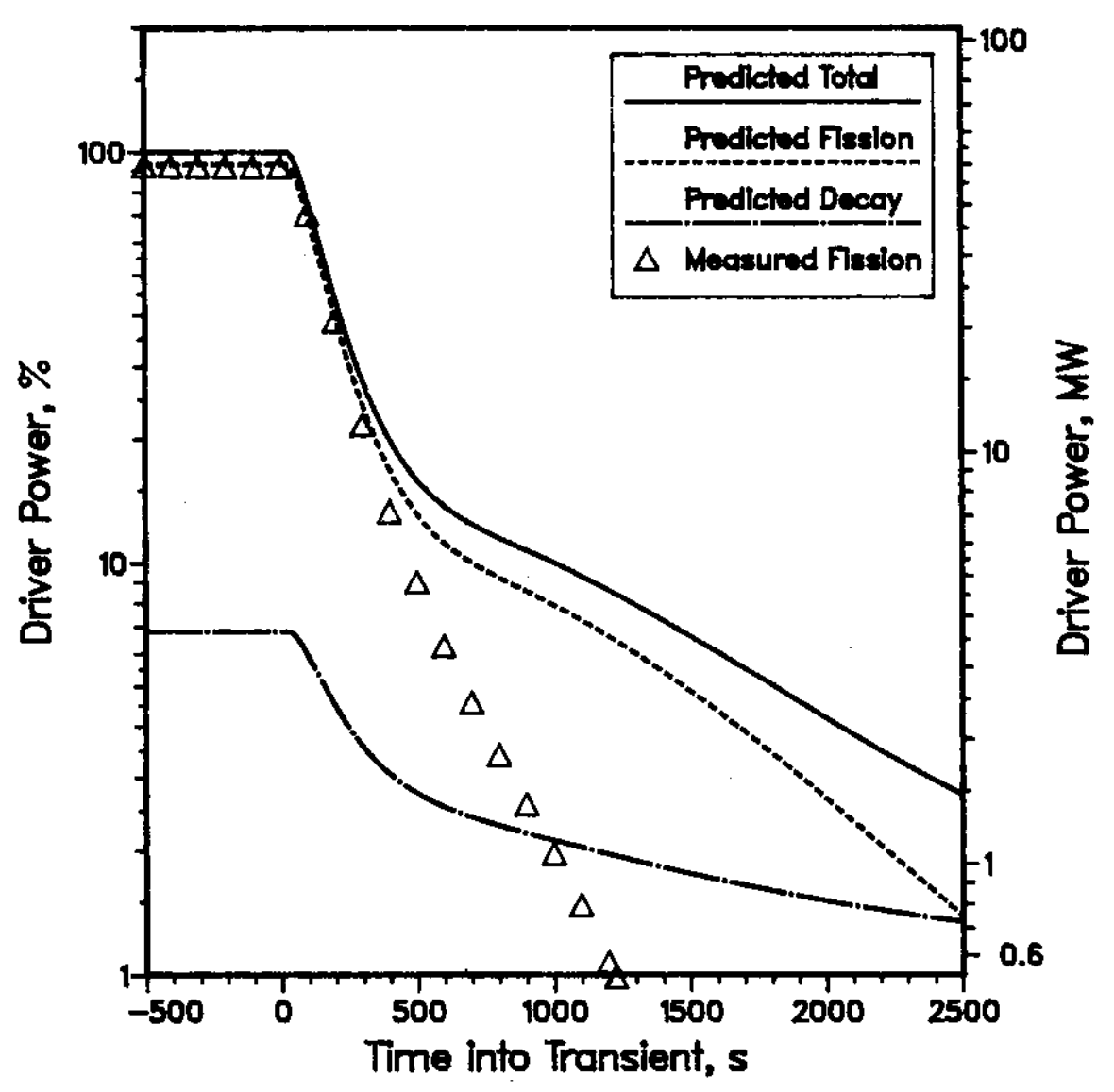

reducing reactor power to decay heat. 


\section{Significance of EBR-II SHRT Tests}

n The EBR-II SHRT tests demonstrate that passive safety mechanisms in sodium-cooled, metal-fueled, pool-type reactors can limit the consequences of double-fault accidents

- No coolant boiling, cladding failure, or fuel melting

- Reliance on inherent performance characteristics: negative reactivity feedback to reduce reactor fission power, and natural circulation decay heat removal

- Larger reactors can be designed to have these performance characteristics

- High thermal conductivity of metallic fuel (low fuel operating temperature) reduces positive Doppler reactivity feedback upon power reduction

- Pool-type design provides thermal inertia to buffer (slow down) impacts of accident initiators

- Arrangement and vertical separation of heat source and sink elevations promotes natural circulation

- Core restraint and support design to provide negative reactivity for increasing coolant temperature (as in FFTF and CRBRP) 


\section{FFTF Loss-of-Flow Without Scram Tests (1986)}

- A series of test intended to simulate passive safety performance of an advanced LMR

- Unprotected (without scram) Loss-of-Flow from reduced power (range $10 \%$ to $50 \%$ ) and full flow

- Nine Gas Expansion Modules (GEMs) were installed to provide negative reactivity during the coolant flow coastdown

- Empty hexcans, sealed at the top, and installed at the core periphery. As the inlet pressure decreases, the coolant level falls, introducing void and increasing neutron leakage

- ULOF tests preceded by flow transients for reactivity feedbacks characterization

- Pump trips with scram to natural circulation

- Static measurements of GEM reactivity worth

- Reactor coolant flow and temperature measurements were obtained with the normal plant instrumentation (pump speed, coolant loop flowmeters, subassembly outlet thermocouples)

- Two fast thermocouples mounted on subassembly outlets in rows 2 and 6; (Post Irradiation Open Test Assembly - PIOTA) 


\section{Why GEMs? Reactivity Swing for Power Reduction}

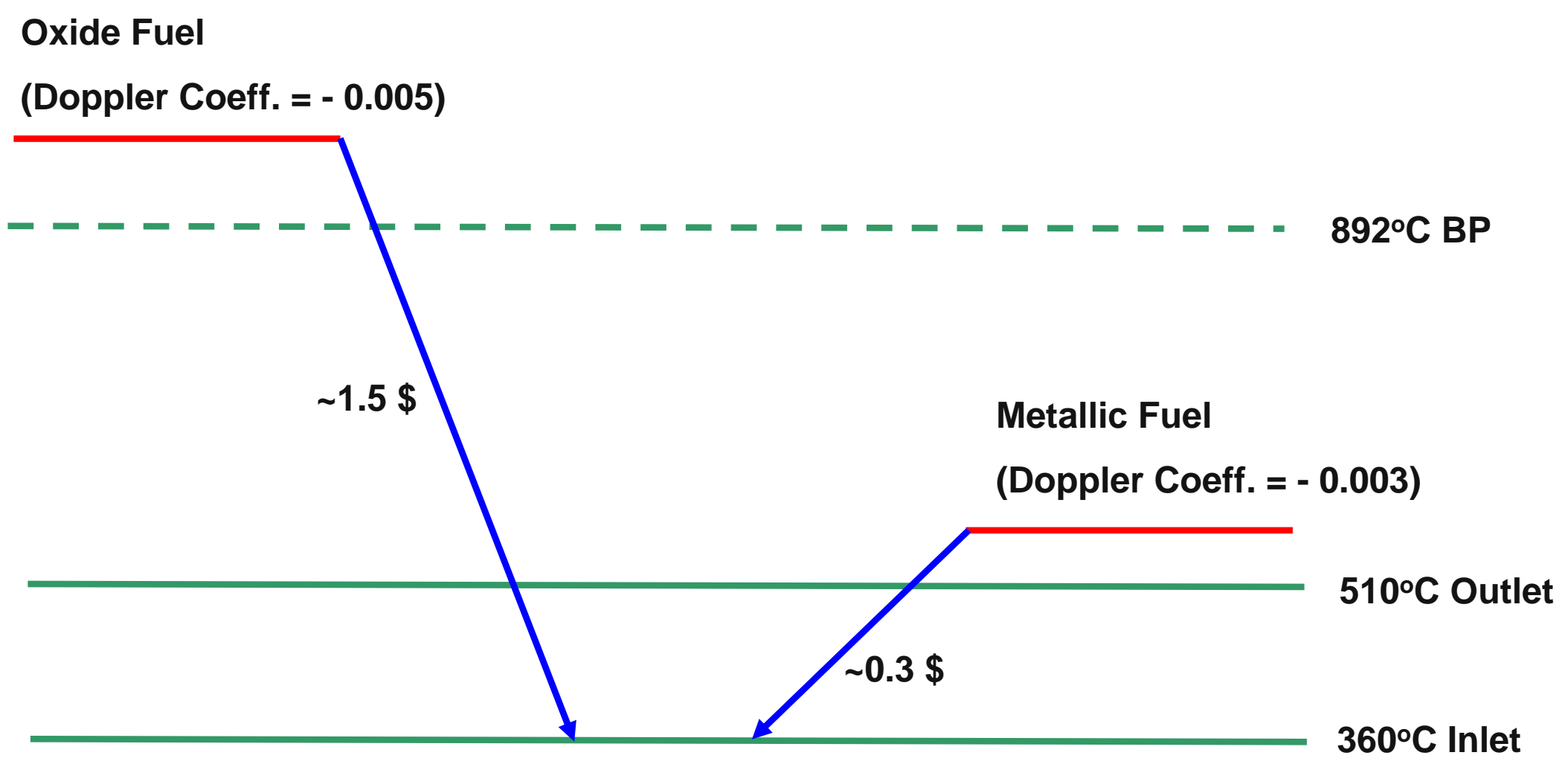




\section{CALCULATED GEM SODIUM LEVEL vs.} PLANT CONDITIONS

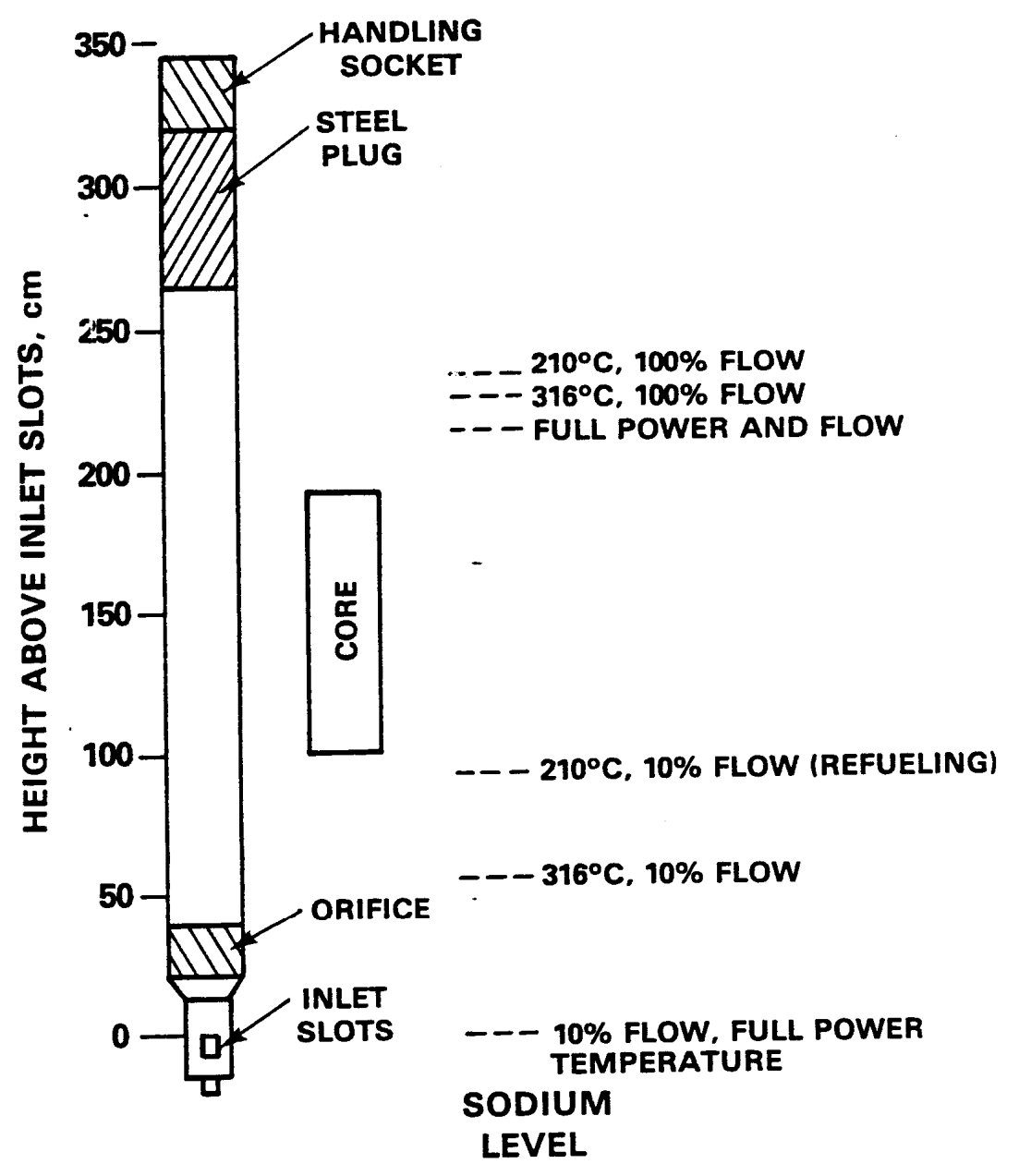




\section{FFTF Core Loading for ULOF Testing}

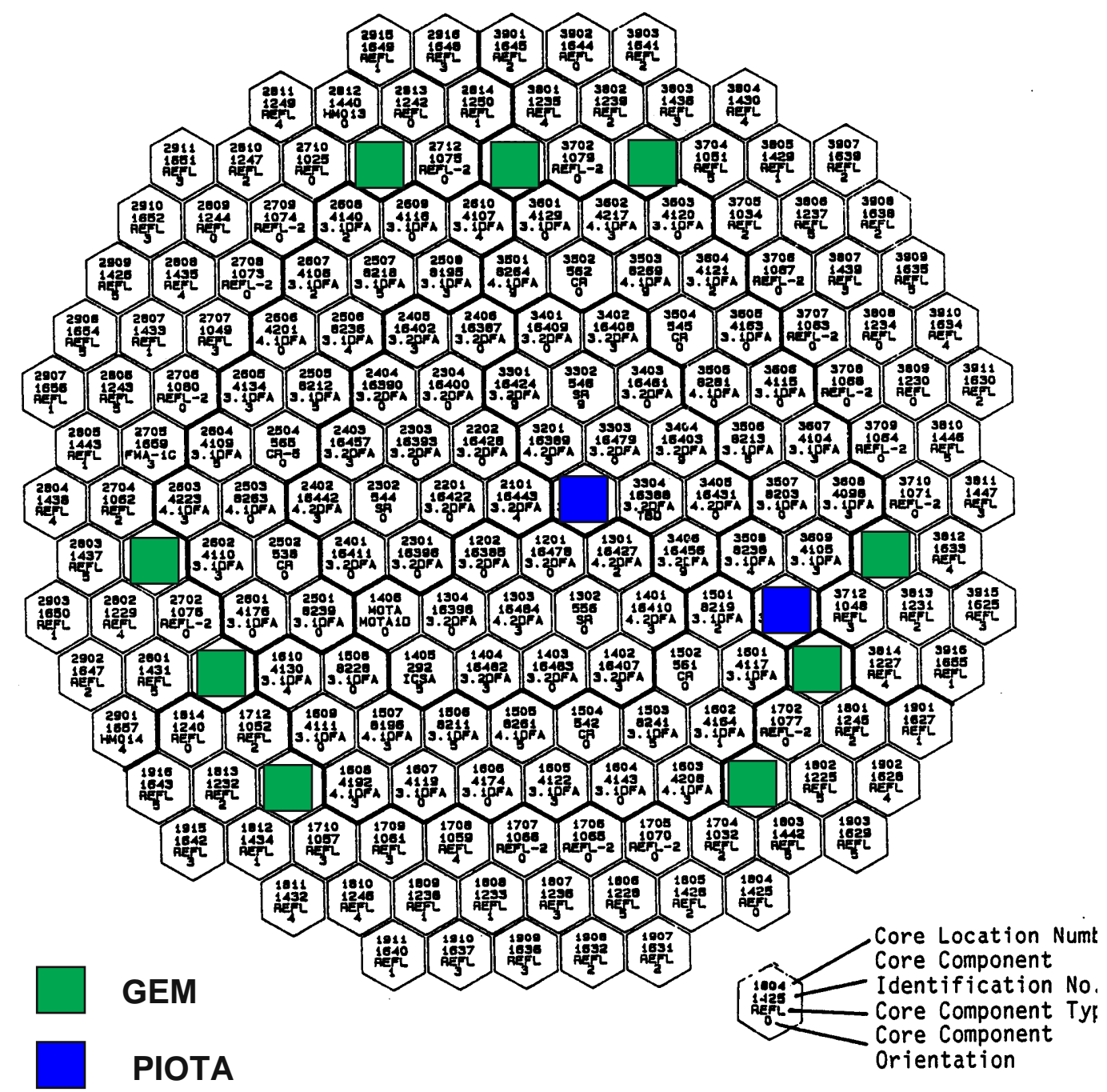

CYCLE OC CORE LOADING - CM.8C.1.0 


\section{FFTF PIOTA Configuration}

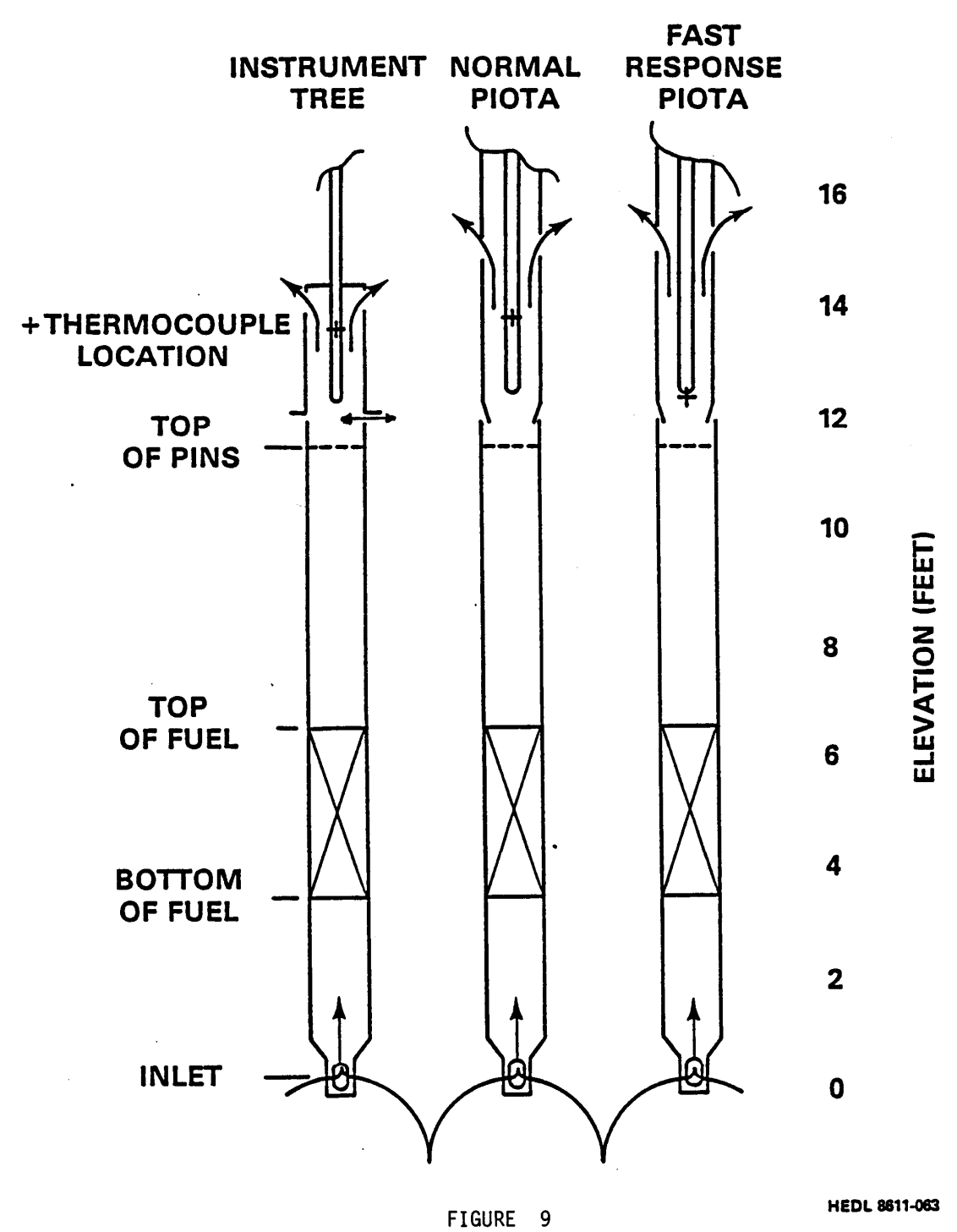

ABOVE CORE THERIIOCOUPLE INSTALLATIONS 


\section{Lessons Learned from EBR-II and FFTF Testing}

- The experience of planning and executing special tests beyond the original mission of the reactor and plant can provide new insights into the capabilities of the facility

- Assurance of safety performance, confirmation of margins

- Results of testing can contribute new knowledge that guides performance expectations and selection of design features for future reactors

- Passive safety performance based on natural circulation shutdown heat removal and inherent reactivity feedbacks

- To maximize test value, special equipment may be necessary

- Instrumentation to measure performance directly

- Flow coastdown (pump power supply)

- Negative reactivity feedback enhancement 


\section{Inherent passive safety}

- Inherent passive safety characteristics of sodium fast reactor systems (wrt loss of flow without scram, etc.).

- Inherent reactivity shutdown

- Natural circulation decay heat removal

- These performance characteristics can be achieved in reactors sized and configured for commercial deployment

- The following examples are provided for a large, low conversion ratio conceptual design to demonstrate passive safety performance for protected and unprotected loss-of-flow accident ssequences 


\section{SFR Safety Analysis}

- Safety analyses were carried out for a $1000 \mathrm{MWt}$ pool-type concept to provide a quantitative safety assessment of reactor and plant performance.

- Evaluations were made for both the metal and oxide core designs.

- Scope of analyses focuses on the ability of the SFR to provide inherent protection against damaging consequences following low-probability accident sequences involving multiple equipment failures.

- Two accident sequences were evaluated:

- Protected Loss of Flow (PLOF)

- Unprotected Loss of Flow (ULOF)

- Analyses were performed with the fast reactor safety analysis code SAS4A/SASSYS-1. 


\section{Safety Analysis Approach}

- Protected Loss of Flow (PLOF)

- Initial conditions assume full power operation at BOEC.

- Total loss of normal power to the reactor cooling system at $t=0$, with complete failure of the emergency power supply system.

- Balance of plant is assumed to cease operation and provide no heat rejection capability.

- Immediate reactor scram following power failure.

- Unprotected Loss of Flow (ULOF)

- Initial and accident conditions are identical to the PLOF case.

- Additionally, the reactor protection system fails to scram either the primary or secondary control rods.

- Power control is exclusively through reactivity feedback mechanisms.

- In both cases, the only heat removal path is through the emergency heat removal system (DRACS) by natural circulation.

- PLOF simulations were carried out to 40,000 seconds ( 11 hours)

- ULOF simulations sere carried out to 4,000 seconds ( 1 hour) 


\section{Analysis Summary}

- Both metal and oxide core designs demonstrate significant safety margins to coolant boiling and fuel damage in PLOF accident sequences.

- The metal core design also exhibits significant safety margins in the ULOF accident sequence. This is a direct consequence of

- High thermal conductivity and low operating temperature of metal fuel.

- Favorable negative reactivity feedback due to thermal expansion

However...

- ULOF analyses for the oxide core design indicate that margins to coolant boiling may not be adequate

- Inadequate margins despite significantly longer flow halving time assumed for oxide (20 seconds) compared to metal (5 seconds).

- Initially high fuel temperatures result in significant positive Doppler feedback when trying to reduce temperatures.

- Additional enhancements, such as a self-actuating shutdown system (SASS) device, may be required for the oxide core to increase ULOF safety margins. 


\section{End of Presentation}

Q Questions? 


\section{SFR Fuel Performance and Approach to Qualification}

Steven L. Hayes and Douglas L. Porter Fuels \& Materials Performance Department Idaho National Laboratory

November 27-28, 2007

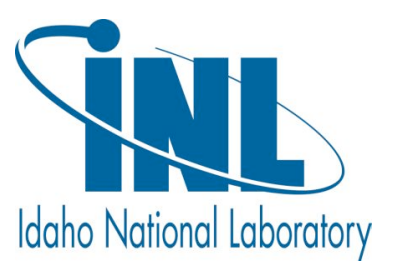




\section{Outline of Presentation}

Idaho National Laboratory

SFR Fuels Experience in the US

- Fuel Types

- Fuel Performance Issues

- Experience/Testing

- Fuel Test Plan (1994) for PRISM Prototype

Fuel Specification

Experience with Fuels Containing Minor Actinides (AFCI/GNEP)

Approach to Fuel Development and Qualification 


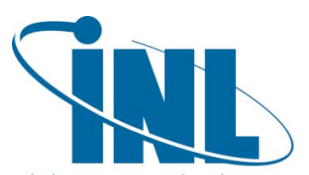

Idaho National Laboratory

\section{SFR Fuels Experience in the US}




\section{SFR Fuels Experience in the US}

Idaho National Laboratory

Metallic Fuels

- EBR-I, Fermi-1, EBR-II, FFTF

- U-Fs, U-Mo, U-Zr, U-Pu-Fs U-Pu-Zr, others

Mixed Oxide Fuels (MOX)

- EBR-II, FFTF

- $\left(\mathrm{U}, \mathrm{Pu}_{0.2-0.3}\right) \mathrm{O}_{2}$

- Mixed Carbide Fuels (MC)

- EBR-II, FFTF

- (U,Pu)C w/15\% (U,Pu $)_{2} \mathrm{C}_{3}$

- No current interest 


\section{Metallic Fuel Design (EBR-II)}

Idaho National Laboratory

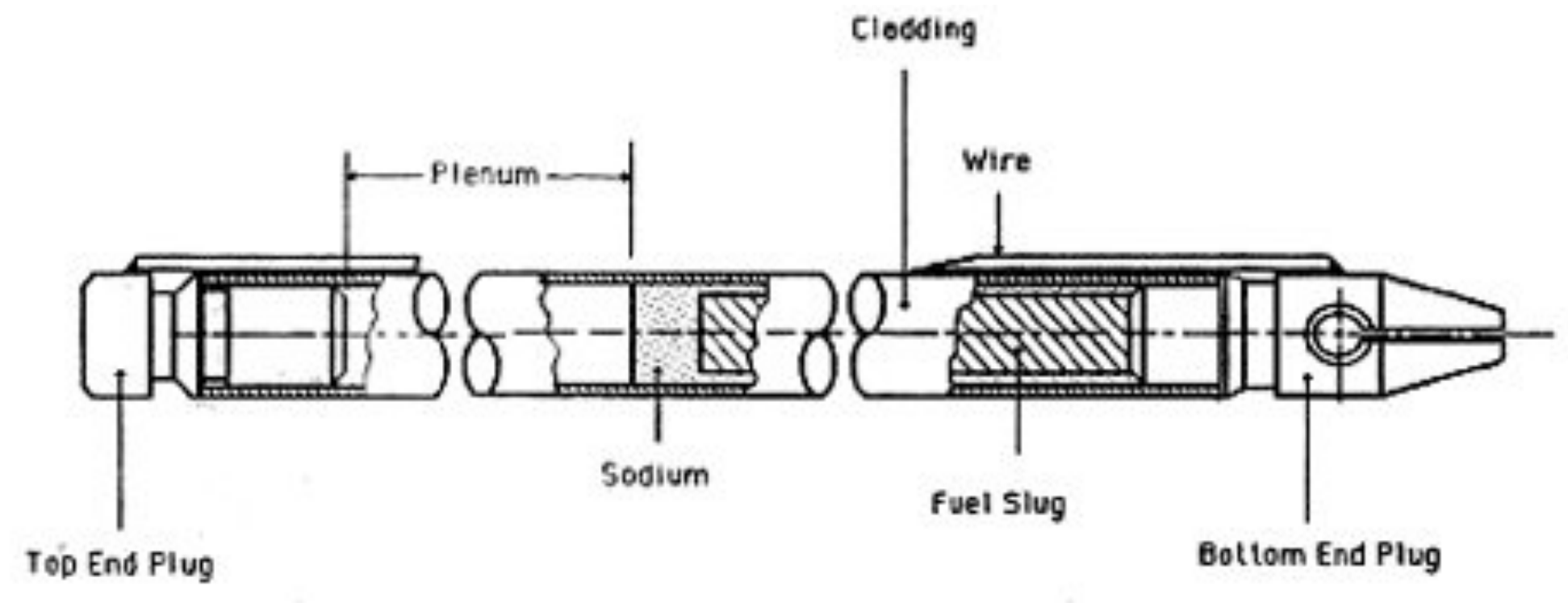

Features of a Metallic Fuel Pin (from Pahl, et al, 1990) 


\section{WL Metallic Fuel Design (FFTF)}

Idaho National Laboratory

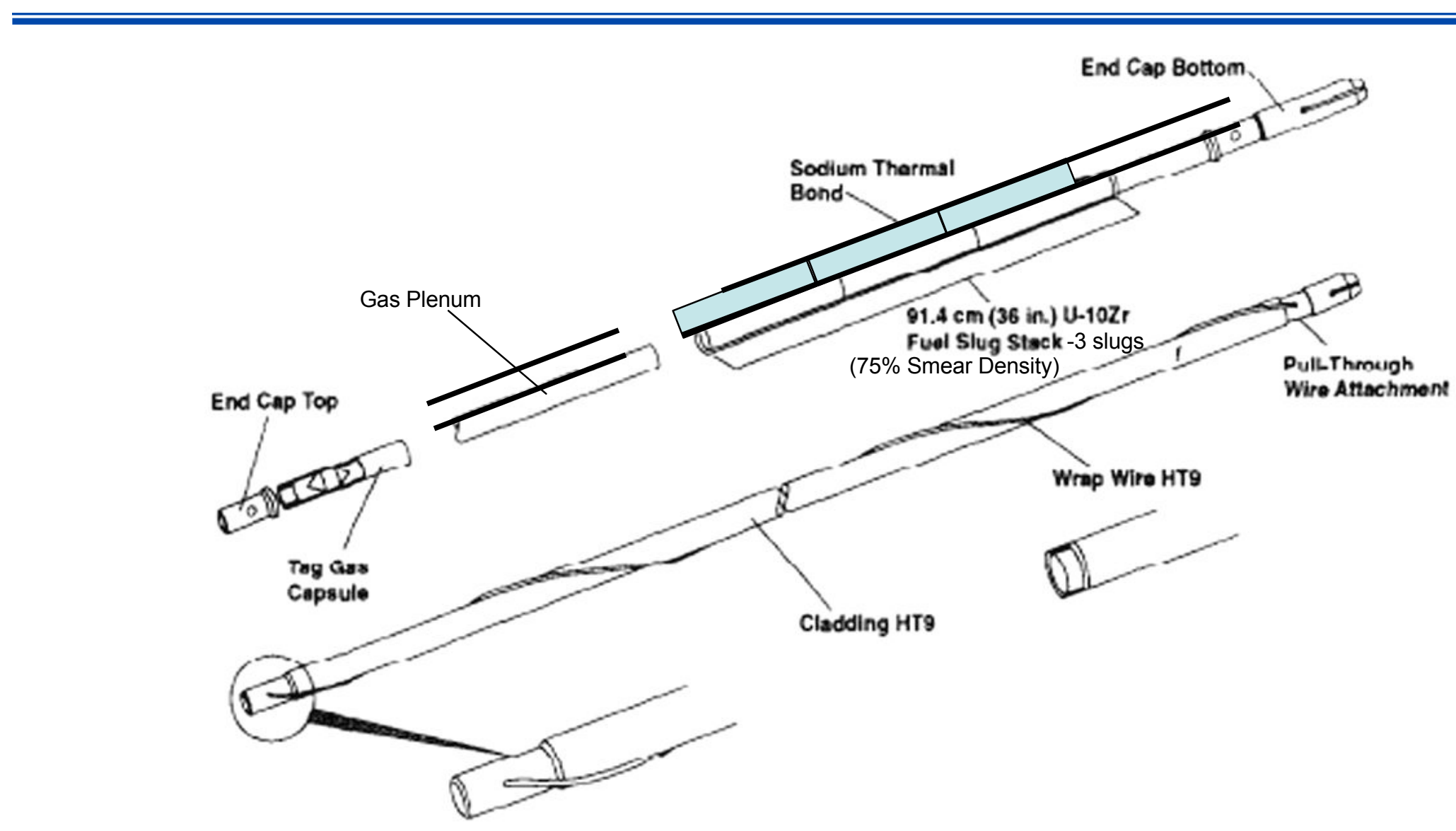

FFTF Series III.b Metallic Driver Fuel Design (from Pitner and Baker, 1993) 


\section{Important Metallic Fuel Performance Phenomena}

Irradiation growth

Fuel swelling and fuel-cladding mechanical interaction (FCMI)

Gas release

Fuel constituent redistribution

Fuel-cladding chemical interaction (FCCI)
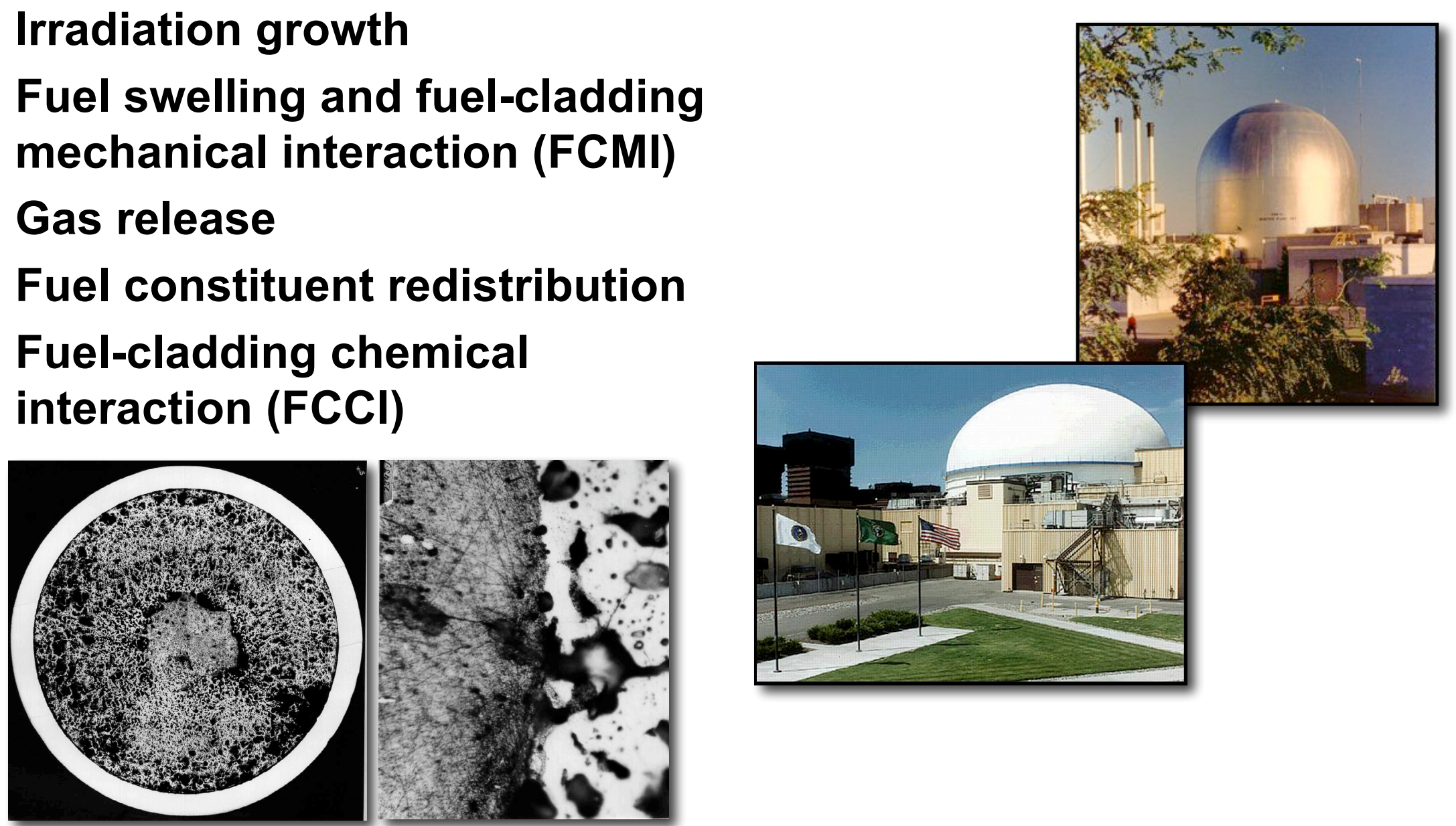


\section{Metallic Fuel Behavior-Axial Growth}

Idaho National Laboratory

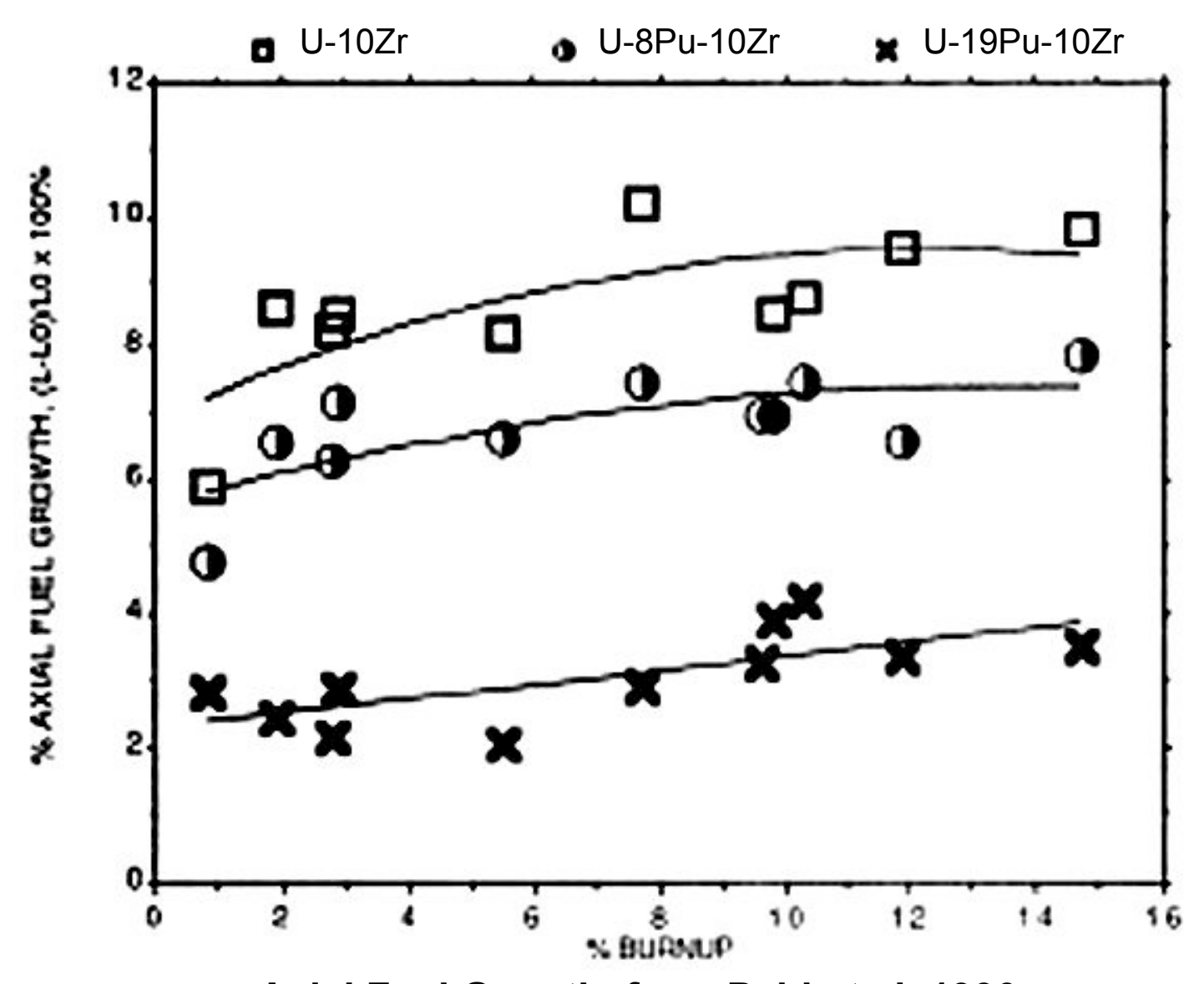

Axial Fuel Growth, from Pahl et al, 1990 


\section{Fi Metallic Fuel Behavior-Swelling \& Restructuring}
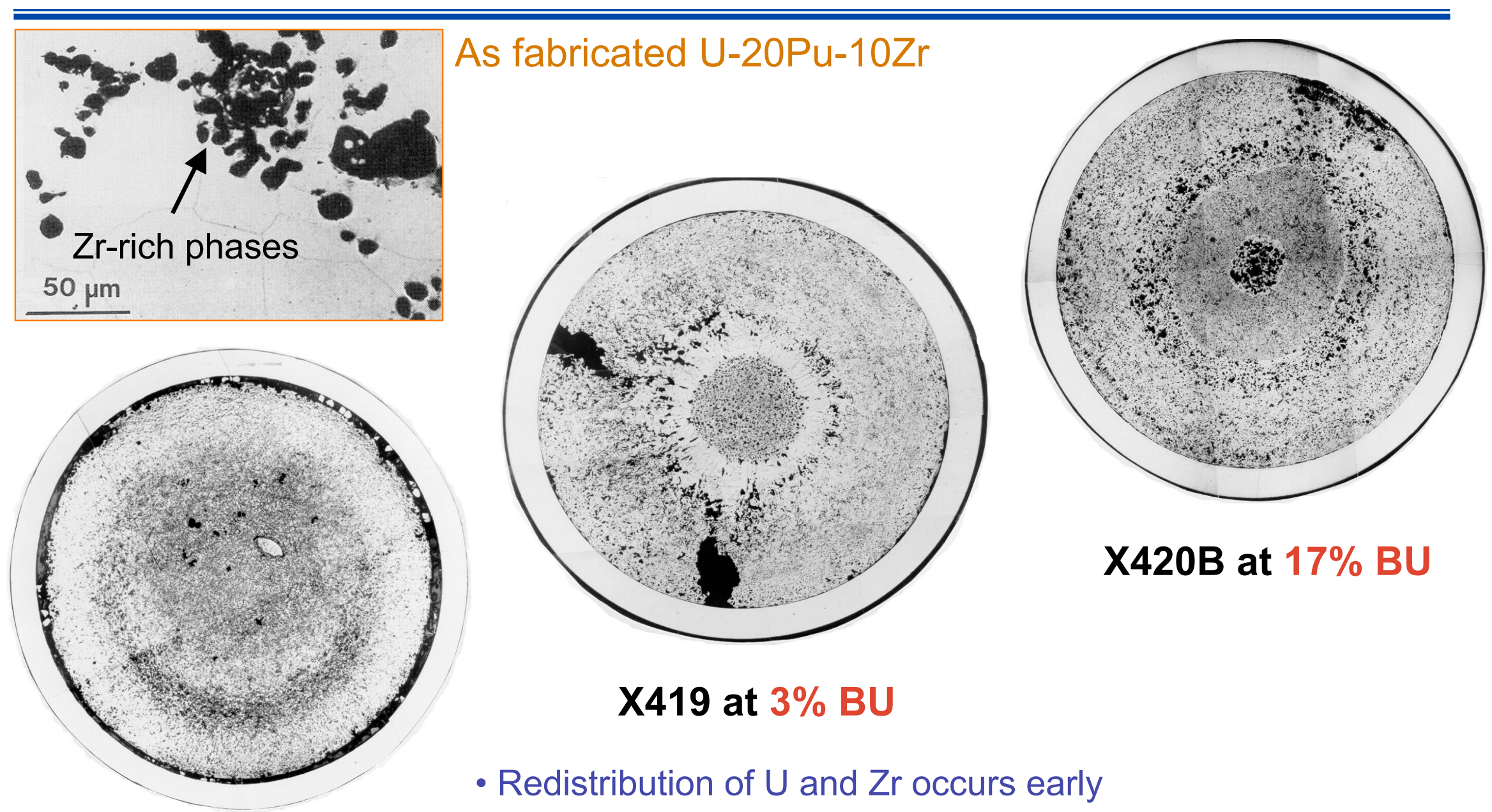

X420B at $17 \%$ BU

X419 at $3 \%$ BU

\section{$\mathrm{X} 423 \mathrm{~A}$ at $0.9 \% \mathrm{BU}$}

November 27-28, 2007 


\section{Metallic Fuel Behavior-Swelling \& Gas Release}

Idaho National Laboratory

Swelling

- Low smear density fuels

- Rapid swelling to 33 vol\% at $\sim 2$ at. \% burnup

- Gas Release

- Inter-linkage of porosity at $33 \mathrm{vol} \%$ swelling results in large gas release fraction

- Decreases driving force fol continued swelling

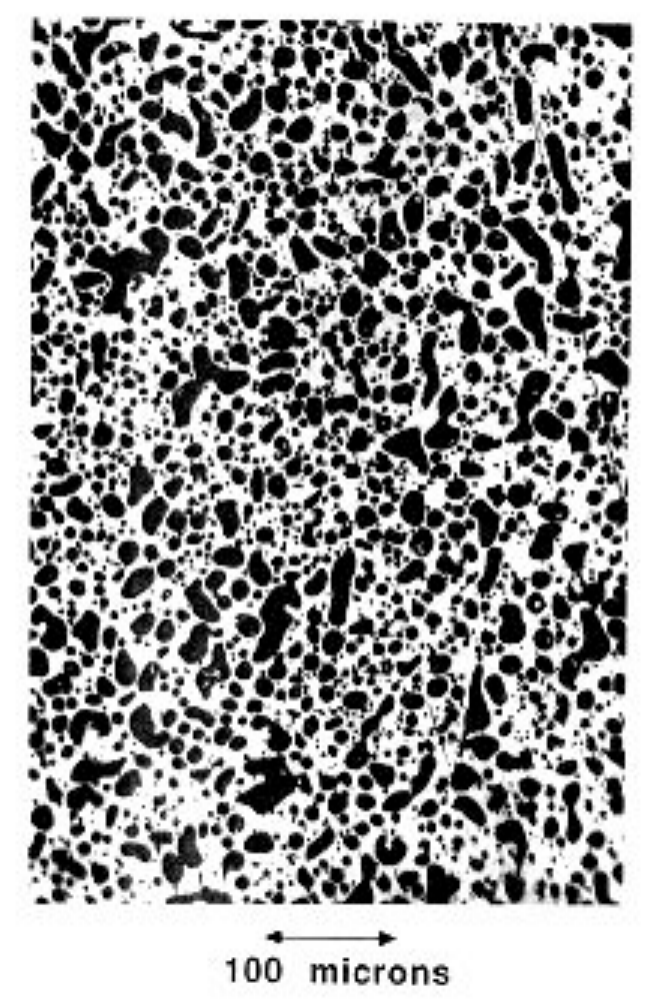

U-19Pu-10Zr ( $\gamma$-phase) at 2 at.\% burnup

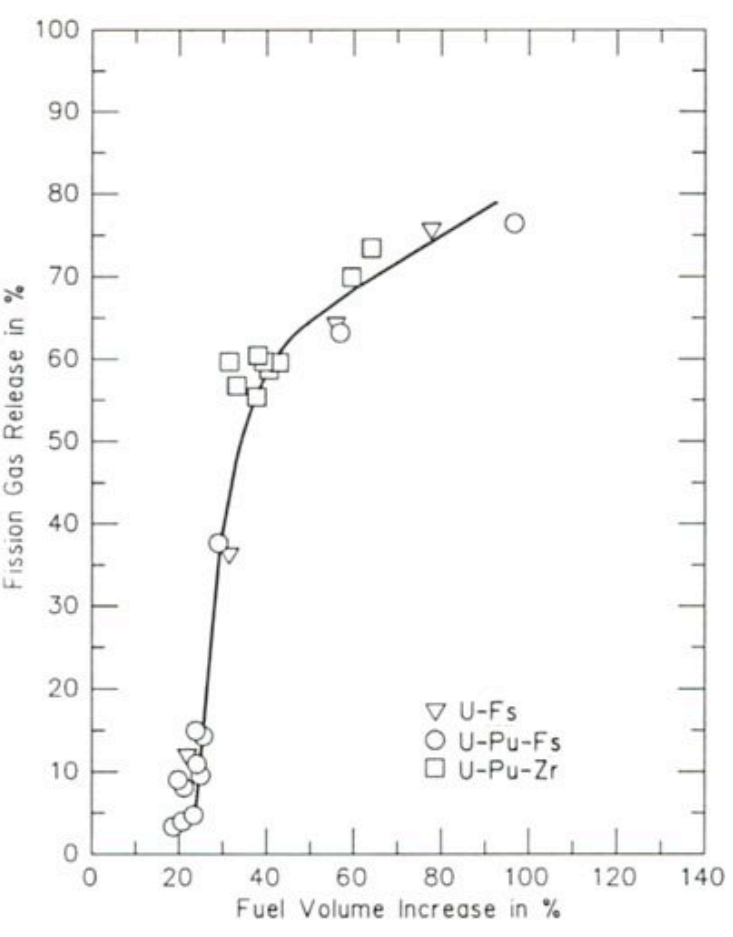




\section{SW Metallic Fuel Behavior-Fuel Constituent

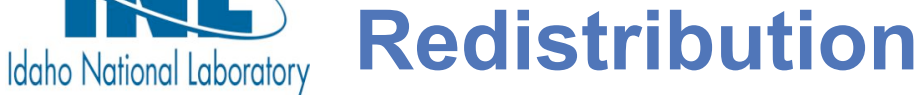

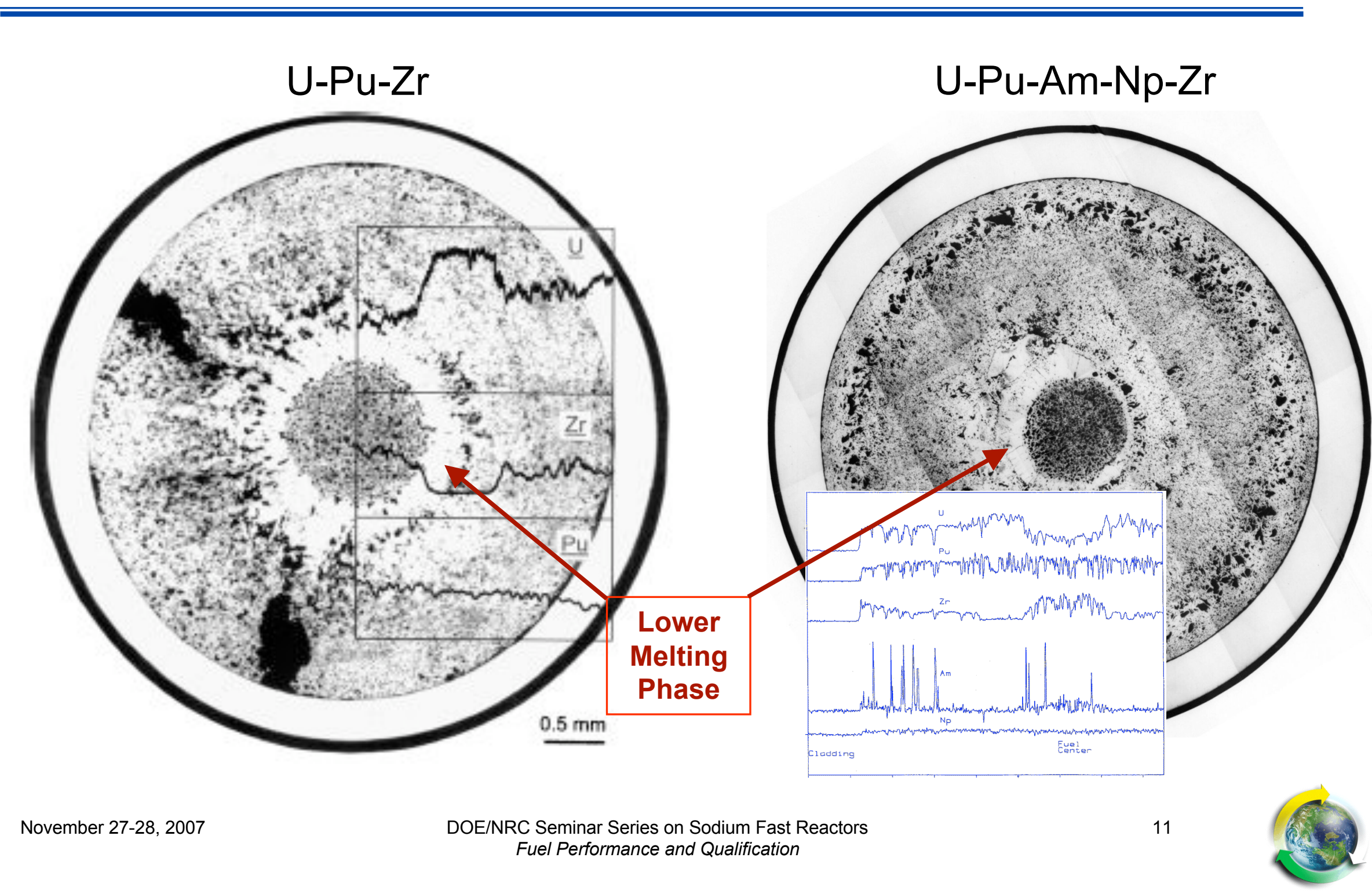




\section{Metallic Fuel Behavior-Steady-state FCCI}

Idaho National Laboratory

Fuel-Cladding Inter-diffusion

- RE fission products (La, Ce, Pr, Nd) and some Pu reacts with SS cladding

- Interaction product brittle

- Considered as cladding wastage

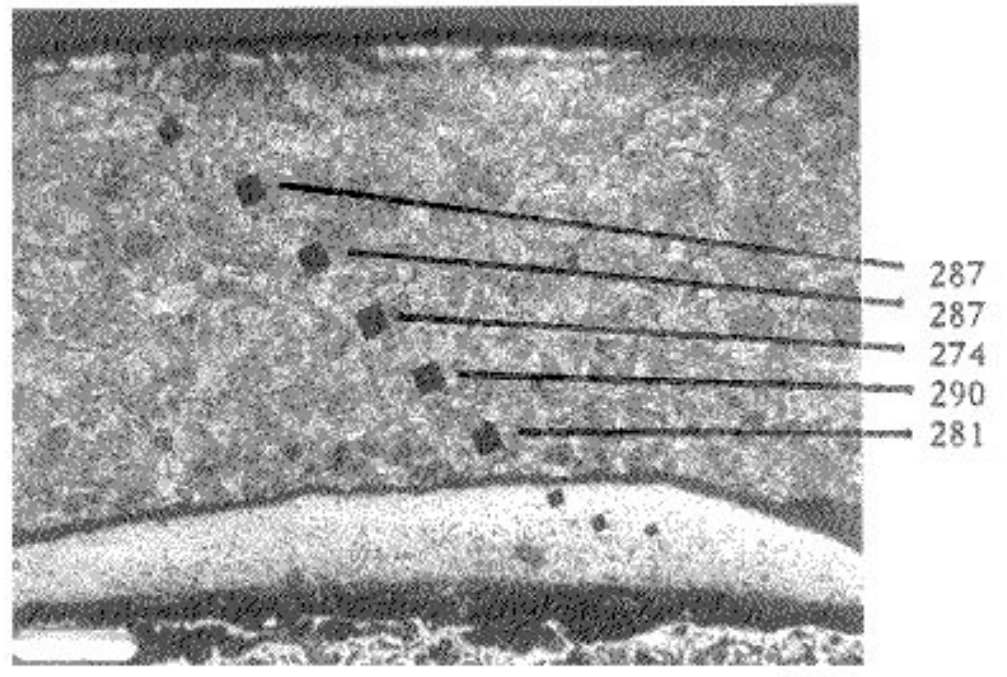

$200 \mathrm{X}$
U-19Pu-10Zr with D9;

12 at. \% burnup

(from Pahl, et al, 1990)

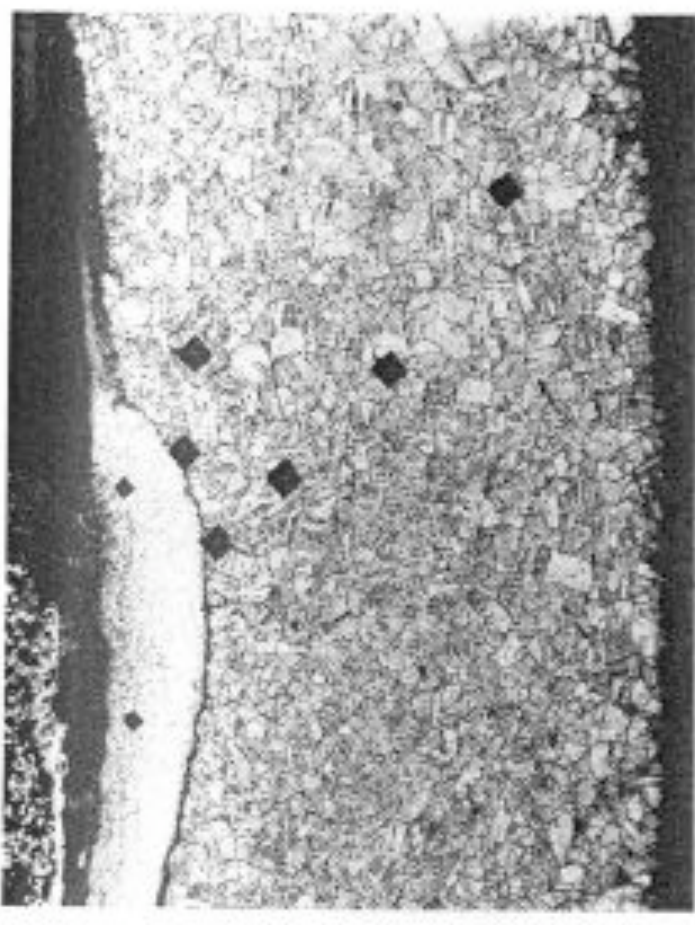

100 microns 


\section{MOX Fuel Design (FFTF)}

Idaho National Laboratory

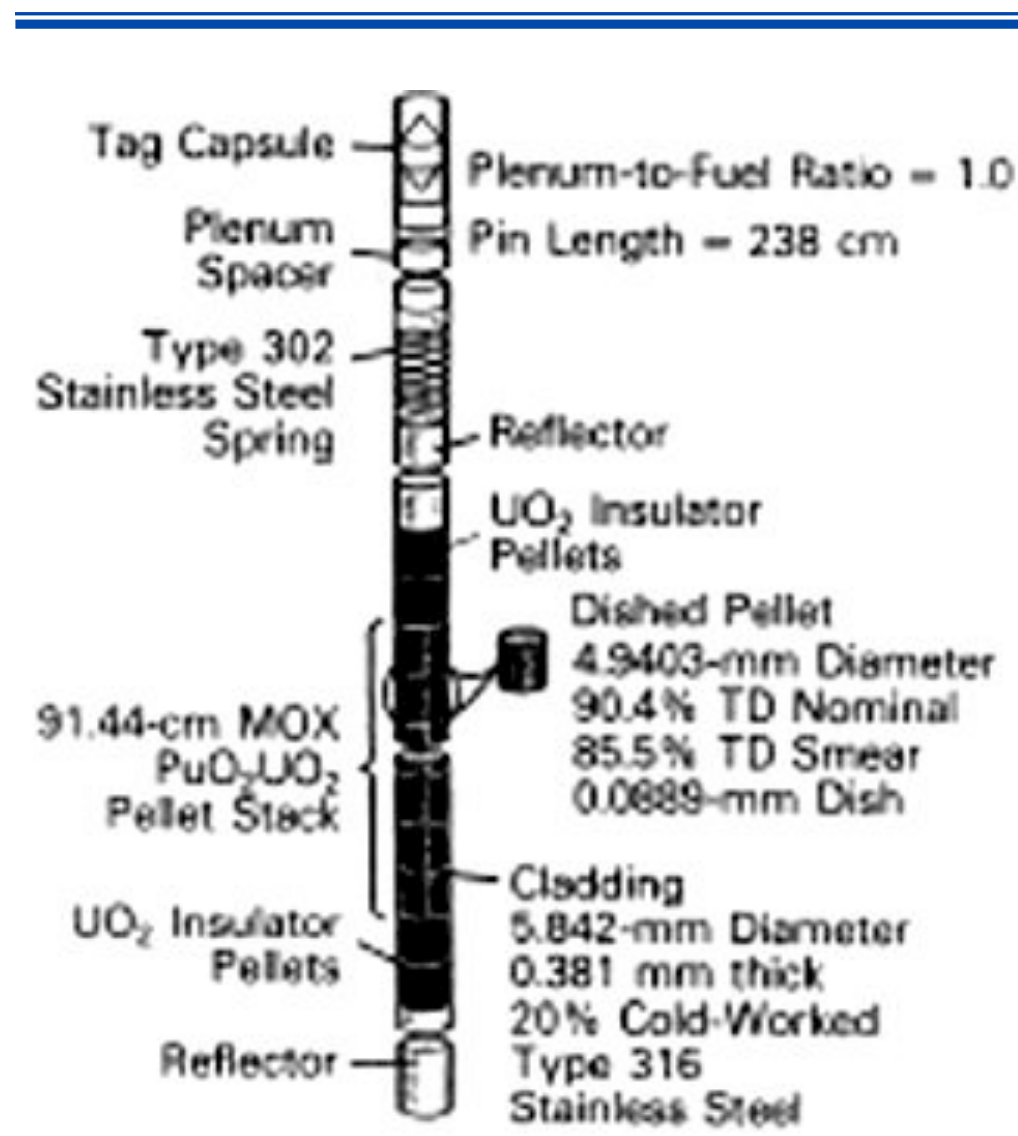

a)

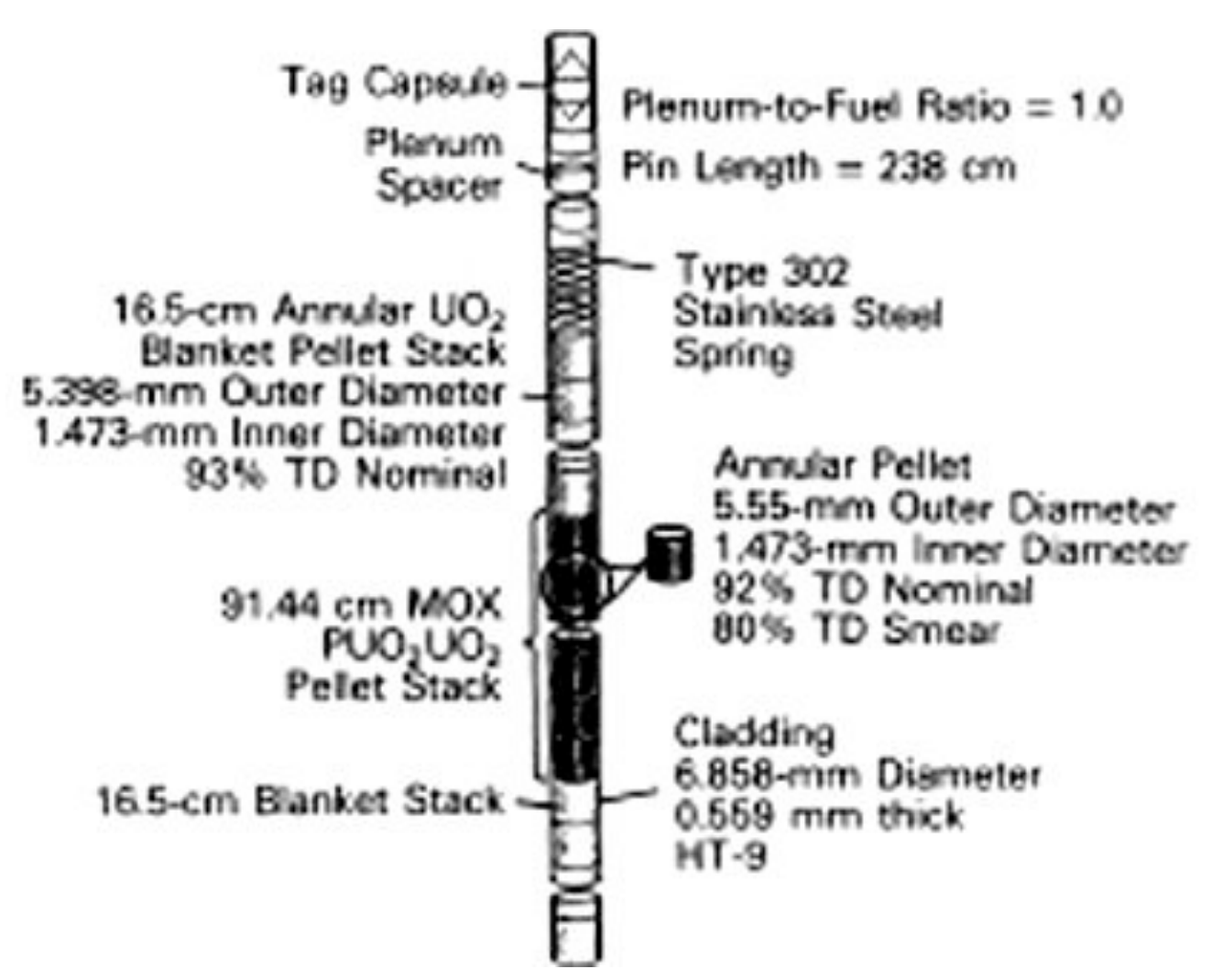

b)

FFTF He-bonded MOX Fuel: a) Driver Fuel and b) Core Demonstration Experiment Fuel (from Bridges et al, 1993) 


\section{Important MOX Fuel Performance Phenomena}

Idaho National Laboratory

Fuel swelling and FCMI

- Fuel restructuring

Gas release

- FCCl

Fuel-coolant compatibility
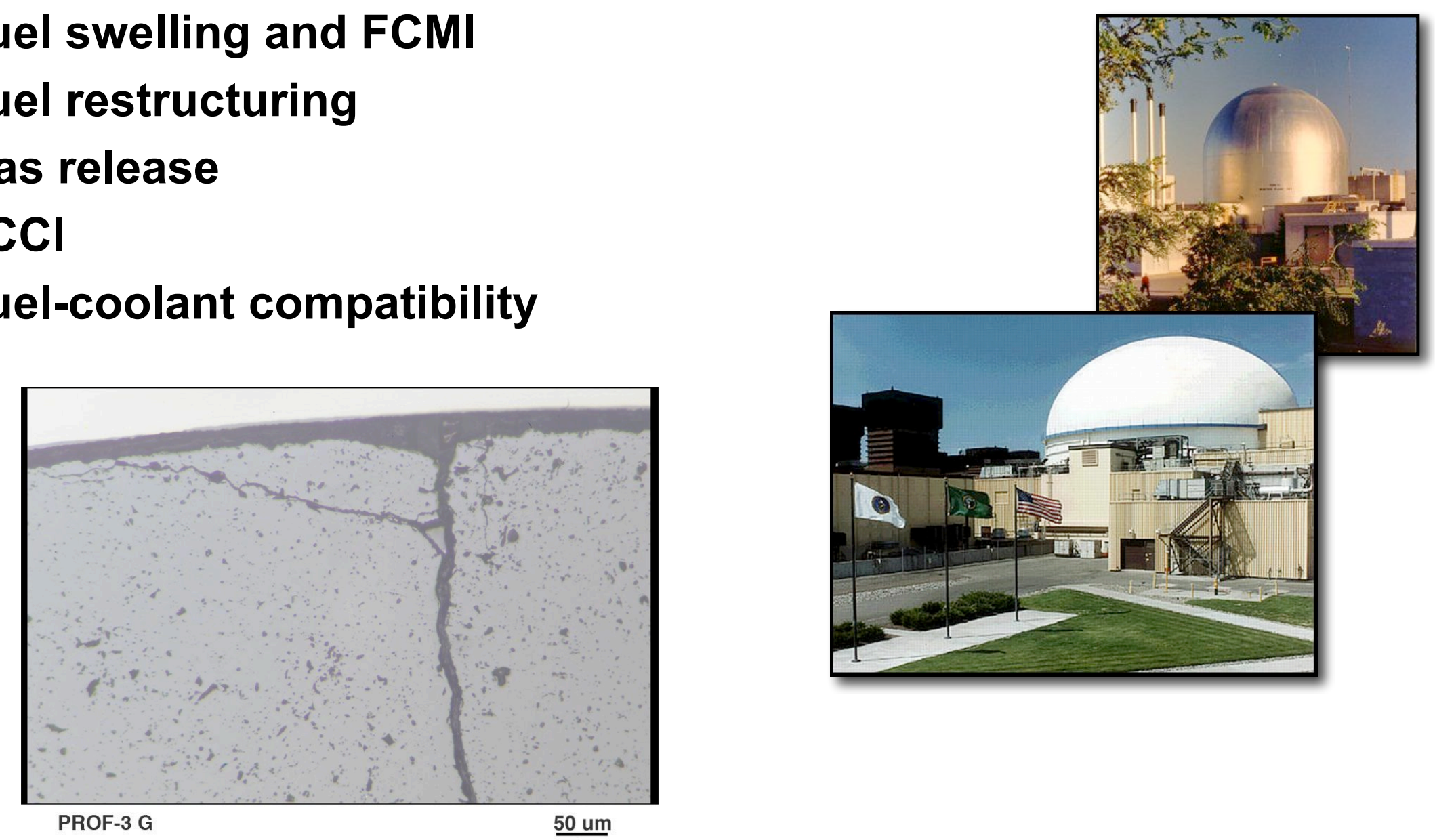


\section{MOX Fuel Behavior-Fuel Swelling and FCMI}

Idaho National Laboratory
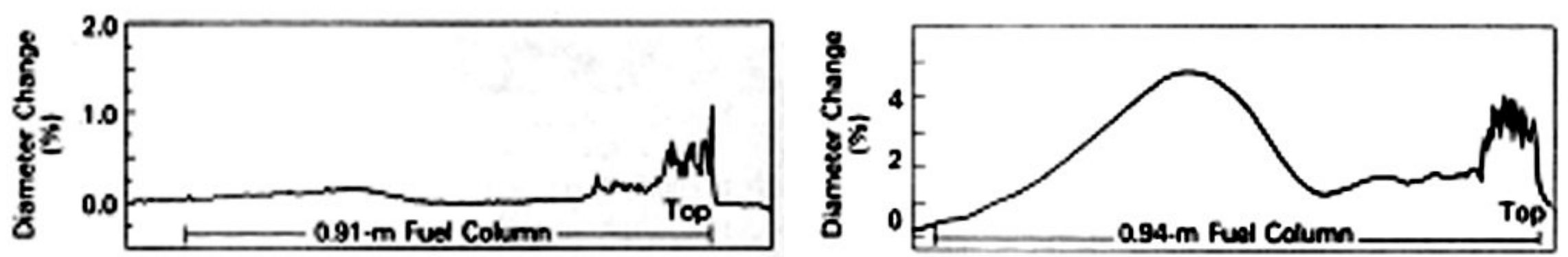

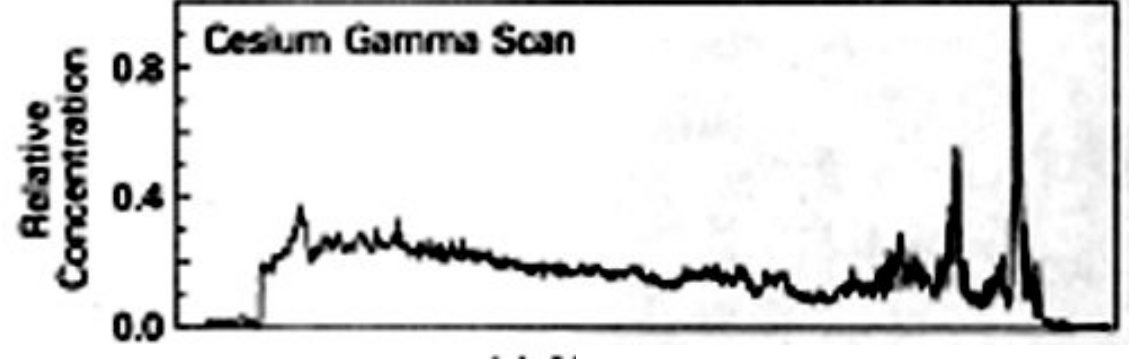

(a)

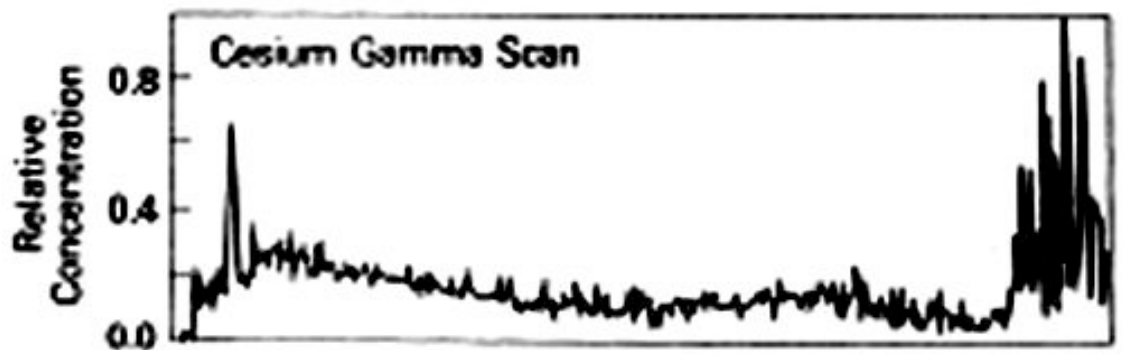

(b)

Diameter and cesium fission product accumulation in high-temperature MOX pins, HT9-clad (a) and D9-clad (b). Cs interacted with MOX fuel causing FCMI.

(from Bridges, et al ,1993) 


\section{MOX Fuel Behavior-Restructuring}

Idaho National Laboratory
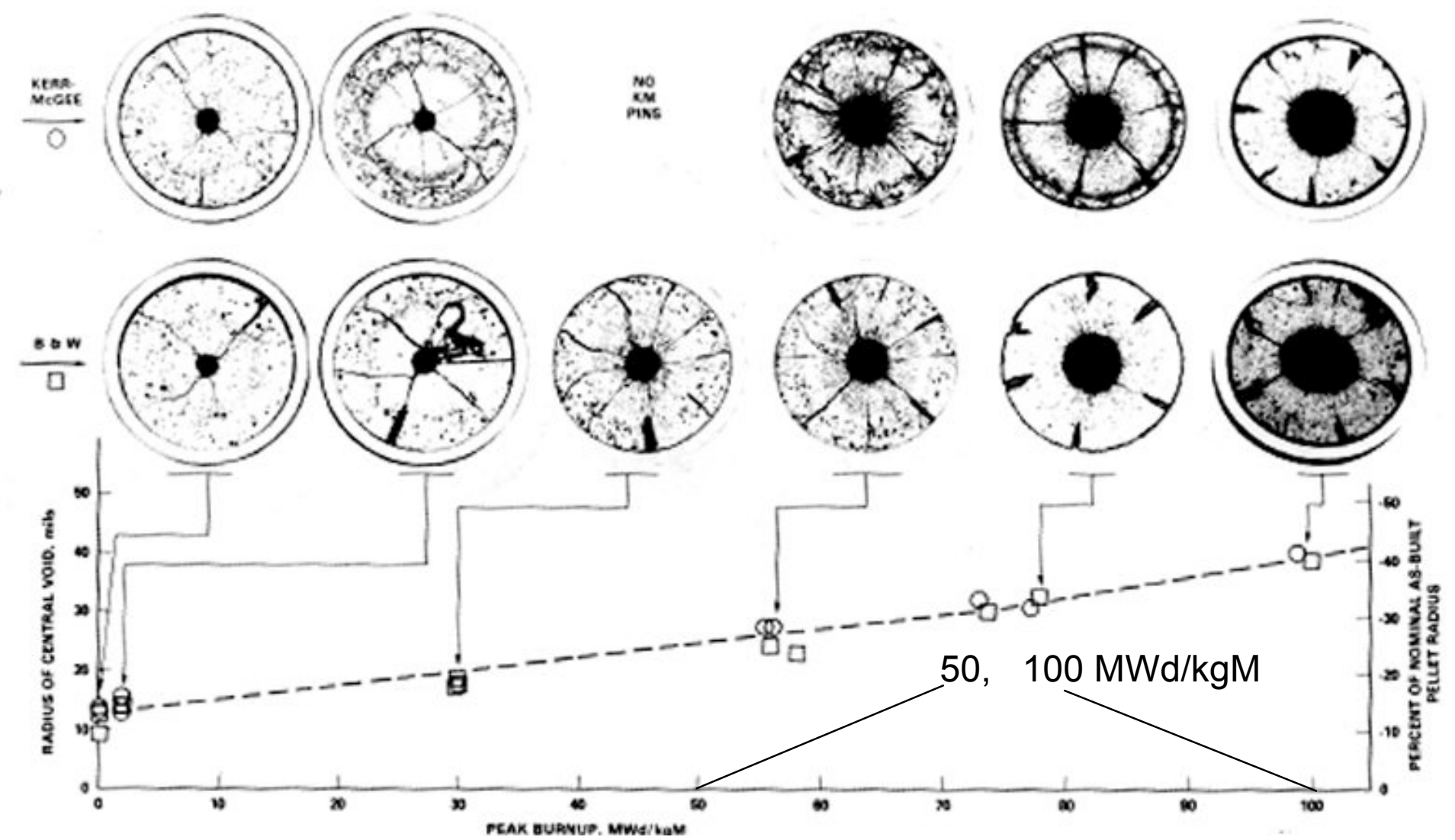

MOX fuel ceramography of FFTF driver fuel produced by Kerr-McGee and Babcock and Wilcox, showing restructuring as a function of burnup. (from Hales, et al, 1986) 


\section{MOX Fuel Behavior-Gas Release}

Idaho National Laboratory

MOX fuel operated at high temperature and undergoing restructuring exhibits high gas release.

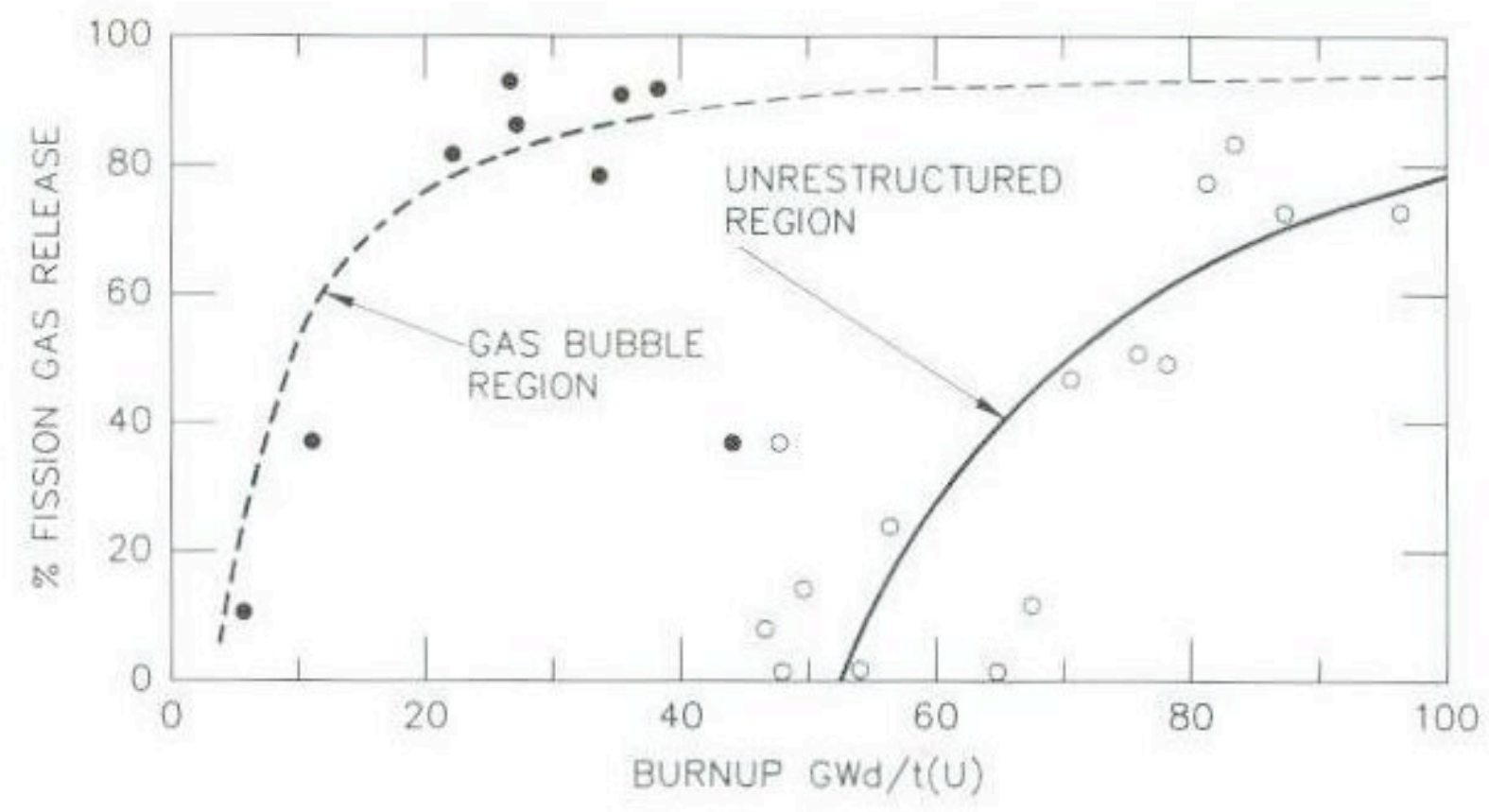

(from Lambert, et al, 1994) 


\section{MOX Fuel Behavior-FCCI}

Idaho National Laboratory

- Hypostoichiometric MOX for SFRs

- As-fabricated $\mathrm{O} / \mathrm{M}<2.00$ to suppress free oxygen at high burnup, mitigate $\mathrm{FCCl}$

- O/M ratio affects fabrication

- O/M ratio affects properties
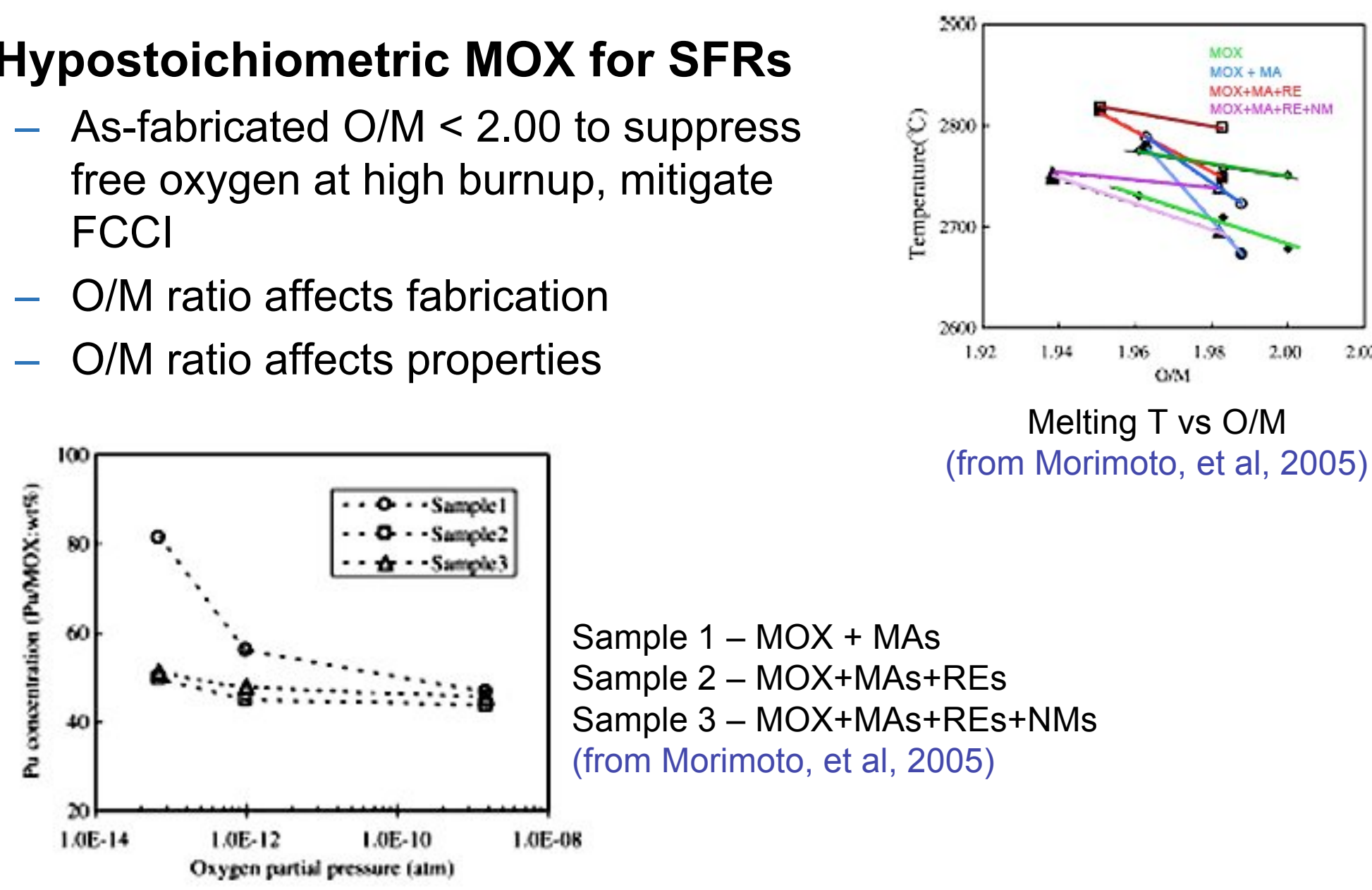

Melting $\mathrm{T}$ vs $\mathrm{O} / \mathrm{M}$

(from Morimoto, et al, 2005)

Sample $1-$ MOX + MAs

Sample $2-$ MOX+MAs+REs

Sample $3-$ MOX+MAs+REs+NMs

(from Morimoto, et al, 2005) 


\section{MOX Fuel Behavior-Fuel-coolant Compatibility}

Run-beyond-cladding-breach (RBCB) of MOX accompanied by fuel/Na reaction and initial crack extension

Fuel loss can be related to degree of interaction.

Reactant layer becomes coherent and inhibits further reaction with coolant.

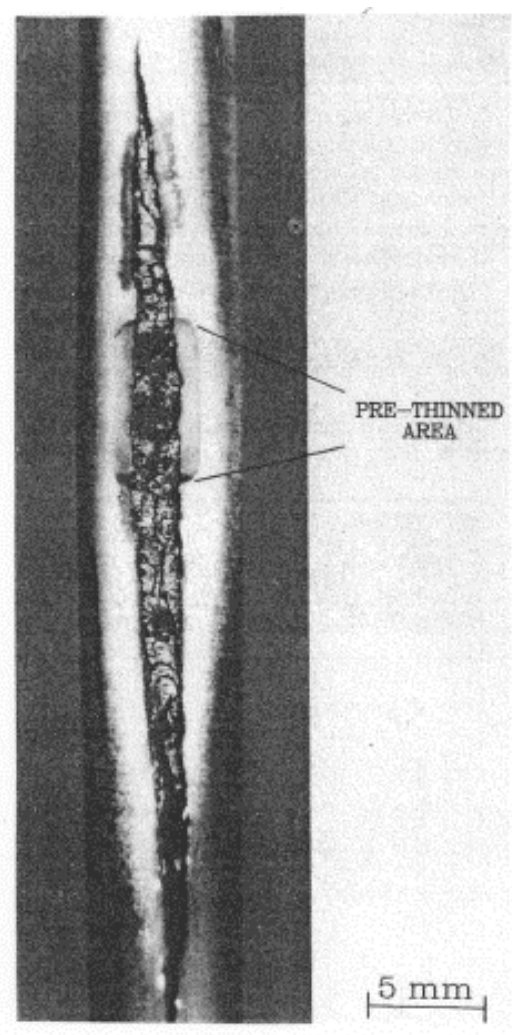

Typical breach extension in induced midlife failure, EBR-II K2B test.

(from Lambert, et al, 1990) 


\section{Stainless-Steel Cladding \& Duct Performance}

Performance Issues

- Cladding dilation

- Duct dilation, bowing, or twisting

- Irradiation Behavior

- Void swelling (AS)

- Irradiation creep (AS \& FMS)

- Irradiation embrittlement (AS \& FMS)

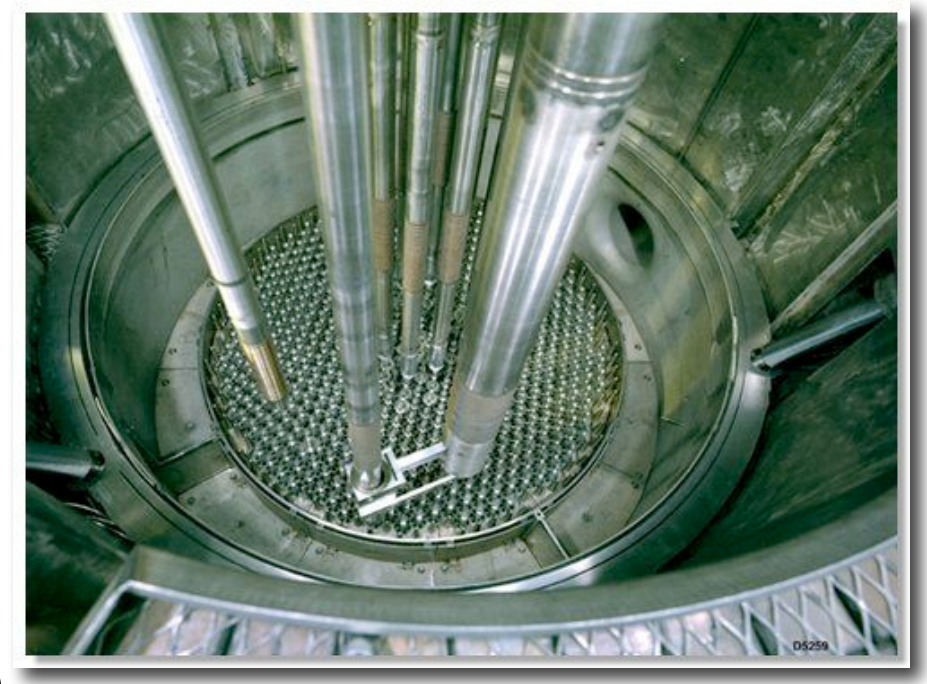

Alloys to Address Issues

- Advanced austenitic stainless steels

- Ferritic \& tempered-martensitic stainless steels

- Oxide-dispersion strengthened steel alloys 


\section{Duct Performance-Bowing \& Dilation}

Idaho National Laboratory
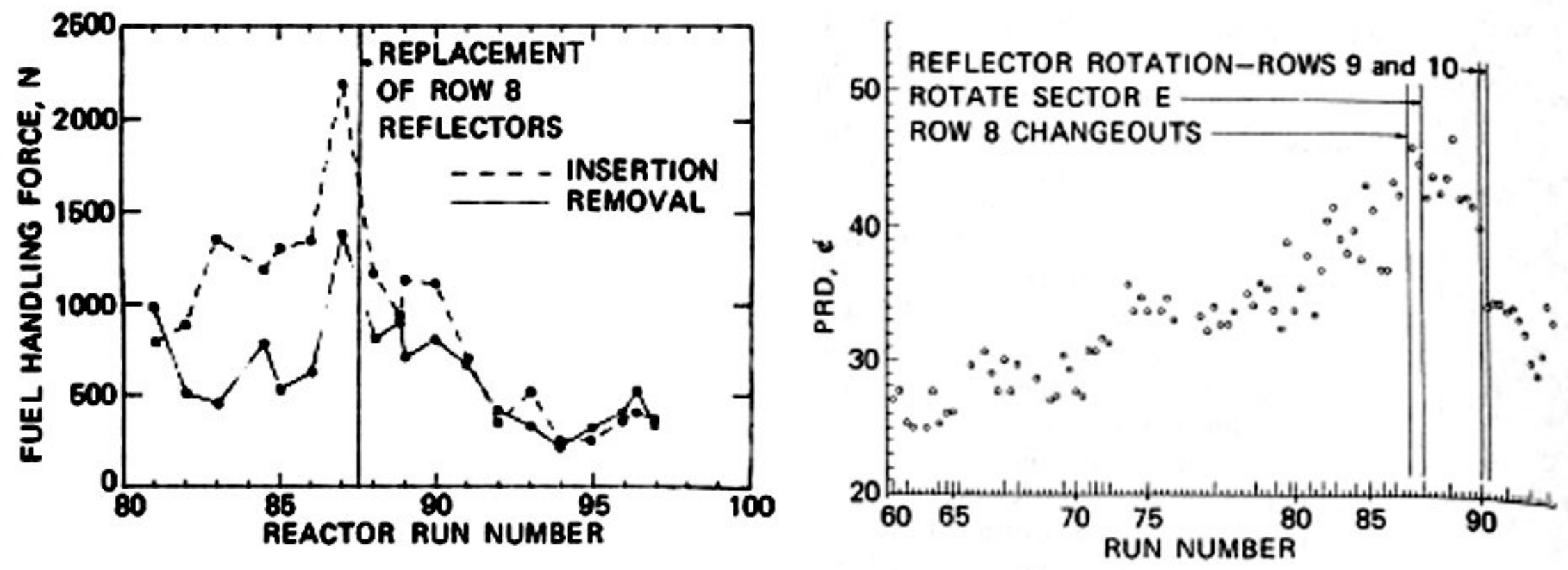

Effects on fuel handling forces and the Power Reactivity Decrement (PRD) to get to $62.5 \mathrm{MWt}$ versus EBR-II run number. Anomalies were caused by assembly hex-duct bowing and dilation. (from Shields, 1981) 


\section{Duct Performance—Length Change}

Idaho National Laboratory

R.D. Leggett, L.C. Walters / Status LMR fuel development in the USA

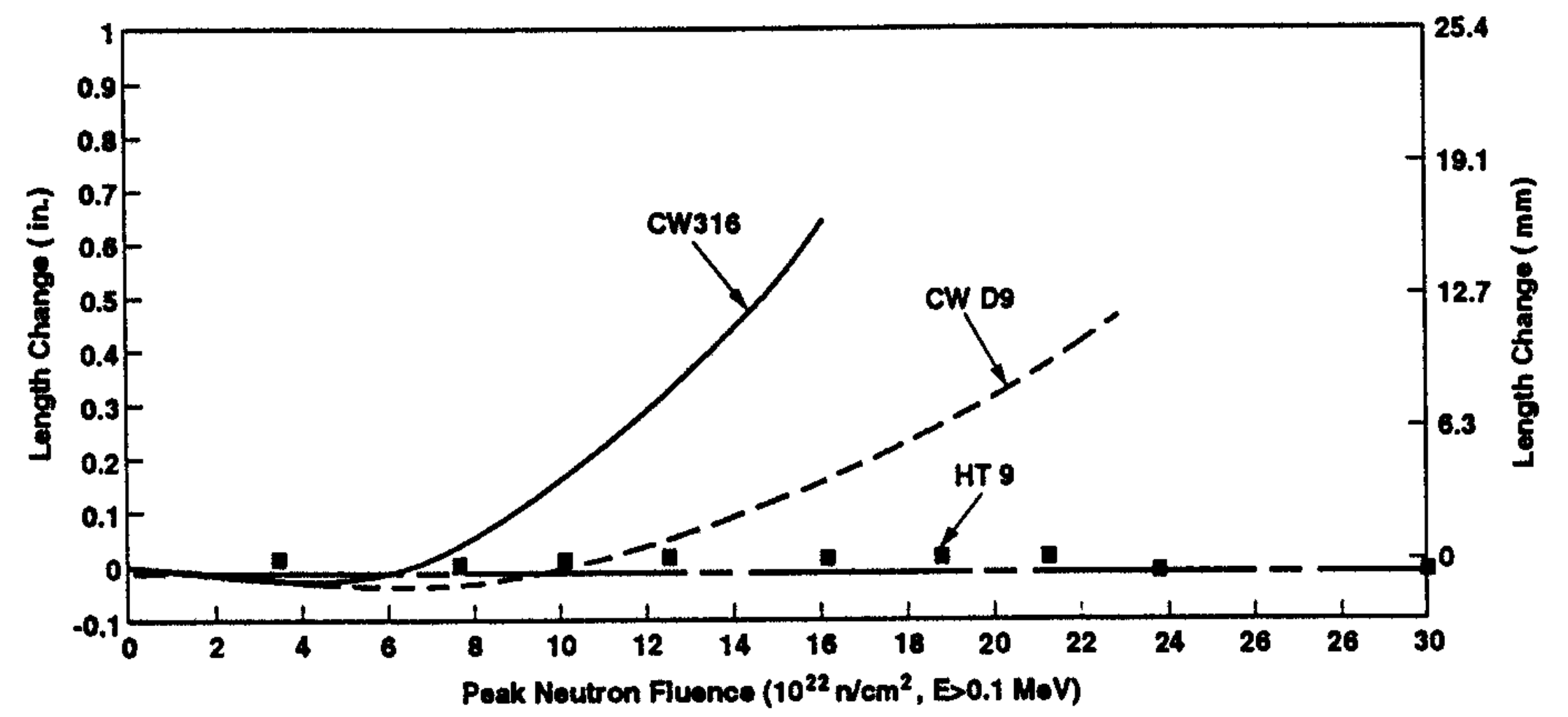

Fig. 4. FFTF subassembly length change with various duct materials. 


\section{Duct Performance-Void Swelling}

Idaho National Laboratory

Void swelling of commercial steels irradiated in EBR-II at $\sim 420^{\circ} \mathrm{C}$.

(from Gelles, 2004)

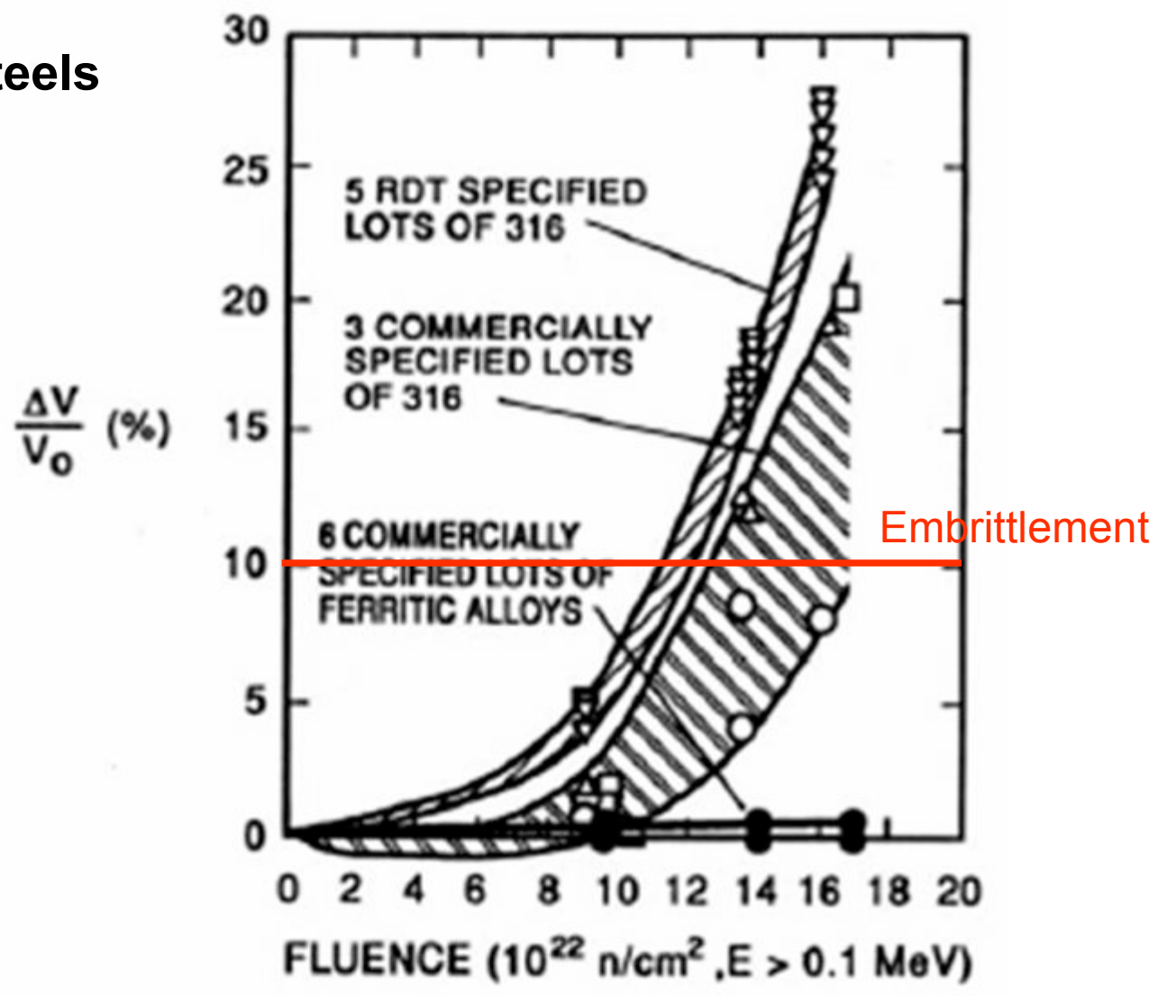




\section{Duct Performance-Void-induced Embrittlement}

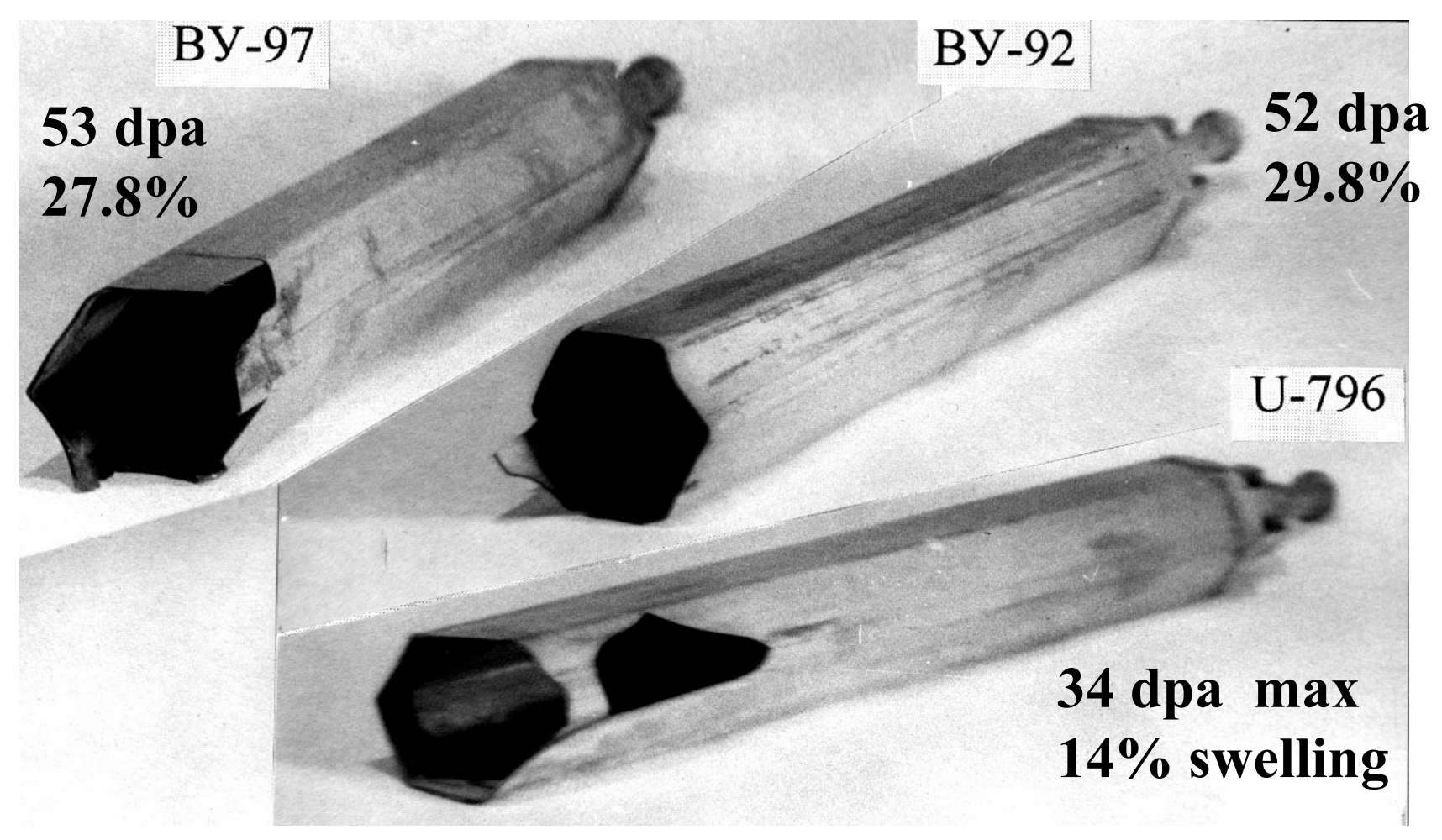

Severe void-induced embrittlement in $\mathrm{X} 18 \mathrm{H} 10 \mathrm{~T}$ (304ss-like) hexagonal assemblies from core and reflector regions of BOR-60. (from Garner, 2000) 


\section{Ferritic/Martensitic Stainless Steel Development}

Idaho National Laboratory

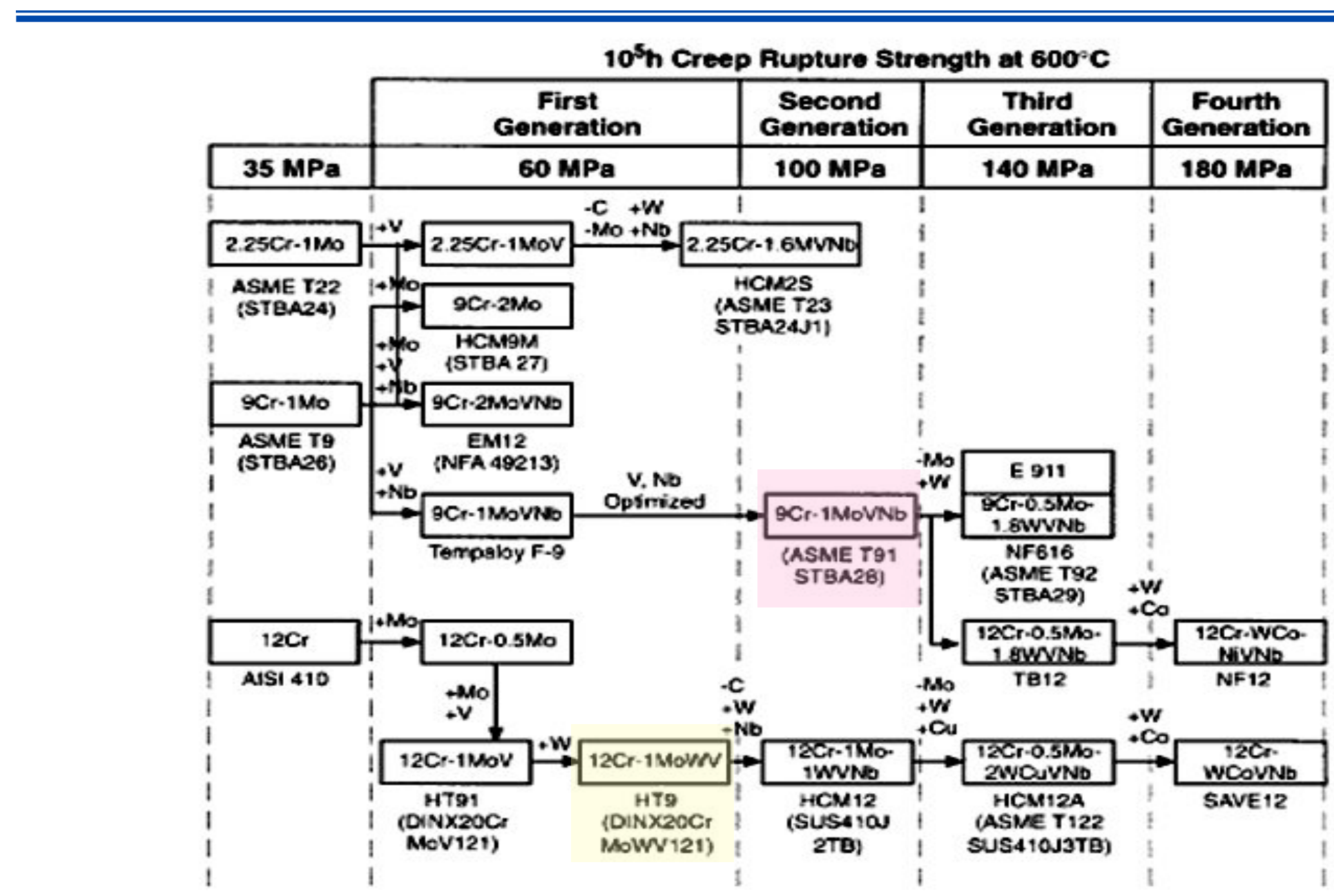

Development of ferritic/martensitic alloys for high-temperature applications. (from Allen, 2004) 


\section{Oxide Dispersion Strengthened (ODS) Ferritic/Martensitic Alloys}

- Ferritic/martensitic alloy use limited by high temperature stress rupture properties.

- Further strengthening achieved by addition of very small oxide particles (usually $\mathrm{Y}_{2} \mathrm{O}_{3}$ ).

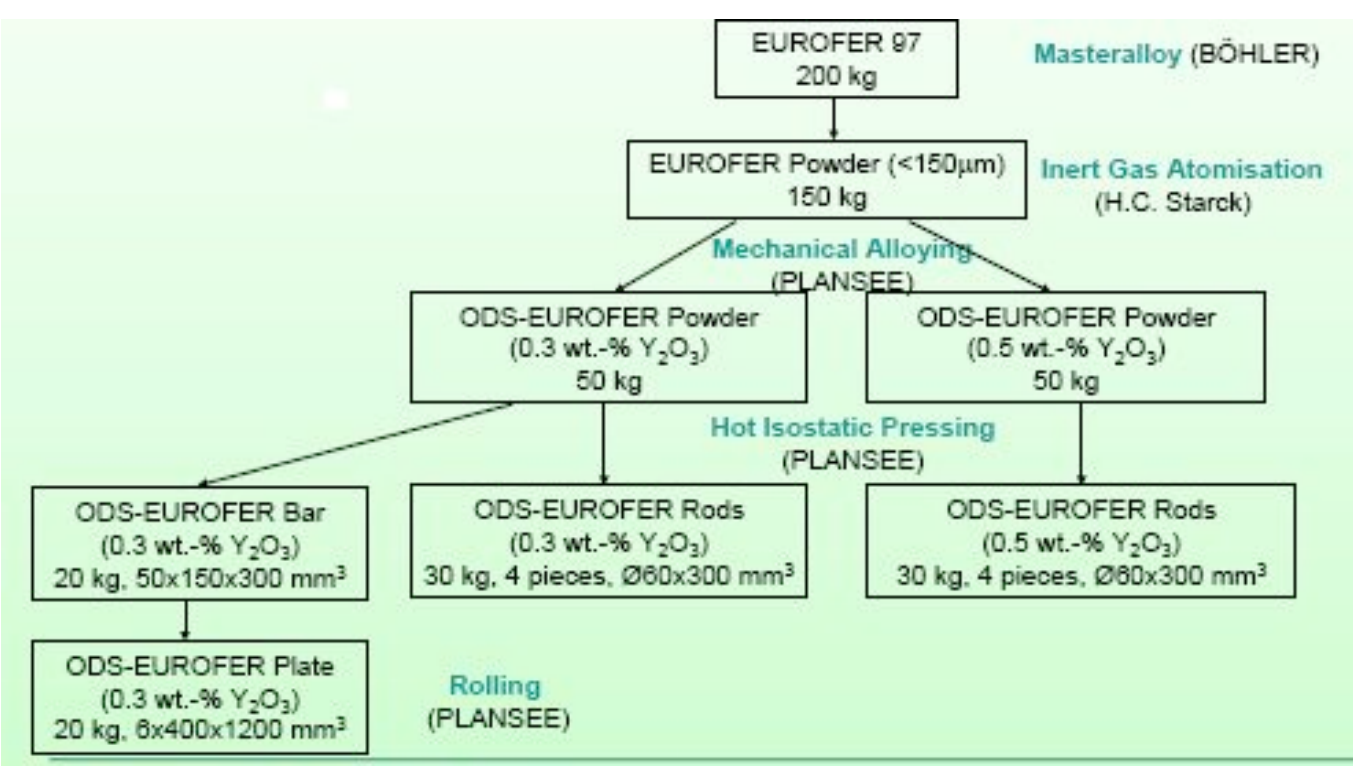

European ODS ferritic/martensitic alloy fabrication.

(from Lindau et al, 2005) 


\section{Oxide Dispersion Strengthened Ferritic/Mart- ensitic Alloys}

\section{Nanocomposited Ferritic (NCF) Steel}

(MA Fe-12Cr-3W-0.4Ti $+0.25 \mathrm{Y}_{2} \mathrm{O}_{3}: 12 \mathrm{YWT}$ ) Miller, Hoelzer, Zinkle ORNL

3-D Atom Probe Tomography

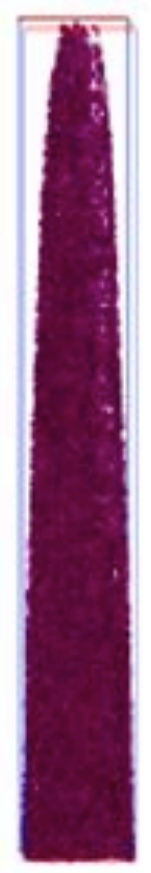

$\mathrm{Cr}$

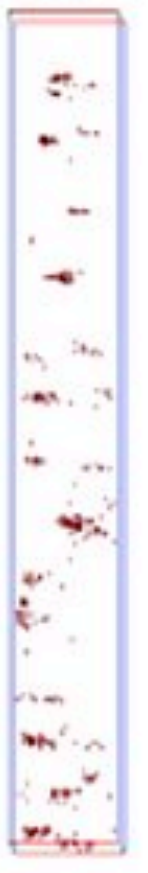

Y

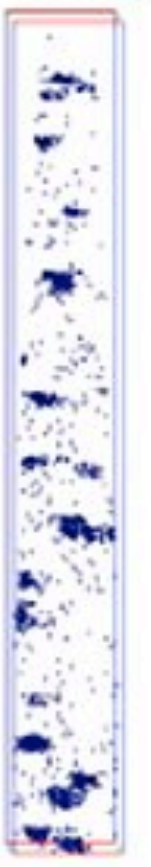

$\mathrm{Ti}$

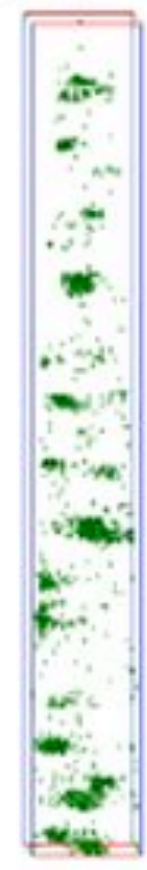

$\mathrm{O}$

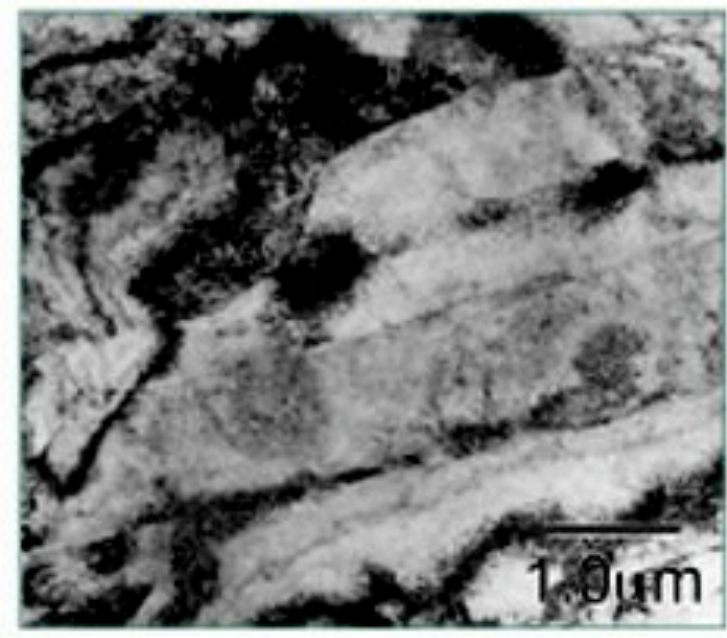

-very high number density of $\sim 10^{24} / \mathrm{m}$ of uniformly distributed nanoclusters - site occupancy on bcc Fe lattice - average size $\mathrm{r}_{\mathrm{g}}=2.0(+1-0.8) \mathrm{nm}$ - elongated grains containing high dislocation number density (TEM) 


\section{Strength of ODS Ferritic/Martensitic Steels}

Idaho National Laboratory
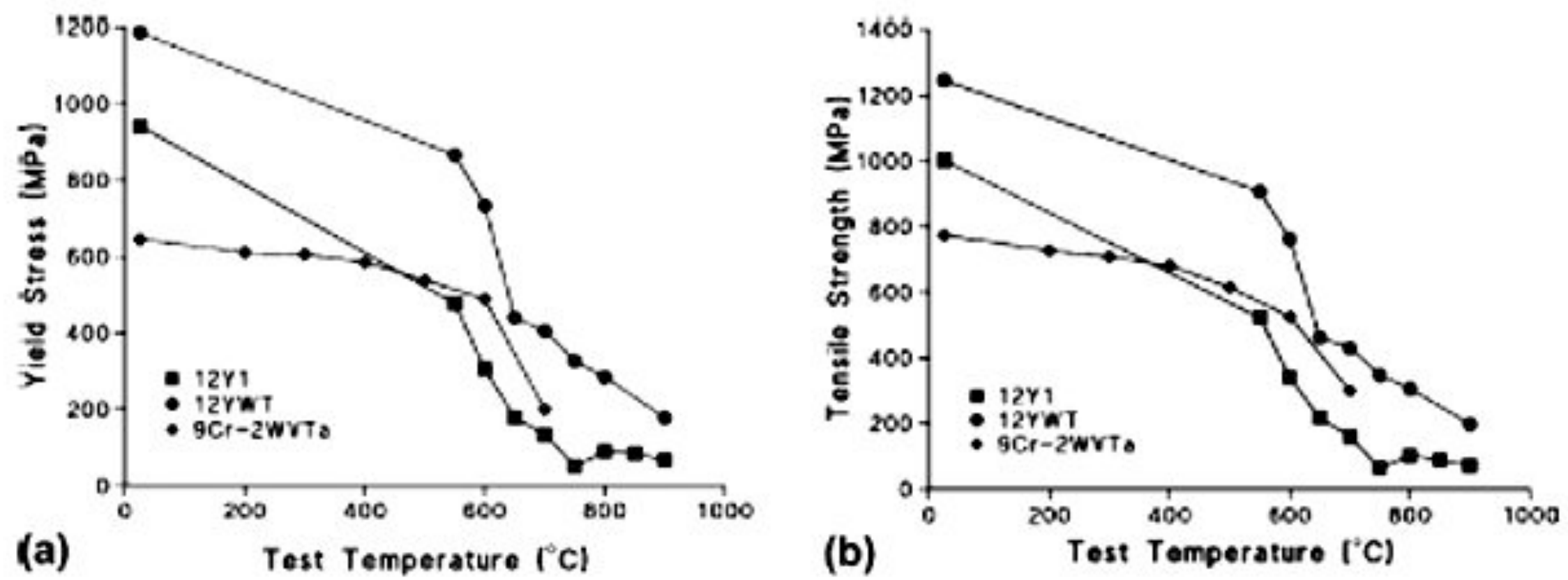

Yield (a) and tensile (b) strength of ODS alloys compared to a non-ODS Ferritic/ Martensitic steel. (from Klueh, et al 2005) 


\section{Stress Rupture of ODS Ferritic/Martensitic Steels}

Idaho National Laboratory

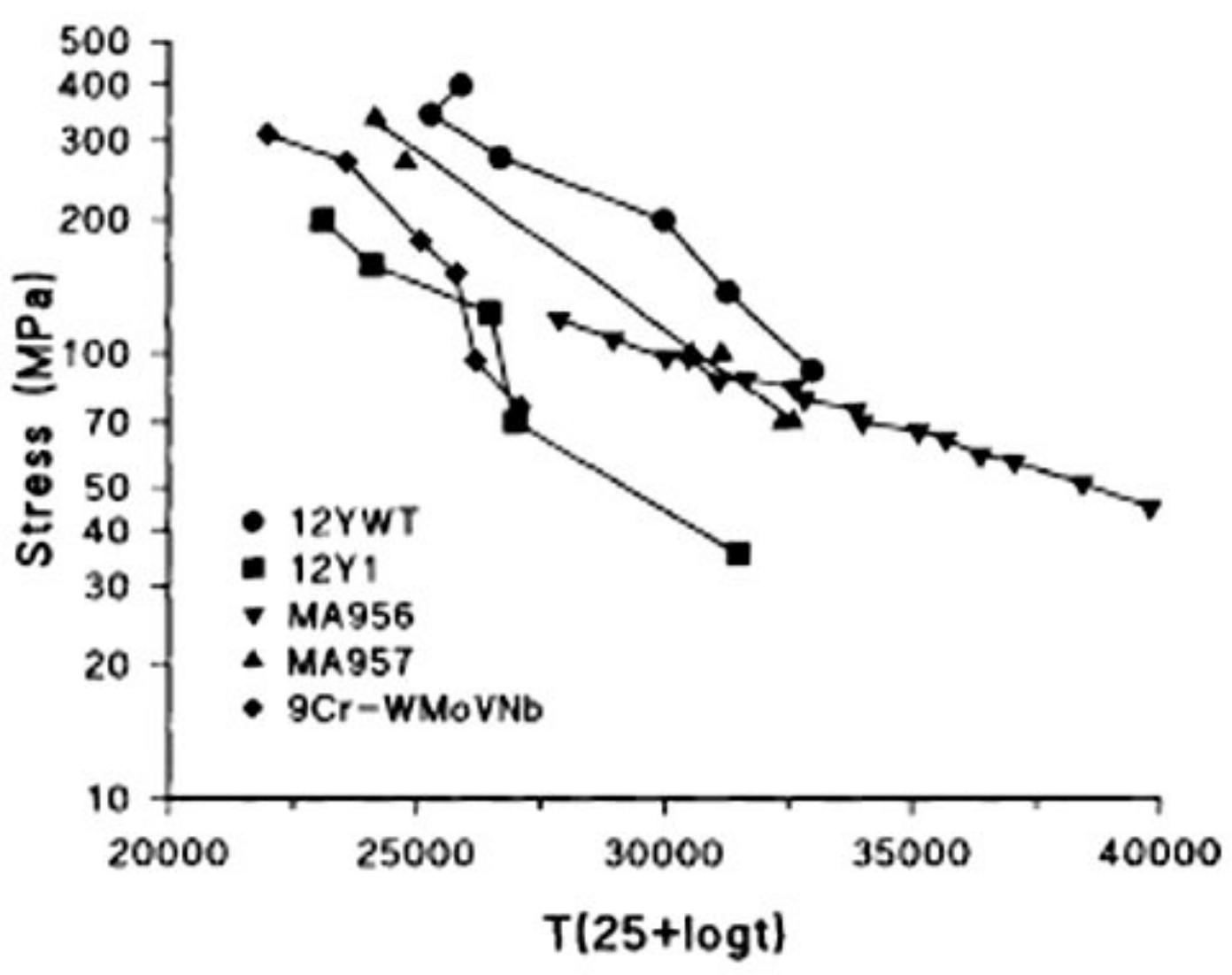

Stress rupture properties of ODS alloys compared to a non-ODS Ferritic/ Martensitic steel. (from Klueh, et al 2005) 


\section{Limitations to Use of Ferritic/Martensitic Steels}

- Ferritic/martensitic stainless steels (e.g., HT9, Mod 9Cr-1Mo, HCM12, etc.) are expected to be applicable to 200 dpa peak dose ( $140 \mathrm{MWd} / \mathrm{kg}$ burnup), $650^{\circ} \mathrm{C}$ peak cladding temperature.

- ODS ferritic-martensitic stainless steels (FMS S/A duct) is expected applicable to 250 dpa peak dose $(\sim 180 \mathrm{MWd} / \mathrm{kg}$ burnup) and $700^{\circ} \mathrm{C}$ peak cladding temperature.

- Major issues are accumulation of high burnup demonstration data and establishment of mass-production technology. 


\section{Base Fuel Technology: US Experience}

Crawford, Porter, Hayes, Journal of Nuclear Materials, 371: 202-231 (2007).

Idaho National Laboratory

\begin{tabular}{|c|c|c|c|}
\hline & Metallic & Mixed Oxide & Mixed Carbide \\
\hline $\begin{array}{l}\text { Driver Fuel } \\
\text { Operation }\end{array}$ & $\begin{array}{l}\geq 120,000 \mathrm{U}-\mathrm{Fs} \text { rods in } \\
304 \mathrm{LSS} / 316 \mathrm{SS} 1-8 \text { at. } \% \text { bu } \\
\sim 13,000 \mathrm{U}-\mathrm{Zr} \text { rods in } \\
316 \mathrm{SS} 10 \text { at. } \% \text { bu }\end{array}$ & $\begin{array}{l}>48,000 \text { MOX rods in } \\
316 S S \text { (Series I\&II) } 8 \text { at. } \% \\
\text { bu; }\end{array}$ & None applicable \\
\hline $\begin{array}{l}\text { Through } \\
\text { Qualification }\end{array}$ & $\begin{array}{l}\text { U-Zr in } 316 S S, \text { D9, HT9 } \geq \\
10 \text { at.\% bu in EBR-II \& } \\
\text { FFTF }\end{array}$ & $\begin{array}{l}\text { MOX in HT9 to } 15-20 \text { at. } \% \\
\text { bu (CDE) } \\
\text { MOX in } 316 S S \text { to } 10 \text { at. } \% \\
\text { bu }\end{array}$ & None applicable \\
\hline $\begin{array}{l}\text { Burnup } \\
\text { Capability \& } \\
\text { Experiments }\end{array}$ & $\begin{array}{l}600 \text { U-Pu-Zr rods; D9 \& } \\
\text { HT9 to > } 10-19 \text { at. } \% \text { in } \\
\text { EBR-II \& FFTF }\end{array}$ & $\begin{array}{l}4300 \text { MOX rods in } 316 S S \text { to } \\
10 \text { at. } \% \text {; fab var's; CL melt } \\
3000 \text { MOX rods in EBR-II; } \\
\text { peak at } 17.5 \text { at. } \% \text { bu } \\
2377 \text { MOX rods in D9 to } 10- \\
12 \text { at. } \% \text { bu; some at } 19 \\
\text { at. } \% \text { bu }\end{array}$ & $\begin{array}{l}18 \text { EBR-Il tests with } 472 \text { rods in } \\
316 \text { SS cladding; } 10 \text { rods up to } 20 \\
\text { at. } \% \text { w/o breach } \\
5 \text { of which experienced } 15 \% \text { TOP } \\
\text { at } 12 \text { at. } \% \\
219 \text { rods in FFTF, incl } 91 \text { in D } 9,91 \\
\text { with pellet \& sphere-pac fuel }\end{array}$ \\
\hline $\begin{array}{l}\text { Safety \& } \\
\text { Operability }\end{array}$ & $\begin{array}{l}6 \text { RBCB tests U-Fs \& U- } \\
\text { Pu-Zr/U-Zr(5) } \\
6 \text { TREAT tests U-Fs in } \\
\text { 316SS (9rods) \& U-Zr/U- } \\
\text { Pu-Zr in D9/HT9 (6 rods) }\end{array}$ & $\begin{array}{l}18 \text { RBCB tests; } 30 \\
\text { breached rods } \\
4 \text { slow ramp tests } \\
9 \text { TREAT tests MOX in } \\
316 S S \text { (14 rods) \& HT9 (5 } \\
\text { rods) }\end{array}$ & $\begin{array}{l}10 \text { TREAT tests ( } 10 \text { rods; Na or } \\
\text { He bond); } \leq 3-6 \text { times TOP } \\
\text { margins to breach } \\
\text { Loss-of-Na bond test; RBCB for } \\
100 \text { EFPD; Centerline melting test }\end{array}$ \\
\hline
\end{tabular}




\section{Transient Phenomena—Metallic Fuels}

- Pre-failure Behavior

- Axial expansion

- Cladding strain due to gas pressure

- Possible fuel-cladding liquefaction

- Failure Behavior

- Failure generally near top of fuel column

- Stress rupture due to gas pressure in cladding thinned by eutectic-like penetration and weakened at high temperature

- Post-failure Behavior

- Fuel injection into coolant

- Low stored energy, no reaction with coolant, local sodium voiding

- Overpower capability 4.0 to 4.4 times nominal power 


\section{Transient Phenomena-Metallic Fuels Fuel/Cladding 'Eutectic' Formation}

\section{$\mathrm{U}-10 \mathrm{Zr} / \mathrm{HT} 9$ at $800^{\circ} \mathrm{C}, 1 \mathrm{hr}$}

(from H. Tsai, et al, 1990)

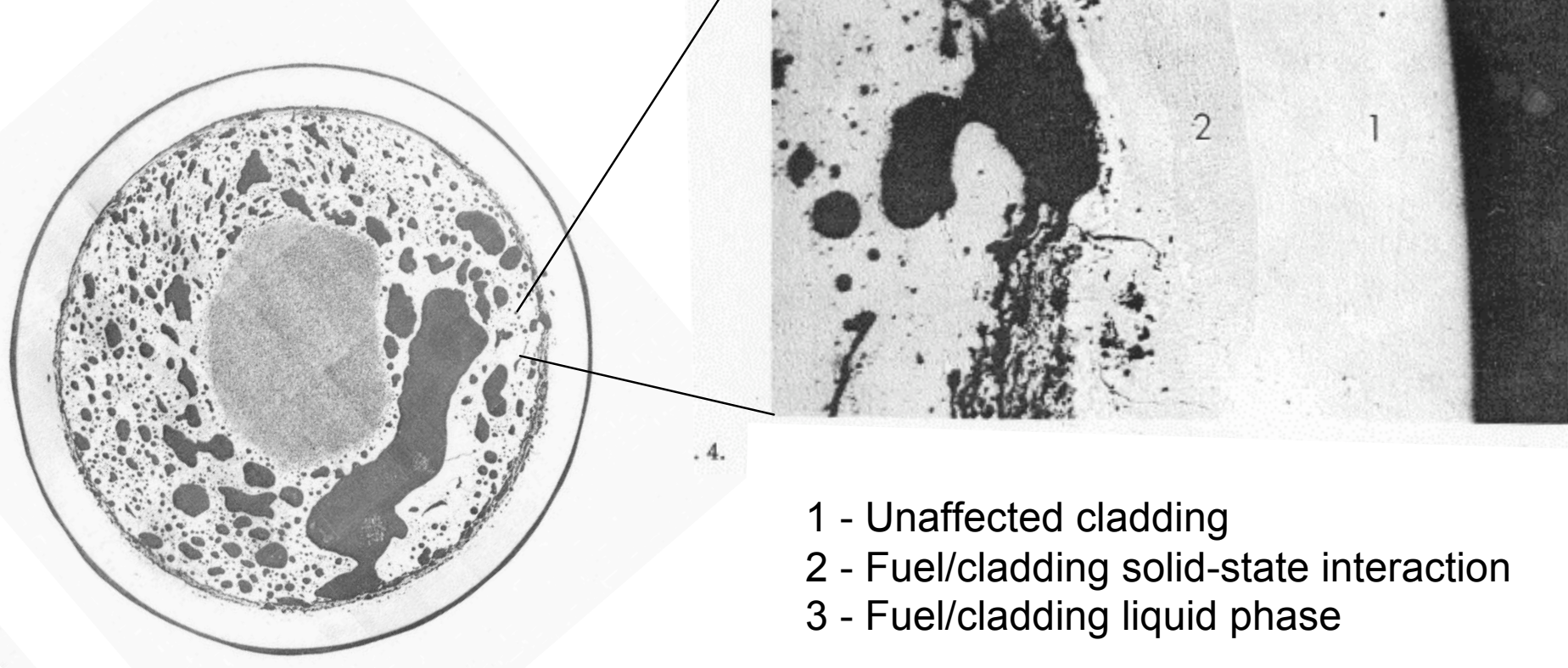




\section{Transient Phenomena-MOX Fuels}

- Pre-failure Behavior

- Axial relocation (apparently, upward axial motion)

- Cladding strain due to FCMI and gas pressure

- Failure Behavior

- Failure generally in upper $1 / 3$ of fuel column

- Cladding melt-through with gas pressure and FCMI, cladding weakened at high temperature

- Post-failure Behavior

- Fuel dispersal into coolant

- Relatively high stored energy, reaction with coolant, local sodium voiding

Overpower capability $\mathbf{3 . 0}$ to 4.5 times nominal power 


\section{Metallic and MOX Fuels Well Developed}

Metallic Fuels (U-Zr or U-Pu-Zr)

- Acceptable performance and reliability demonstrated up to 10 at.\% burnup, with capability demonstrated to 20 at. \% burnup

- Robust overpower capability demonstrated in TREAT tests: $\sim 4$ to $5 x$ 's nominal power; failures near top of fuel column; pre-failure axial expansion

- Performance issues typically creep rupture at high burnup, accelerated due to $\mathrm{FCCl}$.

- Performance phenomena with U-Fs, U-Zr \& U-Pu-Zr are the same. Burnup, temperature and cladding performance are key variables

\section{MOX Fuels}

- Acceptable performance and reliability demonstrated up to 10 at.\% burnup, with capability demonstrated to 20 at.\% burnup

- Robust overpower capability demonstrated in TREAT tests: $\sim 3$ to 4x's nominal power; well above primary and secondary FFTF trips; failures near core midplane; pre-failure axial fuel motion

- Performance issues typically creep rupture at high burnup, accelerated due to $\mathrm{FCMI}$ (and $\mathrm{FCCl}$ if $\mathrm{O} / \mathrm{M}$ not controlled). 


\section{Technical Readiness Levels for SFR Fuels}

Idaho National Laboratory

\begin{tabular}{|c|c|c|c|}
\hline$\overline{T R L}$ & Function & Definition & \multirow{5}{*}{$\begin{array}{l}\text { Transmuta } \\
\text { TRU-metal } \\
\text { (roughly sa } \\
\text { Metal expe } \\
\text { Oxide expe } \\
\text { Internation }\end{array}$} \\
\hline 1 & \multirow{3}{*}{ 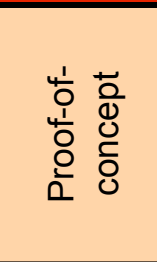 } & $\begin{array}{l}\text { A new concept is proposed. Technical options for the concept are } \\
\text { identified and relevant literature data reviewed. Criteria developed. }\end{array}$ & \\
\hline 2 & & $\begin{array}{l}\text { Technical options are ranked. Performance range and fabrication } \\
\text { process parametric ranges defined based on analyses. }\end{array}$ & \\
\hline 3 & & $\begin{array}{l}\text { Concepts are verified through laboratory-scale experiments and } \\
\text { characterization. Fabrication process verified using surrogates. }\end{array}$ & \\
\hline 4 & \multirow{3}{*}{$\begin{array}{l}\frac{0}{0} \\
\frac{0}{0} \\
\frac{0}{2} \\
0 \\
\frac{1}{0} \\
\frac{1}{0} \\
\frac{1}{0} \\
\frac{0}{0}\end{array}$} & $\begin{array}{l}\text { Fabrication of samples using stockpile materials at bench-scale }(\sim 100 \\
\text { gram batches). Irradiation testing of small-samples (rodlets) in relevant } \\
\text { environment. Design parameters and features establsihed. Basic } \\
\text { properties compiled. }\end{array}$ & \\
\hline 5 & & $\begin{array}{l}\text { Fabrication of pins using prototypic feedstock materials at laboratory- } \\
\text { scale }(10 \mathrm{~kg}) . \text { Pin-scale irradiation testing at relevant environment. } \\
\text { Primary performance parameters with representative compositions } \\
\text { under normal operating conditions quantified. }\end{array}$ & \multirow{5}{*}{$\begin{array}{l}\text { Driver Fuel/ } \\
\text { Analog } \\
\text { Transmutation } \\
\text { Fuel } \\
\text { Metal (U-Pu-Zr) } \\
\text { - Not formally } \\
\text { qualified } \\
\text { - Not used in } \\
\text { industrial-scale }\end{array}$} \\
\hline 6 & & $\begin{array}{l}\text { Fabrication of pins using prototypic feedstock materials at laboratory- } \\
\text { scale }(1 \mathrm{~kg}) \text { and using prototypic fabrication process. Pin-scale } \\
\text { irradiation testing at relevant and prototypic environment (steady-state } \\
\text { and transient testing). Safety basis establis }\end{array}$ & \\
\hline 7 & \multirow{3}{*}{ 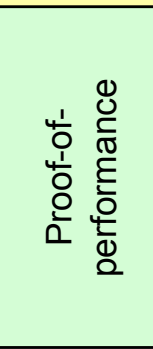 } & $\begin{array}{l}\text { Fabrication of test assemblies using prototypic feedstock materials at } \\
\text { engineering-scale }(100 \mathrm{~kg}) \text { and using prototypic fabrication process. } \\
\text { Assembly-scale irradiation testing at prototypic environment. Safety } \\
\text { basis established for full-core operations. }\end{array}$ & \\
\hline 8 & & $\begin{array}{l}\text { Fabrication of a few core-loads of fuel (tons) and operation of a } \\
\text { prototype reactor with such fuel. }\end{array}$ & \\
\hline 9 & & Routine commercial-scale operations. Multiple reactors operating & \\
\hline
\end{tabular}

Driver Fuel

Analog Transmutation

Fuel

Metal (U-Zr)

Oxide (U,Pu)

- Qualified for reactor

operations

- Successful mission operations

- Operational database wider for MOX, especially considering International experience 


\section{Metallic and MOX Fuels-Summary}

Metallic and MOX fuel performance in SFRs are both well known, with good experience in the US

- MOX fuel is particularly well developed in France and Japan

- GNEP application of these fuel forms to an actinide transmutation mission will bring significant new challenges 


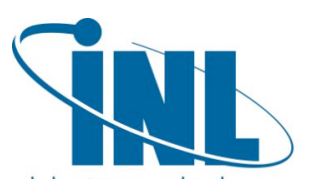

Idaho National Laboratory

\section{Fuel Test Plan for PRISM Prototype}




\section{Fuel Test Plan (Energy Policy Act of 1992 )}

- Created by Argonne National Laboratory, GE and Westinghouse for metallic fuels:

- "In response to the Energy Policy Act of 1992... complete R\&D activities by the end of 1996 for U-Pu-Zr driver fuel and U-Zr blanket fuel in order to initiate Title II design activities for the Prototype ALMR, and, by the end of 1998, to extend the database to include U-Pu-Zr fuel which contains minor actinides (Am, Np) in quantities representative of light water reactor spent-fuel recycle."

- The Fuel Test Plan (June 1994) outlined the remaining issues and schedules for achieving these goals. It also responded to all of the questions concerning fuel performance raised by the NRC in:

- "Pre-application Safety Evaluation Report for the Power Reactor Innovative Small Module (PRISM) Liquid-Metal Reactor, Final Report," U.S. Nuclear Regulatory Commission, NUREG-1368, January 1994. 


\section{Fuel Test Plan (1994)-Issues Identified for U-Pu-Zr Fuels}

- Steady-State Performance

- Fuel Swelling -well characterized; no expectation that MAs and higher concentrations of REs would have an effect

- Constituent Redistribution, FCMI, and FCCI-effects of MAs not well characterized; effect of higher RE concentrations needs to be assessed (also true for MOX)

- Fuel Pin Length (i.e., evaluation of experimental database to longer pin designs)—well characterized; no expectation that MAs and REs would have an effect

- Fission Gas Release-well characterized; no expectation that MAs and REs would have an effect 


\section{Fuel Test Plan (1994)-Issues Identified for U-Pu-Zr Fuels}

Transient Performance

- Fuel/Cladding Compatibility-effect of MAs not well characterized; effects of REs needs to be assessed. (MOX-O/M modifications may be needed)

- FCMI-well characterized; no expectation that MAs and REs would have an effect

- Fuel Melting-unusual compositions may need characterization. (MOX-O/M modifications may be needed)

- Post Failure Performance (Run-Beyond-Cladding-Breach)

- Fuel Loss, Fuel/Coolant Interaction-well characterized; no expectation that MAs and REs would have an effect. (MOX-confirmatory testing may be required depending on $\mathrm{O} / \mathrm{M}$ modifications) 


\section{Fuel Test Plan (1994)—General Issues Identified}

Fuel Reliability

- Statistical evaluation of fuel lifetime-fuel element reliability for recent designs has been controlled by cladding and duct properties (e.g., creep rupture for cladding, swelling for ducts). Expected lack of influence from MAs and REs on fuel reliability needs to be demonstrated in LTAs.

Fuel Modeling

- Semi-empirical models (LIFE4, SIEX, FRAPCON?) seem adequate to predict MOX lifetime.

- Incorporation of 'first principles' or 'atomistic' models may be used to short-cut design to demonstration scope.

- LIFE-METAL needs more mechanistic models. 


\section{Fuel Test Plan (1994)—General Issues Identified}

Fabrication (i.e., do modifications in fabrication methods affect fuel performance?)

- Metallic Fuel: The simplicity of metallic fuel fabrication well suited for transfer to a remote setting. Waste from molds and crucibles, potential losses of Am (due to high vapor pressure) needs to be reduced/eliminated by modification of casting process; replace injection casting with bottom pour (no vacuum, reusable molds, etc.).

- MOX Fuel: Proven fabrication methods in glovebox setting. Hot cell/remote setting may create challenges. O/M control with the inclusion of MAs and REs unproven. 


\section{Fuel Test Plan (1994)—General Issues Identified}

- Cladding and Duct Performance

- Ferritic/martensitic steels expected applicable to 200 dpa dose ( 140 $\mathrm{MWd} / \mathrm{kg}$ fuel burnup), $650^{\circ} \mathrm{C}$ peak temperature; should be applicable for ducts to higher exposures.

- ODS ferritic stainless steel cladding expected applicable to $250 \mathrm{dpa}$ dose ( $180 \mathrm{MWd} / \mathrm{kg}$ fuel burnup) and $700^{\circ} \mathrm{C}$ peak temperature.

- Major issues

$>$ Accumulation of high burnup/dose demonstration data

$>$ Establish industrial production base 


\section{Fuel Test Plan (1994)—Conclusions}

Idaho National Laboratory

Most fuel performance issues are well understood and adequately tested

- U-Pu-Zr metallic fuel

$-(\mathrm{U}, \mathrm{Pu}) \mathrm{O}_{2}$

Variations in fuel compositions to include MAs and possible carry-over of RE fission products will require additional testing

Fuel modeling and code development needs additional effort, especially for metallic fuels 
FivL

Idaho National laboratory

\section{Fuel Specification}




\section{Metallic Fuel Specification-Historical Trend}

EBR-II experience showed that early specifications contained too much 'process control' information

- Chemistry over-specified (i.e., concern for potential minor contaminants that would not affect fuel performance)

- Dimensional control of fuel slug over-specified (i.e., to ensure the fuel and $\mathrm{Na}$ bond height would be as expected, but these did not critically influence thermal hydraulics)

- The last fuel specification (Mark-V) written reflected much-relaxed tolerances and was largely based upon delivering a homogeneous fuel with a known/controlled reactivity. 


\section{Metallic Fuel Specification-Example}

EBR-II Mark-V Fuel Specification

- Recycled metallic fuel (U-Pu-Zr in HT9 cladding) containing carry-over $\mathrm{RE}$ fission products and actinide isotopes characteristic of recycled EBR-II fuel

- Written to exclude process control information.

- Chemistry

$>$ Slug top \& bottom sampled for homogeneity.

$>C, O, N$, and Si impurity analysis to ensure $\mathrm{Zr}$ in solution ( $\mathrm{Zr}$ important to $\mathrm{FCCl}$ and these impurities tie-up $\mathrm{Zr}$ and render it ineffective); all other impurity elements analyzed for information only.

$>$ Actinide tolerances relaxed (e.g., Pu $=20 \pm 1$ wt.\%); isotopics measured for use in determining acceptable slug weight 


\section{Fuel Specification (Example)}

EBR-II Mark-V Fuel Specification

- Fuel slug dimension and weight

$>$ Dimensional guidelines relaxed (e.g., \pm 0.003 in. on diameter, \pm 0.1 in on length)

$>$ Fuel slug mass (tolerances set by physics analysis for EBR-II):

$1.23^{* 239} P u+235 U+0.51 * 240 P u+0.10^{* 238} U=45.4 \pm 2.3$ grams per slug

$>$ Na bond height $(0.50 \pm 0.25$ in.)

- Radiography to measure $\mathrm{Na}$ bond height used for bond quality.

- Closure welds qualified and 100\% visual inspection, $100 \%$ leak check (unless qualification showed this could be eliminated). 


\section{Fuel Specification}

- Draft metallic fuel specification for PRISM (by GE with ANL input) based upon Mark-V approach (GE 23A3912, Rev.B, 2-2892).

- MOX fuel specification should utilize same approach, but performance issues will require some dimensional tolerances to remain tight due to He bond. Control of starting $\mathrm{O} / \mathrm{M}$, etc. may require additional chemistry control. 


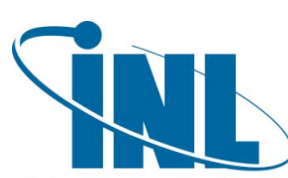

Idaho National Laboratory

\section{Experience with Fuels Containing Minor Actinides}




\section{GNEP Fuels Campaign Objective}

Idaho National Laboratory

- The ultimate objective of the fuel development campaign is to develop and qualify the initial transmutation fuel/target for use in fast burner reactors over the entire range of compositions:

- obtain closure of the fuel cycle,

- maintain the commercial competitiveness for nuclear energy

- If a step-wise approach is adopted by DOE in closing the fuel cycle, develop and qualify fuels to support the intermediate steps.

- Maintain a long-term R\&D program

- risk mitigation

- capabilities and long-term competitiveness

Qualification means "demonstration that the fuel will perform predictably and acceptably under normal and accident conditions". This is achieved by

$>$ Rigorous testing for a limited number of fuel compositions, fabrication processes and cladding materials up to the level of lead-test assemblies

$>$ An extensive modeling and simulation approach to quickly extend the empirical database to the entire range of variables that are needed to meet the GNEP objectives. 


\section{SFR Transmutation Fuels with Minor Actinides (MAs) and Rare Earth (RE) Fission Products}

- Unique Features of SFR Transmutation Fuels

- Pu content, which depending on CR selected my be higher than historic database (with corresponding decrease in $U$ content)

- Minor actinides (Am, Np, Cm) present in significant quantities

- Rare earth fission product (La, Ce, $\mathrm{Pr}, \mathrm{Nd}$ ) carryover from recycle step may be non-trivial

- Gives Rise to Challenges and Unknowns

- Need for remote fuel fabrication

- Likely need for new fabrication methods (e.g., due to Am volatility; waste minimization, etc.)

- Effects on fuel performance must be determined

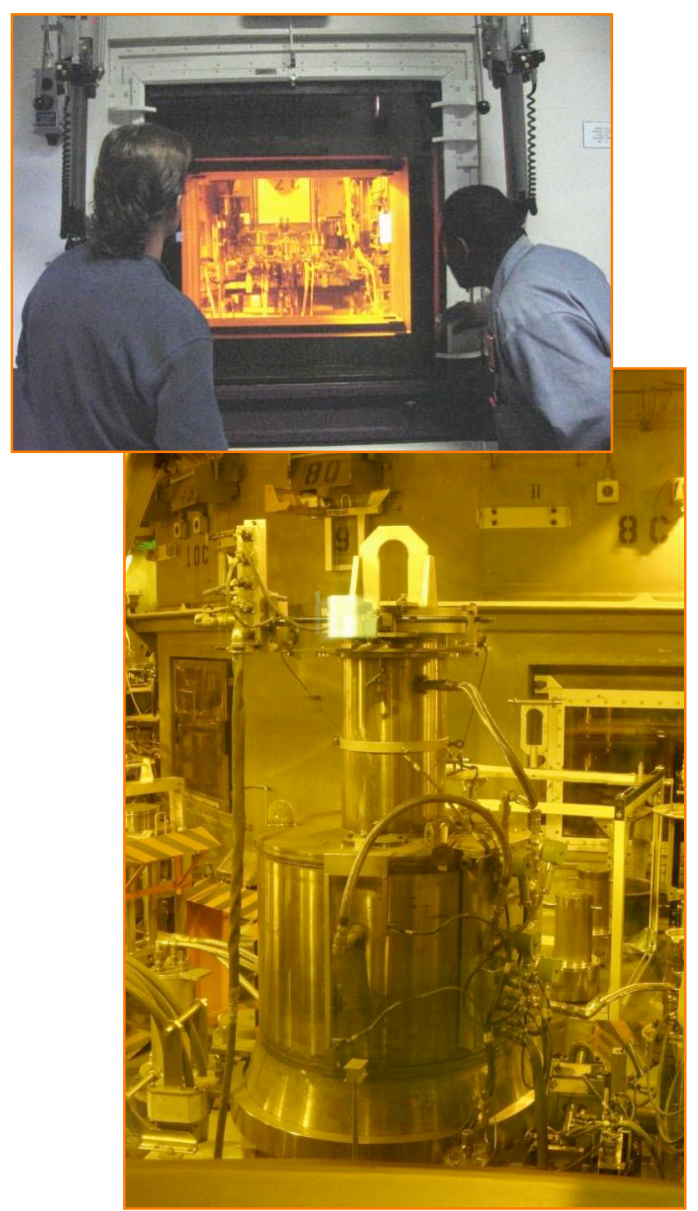




\section{AFC Test Series in the Advanced Test Reactor}

Idaho National Laboratory

\begin{tabular}{|l|l|l|l|l|}
\cline { 2 - 5 } \multicolumn{1}{c|}{} & \multicolumn{1}{c|}{ AFC-1 } & \multicolumn{1}{c|}{ AFC-2 } & \multicolumn{1}{c|}{ AFC-3 } & \multicolumn{1}{c|}{ AFC-4 } \\
\hline \multirow{3}{*}{$\begin{array}{l}\text { Test } \\
\text { Strategy }\end{array}$} & $\begin{array}{l}\text { Scoping - } \\
\text { Many compositions }\end{array}$ & $\begin{array}{l}\text { Scoping - } \\
\text { Focused } \\
\text { compositions }\end{array}$ & $\begin{array}{l}\text { Focused } \\
\text { compositions }\end{array}$ & $\begin{array}{l}\text { Focused } \\
\text { compositions }\end{array}$ \\
\cline { 2 - 5 } & Nominal conditions & Nominal conditions & $\begin{array}{l}\text { Nominal \& limiting } \\
\text { conditions }\end{array}$ & Nominal conditions \\
\hline $\begin{array}{l}\text { Capsule } \\
\text { Type }\end{array}$ & Drop-in & Drop-in & Instrumented lead & Drop-in \\
\hline $\begin{array}{l}\text { Fuel } \\
\text { Types }\end{array}$ & Metals & Metals & $\begin{array}{l}\text { Metals } \\
\text { Oxides }\end{array}$ & $\begin{array}{l}\text { Metals } \\
\text { Oxides }\end{array}$ \\
\hline $\begin{array}{l}\text { Key } \\
\text { Features }\end{array}$ & $\begin{array}{l}\text { Baseline } \\
+ \text { MA }\end{array}$ & $\begin{array}{l}\text { Baseline } \\
+ \text { MA + RE }\end{array}$ & $\begin{array}{l}\text { Temperature } \\
\text { control }\end{array}$ & $\begin{array}{l}\text { Recycle feed } \\
\text { Remote fabrication }\end{array}$ \\
\hline $\begin{array}{l}\text { Time } \\
\text { Frame }\end{array}$ & $\begin{array}{l}\text { FY 2003 - } \\
\text { FY 2008 }\end{array}$ & $\begin{array}{l}\text { FY 2008 - } \\
\text { FY 2013 + }\end{array}$ & $\begin{array}{l}\text { FY 2009 - } \\
\text { FY 2013 }\end{array}$ & $\begin{array}{l}\text { FY 2010 - } \\
\text { FY 2014 }\end{array}$ \\
\hline
\end{tabular}




\section{AFC-2A,B Currently Under Irradiation in the ATR}

Idaho National Laboratory

AFC-2A,B Test Matrix

\begin{tabular}{|c|c|}
\hline Rodlet & AFC-2A\&B \\
\hline 1 & U-20Pu-3Am-2Np-15Zr \\
2 & U-20Pu-3Am-2Np-1.0RE-15Zr \\
3 & U-20Pu-3Am-2Np-1.5RE-15Zr \\
4 & U-30Pu-5Am-3Np-1.5RE-20Zr \\
5 & U-30Pu-5Am-3Np-1.0RE-20Zr \\
6 & U-30Pu-5Am-3Np-20Zr \\
\hline
\end{tabular}
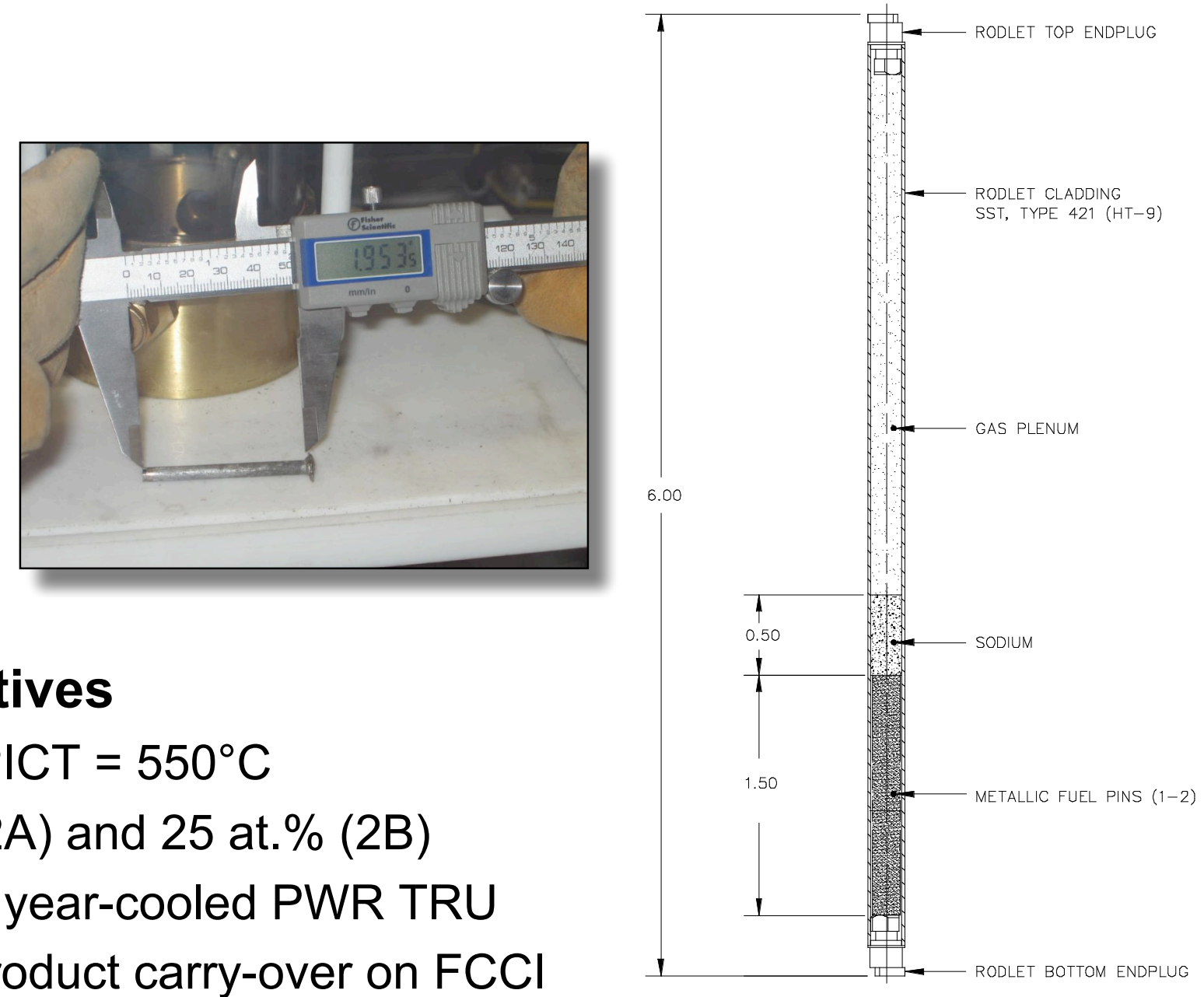

AFC-2A,B Test Objectives

- $\mathrm{LHGR}=350 \mathrm{~W} / \mathrm{cm} ; \mathrm{PICT}=550^{\circ} \mathrm{C}$

- Burnups of 10 at.\% (2A) and 25 at.\% (2B)

- Group recovery of 30 year-cooled PWR TRU

- Effect of RE fission product carry-over on $\mathrm{FCCl}$ 


\section{AFC-2C,D Currently in Fabrication}

Idaho National Laboratory

AFC-2C,D Test Matrix

\begin{tabular}{|c|c|}
\hline Rodlet & AFC-2C\&D \\
\hline 1 & $\left(\mathrm{U}_{0.75}, \mathrm{Pu}_{0.20}, \mathrm{Am}_{0.03}, \mathrm{~Np}_{0.02}\right) \mathrm{O}_{1.95}$ \\
2 & $\left(\mathrm{U}_{0.80}, \mathrm{Pu}_{0.20}\right) \mathrm{O}_{1.98}$ \\
3 & $\left(\mathrm{U}_{0.75}, \mathrm{Pu}_{0.20}, \mathrm{Am}_{0.03}, \mathrm{~Np}_{0.02}\right) \mathrm{O}_{1.98}$ \\
4 & $\left(\mathrm{U}_{0.75}, \mathrm{Pu}_{0.20}, \mathrm{Am}_{0.03}, \mathrm{~Np}_{0.02}\right) \mathrm{O}_{1.95}$ \\
5 & $\left(\mathrm{U}_{0.80}, \mathrm{Pu}_{0.20}\right) \mathrm{O}_{1.98}$ \\
6 & $\left(\mathrm{U}_{0.75}, \mathrm{Pu}_{0.20}, \mathrm{Am}_{0.03}, \mathrm{~Np}_{0.02}\right) \mathrm{O}_{1.98}$ \\
\hline
\end{tabular}

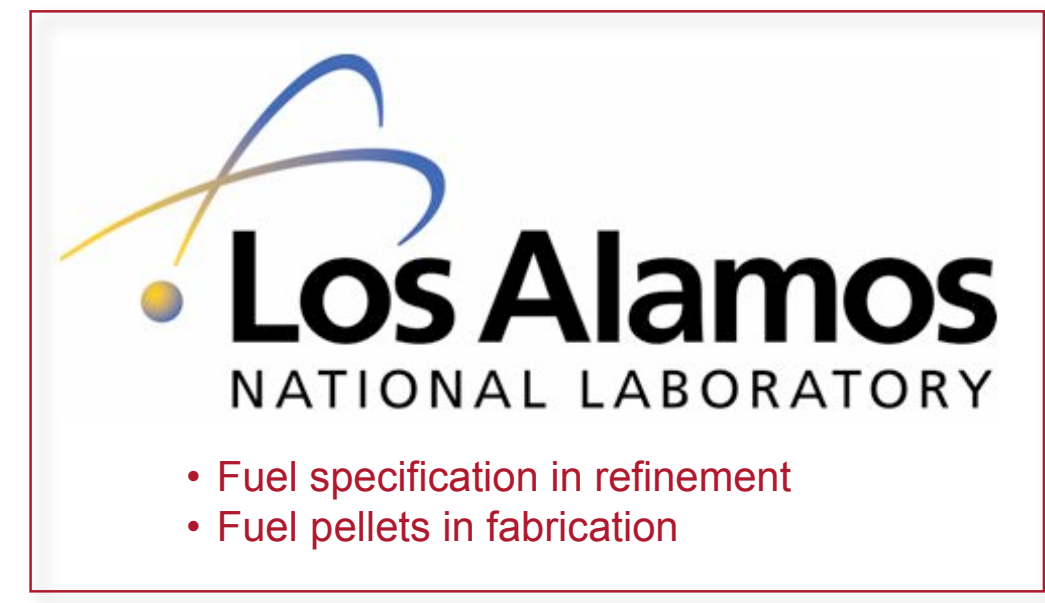

AFC-2C,D Test Objectives

- $\mathrm{LHGR}=350 \mathrm{~W} / \mathrm{cm} ; \mathrm{PICT}=550^{\circ} \mathrm{C}$

- Burnups of 10 at.\% (2A) and 25 at.\% (2B)

- Group recovery of 30 year-cooled PWR TRU

- Effect of O/M on FCCI

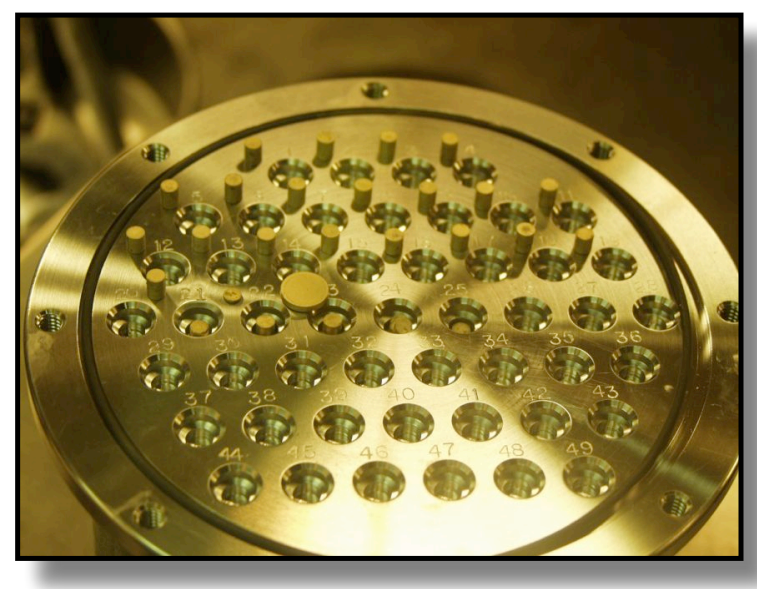




\section{Metallic Fuel with MA-X501 Fabrication}

Idaho National Laboratory

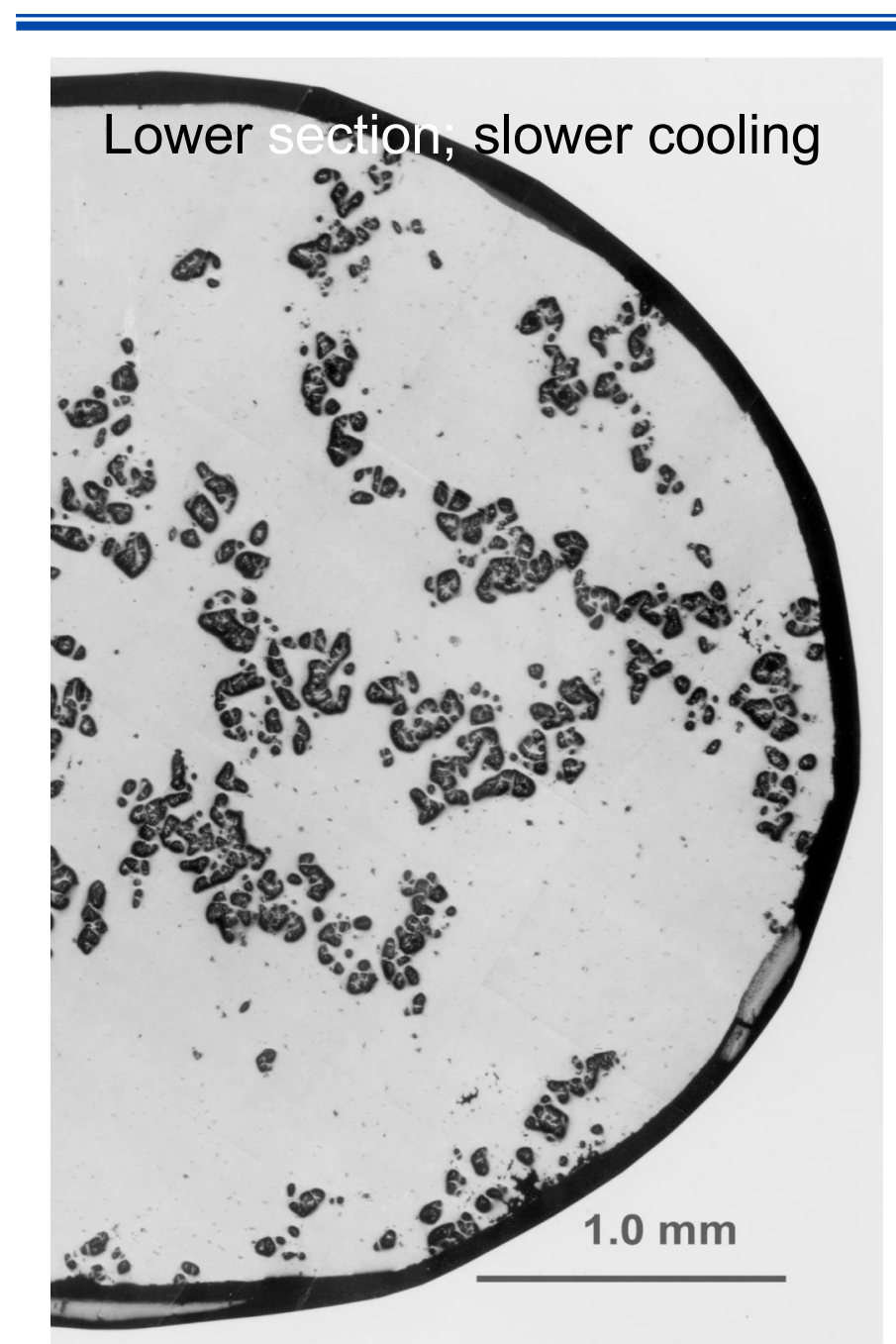

U-20.2Pu-9.1Zr-1.2Am-1.2Np

- Injection cast at $1450^{\circ} \mathrm{C}$

- Inhomogeneous microstructure

- Am and Np segregate to phases with variable composition

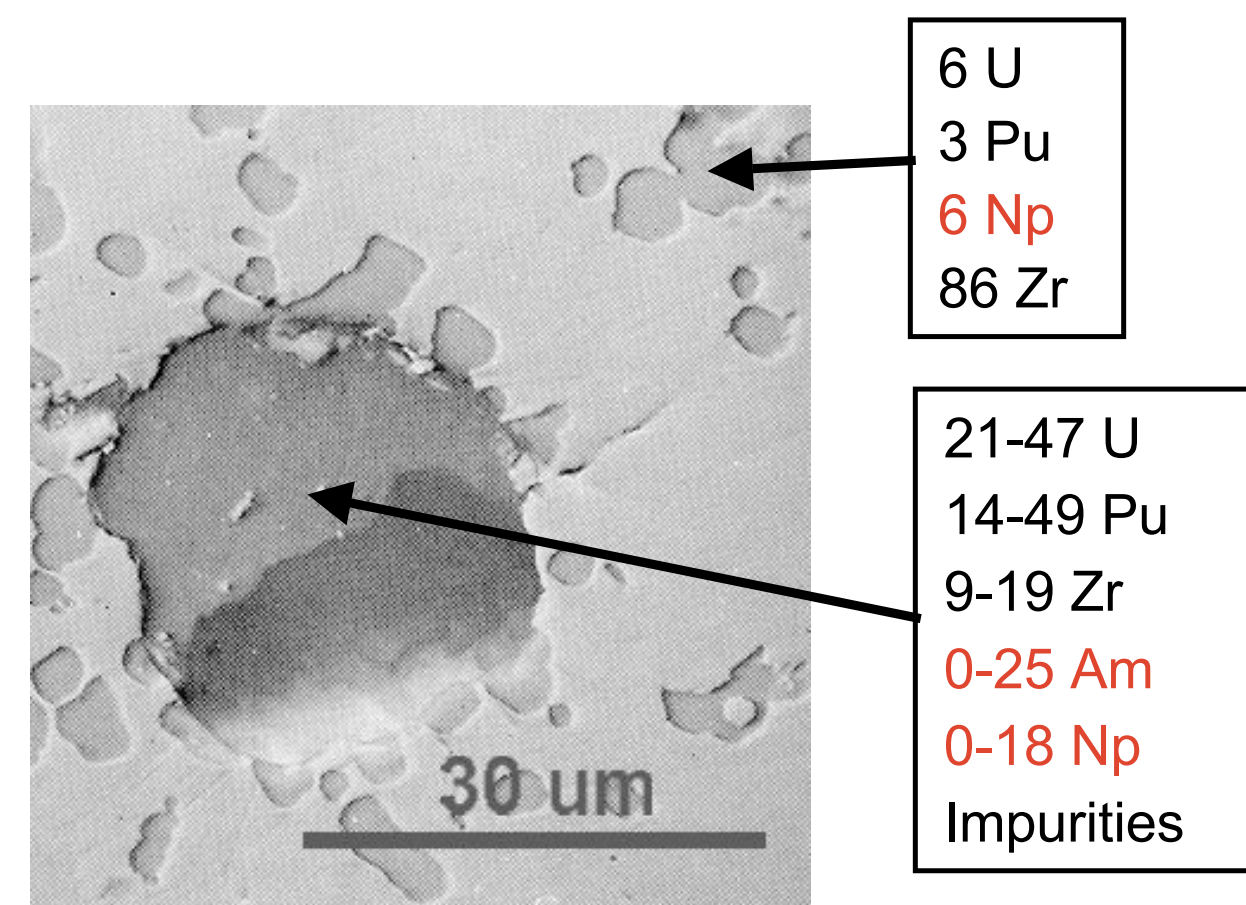




\section{Metallic Fuel with MA—X501 Irradiation}

Idaho National Laboratory
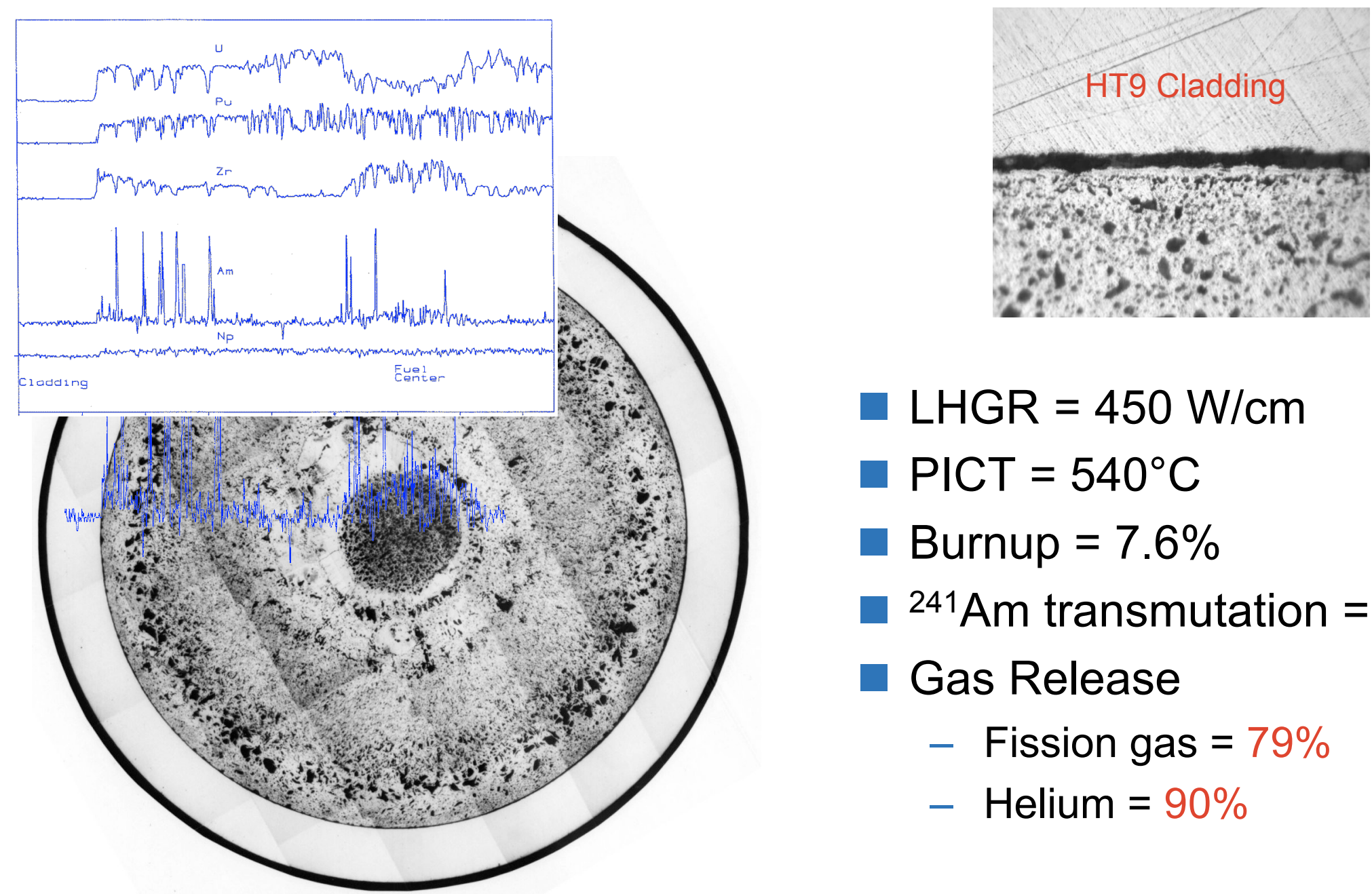


\section{Metallic Fuel with MA-FUTURIX-FTA}

U-29Pu-4Am-2Np-30Zr and Pu-12Am-40Zr Fuel Pins

$\checkmark$ Pins received at Phénix, Sept06

$\checkmark$ Safety Report Completed, Jan07

$\checkmark$ Approval granted by Phénix Safety Committee, Feb07

$\checkmark$ Assembly Fabrication Complete, Mar07

$\checkmark$ Approval by French National Safety Authority, Apr07

$\checkmark$ Insertion into Phénix Reactor, Apr07

$\checkmark$ Phénix startup for Cycle 55-1, May 5, 2007

$\checkmark$ Irradiation currently underway

- Irradiation complete at 240 EFPDs, Jan09
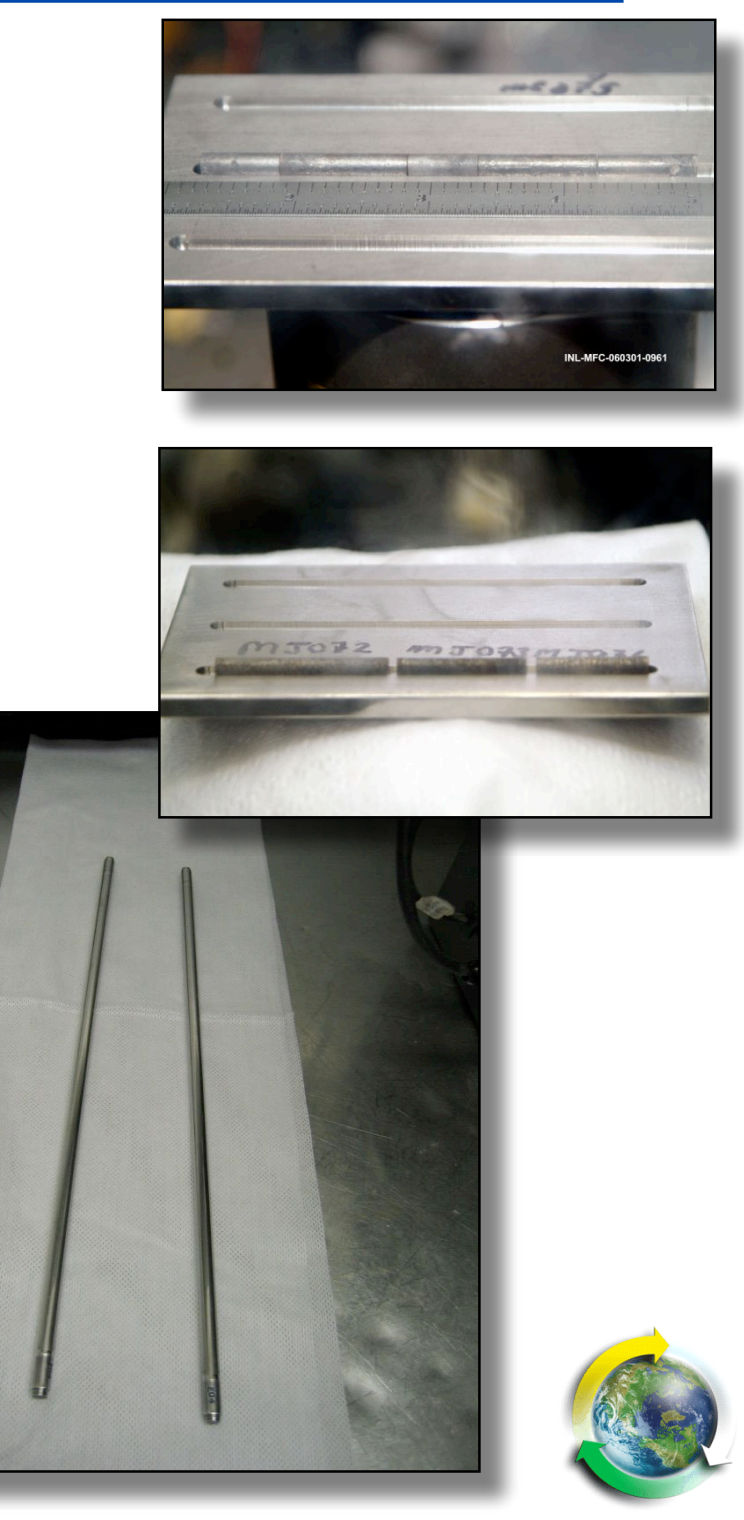


\section{Metallic Fuel with MA+RE-METAPHIX}

Idaho National Laboratory

$>$ Joint research with $\mathbf{I T U}$

> Fabrication MA-Metal slug by arc-melting

> Property measurements of MA-Metal slug

\# Melting temperature \# Thermal conductivity

\# Mechanical property \# Microstructure

\# Compatibility with cladding material U-rich phase

Irradiation tests at Phenix (Jan. 2004 )

(METAPHIX-1-2-3)

$\checkmark$ Reference Metal (U-Pu-Zr) fuel

$\checkmark 5 \%$ MA-Metal fuel

$\checkmark 2 \%$ MA $/ 2 \%$ RE-Metal fuel

$\checkmark$ 5\%MA/5\%RE-Metal fuel

(Burnup, 1at.\%, 5at.\%, 10at.\%)

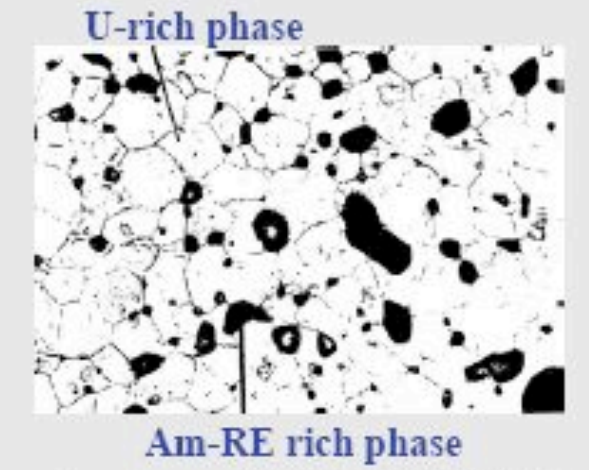

Microstructure of $5 \% \mathrm{MA} / 5 \% \mathrm{RE}$ -

$\mathrm{U}-\mathrm{Pu}-\mathrm{Zr}$ metal fuel

(From Arai and Pillon, 2004) 


\section{MOX Fuel with MA+RE-Fabrication}

Idaho National Laboratory

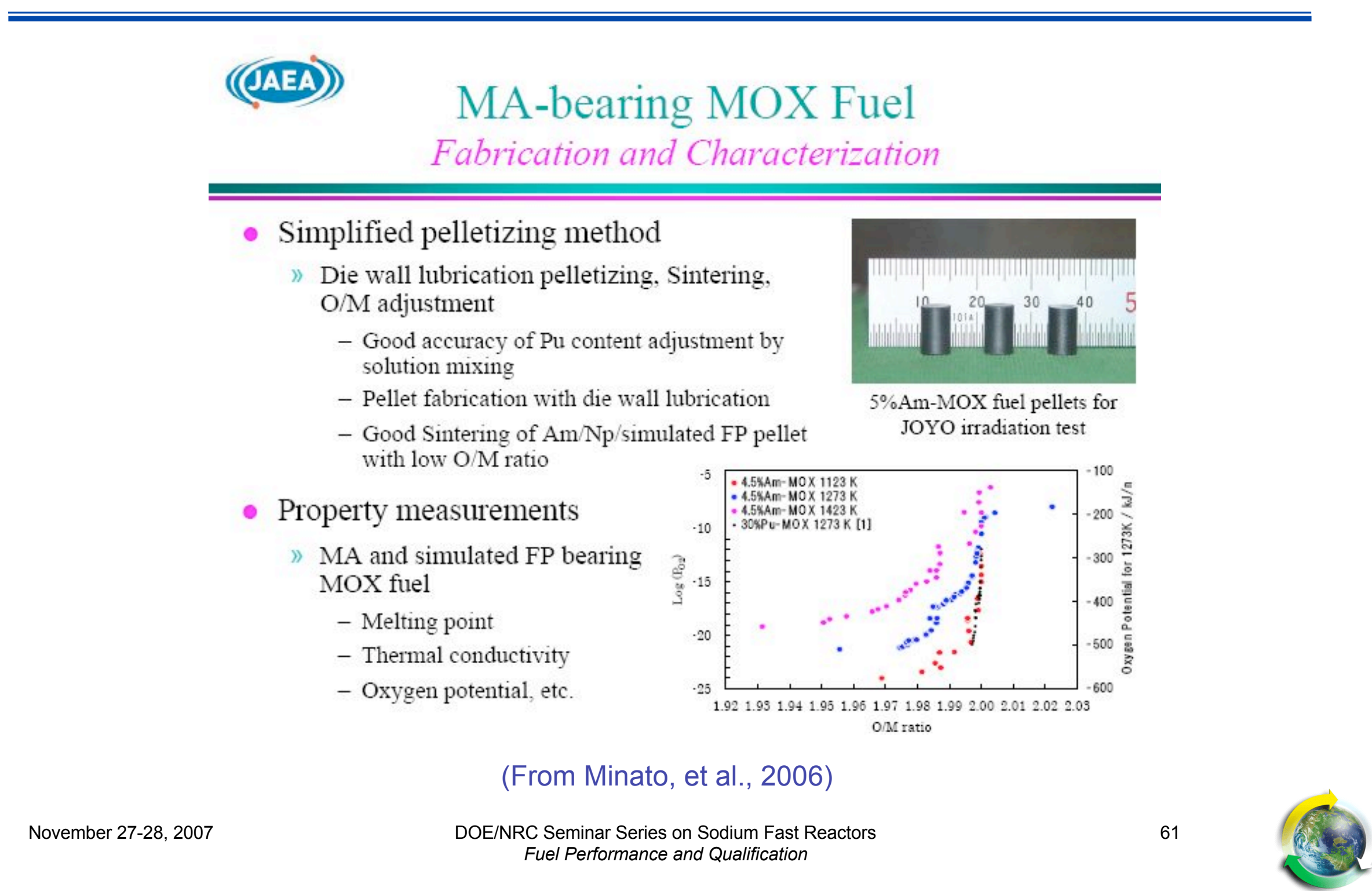




\section{MOX Fuel with MAs_Irradiation Performance}

Idaho National Laboratory

\section{MA-MOX Fuel Development in Europe (2) CEA/ITU Collaboration (1984-1992)}

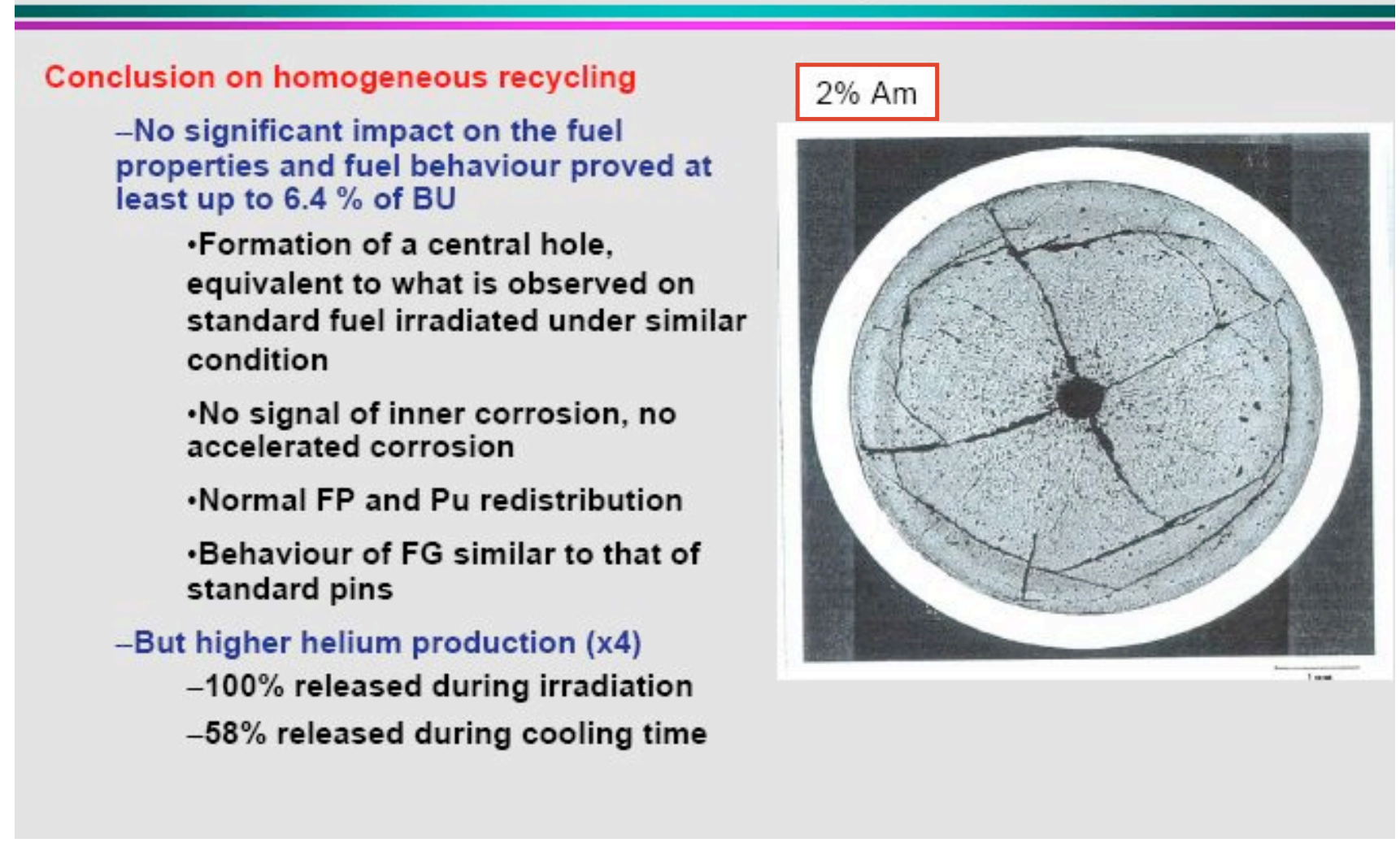

(From Arai and Pillon, 2004) 


\section{Modeling \& Simulation Fully Integrated with Fuel Development and Qualification}

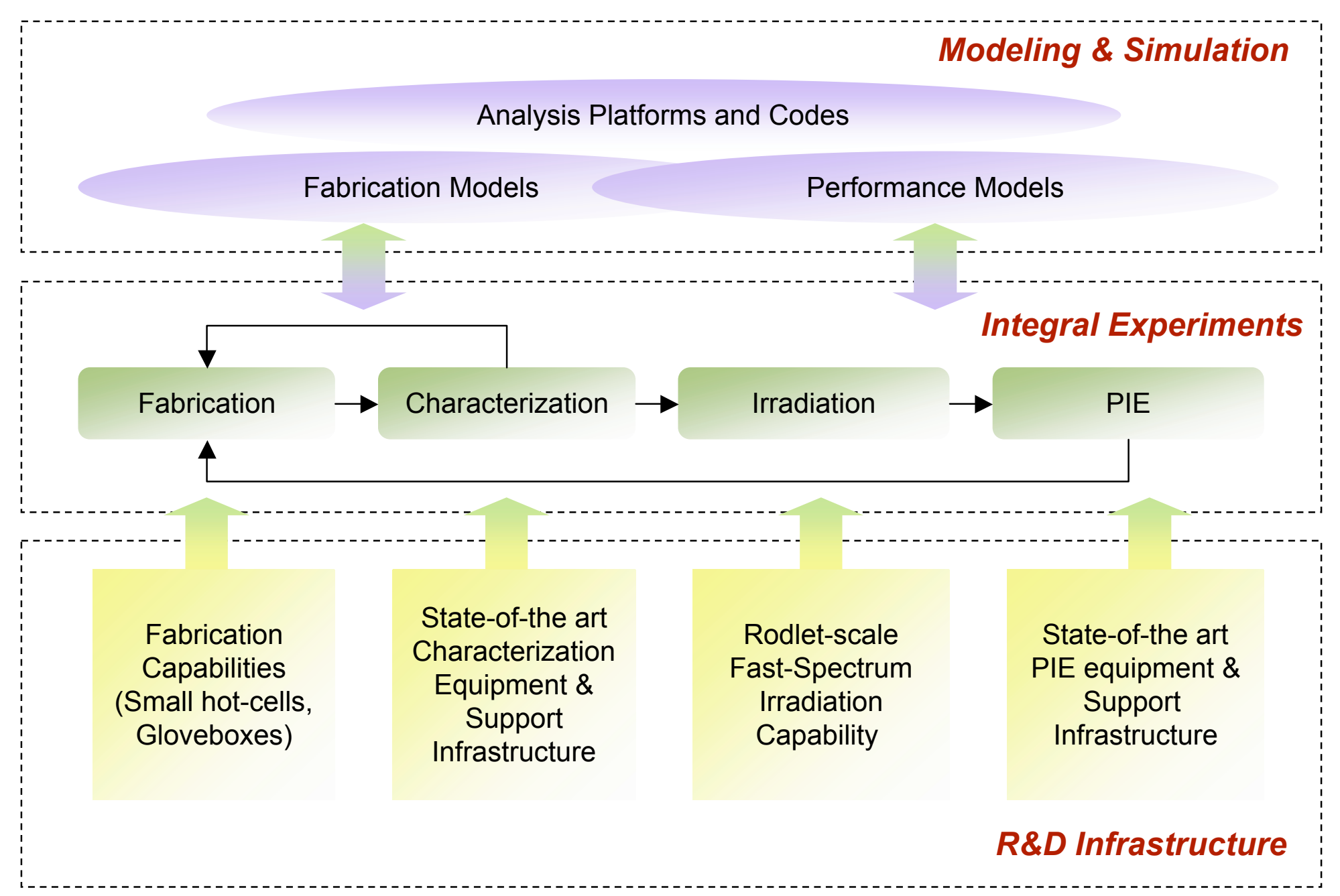




\section{Modeling and Simulation Strategy}

Idaho National Laboratory

(LIFE4, SIEX, LIFE-METAL, FRAPCON)

Legacy Codes:

- Sensitivity studies

- Design support for fuels

- Empirical model support

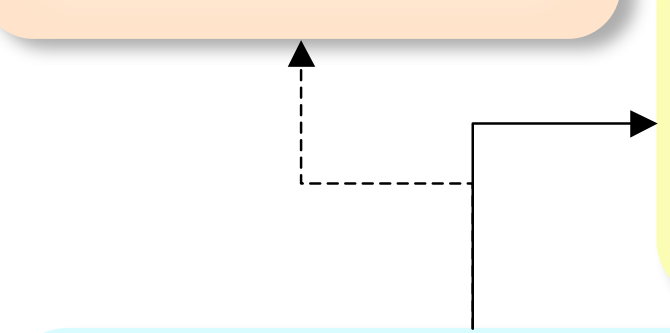

ASCI Thermo-Mechanical Codes:

- Intermediate-term results

- Test bed and feasibility assessment

- Import ASCI technology to NE needs

Lower length-scale Modeling:

- Fundamental understanding

- Reduced reliance on empirical data

- Collaborations with Office of Science

Basic Experiments

- Fundamental properties

- Phenomenological tests for model development

Next Generation Fuel Performance Code:

- Long-term qualification code

- Includes all important phenomenology

- Specifically tailored to fuel physics

- State-of-the art numerical models 


\section{Modeling and Simulation Forecast}

Idaho National Laboratory

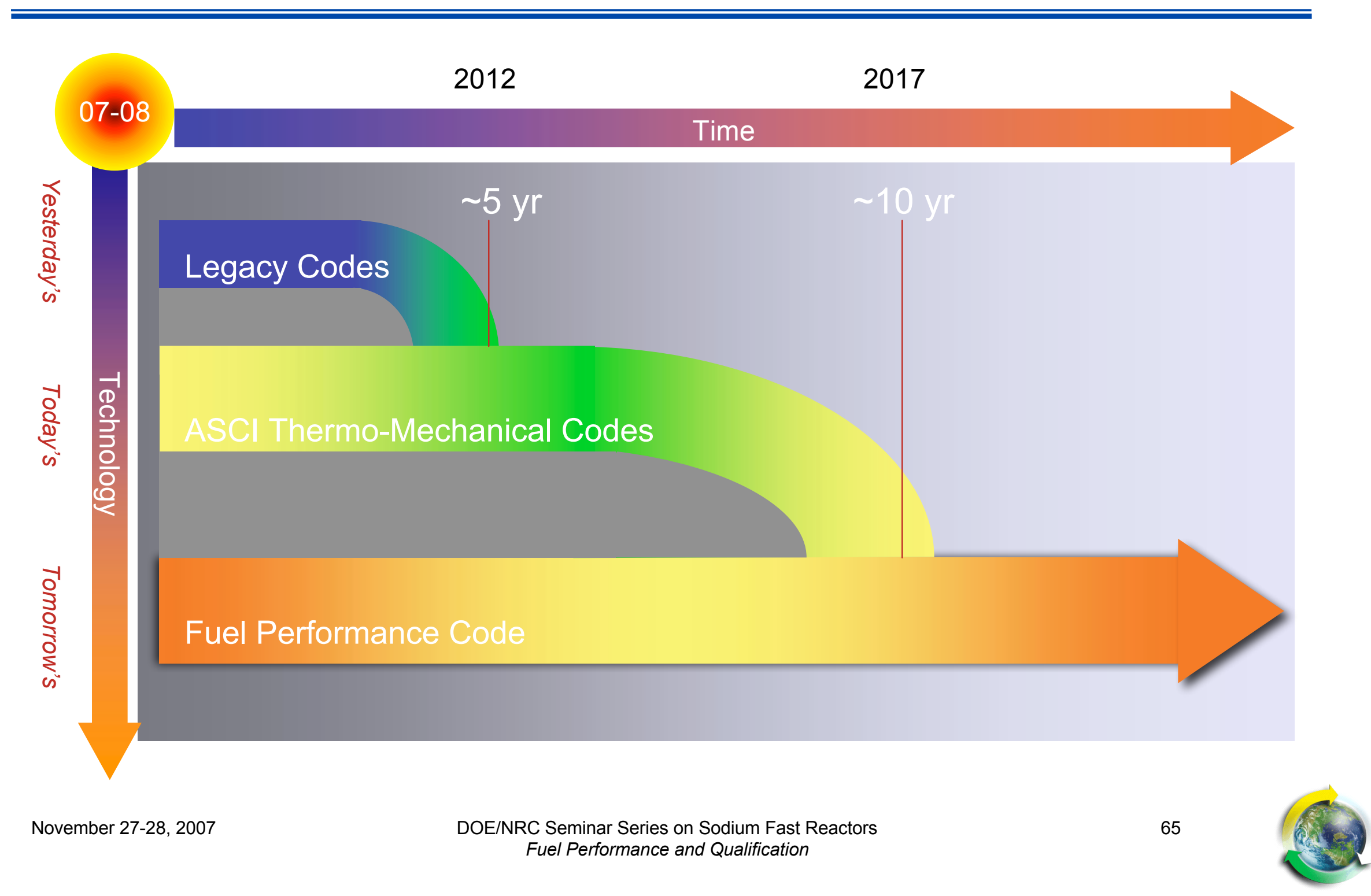




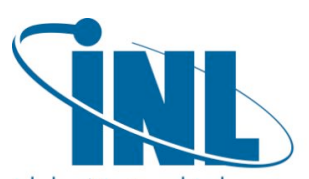

Idaho National Laboratory

\section{Approach to Fuel Development and Qualification}




\section{Fuel Development \& Safety Testing}

Crawford, et al., Journal of Nuclear Materials, 371: 232-242 (2007).

Review of 4 phases of fuel development process

- 1. Fuel candidate selection

- 2. Concept definition and feasibility

- 3. Design improvement and evaluation

- 4. Fuel qualification and demonstration

- Example of EBR-II \& FFTF experience with fuel qualification/confirmation

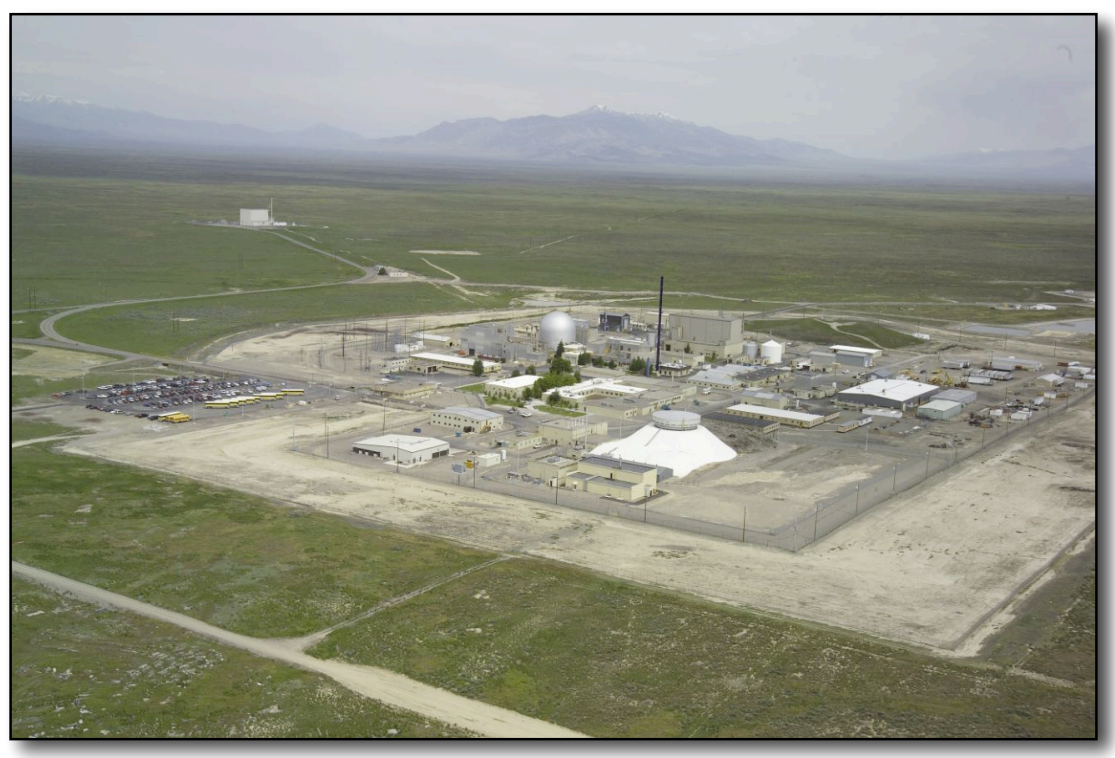
testing 


\section{TRL Objective in Fuel Qualification}

Idaho National Laboratory

\begin{tabular}{|c|c|c|}
\hline$\overline{T R L}$ & Function & Definition \\
\hline 1 & \multirow{3}{*}{\begin{tabular}{ll}
$\frac{1}{0}$ & \multicolumn{2}{c}{} \\
& \\
$\frac{1}{0}$ & 0 \\
0 & 0 \\
0 & 0 \\
0 & 0
\end{tabular}} & $\begin{array}{l}\text { A new concept is proposed. Technical options for the concept are } \\
\text { identified and relevant literature data reviewed. Criteria developed. }\end{array}$ \\
\hline 2 & & $\begin{array}{l}\text { Technical options are ranked. Performance range and fabrication } \\
\text { process parametric ranges defined based on analyses. }\end{array}$ \\
\hline 3 & & $\begin{array}{l}\text { Concepts are verified through laboratory-scale experiments and } \\
\text { characterization. Fabrication process verified using surrogates. }\end{array}$ \\
\hline 4 & \multirow{3}{*}{$\begin{array}{l}\frac{0}{0} \\
\frac{0}{0} \\
. \frac{1}{0} \\
\frac{1}{0} \\
\frac{1}{0} \\
\frac{1}{0} \\
\frac{1}{2} \\
0\end{array}$} & $\begin{array}{l}\text { Fabrication of samples using stockpile materials at bench-scale }(\sim 100 \\
\text { gram batches). Irradiation testing of small-samples (rodlets) in relevant } \\
\text { environment. Design parameters and features establsihed. Basic } \\
\text { properties compiled. }\end{array}$ \\
\hline 5 & & $\begin{array}{l}\text { Fabrication of pins using prototypic feedstock materials at laboratory- } \\
\text { scale }(10 \mathrm{~kg}) \text {. Pin-scale irradiation testing at relevant environment. } \\
\text { Primary performance parameters with representative compositions } \\
\text { under normal operating conditions quantified. }\end{array}$ \\
\hline 6 & & $\begin{array}{l}\text { Fabrication of pins using prototypic feedstock materials at laboratory- } \\
\text { scale }(1 \mathrm{~kg}) \text { and using prototypic fabrication process. Pin-scale } \\
\text { irradiation testing at relevant and prototypic environment (steady-state } \\
\text { and transient testing). Safety basis establis }\end{array}$ \\
\hline 7 & \multirow{3}{*}{ 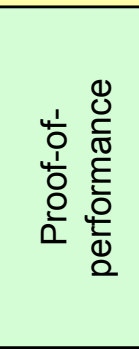 } & $\begin{array}{l}\text { Fabrication of test assemblies using prototypic feedstock materials at } \\
\text { engineering-scale }(100 \mathrm{~kg}) \text { and using prototypic fabrication process. } \\
\text { Assembly-scale irradiation testing at prototypic environment. Safety } \\
\text { basis established for full-core operations. }\end{array}$ \\
\hline 8 & & $\begin{array}{l}\text { Fabrication of a few core-loads of fuel (tons) and operation of a } \\
\text { prototype reactor with such fuel. }\end{array}$ \\
\hline 9 & & Routine commercial-scale operations. Multiple reactors operating \\
\hline
\end{tabular}




\section{Conceptual Fuel Development Schedule}

Idaho National Laboratory

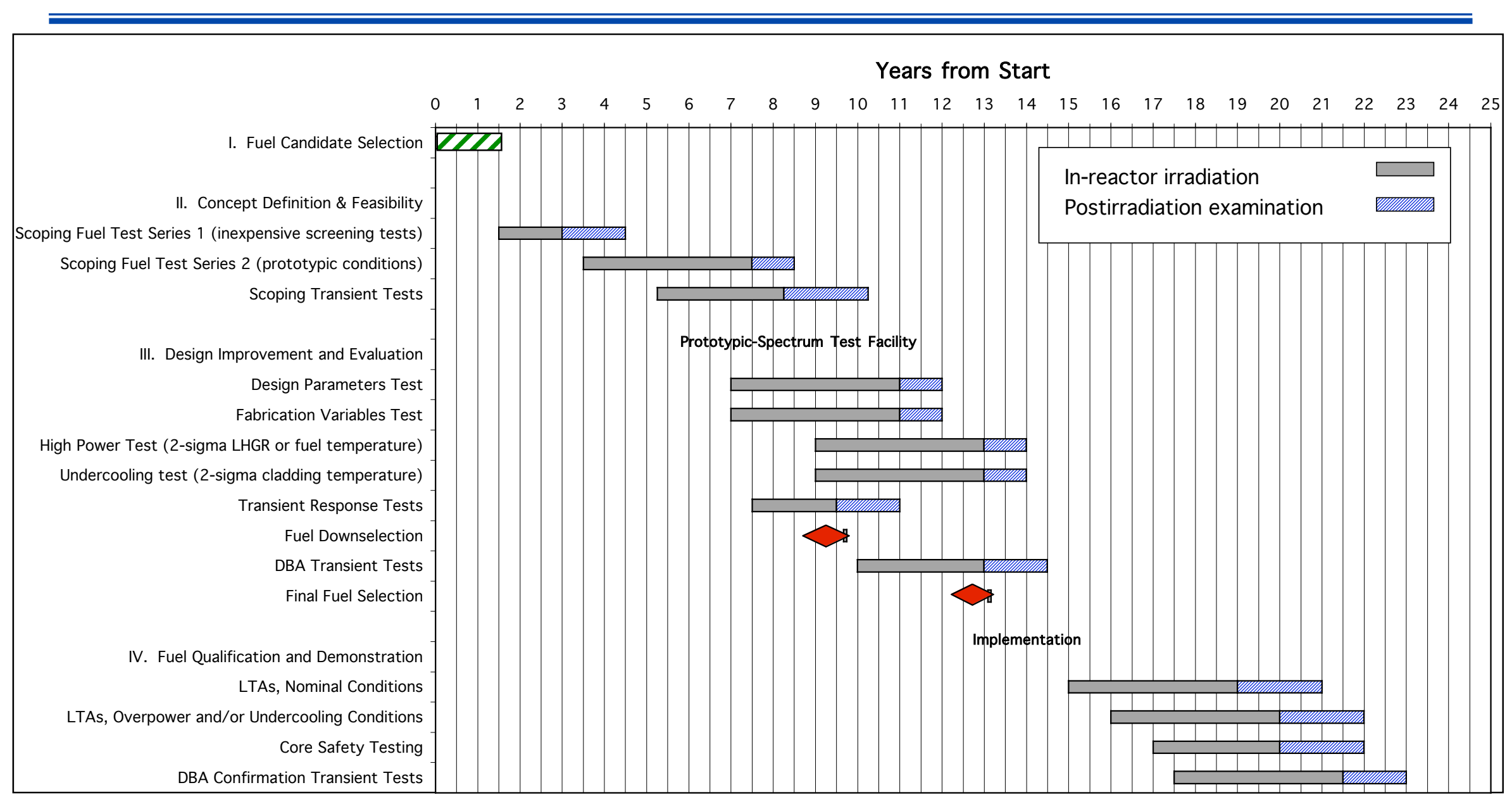




\section{Fuel Development Phase 1: Fuel Candidate Selection}

- Objective: Based on previous experience, identify candidate fuel forms/concepts that appear capable of meeting mission needs.

- Selection criteria might include:

- Ability to accommodate desired fuel compositions

- Experience with similar fuel types or analogues

- Suitability of established fabrication techniques, or the potential for successful innovative techniques

- Anticipated performance capabilities (e.g., temperature, burnup, or fluence)

- Anticipated safety-related behavior (which may be quite speculative at an early stage)

- Suitability of design, considering issues such as fuel-cladding compatibility, fuelcoolant compatibility, and fuel properties

- Compatibility with envisioned back-end fuel cycle technology

- Expected cost of fabrication

achieves TRL 2 


\section{Fuel Development Phase 2: Concept Definition and Feasibility}

Objective: Establish a reference concept/design

Determine how the fuel can be fabricated

- Process scoping \& feasibility

- Fabricate characterization and test samples

- Determine and assess key properties

- Feasibility issues for irradiation testing

- Use scoping irradiation tests to assess phenomena envisioned to impact feasibility and fuel lifetime

- Simple experiments

- Prototypic conditions as possible

- Achieves TRL 4 


\section{Fuel Development Phase 3: Design Improvement and Evaluation}

Objectives:

- Optimize the fuel design for economics, performance and safety

- Produce a Fuel Specification and a Fuel Safety Case for a core of fuel

- Establish predictive fuel performance code (or codes)

Develop engineering-scale fabrication processes and equipment

Assess fuel properties vs. composition or processing variations

- Irradiation testing to:

- Determine sensitivity of performance to fuel design and fabrication variables and to operating conditions

- Establish burnup limits and safety margins for various operating conditions (normal and off-normal)

- Develop fuel behavior models and predictive codes

achieves TRL 6 


\section{Fuel Development Phase 4: Fuel Qualification and Demonstration}

\section{Objectives:}

- Qualify production-line fuel as the driver fuel for a demonstration reactor

- Demonstrate the safety and reliability of a core of fuel through successful operation of the demonstration reactor

- Validate predictive fuel performance code (or codes)

- Demonstrate production of fuel in conformance with Fuel Specification

- Demonstrate through LTA irradiation that fuel/fuel assembly behavior is within the bounds of the Fuel Safety Case

- Accumulate reactor performance data and operating experience with a core of fuel to support licensing of first-of-a-kind unit

achieves TRL 7 or 8 


\section{Fuel Development Phase 4: Fuel Qualification and Demonstration}

- Example for Metallic Fuels in EBR-II

- Confirmation Testing (Mark-III, IIIA, and IV)

$>$ Performance phenomena limiting useful lifetime of a fuel assembly (breach, hardware dimensional change, etc.) are known. Limits can be predicted and pre-set.

$>$ Use of modeling [Cumulative Damage Fraction (CDF) or other].

$>$ Run a set of assemblies representing the range of possible operating conditions to an exposure (burnup, neutron fluence, etc.) in excess of the limiting exposure to prove capability is as predicted.

$>$ The tests lead the remaining core in exposure.

$>$ Four assemblies used [1 inner core, 1 outer core (normal flow), 1 outer core (high flow), 1 orificed to nominally achieve 2- $\sigma$ peak cladding temperatures] 


\section{Fuel Development Phase 4: Fuel Qualification and Demonstration}

Example for Oxide and Metallic Fuels in FFTF

Confirmation Tests in FFTF to Support Exposure Limits

(from Baker, et al, 1990)

\begin{tabular}{|c|c|c|c|c|c|}
\hline Type & Fuel & $\begin{array}{l}\text { Duct \& } \\
\text { Cladding } \\
\text { Material }\end{array}$ & $\begin{array}{c}\text { Number of } \\
\text { FFTF } \\
\text { Tests* }\end{array}$ & $\begin{array}{c}\text { Transient } \\
\text { Testing }\end{array}$ & $\begin{array}{c}\text { Driver } \\
\text { Cores } \\
\text { Produced }\end{array}$ \\
\hline Series I & $(\mathrm{U}, \mathrm{Pu}) \mathrm{O}_{2}$ & 316 & $17 \mathrm{~F}$ & Yes & 2 cores \\
\hline Series II & $(\mathrm{U}, \mathrm{Pu}) \mathrm{O}_{2}$ & 316 & -- & -- & 2 cores \\
\hline Series III.a & $(\mathrm{U}, \mathrm{Pu}) \mathrm{O}_{2}$ & D9 & $1 F, 4 R$ & No & -- \\
\hline Series III.b & $U-10 Z r$ & HT9 & $2 P, 6 F$ & No & -- \\
\hline Series IV & $\mathrm{UO}_{2}$ & D9 & 1P & No & -- \\
\hline
\end{tabular}

${ }^{*} \mathrm{~F}=$ full assembly, $\mathrm{P}=$ partial assembly, $\mathrm{R}=$ related test 


\section{Summary}

SFR Fuels Experience in the US

- Fuel Types

- Fuel Performance Issues

- Experience/Testing

- Fuel Test Plan (1994) for PRISM Prototype

- Experience with Fuels Containing Minor Actinides

Fuel Specification

- Fuel Development and Qualification 


\title{
Spent Nuclear Fuel Reprocessing
}

\author{
Dr. Terry Todd
}

Idaho National Laboratory

Nuclear Regulatory Commission Seminar Rockville, MD

March 25, 2008 


\section{Outline}

- Spent nuclear fuel

- Background and history of spent nuclear fuel reprocessing

- PUREX process description

- Current reprocessing activities in the world

- Criticality control in PUREX plants

- Accidents in PUREX plants

- Recent process modifications to PUREX

- COEX/NUEX/UREX

- Questions 


\section{Spent Nuclear Fuel - what is it?}

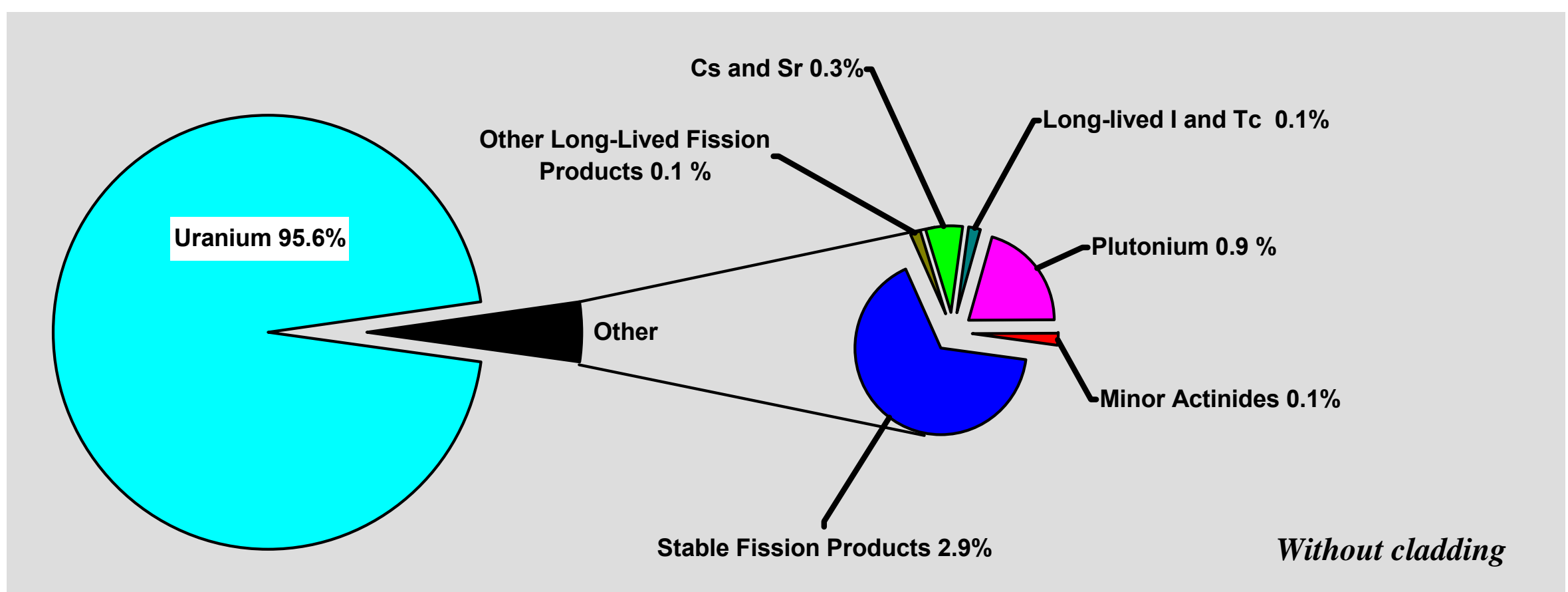

Most heat production is from $\mathrm{Cs}$ and $\mathrm{Sr}$, which decay in $\sim 300 \mathrm{yr}$

Most radiotoxicity is in long-lived fission products and the minor actinides, which can be transmuted and/or disposed in much smaller packages 


\section{Spent Nuclear Fuel - current US situation}

- Currently stored in pools or dry storage at the $60+$ nuclear reactor sites in the U.S.

Generated at approximate rate of $\mathbf{2 1 0 0}$ MTHM/yr

- Slated for direct disposal into Yucca Mountain geologic repository

- Yucca Mountain is not licensed or open at this time, spent fuel inventory will exceed legislated capacity before it is opened
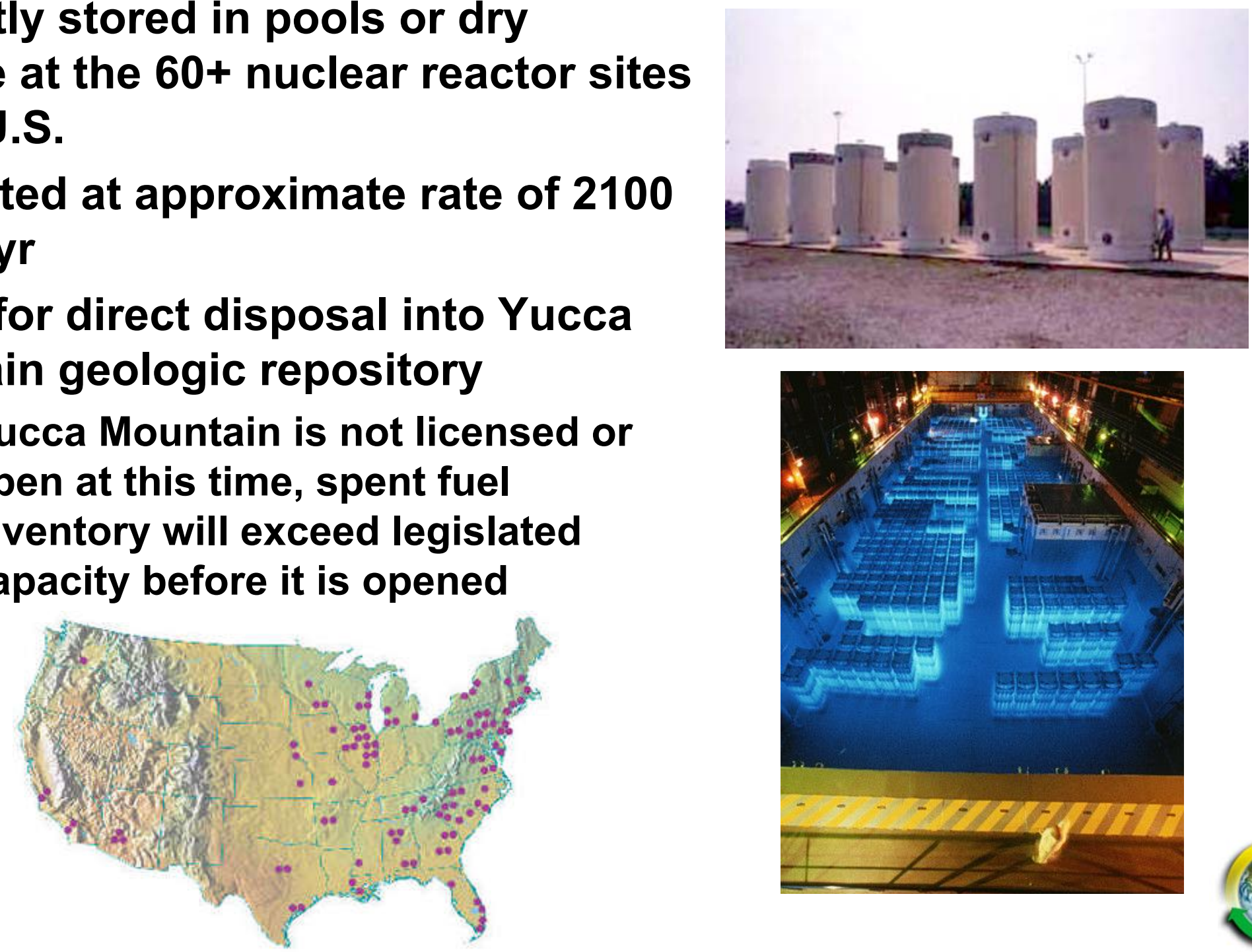


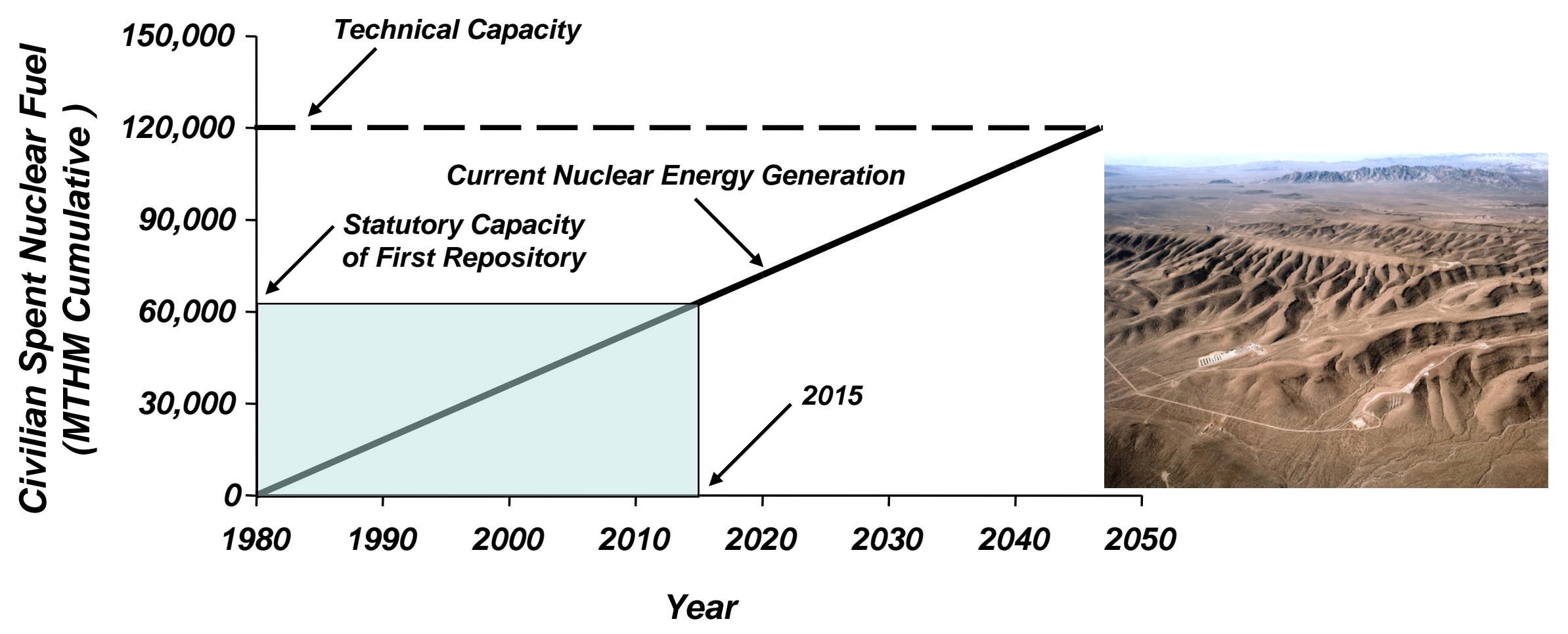




\section{Spent Fuel Processing (recycling)}

96\% of the metals in Spent Fuel (excluding cladding and hardware) can be recovered, with only a small fraction sent to the geologic repository

Spent Fuel

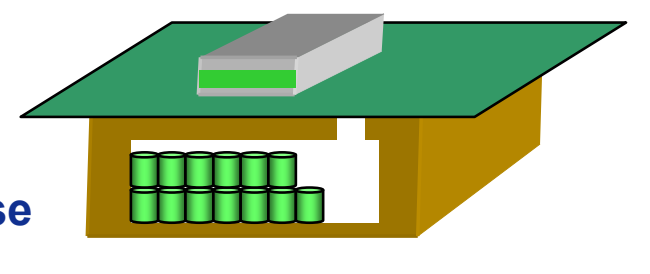

URANIUM ( 95\%)

( 0.8\% $\left.{ }^{235} \mathrm{U}\right)$

Low Level Waste or storage for reuse

IIII 


\section{Spent fuel recycling}

- Benefits

- Natural resource conservation

- Reduction of waste heat load and radiotoxicity

- Reduced dependence on foreign oil, LNG, and coal

- Challenges

- Cost

- Impact to the environment

- Proliferation and safety concerns

- Public acceptance 


\section{Spent fuel - radiotoxicity}

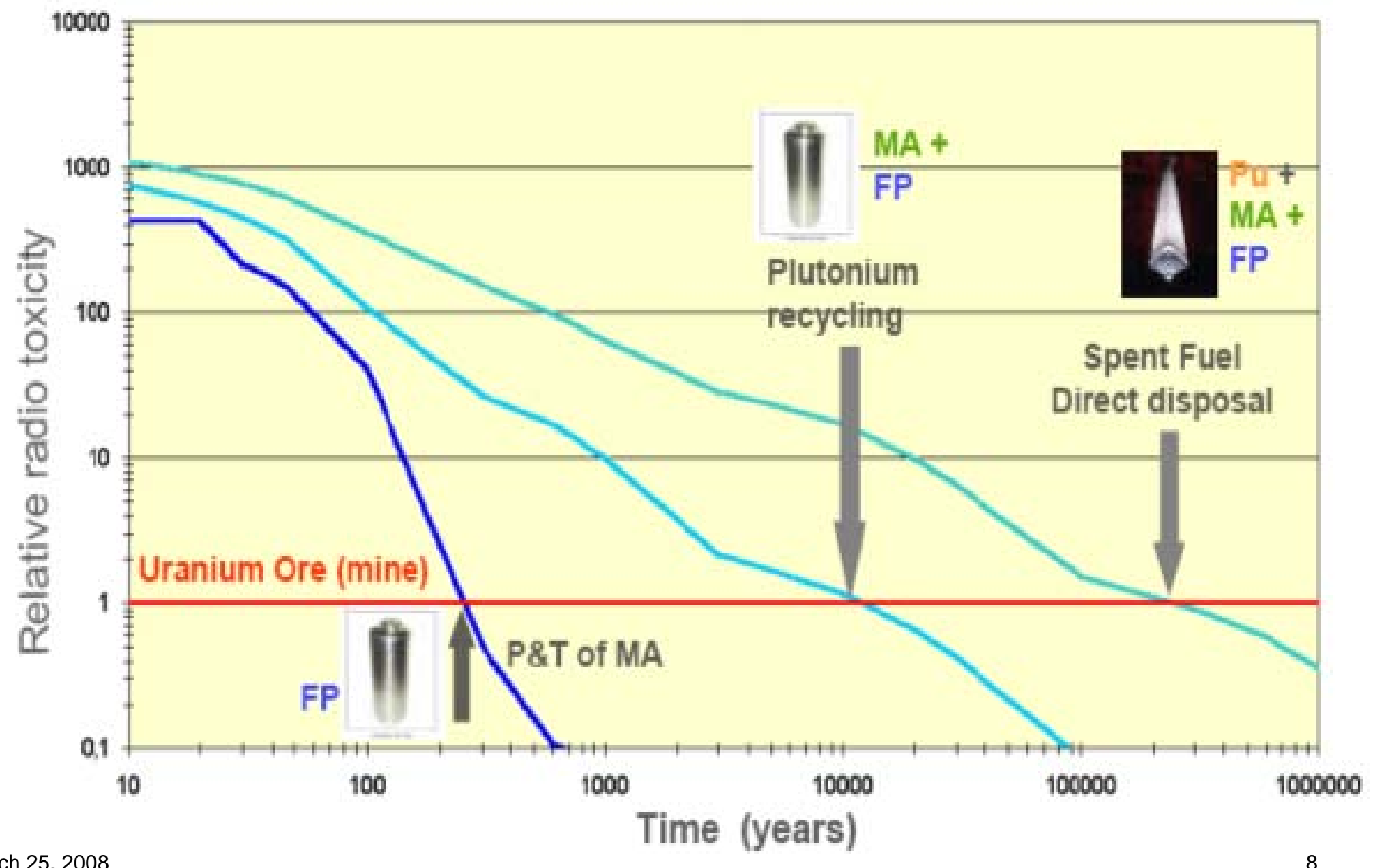


- Began during Manhattan Project to recover Pu-239

- Seaborg first separated microgram quantities of Pu in 1942 using bismuth-phosphate precipitation process

- Process scaled to kilogram quantity production at Hanford in 1944

- A scale-up factor of $10^{9}$ !!!

- Solvent extraction processes followed to allow concurrent separation and recovery of both $\mathrm{U}$ and $\mathrm{Pu}$ and

Reprocessing transitioned from defense to commercial use

- Focus on recycle of uranium and plutonium

- Waste management 


\section{Bismuth Phosphate Process}

Dissolution of irradiated fuel or targets in nitric acid

- Pu valance adjusted to Pu (IV) with sodium nitrite

Add sodium phosphate and bismuth nitrate

- Pu (IV) precipitates as $\mathrm{Pu}_{3}\left(\mathrm{PO}_{4}\right)_{4}$

- PPT re-dissolved in nitric acid, oxidized to $\mathrm{Pu}(\mathrm{VI})$, then re-ppt $\mathrm{BiPO}_{4}$ to decontaminate $\mathrm{Pu}$ from fission products

Recover Pu by reducing to Pu (IV) and reppt

- Repeat cycles w/ LaF to further decontaminate 


\section{Bismuth Phosphate Process}

- Advantages of Bismuth Phosphate Process

- Recovery of $>95 \%$ of Pu

- Decontamination factors from fission products of $10^{7}$

- Disadvantages of Bismuth Phosphate Process

- Batch operations

- Inability to recovery uranium

- Required numerous cycles and chemicals

- Produced large volumes of high-level

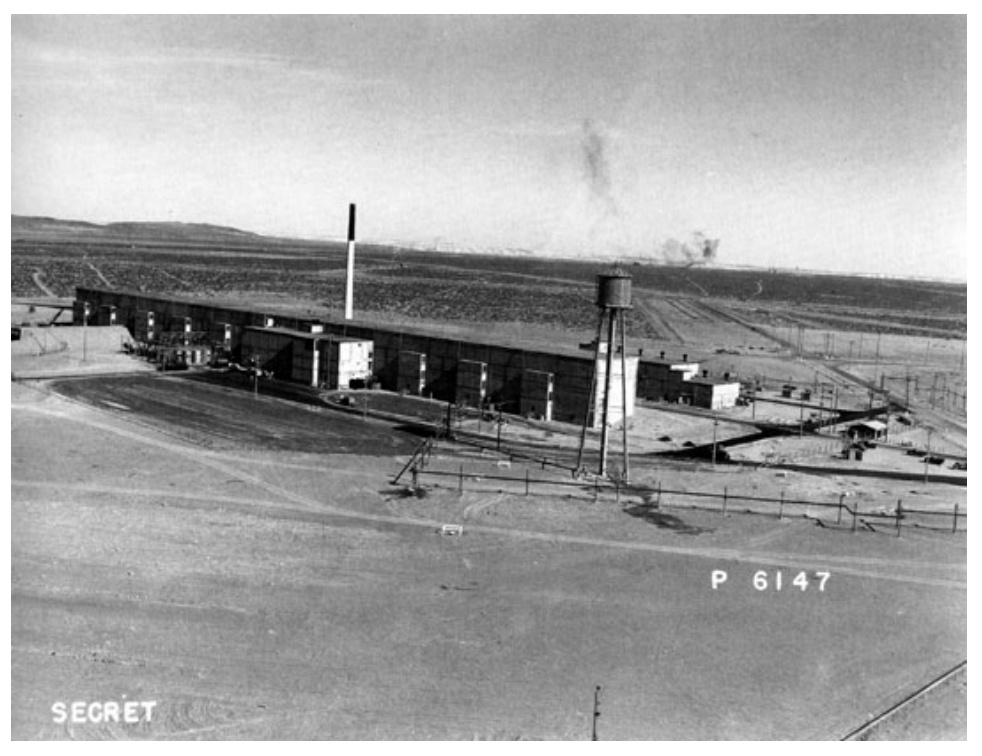
waste 


\section{REDOX Process}

- First solvent extraction process used in reprocessing

- Continuous process

- Recovers both $U$ and Pu with high yield and high decontamination factors from fission products

Developed at Argonne National Laboratory

- Tested in pilot plant at Oak Ridge Nat. Lab 1948-49

REDOX plant built in Hanford in 1951

Used at Idaho for U-235 recovery

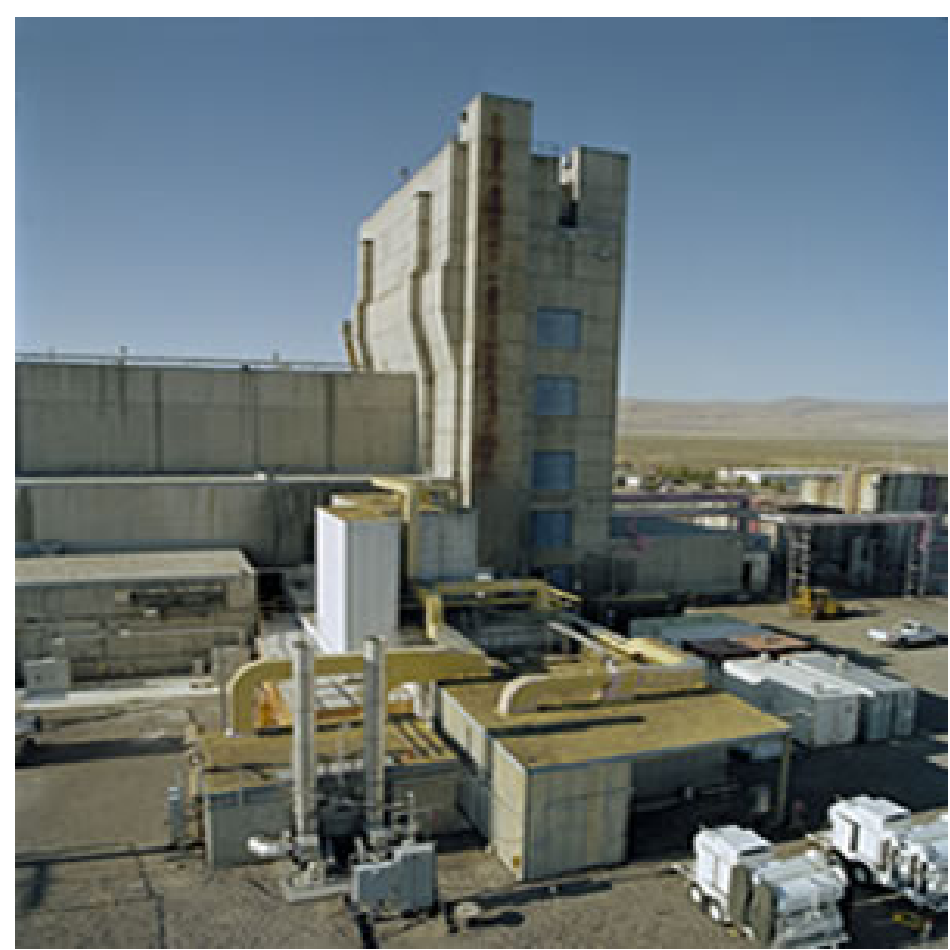

Hanford REDOX -Plant (1951) 


\section{REDOX Process}

- Hexone (methyl isobutyl ketone) used as the extractant

- Immiscible with water

- Used to purify uranium ore concentrates

- Extracts both uranyl and plutonyl nitrates selectively from fission products

- Plutonium oxidized to $\mathrm{Pu}(\mathrm{VI})$ for highest recovery

- $\mathrm{U}(\mathrm{VI})$ and $\mathrm{Pu}(\mathrm{VI})$ co-extracted, then $\mathrm{Pu}$ is reduced to $\mathrm{Pu}$ (III) by ferrous sulfamate and scrubbed from the solvent

- Hexone is highly flammable and volatile

- Large amounts of nonvolatile salt reagents added to process increased waste volume 


\section{BUTEX Process}

- Developed in late 1940's by British scientists at Chalk River Laboratory

- Utilized dibutyl carbitol as solvent

- Lower vapor pressure than hexone

- Nitric acid was used as salting agent

- Replaced need to use aluminum nitrate as in REDOX process

- Lower waste volumes

- Industrial operation at Windscale plant in UK until 1976 
Tributyl phosphate used as the extractant in a hydrocarbon diluent (dodecane or kerosene)

- Suggested by Warf in 1949 for the recovery of Ce (IV) from rare earth nitrates

- Developed by Knolls Atomic Power Lab. and tested at Oak Ridge in 1950-52

- Used for Pu production plant at Savannah River in 1954 (H-canyon facility still operational in 2008)

- Replaced REDOX process at Hanford in 1956

- Modified PUREX used in Idaho beginning in 1953 (first cycle)
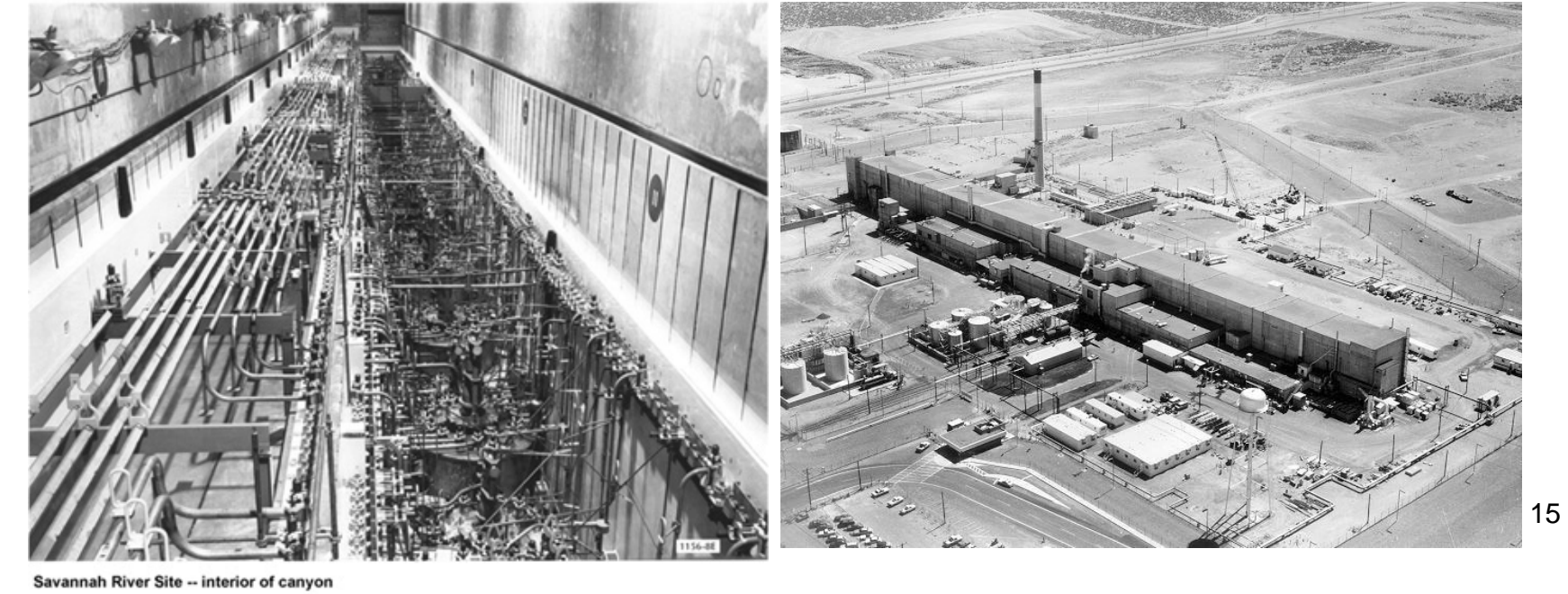
- Advantages of PUREX over REDOX process

- Nitric acid is used as salting and scrubbing agent and can be evaporated - results in less HLW

- TBP is less volatile and flammable than hexone

- TBP is more chemically stable in a nitric acid environment

- Operating costs are lower

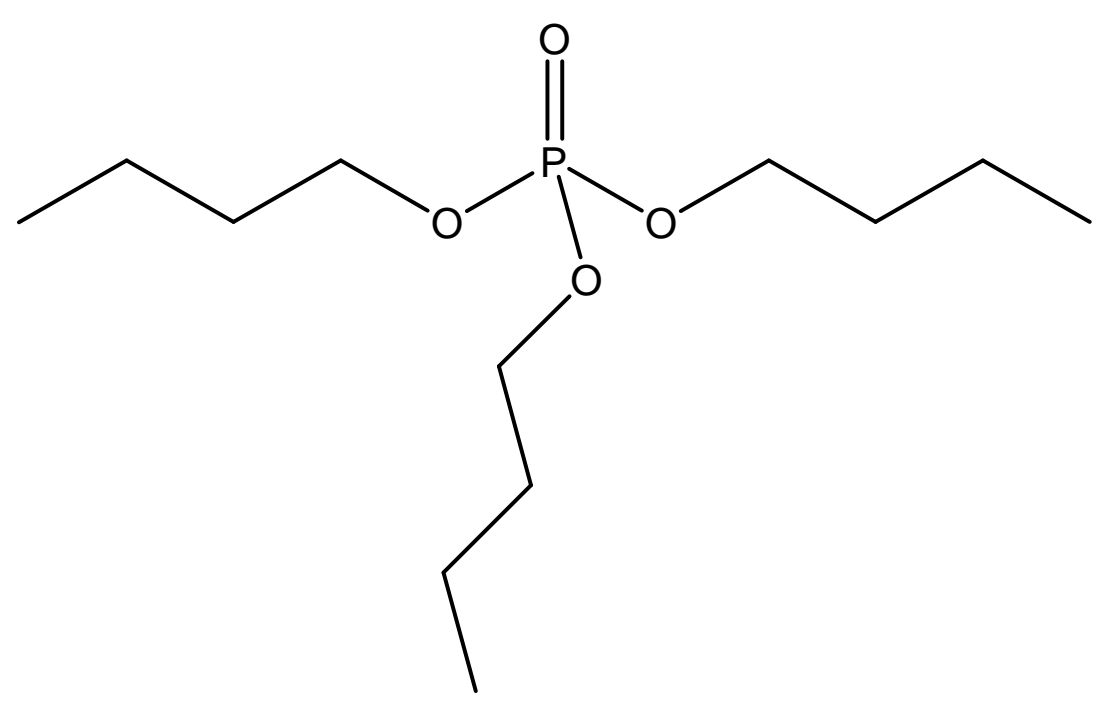




\section{PUREX Process - commercial history in US}

West Valley, NY

- First plant in US to reprocess commercial SNF

- Operated from 1966 until 1972

- Capacity of 250-300 MTHM/yr

- Shutdown due to high retrofit costs associated with changing safety and environmental regulations and construction of larger Barnwell facility

- Morris, IL

- Construction halted in 1972, never operated

- Close-coupled unit operations with fluoride volatility polishing step

- Barnwell, SC

- 1500 MTHM capacity

- Construction nearly completed- startup testing was in progress

- 1977 change in US policy on reprocessing stopped construction

- Plant never operated with spent nuclear fuel 
- France

- Magnox plant in Marcoule began operation in 1958 ( 400 MT/yr)

- Magnox plant in La Hague began operation in 1967 ( 400 MT/yr)

- LWR oxide plant (UP2) began in La Hague in 1976 (800 MT/yr)

- LWR oxide plant (UP3) began in La Hague in 1990 (800 MT/yr)

United Kingdom

- Windscale plant for Magnox fuel began in 1964 (1200-1500 MT/yr)

- THORP LWR oxide plant began in 1994 ( 1200 MT/yr)

- Japan

- Tokai-Mura plant began in 1975 ( 200 MT/yr)

- Rokkasho plant currently undergoing hot commissioning (800 $\mathrm{MT} / \mathrm{yr})$ 


\section{Reprocessing history in Russia}

- Mayak

- Plant B operated from 1949 to 1960

- Acetate precipitation followed by precipitation from fluoride solutions

- High level wastes discharge to Techa river, then Lake Karachai

- Plant BB operated from 1957 to 1987

- Similar acetate precipitation process, but repeated twice

- Plant RT-1 (PUREX Process)

- Operation began in 1976

- 400 MTHM/yr capacity

- Multiple lines to process commercial, HEU and naval fuels 
- Krasnoyarsk -26

- Processing of Pu production reactor fuel began in 1964 using PUREX process

- Construction of new RT-2 plant began in 1972 (1000-1500 MTHM/yr capacity)

- Plant construction never completed

- Tomsk -7

- Processing of Pu production reactor fuel began in sometime after 1955 using PUREX process 


\section{PUREX Process- Basic principles}

- Tri-butyl phosphate forms soluble complexes with uranyl nitrate and plutonium nitrate (neutral species of $\mathrm{U}(\mathrm{VI})$ and $\mathrm{Pu}(\mathrm{IV})$ )

- Spent fuel is dissolved in nitric acid and is then mixed with a solution of TBP in a hydrocarbon diluent (immiscible with aqueous phase)

- At higher nitric acid concentrations $(>0.5 \mathrm{M})$ the plutonium and uranium partition to the organic (solvent) phase while most of the metals and fission products stay in the aqueous phase

- Once separated from the fission products, the solvent can be mixed with another aqueous solution of low acidity $(<0.01 \mathrm{M})$ and the uranium and plutonium will partition back to the aqueous phase.

- To separate plutonium from uranium, a reductant is added to the aqueous stream, reducing $\mathrm{Pu}(\mathrm{IV})$ to $\mathrm{Pu}$ (III), which is not soluble in the organic solvent and partitions to the aqueous phase while $\mathrm{U}(\mathrm{VI})$ remains in the solvent 


\section{PUREX Process- Basic principles}

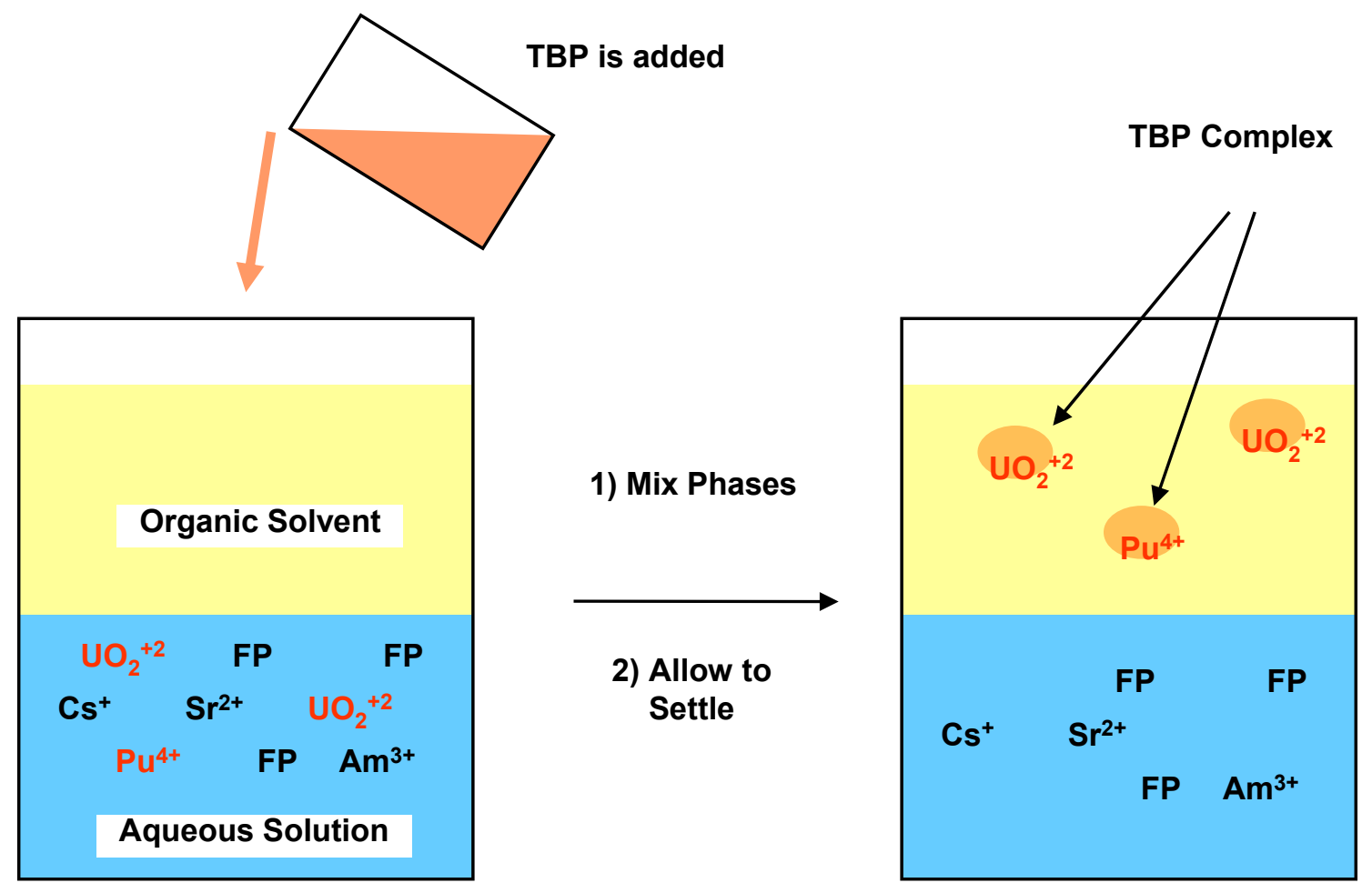

$$
\begin{aligned}
& \mathrm{UO}_{2}{ }^{2+}+2 \mathrm{NO}_{3}{ }^{-}+2 \mathrm{TBP} \leftrightarrows \mathrm{UO}_{2}\left(\mathrm{NO}_{3}\right)_{2} \bullet 2 \mathrm{TBP} \\
& \mathrm{Pu}^{4+}+4 \mathrm{NO}_{3}{ }^{-}+2 \mathrm{TBP} \leftrightarrows \mathrm{Pu}\left(\mathrm{NO}_{3}\right)_{4} \bullet 2 \mathrm{TBP}
\end{aligned}
$$


Extraction

Scrubbing

Stripping

\begin{tabular}{|c|}
\hline Organic Solvent \\
\hline 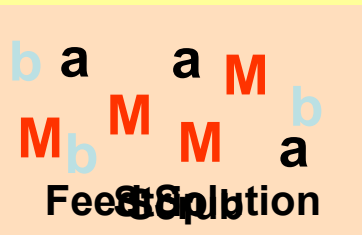 \\
\hline
\end{tabular}

Separates metal to be recovered

Removes impurities from metal

Recovers product in solution 


\section{PUREX Process- Basic Principles}

- TBP is an effective extractant, but is too dense and viscous to use pure

- Hydrocarbon diluent used to improve physical characteristics

- Typically 30 vol\% TBP is used in the PUREX process

- Diluents typically dodecane or kerosene (straight or branch chain hydrocarbons ranging from $\mathrm{C}-10$ to $\mathrm{C}-14$ )

- Salting effect

- Uranium and plutonium extraction is a function of nitrate concentration (called salting effect) 
PUREX Process - Nitric acid dependence

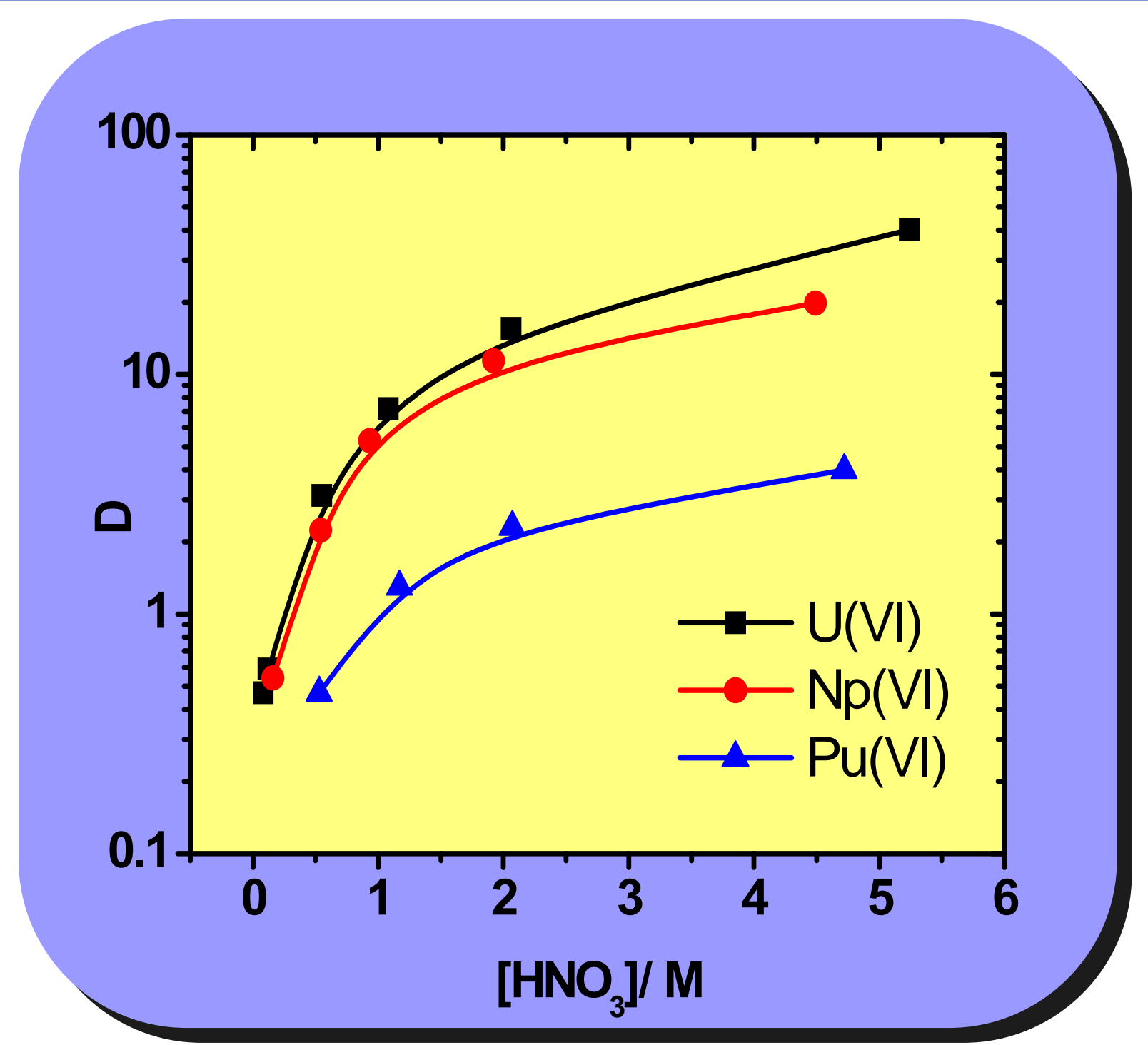


PUREX Process - Nitric acid dependence

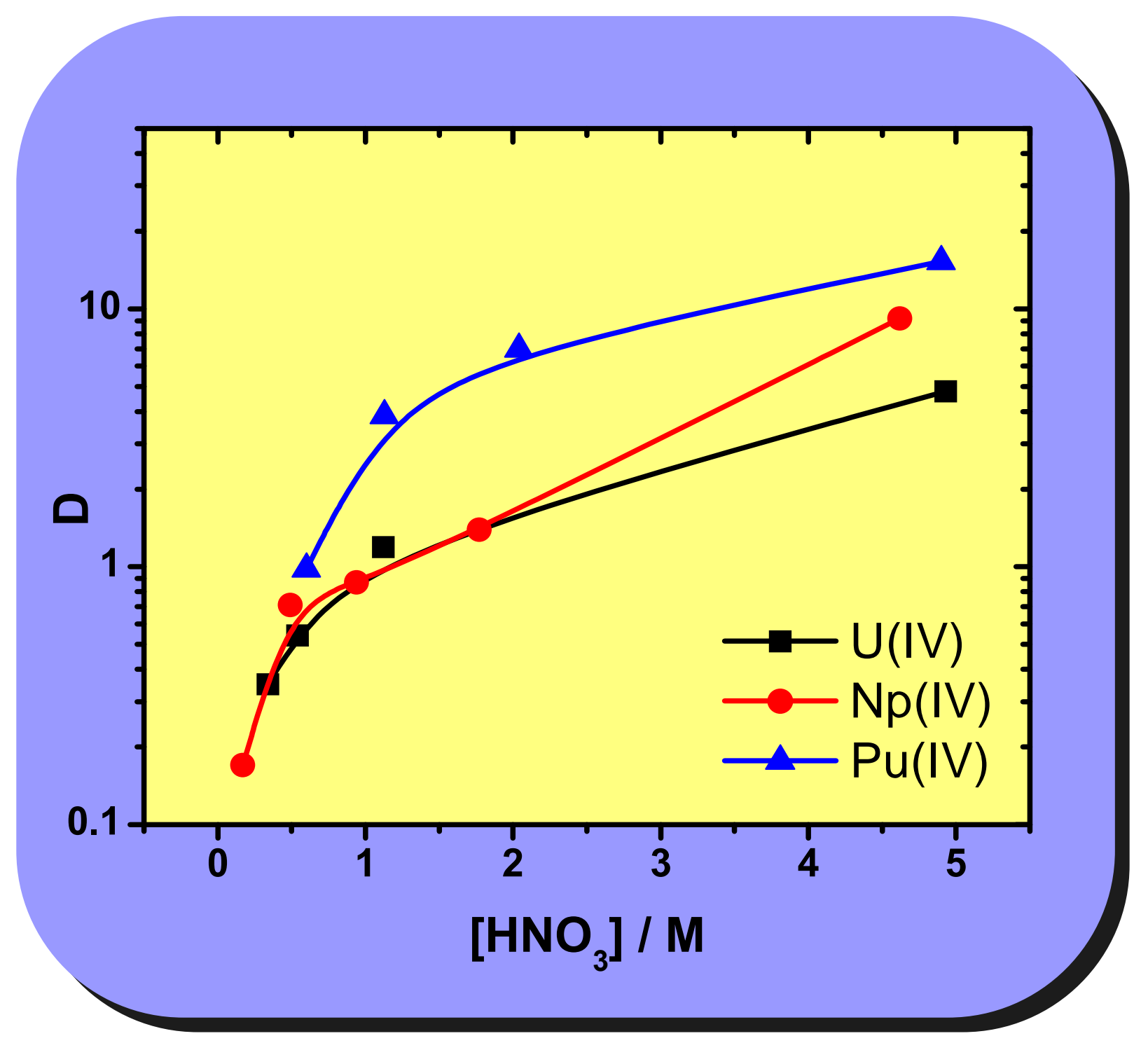


- Advantages of liquid-liquid extraction

- Continuous operation/ High throughput

- Countercurrent operation/ High purity and selectivity

- Recycle solvent, minimizing waste

- Disadvantages of liquid-liquid extraction

- Solvent degradation due to hydrolysis and radiolysis

- Degradation products interfere with process chemistry

- Dibutyl and monobutyl phosphates

- Efficiently extract Pu, but cannot strip Pu from DBP or MBP

- Requires substantial tankage and reagents 
PUREX Process - Process unit operations

Fuel decladding

- Dissolution/ feed clarification

- Separations

- Product conversion

Waste treatment

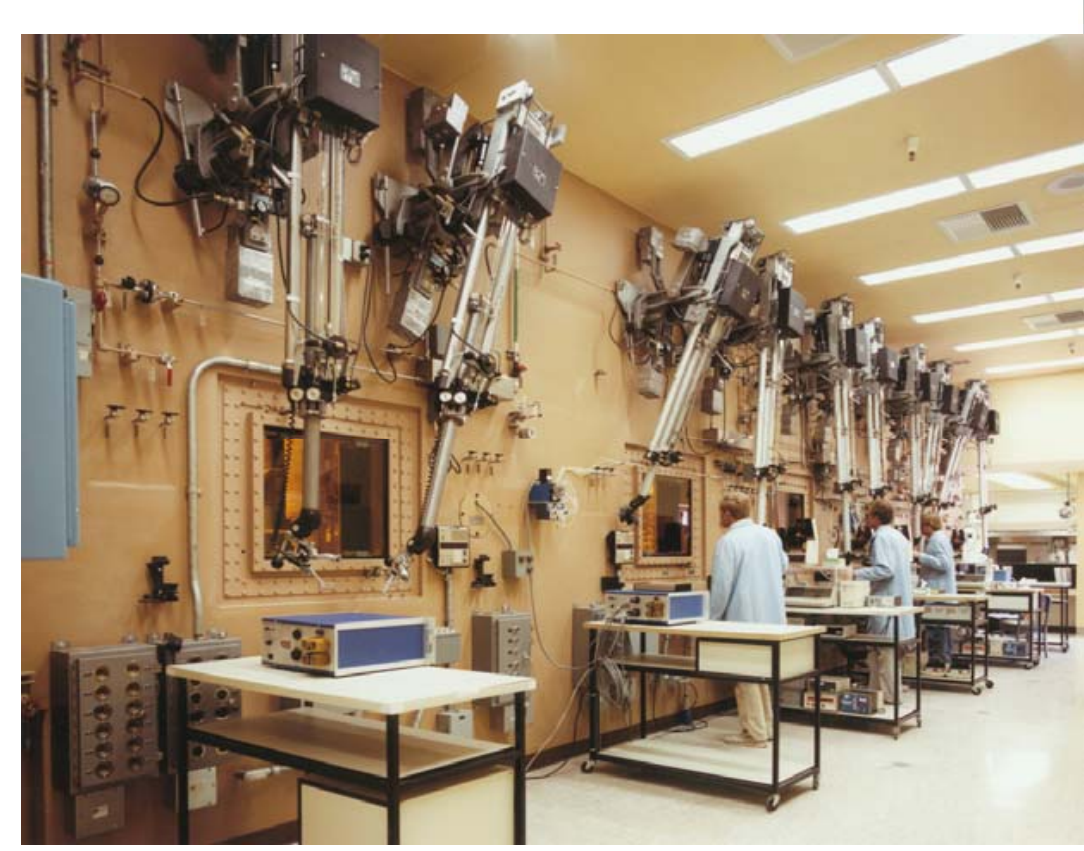




\section{PUREX Process - Process unit operations}

\section{Fuel Decladding}

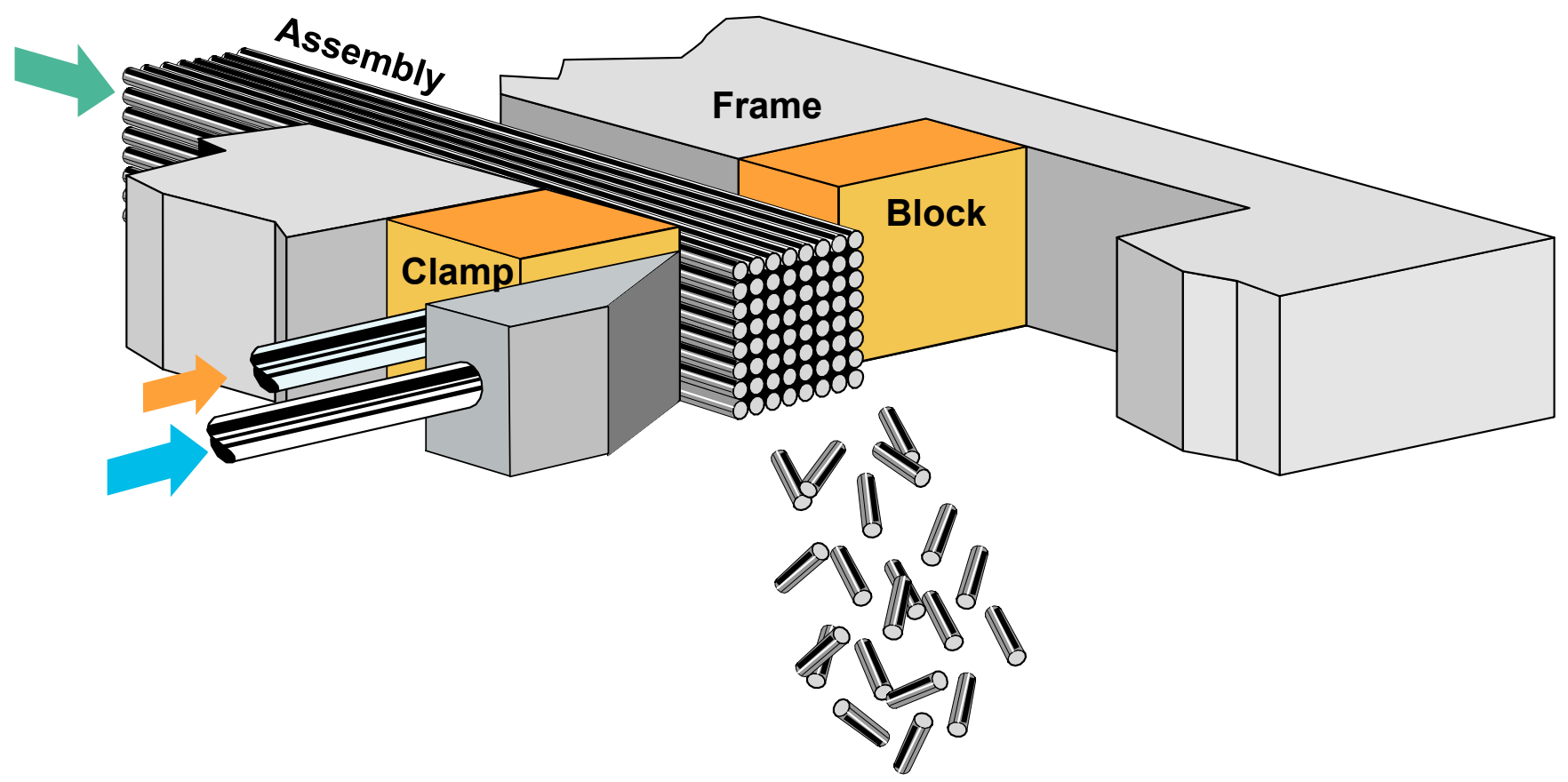


- Dissolution/ feed clarification

- Nitric acid dissolves $\mathrm{UO}_{2}$ pellet from cladding hull, forming $\mathrm{UO}_{2}\left(\mathrm{NO}_{3}\right)_{2}$ in solution

- Dissolver product contains approx. $\mathbf{3 0 0} \mathrm{g} / \mathrm{l}$ uranium

- Releases radioactive off-gas (iodine, krypton, xenon, carbon14 , small amounts of tritium)

- Undissolved solids are removed by centrifugation before transfer to extraction process

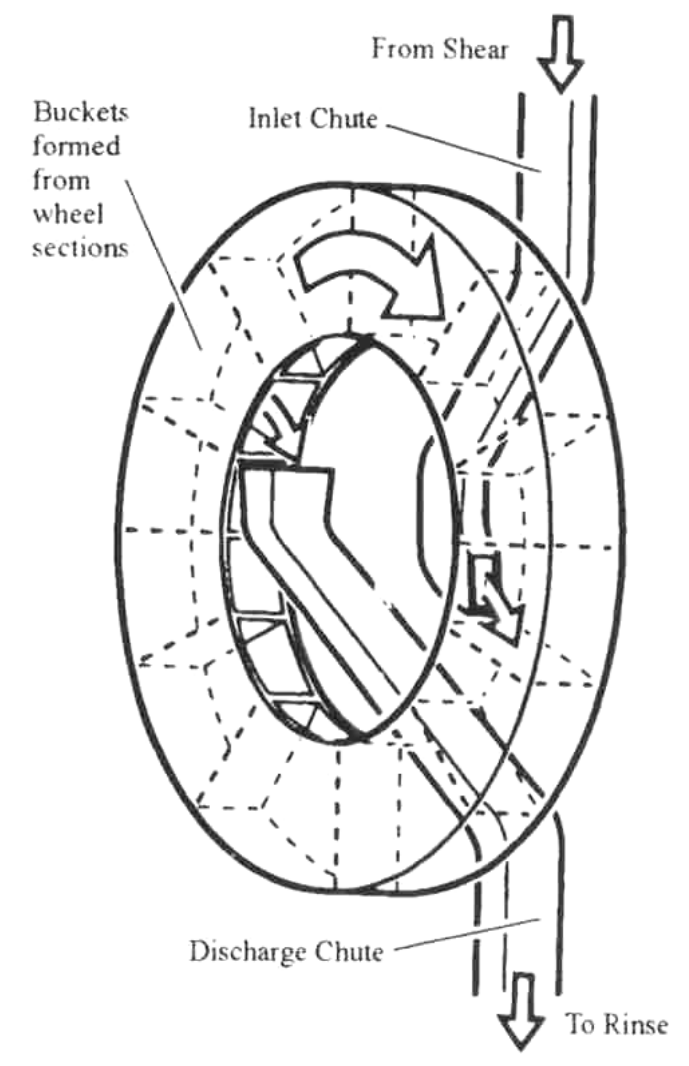




\section{- Separations}

- Continuous, countercurrent extraction operations are performed in mixer settlers, pulse columns or centrifugal contactors

- First cycle separates uranium and plutonium together from fission products

- $U$ and Pu are then separated and sent to separate

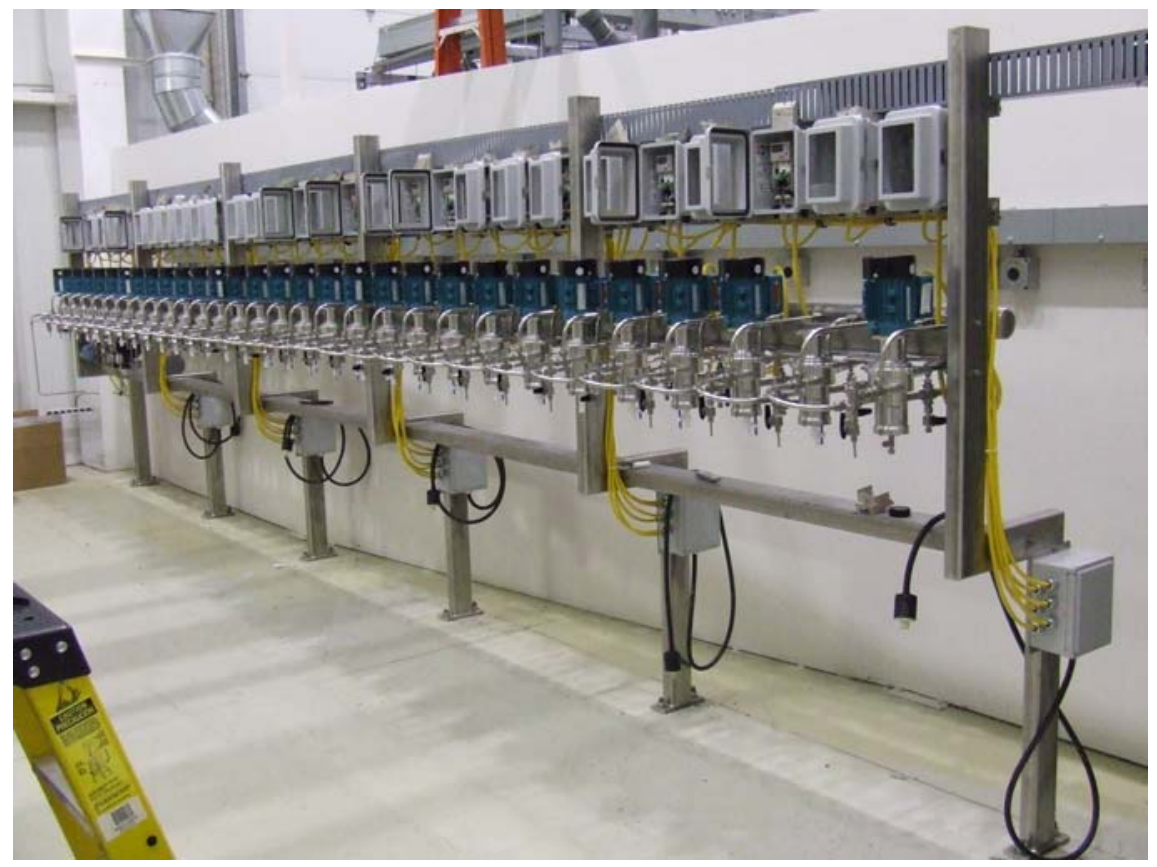
purification cycles 


\section{PUREX Process - Process unit operations}

\section{- Separations}

- Countercurrent PUREX flowsheet

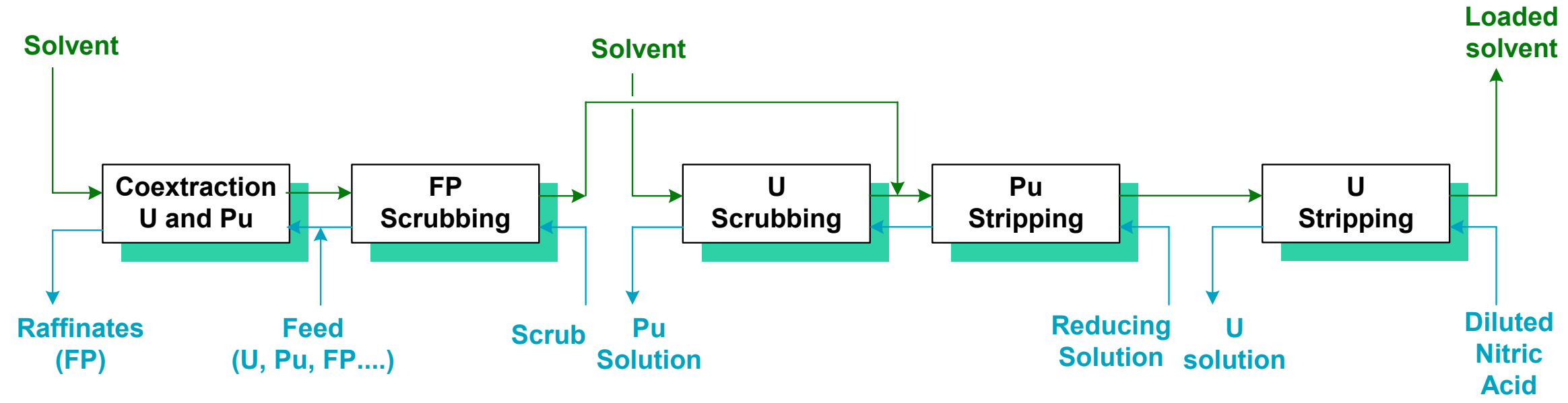


Mixer Settlers

- Discrete stage units (with efficiencies $<1$ )

- Low capital cost

- Requires large amount of floor space (but low headroom)

- Large solvent inventory

- Long residence times

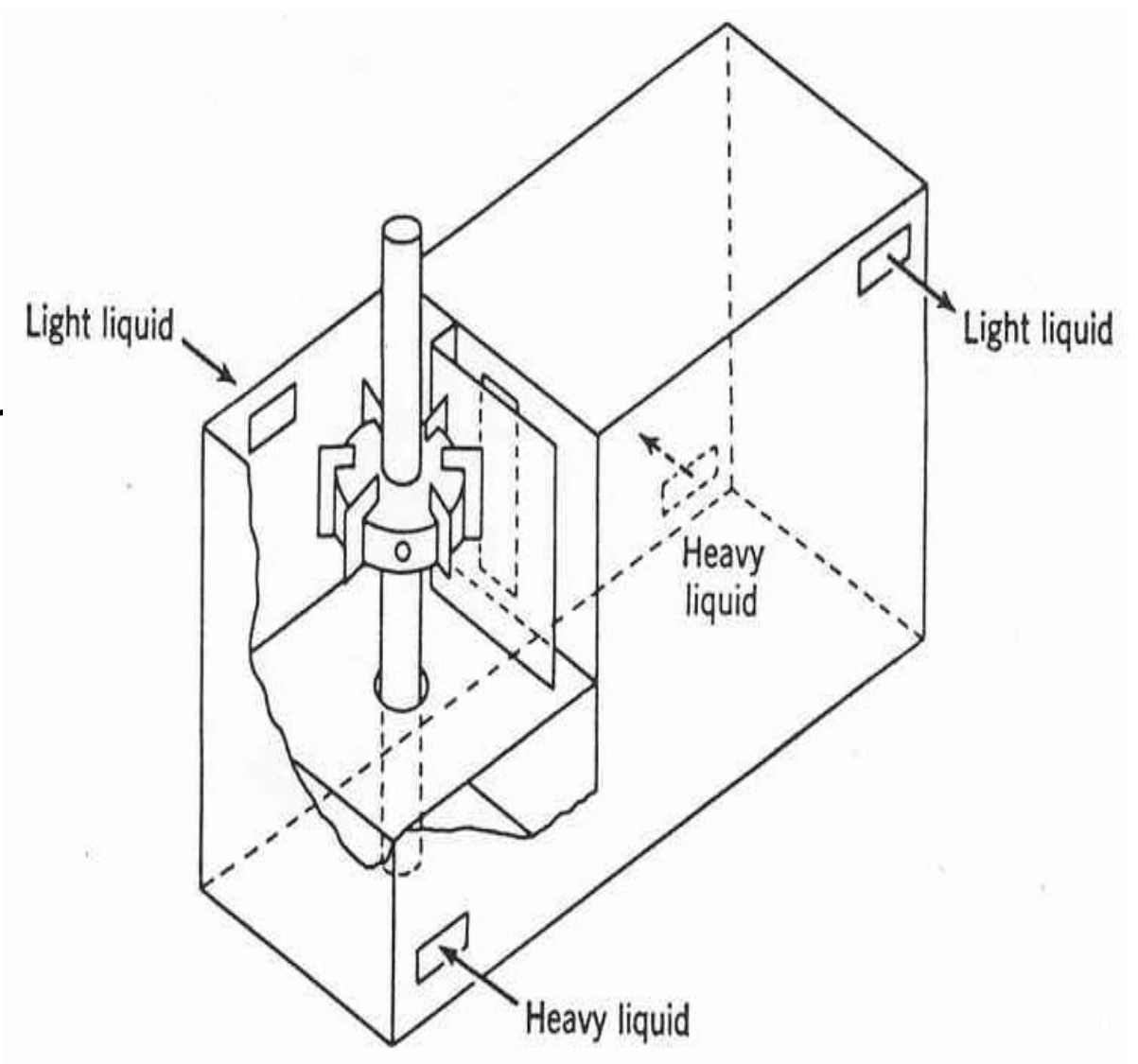




\section{- Pulse Extraction Column}

- Several feet of column needed for one theoretical stage

- Low capital cost

- Requires large amount of head space (40-50'), but little floor space

- Moderate solvent inventory

- Long residence times

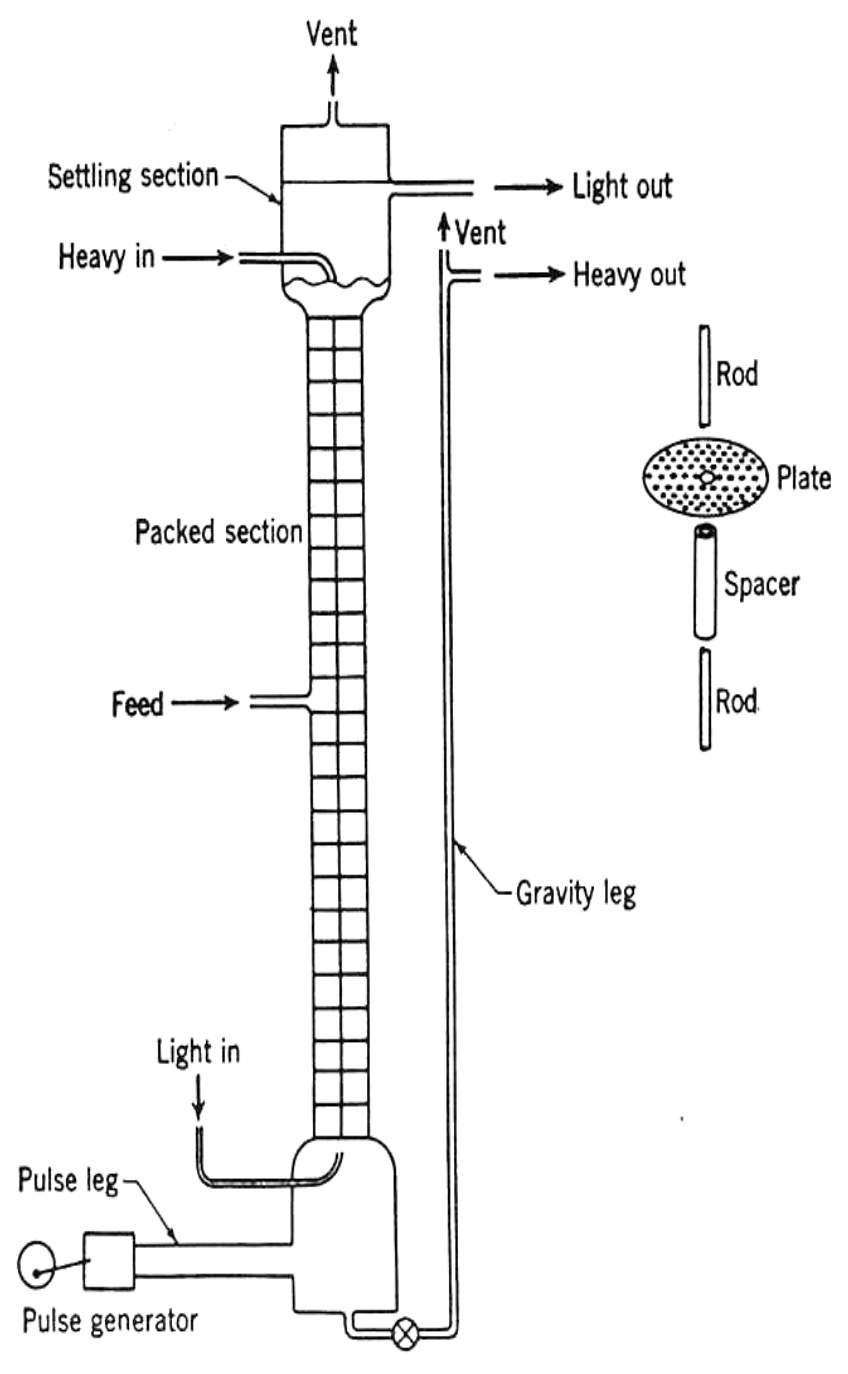


PUREX Process - Process unit operations

- Pulse column at La Hague UP3 plant

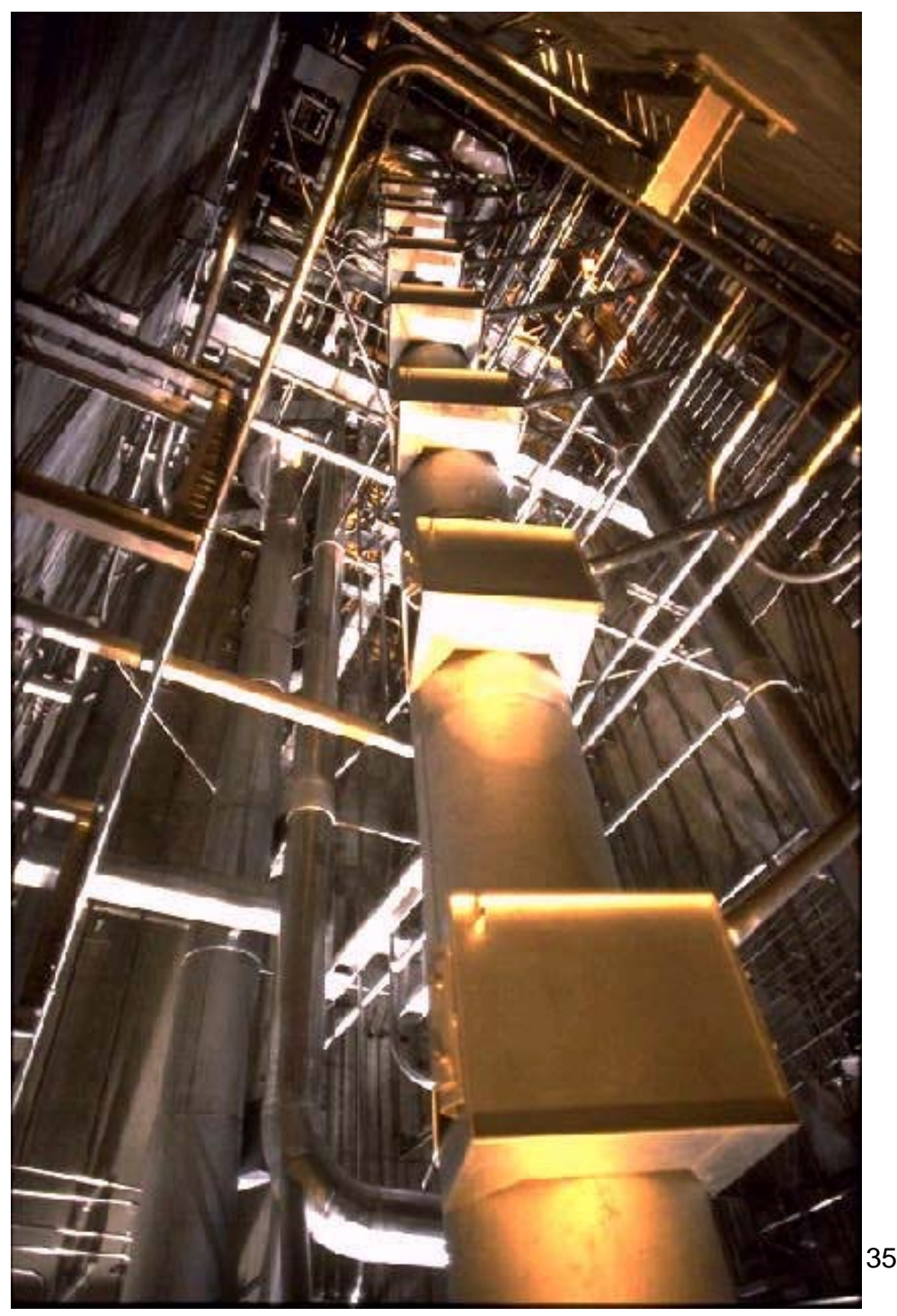




\section{- Centrifugal Contactors}

- Each unit near one theoretical stage

- Higher capital cost

- Requires little headroom or floor space, but requires remote maintenance capability

- Small solvent inventory

- Short residence times

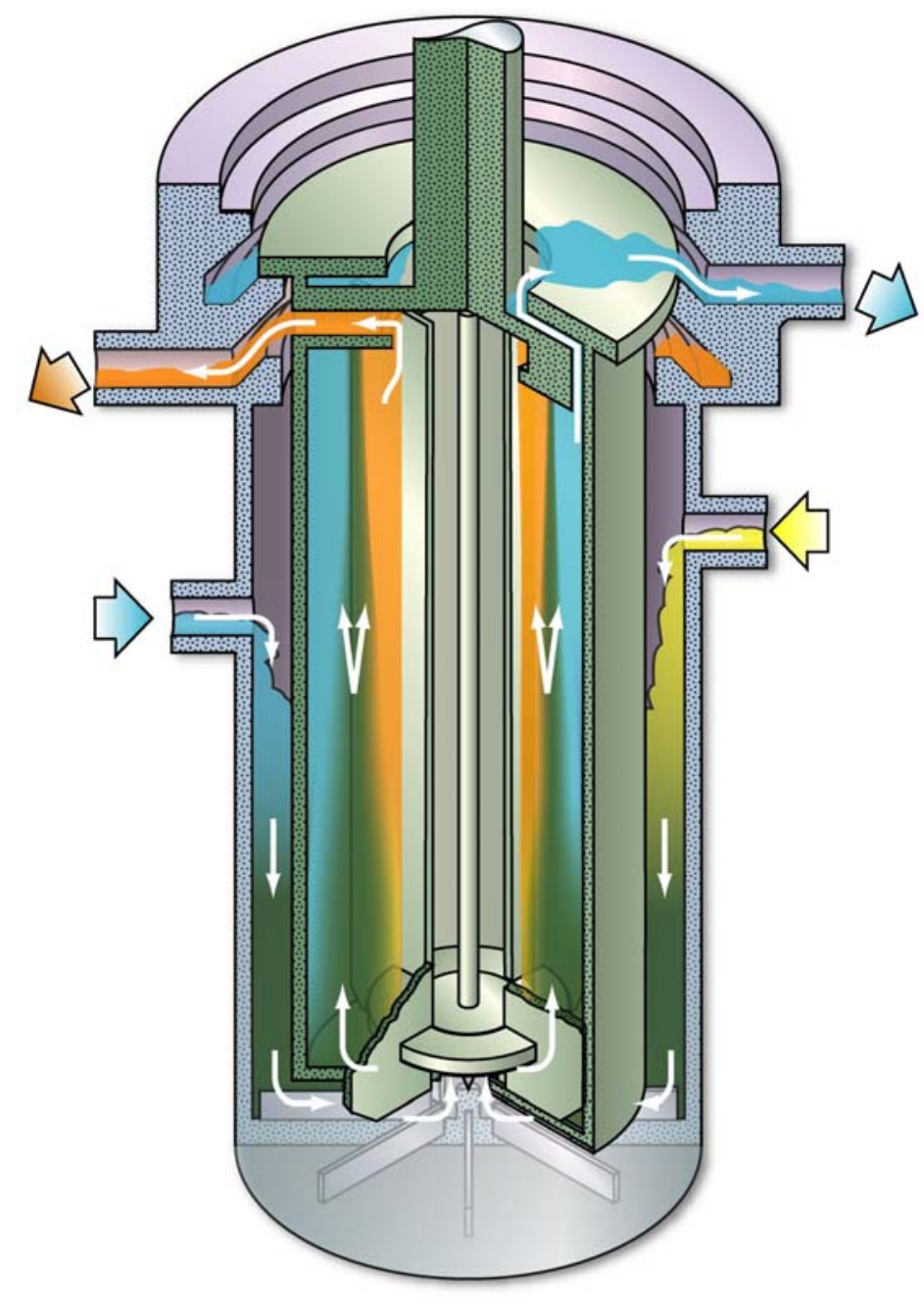




\section{- Product Conversion}

- Uranyl nitrate is converted to $\mathrm{UO}_{3}$ by denitration at elevated temperature

- Produces $\mathrm{NO}_{x}$ off-gas

- Plutonium nitrate is precipitated by oxalate or peroxide and calcined to $\mathrm{PuO}_{2}$

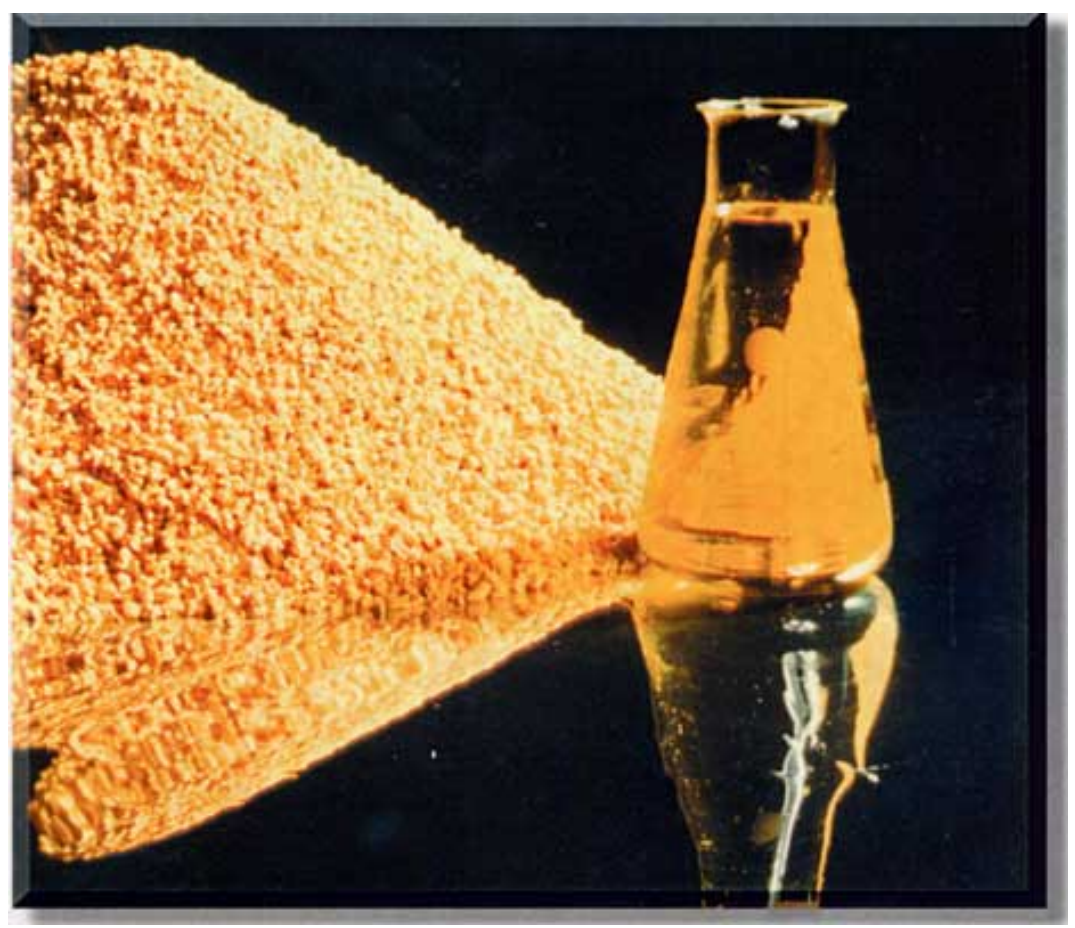




\section{LIQUIDS}

- HLW (RAFFINATE FROM FIRST CYCLE - TANK WASTE)

- LAW (SOLVENT SCRUB; EVAPORATORS)

GASES

- ${ }^{85} \mathrm{Kr}$ (DISSOLVER OFF-GAS; UNTREATED IN THE PAST)

- ${ }^{129}$ (DISSOLVER OFF-GAS; REMOVED FROM EARLIEST DAYS)

$-{ }^{14} \mathrm{C}(\mathrm{AS} \mathrm{CO})$ (DISSOLVER OFF-GAS; UNTREATED IN THE PAST)

- ${ }^{3} \mathrm{H}$ (MOSTLY AS TRITIATED WATER VAPOR)

SOLIDS

- HLW (CONTAMINATED EQUIPMENT; CLADDING HULLS?)

- LAW (MISCELLANEOUS WASTES FROM OPERATIONS) 


\section{PUREX Process - Process unit operations}

\section{- High Level Waste Treatment}

- High level waste is the remaining liquid after $U$ and $P u$ have been removed (contain fission products and transuranium actinides)

- Wastes from weapons production at Hanford and Savannah River were neutralized using $\mathrm{NaOH}$ and stored in carbon steel underground tanks

- Hanford - 177 one million gallon tanks

- Savannah River - 51 - 750,000 gallon tanks

- Multi-billion dollar waste treatment plants are in operation (Savannah River) or under construction (Hanford) to treat these wastes by converting the highly radioactive liquids into glass

- France, Russia and the UK convert their high-level waste into glass
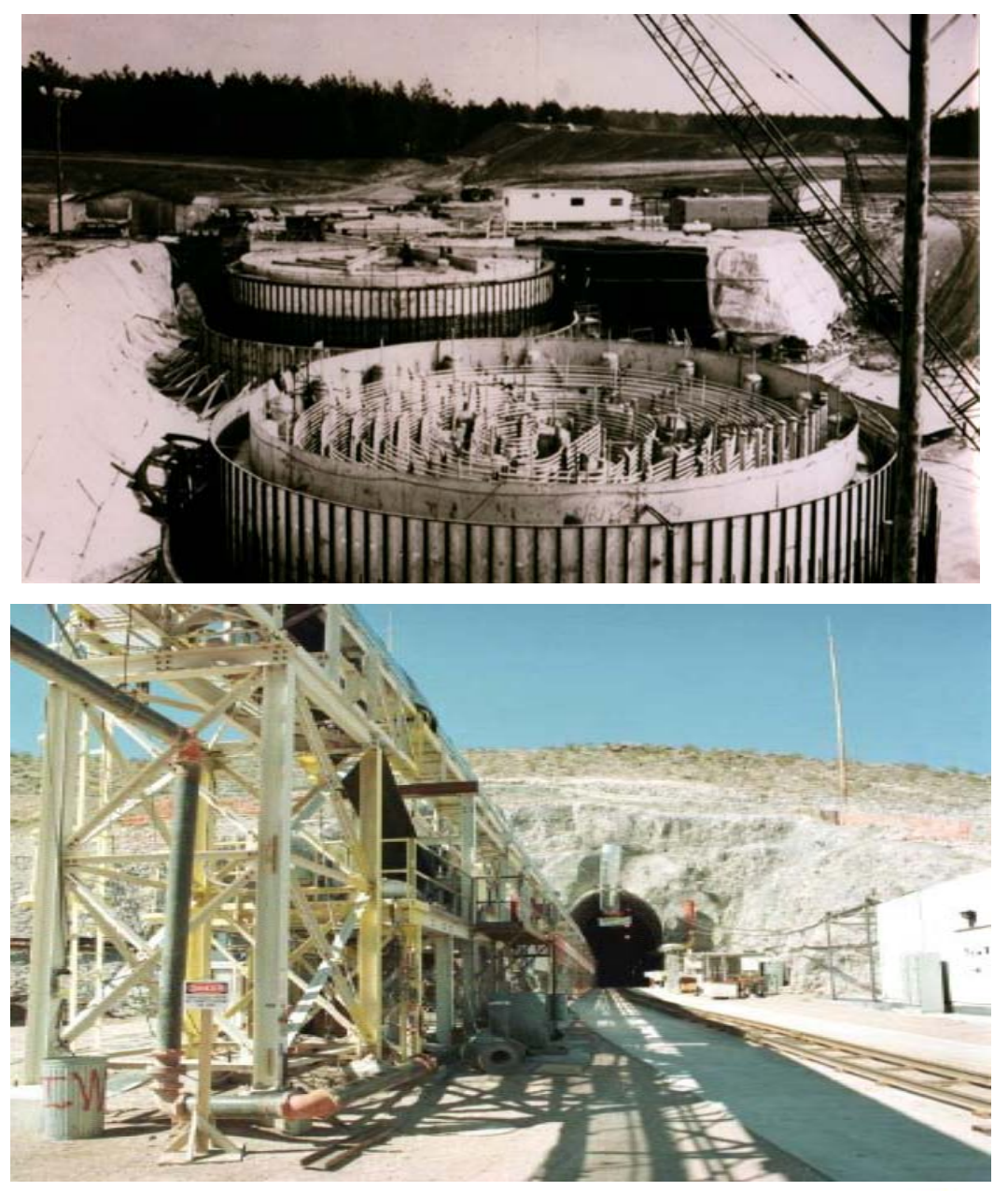


\section{PUREX Process - Current Commercial Operating}

Facilities

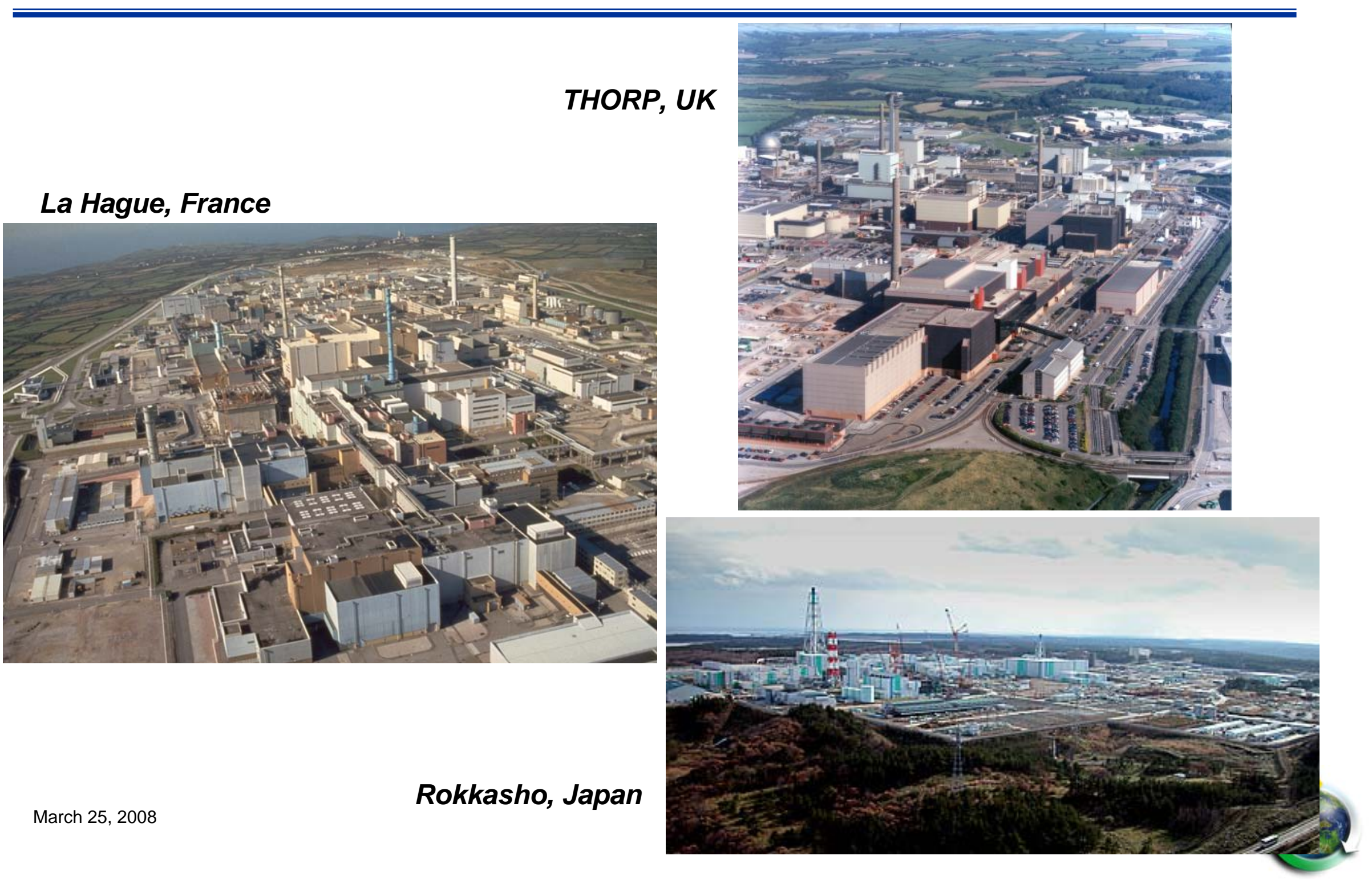




\section{Commercial PUREX operations}

- La Hague, Rokkasho and THORP

- Utilize pulse columns for first cycle extraction

- Mixer settlers and centrifugal contactors in purification cycles

- All are located near the ocean, discharge iodine to the ocean

- La Hague UP2 and UP3 plants - 800 MTHM/yr each

- Rokkasho - based on UP3 design- $800 \mathrm{MTHM} / \mathrm{yr}$

- THORP - 1200 MTHM/yr design capacity, actual capacity less than $1000 \mathrm{MTHM} / \mathrm{yr}$ 


\section{Commercial PUREX operations - La Hague UP2/UP3}

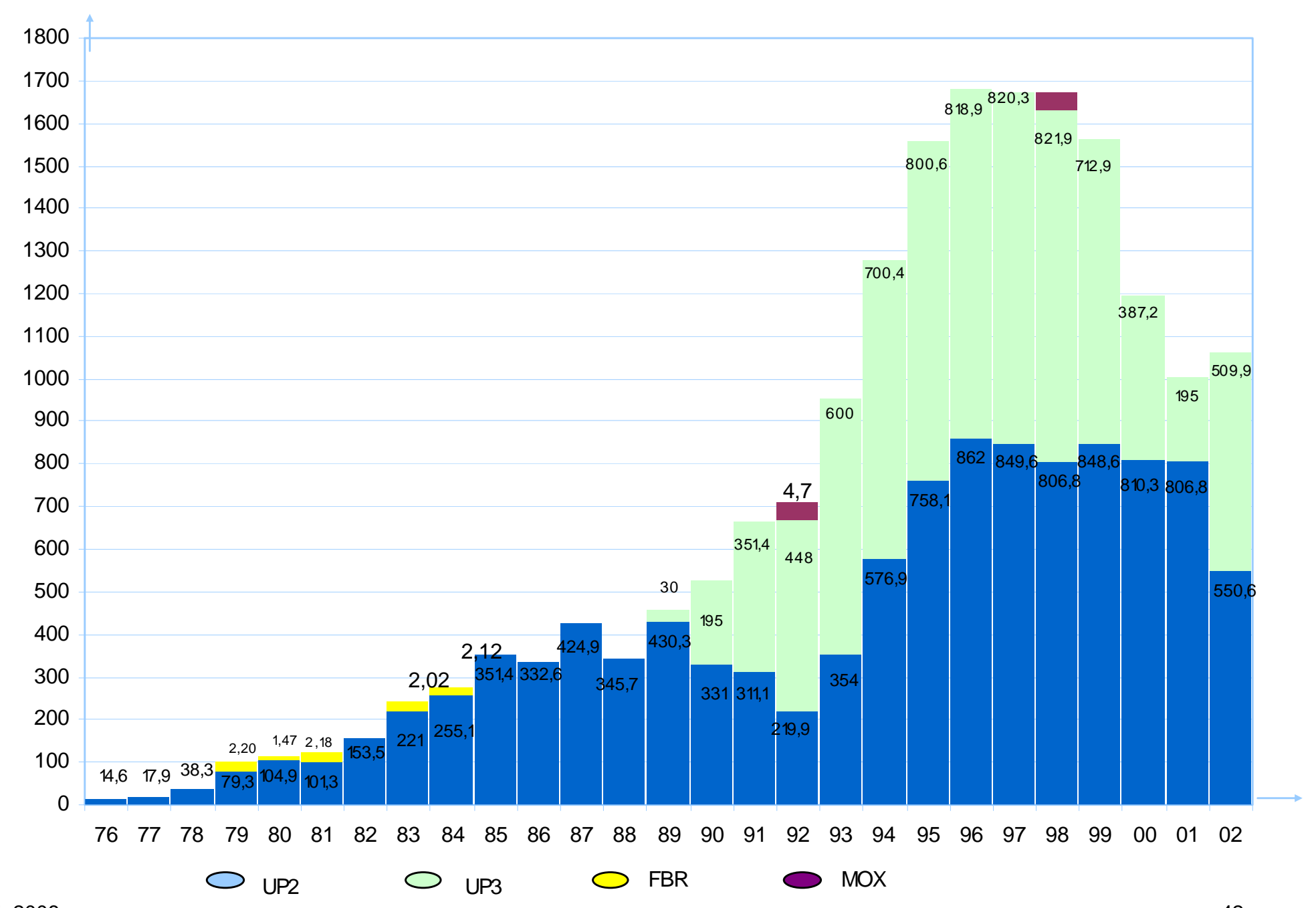




\section{THORP Reprocessing Flowsheet}

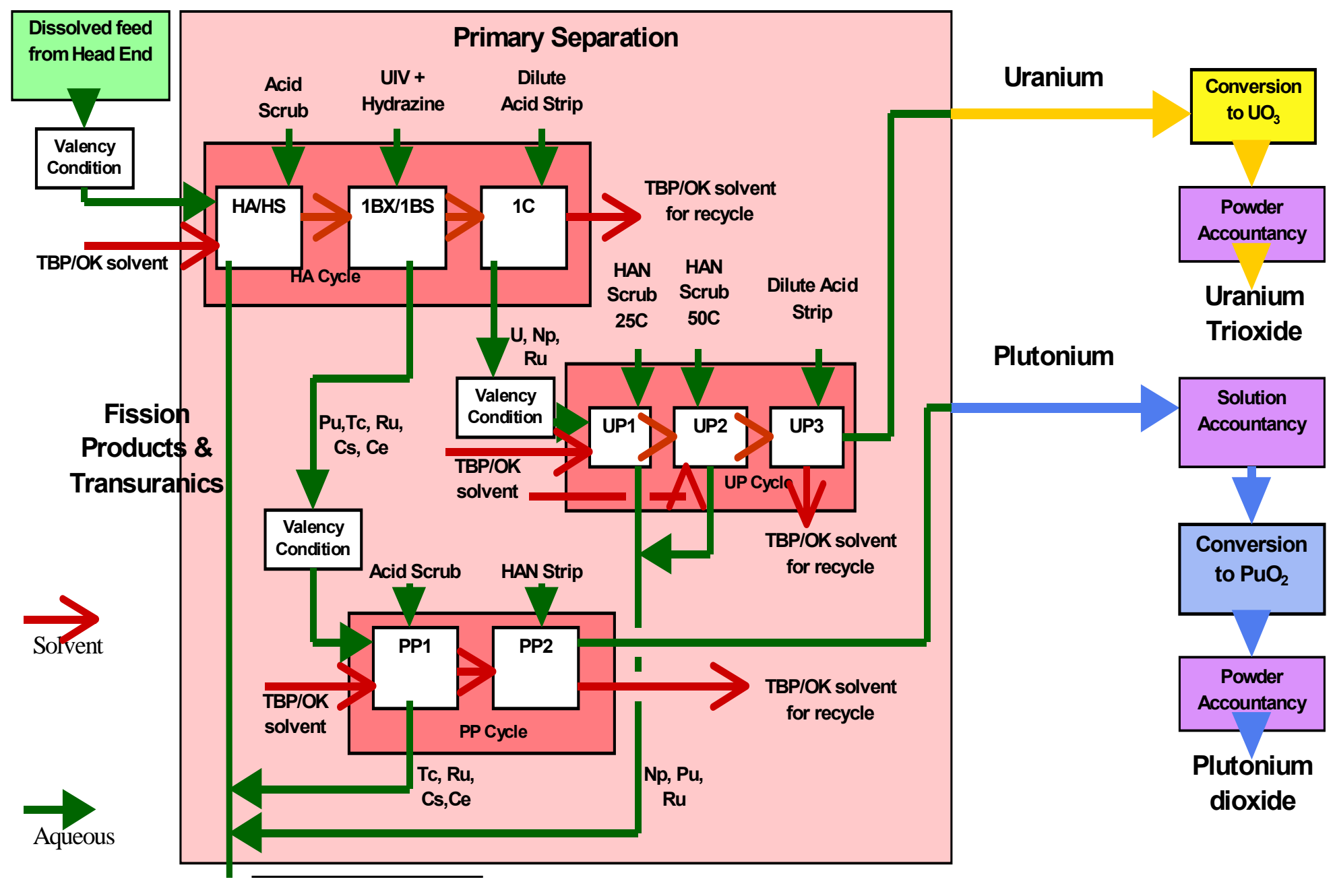




\section{Criticality Control in the PUREX Process}

- Factors that affect criticality safety

- Fissile nuclide ( ${ }^{235} \mathrm{U},{ }^{233} \mathrm{U}$ or $\left.{ }^{239} \mathrm{Pu}\right)$

- Fraction of fertile nuclide diluting fissile nuclide $\left({ }^{238} \mathrm{U},{ }^{232} \mathrm{Th}\right.$ or $\left.{ }^{240} \mathrm{Pu}\right)$

- Mass of fissile nuclide

- Geometry

- Volume

- Concentration of fissile nuclide

- Neutron moderators

- Neutron reflectors

- Neutron absorbers 
- The preferred method of criticality control are engineered controls, such as limiting geometry to be criticality safe under any credible conditions

- This often leads to conservative assumptions for credible conditions and adds to cost and complexity of the process

- Limits equipment size and process throughput

- Administrative controls have greater operational complexity (procedures, standards, etc), but offer greater design flexibility and throughput

- Typically, administrative controls require a double parameter failure for a criticality to occur (no one single control failure would cause a criticality) 
- Single-parameter subcritical limits for uniform aqueous solutions

\begin{tabular}{|l|c|c|c|}
\hline Parameter & ${ }^{235} \mathrm{U}$ & ${ }^{233} \mathrm{U}$ & ${ }^{239} \mathrm{Pu}$ \\
\hline Mass of fissile material, g & 760 & 550 & 510 \\
\hline Solution cylindrical diameter, cm & 13.9 & 11.5 & 15.7 \\
\hline Solution slab thickness, cm & 4.6 & 3.0 & 5.8 \\
\hline Solution volume, L & 5.8 & 3.5 & 7.7 \\
\hline $\begin{array}{l}\text { Concentration of fissile nuclide, } \\
\text { g/L }\end{array}$ & 11.5 & 10.8 & 7.0 \\
\hline $\begin{array}{l}\text { Areal density of fissile nuclide, } \\
\text { g/cm }\end{array}$ & 0.4 & 0.35 & 0.25 \\
\hline Uranium enrichment wt\% ${ }^{235 \mathrm{U}}$ & $1.0 \%$ & & \\
\hline
\end{tabular}




\section{Criticality accidents in reprocessing plants}

\section{Mayak 1953}

- Procedural errors led to an unrecognized accumulation of $842 \mathrm{~g}$ of plutonium (as $\mathrm{Pu}$ nitrate solutions) in one vessel, which became critical and brought the vessel contents to boiling. The operators transferred contents of another vessel to the first, ending the reaction

\section{Mayak 1957}

- The accident occurred in a glovebox assembly within which uranium solution was precipitated into vessels. An unexpectedly large amount of uranium precipitate accumulated in a filter receiving vessel. The operator at the glovebox observed the filter vessel bulge prior to ejection of gas and some solution and precipitate from the vessel within the glovebox.

\section{Mayak 1958}

- Following the criticality accident at the same facility in 1957, an apparatus had been constructed to test criticality phenomena in fissile solutions. A 400-liter tank on a platform was used for measurements involving solutions; after each experiment, the tank was drained into individual 6-liter containers of favorable geometry. On this occasion, the tank contained uranyl nitrate solution (90\% U-235) and was being drained for another experiment. After filling several 6-liter containers, operators decided to circumvent the standard procedure to save time. Three operators unbolted the tank and lifted it to pour directly into containers. The presence of the operators provided sufficient neutron reflection to cause a criticality excursion, producing a flash of light and ejecting solution as high as the ceiling, 5 meters above the tank. 


\section{Criticality accidents in reprocessing plants}

- Oak Ridge 1958

- A leak in a tank containing uranyl nitrate solution (93\% U-235) was discovered on 15 June. The leak was not properly logged. The following day other tanks were being drained into a 55-gallon drum; uranium solution from the leaking tank also entered the drum. The operator nearest the drum noticed yellow-brown fumes rising from the drum's contents; he retreated before seeing a blue flash as the criticality excursion occurred. Excursion power output rose for at least 3 minutes, then ended after 20 minutes

Idaho 1959

- Air sparging cylinders containing highly enriched uranyl nitrate solution initiated a siphon that transferred $200 \mathrm{~L}$ of solution to a 5000 gallon tank containing about 600 liters of water. The resulting criticality lasted about 20 minutes 


\section{Criticality accidents in reprocessing plants}

Idaho 1961

- $40 \mathrm{~L}$ of $200 \mathrm{~g} / \mathrm{L}$ uranyl nitrate solution was forced up from a 5 in diameter section of an evaporator into a 24 in diameter disengagement cylinder, well above normal solution level. Operators were attempting to clear a plugged line with air, which entered the evaporator, forcing the solution upward

- Hanford 1962

- Plutonium solution was spilled onto the floor of a solvent extraction hood. Improper operation of valves allowed a mixture of plutonium solutions in a tank that became supercritical. The excursion continued at low power levels for 37.5 hours, during which a remotely controlled robot was used to check conditions and operate valves. Criticality was probably terminated by precipitation of plutonium in the tank to a noncritical state 


\section{Criticality accidents in reprocessing plants}

- Mayak 1968

- Solutions of plutonium were being transferred from a large tank into a stainless steel vessel using a glass bottle. While a worker was pouring a second load from the glass bottle into the vessel, a criticality excursion occurred.

- Idaho 1978

- A leaking valve allowed water to dilute the scrub solution used in the first cycle extraction process. This leak was undetected because of a failed alarm system. Because of the dilution, highly enriched uranium was stripped from the organic solvent (normally would remain in solvent). Over the course of a month, the concentration of uranium increased in the large diameter bottom of the scrub column, resulting in a criticality. 
Tokai-mura 1999

- Three operators were engaged in processes combining uranium oxide with nitric acid to produce a uranium-containing solution for shipment. The uranium involved was $18.8 \% \mathrm{U}-235$. The procedure used deviated from that licensed to the facility. In particular the uranium solution was being placed in a precipitation tank for dispensing into shipment containers, not the more narrow vessel (geometrically favorable to minimizing criticality risks) prescribed by license. While two workers were adding a seventh batch of uranium solution to the tank, a criticality excursion occurred.

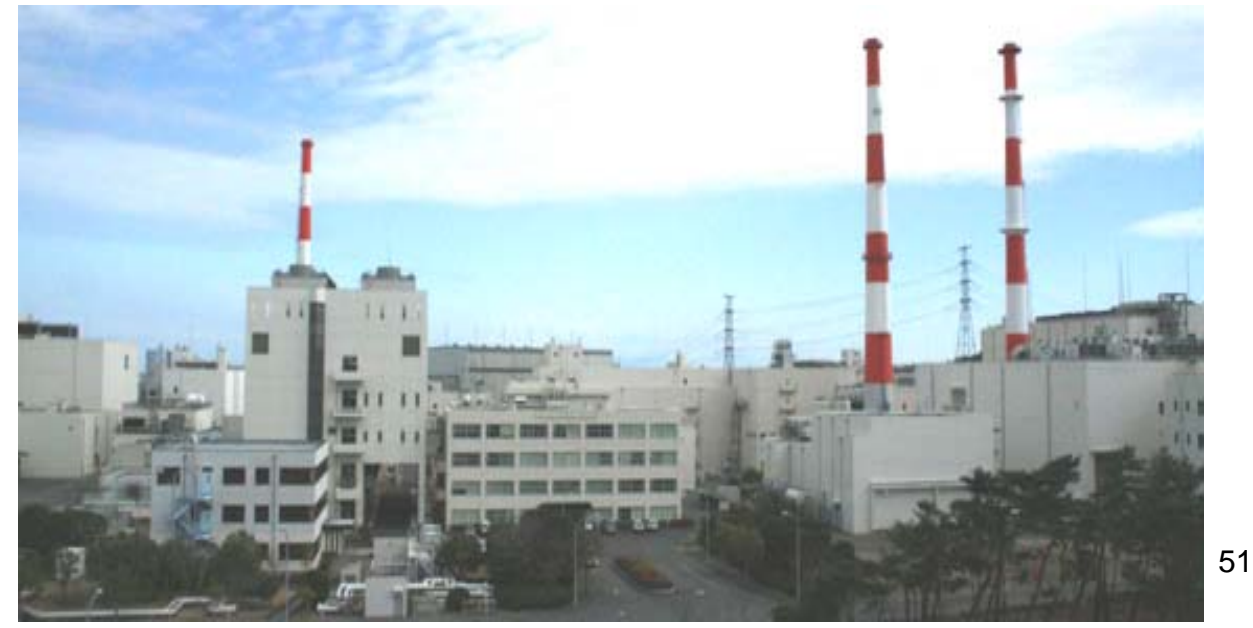




\section{Major industrial accidents in reprocessing plants}

- Red Oil

- Created by decomposition of TBP by nitric acid, under elevated temperature

- Influenced by presences of heavy metal (U or Pu), which causes higher organic solubility in aqueous solution and increases the density of the organic solution (possibly > aqueous phase)

- Decomposition of TBP is a function of nitric acid concentration and temperature

- Primary concern is in evaporators that concentrate heavy metals in product

- Red oil reactions can be very energetic, and have resulted in large explosions at reprocessing facilities

- Typical safety measures include diluent washes or steam stripping of aqueous product streams to remove trace amounts of TBP before evaporation or denitration

- Major accidents detailed in DNFSB report "Tech 33" Nov. 2003 


\section{Controls to avoid Red Oil accidents}

How do we avoid red oil in reprocessing facilities?

- Temperature control

- Maintain solutions at less than $130^{\circ} \mathrm{C}$ at all times

- Pressure control

- Adequate ventilation to avoid buildup of explosive gases

- Mass control

- Minimize or eliminate organics (TBP) from aqueous streams

- Decanters, diluent washes, etc.

- Concentration control

- $<10 \mathrm{MHNO}_{3}$

- With solutions of uranyl nitrate, boiling temperature and density must be monitored

- Multiple methods need to be employed so that no single parameter failure can lead to red oil formation 
- Mayak 1957

- Liquid high-level waste was stored in underground tanks. The high level waste, coming from the B plant, contained sodium nitrate and acetate salts, from the acetate precipitation process. Cooling system in one of the tanks failed, and the temperature in the tank rose to $350^{\circ} \mathrm{C}$. The tank contents evaporated to dryness, causing a massive explosion (estimated to be equivalent to 75 tons of TNT). Over $20 \mathrm{MCi}$ of radioactivity were released to the environment.

- Tokai-mura 1997

- A fire occurred in the bitumen waste facility of the demonstration reprocessing plant at Tokai-mura. Bitumen is used to solidify intermediate-level activity liquid radioactive waste. The fire apparently occurred after errors made in monitoring a chemical reaction. The fire was not completely extinguished and about ten hours later, after chemicals had accumulated, an explosion occurred which ruptured the confinement of the facility. 
- Hanford 1997

- Hydroxylamine nitrate and nitric acid were stored in a tank and allowed to evaporate to dryness. The resulting explosion destroyed the tank and blew a hole in the roof of the building. Hydroxylamine is a reagent used to reduce plutonium valance from (IV) to (III).

THORP 2005

- A pipe failure resulted in about $83,000 \mathrm{~L}$ of highly radioactive dissolver solution leaking into the stainless-steel lined feed clarification of the THORP facility. This solution contained about 20 MT of uranium and plutonium. The leak went undetected for months before being discovered. No injuries or exposure to radiation. The plant is still shutdown in 2008. 
- Industrial reprocessing firms have a high degree of confidence in the PUREX process, however, the PUREX process has been the subject of criticism for the past 30 years related to the separation of a pure plutonium stream

- Recall that the PUREX process co-extracts both uranium and plutonium, then partitions them into separate streams

- Modifications to the PUREX process have recently been proposed and developed that leave a small fraction of the uranium with the plutonium, producing a mixed product for production of mixed oxide (MOX) fuel

- These modified processes have been called COEX ${ }^{\mathrm{TM}}$, NUEX or UREX+ 3 and are all based on modified PUREX chemistry

- Calling these processes "co-extraction" to differentiate them from PUREX is misleading because the PUREX process also coextracts uranium and plutonium 
- Each specific process has its own proprietary methods of stripping plutonium from the solvent, with a fraction of uranium

- In the PUREX process, the nitric acid concentration in the second scrub is kept higher that $\sim 0.5 \mathrm{M}$ to keep the uranium in the organic solvent, while the plutonium is reduce to the trivalent state and partitions to the aqueous phase.

- In the modified process, the acid concentration in the second scrub stream is maintained at a controlled value (typically lower than $0.5 \mathrm{M})$ to allow a small amount $(\sim 1 \%)$ of the uranium to partition to the aqueous stream along with the plutonium (III)

- After the plutonium and small fraction of uranium are removed in the second scrub stream, uranium is stripped from the solvent by using dilute $(0.01 \mathrm{M})$ nitric acid 
Simplified flowsheet for $U$ and U/Pu products

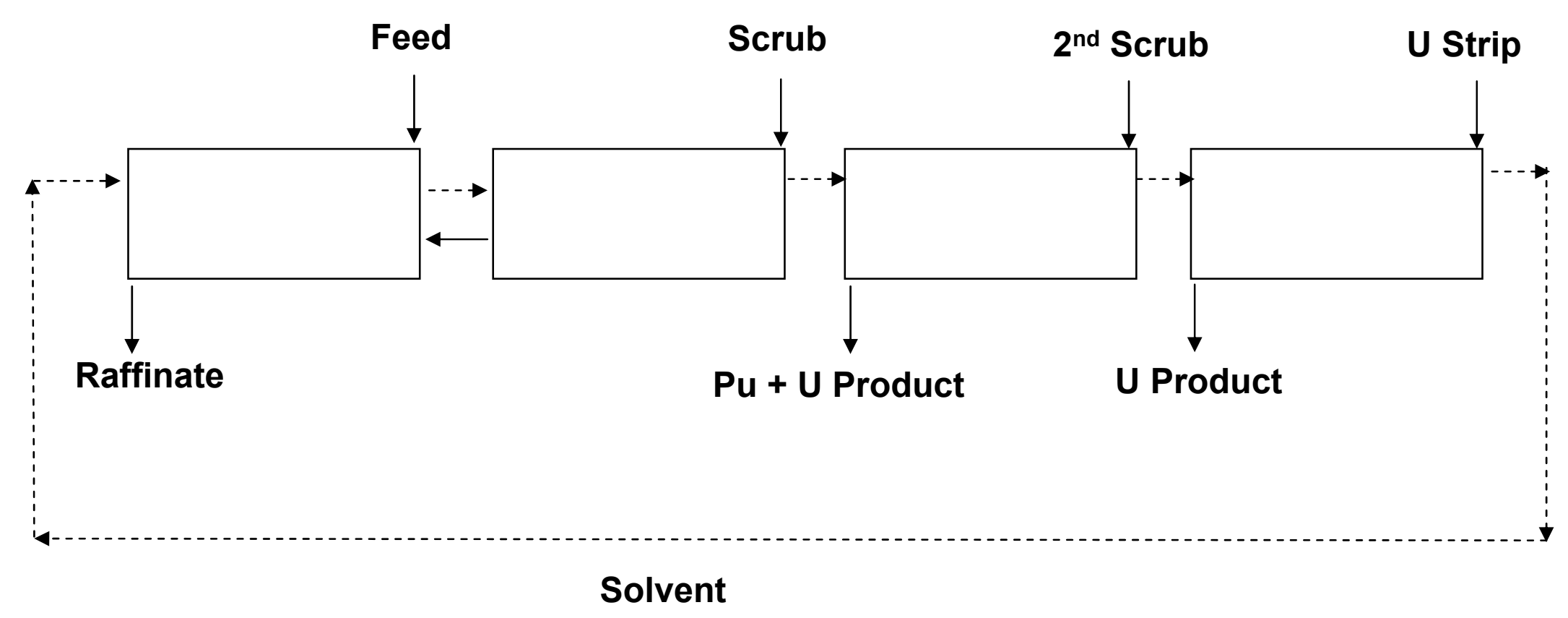


- Spent nuclear fuel reprocessing is a mature technology, having over 50 years of industrial experience with the PUREX process

- Nuclear energy must solve the waste disposal issue soon for it to grow. This solution could include building more repositories, reprocessing fuel and/or a combination of both

- History has shown that there must be a strong emphasis on safety, including criticality safety, safeguards and industrial safety

- New "evolutionary" processes employ minor adjustments to PUREX process chemistry to keep from producing pure plutonium and facilitate more near-term implementation 


\section{UREX+ Process Overview}

Candido Pereira

Argonne National Laboratory

Topical Seminar Series on Nuclear Fuel Separation Processes

March 26, 2008 


\section{Outline}

- Separations Overview

- Solvent Extraction

Process Modeling and Simulation

- Processing Options

Demonstration of UREX+ Processes 


\section{Separations are a central component of the GNEP scheme and implementation of an advanced fuel cycle in the U.S.}

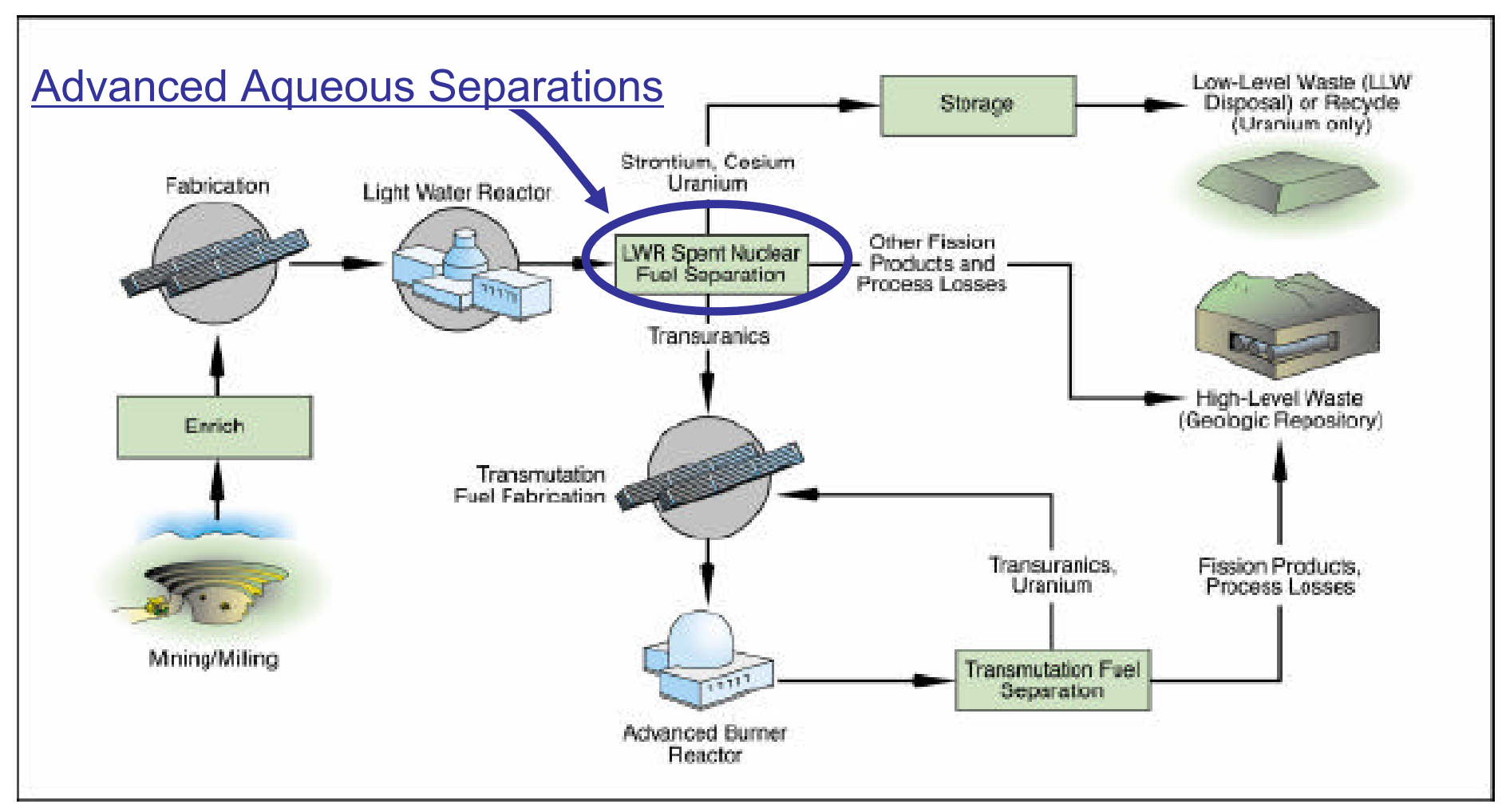




\section{Separations Can Potentially Reduce the Volume, Activity and Toxicity of the Waste Bound for the Repository}

\begin{tabular}{|c|c|c|}
\hline Radionuclide & Oxide Fuel \% & Significance \\
\hline $\mathbf{u}$ & $\sim 95$ & Hazard comparable to ore. \\
\hline Cs and Sr & 0.3 & -30 yr half-life. Significant heat source. \\
\hline Pu and Np & $\sim 1$ & Isotopes have long half-lives. Recycle. \\
\hline $\mathrm{Am}$ and $\mathrm{Cm}$ & 0.1 & $\begin{array}{l}\text { Isotopes have long half-lives and high } \\
\text { toxicity. Can be recycled to fast } \\
\text { reactors. }\end{array}$ \\
\hline I and Tc & 0.1 & $\begin{array}{l}>10^{5} \mathrm{yr} \text { half-life. Mobile in groundwater. } \\
\text { Separate and stabilize for long-term } \\
\text { disposal. }\end{array}$ \\
\hline $\begin{array}{l}\text { Other Fission } \\
\text { Products }\end{array}$ & -3.5 & $\begin{array}{l}\text { Low heat and toxicity. Stabilize for } \\
\text { disposal. }\end{array}$ \\
\hline
\end{tabular}




\section{Examples of Some Potential Aqueous Processing Options Meeting GNEP Objectives: UREX+}

\begin{tabular}{|c|c|c|c|c|c|c|c|}
\hline Process & $\begin{array}{c}\text { Product } \\
\# 1\end{array}$ & $\begin{array}{c}\text { Product } \\
\# 2\end{array}$ & $\begin{array}{c}\text { Product } \\
\# 3\end{array}$ & $\begin{array}{c}\text { Product } \\
\# 4\end{array}$ & $\begin{array}{c}\text { Product } \\
\# 5\end{array}$ & $\begin{array}{c}\text { Product } \\
\# 6\end{array}$ & $\begin{array}{c}\text { Product } \\
\# 7\end{array}$ \\
\hline UREX+1 & U & Tc & $\mathrm{Cs} / \mathrm{Sr}$ & TRU/Ln & FP & & \\
\hline UREX+1a & $U$ & Tc & $\mathrm{Cs} / \mathrm{Sr}$ & TRU & $\mathrm{FP} / \mathrm{Ln}$ & & \\
\hline UREX+1b & $U$ & Tc & $\mathrm{Cs} / \mathrm{Sr}$ & U/TRU & FP/Ln & & \\
\hline UREX+2 & $U$ & Tc & $\mathrm{Cs} / \mathrm{Sr}$ & $\mathrm{Pu} / \mathrm{Np}$ & $\mathrm{Am} / \mathrm{Cm} / \mathrm{Ln}$ & $\mathrm{FP}$ & \\
\hline UREX+2a & $U$ & Tc & $\mathrm{Cs} / \mathrm{Sr}$ & U/Pu/Np & $\mathrm{Am} / \mathrm{Cm} / \mathrm{Ln}$ & $\mathrm{FP}$ & \\
\hline UREX+3 & $U$ & Tc & $\mathrm{Cs} / \mathrm{Sr}$ & $\mathrm{Pu} / \mathrm{Np}$ & $\mathrm{Am} / \mathrm{Cm}$ & FP/Ln & \\
\hline UREX+3a & $U$ & Tc & $\mathrm{Cs} / \mathrm{Sr}$ & U/Pu/Np & $\mathrm{Am} / \mathrm{Cm}$ & FP/Ln & \\
\hline UREX+4 & $U$ & Tc & $\mathrm{Cs} / \mathrm{Sr}$ & $\mathrm{Pu} / \mathrm{Np}$ & $\mathrm{Am}$ & $\mathrm{Cm}$ & FP/Ln \\
\hline UREX $+4 a$ & $U$ & Tc & $\mathrm{Cs} / \mathrm{Sr}$ & U/Pu/Np & Am & $\mathrm{Cm}$ & FP/Ln \\
\hline
\end{tabular}

Notes: (1) in all cases, iodine is removed as an off-gas from the dissolution process.

(2) processes are designed for the generation of no liquid high-level wastes

$\mathrm{U}: \quad$ uranium (contributor to dose rate, and the mass and volume of high-level waste)

Tc: $\quad$ technetium (long-lived fission product, minor contributor to long-term dose)

Cs/Sr: cesium and strontium (primary short-term heat generators, affect waste form loading and repository drift loading)

TRU: transuranic elements: $\mathrm{Pu}$ - plutonium, $\mathrm{Np}$ - neptunium, Am - americium, $\mathrm{Cm}$ - curium (primary long-term dose rate contributors)

Ln: lanthanide (rare earth) fission products

FP: fission products other than cesium, strontium, technetium, iodine, and the lanthanides 


\section{Advanced Aqueous Processing of LWR Spent Fuel}

Aqueous solvent extraction processes are the reference methods under GNEP for treatment of LWR spent fuel

- High degree of technological maturity; industrial practice in France, the United Kingdom, Russia, and Japan

- Capable of achieving high decontamination factors for separated products

- For thermal recycle, must eliminate high cross section fission products nearly completely (DF>10,000 required)

- For fast reactor recycle, must reduce the rare earth content (DF>250 for separation of lanthanides from transuranics)

- Provides flexibility in degree of partitioning of radionuclides present in spent fuel

- Suite of process variants under development 


\section{Example of Process Flowsheet Design}

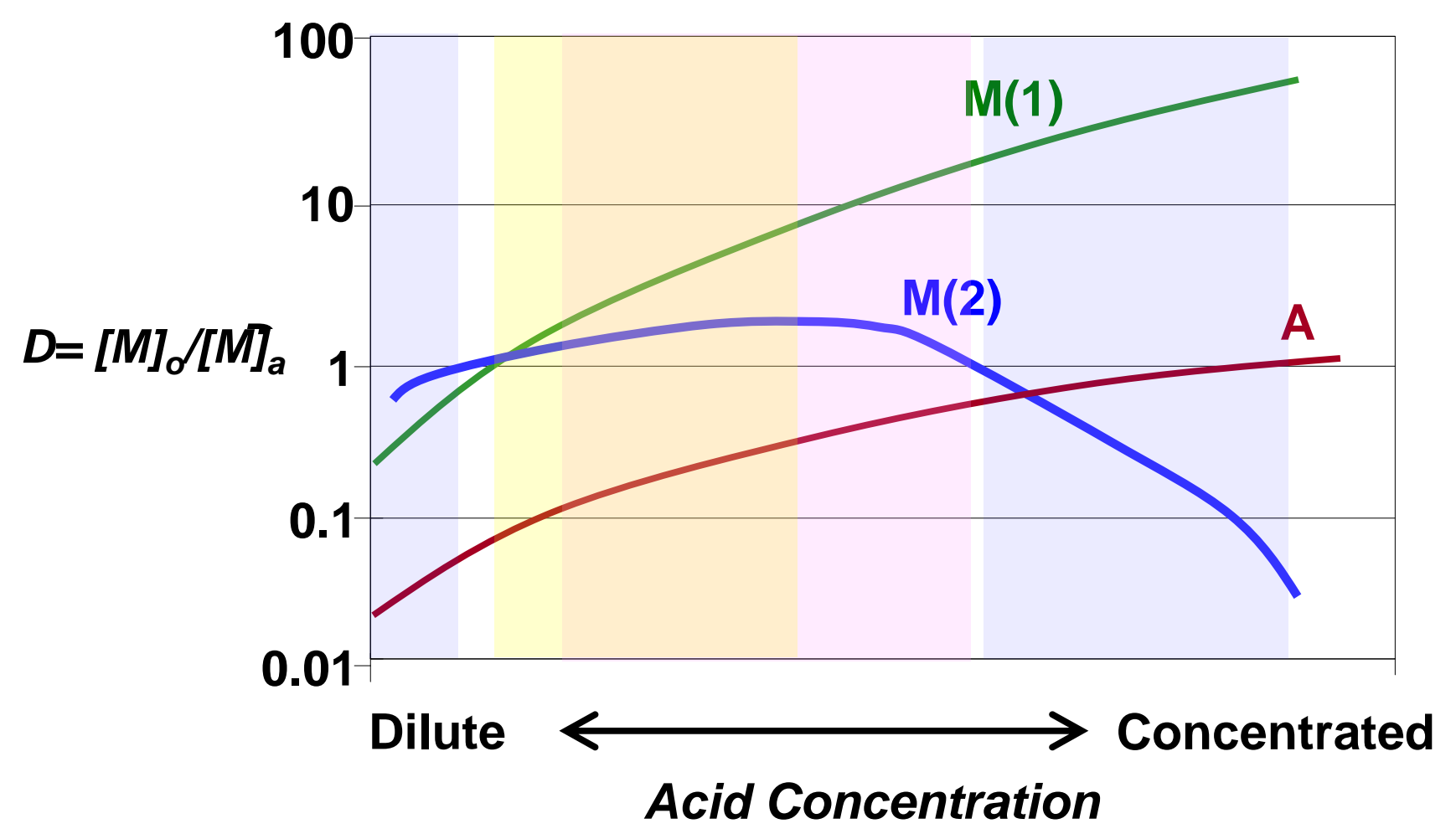




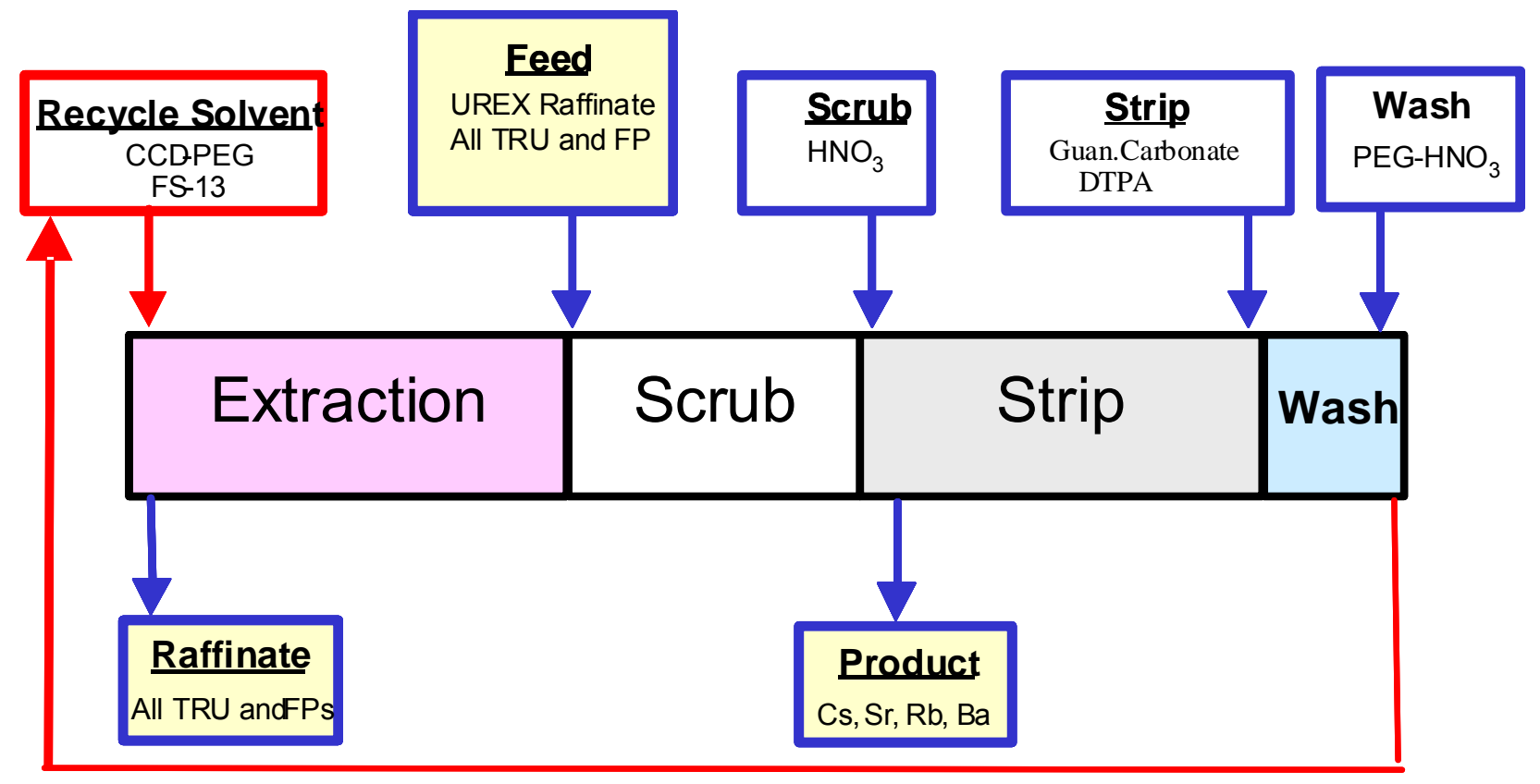




\section{Typical Profiles for Extraction Processes}

\section{AMUSE Simulation of Cs and La in CCD-PEG Process}
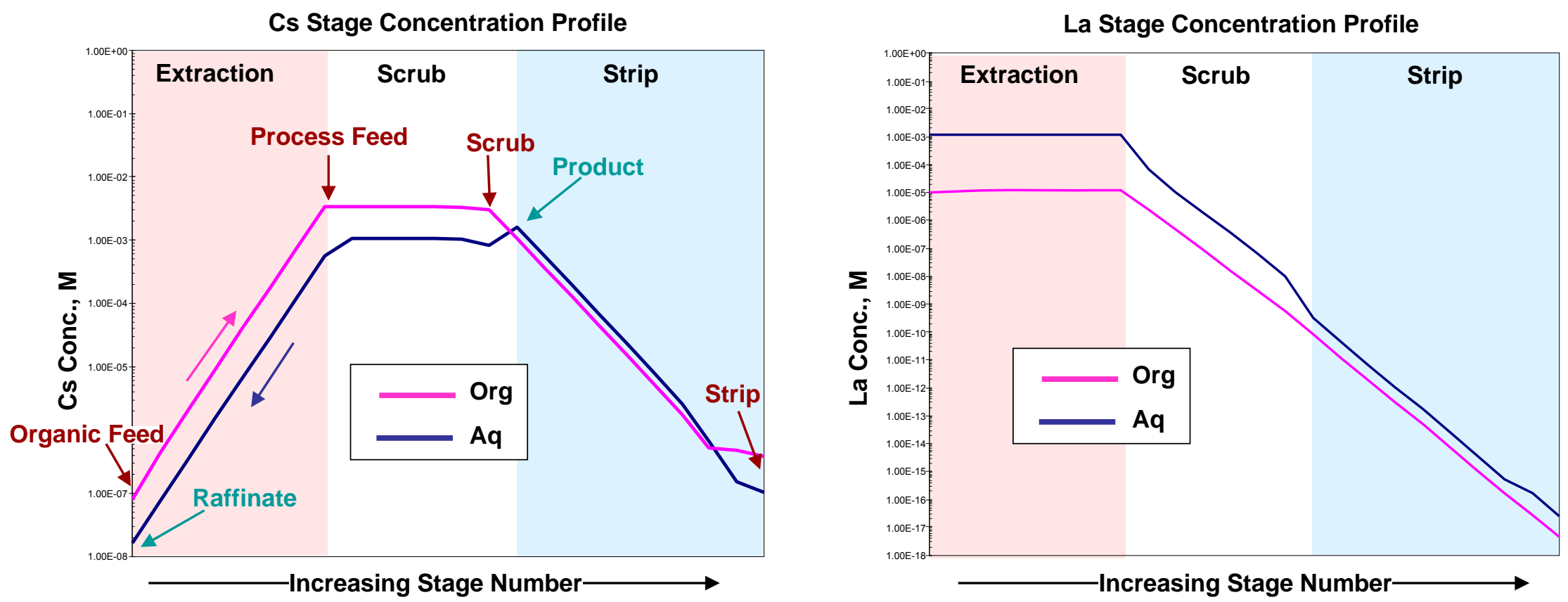


\section{Process Modeling and Simulation}




\section{Process Design and Modeling for UREX+ is Done With AMUSE}

- The Argonne Model for Universal Solvent Extraction-AMUSE is used to:

- Design and optimize solvent extraction flowsheets

- PUREX, UREX, NPEX, TRUEX, CCD-PEG, SREX

- TALSPEAK module is under development

- Perform sensitivity analysis to determine key process variables and their control bound

- Flow rates, number of stages, concentration of feed components, concentration of solvent, temperature 


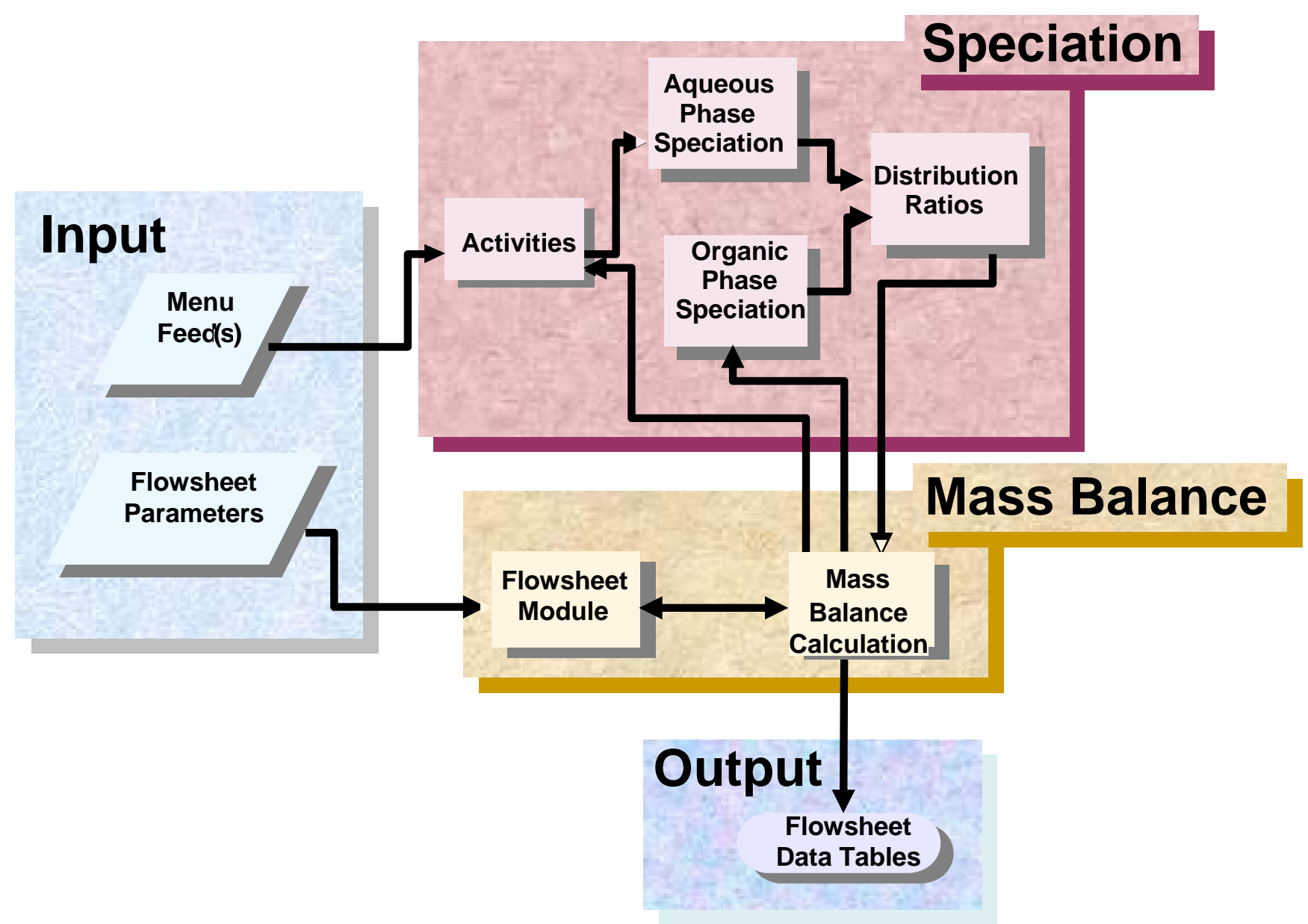


Distribution of Y(III)

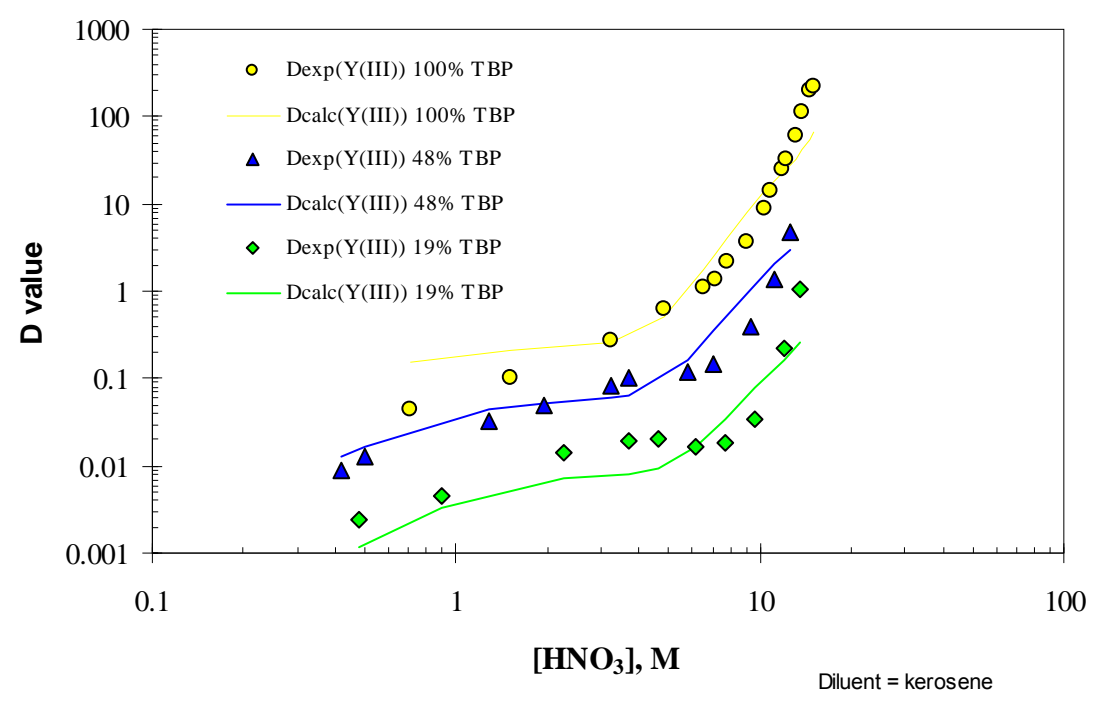

Model of extraction behavior for Yttrium (III)

- Nitric acid (0.4-15 M)

- TBP in Kerosene

- D value data from SCARGILL (1957) 


\section{GRAPHICAL}

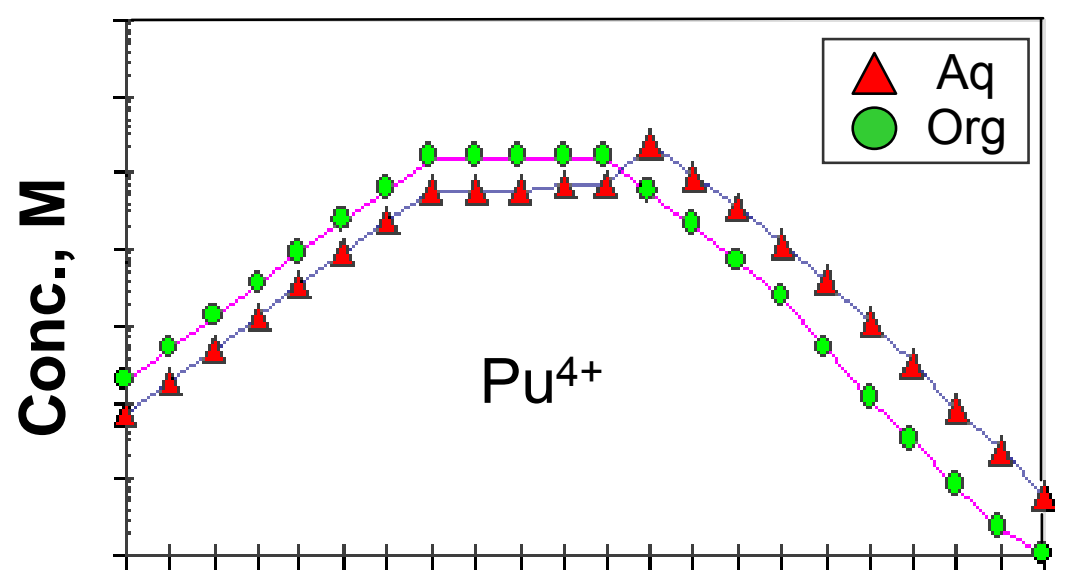

Stage Number

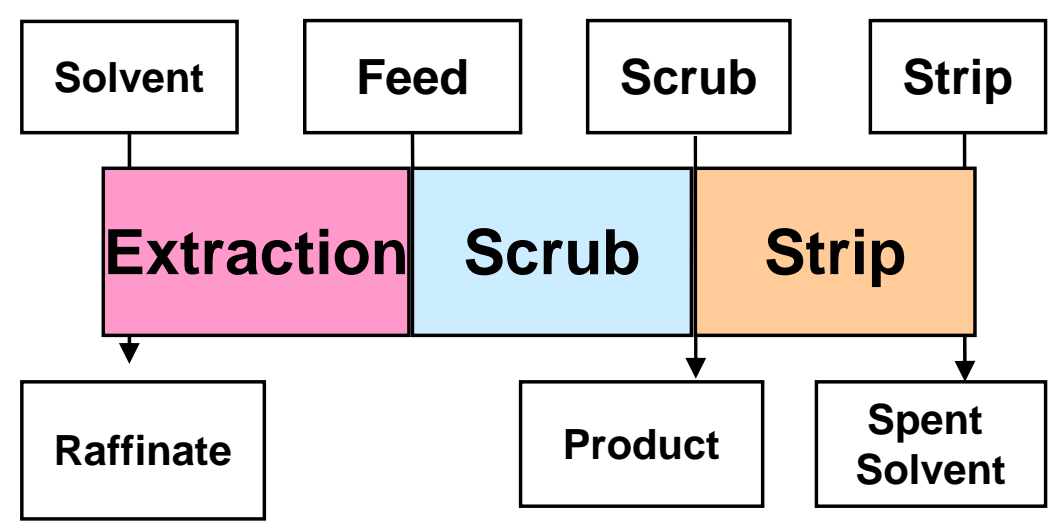

\section{TABULAR}

- Tabular reports are created for

- Influent and effluent compositions and flow rates

- Stage profiles that include

- Distribution ratios

- Component concentrations in organic and aqueous phases

\begin{tabular}{|cccccc|}
\hline $\begin{array}{c}\text { Stream } \\
\text { Identity }\end{array}$ & $\begin{array}{c}\text { Flow } \\
\text { Rate }\end{array}$ & $\mathrm{Ag}$ & $\mathrm{Am}$ & $\mathrm{Ba}$ & $\mathrm{Cd}$ \\
\hline $\mathrm{DX}$ & $2.50 \mathrm{E}+01$ & $0.00 \mathrm{E}+00$ & $0.00 \mathrm{E}+00$ & $0.00 \mathrm{E}+00$ & $0.00 \mathrm{E}+c$ \\
DX & $1.00 \mathrm{E}-03$ & $0.00 \mathrm{E}+00$ & $0.00 \mathrm{E}+00$ & $0.00 \mathrm{E}+00$ & $0.00 \mathrm{E}+\mathrm{c}$ \\
DF & $1.00 \mathrm{E}+01$ & $3.50 \mathrm{E}-06$ & $6.80 \mathrm{E}-04$ & $5.40 \mathrm{E}-03$ & $2.40 \mathrm{E}-0$ \\
DS & $4.00 \mathrm{E}+00$ & $0.00 \mathrm{E}+00$ & $0.00 \mathrm{E}+00$ & $0.00 \mathrm{E}+00$ & $0.00 \mathrm{E}+c$ \\
DW & $1.00 \mathrm{E}+00$ & $2.33 \mathrm{E}-06$ & $4.53 \mathrm{E}-04$ & $3.60 \mathrm{E}-03$ & $1.60 \mathrm{E}-0$ \\
DP & $2.50 \mathrm{E}+01$ & $9.45 \mathrm{E}-20$ & $1.35 \mathrm{E}-16$ & $1.46 \mathrm{E}-16$ & $6.48 \mathrm{E}-1$ \\
\hline
\end{tabular}




\section{Aqueous Spent Fuel Processing Involves A Number Of Key Operations in Addition Solvent Extraction}

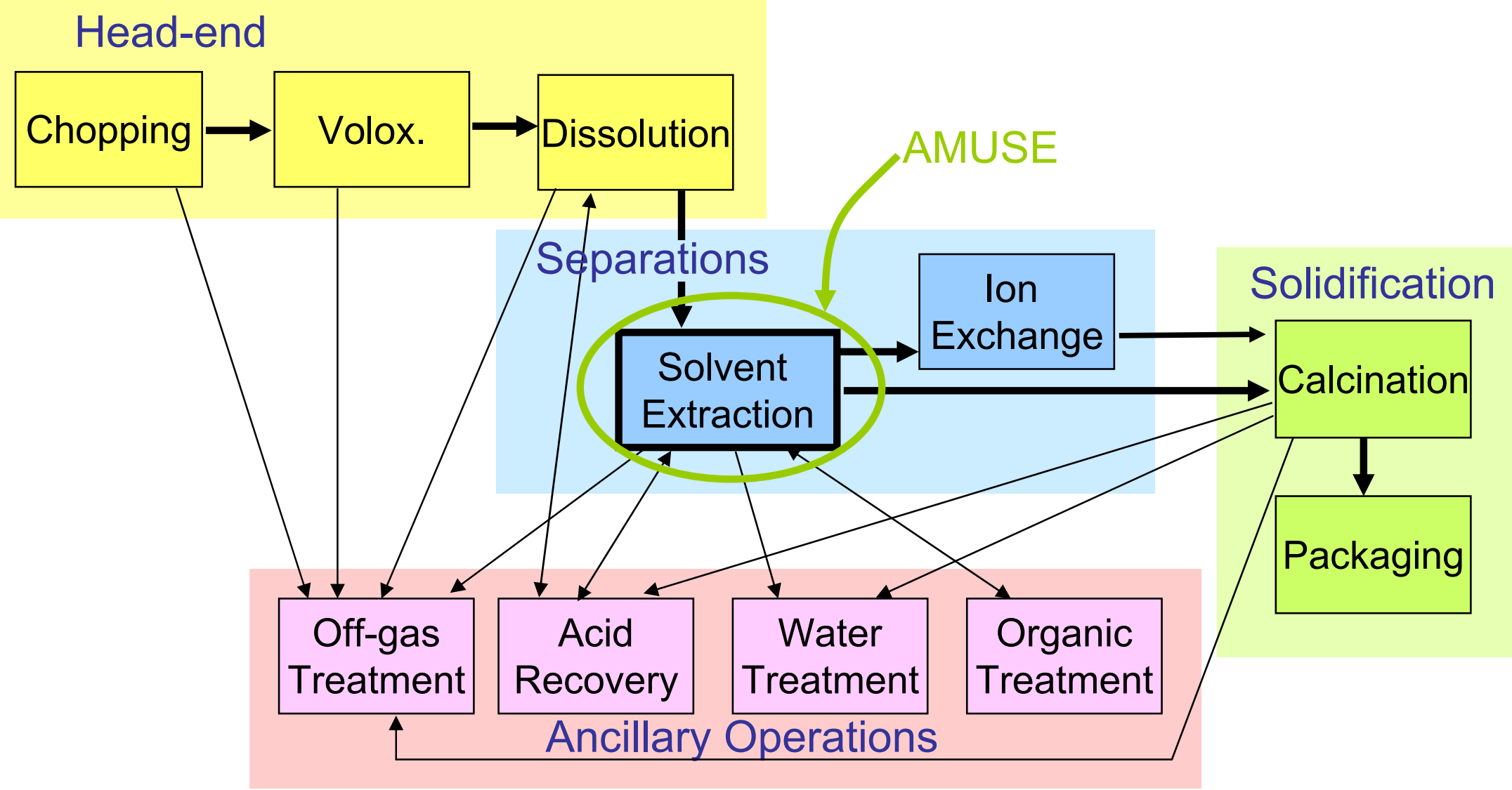




\section{UREX+3a Process Plant Worksheet}

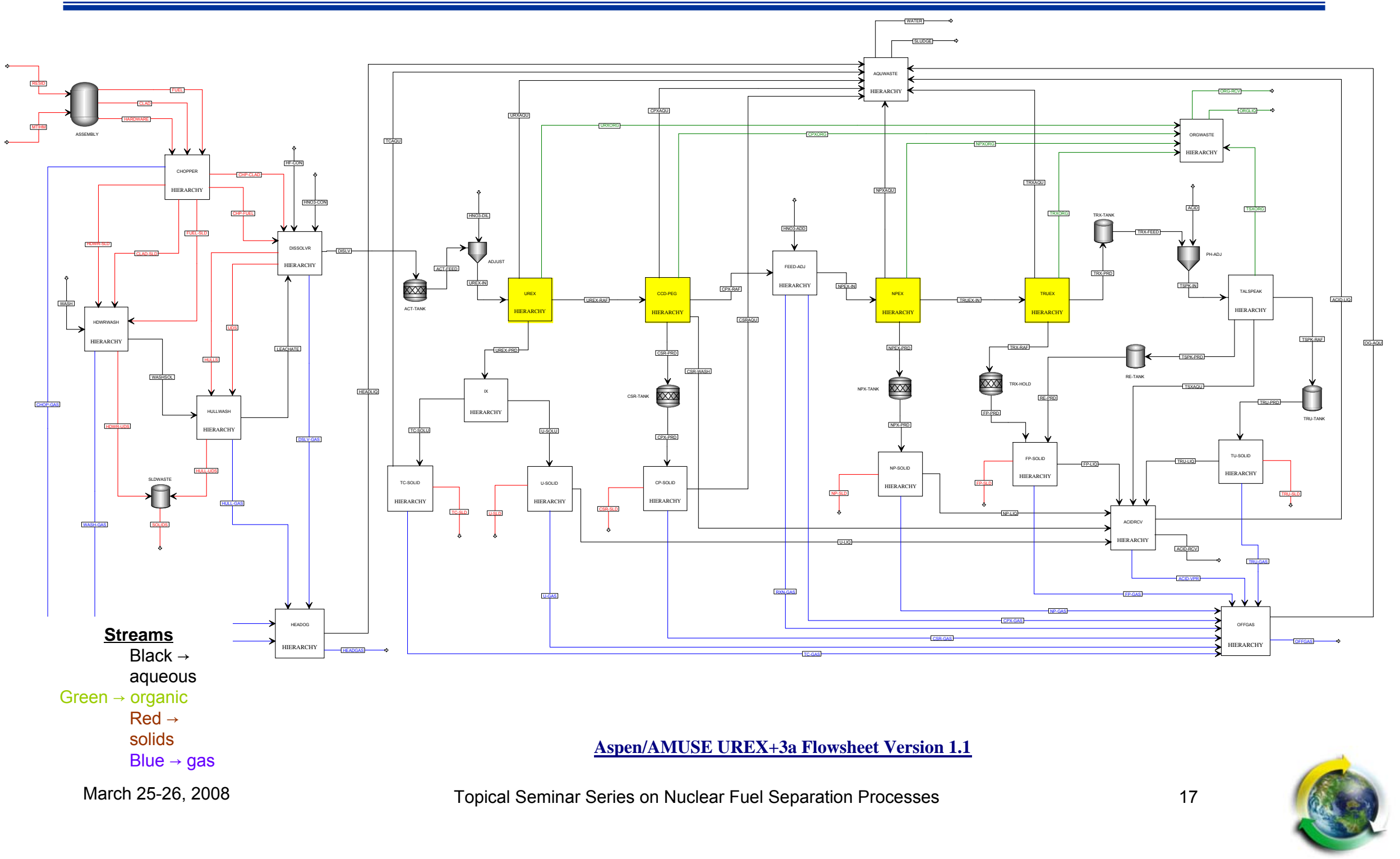




\section{Top-level Modeling of Aqueous Separations Operations: UREX}

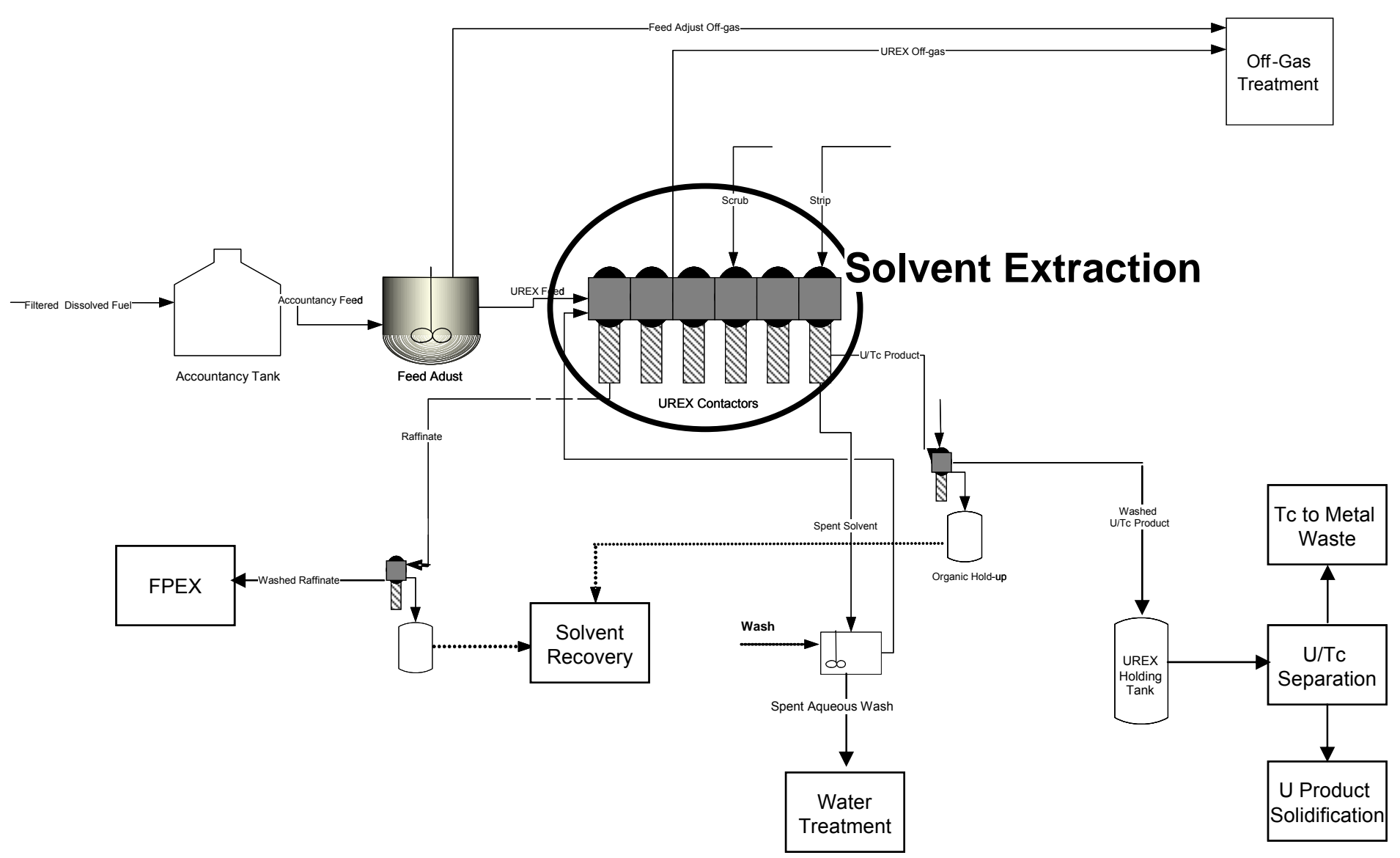




\section{Demonstration of the UREX+ Processes}


A baseline process for LWR treatment

Demonstrated with dissolved spent fuel

- Flowsheets developed using the AMUSE code

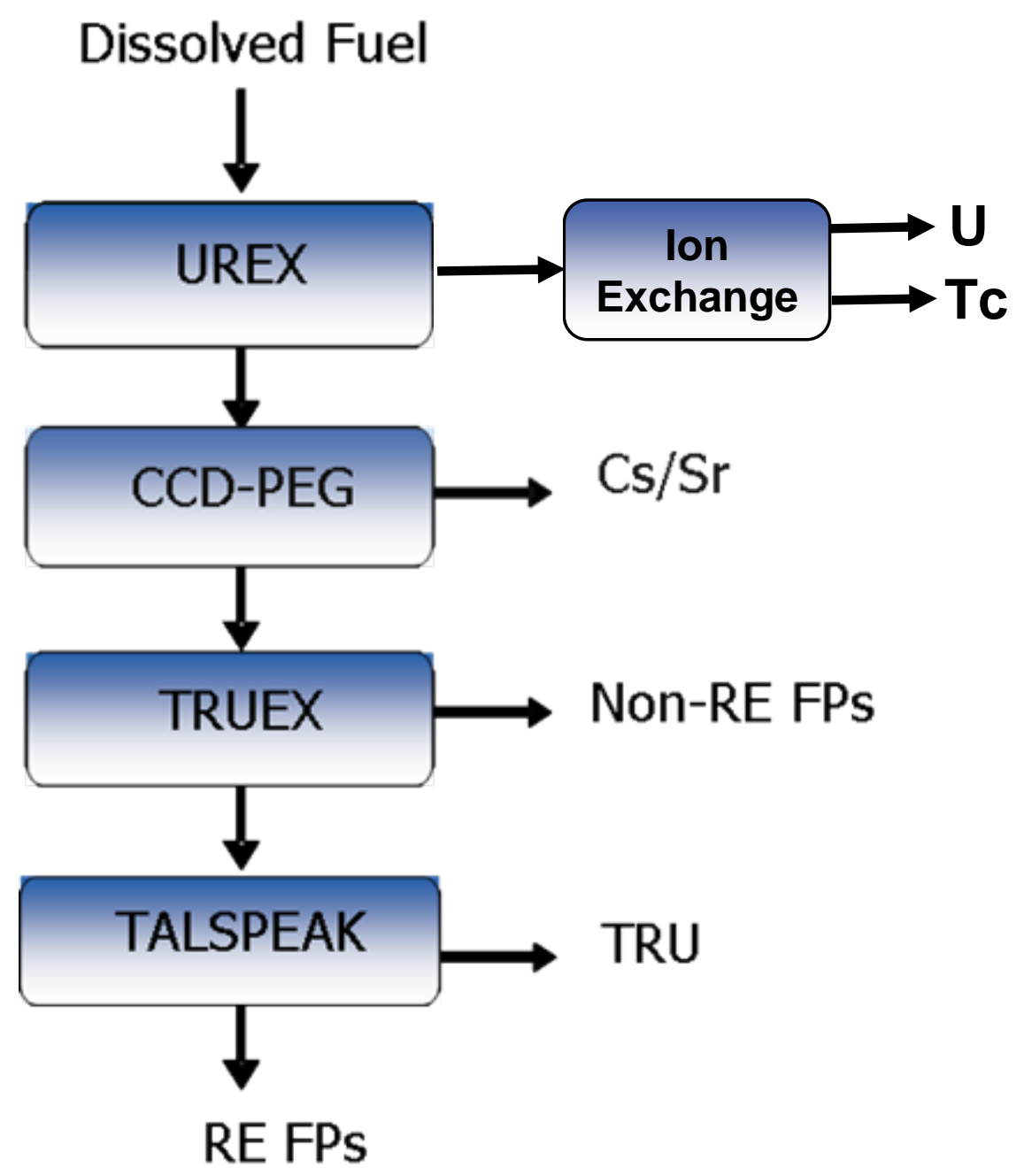




\section{Fission Products and Actinides Are Separated Based on Chemical Differences: UREX+1a Example}

\begin{tabular}{|c|c|c|c|c|c|c|c|c|c|c|c|c|c|c|c|c|c|c|}
\hline H & & & & & & & & & & & & & & & & & & $\mathrm{He}$ \\
\hline Li & $\mathrm{Be}$ & & & & & & & & & & & & B & C & $\mathbf{N}$ & 0 & $\mathbf{F}$ & $\mathrm{Ne}$ \\
\hline $\mathrm{Na}$ & $\mathbf{M g}$ & & & & & & & & & & & & Al & Si & $\mathbf{P}$ & $\mathbf{S}$ & $\mathrm{Cl}$ & Ar \\
\hline K & $\mathrm{Ca}$ & S & $\mathrm{Ti}$ & V & $\mathrm{Cr}$ & $\mathrm{Mn}$ & $\mathrm{Fe}$ & & & $\mathrm{Ni}$ & $\mathrm{Cu}$ & $\mathrm{Zn}$ & Ga & $\mathrm{Ge}$ & As & Se & $\mathrm{Br}$ & $\mathrm{Kr}$ \\
\hline Rb & Sin & $Y$ & $\mathrm{Zr}$ & Nb & Mo & Tc & $\mathbf{R} \mathbf{L}$ & & & $\mathbf{P d}$ & $\mathrm{Ag}$ & Cd & In & Sn & $\mathrm{Sb}$ & Te & I & $\mathbf{X e}$ \\
\hline cs & $B a$ & L & $\mathrm{Hf}$ & $\mathrm{Ta}$ & w & $\operatorname{Re}$ & Os & & & $\mathbf{P t}$ & $A u$ & $\mathrm{Hg}$ & $\mathrm{TI}$ & $\mathrm{Pb}$ & $\mathrm{Bi}$ & Po & At & Rn \\
\hline $\mathrm{Fr}$ & $\mathbf{R a}$ & A & & & & & & & & & & & & & & & & \\
\hline
\end{tabular}

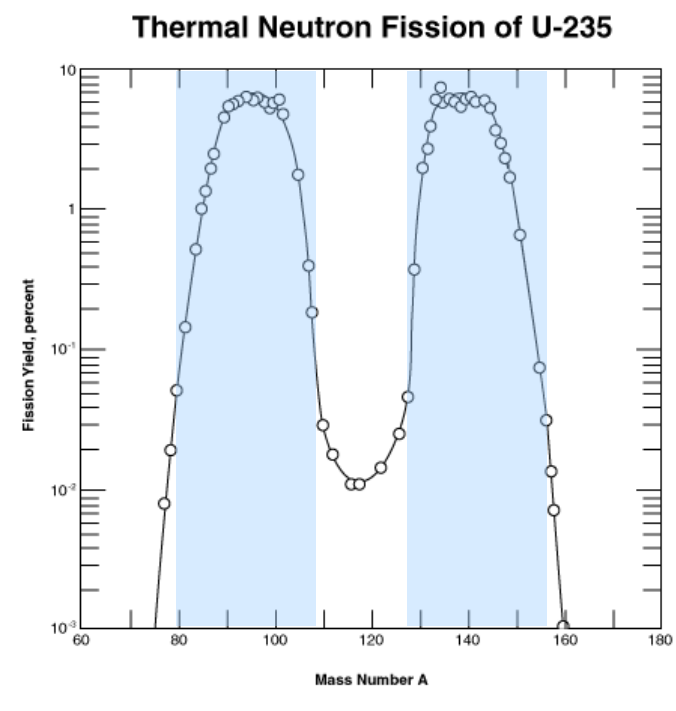

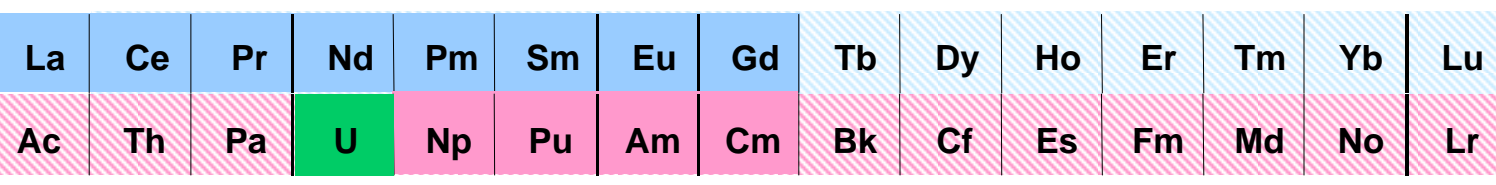




\section{Processing Options for Recovery of $\mathrm{U}, \mathrm{Pu}, \mathrm{Np}$}

- UREX

- Uses same solvent as PUREX (TBP in n-dodecane)

- Recovers high purity $U$ while leaving Pu with fission products

- Recovers Tc in high yield

- NPEX

- Uses same solvent as PUREX

- Recovers mixed Pu and Np

- Can generate a U/Pu/Np product in a predictable ratio

- Requires UREX be run first to remove $U$ from feed

Co-Extraction

- Uses same solvent as PUREX

- Recovers $U$ and Np/Pu or U/Pu/Np mixture

- Likely requires multiple cycles to control U:Pu/Np ratio

- Tc not targeted; recovery complicates processing 


\section{UREX Process for U and Tc Recovery}

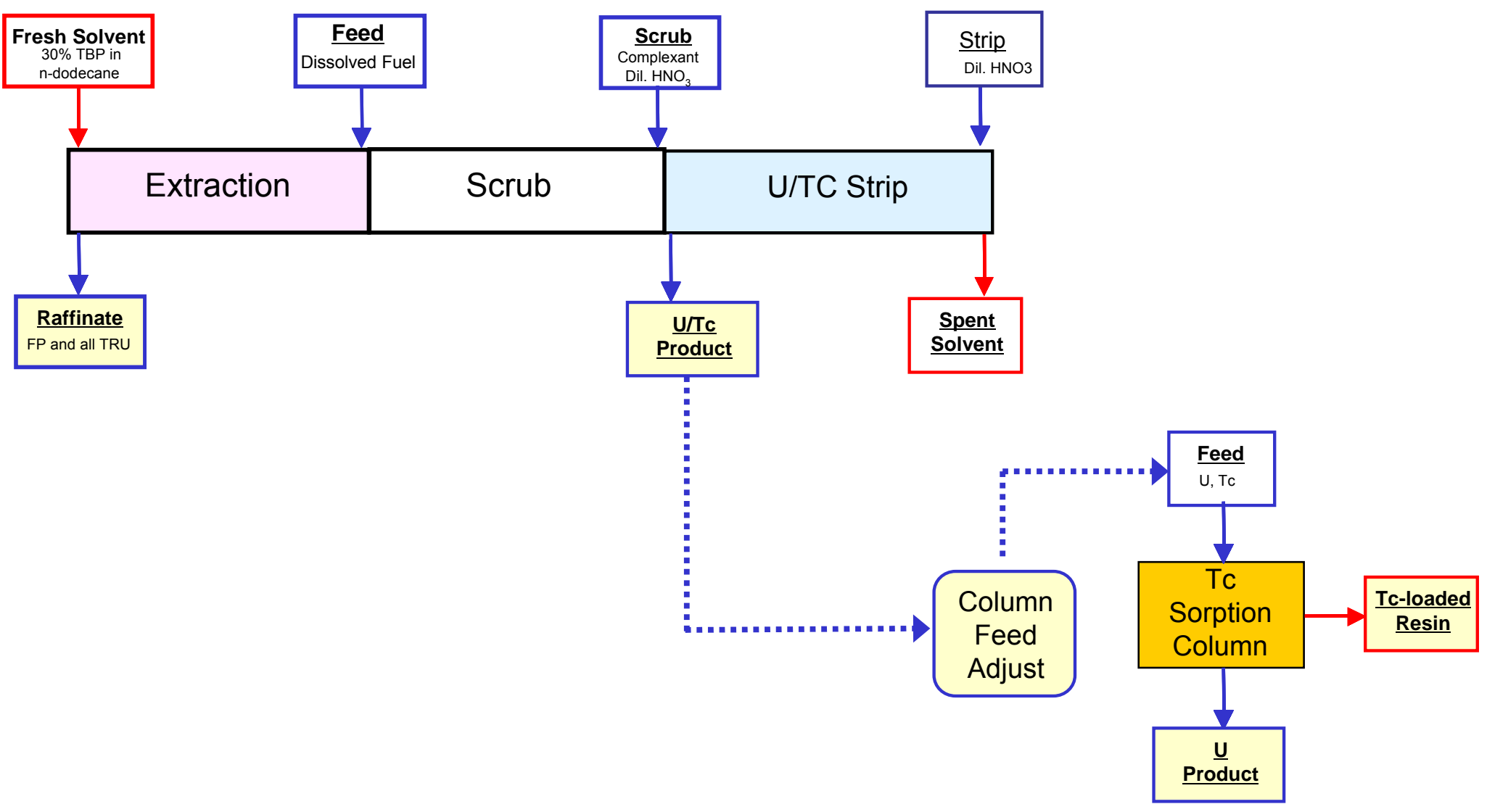




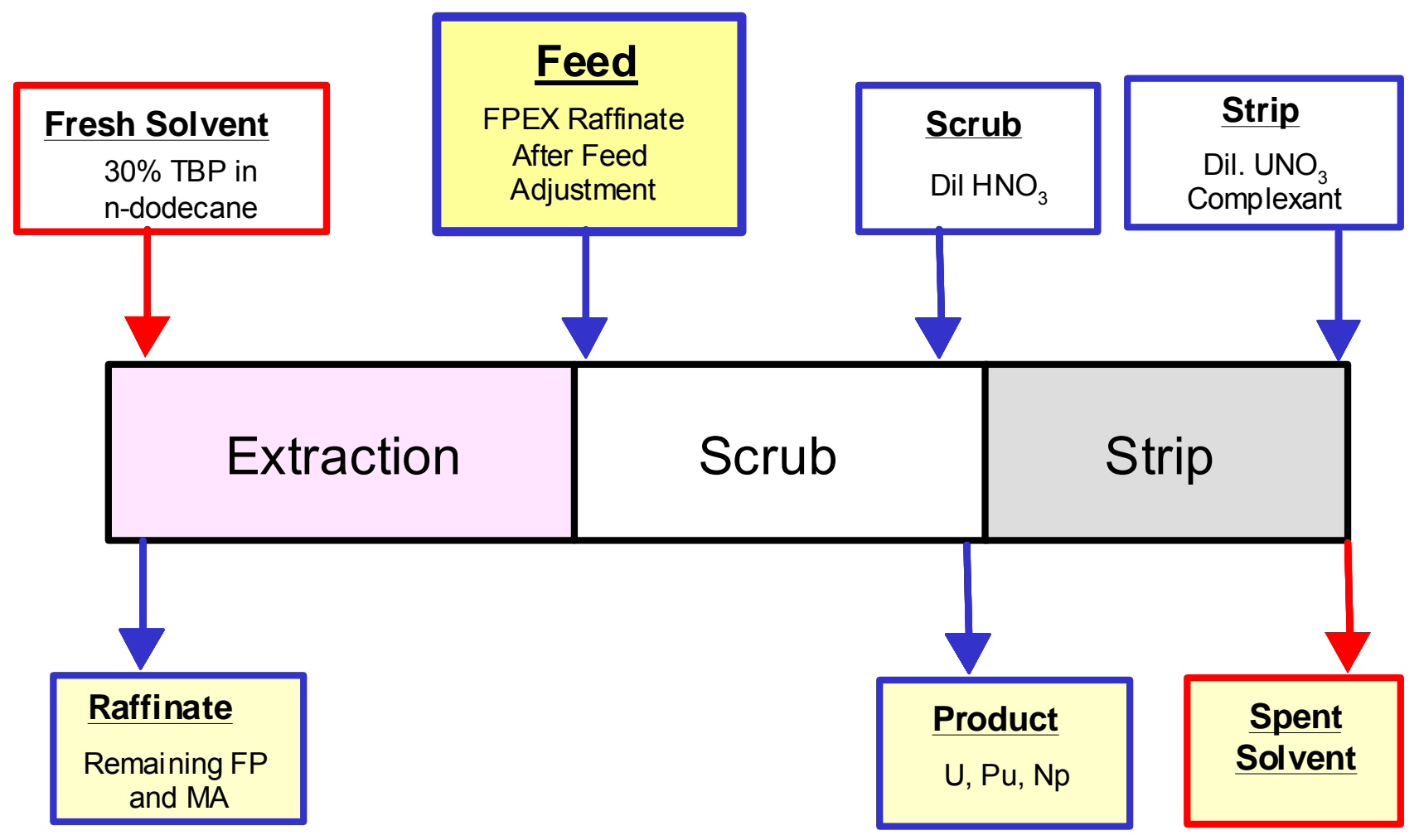




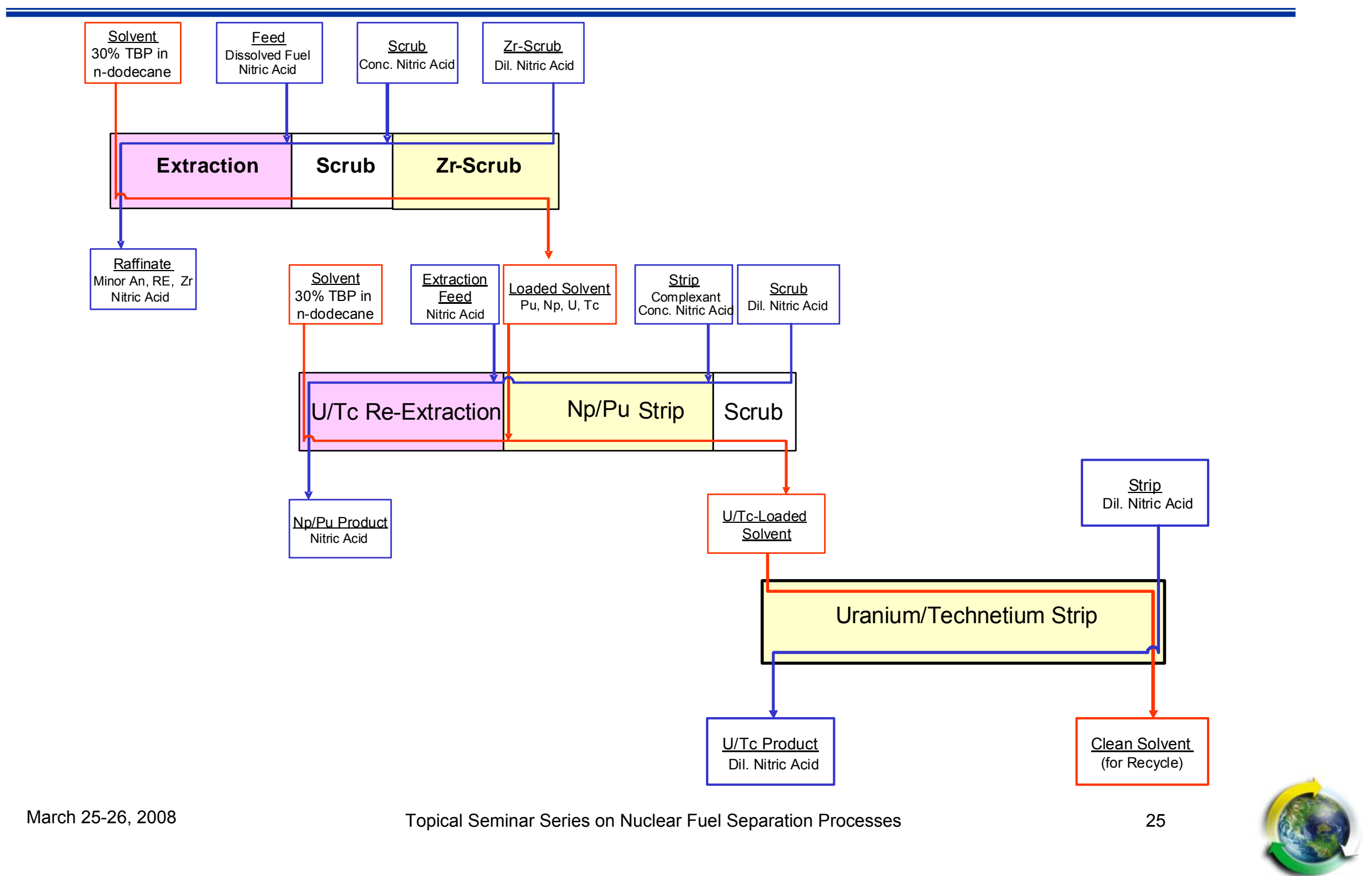




\section{Processing Options for Cs and Sr Recovery}

CCD-PEG

- Solvent is chlorinated dicarbollide and polyethylene glycol in FS-13

- Recovers Cs and Sr in high yield

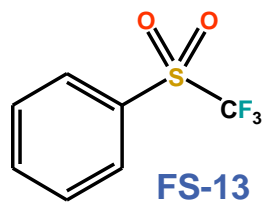

Phenyltrifluoromethyl Sulfone

- Solvent requires a dense sulfone diluent

- $\quad$ PEG is partially soluble in aqueous phase

- Acidity of feed is low

$\mathrm{HOCH}_{2} \mathrm{CH}_{2}\left(\mathrm{OCH}_{2} \mathrm{CH}_{2}\right)_{7} \mathrm{OCH}_{2} \mathrm{CH}_{2} \mathrm{OH}$

Polyethylene Glycol (PEG-400)

- Requires feed adjustment when run after NPEX, TRUEX, COEX

- Degradation of complexants affects extraction

- Complexant required is used to strip solvent

- FPEX

- Solvent contains a calixrene, crown ether, and modifier in Isopar-L®

- Isopar- $L$ is a refined kerocene and similar to that of other UREX+ processes

- Derived from CSSX process being implemented at SRS

- $\quad$ Less-developed than CCD-PEG process: composition not yet finalized

- Cs and Sr D-values slightly lower than for CCD-PEG

- Acidity of feed is low

- Requires feed adjustment when run after NPEX, TRUEX, COEX

- Degradation of complexants affects extraction

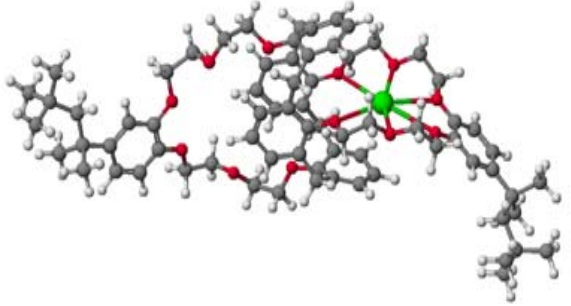

Calix[4]arene-bis(t-octylbenzo-crown-6) (complexed with Cs)

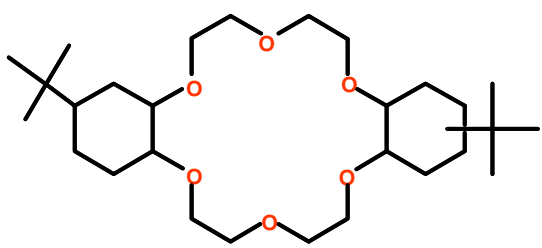

4,4'(5')-di-t-butylcyclohexano 18-crown-6 


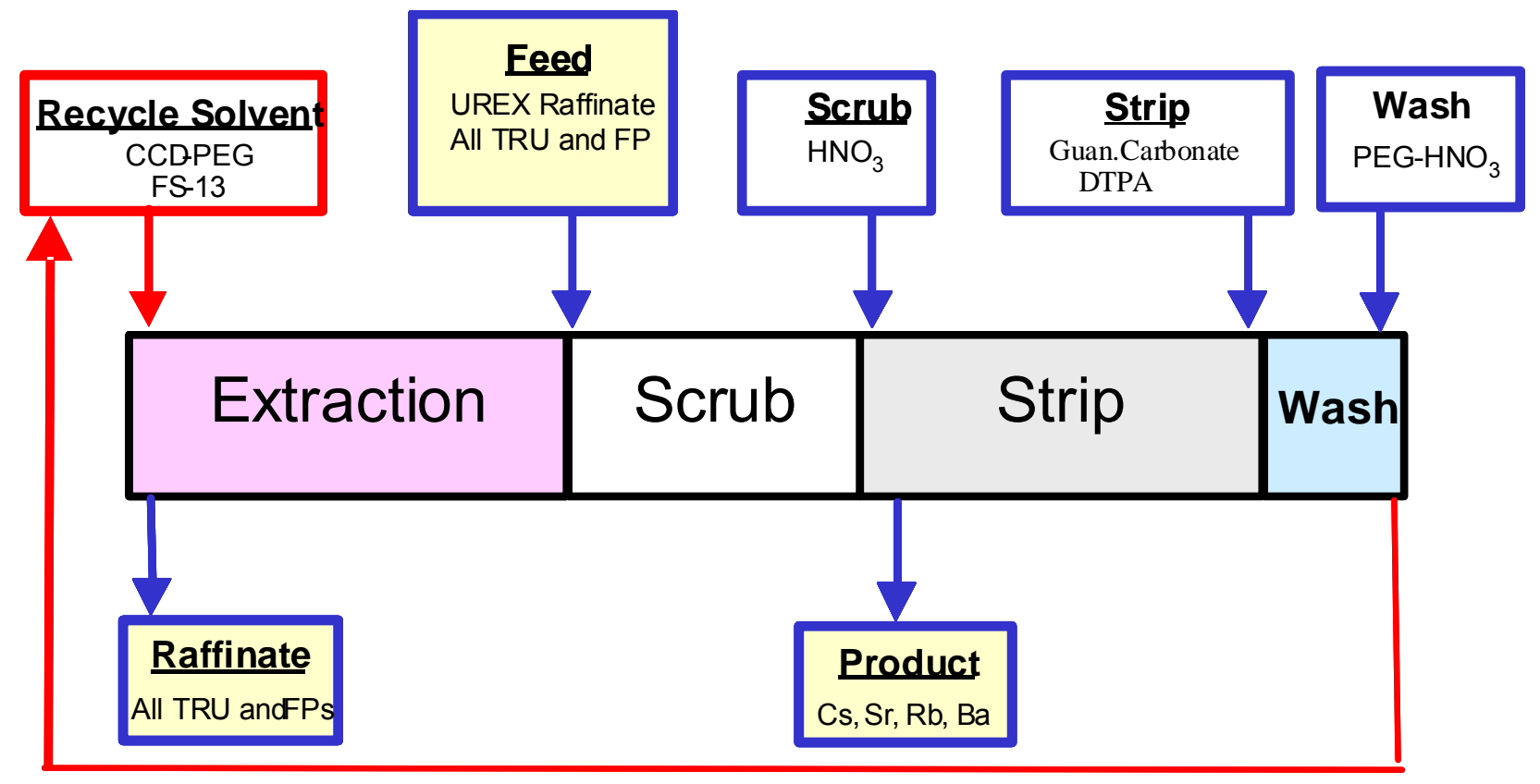




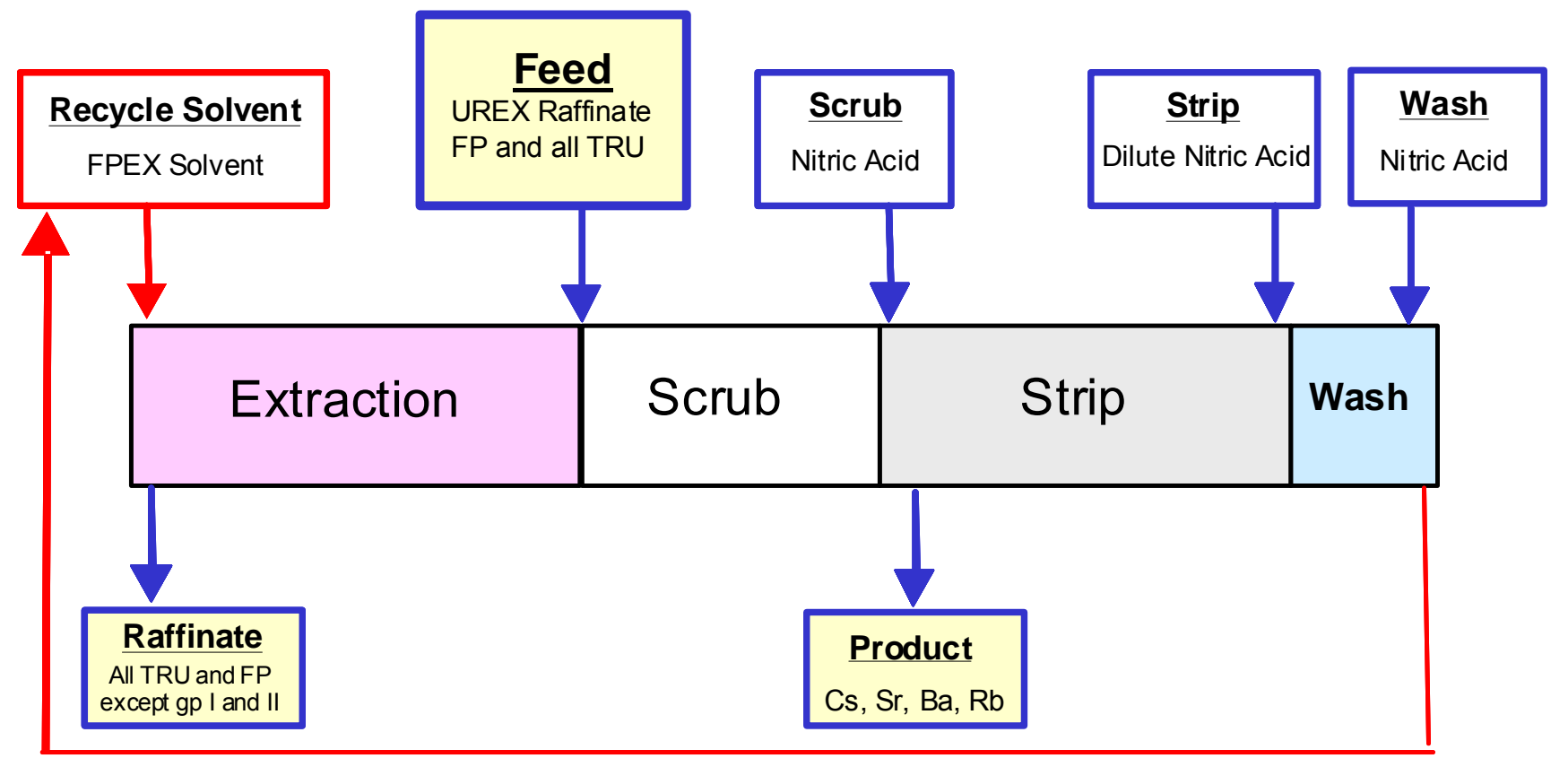


- TRUEX

- Solvent is CMPO and TBP in n-dodecane

- Recovers rare earths and transuranics

- Extensive database and development

- Readily compatible with NPEX, COEX, UREX

- Expensive extractant but $\mathrm{n}$-dodecane diluent

- May require multiple scrubs to achieve purity requirements

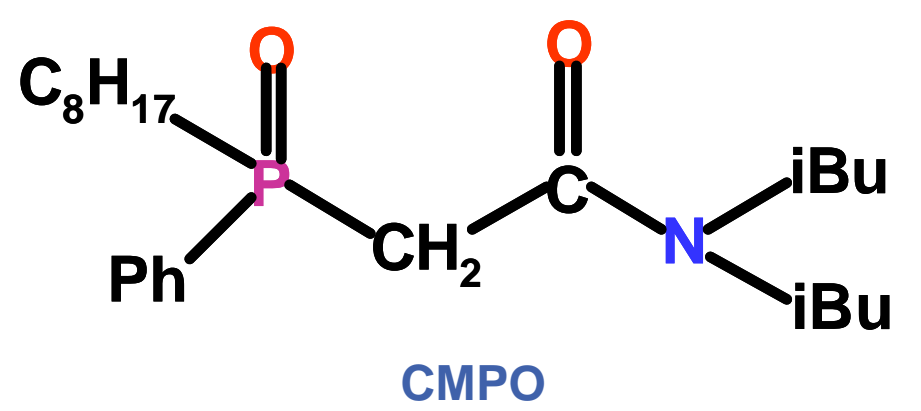

octyl(phenyl)-N,N -diisobytylcarboylmethyl phosphine oxide 


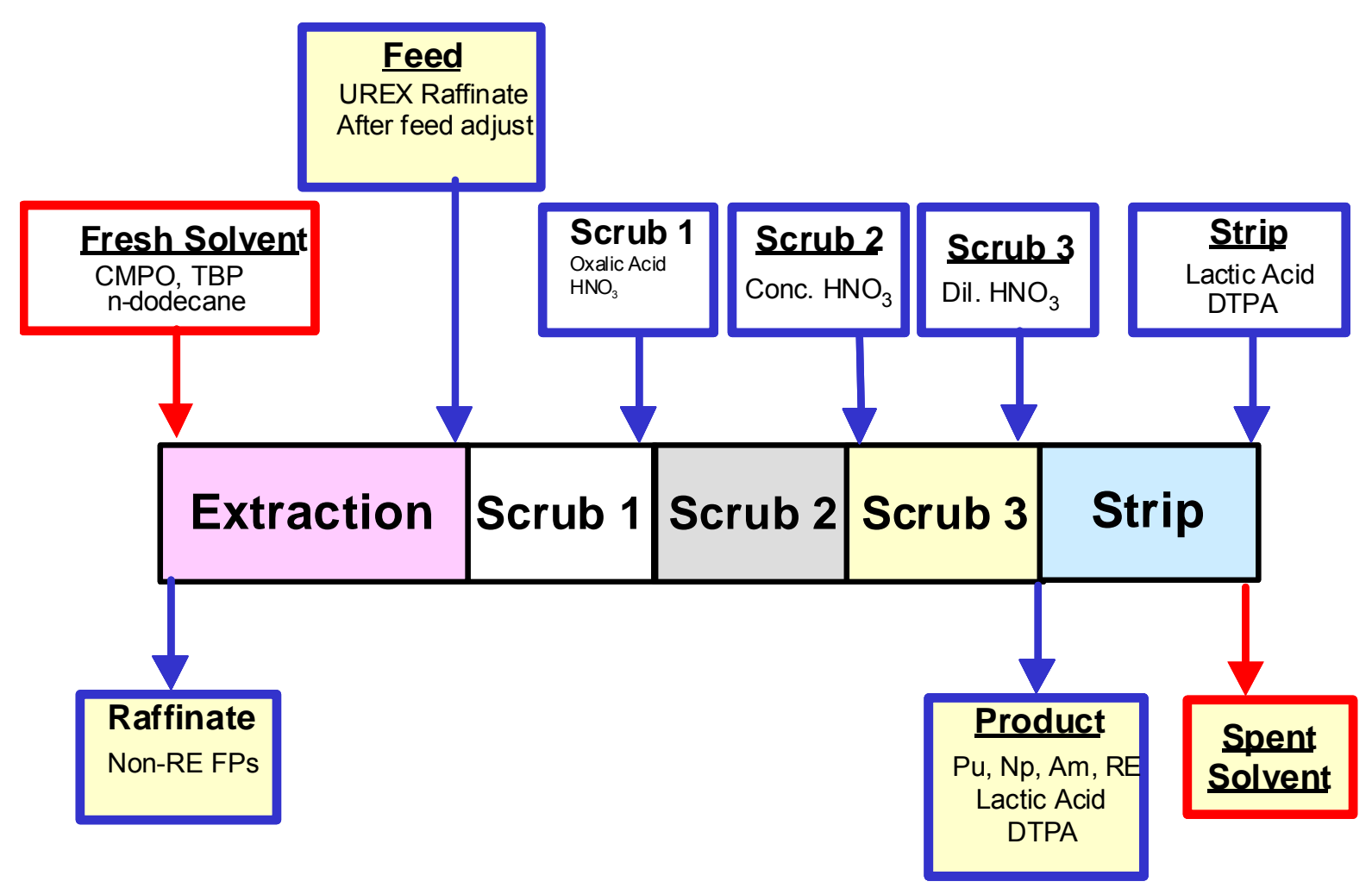




\section{Processing Options for An and Ln Separation}

- TALSPEAK

- HDEHP in n-dodecane

- High separation factors and An recoveries have been demonstrated

- Can be run for Am/Cm or Group TRU recovery (Pu/Np/Am/Cm)

- Feed requires good $\mathrm{pH}$ control

- Slow Extraction Kinetics

- TRU product in complex

- Cyanex 301® Extractant

- Cyanex 301 in n-dodecane

- High An recoveries

- Feed requires good $\mathrm{pH}$ control

- Only partial An-Ln separation was observed

- Poor solvent stability > limited recycle

- No longer under consideration
HDEHP

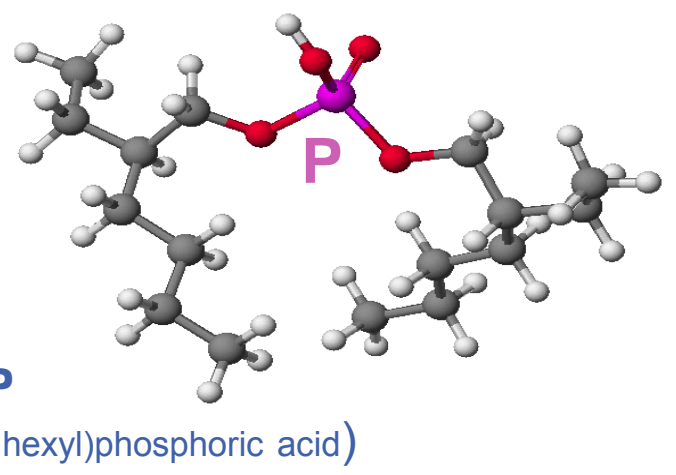

(di(2-ethylhexyl)phosphoric acid)

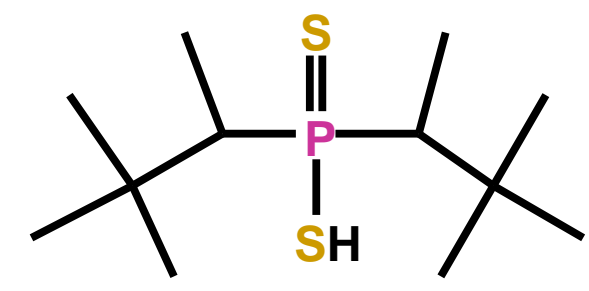

Cyanex 301

(bis(2,4,4-trimethylpentyl)dithiophosphinic acid) 


\section{TALSPEAK Flowsheet from 2006 UREX+ Demonstration}

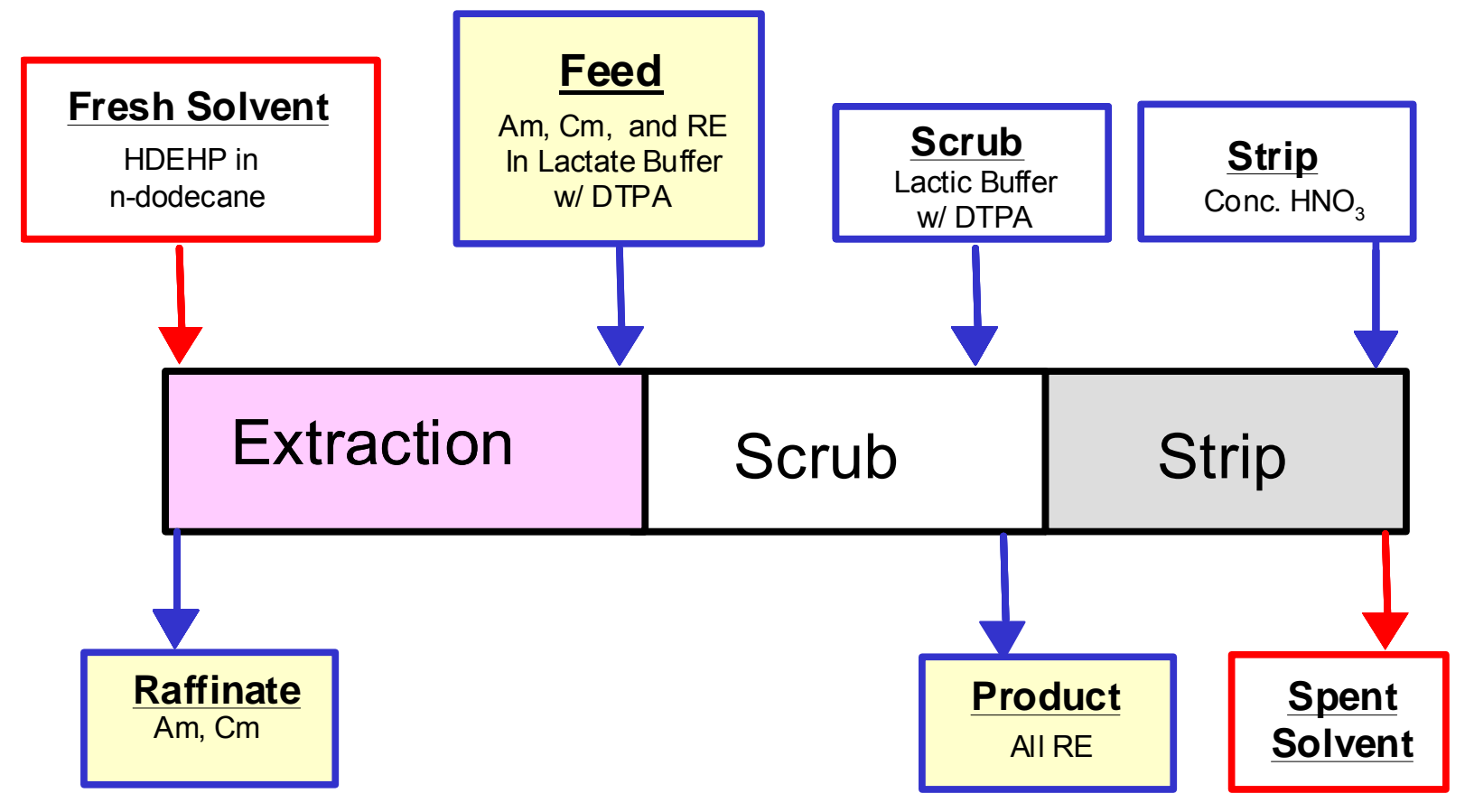




\section{Cyanex-301 Extractant Flowsheet from 2003 UREX+ Demonstration}

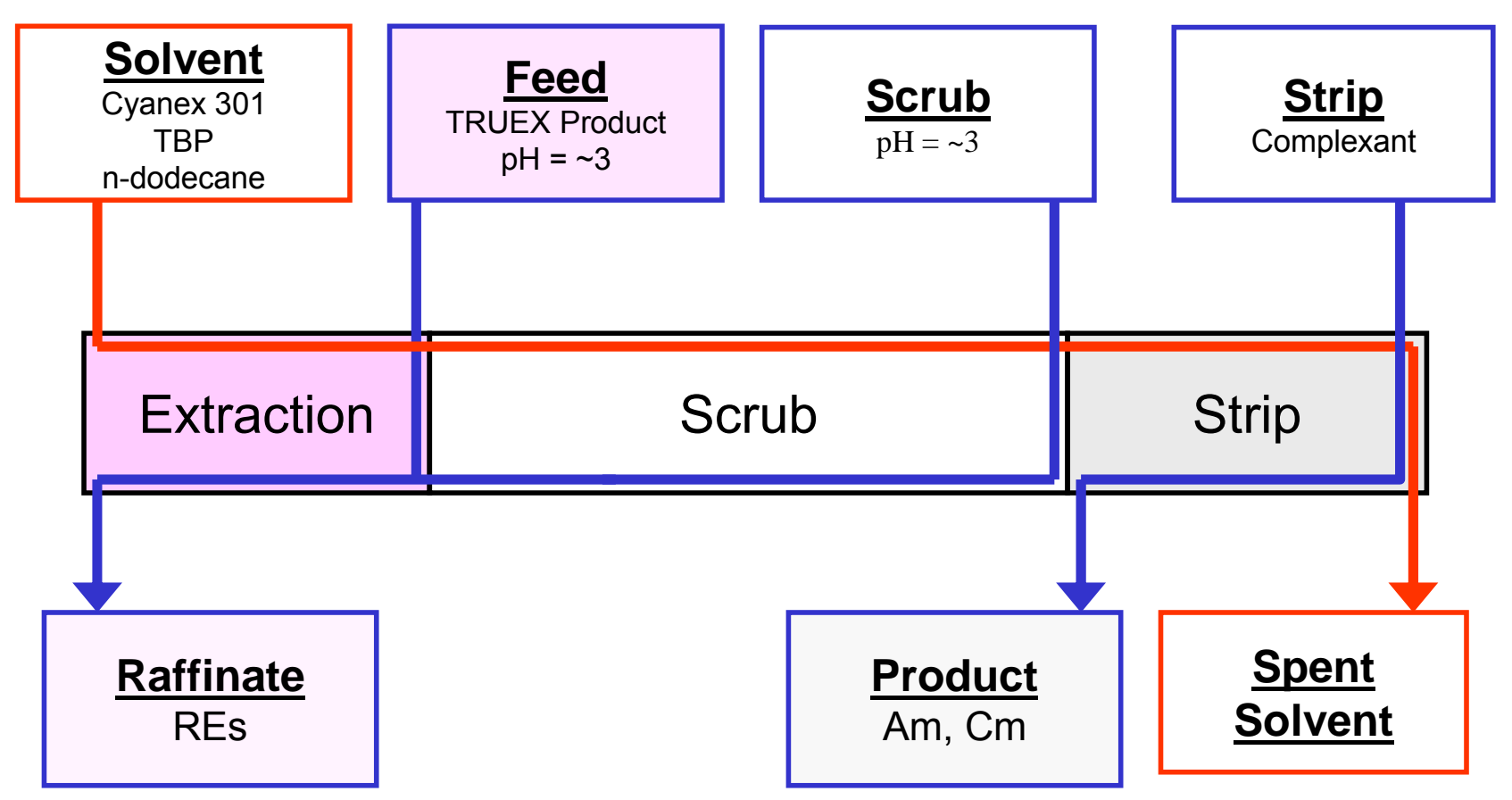




\section{Potential Aqueous Processing Options That Have Been Demonstrated At Argonne}

\begin{tabular}{|c|c|c|c|c|c|c|c|}
\hline Process & $\begin{array}{c}\text { Product } \\
\# 1\end{array}$ & $\begin{array}{c}\text { Product } \\
\# 2 \\
\end{array}$ & $\begin{array}{c}\text { Product } \\
\# 3\end{array}$ & $\begin{array}{c}\text { Product } \\
\# 4\end{array}$ & $\begin{array}{c}\text { Product } \\
\# 5\end{array}$ & $\begin{array}{c}\text { Product } \\
\# 6\end{array}$ & $\begin{array}{c}\text { Product } \\
\# 7 \\
\end{array}$ \\
\hline UREX+1 & U & Tc & $\mathrm{Cs} / \mathrm{Sr}$ & TRU/Ln & $F P$ & & \\
\hline UREX+1a & $U$ & Tc & $\mathrm{Cs} / \mathrm{Sr}$ & TRU & FP/Ln & & \\
\hline UREX+1b & 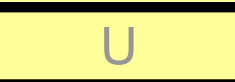 & $\overline{T C}$ & $\mathrm{Cs} / \mathrm{Sr}$ & $\bar{U} / \mathrm{TRU}$ & $\overline{F P / L n}$ & & \\
\hline UREX+2 & $U$ & Tc & $\mathrm{Cs} / \mathrm{Sr}$ & $\mathrm{Pu} / \mathrm{Np}$ & $\mathrm{Am} / \mathrm{Cm} / \mathrm{Ln}$ & FP & \\
\hline UREX+2a & $U$ & Tc & $\mathrm{Cs} / \mathrm{Sr}$ & U/Pu/Np & $\mathrm{Am} / \mathrm{Cm} / \mathrm{Ln}$ & FP & \\
\hline UREX+3 & $U$ & Tc & $\mathrm{Cs} / \mathrm{Sr}$ & $\mathrm{Pu} / \mathrm{Np}$ & $\mathrm{Am} / \mathrm{Cm}$ & FP/Ln & \\
\hline UREX+3a & $U$ & TC & $\mathrm{Cs} / \mathrm{Sr}$ & U/Pu/Np & $\mathrm{Am} / \mathrm{Cm}$ & FP/Ln & \\
\hline UREX+4 & $U$ & Tc & $\mathrm{Cs} / \mathrm{Sr}$ & $\mathrm{Pu} / \mathrm{Np}$ & Am & $\mathrm{Cm}$ & $F P / L n$ \\
\hline UREX+4a & $U$ & $T c$ & $\mathrm{Cs} / \mathrm{Sr}$ & U/Pu/Np & $\mathrm{Am}$ & $\mathrm{Cm}$ & FP/Ln \\
\hline
\end{tabular}

Notes: (1) in all cases, iodine is removed as an off-gas from the dissolution process.

(2) processes are designed for the generation of no liquid high-level wastes

$\mathrm{U}: \quad$ uranium (contributor to dose rate, and the mass and volume of high-level waste)

Tc: $\quad$ technetium (long-lived fission product, minor contributor to long-term dose)

$\mathrm{Cs} / \mathrm{Sr}$ : cesium and strontium (primary short-term heat generators, affect waste form loading and repository drift loading)

TRU: transuranic elements: $\mathrm{Pu}$ - plutonium, $\mathrm{Np}$ - neptunium, Am - americium, $\mathrm{Cm}$ - curium (primary long-term dose rate contributors)

Ln: lanthanide (rare earth) fission products

FP: fission products other than cesium, strontium, technetium, iodine, and the lanthanides 


\section{Five Demonstrations of UREX+ Processes With Spent Fuel Have Been Completed Successfully}

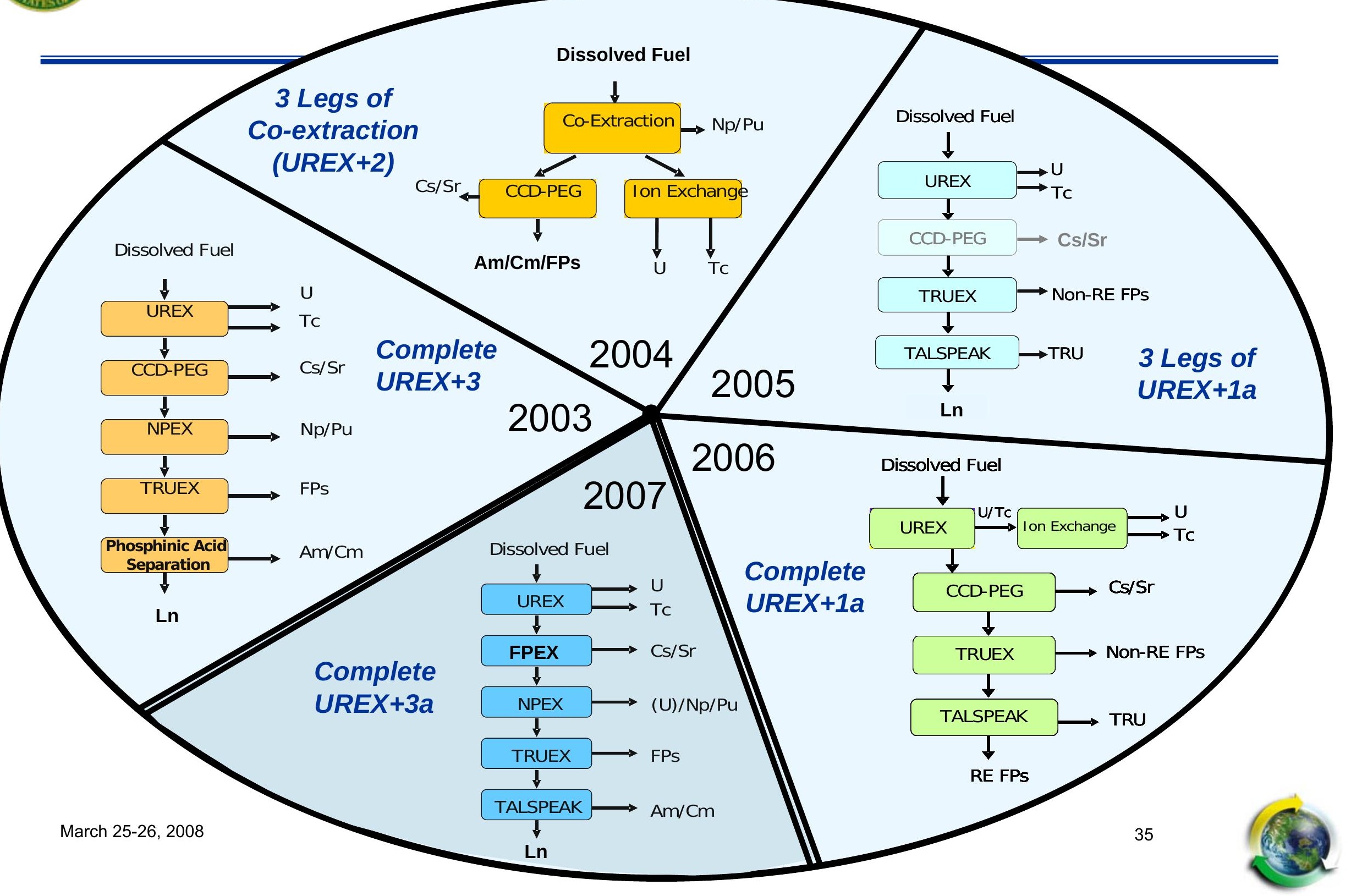




\section{The UREX+ Process Demonstrations}

R\&D for UREX+ process development includes:

- Process design and optimization using AMUSE

- Equipment design

- Process demonstration and post-test analysis

- Objective of demonstration:

- Demonstrate that all desired spent-fuel constituents can be separated by aqueous processing

- Show that product specifications for recycle or disposal are achievable

- Flowsheets developed using AMUSE

- Test run with spent fuel in 2-cm contactor

- All processes were run until steady state was achieved 


\section{ANL Centrifugal Contactor Bank in Shielded Cell}

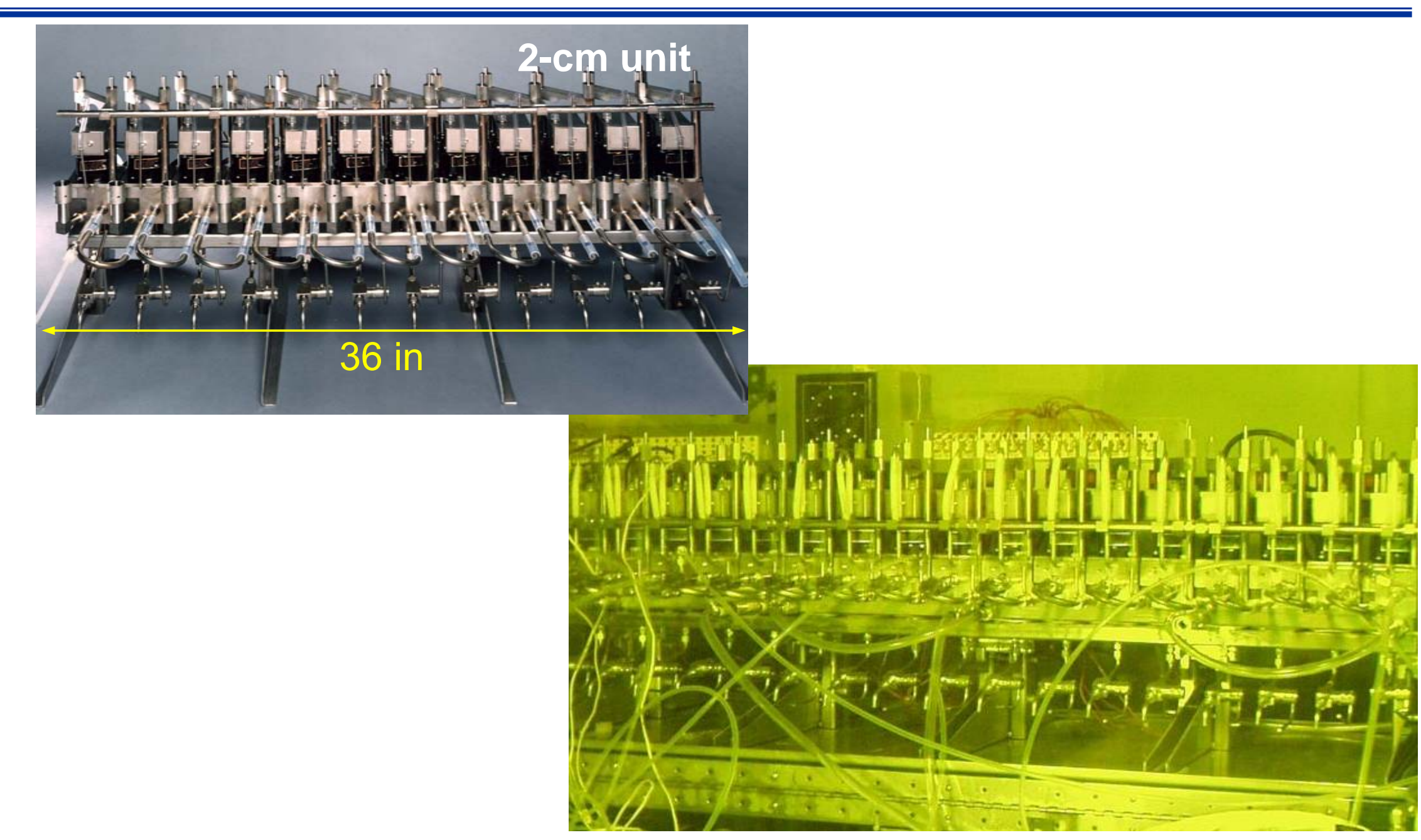




\section{Spent Fuel Was Dissolved in Nitric Acid at Ambient}

Pressure and Under Moderately Higher Pressures

Tests were run with both clad and declad fuel

0.5-1 kg fuel batches

- Sealed and ambient pressure vessels have been used

- Undissolved solids were generally minimal

- Solutions were stable

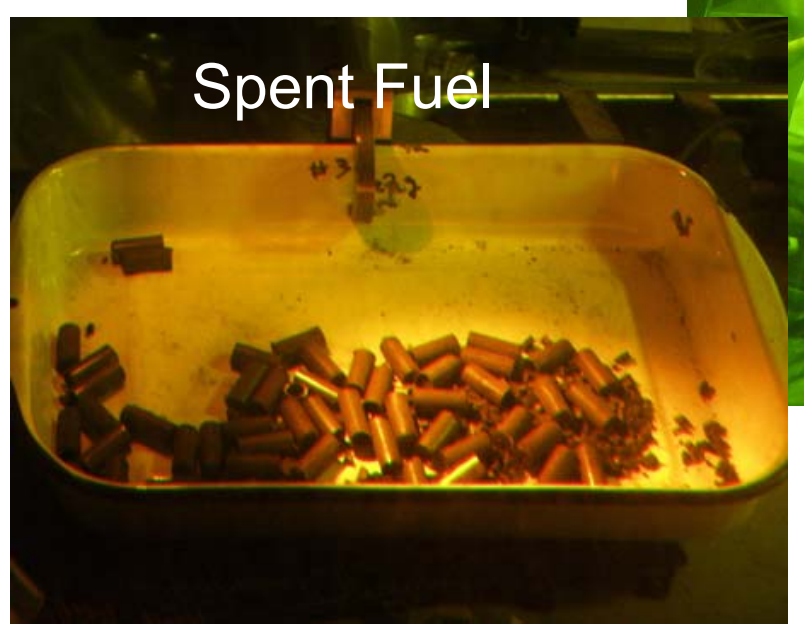

Dissolution Vessel

\section{Cladding}

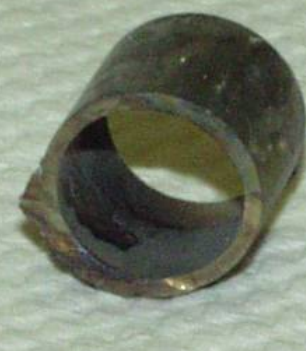




\section{UREX+2 and UREX+3 Were First Two UREX+ Process Demonstrations}

UREX+3, as initially designed, differed significantly from more recent process flowsheets

- U-Tc separation was accomplished by selectively stripping

- The Cyanex process was used for the Am/Cm separation

Co-extraction of $\mathrm{U}, \mathrm{Pu}, \mathrm{Np}$, and Tc was used in first demonstration of UREX+2 process

- Pu/Np separated from U/Tc by selective stripping of solvent

- $\quad U$ and Tc separated by ion

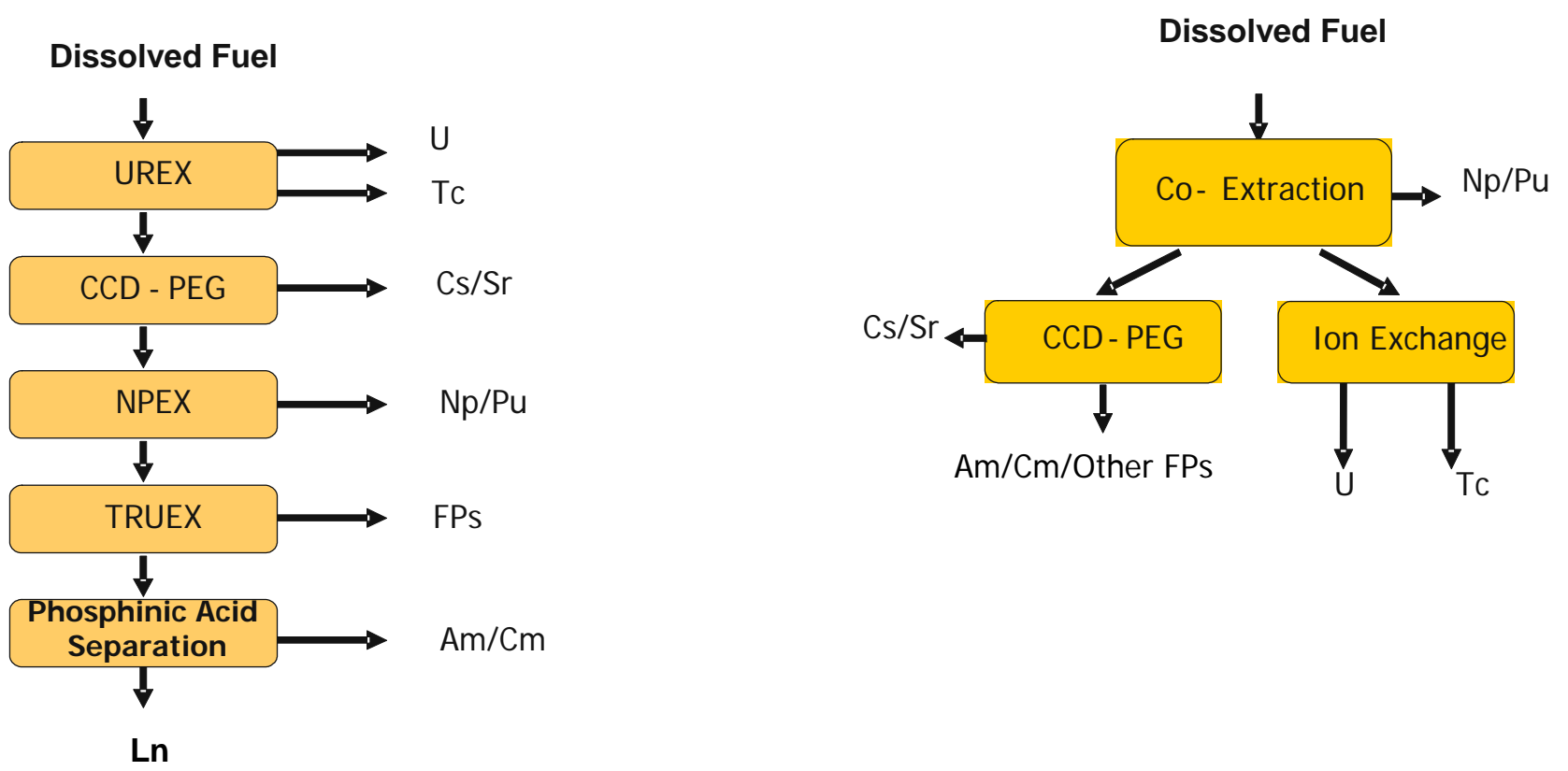




\section{UREX+3: Product Distributions}

\section{All primary components report to desired product streams}

- Np and Tc fractions lower than targets

- $\quad U$ and Tc separated by selective stripping rather than ion exchange

- High rare earth content in Am/Cm product

Distribution in process effluent streams (\%)

\begin{tabular}{|c|c|c|}
\hline Component & Product & Raffinate \\
\hline & $\underline{2003 \text { UREX }}$ & \\
\hline Tc & 94.40 & 4.60 \\
\hline $\mathrm{U}$ & 99.96 & 0.02 \\
\hline & $\underline{2003 \mathrm{NPEX}}$ & \\
\hline $\mathrm{Pu}$ & 99.6 & 0.4 \\
\hline $\mathrm{Np}$ & 70.3 & 29.7 \\
\hline $\mathrm{RE}$ & Cyanex 301 & \\
\hline $\mathrm{Am}$ & 27.2 & 82.8 \\
\hline
\end{tabular}




\section{UREX+2 Co-Extraction Process: Product}

Distributions

All primary components report to desired product streams

- Tc, Np fractions lower than targets

- $\mathrm{Zr}$ in Np/Pu product rather than raffinate due to other-phase carryover because of mis-match between contactor design and loaded-solvent density

\begin{tabular}{|c|c|c|}
\hline Component & $\begin{array}{c}\text { Product } \\
\text { 2004 Co-Extraction }\end{array}$ & Raffinate \\
\hline U & $>99.9994$ & 0.003 \\
\hline Tc & 80.1 & 18.6 \\
\hline Pu & 99.8 & 0.2 \\
\hline Np & 87.2 & 12.8 \\
\hline Cs & 2004 CCD-PEG & \\
\hline Sr & 99.7 & 0.3 \\
\hline
\end{tabular}




\section{Urex+1a Spent Fuel Demonstration Consisted of Four Extraction Processes and an Ion Exchange Process}

- Produces a TRU product to serve as the feedstock for a fast reactor fuel

- Process was run in 2005 and 2006

- CCD-PEG was omitted in 2005

- TALSPEAK process flowsheet was reworked in 2006 to account for slow process kinetics

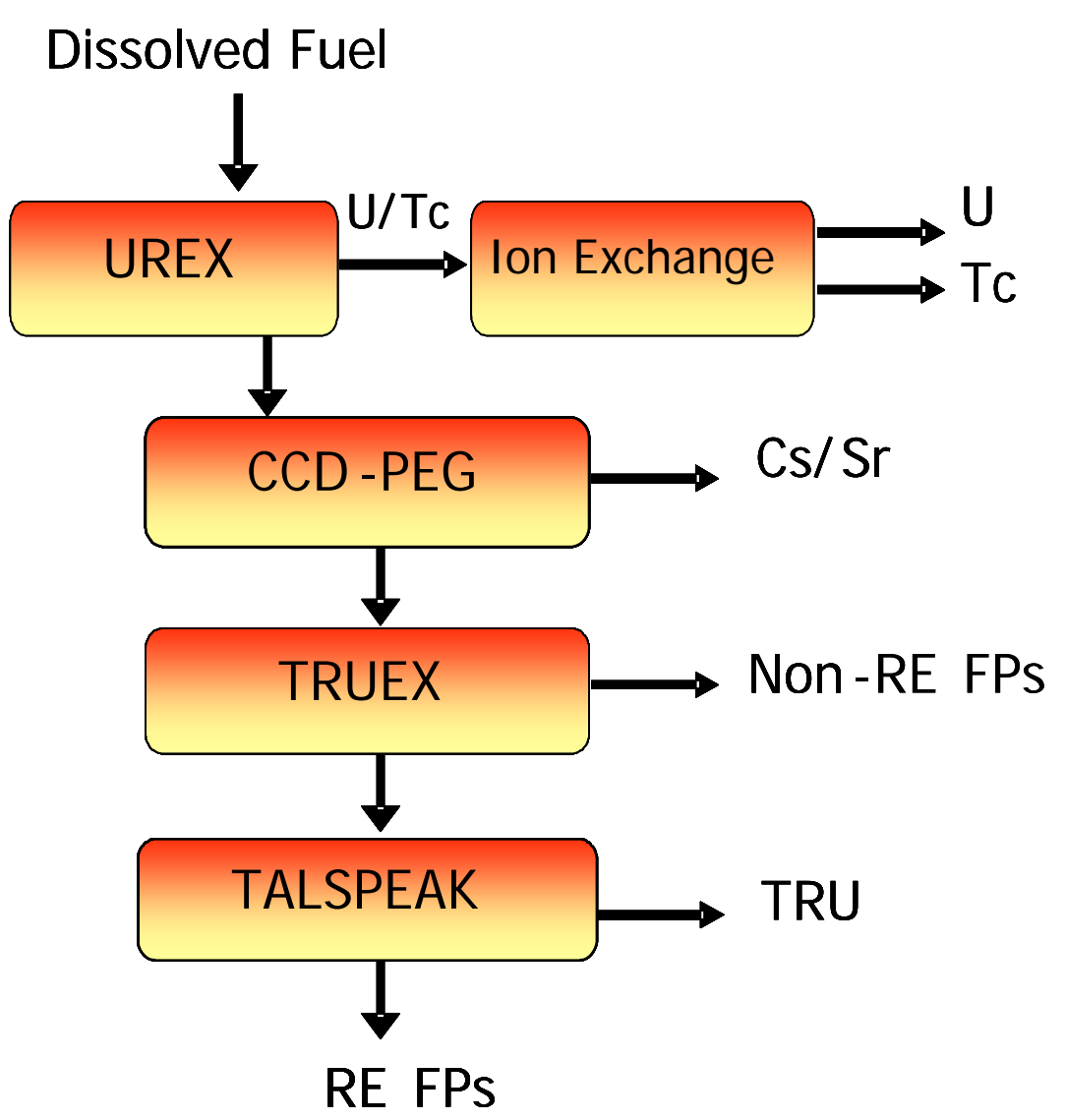




\section{UREX+1a: UREX Process Results}

- Excellent hydraulic performance

- High recovery of all products

- Excellent TRU/Ln recovery obtained with TRUEX

- Refined TALSPEAK process for 2006 test met targets

Distribution in process effluent streams (\%)

\begin{tabular}{|c|c|c|c|c|}
\hline \multirow{2}{*}{ Year } & \multicolumn{3}{|c|}{2005} & \multicolumn{2}{|c|}{2006} \\
Component & Product & Raffinate & Product & Raffinate \\
\hline U & & UREX & & \\
\hline Tc & $>99.98$ & $<0.02$ & 99.997 & 0.003 \\
\hline & 97.1 & 2.9 & 95.5 & 4.5 \\
\hline Cs & NA* & CCD-PEG & & \\
\hline Sr & NA & NA & $>99.85 \%$ & $<0.15 \%$ \\
\hline & & NALSPEAK & $99.9 \%$ & $0.1 \%$ \\
\hline Pu & 99.8 & 0.2 & $<0.005$ & $>99.995$ \\
\hline Am & 0.001 & 99.999 & $<0.03$ & $>99.97$ \\
\hline Ln & 88 & 12 & $>99.97$ & $<0.03$ \\
\hline
\end{tabular}




\section{U/Tc Separation by Ion Exchange Chromatography}

Determine breakthrough capacity of IX resin - Experimental conditions

- Three column test

- Room temperature
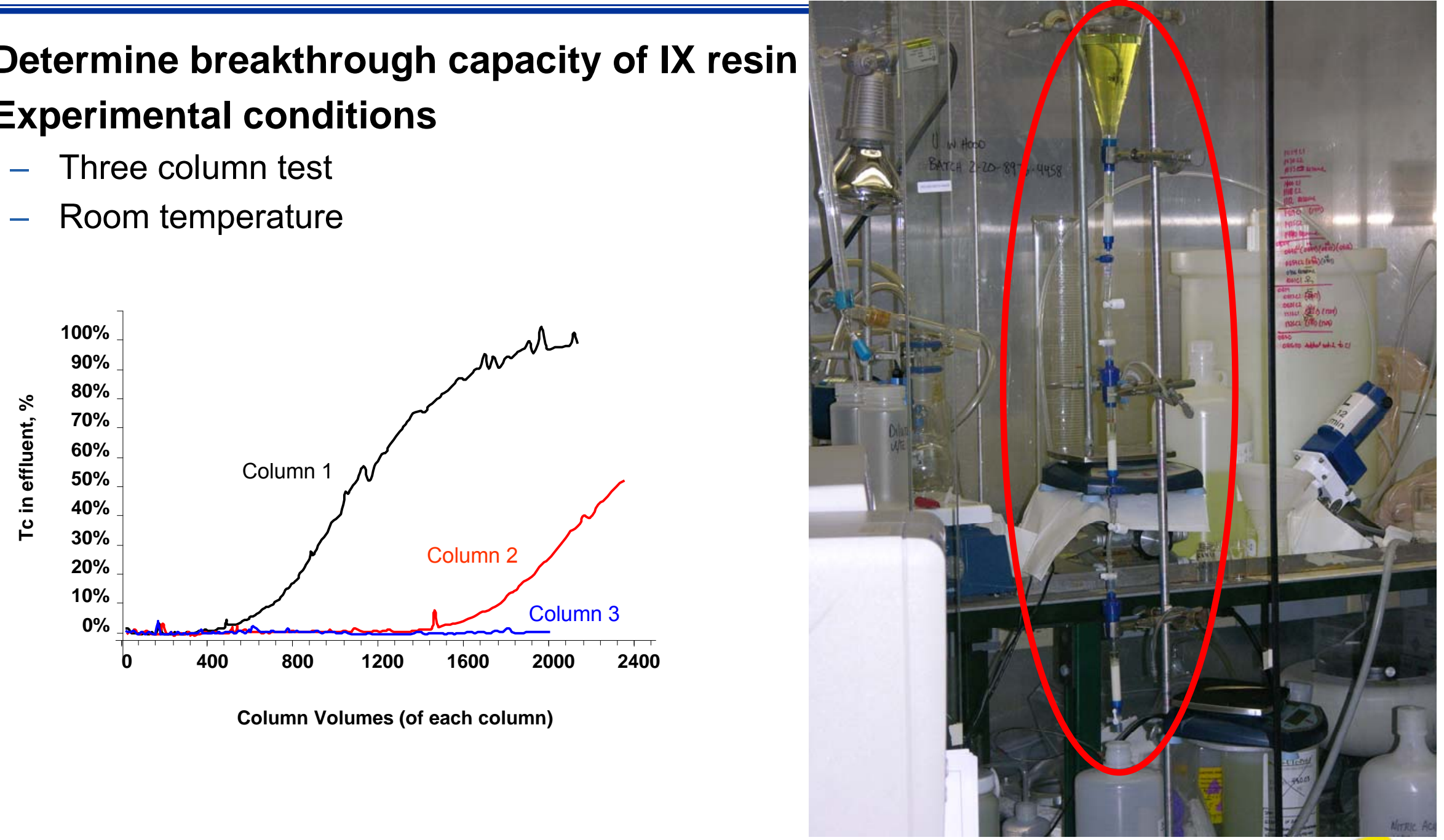


\section{ANL UREX+ Spent Fuel Demonstrations}

- UREX achieved process targets

- Excellent TRU/RE recovery obtained with TRUEX

- Refined TALSPEAK process for 2006 test met targets

- Fuel requirements - DF > 2000

- Repository requirement - TRU loss $<0.01 \%$

- Excellent hydraulic performance in all processes 


\section{In FY-2007 UREX+3a Was Demonstrated}

- UREX+3a is being developed to produce a U/Pu/Np product

- Am/Cm product for targets

- FPEX was run in place of CCDPEG for Cs/Sr recovery

- In NPEX, U was added to yield a U/Np/Pu product

- Chemical analysis is to be completed in FY-2008

${ }^{*}$ CCD-PEG may be run as an alternate for FPEX

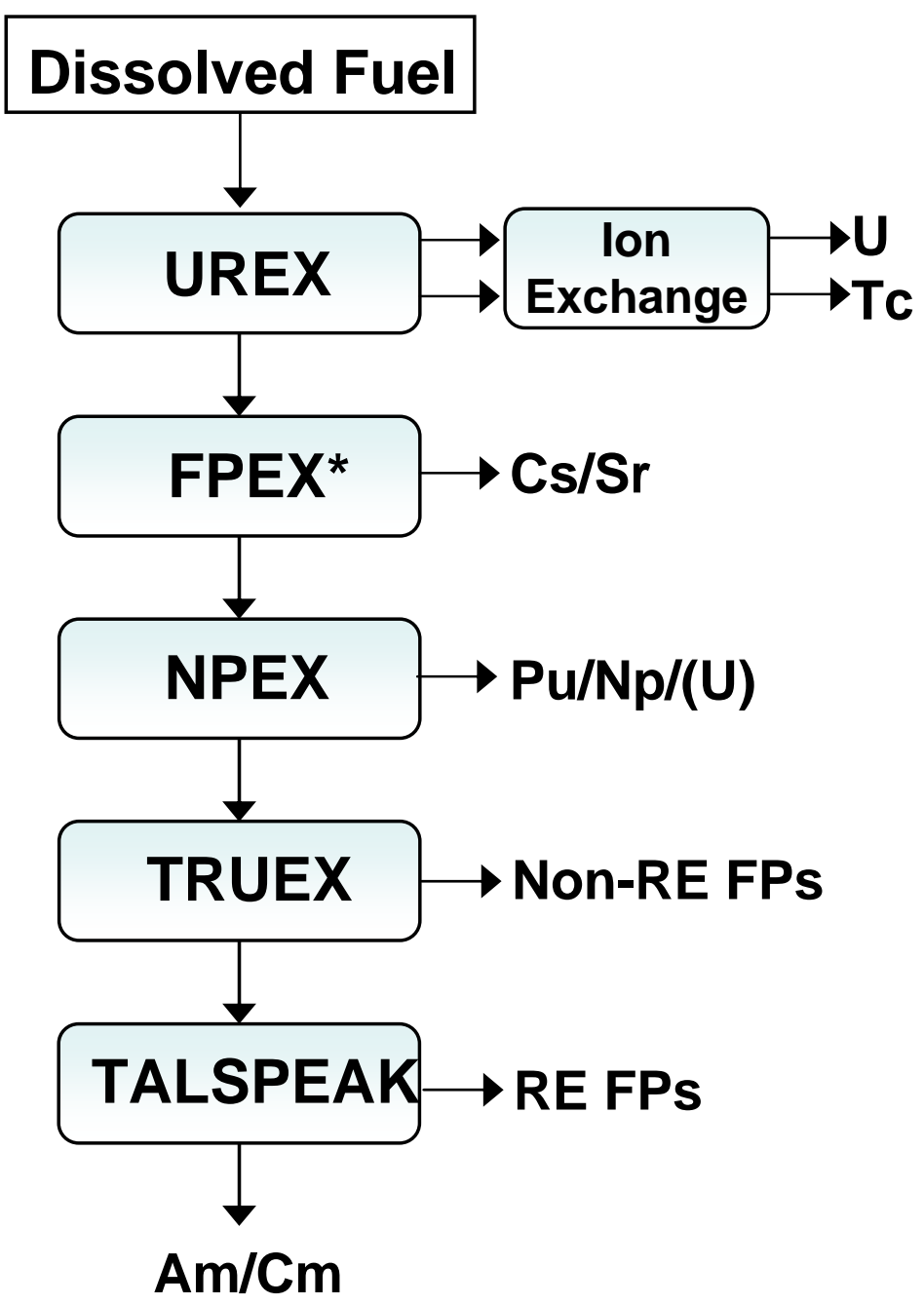




\section{FY07 UREX+3a Flowsheet}

\section{UREX}

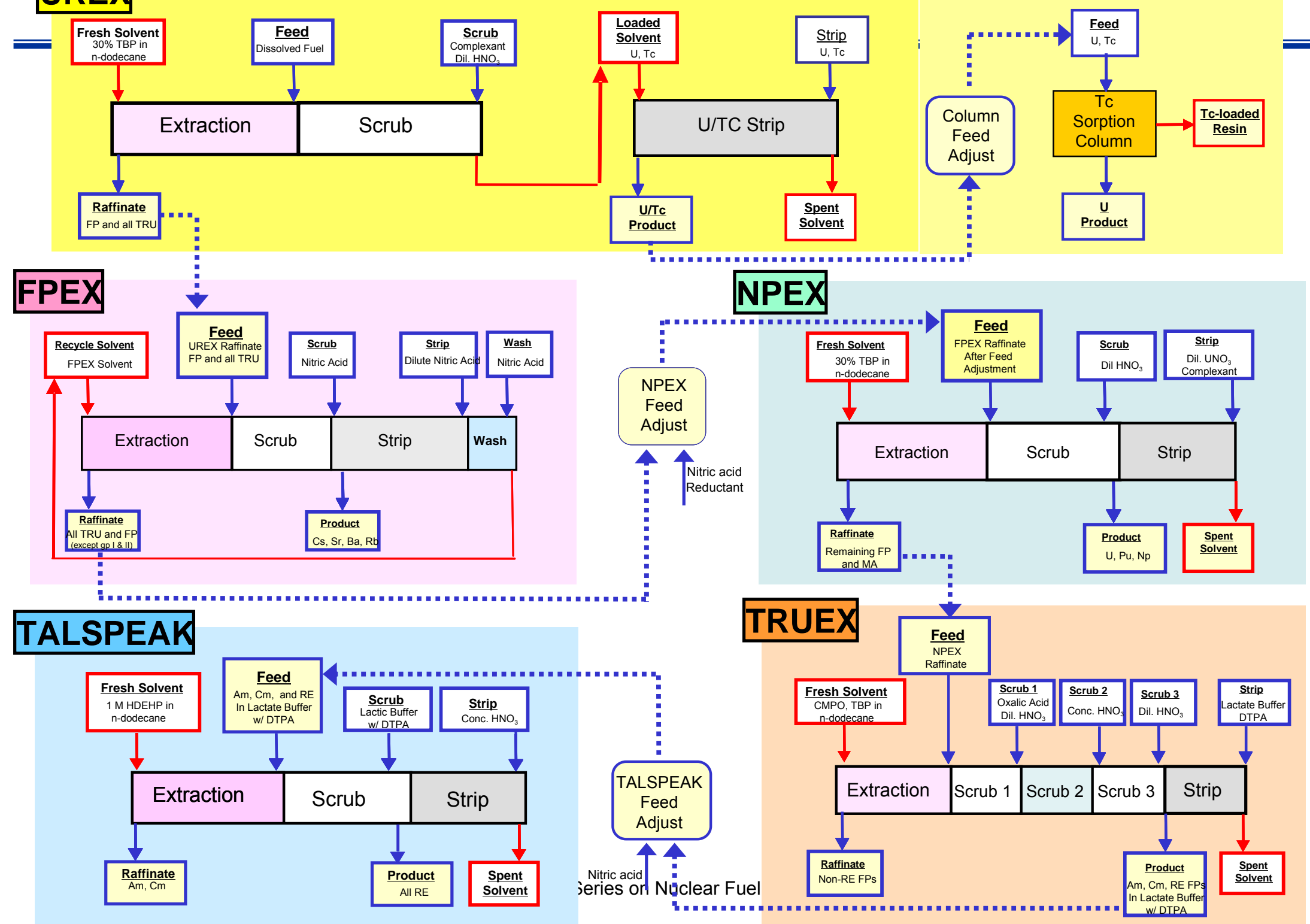


Elements report to desired product streams in all processes

- FPEX demonstrated high Cs and Sr recoveries

- Refined TRUEX process showed excellent recovery of An and Ln

- Analysis is incomplete, additional results are pending

Distribution in process effluent streams (\%)

\begin{tabular}{|c|c|c|}
\hline Element & \multicolumn{1}{|c|}{ Raffinate } & Product \\
\hline & $\underline{2007 \text { UREX }}$ & \\
\hline $\mathrm{U}$ & $0.001 \%$ & $99.999 \%$ \\
\hline $\mathrm{Fs}$ & $\underline{\mathrm{FPEX}}$ & $(100 \%)$ \\
\hline $\mathrm{Sr}$ & $\mathrm{BD}$ & $>99.9 \%$ \\
\hline $\mathrm{Pu}$ & $\underline{2007 \%} \mathrm{NPEX}$ & \\
\hline $\mathrm{Np}$ & $0.07 \%$ & $99.93 \%$ \\
\hline Am & Bkgd* & $(100 \%)$ \\
\hline *BD $=$ below detection limits; bkgd = at background levels \\
\hline
\end{tabular}




\section{Effects of pH on Ln Distribution}

D-value Dependence on pH

- Light lanthanide (La) has lowest power dependency

- Heavier lanthanide (Gd) has higher dependency

D value dependency on $\mathrm{pH}$ for HDEHP-

D extraction alone is +3 order

$$
\mathrm{Me}^{3+}+3(\mathrm{HL})_{2} \Leftrightarrow \mathrm{Me}(\mathrm{L} \cdot \mathrm{HL})_{3}+3 \mathrm{H}^{+}
$$

D value dependency based on DTPAcomplexation can be up to -5 order

- Depending on $\mathrm{H}_{5}$ DTPA acid equilibria at each pH

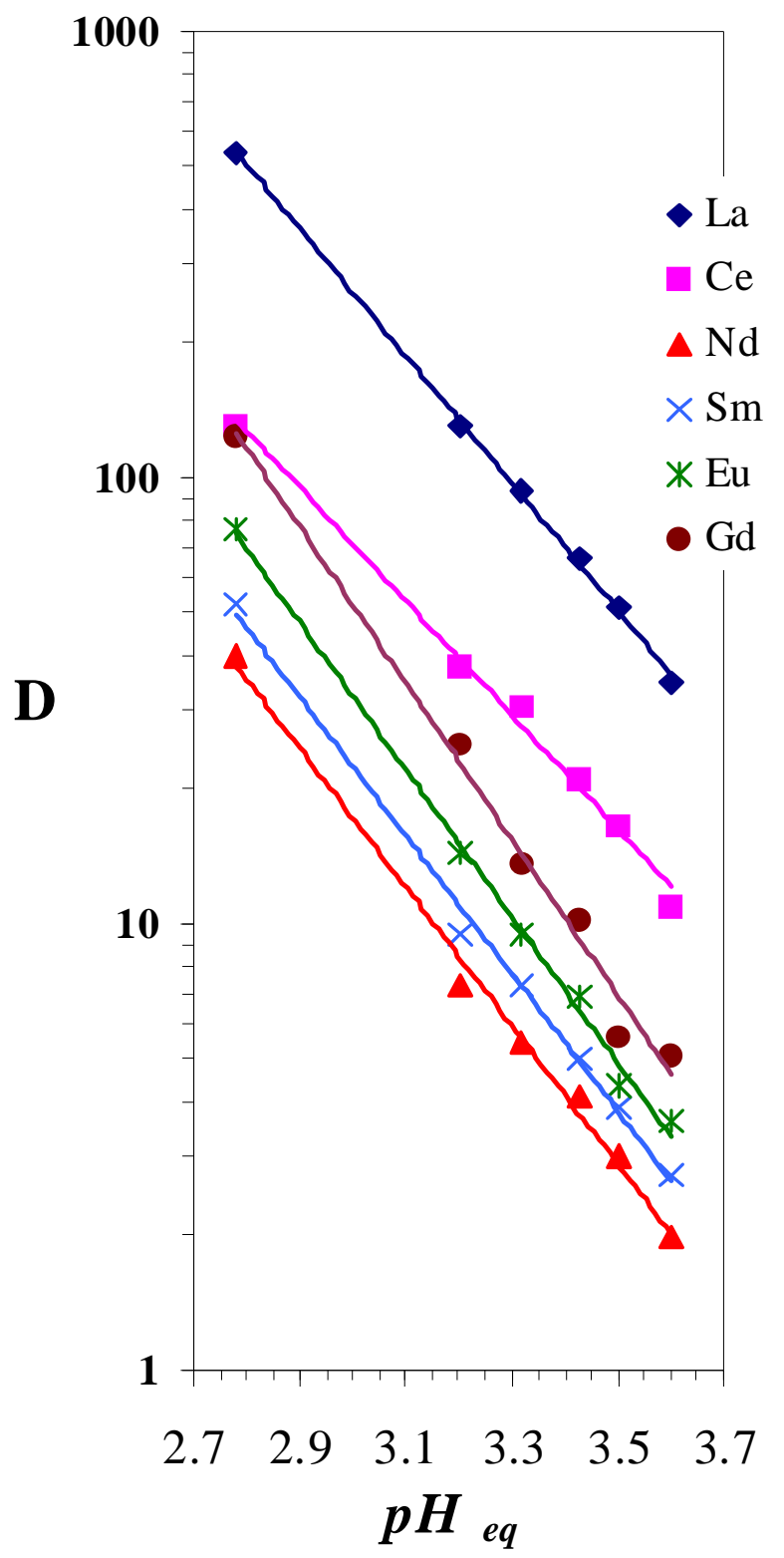




\section{TALSPEAK-Process Development-Kinetics}

- Performed a series of one-stage tests in a 2-cm centrifugal contactor

- As flow rate increases, the minimum is shifted from $\mathrm{Nd}$ to Sm-Eu

- Based on contactor tests, it appears that D

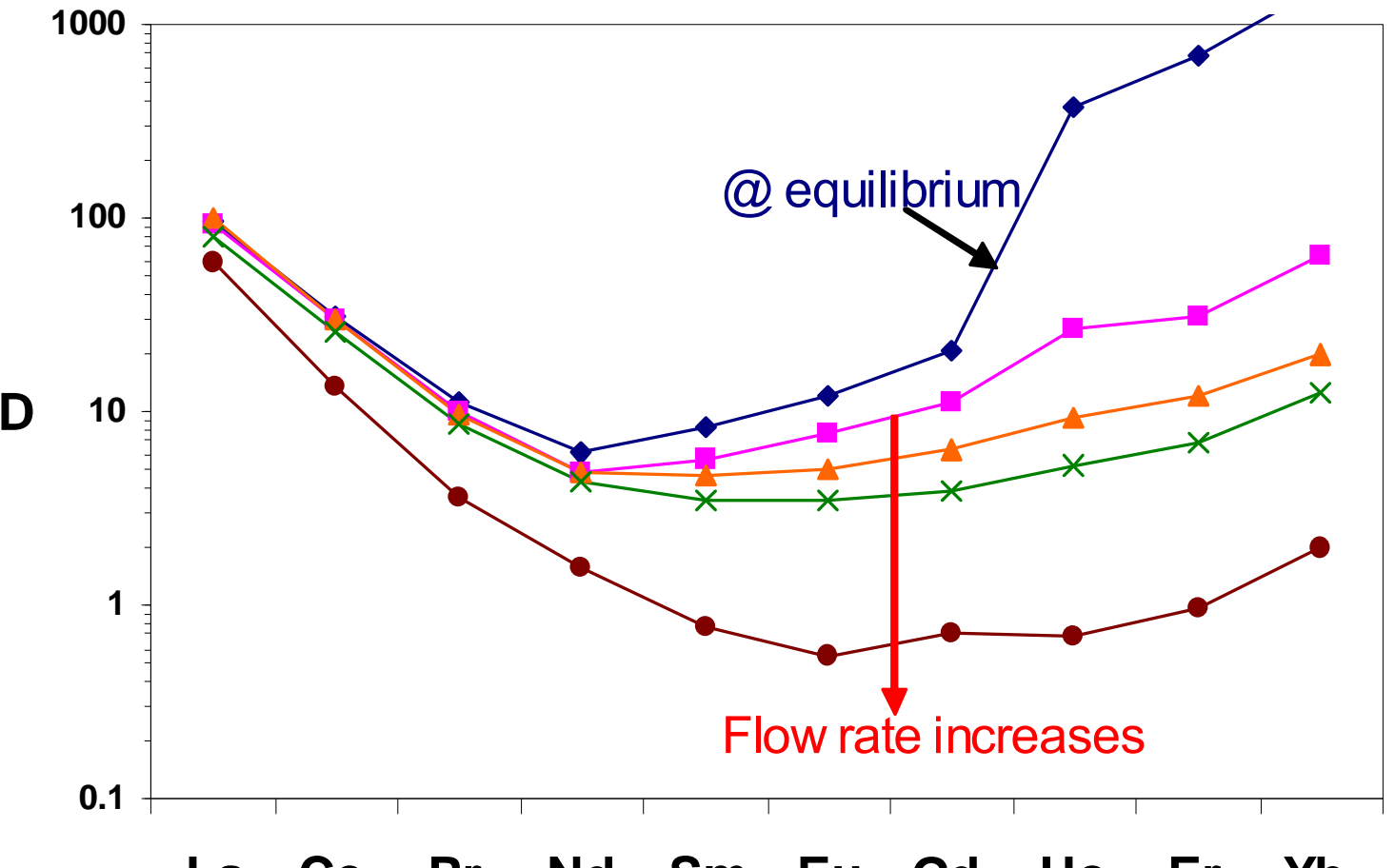
mixing is less intense in the contactor than in our batch vessel

La Ce Pr Nd Sm Eu Gd Ho Er Yb 
Distribution of lanthanides and TRU easily met process goals

$-<1 \%$ mass of actinide product was lanthanides

- $\leq 0.01 \%$ of TRU in Ln product

Effects of higher throughputs (shorter contacting time) were seen

- Effect of flow rate not as strong as suspected

- Actinide behavior was more consistent than that of lanthanides

Distribution in process effluent streams (\%)

\begin{tabular}{|c||c|c||c|c|}
\hline \multirow{2}{*}{$\begin{array}{c}\text { Feed Flow } \\
\text { Rate }\end{array}$} & \multicolumn{2}{|c||}{ Rare Earth Product } & \multicolumn{2}{c|}{ TRU Product } \\
\hline Low & 99.9998 & TRU, \% & RE, \% & TRU, \% \\
\hline Mid & 99.7 & BD & 0.002 & $(100)$ \\
\hline High & 99.997 & 0.002 & 0.03 & $(100)$ \\
\hline
\end{tabular}

$\mathrm{BD}=$ Below Detection Limits 


\section{Lanthanide Behavior-Aqueous-Phase Stage Profiles}
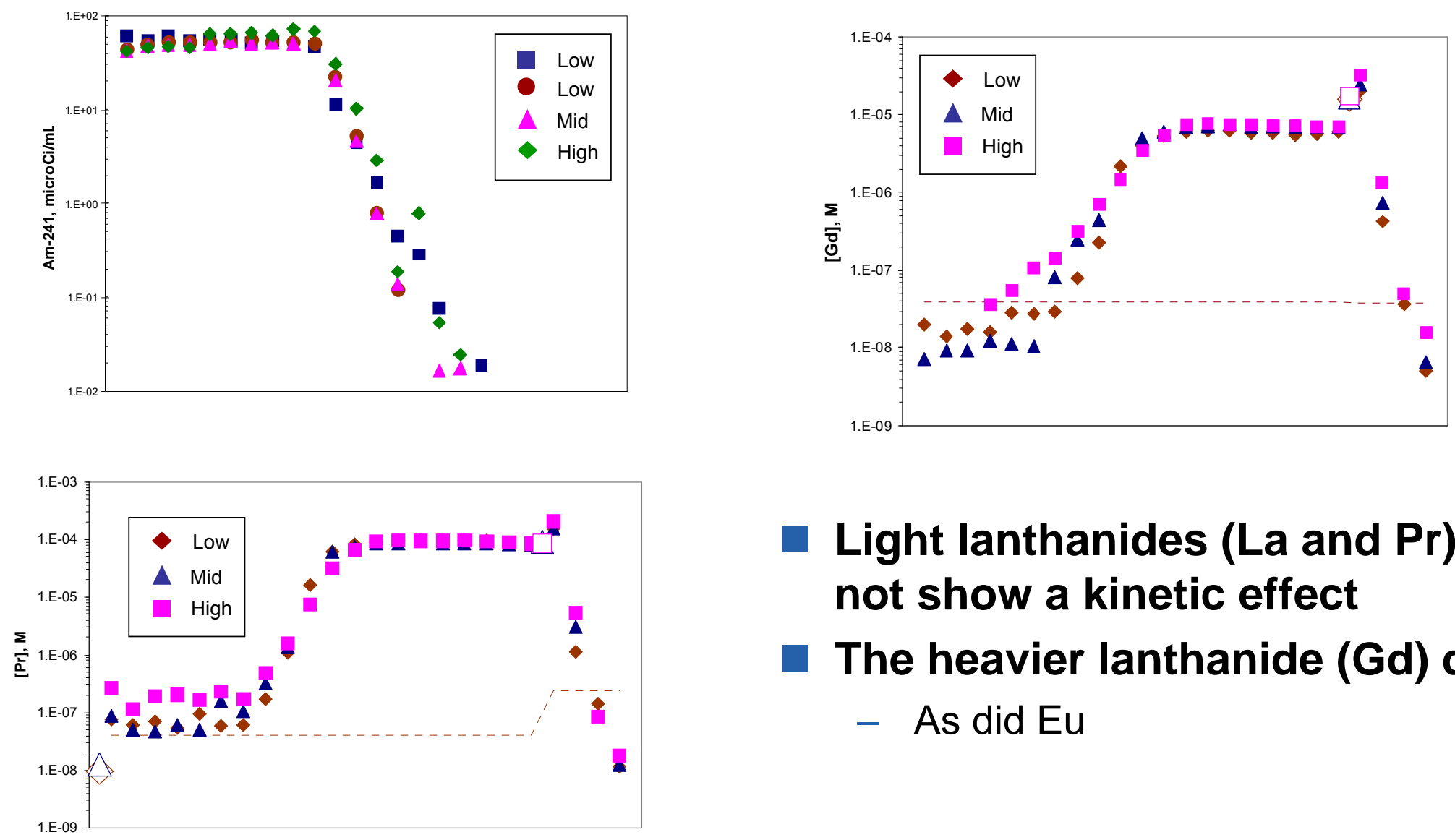

- Light lanthanides (La and Pr) do not show a kinetic effect

- The heavier lanthanide (Gd) does

- As did Eu 


\section{Am vs. Eu Behavior--Stage Profile}
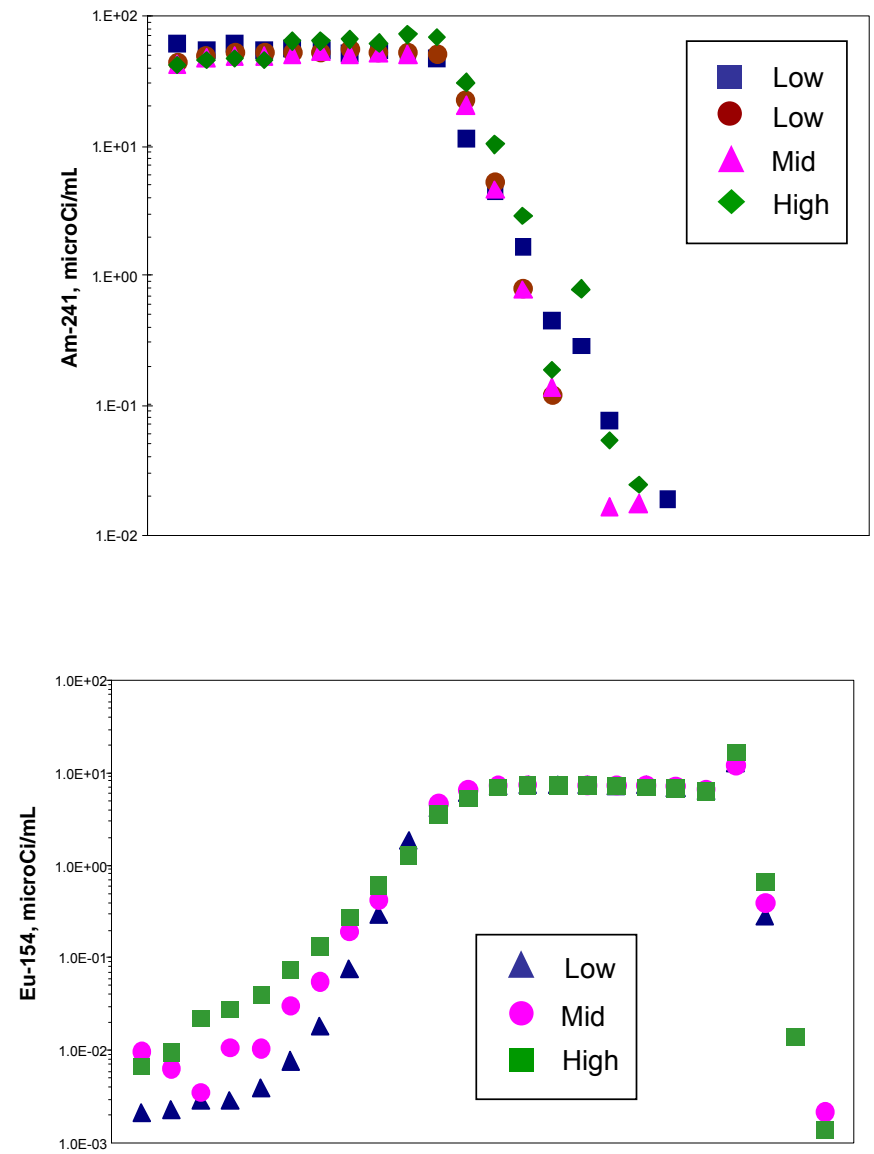

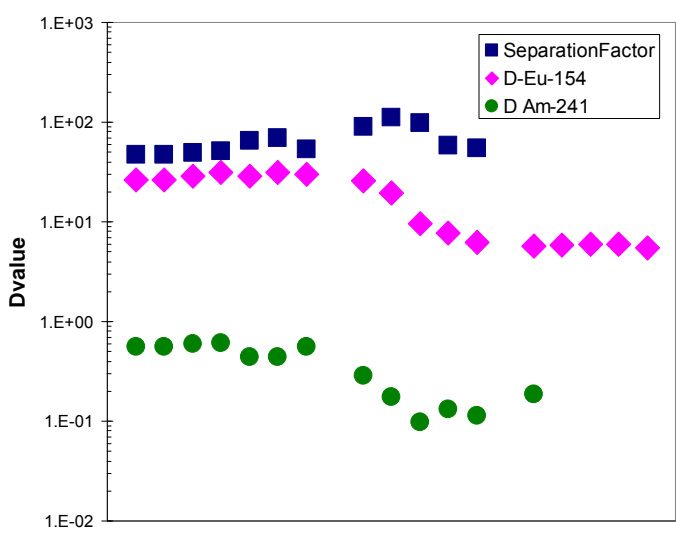

- Effects at higher flow rates (less contact time) are seen for Eu aqueous-phase stage profile

- Better extraction at lower flow rates

- However, even at highest flow rate, separation factors for Eu over Am are $\sim 50$ in extraction section.

- $\quad 100$ in scrub section 


\section{Summary of UREX+ Process Demonstrations with Spent Nuclear Fuel}

All demonstrations have proven the feasibility of the UREX+ processes to achieve program goals

- UREX has been repeatedly demonstrated to be viable for the selective extraction of $U$ and Tc

- Co-extraction of $\mathrm{U}, \mathrm{Pu}, \mathrm{Np}$, and Tc with subsequent selective stripping of $\mathrm{Pu} / \mathrm{Np}$ and $\mathrm{U} / \mathrm{Tc}$ proved viable

- Cs/Sr recovery was achieved using both CCD-PEG and FPEX

- NPEX process recovers Pu and Np; produces U/Pu/Np product

- TRUEX has been demonstrated in four tests for An/Ln recovery

- TALSPEAK successfully separated actinides from lanthanides at high purities as required for fuel fabrication

- Tests at different flow rates proved the robustness of the process for scale-up 


\title{
Electrochemical Processing of Spent Nuclear Fuel
}

\author{
Dr. Michael Goff
}

Idaho National Laboratory

Nuclear Regulatory Commission Seminar

Rockville, MD

March 25, 2008 
Dry processing

- Pyroprocessing

Pyrochemical processing

- Pyrometallurgical processing

Electrometallurgical treatment

Etc. 
"Pyrometallurgical processing techniques involve several stages: volatilisation, liquid-liquid extraction using immiscible metal-metal phases or metal-salt phases, electrorefining in molten salt, fractional crystallisation, etc. They are generally based on the use of either fused (low-melting point) salts such as chlorides or fluorides (eg $\mathrm{LiCl}+\mathrm{KCl}$ or $\mathrm{LiF}+\mathrm{CaF}$ ) or fused metals such as cadmium, bismuth or aluminium."

From Wikipedia 
"Pyrochemical reprocessing methods use high temperature oxidation -reduction reactions in non-aqueous media to separate the actinides, $\mathrm{U}$ and $\mathrm{Pu}$ from the fission products. These methods exploit the differences in the volatilities or thermodynamic stabilities of the compounds of actinides and fission products to achieve the separation. Pyrochemical separations can be achieved by using electrochemical methods instead of chemical equilibrations."

From PYROCHEMICAL Reprocessing of Fast Reactor Fuels on IGCAR Website 
Work being performed in the United States is focused on an electrochemical process involving molten salts and liquid metals.

- Work is performed primarily at Idaho National Laboratory and Argonne National Laboratory.

- This talk will focus on that technology and its development.
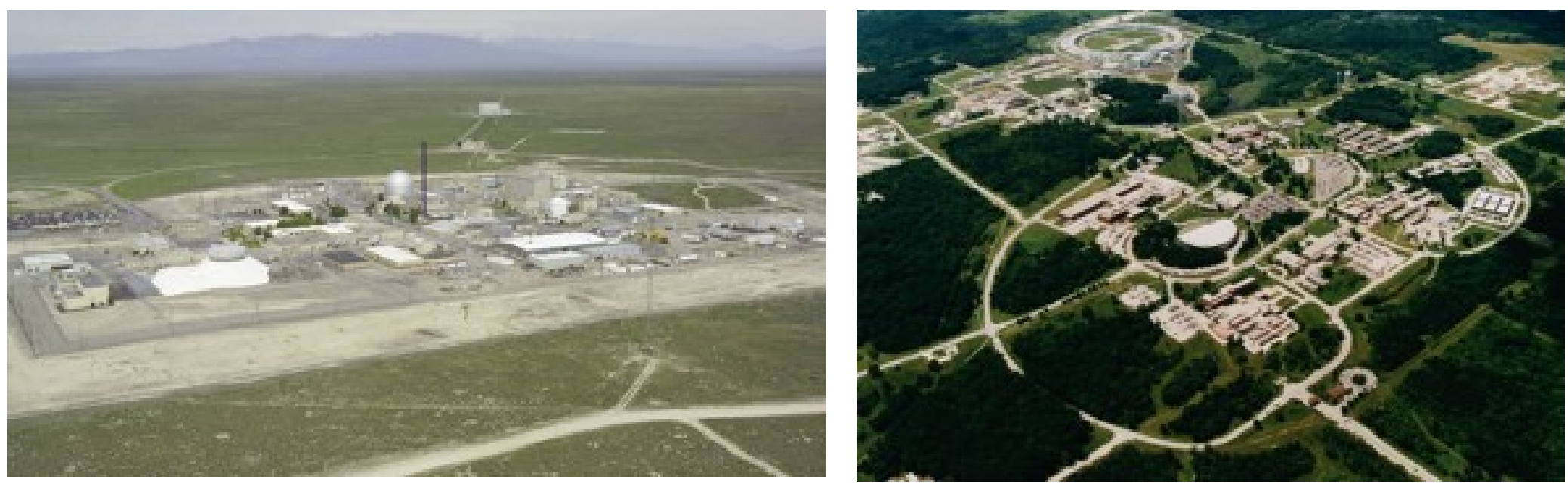


\section{Electrochemical Processing Background}
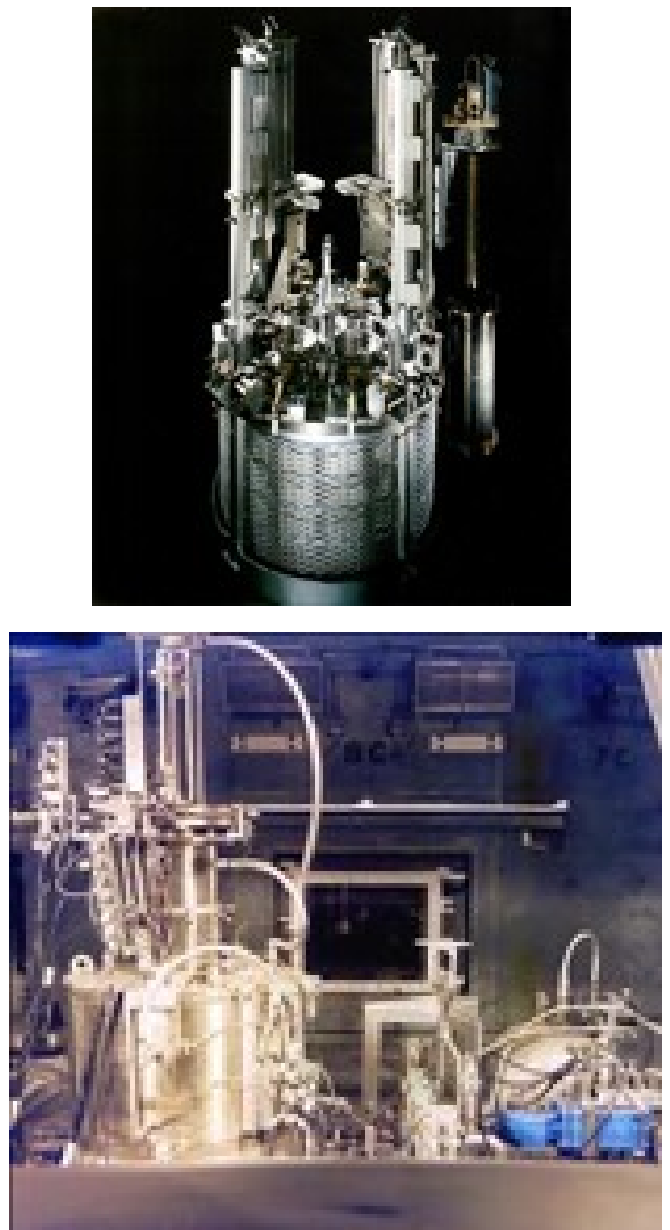

- Present generation of technology for recycling or treating spent fuel started in the 1980s.

- Electrochemical processes were developed for the fast reactor fuel cycle.

- The fast reactor fuel does not require a high degree of decontamination.

- Reasons technology pursued include:

- Capable of low purity products

- Potential compactness (co-location with reactor)

- Resistance to radiation effects (short-cooled fuel can be processed)

- Criticality control benefits

- Compatibility with advanced fuel types

- Process was integrated with remote fuel fabrication for fast reactors. 


\section{Melt Refining Performed Prior to Electrochemical Processing}

\section{Technology deployed in the late 1960s}

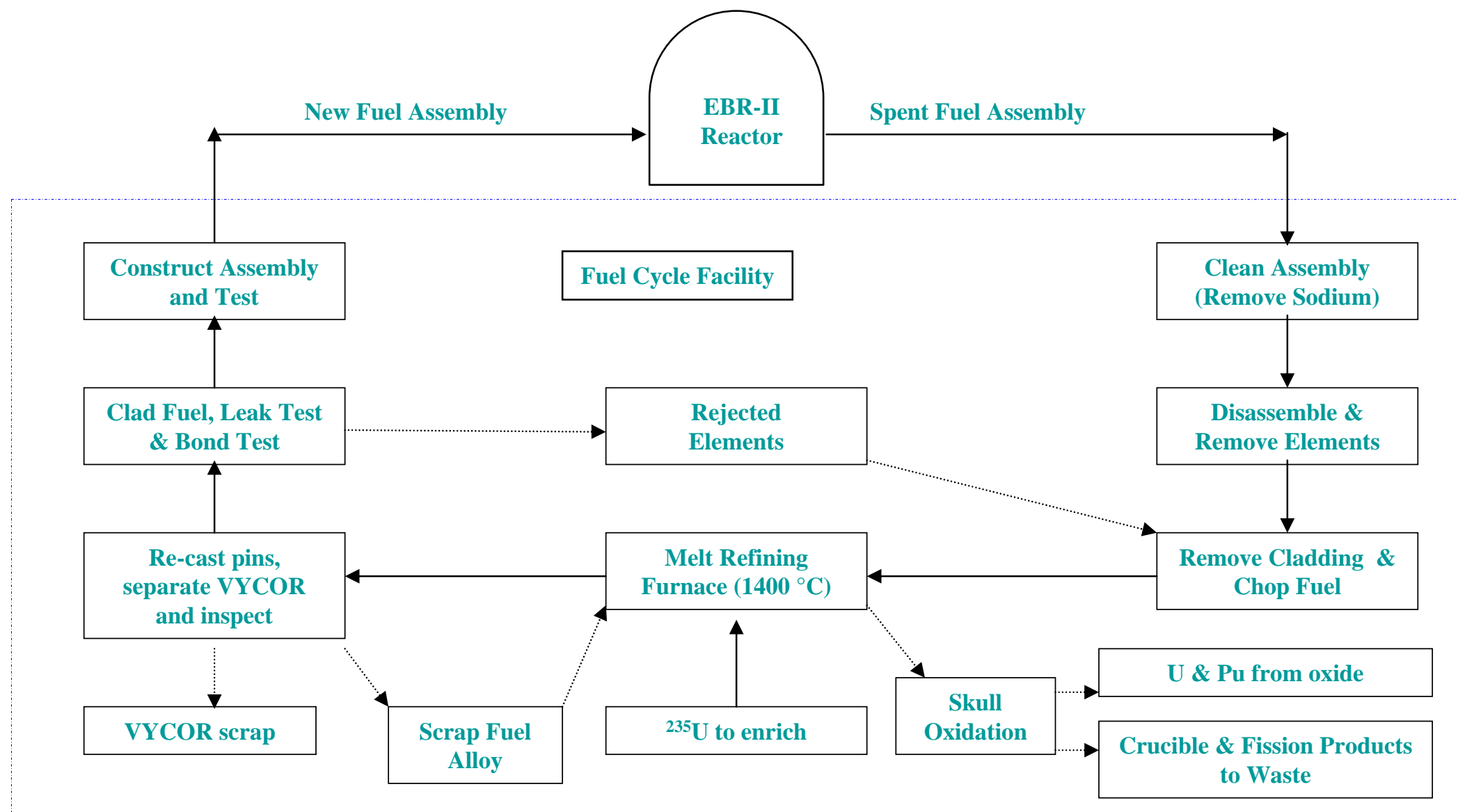




\section{Chemical Bases for Electrochemical Processing}

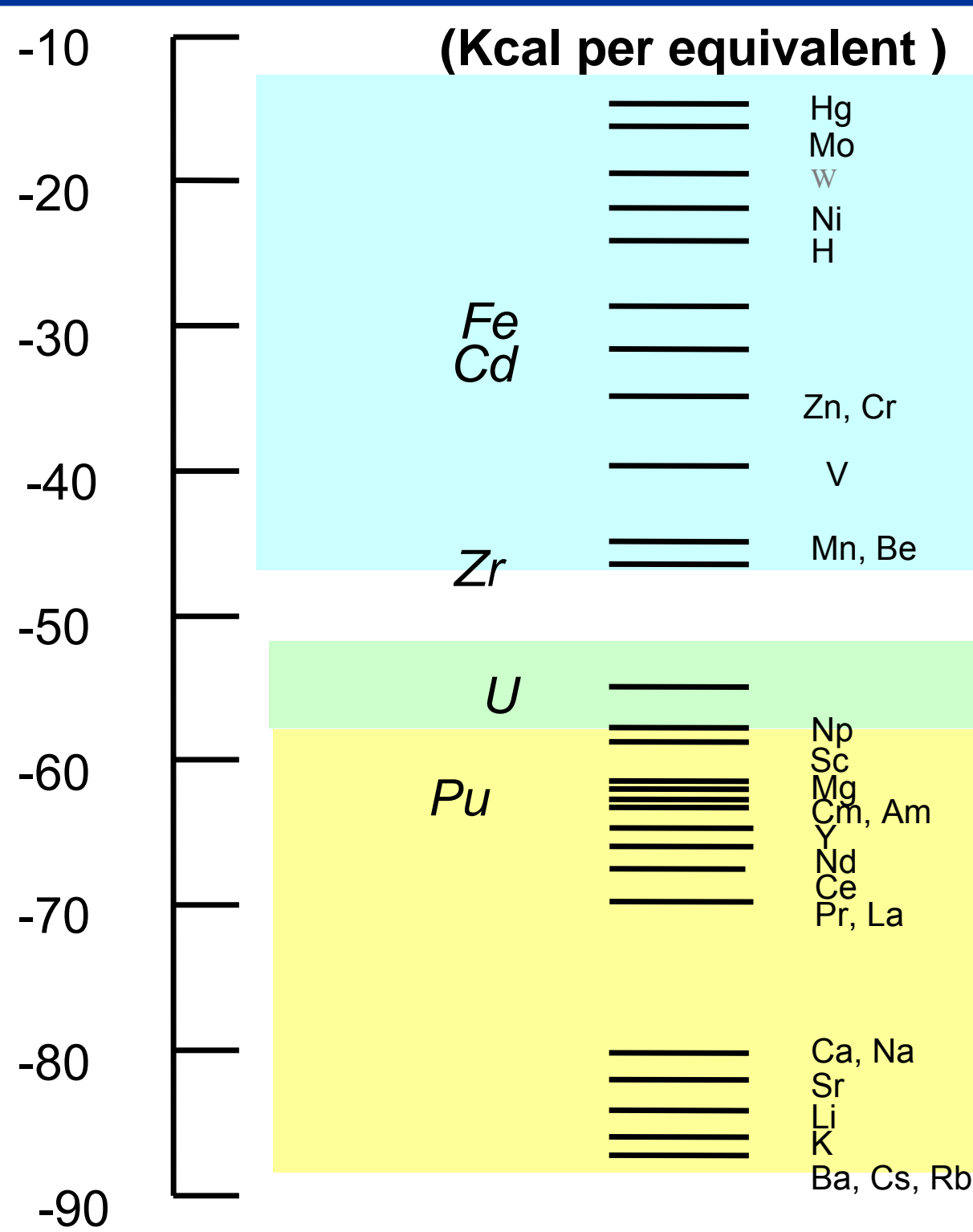

Uranium Product 


\section{Electrochemical Process Flowsheet}

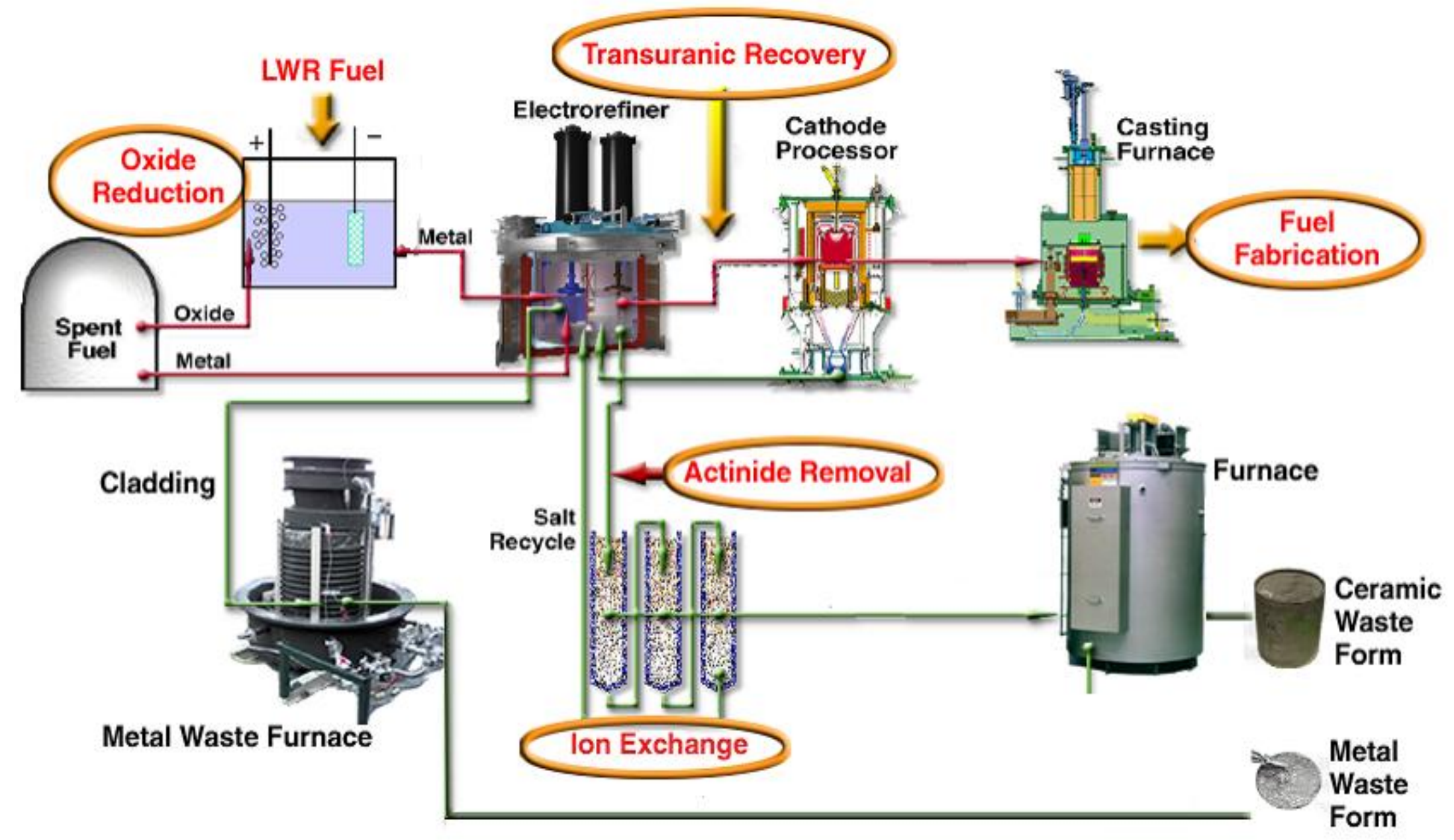




\section{Electrorefining}
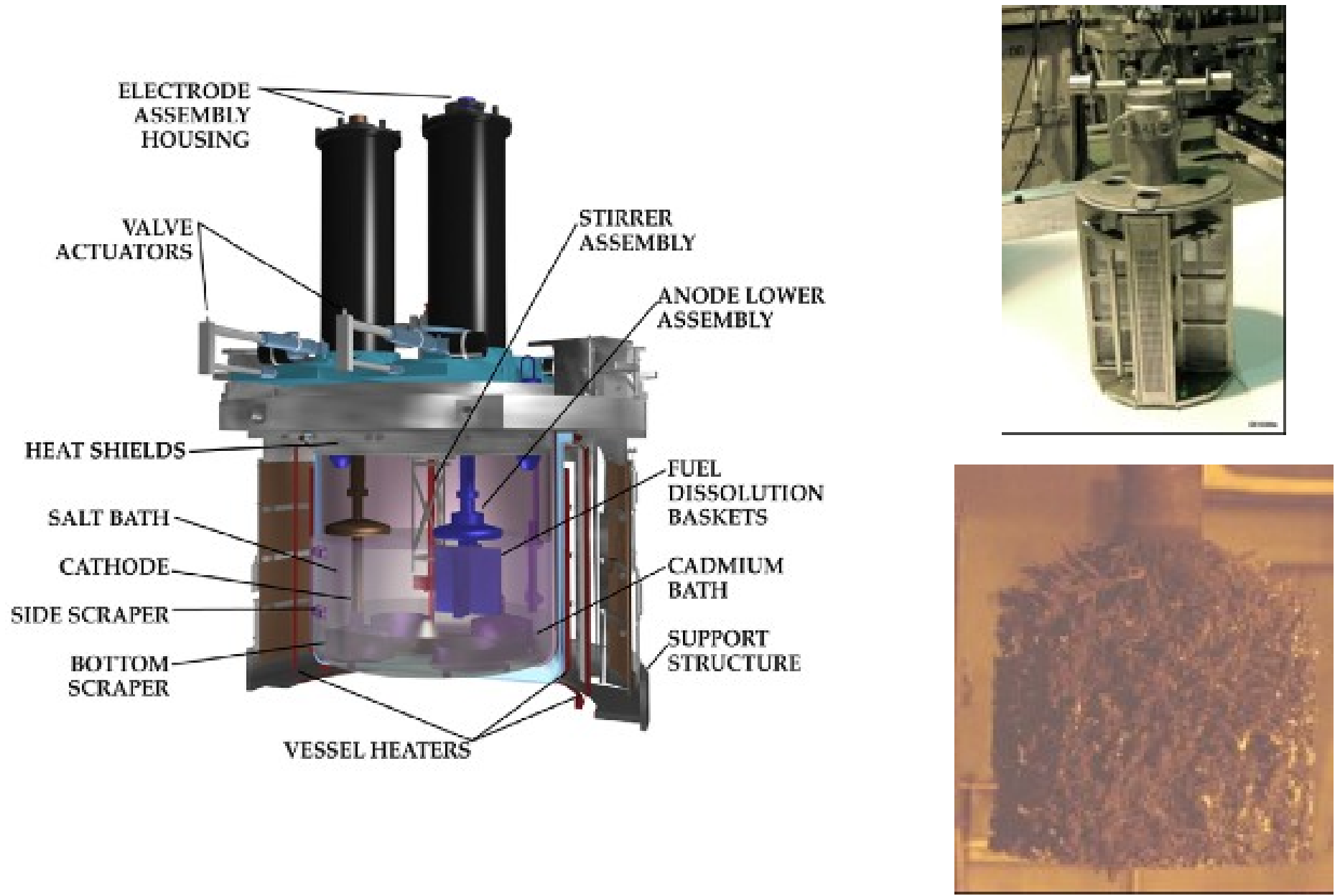
- Salt must be separated from recovered actinides.

- Salt is distilled and recycled back to electrorefiners.

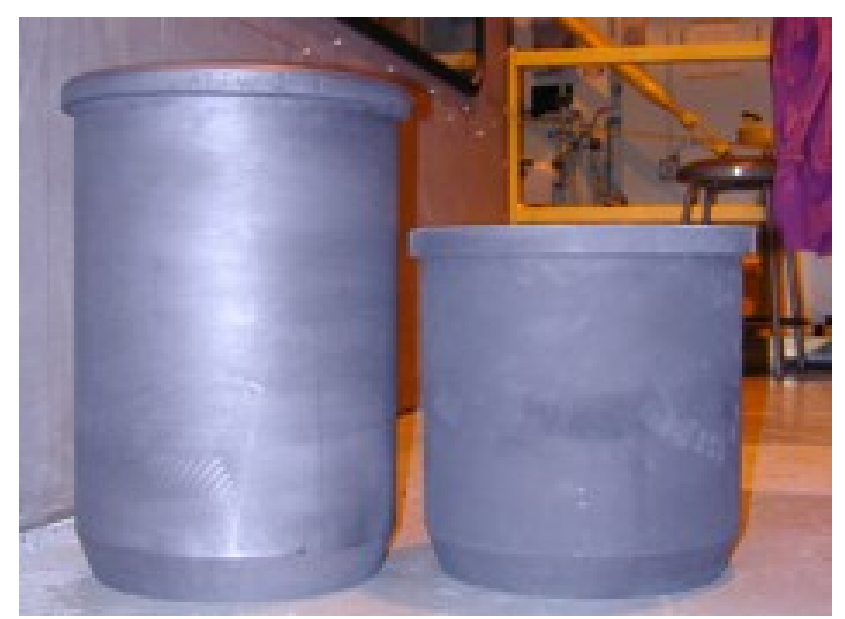

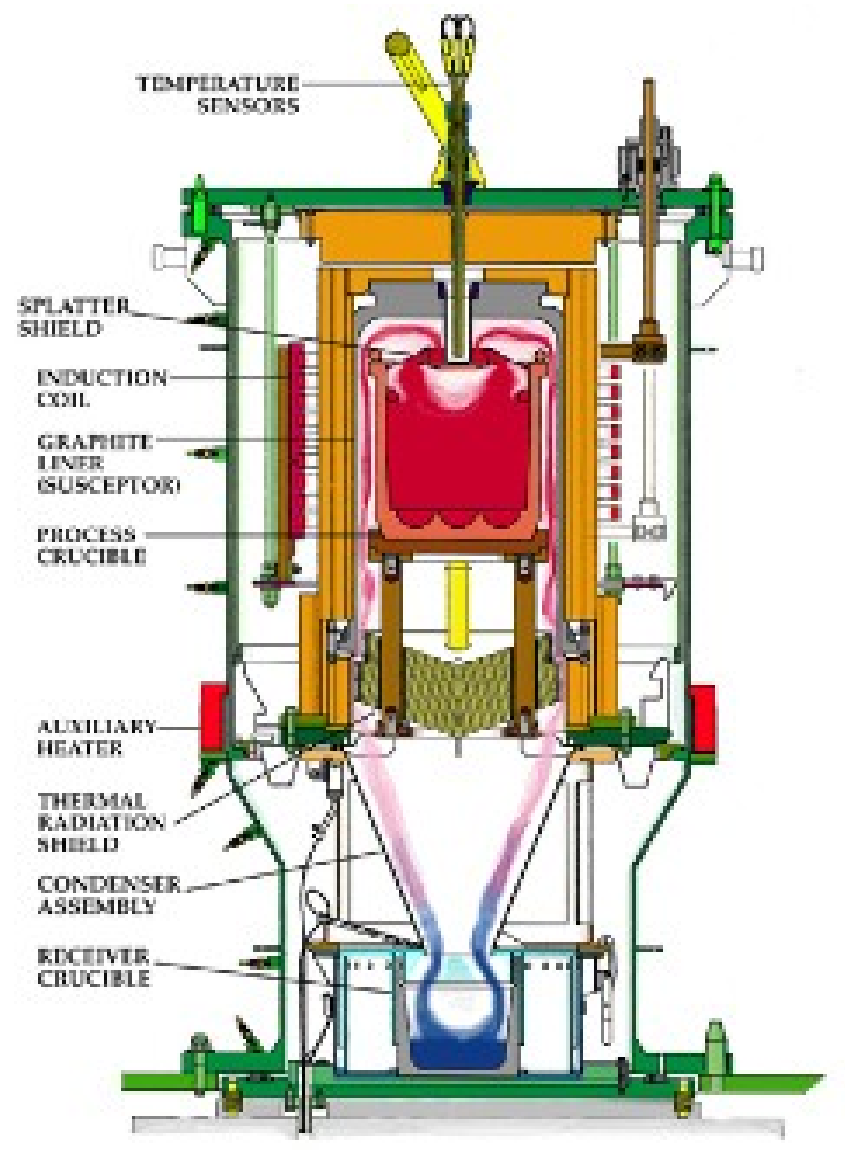


- EBR-II used a sodium-bonded metallic fuel.

- Reactive materials (sodium and uranium metal)

- Highly enriched uranium in driver fuel (53-78\% U-235)

- Approximately $1 \%$ plutonium in blanket fuel

- Technology was formally demonstrated with spent fuel between 1996 and 1999.

- Demonstration was reviewed for the National Research Council.

- Finding: The Committee finds that ANL has met all of the criteria developed for judging the success of its electrometallurgical demonstration project. 
- Until 1994, focus was on demonstration of closed fuel cycle with a fast reactor.

- Recycle of fast reactor fuel

- Limited work on production of fast reactor feed material from LWRs

- In 1994, activities were redirected to treatment for disposal.

- Engineering-scale experience was gained with spent fuel.

With the formation of the Advanced Fuel Cycle Initiative (AFCl) in 2002 and the Global Nuclear Energy Partnership (GNEP) in 2006, recycle focus was renewed and stressed.
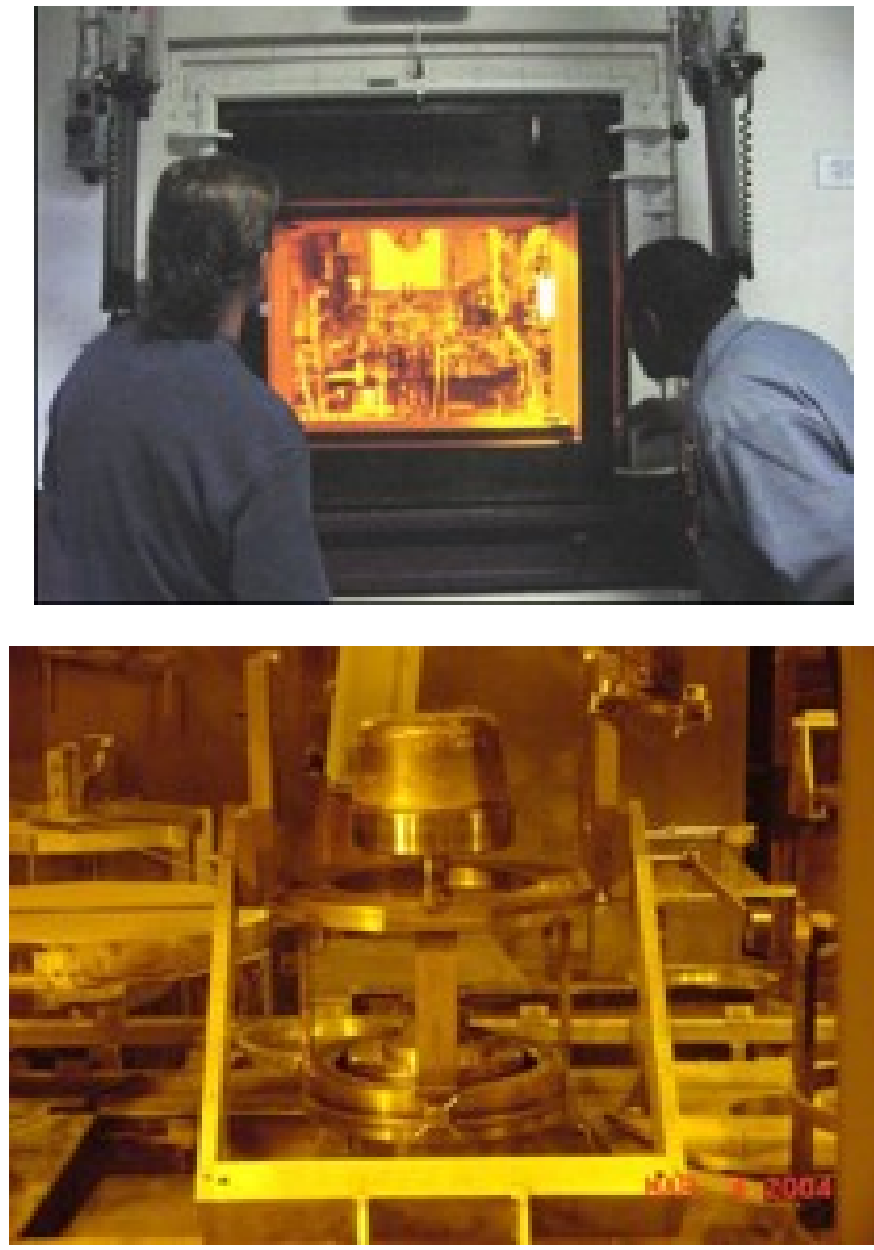
- The Fuel Conditioning Facility (FCF) is a one-of-a-kind electrochemical processing facility.

- FCF is used for treatment of fuel and demonstration of electrochemical process operations.

- Work includes development, qualification, and production of high-level waste.

- High-level waste work is performed in the Hot Fuel Examination Facility (HFEF).
Fuel Conditioning Facility for Spent Nuclear Fuel Treatment
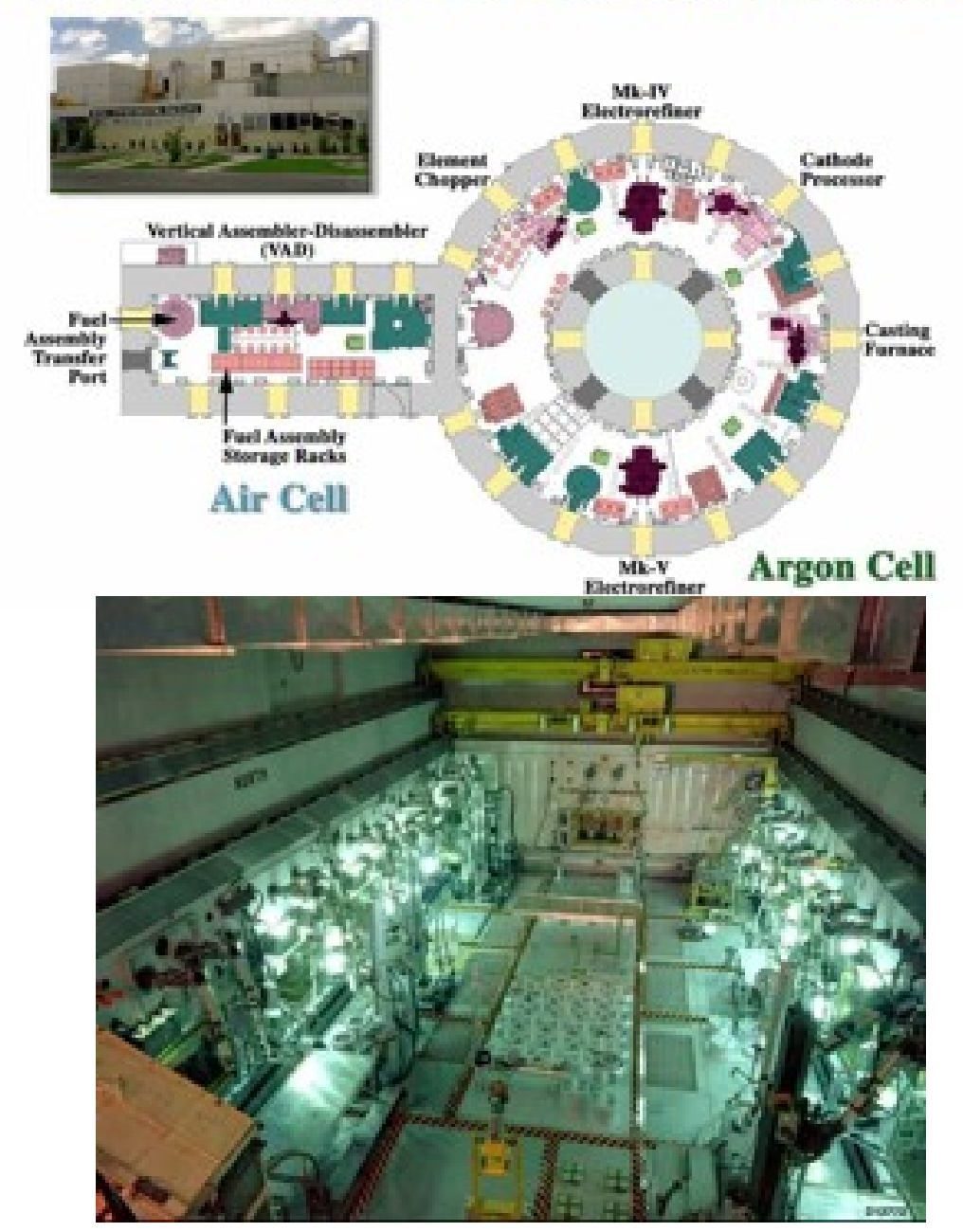

Hot Fuel Examination Facility 


\section{Processing Lines in FCF}

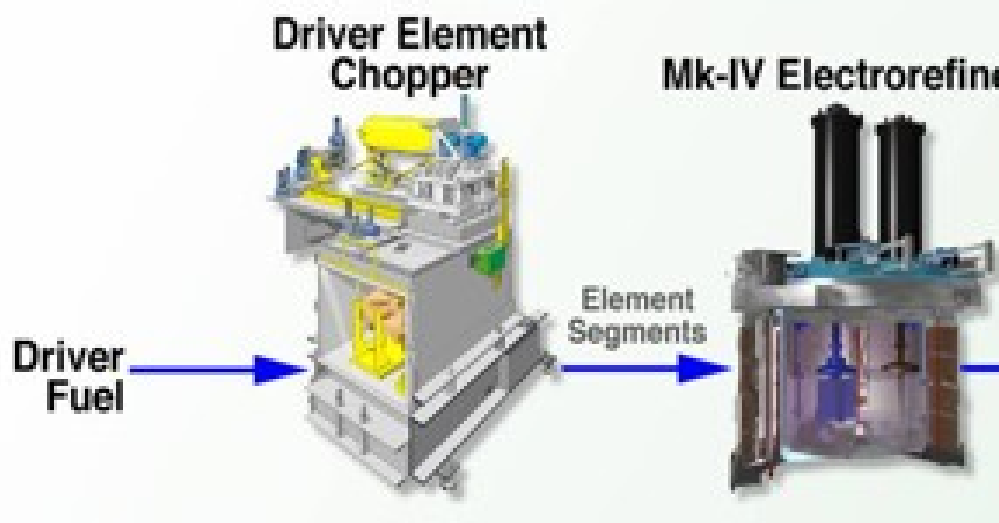

Driver and Blanket Fuel are Treated in Parallel

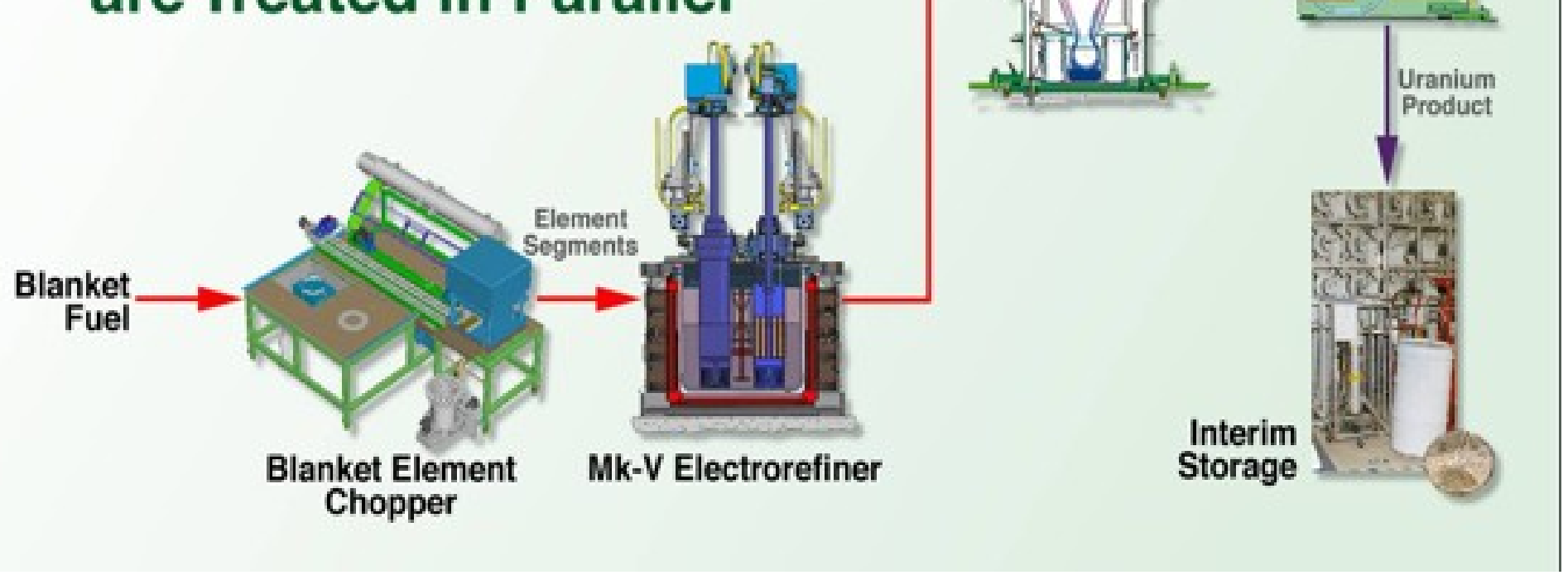




\section{Electrochemical Treatment of Spent Fuel}

- Electrochemical processing has been performed on the engineeringscale with irradiated fuel since 1996.

- Approximately 3.5 MTHM of fuel, including highly enriched uranium fuels, have been treated.

- Installed process equipment could support throughputs between 3 and

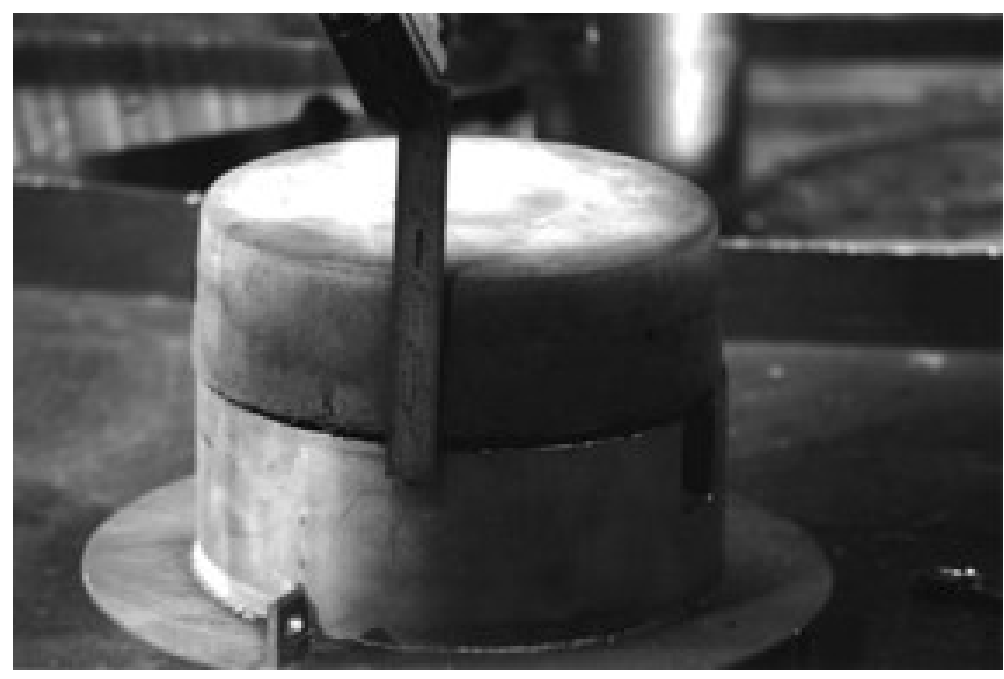
5 MTHM per year.

- Advancements in the technology are a major focus of GNEP.

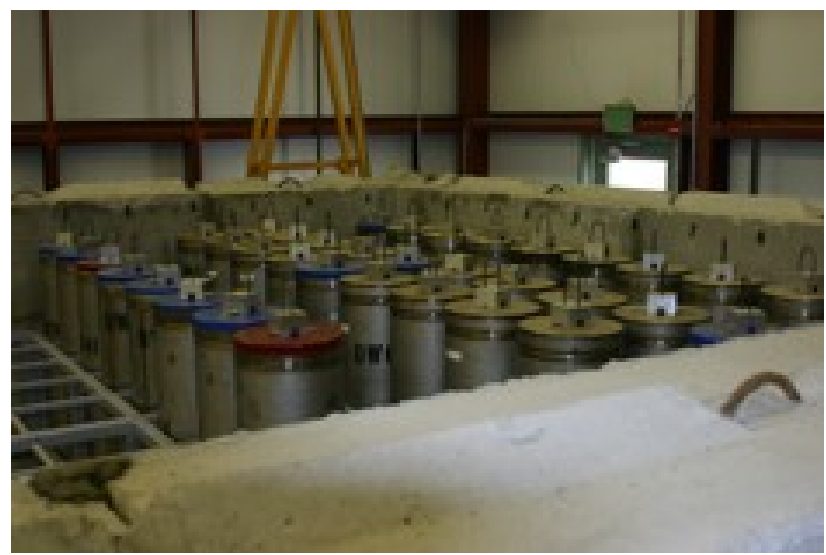




\section{Hot Cell Electrorefiner Scale-up}

- Throughout development of electrochemical processing, electrorefining has been scaled significantly for hot cell application.

- First hot cell electrorefiner has a current capacity of 3.5 amps.

- Mark IV electrorefiner has a current capacity of 200 amps.

- Mark V electrorefiner has a current capacity of 2400 amps.

- Technology has been scaled in cell by three orders of magnitude.
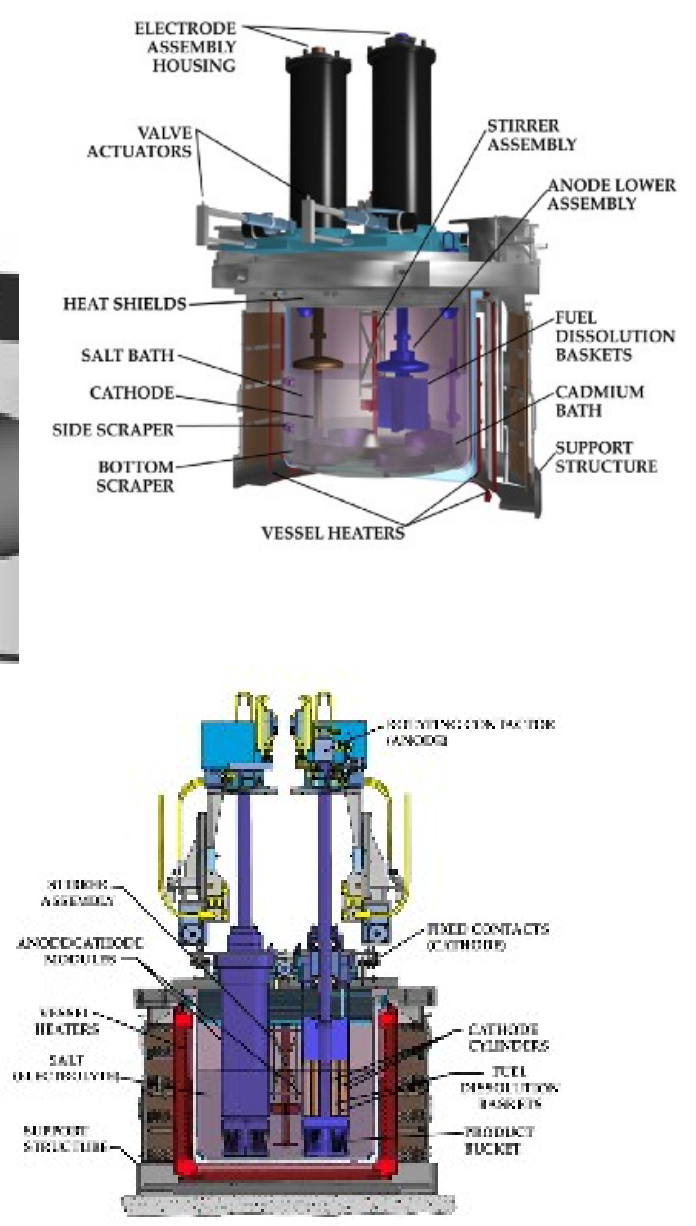


\section{Electrochemical Processing Accomplishments}

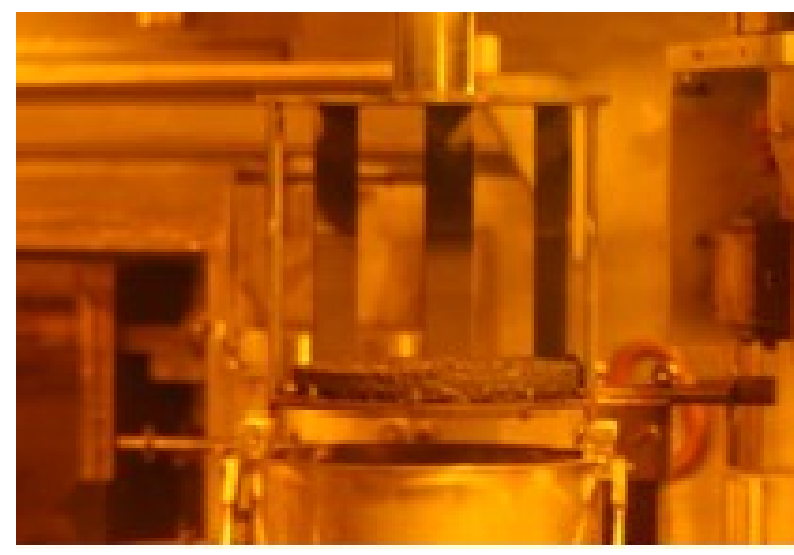

Recovered Transuranic Ingot

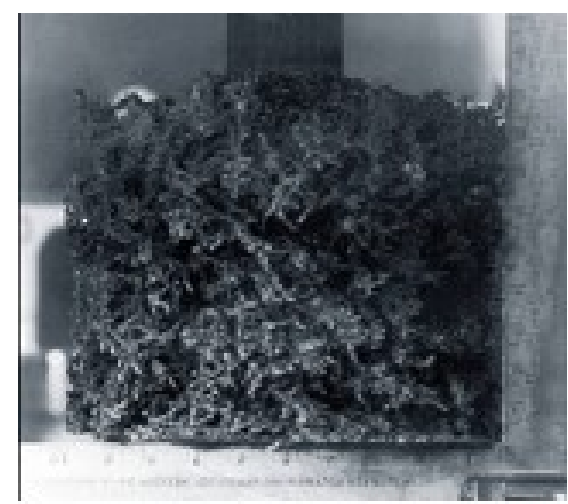

Uranium Deposit from Electrorefining
- Group transuranic recovery tests have been successfully performed at laboratory and engineering-scales.

- Recoveries of more than $1 \mathrm{~kg}$ of transuranics have been obtained.

- Purity requirements for fast reactor fuel have been demonstrated at both scales.

Engineering-scale electrorefining operations continue to demonstration high dissolution of actinides $(99.7 \%)$. 


\section{Electrochemical Processing Accomplishments}

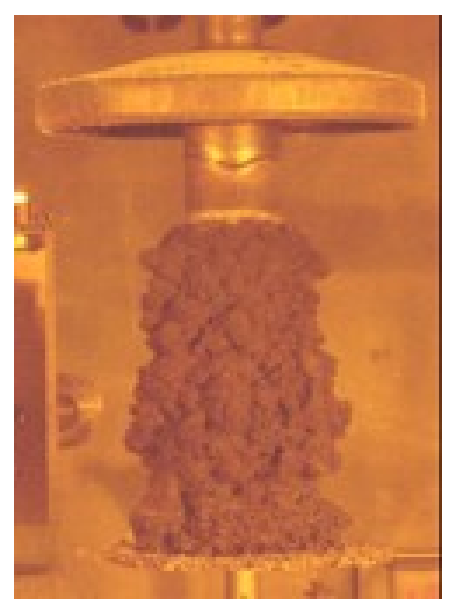

Zirconium-rich cathode

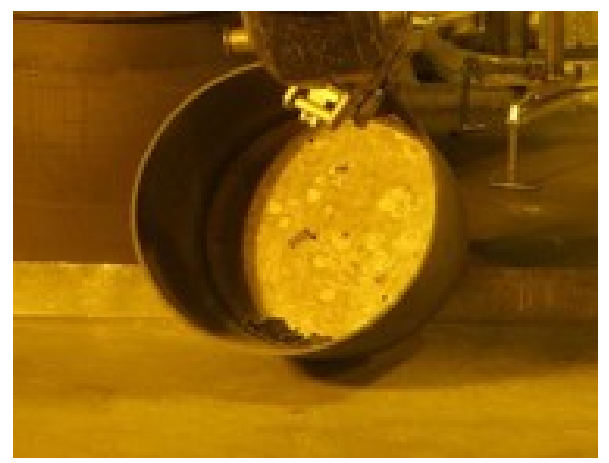

- Electrochemical recovery of zirconium has been demonstrated.

- Improved crucible materials for high temperature processing have been successfully tested at engineering-scale.

- Crucibles are reusable, which supports increased throughput.

- Very little dross forms in new crucibles. 


\section{Metallic Fuels}

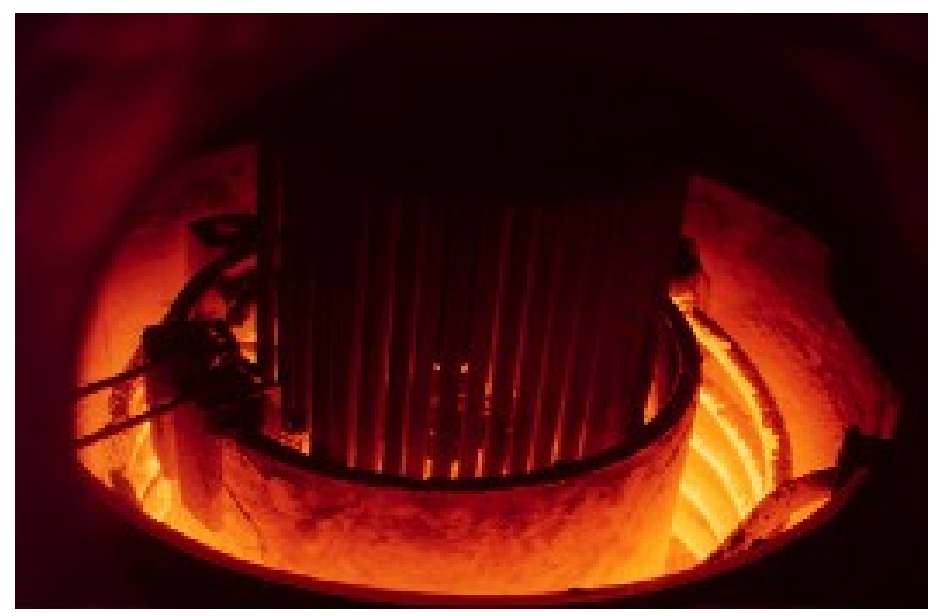

- Process development work has focused on metallic fuels.

- Metallic fuels are amendable to remote fabrication.

- Metallic fuels are capable of high burnups.
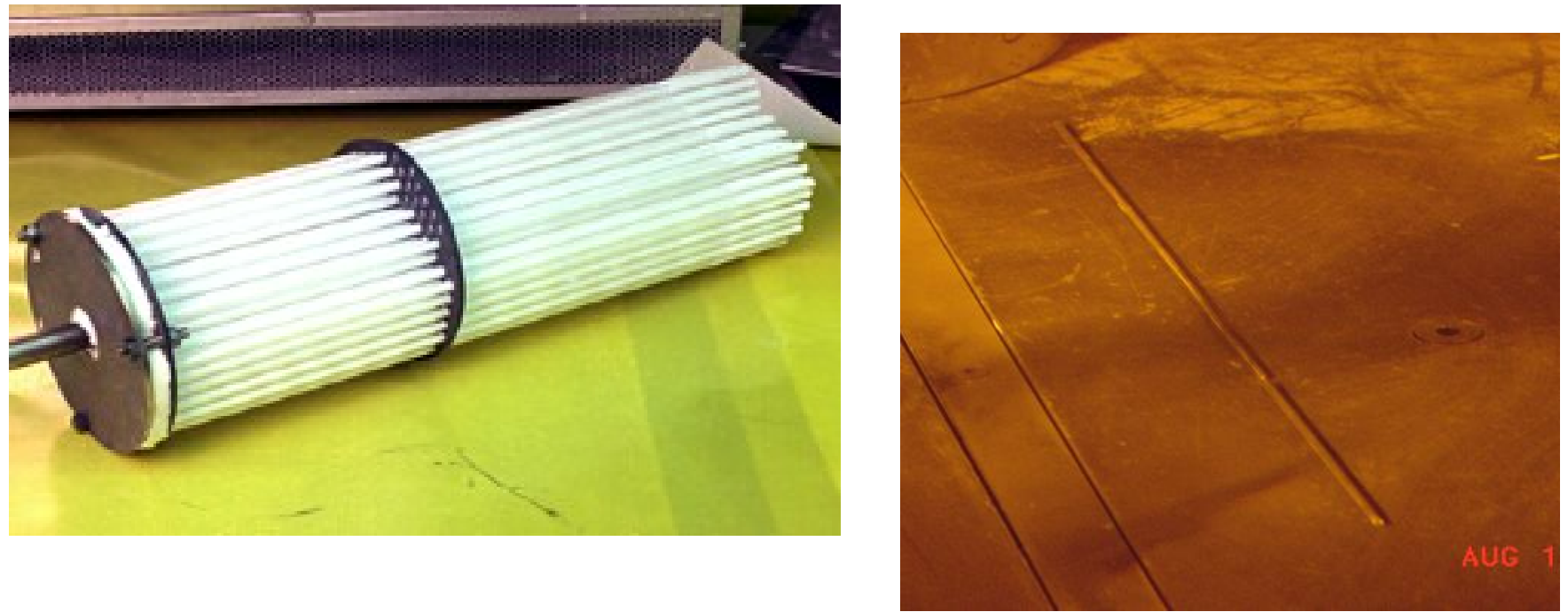


\section{Electrolytic Reduction Process Scale-Up}

- Pre-conceptual layouts of an engineering-scale electrolytic reduction vessel (20 to $40 \mathrm{~kg}$ oxide fuel batch size) based on a planar electrode configuration have been generated.

- A pre-conceptual design of a facility to treat spent oxide fuel has been prepared to help focus research on critical activities.

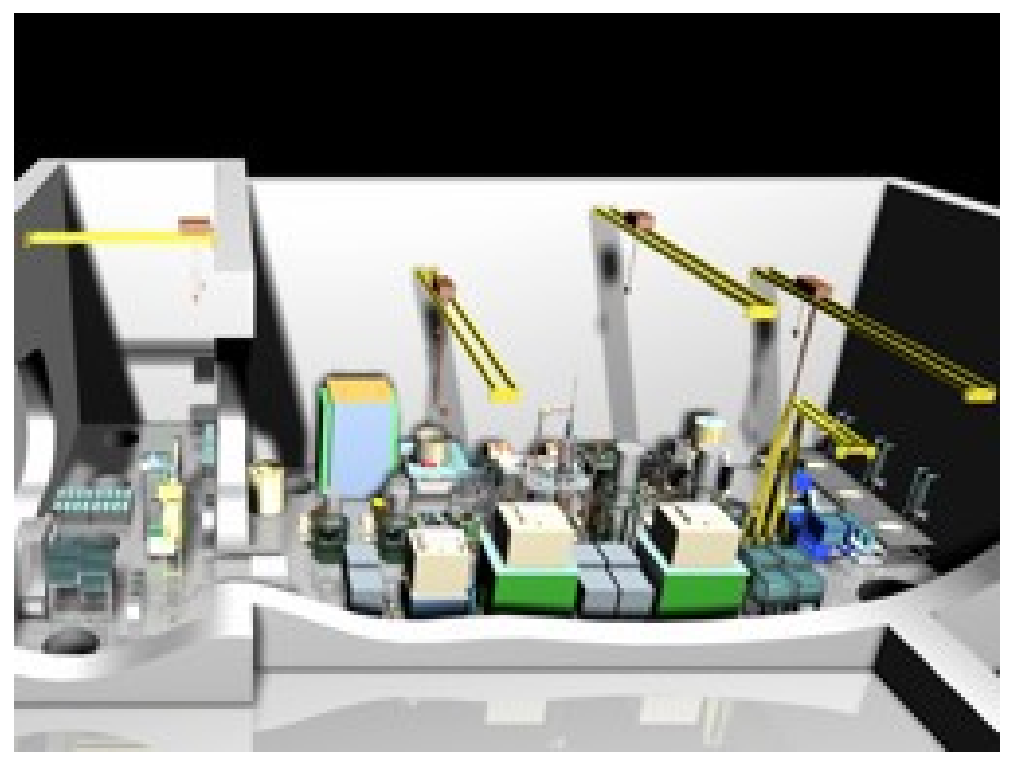




\section{Chemical Bases for Electrochemical Processing}

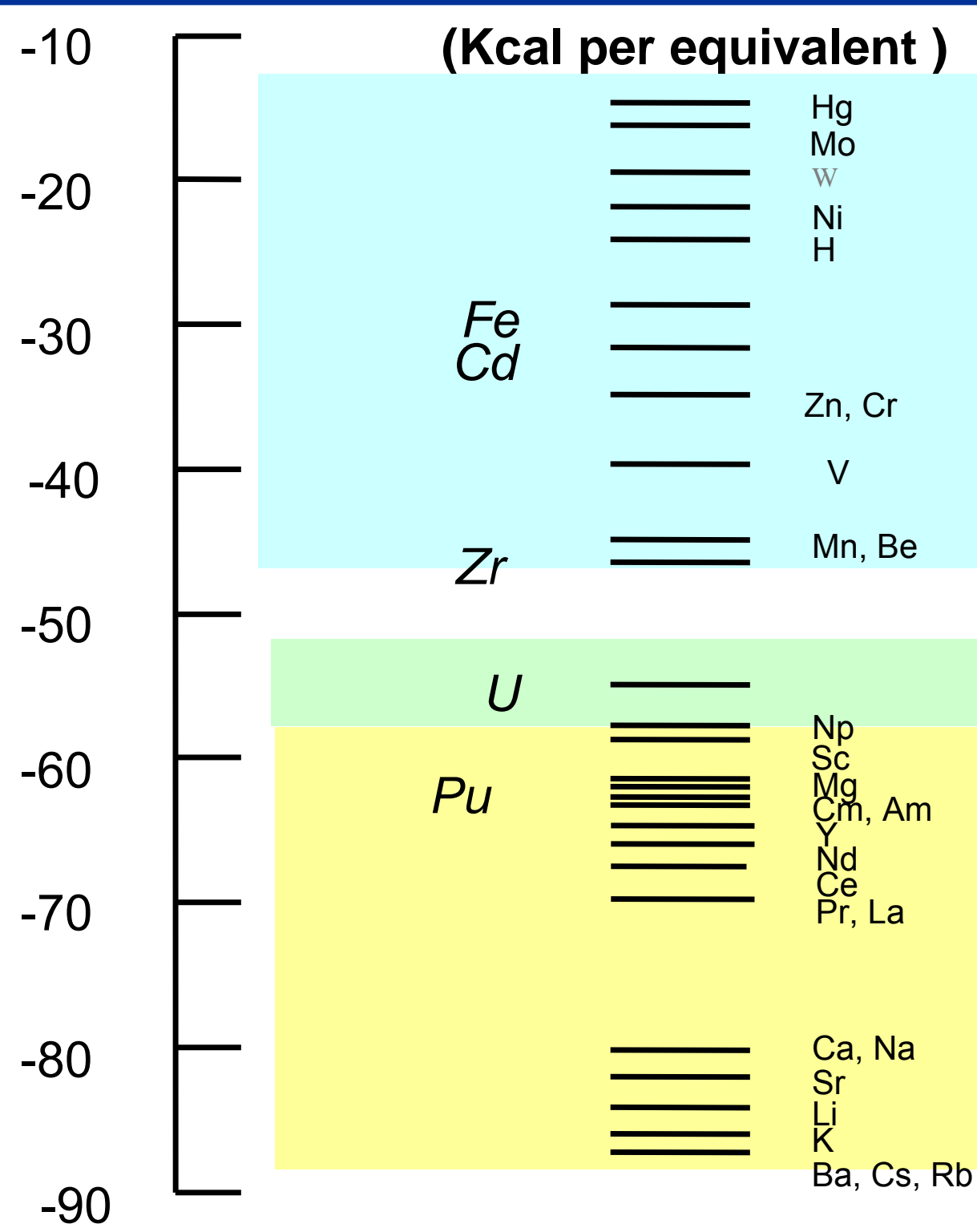

Uranium Product 


\section{High-Level Wastes from Electrochemical}

Processing

- Two high-level wastes are produced from electrochemical processing.

- A zeolite-based ceramic waste stabilizes fission products that form chlorides.

A stainless-steel-15\% zirconium metal waste stabilizes the cladding hulls and more noble fission products.

Unit Cell of Zeolite A : $\mathrm{Na}_{12}\left[\left(\mathrm{AlO}_{2}\right)_{12}\left(\mathrm{SiO}_{2}\right)_{12}\right]$
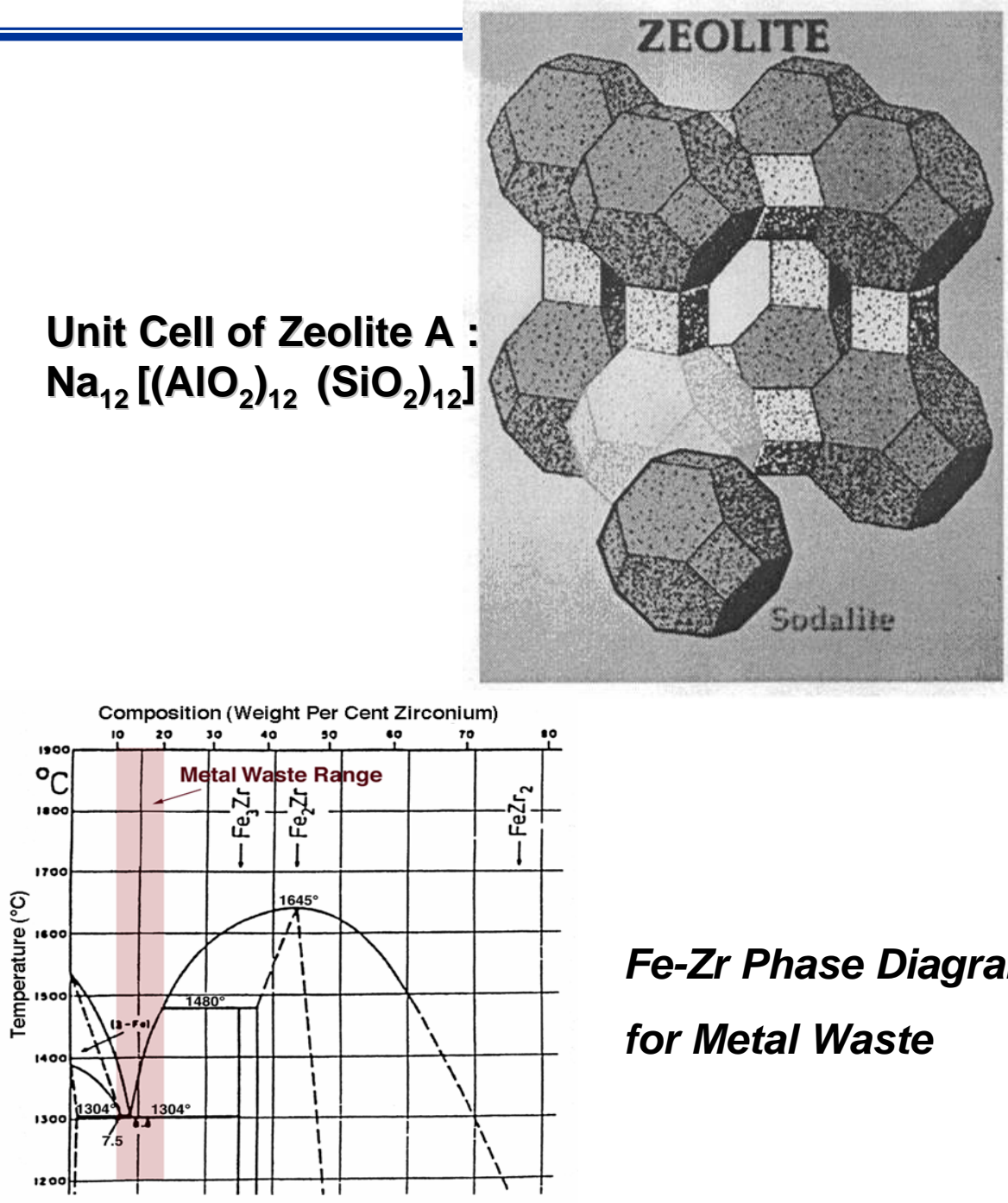

Fe-Zr Phase Diagram for Metal Waste 


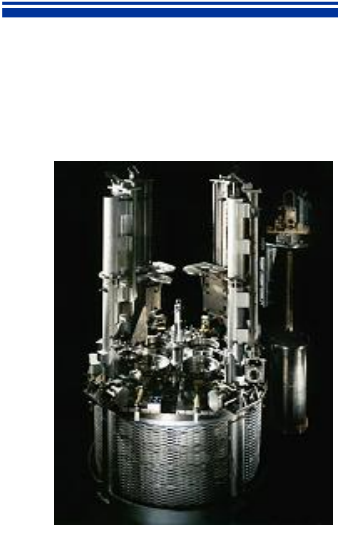

ELECTROREFINER

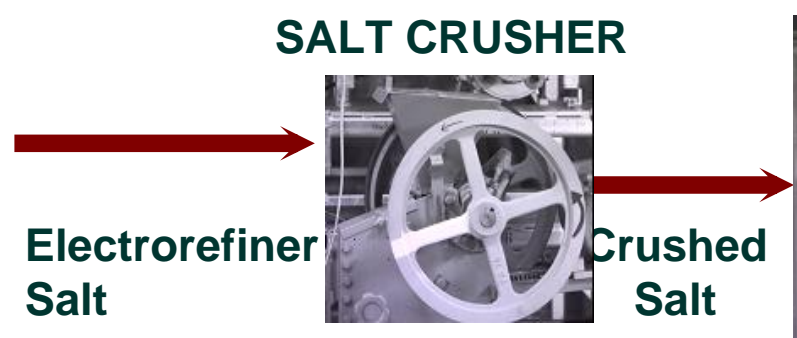

Salt

Salt

\section{MILL/CLASSIFIER}

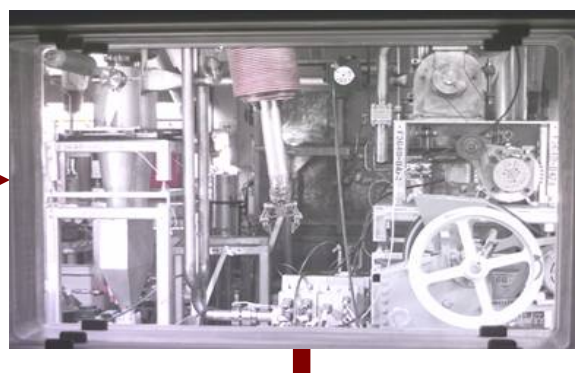

Ground

Salt

HEATED V-MIXER

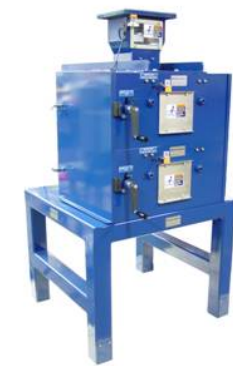

Dried

Milled

Zeolite

Zeolite

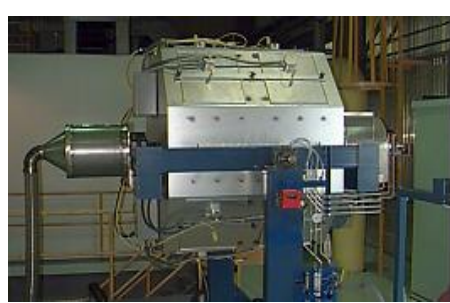

ZEOLITE MILL

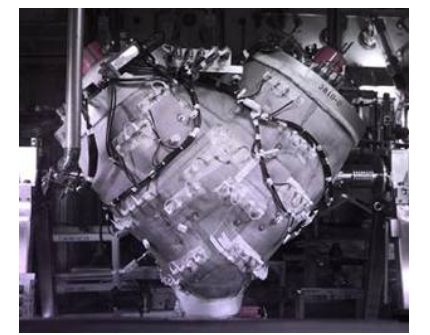

\section{Glass and}

Salt-Loaded

Zeolite

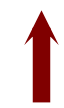

Glass added after

producing saltloaded zeolite

\section{FURNACE}

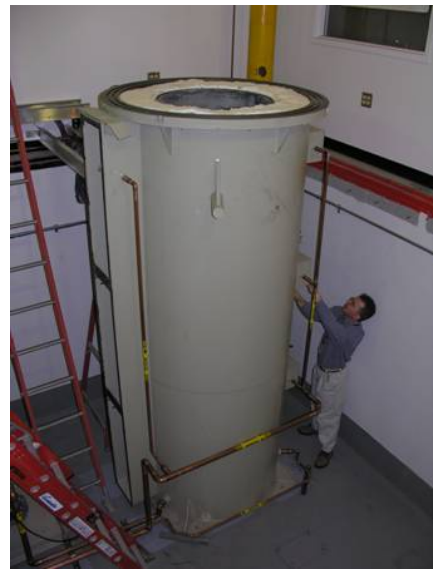

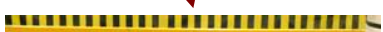
|| || ||| |||||||||

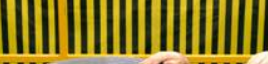

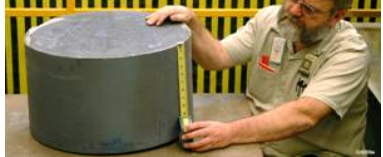

CERAMIC WASTE 


\section{Production Scale Ceramic Waste Form Furnace}

- Installation was completed in March 2005.

- Process development testing is ongoing.

- Maximum operating temperature is $1025^{\circ} \mathrm{C}$.

- Dimensions of the internal cylindrical cavity are:

- Diameter of $0.6 \mathrm{~m}(2 \mathrm{ft})$

- Length of $3 \mathrm{~m}$ (10 ft)

- System is capable of processing waste forms in excess of $320 \mathrm{~kg}$.

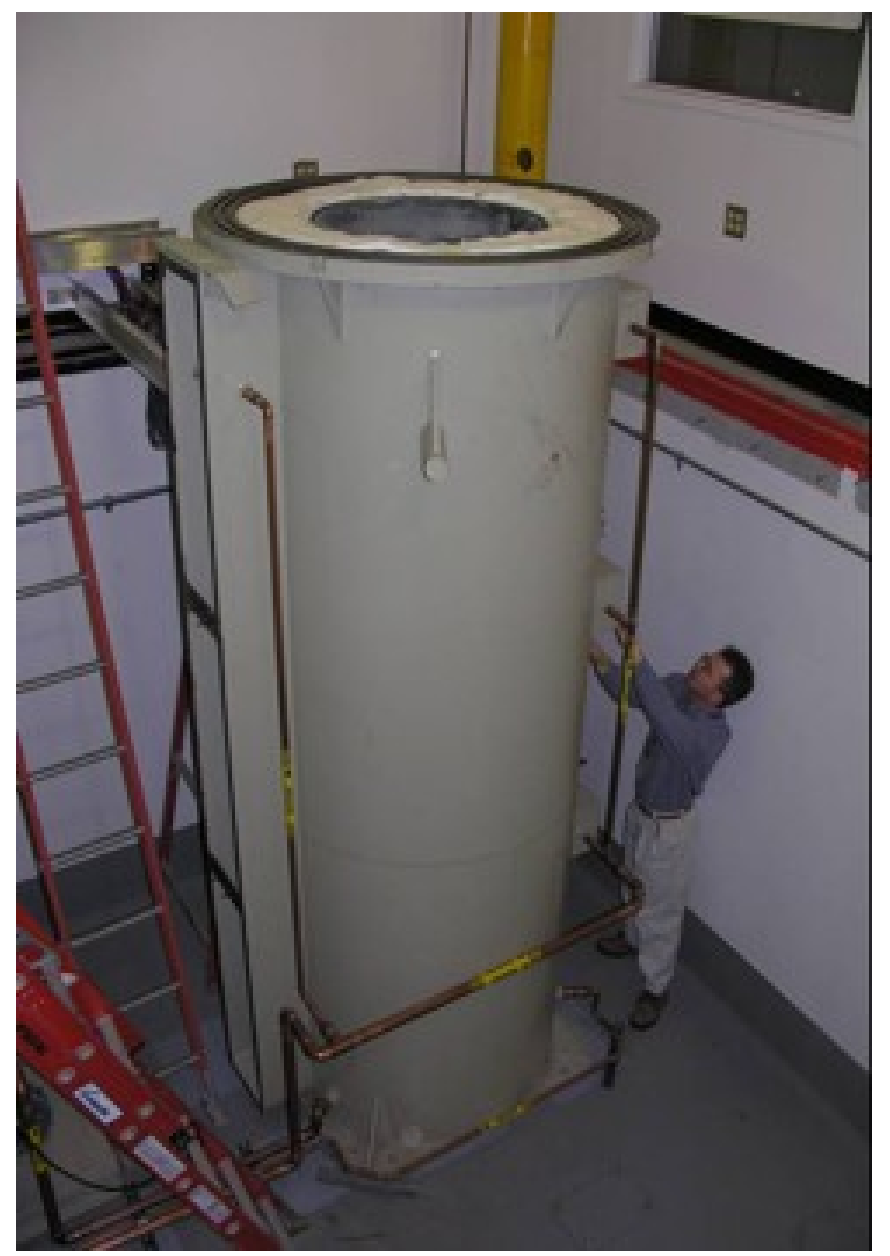




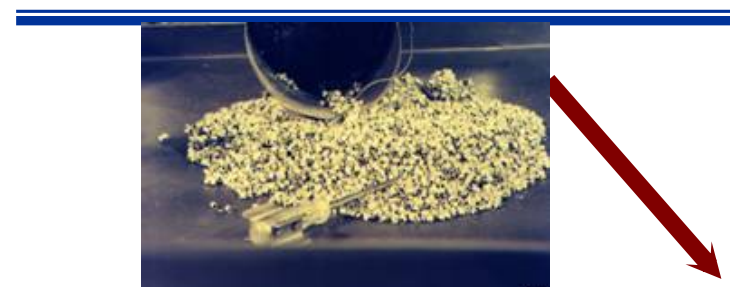

CLADDING HULLS
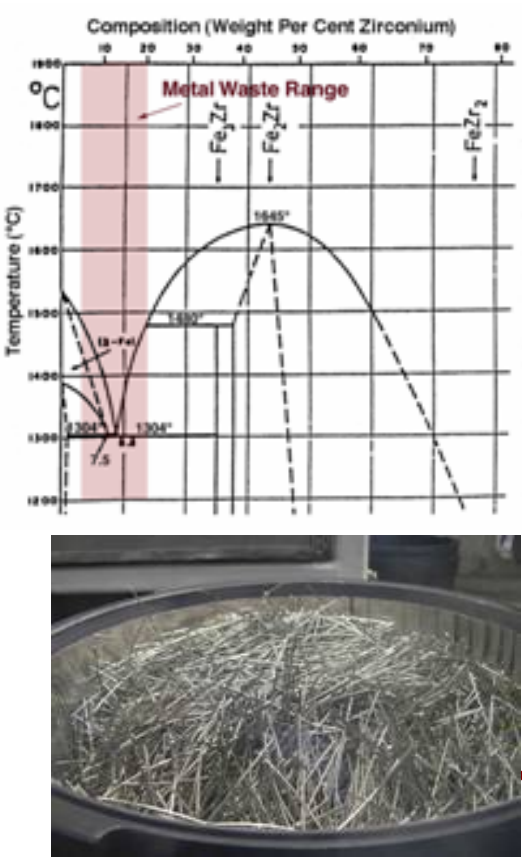

ZIRCONIUM
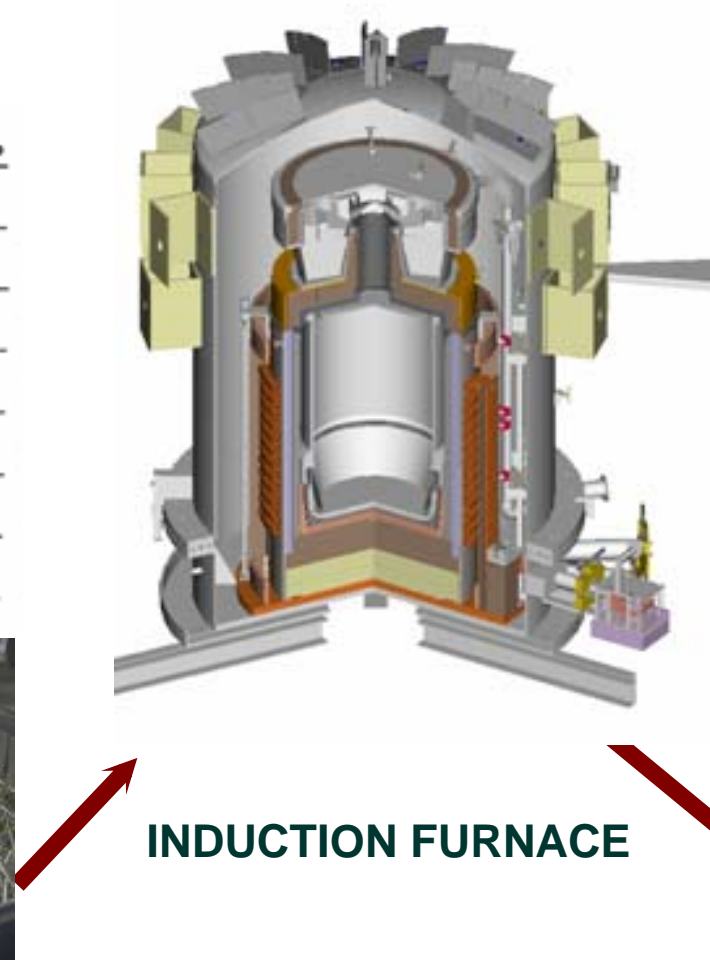

INDUCTION FURNACE
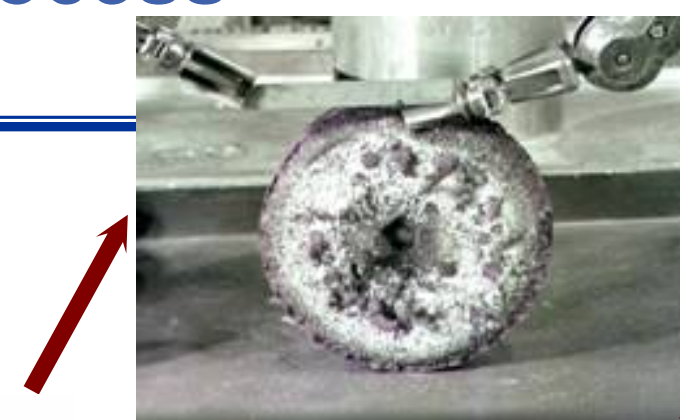

SALT

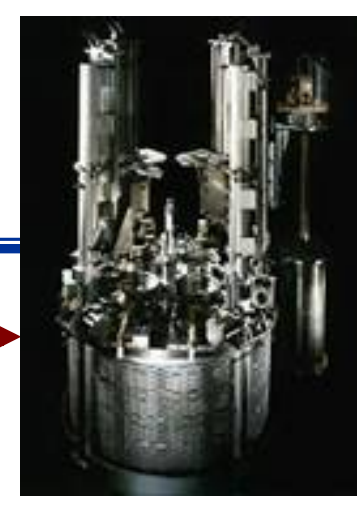

ELECTROREFINER

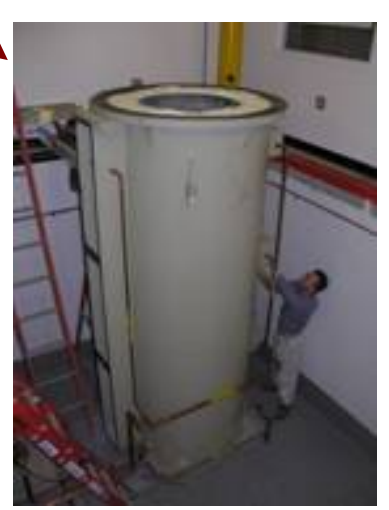

CERAMIC WASTE

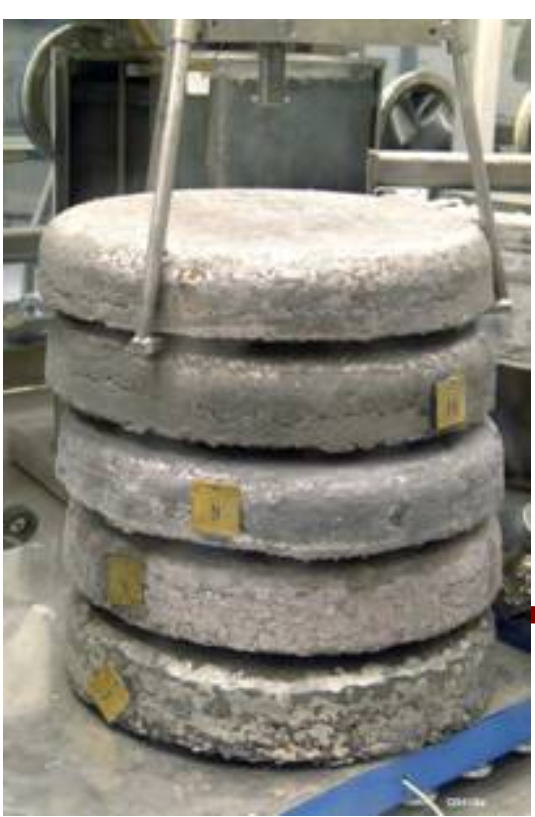

INGOTS

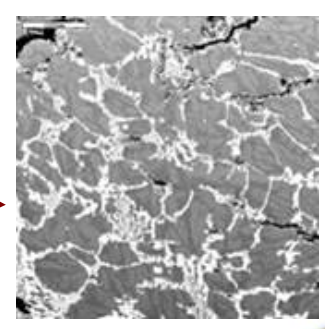

26 


\section{Metal Waste Development Activities}

- The Prototype Metal Waste Furnace is installed in a large inerted glovebox for processing testing.

- A series of test runs were completed to show equivalency of the Prototype to the Production Metal Waste Furnace in mockup.

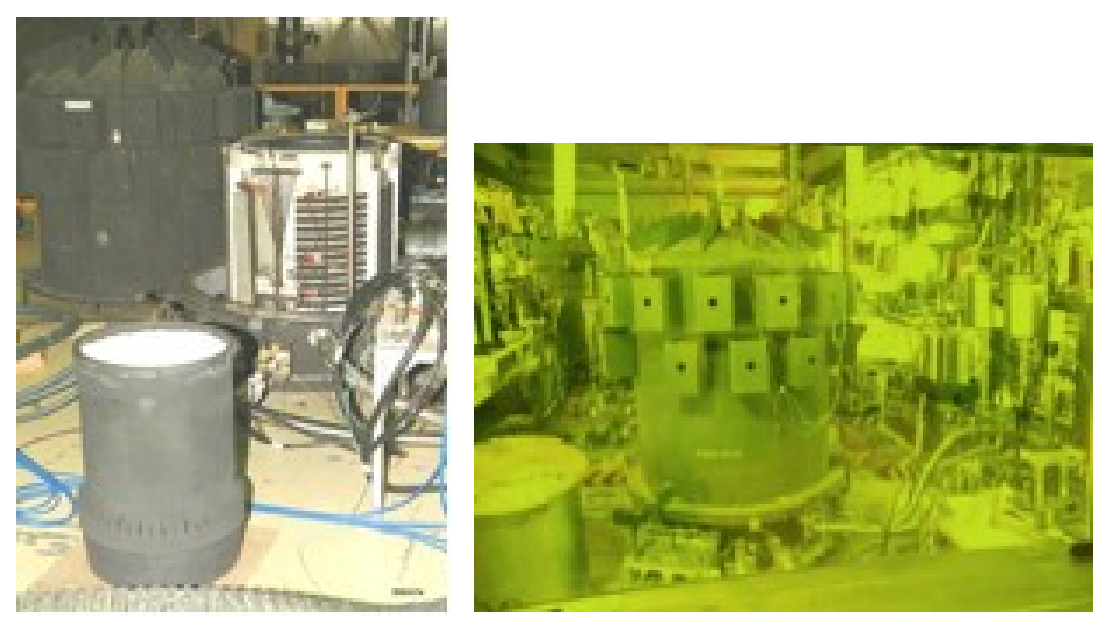

- The Prototype furnace is being used to

- Finalize the full-scale production process $(\leq 90 \mathrm{~kg})$ which will be used in cell

- Demonstrate the reliability of each process step, including sodium oxidation, salt distillation, and ingot formation prior to installation of the Production Furnace in a hot cell

- Validate acceptability of the produced ingots through 5 qualification runs

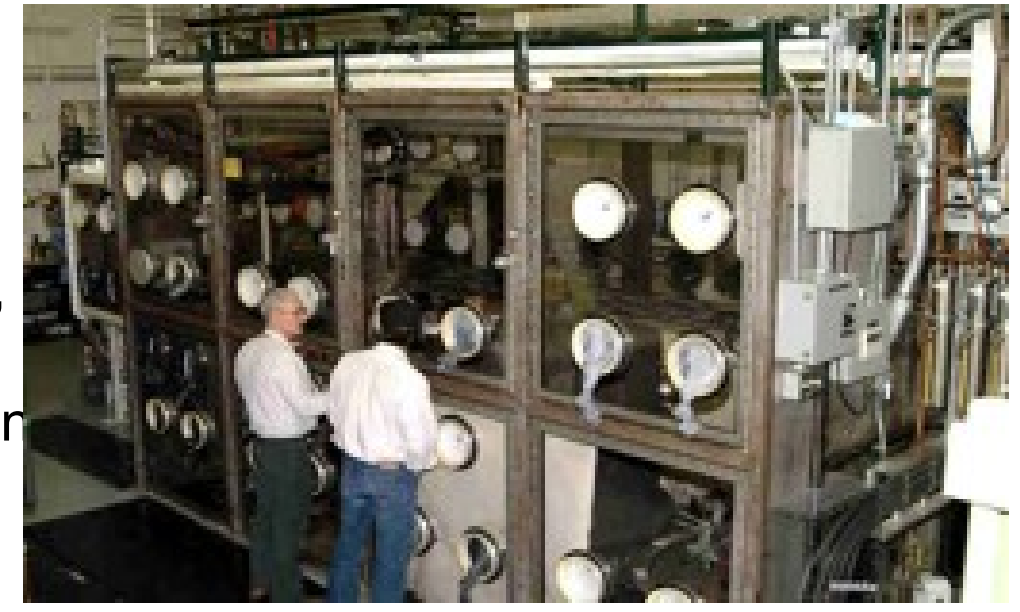




\section{Waste Form Qualification}

Waste forms were extensively characterized for qualification.

Waste form degradation models were developed for each waste form.

Repository performance assessment calculations to assess the impact of the waste forms on the repository were performed.

Report prepared for Congress addressing the disposal of the waste forms.

- DOE-NE, DOE-RW (Office of Civilian and Radioactive Waste Management), and DOE-EM (Environmental Management) concurred on disposal plans.

Waste forms are now classified formally as high-level wastes in DOE orders. 
A data package was compiled for the ceramic and metal waste forms. This document included 71 reports containing data and analyses needed to support acceptance into Yucca Mountain. Issues addressed in the reports include:

- waste form specifications

- waste form characteristics and degradation data,

- production information

- radiation effects

- product consistency

- impact of processing on waste characteristics

- leach behavior

- radionuclide distribution

- modeling of degradation behavior 


\section{International Collaborations}

- International collaborations on aspects of electrochemical processing have occurred with

- Japan

- Korea

- France

- United Kingdom

- Australia
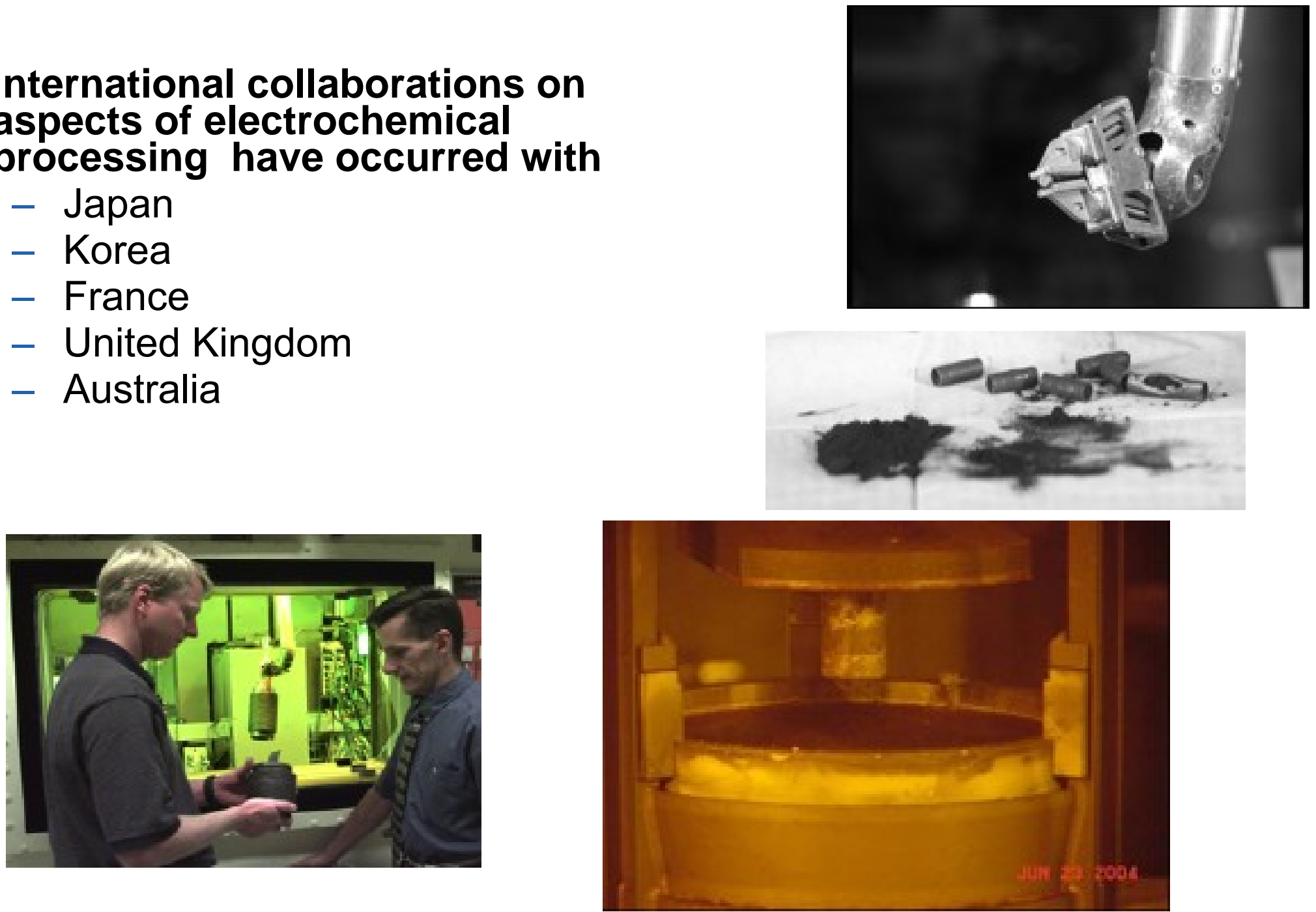


\section{International Pyroprocessing Conference}

- INL hosted first International

Pyroprocessing Research Conference in August.

- There were approximately 75 attendees, 34 from outside US.

- Papers were presented from 7 countries:

- US

- ROK

- Japan

- France

- United Kingdom

- India

- Russia

70 presentations were made.

Next conference will be in Korea.

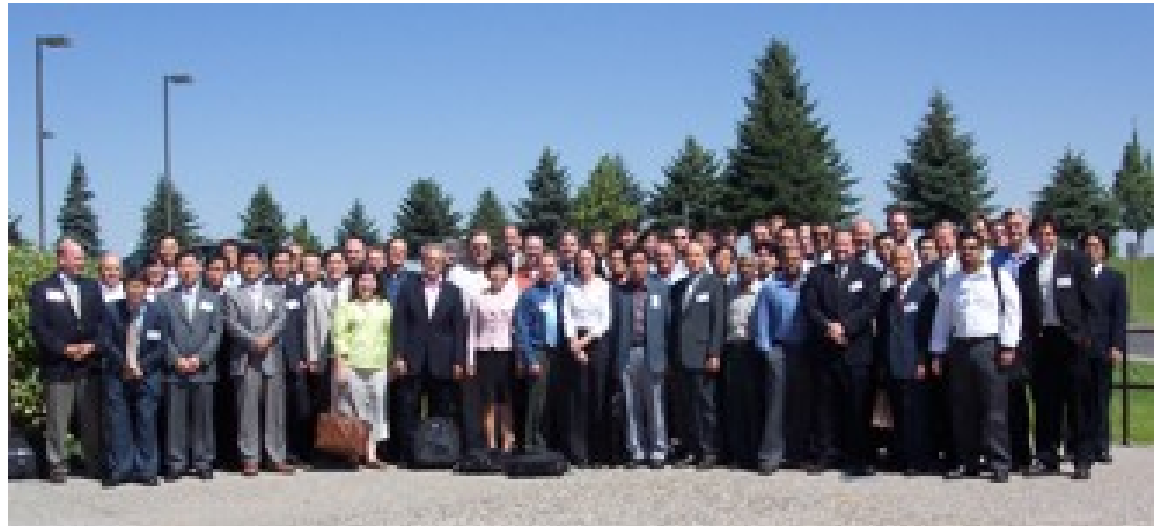


- Electrochemical fuel cycle can be used for recycle of fast reactor spent fuel and treatment of thermal reactor spent fuel to product a feed for fast reactors.

- Electrochemical processing of spent metallic nuclear fuel has been successfully demonstrated at engineering scale.

- Critical infrastructure exits domestically to support development and demonstration of technology.

- Work activities are focused on research, development, and demonstration in support of GNEP.

- Development and qualification of high-level wastes are integrated with overall process development. 


\section{GNEP Waste Form Technology Development}

Global Nuclear Energy Partnership
John D. Vienna, PhD

Pacific Northwest National Laboratory, Richland, WA

DOE/NRC Seminar No. 1 in Topical Series on Advanced Waste Management and Waste Forms

April, 2008 


\section{Outline}

Aqueous Waste Streams and Waste Forms

Electrochemical Waste Streams and Waste Forms

- Technology Readiness Assessment

- Testing Approaches/Waste Form Qualification 


\section{Aqueous Process \& Waste Streams}

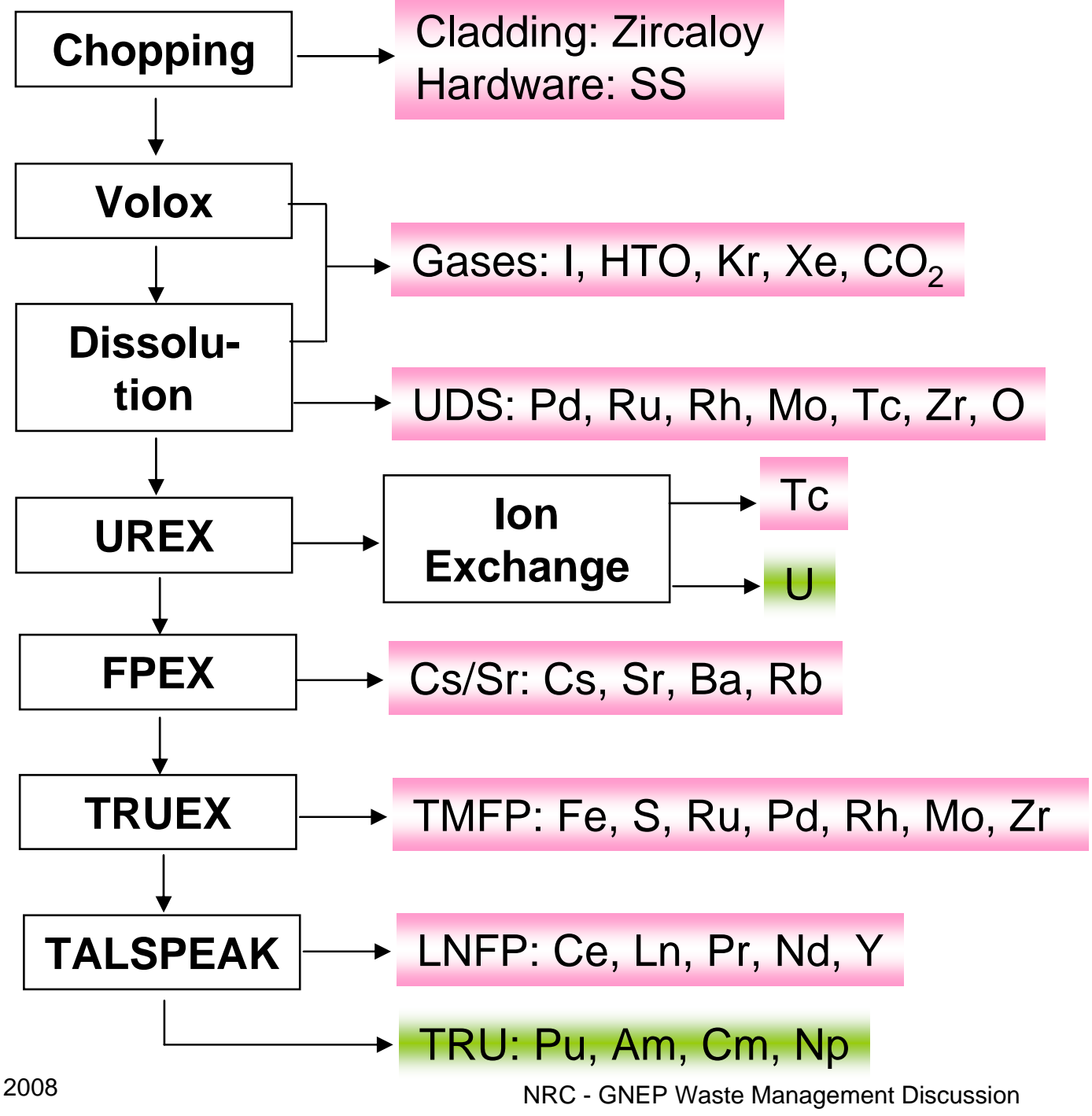

LLW:

Solvents

PPE

RBT

lab returns off-gas... 


\section{Compacted Metals}

\section{- Hulls}

- $<1 \%$ fuel after voloxidation and filter

- leaching removes all measurable residual fuel meat

- likely to be $>100 \mathrm{nCi}$ TRU/g due to activation of $U$ impurities in Zircaloy $\rightarrow$ GTCC

\section{- Hull/hardware compaction}

- proven technology employed worldwide

- potential for encapsulation in metal matrix

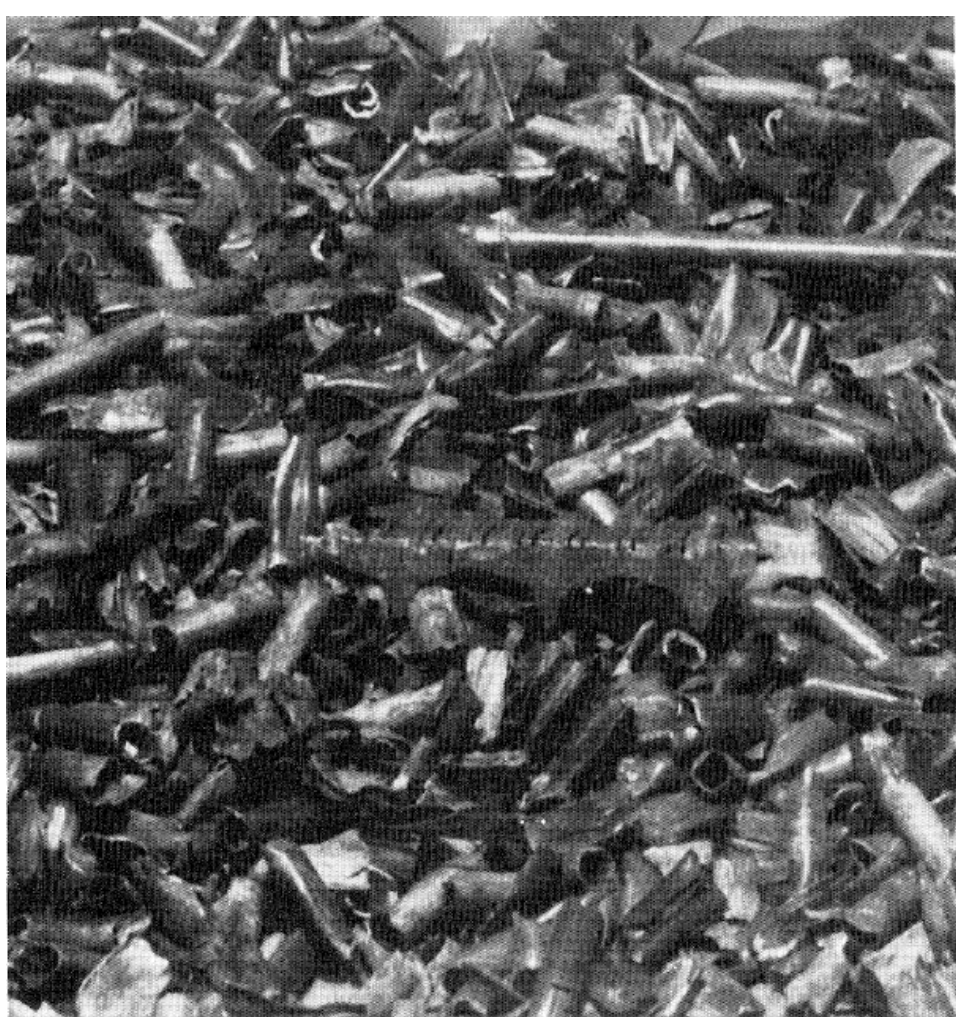

Zircaloy and SS Scrap from Cogema Plant, LaHauge from: Management of Cladding Hulls and Fuel Hardware,Tech report 258, IAEA, Vienna, 1985 


\section{Aqueous Primary Off-gas Streams}

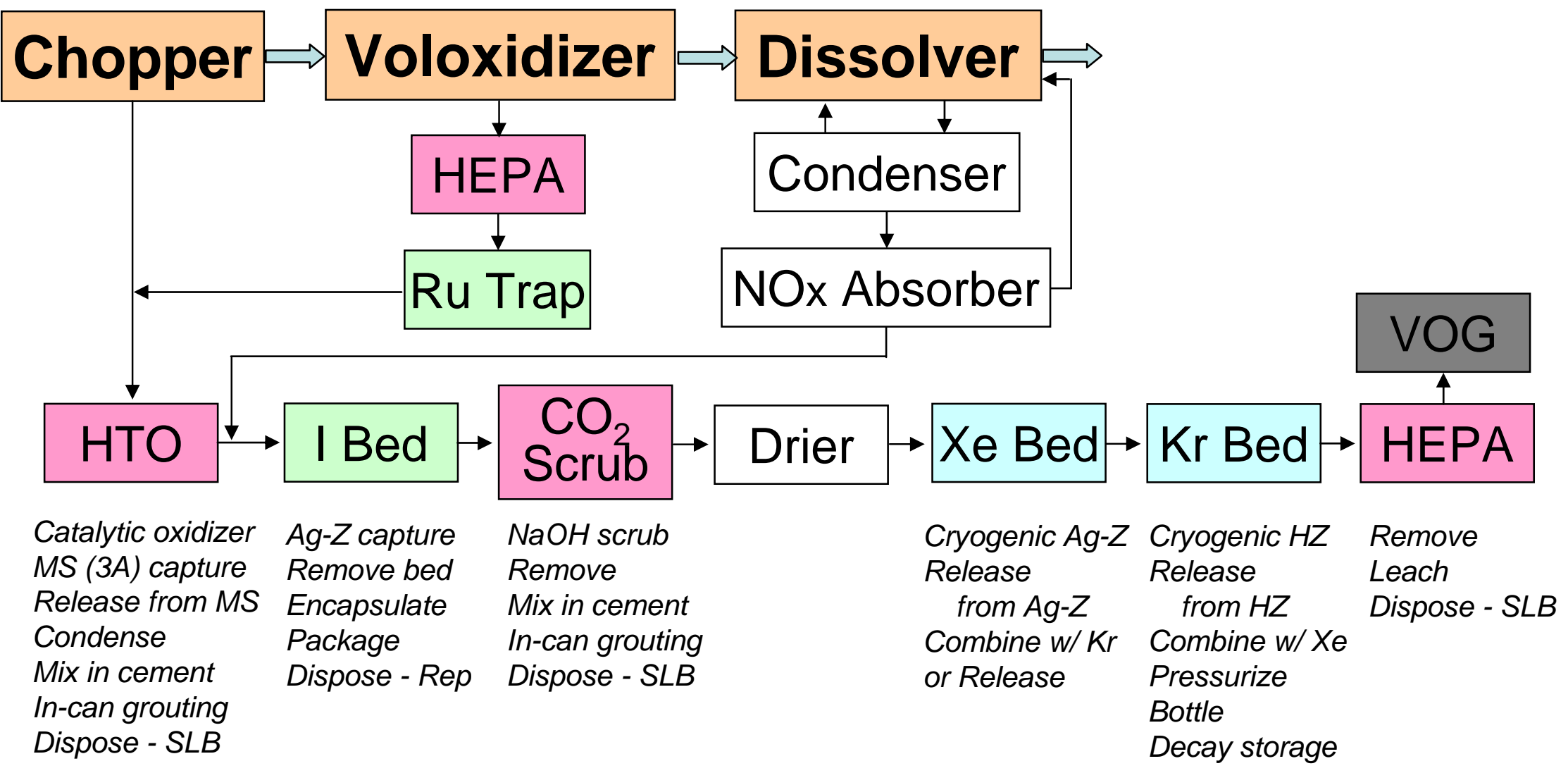




\section{lodine on Ag-Z}

Mordenite selected as baseline getter/waste form

- demonstrated at pilot scale in US

- adopted for use in Hanford WTP

- high DF and loading as getter

- nitrate tolerant

- base of a good waste form

- Likely to be encapsulated

- to form monolith

- improve leach resistance

- geo-polymer at low temperature $\left(<200^{\circ} \mathrm{C}\right)$

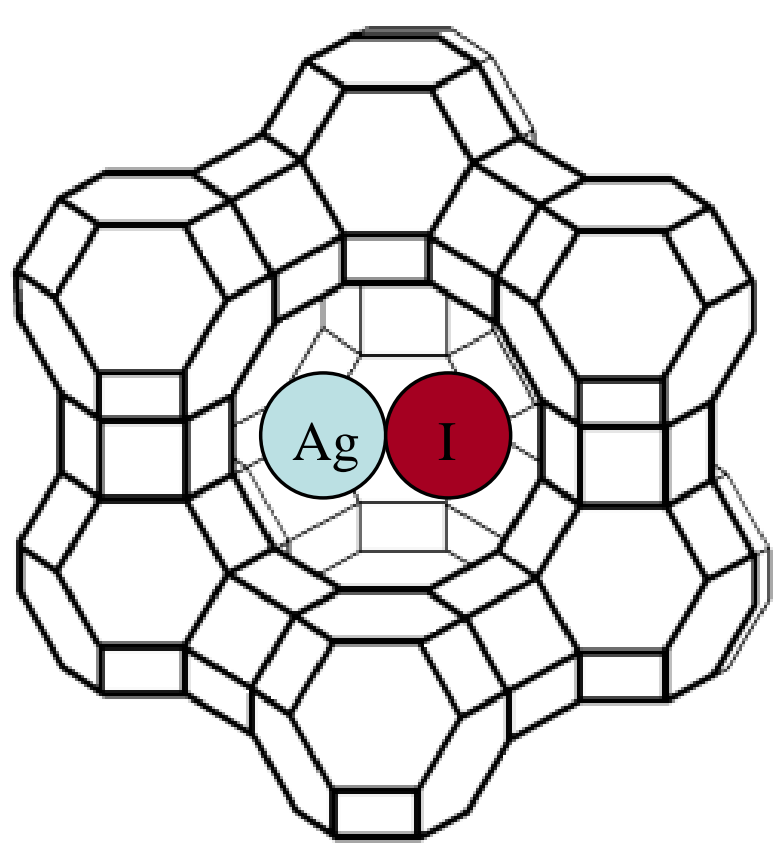

- low temperature glass $\left(<500^{\circ} \mathrm{C}\right)$ 


\section{Aqueous Tc and UDS}

\section{Dissolver Clarifier}

Filter UDS solids, blend with other metal streams

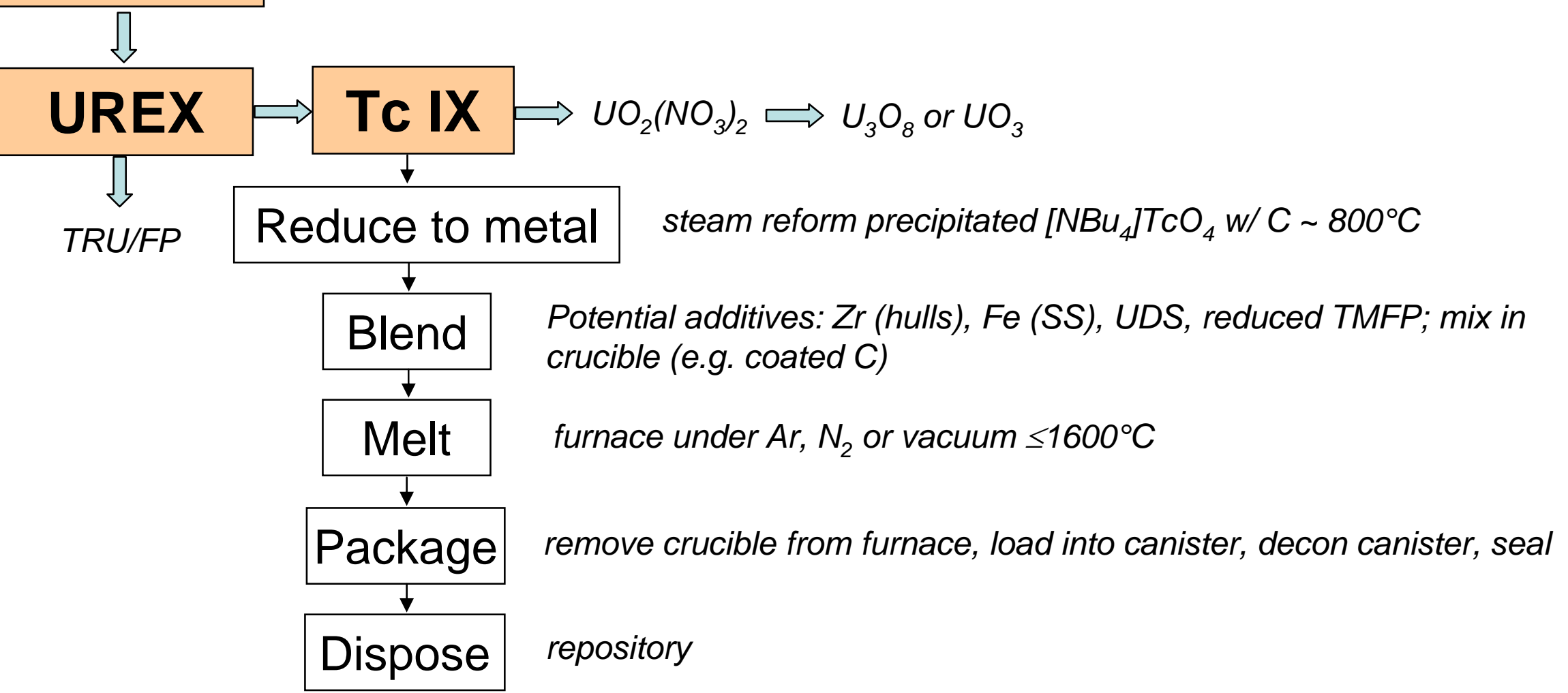




\section{Metal Waste Form}

Based on Zr-Fe alloys

- solubility of Tc, PGM, Mo, and other impurities in durable phases

- corrosion rate similar to alloy 22 and SS316

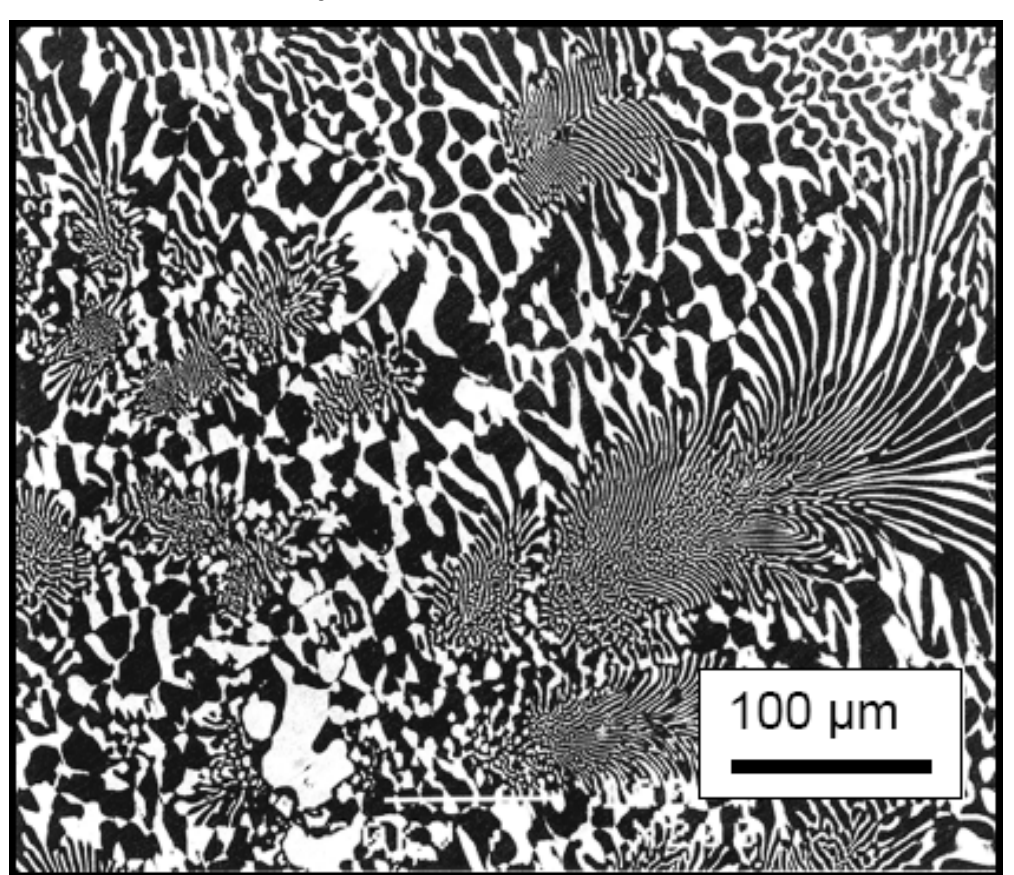

$2000-7$

${ }_{1855^{\circ} \mathrm{C}} \mathrm{Zr}-8 \mathrm{SS}$

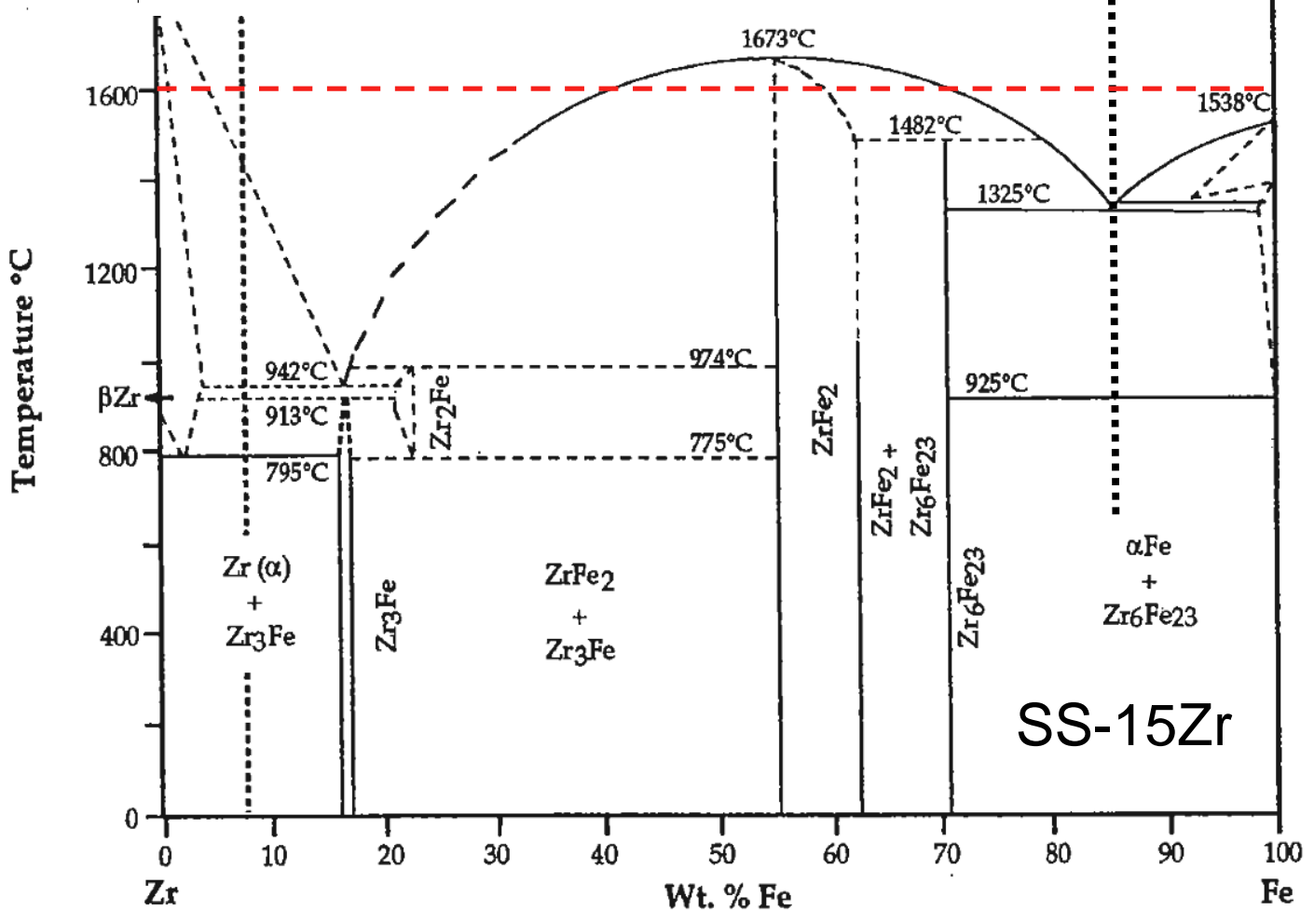

Testing to Evaluate the Suitability of Waste Forms

Developed for Electrometallurgically-treated Spent Sodiumbonded Nuclear Fuel for Disposal in the Yucca Mountain Repository, ANL-05/43, Argonne National Laboratory, 2005 


\section{Metal Waste Form Corrosion}

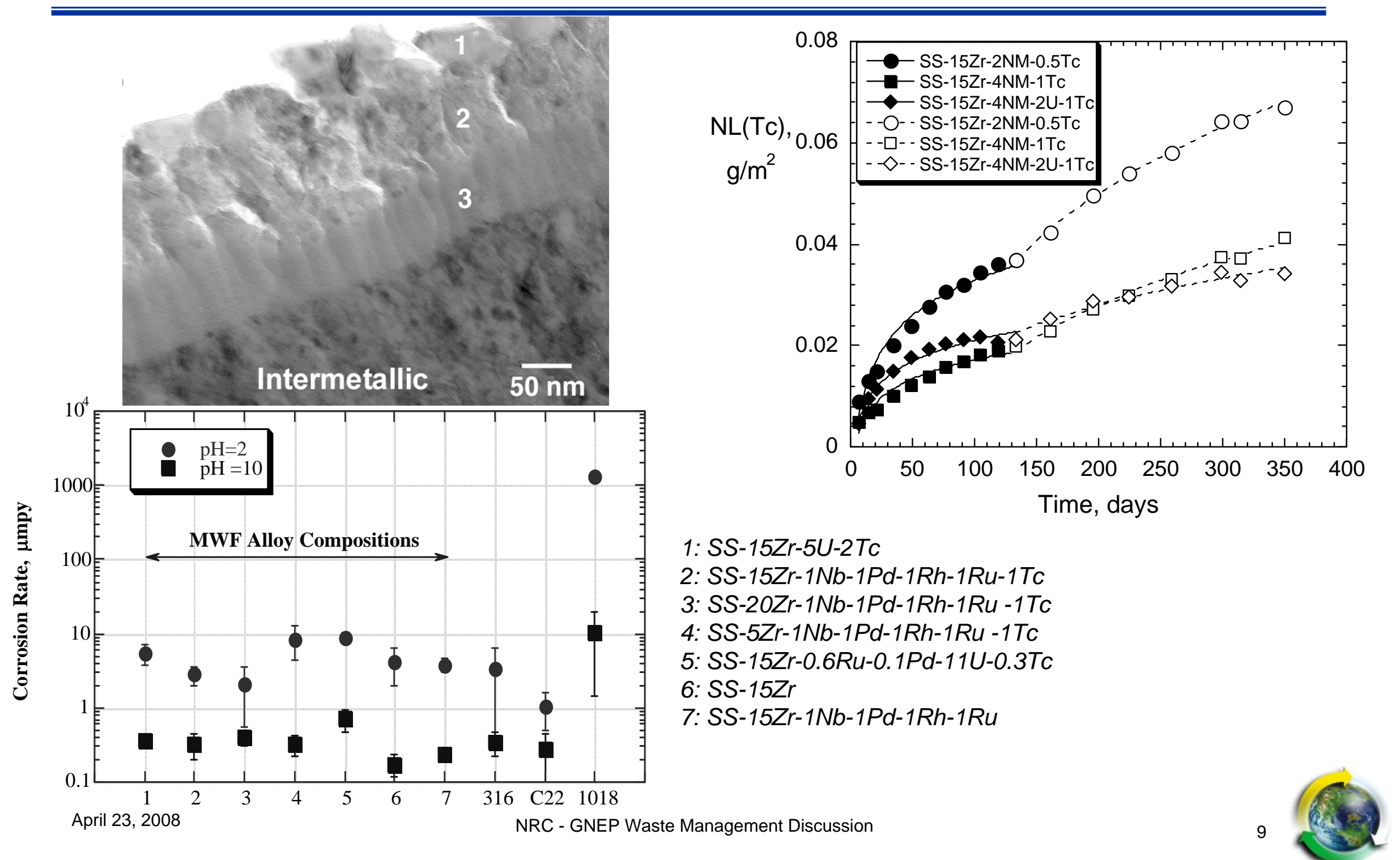




\section{Aqueous Cs/Sr}

\section{FPEX $\Rightarrow$}

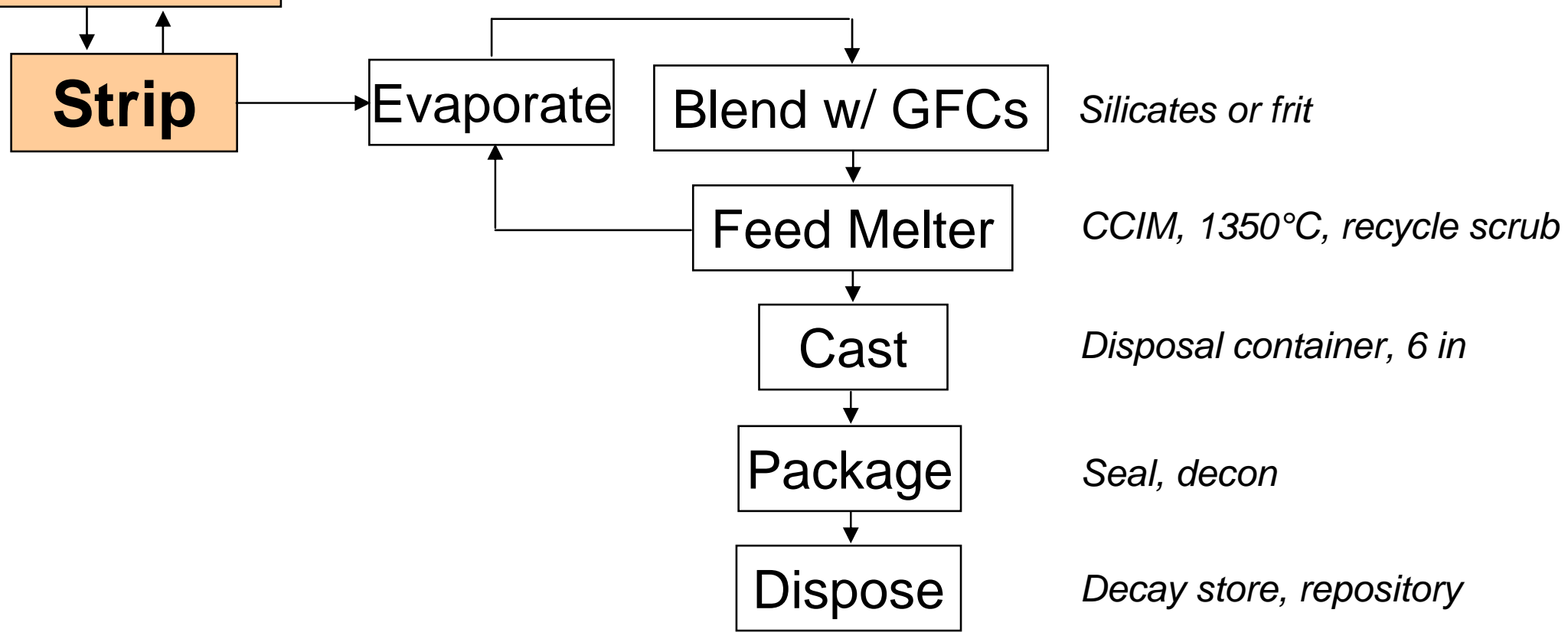




\section{Cs/Sr Glass}

Based on well developed and demonstrated technology

Alumino-silicate glasses and glass ceramics

- $\mathrm{Fe}_{2} \mathrm{O}_{3}$ or $\mathrm{SnO}_{2}$ used for charge compensation, e.g.:

$$
\begin{aligned}
& \mathrm{SrO}+\mathrm{Fe}_{2} \mathrm{O}_{3} \stackrel{\beta \beta}{\longrightarrow} \mathrm{ZrO}_{2}+2 \mathrm{FeO} \\
& \mathrm{Cs}_{2} \mathrm{O}+\mathrm{Fe}_{2} \mathrm{O}_{3} \stackrel{\beta \gamma}{\longrightarrow} 2 \mathrm{BaO}+2 \mathrm{FeO}
\end{aligned}
$$

- 30 to 64 wt\% waste loading

- density between 3 and $4 \mathrm{~g} / \mathrm{mL}$
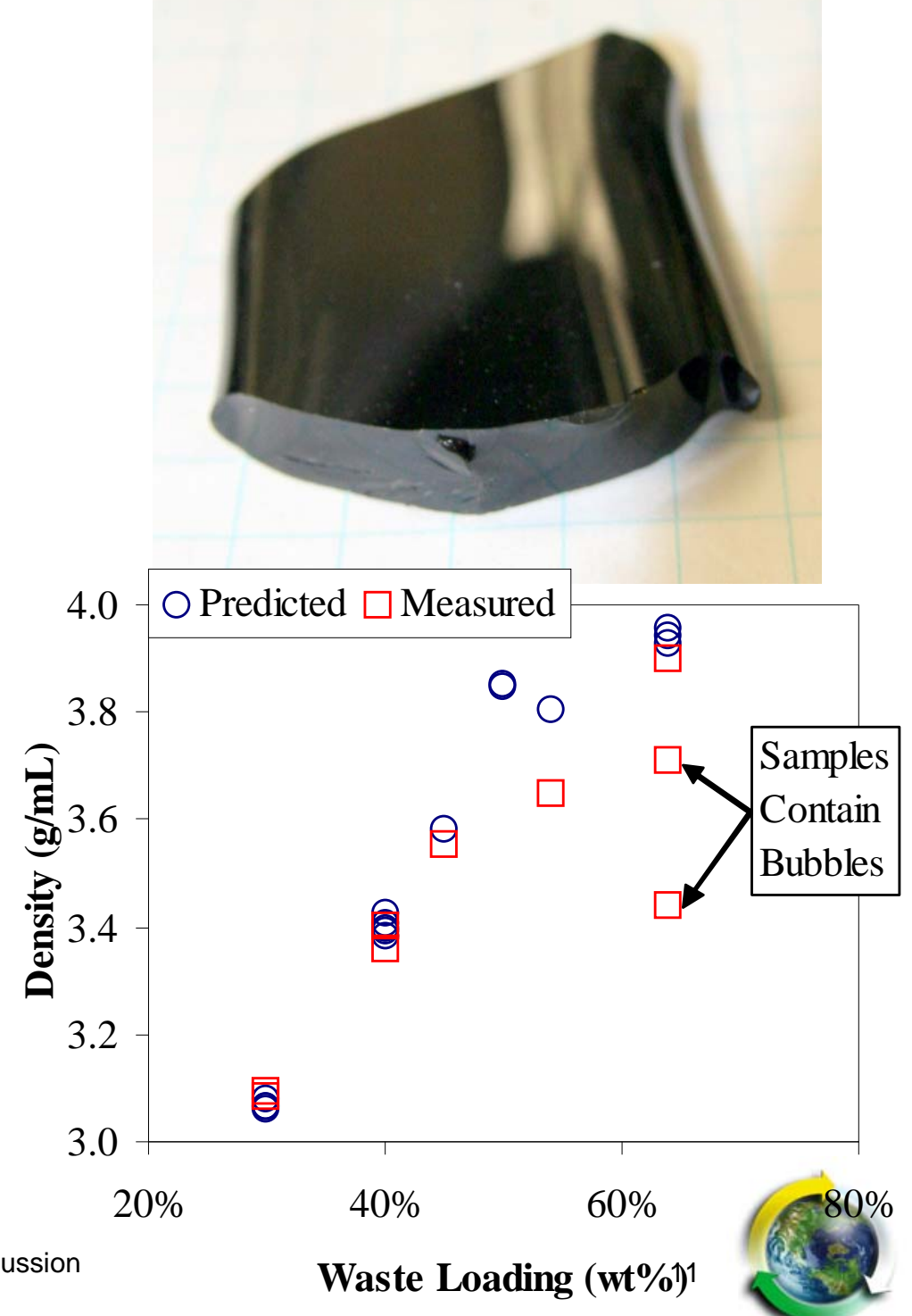

Waste Loading (wt $\%)^{1}$ 


\section{Cs/Sr Glass/Glass Ceramic}
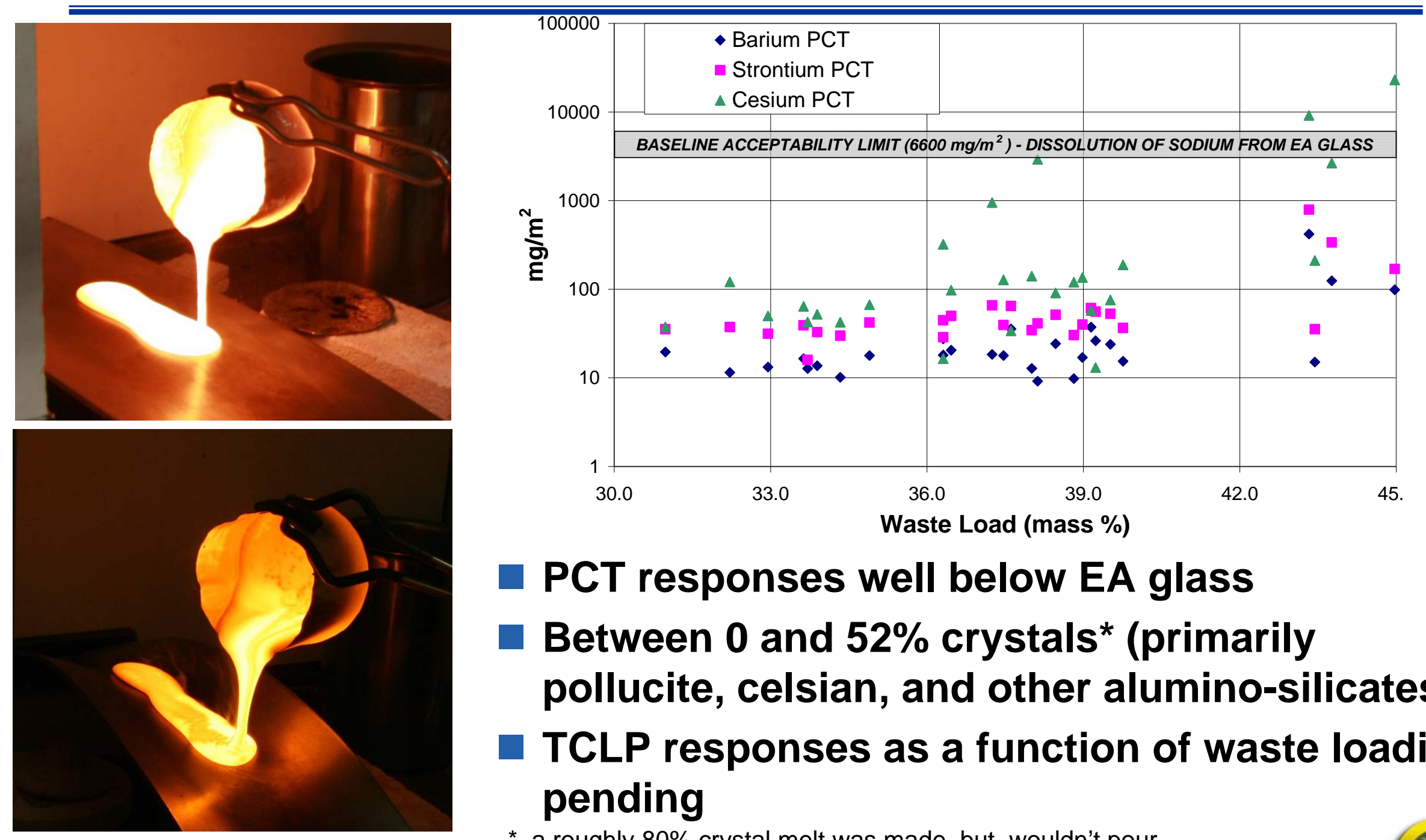

- PCT responses well below EA glass

Between 0 and $52 \%$ crystals* (primarily pollucite, celsian, and other alumino-silicates)

- TCLP responses as a function of waste loading pending 


\section{Aqueous Transition Metal Fission Products}

\section{TRUEX Raffinate}


- Contain significant concentrations of platinum group metals (PGM) not soluble in glass

Alloy properties the same as earlier described metal

Adds little to volume of metal waste form volume, but, would increase glass volume by $\sim 3 x$

Requires reduction from nitrate solution $\rightarrow$ electrochemical reduction is being investigated 


\section{Aqueous Lanthanide Fission Products Glass}

\section{TALSPEAK Product}

Blend

$\downarrow$

\section{Feed Melter}

$\downarrow$

Cast

$\downarrow$

Package

$\checkmark$

Dispose
Glass forming chemicals, (potentially Cs/Sr and/or TMFP)

HWIM, $1350^{\circ} \mathrm{C}$ (or CCIM if w/ Cs/Sr and/or TMFP)

Disposal container

Seal, decon

Repository 


\section{Lanthanide Glass}

Based on well developed and demonstrated technology

- developed for SRS Am/Cm treatment

- chosen and demonstrated for PIP

Loadings at $60 \mathrm{wt} \%$ (oxide basis)

Outstanding durability
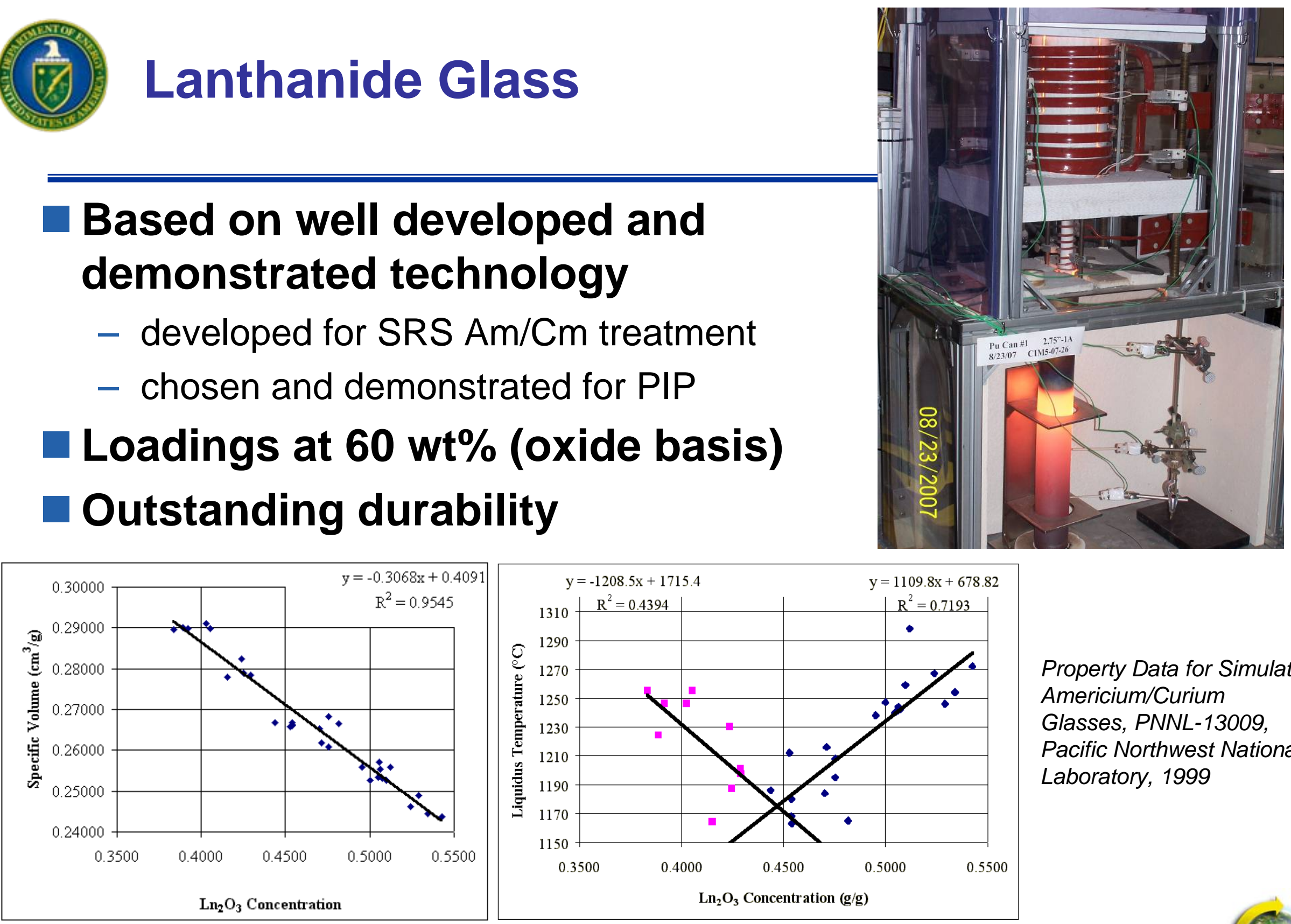

Property Data for Simulated Americium/Curium Glasses, PNNL-13009, Pacific Northwest National Laboratory, 1999 


\section{Electrochemical Process \& Waste Streams}

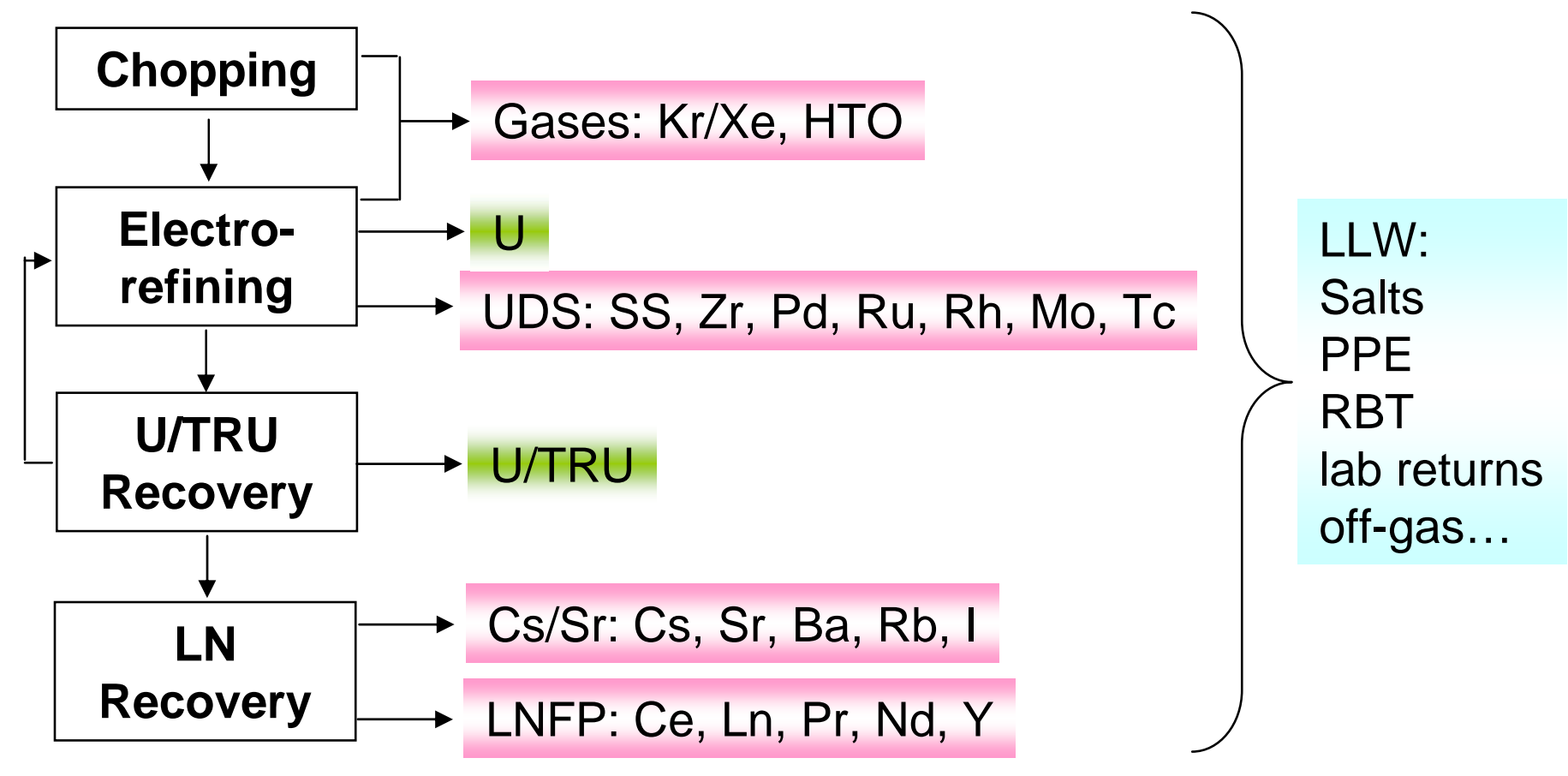




\section{Electro-Chemical Metallic Wastes}

\section{Electro-Refiner}

$\downarrow$

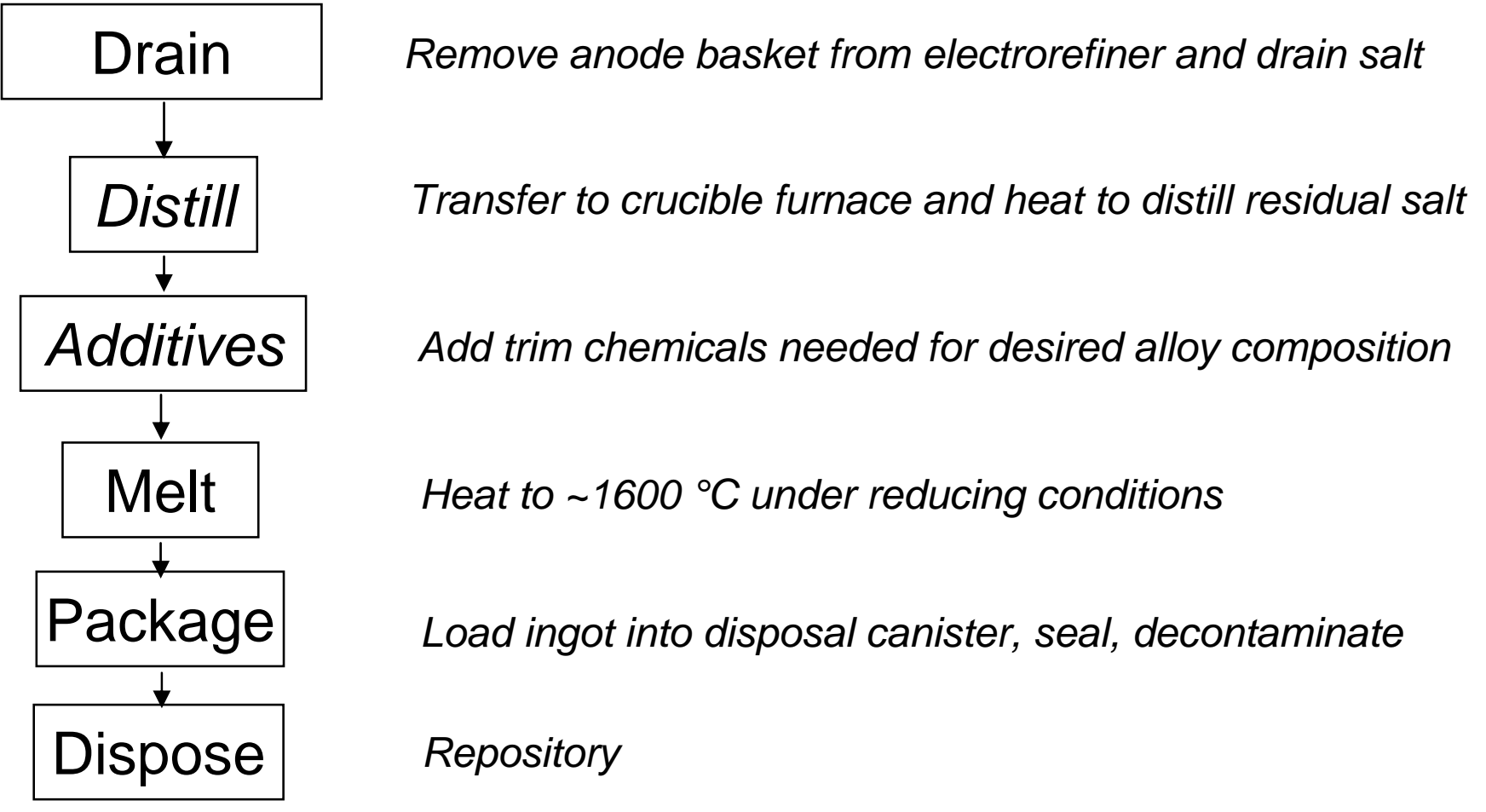


- Developed for EBR-II fuel and blankets

- Demonstrated at full scale

\section{- Same SS-15 Zr discussed for aqueous} wastes

- high durability

- qualification testing well underway

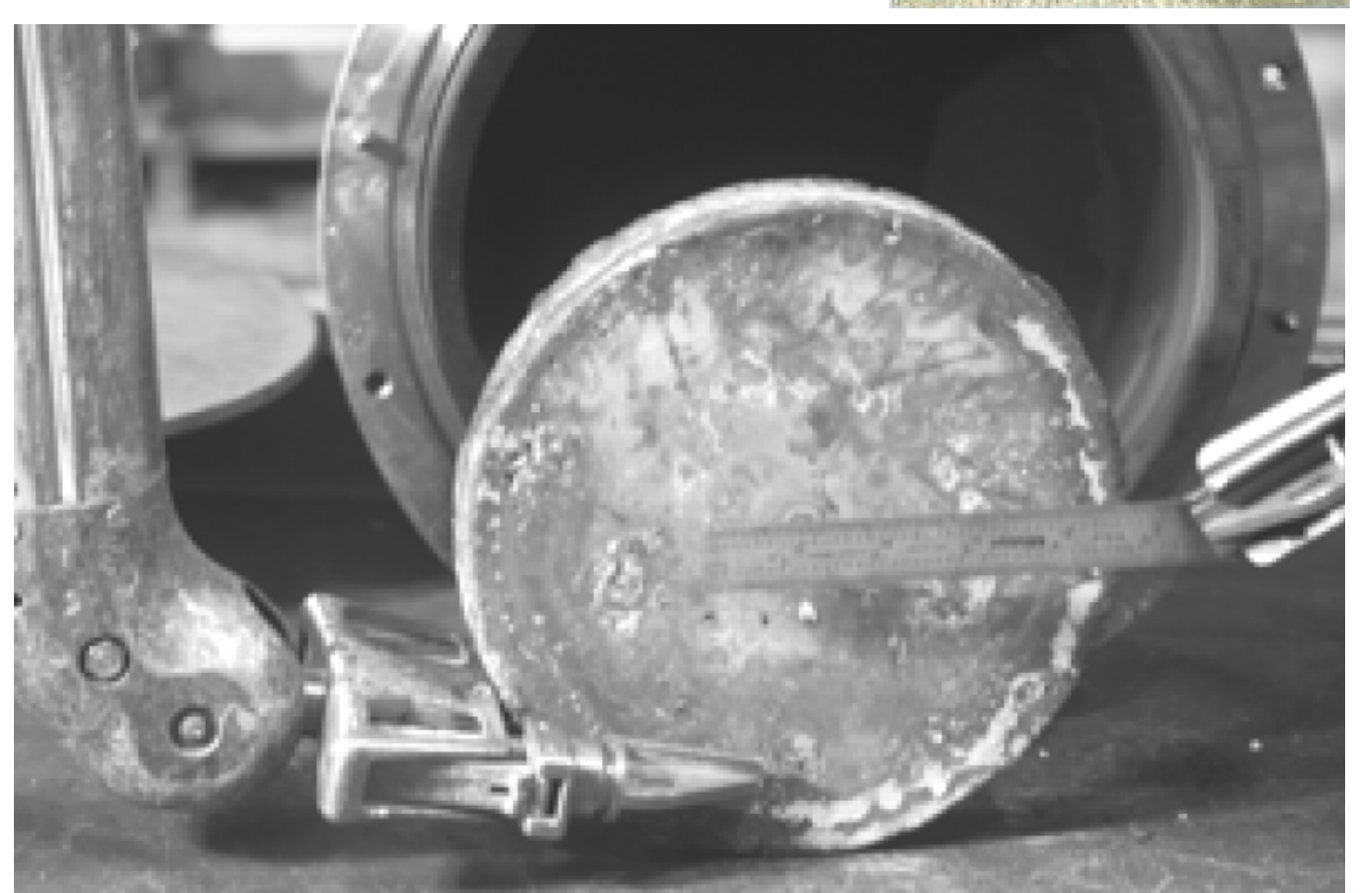




\section{Electro-Chemical Fission Products}

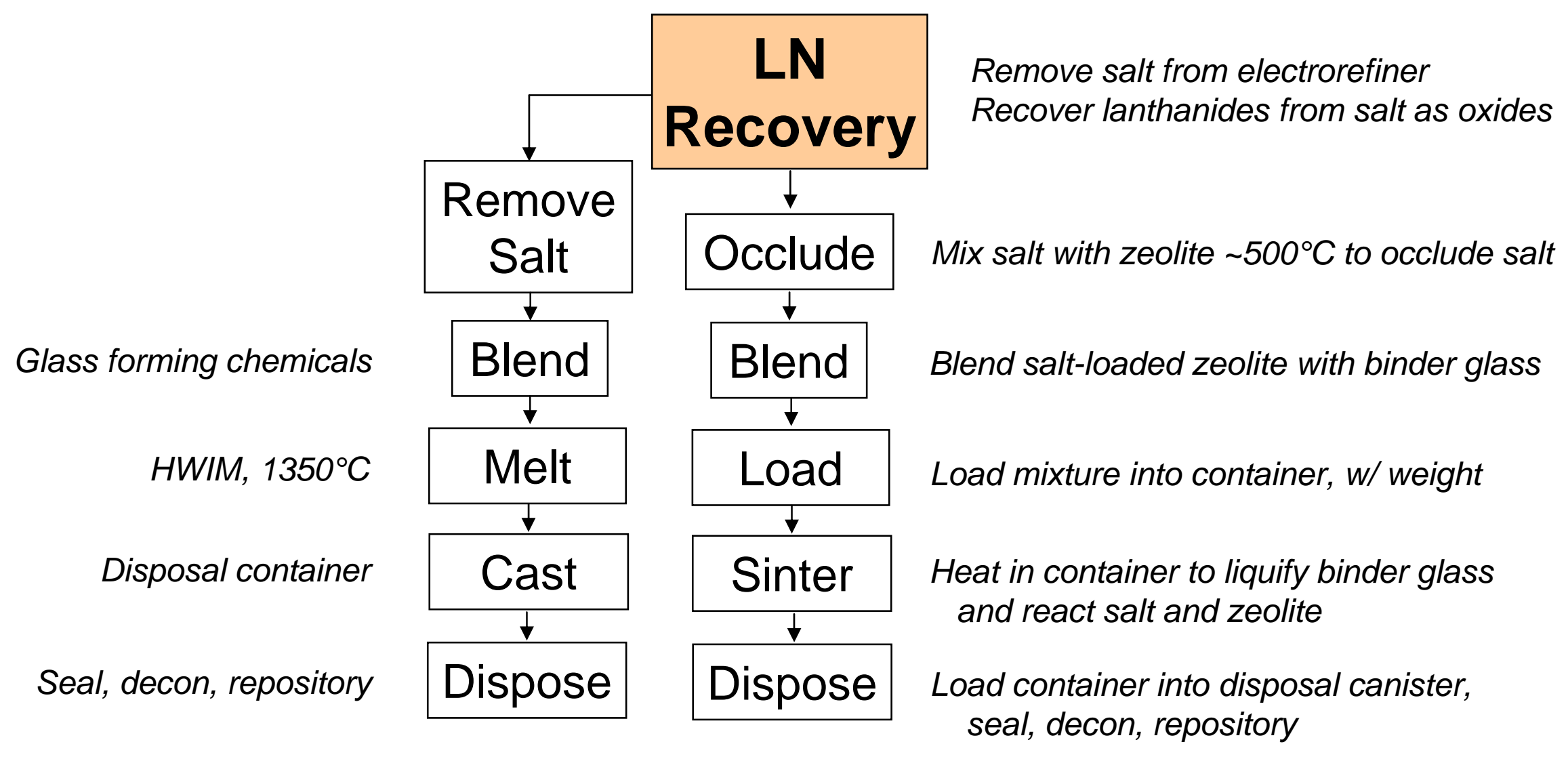


Developed for EBR-II fuel/blankets

$\mathrm{Na}_{12}\left(\mathrm{AlSiO}_{4}\right)_{12}+4 \mathrm{NaCl} \rightarrow 2 \mathrm{Na}_{8}\left(\mathrm{AlSiO}_{4}\right)_{6} \mathrm{Cl}_{12}$

Demonstrated at full scale

Durability determined by glass corrosion rate $\rightarrow$ HLW rate-law used 


\section{Waste Form Testing}

Waste form testing performed to meet three objectives

- model/predict long-term degradation

- demonstrate qualification

- define acceptable operating range

The tests best suited to meet these objectives are in various states of development, acceptance, and use

- appropriate test for more mature waste forms (e.g., HLW glass) are readily available

- testing protocol for less common nuclear waste forms (e.g., encapsulated zeolite with AgI) have not been as well established

- Panel evaluated the test methods appropriate to meet each of the objectives 


\section{Testing Protocols for GNEP Waste Forms}

- Test method selection and testing protocols based on consensus standards (ASTM, ANS, ...)

- Panel recommended initial testing for each baseline waste form for each disposal condition

More complete list for glass and ceramics

Acceptable test responses depends on a host of assumptions

- General repository release models being developed to aid in determining acceptable test responses for various environments

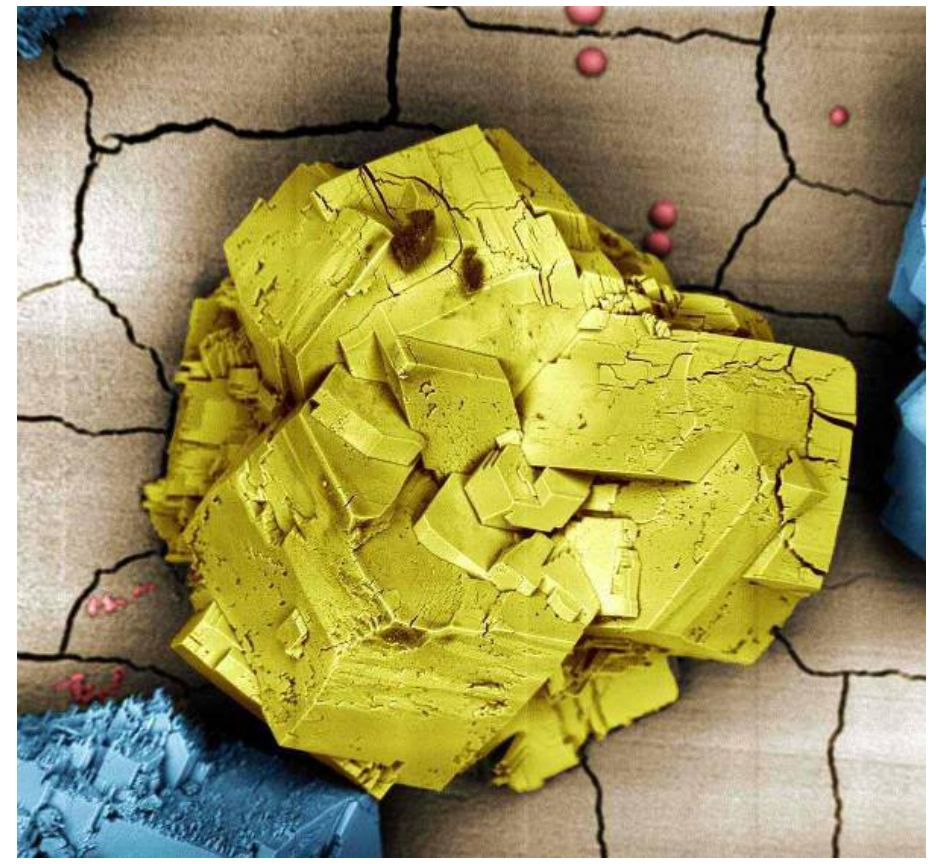

Hanford Immobilized LAW Product Acceptance Testing: Tanks Focus Area Results, PNNL-13744, Pacific Northwest National Laboratory, 2001. 


\section{Technology Readiness Assessment (TRA)}

- Evaluating a technology (waste process/form) for readiness to implement/produce

- Concept from NASA, adopted by DOD, now being adopted by DOE

- Generates technology readiness level (TRL, 1-9) and technology maturation plan (TMP)

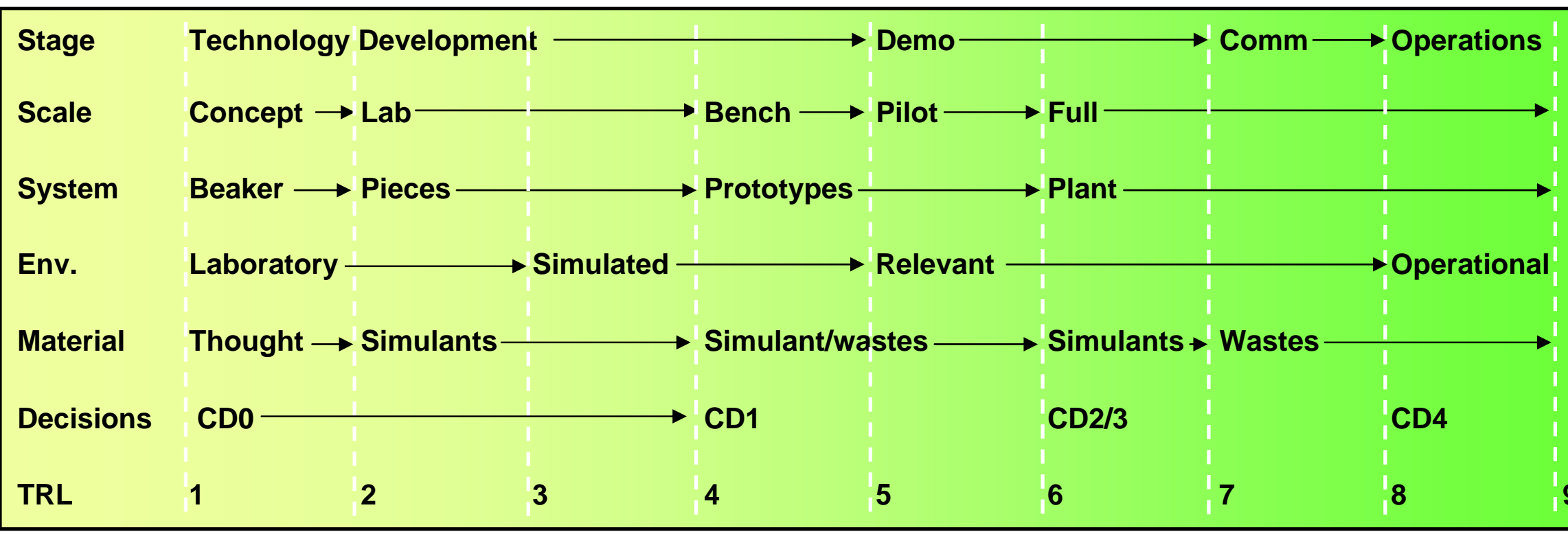




\section{Technology Readiness Assessment}

- Screening technology readiness assessment performed for each of the key waste streams

Certain technology elements for each waste form rank low on the readiness scale

- Generally resulting in low TRL for all waste forms

- Misleading to take TRL out of context

- Qualitative judgments were made based on EM TRA process

Screening TRA being reviewed by an independent expert panel and is being updated before issue

Complete TRA to be performed after resolution of some waste form baseline issues 


\section{Technology Readiness Assessment}

\begin{tabular}{|c|c|c|c|}
\hline Stream & Description & Process/Form & Maturity \\
\hline Hulls (LWR) & Zirc-alloy & Leach, compact & $\mathrm{H}$ \\
\hline${ }^{3} \mathrm{H}$ (both) & HTO & Cement & $\mathrm{H}$ \\
\hline $\mathrm{I}(\mathrm{Aq})$ & AgZ & $\begin{array}{l}\text { Encapsulated } \\
\text { AgZ }\end{array}$ & $\mathrm{L}$ \\
\hline Kr (both) & AgZ & Compressed gas & M \\
\hline${ }^{14} \mathrm{C}(\mathrm{Aq})$ & $\mathrm{CO}_{3}$ in $\mathrm{NaOH}$ soln & Cement & $\mathrm{H}$ \\
\hline UDS (both) & $\begin{array}{l}\text { PGM, Mo, Tc, Zr, (O } \\
\text { in Aq, SS in Echem) }\end{array}$ & Metal alloy & $\mathrm{L}$ \\
\hline${ }^{99}$ Тс (Aq) & IX eluate & Metal alloy & M \\
\hline $\begin{array}{l}\mathrm{Cs} / \mathrm{Sr} / \mathrm{Ba} / \mathrm{Rb} \\
(\mathrm{Aq})\end{array}$ & $\mathrm{HNO}_{3}$ soln & $\begin{array}{l}\text { Aluminosilicate } \\
\text { ceramic or glass }\end{array}$ & M \\
\hline LNFP (both) & $\begin{array}{l}\mathrm{LN} \text { in } \mathrm{HNO}_{3} \text { soln } \\
\text { (Aq) } \mathrm{LN}_{2} \mathrm{O}_{3} \text { (Echem) }\end{array}$ & Glass & $\mathrm{H}$ \\
\hline TMFP (Aq) & $\begin{array}{l}\mathrm{Fe}, \mathrm{S}, \mathrm{PGM}, \mathrm{Zr}, \mathrm{Mo} \\
\text { in } \mathrm{HNO}_{3} \text { soln }\end{array}$ & Metal alloy & $\mathrm{L}$ \\
\hline FP (Echem) & Cs, Sr, Ba, Cl, K, Li & $\begin{array}{l}\text { Glass bonded } \\
\text { sodalite }\end{array}$ & M \\
\hline
\end{tabular}




\section{Waste Form Strategy Evolution}

Critical evaluation of waste management baseline currently underway

New baseline will strive to

- minimize complexity and number of waste processes

- minimize amounts of various waste types

- use nature to guide $\rightarrow$ match waste form to waste and disposal chemistries

- Key unknowns/uncertainties

- repository type (Yucca Mtn currently limited to 70,000 MTHM)

- waste type classification (NWPA based on PUREX)

- requirements for capture of fission product gases

- GTCC disposal 


\section{Treatment of Aqueous Wastes}

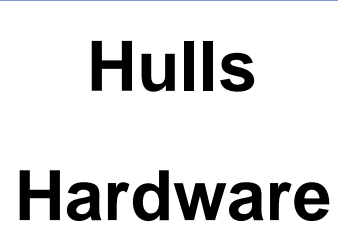

${ }^{\mathrm{HTO}}$

lodine

UDS

Tc

TMFP

$\mathrm{Cs} / \mathrm{Sr}$

LN
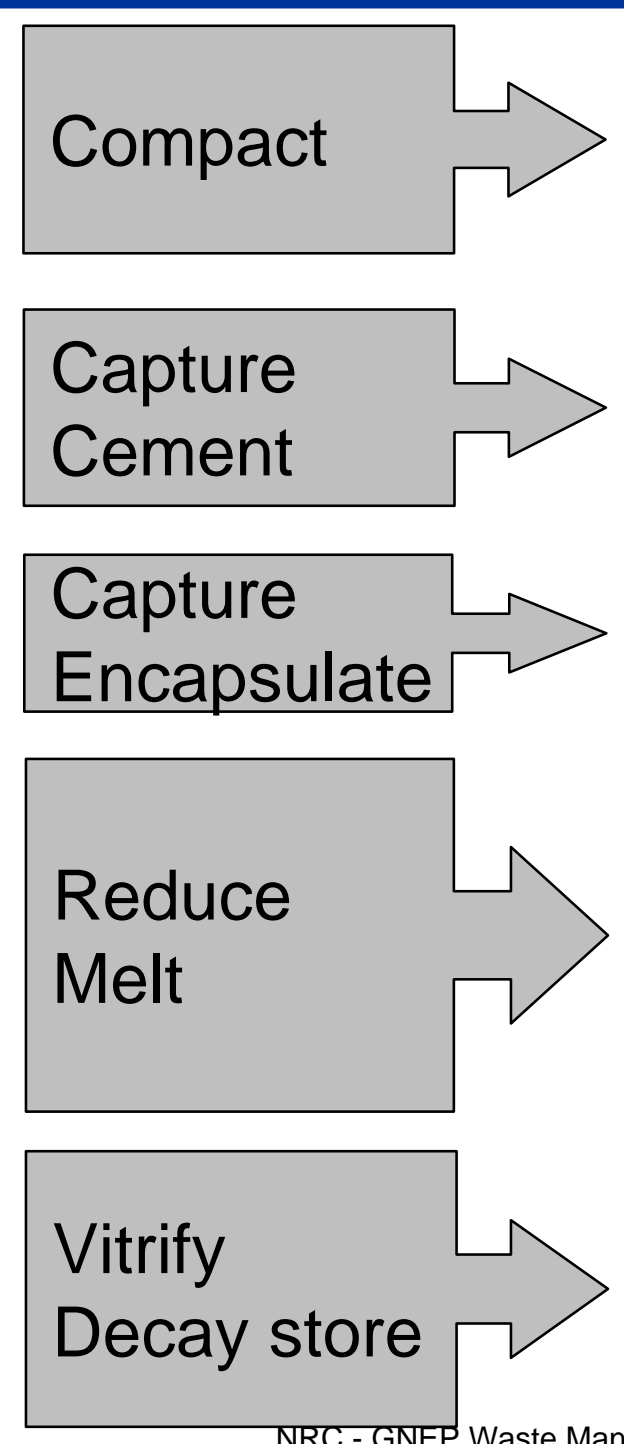

Metal for GTCC or Repository Disposal

\section{Cement for \\ LLW Disposal}

Zeolite in Geo-polymer for Repository Disposal

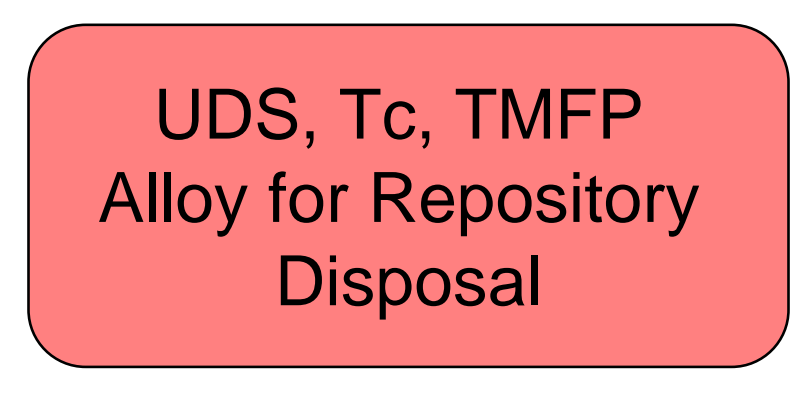

Cs/Sr, LN Glass for Repository Disposal 


\section{Treatment of Electrochemical Wastes}

HTO

Capture Cement

UDS

LNFP

$\mathrm{Cs} / \mathrm{Sr}$

OFP

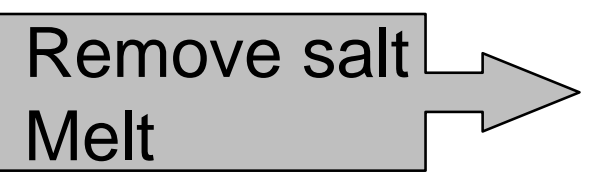

Separate Remove salt Vitrify

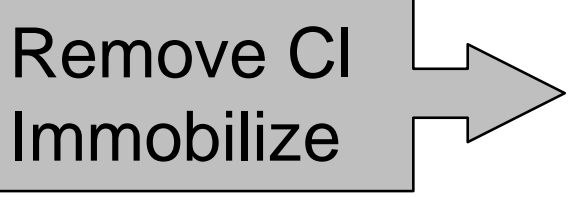

\section{Cement for \\ LLW Disposal}

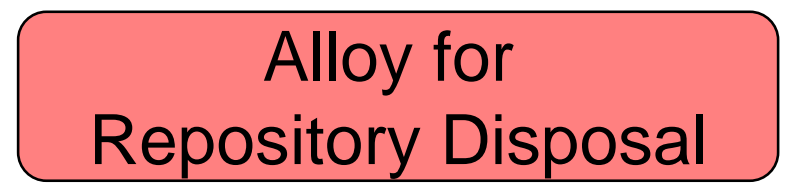

High Ln Glass for Repository Disposal

Glass or Ceramic for Repository Disposal 


\section{Conclusions}

GNEP waste treatment is on sound foundation

- waste forms selected to match waste chemistry and disposal environments $\rightarrow$ nature guides selection

- many waste processes are based on mature technologies

- no technical show stoppers identified

Waste form formulation and testing is well underway

- preliminary testing on all key waste forms

- test methods being developed to meet three testing criteria

- program in place to fill technology and qualification gaps

Waste form campaign is evolving

- reduce complexity and amount

- take advantage of unique waste characteristics

- focus efforts on increasing technology readiness 


\section{Global Nuclear Energy Partnership (GNEP) Waste Treatment Baseline and Integrated Waste Management Strategy}

Dirk Gombert, Consulting Engineer Idaho National Laboratory

DOE/NRC Seminar No. 1 in Topical Series on Advanced Waste Management and Waste Forms

April, 2008 


\section{Presentation Outline}

Waste Treatment Overview

- Waste Streams

- Evaluation Criteria

- Recommended Waste Form Baseline

- R\&D and Trade Studies

- Integrating Waste Management

- Integrating the fuel cycle

- New concepts for risk based regulations \& collaboration

- Details of a strategy for managing all radioactive wastes

- Concluding Points 


\section{GNEP Overview}

- Reduce America's dependence on fossil fuels

- Provide abundant energy without generating carbon emissions or greenhouse gases

Recycle used nuclear fuel to minimize waste and curtail proliferation concerns

- Safely and securely allow developing nations to deploy nuclear power to meet energy needs

- Assure maximum energy recovery from still-valuable used nuclear fuel

- Reduce the number of required U.S. geologic waste repositories needed for the remainder of this century 


\section{Closing the Fuel Cycle}

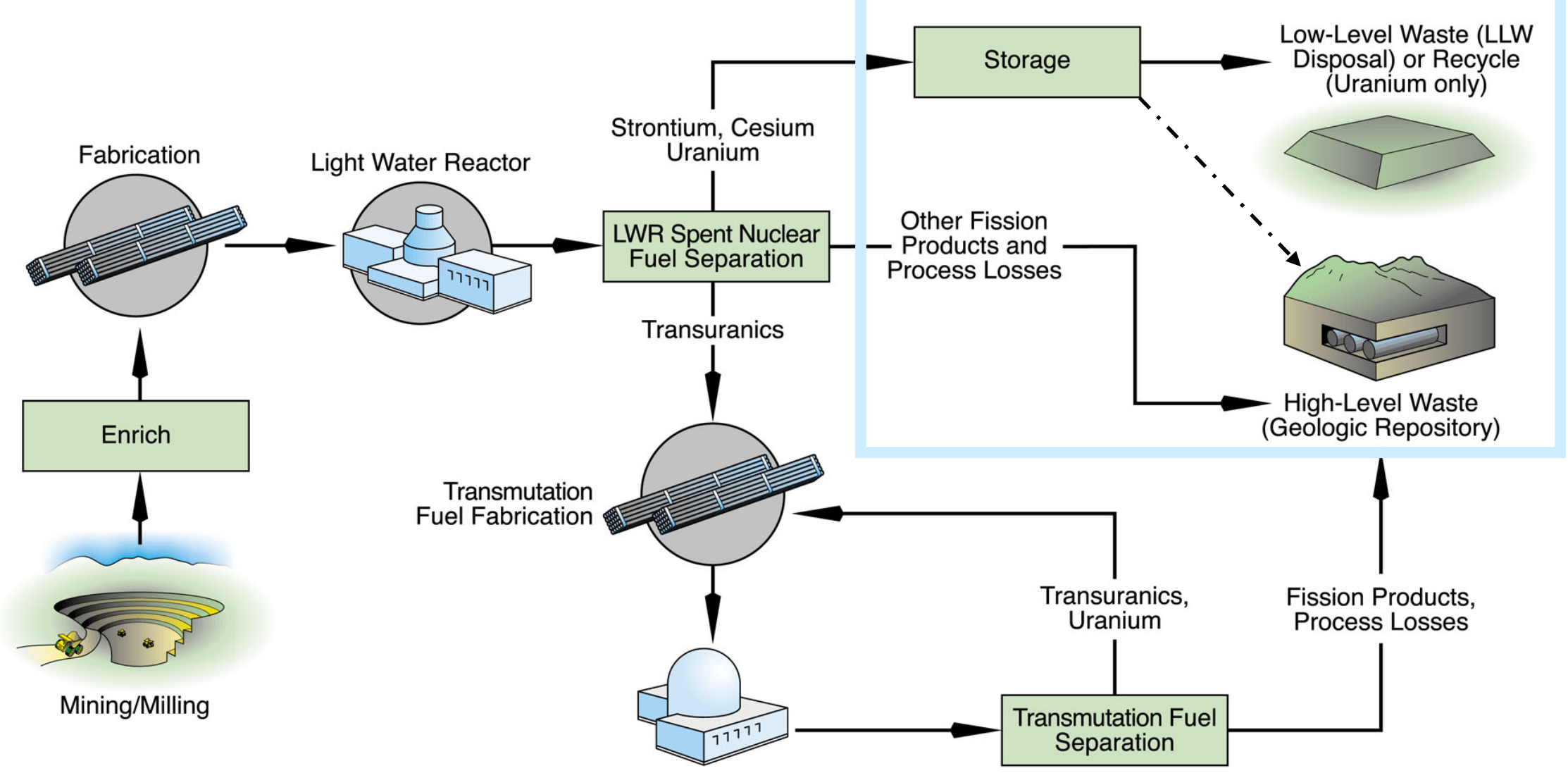

Advanced Burner

Reactor 


\section{Optimize Repository Disposal}

Significantly reduce the long-lived nuclear waste to be disposed of in a geologic repository making disposal less complex and minimizing the need for additional repositories

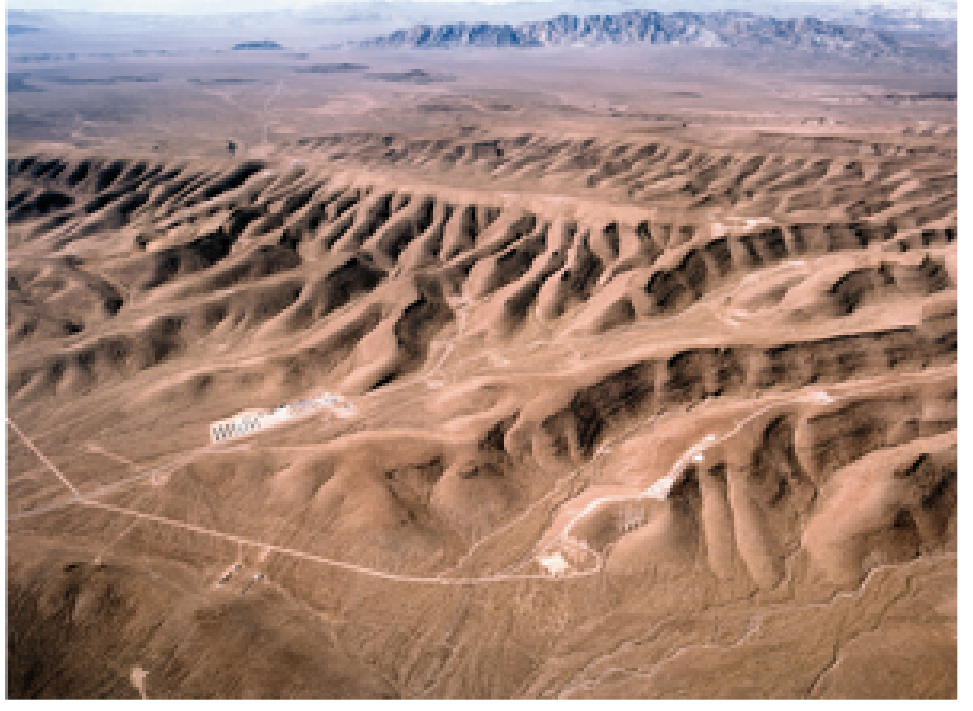

- Repository needed in all cases

- One repository may meet U.S. needs this century with GNEP 


\section{Treatment Baseline Report Scope}

- Technical Recommendations to Stabilize:

- UDS

- Tc

- Metals - hulls/hardware

- Fission products

- Cs/Sr

- Lanthanides

- Gaseous FP - I, H, C, Kr, Xe

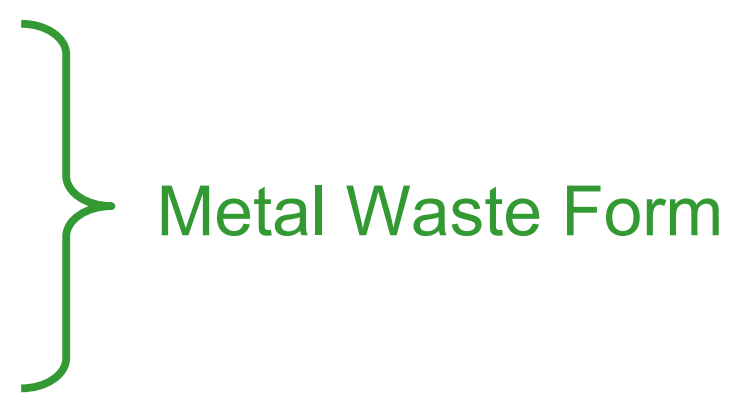

Decay Storage Waste Form Oxide Waste Form (possibly combining $\mathrm{Cs} / \mathrm{Sr}$ with $\mathrm{Ln}$ ) Specialized Waste Forms 


\section{Evaluation Criteria}

Commercial Practicability (weighted $\mathbf{4 0 \%}$ )

- Technical Practicality, Flexibility, Scalability, Waste Loading, Processing Cost, Secondary Waste Generation

Technical Maturity (weighted 10\%)

- Development Cost/Schedule to Implement,

Waste Form Performance (weighted 40\%)

- Thermodynamic/Rad/Mech/Thermal Stability, Chemical Durability

- Stream Specific Criteria:

- Heat transfer, RedOx Sensitivity, Resistance to degradation by decay, Resistance to radiolysis, Ability to treat more than one waste, Experience with disposal of similar materials

- Stakeholder Acceptance (weighted 10\%)

- All processes designed to meet standards 
Treatment Baseline Report Recommendations

\begin{tabular}{|l|l|l|}
\hline \multirow{2}{*}{$\begin{array}{c}\text { Waste } \\
\text { Stream }\end{array}$} & \multicolumn{2}{c|}{ Waste Form(s) } \\
\cline { 2 - 3 } & \multicolumn{1}{|c|}{ UREX+ } & \multicolumn{1}{c|}{ Echem } \\
\hline Tc & $\begin{array}{l}\text { Metal Alloy, possibly containing } \\
\text { UDS and transition metal FP. }\end{array}$ & $\begin{array}{l}\text { Metal Alloy containing UDS and } \\
\text { transition metal FP. }\end{array}$ \\
\hline Ln Sr & Glass or Ceramic & $\begin{array}{l}\text { Glass-bonded sodalite. May contain } \\
\text { 129 I carried over from electro- } \\
\text { reduction. }\end{array}$ \\
\hline FP & $\begin{array}{l}\text { Glass, may be combined with } \\
\text { Cs/Sr }\end{array}$ & $\begin{array}{l}\text { Borosilicate glass or glass-bonded } \\
\text { sodalite if combined with Cs/Sr. }\end{array}$ \\
\hline UDS & $\begin{array}{l}\text { Included in metal waste form with } \\
\text { Tc described above or Ln glass. }\end{array}$ & $\begin{array}{l}\text { Included in metal waste form with } \\
\text { Tc described above. }\end{array}$ \\
\hline $\begin{array}{l}\text { Metals- } \\
\text { Cladding \& } \\
\text { Hardware }\end{array}$ & $\begin{array}{l}\text { Included in metal waste form with } \\
\text { Tc described above. }\end{array}$ & $\begin{array}{l}\text { Included in metal waste form with } \\
\text { Tc described above. }\end{array}$ \\
Metal ingot if cost effective or & $\begin{array}{l}\text { Compacted metal. } \\
\text { required for disposal. }\end{array}$ & $\begin{array}{l}\text { Metal ingot if cost effective or } \\
\text { required for disposal. }\end{array}$ \\
\hline
\end{tabular}




\section{Treatment Baseline Report Recommendations (cont)}

\begin{tabular}{|l|l|l|}
\hline \multirow{2}{*}{ Waste Stream } & \multicolumn{2}{|c|}{ Waste Form(s) } \\
\cline { 2 - 4 } & \multicolumn{1}{|c|}{ UREX+ } & \multicolumn{1}{|c|}{ Echem } \\
\hline Tritium & Grouted tritiated water (HTO). & Grouted tritiated water (HTO). \\
\hline Iodine & Encapsulated silver zeolite. & $\begin{array}{l}\text { Glass-bonded sodalite w/Cs/Sr } \\
\text { and/or lanthanide FP. }\end{array}$ \\
\hline Carbon-14 & $\begin{array}{l}\text { Grouted Na } / \mathrm{CaCO}_{3} \text { potentially } \\
\text { including the tritiated waster. }\end{array}$ & $\begin{array}{l}\text { Grouted Na } / \mathrm{CaCO}_{3} \text { with residual } \\
\text { in glass-bonded sodalite w/Cs/Sr } \\
\text { and/or lanthanide FP. }\end{array}$ \\
\hline Kr & $\begin{array}{l}\text { Decayed in fuel then released. } \\
\text { Pressurized gas cylinder w/wo } \\
\text { Xe if fuel storage is insufficient. }\end{array}$ & $\begin{array}{l}\text { Decayed in fuel then released. } \\
\text { Pressurized gas cylinder w/wo Xe } \\
\text { if fuel storage is insufficient. }\end{array}$ \\
\hline
\end{tabular}


- Chemically reduce and effectively capture the soluble Tc and transition metal elements from the expected aqueous solutions

- Optimize alloy formulations for waste loading to immobilize $\mathrm{Zr}$, Mo, Ru, Rh, Pd, and Tc

- Evaluate alternative reductants to ferrous sulfamate in separations

Quantify capacity of alloys to accommodate nonmetallic feed materials including $\mathrm{Zr}(\mathrm{MoO} 4) 2$ and $\mathrm{TcO} 2$

Develop a mechanistically-based model for alloy degradation 


\section{R\&D Tasks - Cs/Sr (Decay Storage)}

- Determine effects of transmutation and fate of the stable decay daughters.

- Optimize glass and ceramic formulations for waste loading, considering the effects of radiolysis, transmutation, thermal output, and durability during decay storage.

- Develop process for removal of Cs and Sr from Echem salts

- Develop and demonstrate flowsheets for Cs/Sr immobilization

- Evaluate benefits of heat management concepts including incorporating waste form in a metal matrix, internal or external fins, wet vs. dry storage, etc.

- Evaluate disposal options following decay storage

- Consider combination with other streams into common form 


\section{R\&D Tasks - Lanthanides/FP (Oxide form)}

- Optimize glass/ceramic formulations to immobilize Fe, Ln, Zr, Mo, Ru, Rh, and Pd for combined Ln/FP streams

- Optimize Ln-glass formulations

- Define operating envelope for processing glasses/ceramics in induction melter (CCIM for Ln/FP and HWIM for Ln)

- Evaluate alternative reductants to ferrous sulfamate in separations

- Develop glass/ceramic formulations for waste loading of $\mathrm{Cs} / \mathrm{Sr} / \mathrm{Ln}$ elements for processing in the CCIM

- Develop process for removal of Ln/FP from Echem salts and optimize waste form 


\section{R\&D Tasks - Volatile radionuclides}

- Characterize selectivity of radionuclides in gas treatment steps

Evaluate disposal of ${ }^{14} \mathrm{C}$ and HTO as LLW

- Select baseline I capture and immobilization materials and processes

Evaluate long-term retention of iodine on waste form

- Evaluate need for $\mathrm{Kr}$ capture

- Develop non-cryogenic $\mathrm{Xe} / \mathrm{Kr}$ separation methods if required

- Determine tritium DF on 3A molecular sieve from very low dew point gas streams

- Develop ${ }^{14} \mathrm{C}$ waste forms for GTCC disposal 


\section{R\&D Tasks - Activated Metals}

- Characterize activation of hardware components to evaluate co-disposal versus segregation of hardware and TRU contaminated cladding.

- Define conditions required to melt the collected hardware, including the needed additives, melting temperature 


\section{R\&D Tasks - General Studies}

Evaluate all waste/byproducts for beneficial reuse.

- Characterize recommended waste forms to support eventual acceptance to planned or conceptual disposal facilities.

Evaluate potential for cross-contamination in waste streams and potential ramifications to disposition strategy

- Determine the optimal waste stream combinations for coimmobilization and disposal.

- Perform trade studies for LLW treatment to reduce volume, recover radionuclides, and dispose.

- Develop detailed mass balances to show radionuclide inventories in various waste streams and amounts and categories of LLW.

- Collect data to qualify waste forms for disposal 
- GNEP Separations enable consideration of more efficient waste management strategy

- May make "HLW" classification obsolete

Waste chemistry matched to waste form and environment to maximize durability and minimize mobility

Many waste forms still conceptual

- Significant work needed to define characterization needs

More work need to make waste forms and perform characterization 


\section{GNEP Integrated Waste Management Strategy}

IWMS proposes a simpler system to dispose of all radioactive wastes

- Builds on a fuel cycle using advanced separations

- Assumes 70,000 MTHM limit is lifted, or strategy applies to second repository

- Suggests need for NWPA modification to allow risk-based waste management similar to provisions of 10 CFR 61 with added radionuclides

- Could be applied to DOE, NRC, space, defense, medical, and diagnostic wastes

Emphasizes recycle and reuse, but based on economic recovery evaluation factoring in value of material and cost avoidance of disposal

- Considers need for industry to have a reliable system to routinely transport nuclear materials and dispose wastes

- Integrates current EM GTCC EIS effort

Based on a collaborative approach among DOE-NE/EM/RW and NRC/EPA 


\section{Nuclear Fuel Cycle Integrating Waste Management}

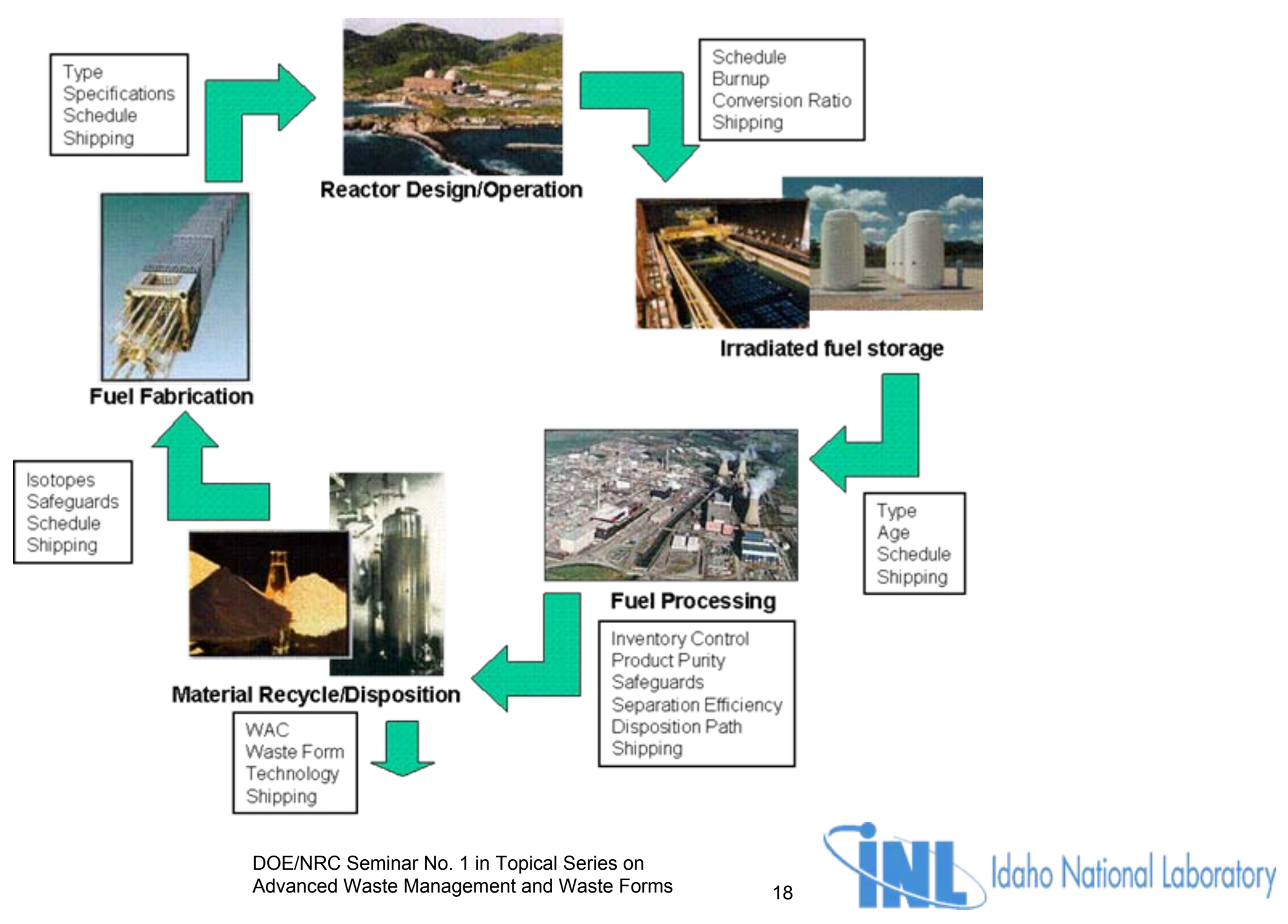




\section{Separations and Stabilization by Chemical Family}

\begin{tabular}{|c|c|c|c|c|c|c|c|c|c|c|c|c|c|c|c|c|c|}
\hline H & & & & & & & & & & & & & & & & & $\mathrm{He}$ \\
\hline Li & Be & & & & & & & & & & & B & c & $\mathbf{N}$ & 0 & $F$ & $\mathrm{Ne}$ \\
\hline $\mathrm{Na}$ & $\mathrm{Mg}$ & & & & & & & & & & & Al & Si & $P$ & $\mathbf{s}$ & $\mathrm{Cl}$ & Ar \\
\hline K & $\mathrm{Ca}$ & So & $\mathrm{Ti}$ & v & $\mathrm{Cr}$ & $\mathrm{Mn}$ & $\mathrm{Fe}$ & $\mathrm{Co}$ & $\mathrm{Ni}$ & $\mathrm{Cl}$ & $\mathrm{Zn}$ & $\mathrm{Ga}$ & $\mathrm{Ge}$ & As & $\mathrm{Se}$ & $\mathrm{Br}$ & $\mathrm{Kr}$ \\
\hline$k b$ & $\$ \pi$ & $Y$ & $\mathrm{Zr}$ & $\mathrm{Nb}$ & Mo & Tc & $\mathrm{Ru}_{\mathrm{L}}$ & $\mathrm{Rh}$ & $\mathrm{Pc}$ & $A_{g}$ & $\mathrm{Cd}$ & In & Sn & Sb & $\mathrm{Te}$ & 1 & $\mathrm{Xe}$ \\
\hline (ब) & $B 3$ & L & $\mathrm{Hf}$ & $\mathrm{Ta}$ & w & $\mathrm{Re}$ & $O=$ & Ir & $\mathrm{Pt}$ & $A_{L}$ & $\mathrm{Hg}$ & TI & $\mathrm{Pb}$ & $\mathrm{Bi}$ & Po & At & $\mathrm{Rn}$ \\
\hline $\mathrm{Fr}$ & $\mathrm{Ra}$ & A & & & & & & & & & & & & & & & \\
\hline
\end{tabular}

Thermal Neutron Fission of U-235

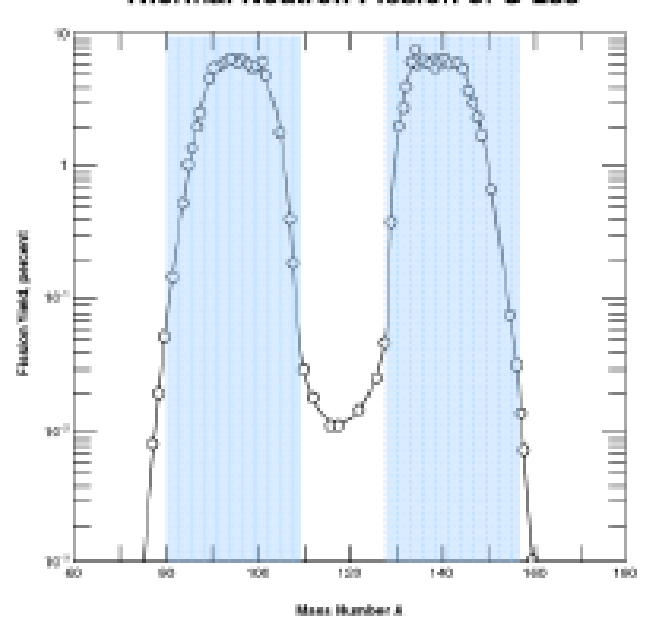

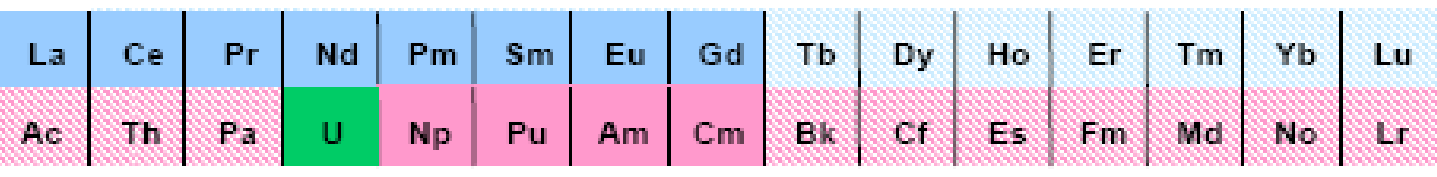




\section{Advanced Separations Enables New WM Strategy New wastes $=$ New Options $=$ New Strategy}

- Consider useful materials and radionuclides for recycle/reuse

- Fissile isotopes

- Commercial use of radionuclides

- Expand technical bases for additional waste forms

- Designation of a routine disposal pathway for GTCC not requiring a case-by-case performance assessment.

$-\geq 100 \mathrm{nCi} \mathrm{TRU/g}$

- Activated metals

- Short and long half-life radionuclides

- Consideration of the concept of "decay storage" in secure storage facilities to reduce heat impacts of radionuclides such as ${ }^{137} \mathrm{Cs},{ }^{90} \mathrm{Sr},{ }^{3} \mathrm{H}$, and ${ }^{85} \mathrm{Kr}$ to decay to LLW/release limits. 


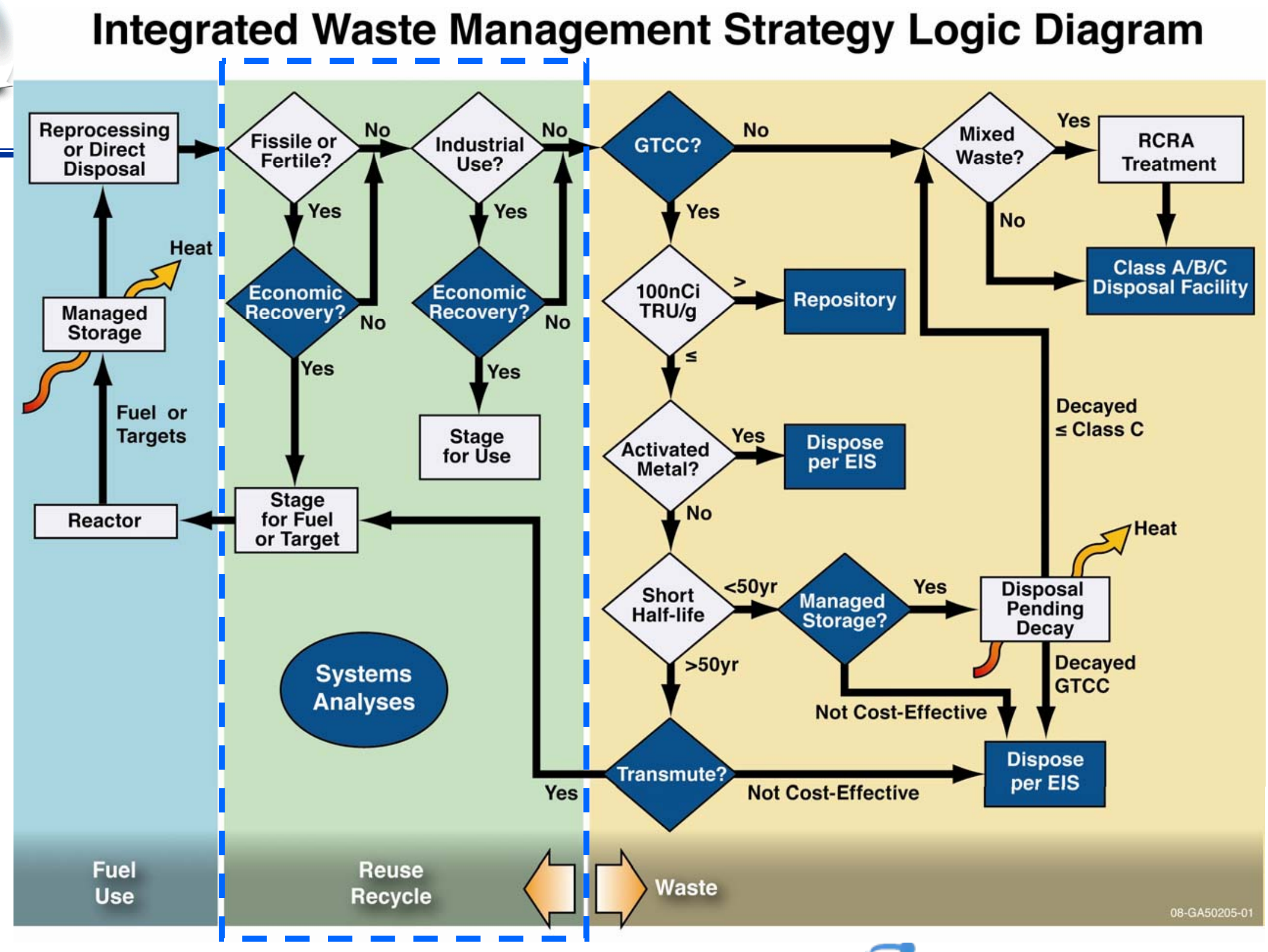




\section{Recycle/Reuse of Byproducts/Wastes}

- Similar to Rocky Flats Economic Discard Limit for Pu

- Considered value of uranium

- Considered reactor time

- Did NOT consider waste management

Economic Recovery Limit

- Value as fuel or industrial application

- Cost of recovery/purification

- Reduction to repository source term (inventory/duration) and heat

- Fuel/target fabrication/irradiation/recycle costs

- Remote vs. glovebox operations

- Secondary waste generation

- Potential for diversion and accidents 


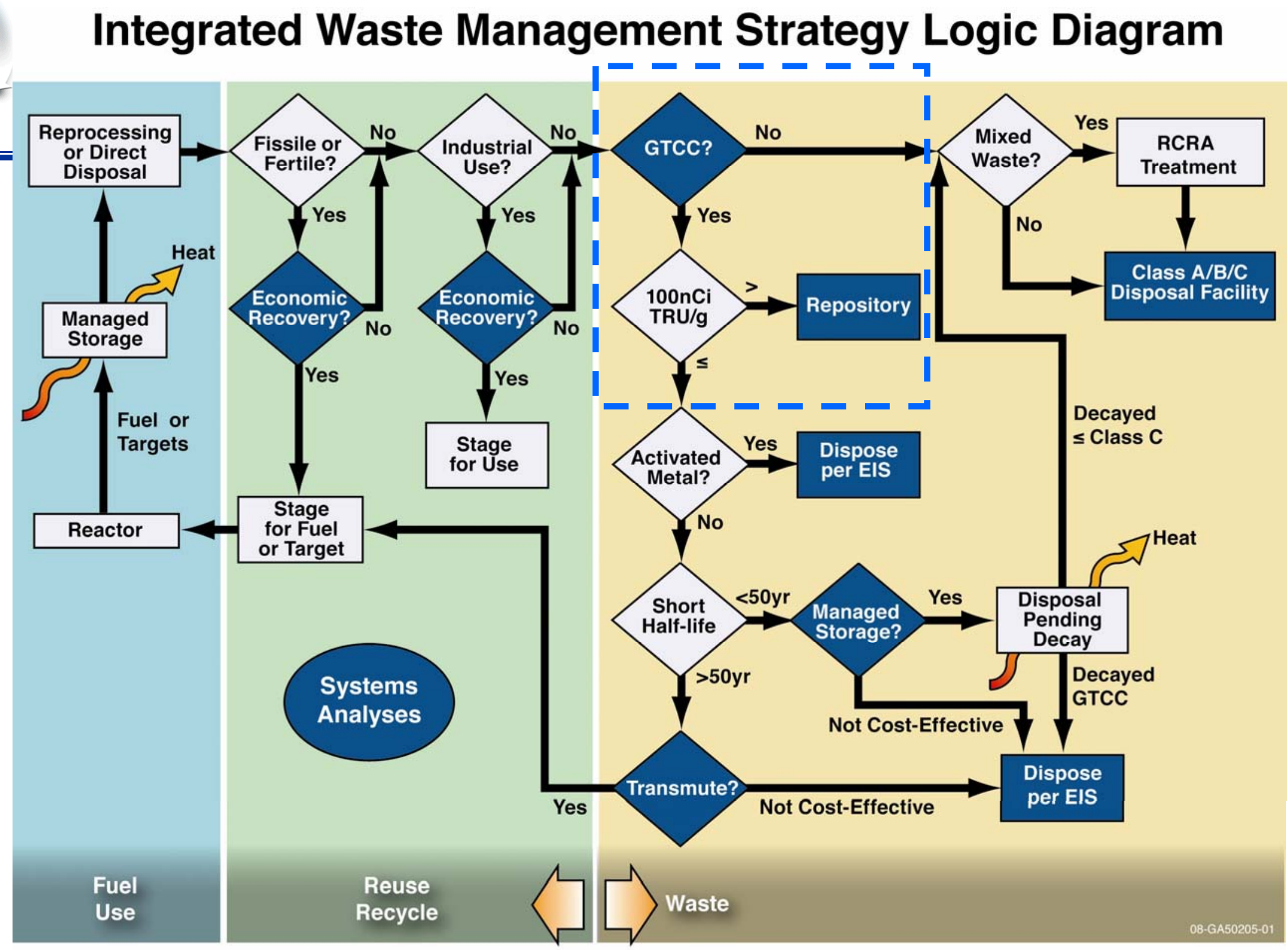




\section{GTCC $\geq 100 \mathrm{nCi} \mathrm{TRU/g}$}

- Source of materials

- Contaminated cladding

- Separations losses

- Fuel fabrication losses

- HVAC \& process filters, maintenance, job-control, and balance-of-plant

- Value of reconsidering contamination limit

WIPP precedent for defense wastes

- Japanese definition of TRU is long-lived, low heat

- Actinides

- Technetium

- lodine

- Pending EIS IWMS assumes WIPP precedent for defense-TRU 


\section{Integrated Waste Management Strategy Logic Diagram}

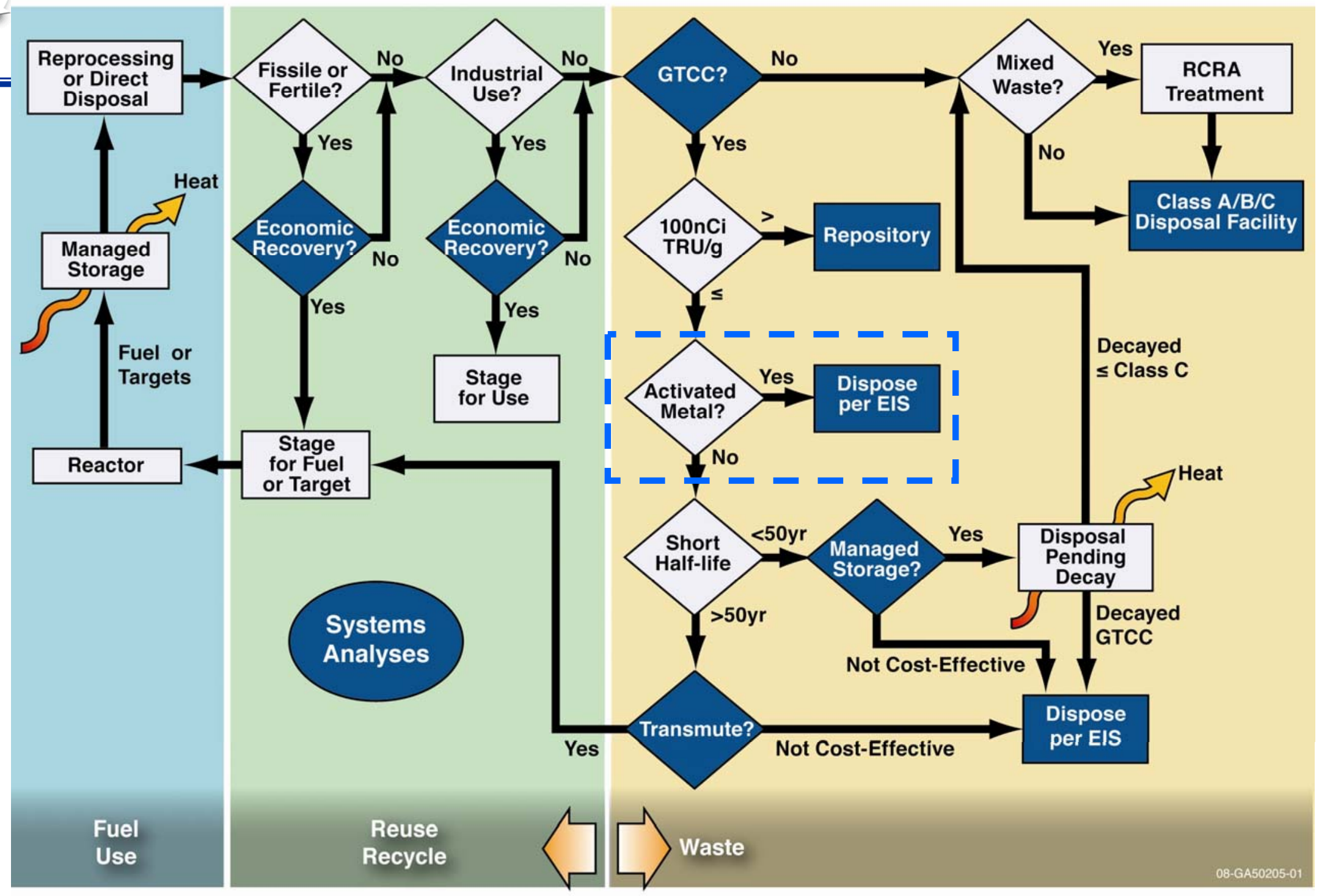




\section{Activated Metals}

- A Primary Category in the DOE-EM GTCC EIS

- GNEP sources of materials

- Fuel cladding

- Non-fuel-bearing hardware

- Pressure vessels (other D\&D metals)

EIS options

- Enhanced Surface Disposal

- Borehole

- Geologic Repository

- Pending EIS IWMS 


\section{Integrated Waste Management Strategy Logic Diagram}

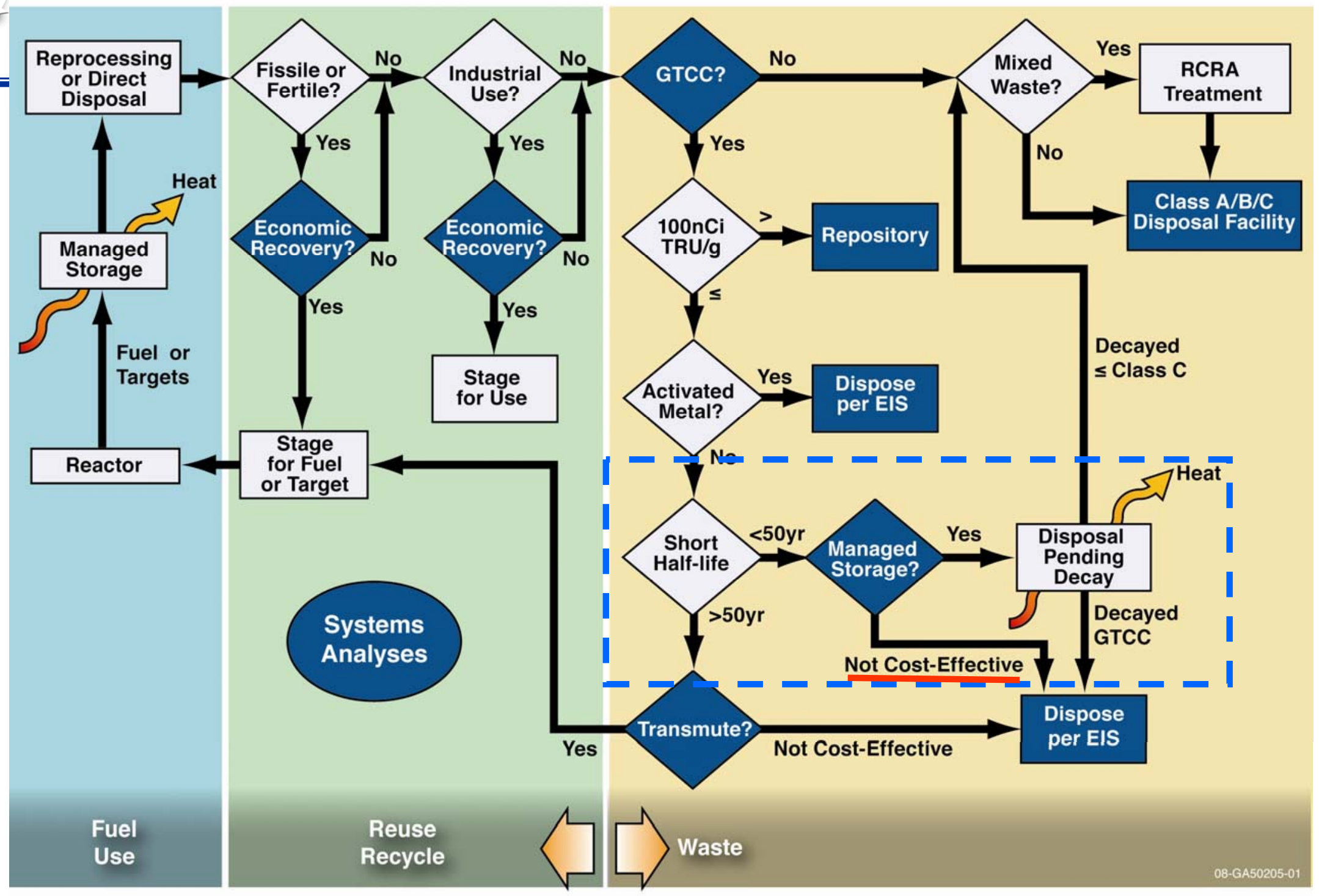




\section{Engineered Storage for Decay}

- Potential Radionuclies

$-{ }^{137} \mathrm{Cs}$

- $90 \mathrm{Sr}$

$-{ }^{85} \mathrm{Kr}$

$-{ }^{3} \mathrm{H}$

- ${ }^{\mathrm{xxx}} \mathrm{Cm}$

- Heat Management Strategy Trade-Studies of Various Concepts

- Extended SNF aging

- Interim waste form storage for up to 10 half-lives

- Storage at reactor, reprocessing plant, repository, interim facility

- Transportation, handling, processing, security, permitting issues

- Facility M\&O costs

- Ultimate disposition of materials (cross-contamination, specific isotopes) 


\section{Integrated Waste Management Strategy Logic Diagram}

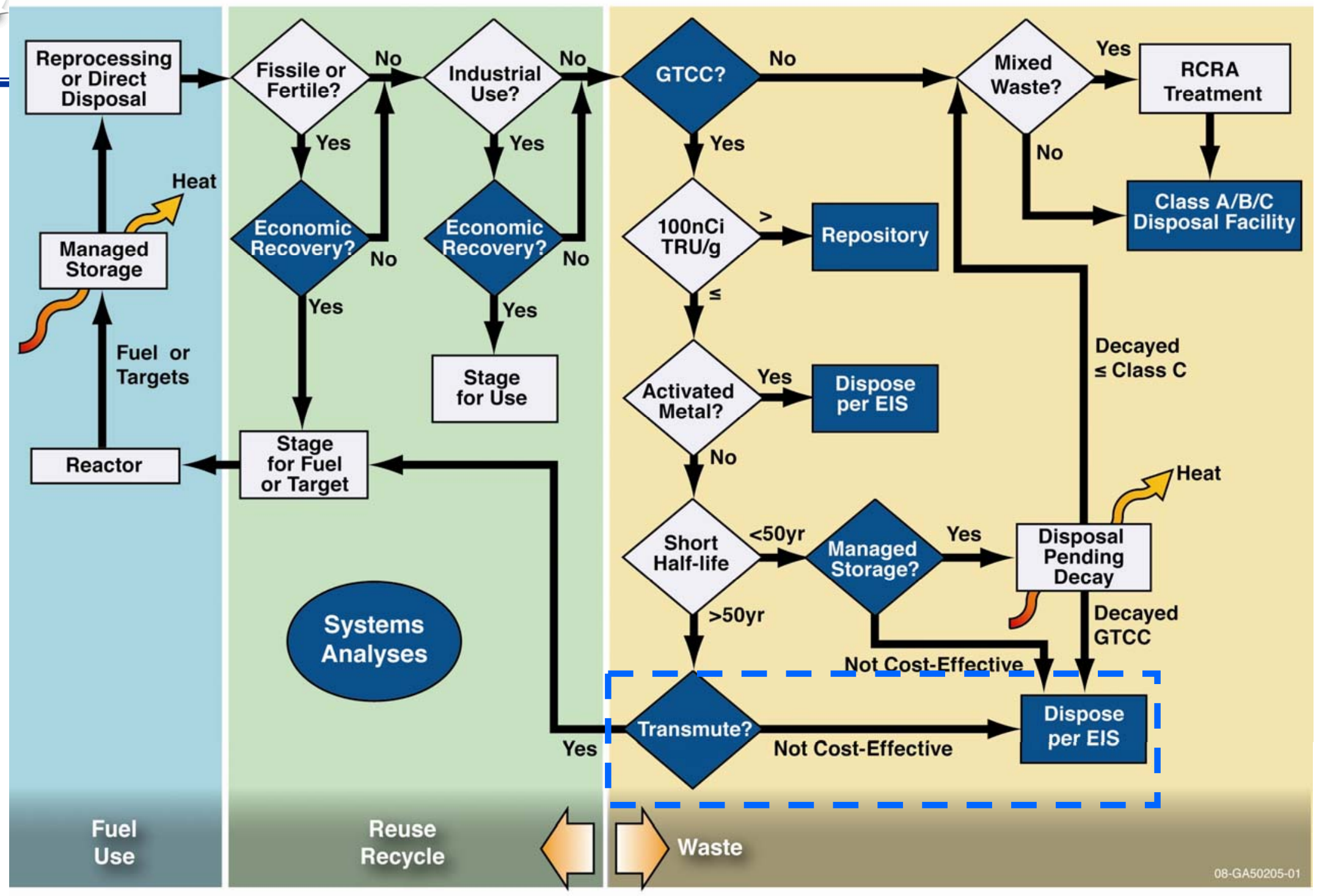




\section{Transmutation of Long-lived Radionuclides}

- Potential Radionuclides

- ${ }^{99} \mathrm{TC}$

$-129$

- xxxAm

- ${ }^{\mathrm{xxx}} \mathrm{Cm}$

Destruction in fuel or targets

- Remote fabrication

- Irradiation costs

- Multiple recycles

- Waste generation 


\section{Volume Effects in Waste Management}

- Repository capacity limited by legislation, dose, heat, or volume

- NWPA limits first repository/MRS until second repository is in operation

- Potential dose is ultimate functional design criteria

- Operational design criteria has thermal limits to meet dose requirement

- Volume is generally not a limiting factor for repository capacity

- Waste volume affects transportation and placement operations

Canistered (TAD) SNF 1.24-1.51 $\mathrm{m}^{3} / \mathrm{MTHM}$

Areva reports $\sim 0.31 \mathrm{~m}^{3}$ HLW+ILW/MTHM for $40 \mathrm{GWd} / \mathrm{MTHM}$

- $\sim 0.13 \mathrm{~m}^{3}$ glass/MTHM (Vitrified HLW MA/FP/UDS)

- $\sim 0.18 \mathrm{~m} 3 \mathrm{metal} / \mathrm{MTHM}$ (Supercompacted ILW hulls and hardware)

- Rokassho is similar to La Hague 


\section{Comparison of WM volumes w/wo Reprocessing}

- IWMS suggests classification by risk using Class A/B/C, GTCC

- 0.013-0.060 $\mathrm{m}^{3}$ glass/MTHM (Cs/Sr/Ln w/wo TMFP from $50 \mathrm{GWd} / \mathrm{MTHM}$ )

- $\underline{0.007-0.004 \mathrm{~m}^{3}}$ metal/MTHM (Tc/UDS w/wo TMFP varies inversely with glass)

- 0.020-0.064 $\mathrm{m}^{3}$ total repository waste not including hulls/hardware or offgas wastes (iodine, ${ }^{14} \mathrm{C}$ )

- 0.047-0.072 $\mathrm{m}^{3}$ Hulls \& Hardware

- 0.002-0.009 $\mathrm{m}^{3}$ lodine concept (order-of-magnitude)

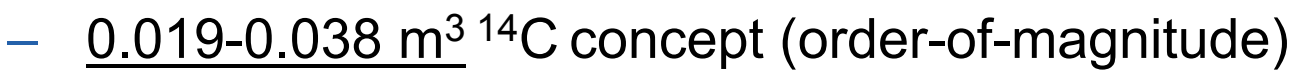

- 0.088-0.183 $\mathrm{m}^{3} \Sigma \mathrm{GTCC}$

Volume reduction $\sim 2-6.5$ glass + metal forms vs COEX HLW glass

- Volume reduction $\sim 8-14 \Sigma$ IGTCC vs. canistered SNF

- Primary benefit is not volume reduction, rather more durable waste forms and a strategy to increase repository capacity 


\section{Secondary Wastes}

- Job Control (maintenance, decontamination, PPE)

- Balance of Plant (laboratories, waste water, utilities, filters, etc.)

- GTCC estimated at $\sim 5-20 x H L W$

- LLW Class A/B/C estimated at $\sim 3-5 x G T C C$

- Economics of volume reduction

- Limited waste disposal options

- Industry has essentially eliminated MLLW generation

- Waste minimization programs

- Compaction, steam-reforming, and possibly incineration if cost-effective

- DOE has taken responsibility for GTCC similar to SNF

- Limited commercial cost incentive for GTCC waste disposal 


\section{IWMS Conclusion}

- IWMS describes simplified process for managing all radioactive wastes based on risk

- Repository wastes grouped chemically with waste form matched to wastes

- Maximizes durability

- Minimizes volume

- Identifies trade studies to evaluate cost effectiveness of options

- Provides basis for collaboration among DOE-NE/EM/RW and NRC/EPA

- Independent of repository environment, thermal vs fast reactor recycling, fuel or target type, allows phased approach to separations including PUREX, COEX, UREX+, and Echem 


\title{
Thank you for your kind attention.
}

\author{
Questions?
}

\section{Dirk.gombert@inl.gov 208-526-4624}




\section{The Global Nuclear Energy Partnership (GNEP)}

\section{Overview of Systems Analysis and Waste Form Campaigns}

Kathryn McCarthy

GNEP Systems Analysis Campaign Director

Mark Peters

GNEP Waste Form Campaign Director

April 23, 2008

Presentation to Nuclear Regulatory Commission Rockville, MD 


\section{Outline}

- GNEPIAFCI Mission and Requirements

- Overview of Systems Analysis Campaign

- Overview of Waste Form Campaign

- Questions and Discussion 


\section{GNEPIAFCI Mission Statement}

Conduct a nuclear energy research, development, and demonstration program focused on nuclear fuel recycling and waste management to provide the infrastructure, technologies, and qualified personnel needed to enable the United States to close the nuclear fuel cycle and to support the safe, secure, economic, and sustainable global expansion of nuclear energy in a way that reinforces United States technological leadership. 


\section{GNEPIAFCI Program Requirements}

\section{Develop and demonstrate technologies to:}

1. Reduce the environmental and financial burden and uncertainty associated with long-term nuclear waste management.

2. Optimize nuclear waste management by:

- Minimizing the risk of waste that needs to be handled or stored.

- Producing only solid wastes in robust waste forms.

- Recycling and reusing materials to the maximum extent possible.

3. Recover the unused energy value of materials separated from spent nuclear fuel for future use.

4. Enhance the ability to safeguard the advanced fuel cycle facilities by developing technologies to more accurately account for, track, and manage nuclear materials.

5. Support the near-term deployment of fuel cycle technologies (20 years) as well as define longer term deployments of next-generation technologies ( 50 years).

6. Make the closed fuel cycle as economical as possible.

7. Accelerate deployment of nuclear reactors that are appropriate for regions with limited capacity electricity grids.

8. Permit deployed facilities to be licensable by the appropriate civil regulatory authorities. 


\section{GNEPIAFCI Program Requirements (cont.)}

9. Develop the research and development infrastructure needed to demonstrate closure of the fuel cycle at an engineering-scale in the United States.

10. Support the development of programs and processes that will encourage the education and training of the personnel that will be needed to staff industry, regulators, government, universities and national laboratories to allow closure of the fuel cycle in the United States and reinforce United States technological leadership in the world. 


\section{GNEP Program Organizational Structure}

\section{PROJECTS}
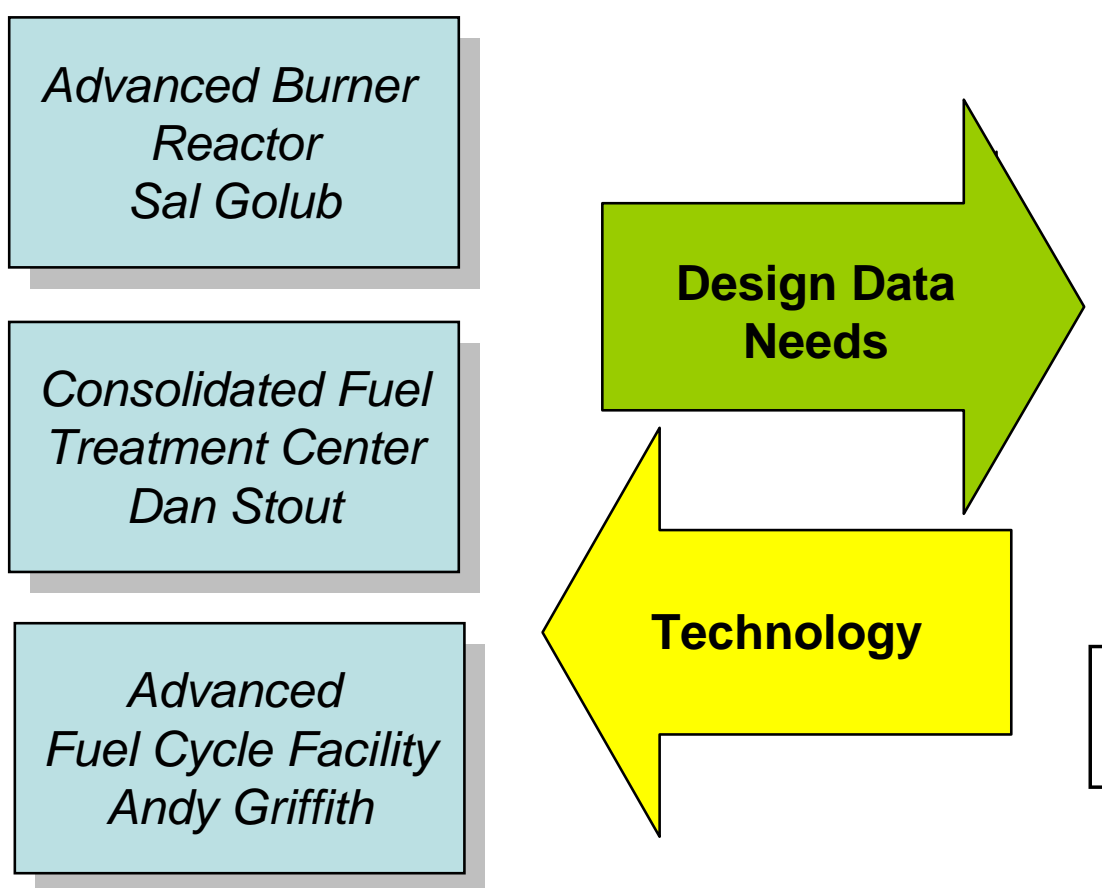

Cross Cut Coordination -Modeling/Simulation (Nowak- ANL) -Safety and Regulatory (Kelly- SNL)

\section{$R \& D$}

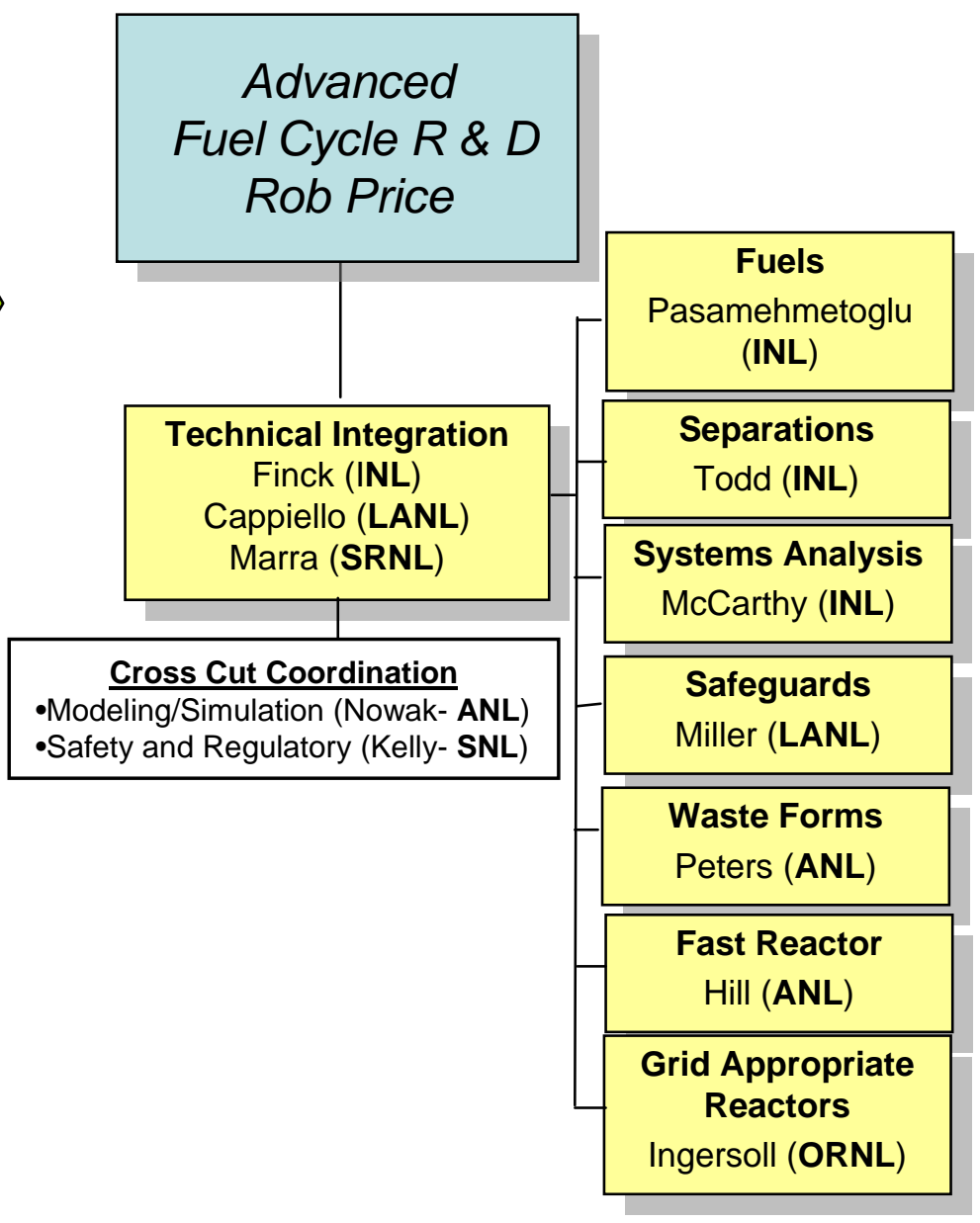




\section{Systems Analysis Campaign}

Mission: Carry out integrating analyses for GNEP development and infrastructure deployment, and enable a requirementsdriven process for all technical activities

Objectives:

- Integrates information from the diverse technology development and R\&D efforts

- Enables examination of a diverse set of scenarios

- Evaluate off-ramps

- Evaluate technology alternatives

- Examine deployment options

- Understand dynamics

Assumptions

- Focus on 1-tier and 2-tier relative to once-through

- All transuranics are recycled 


\section{Systems Analysis Increases Understanding of the Fuel Cycle}

- Analyzes the entire fuel cycle to understand trends and relative relationships

- Systematically considers multiple objectives and metrics of performance - waste management, TRU reduction, uranium, economics

- Clarifies tradeoffs, e.g., 1-tier vs. 2-tier, fast reactor conversion ratio, timing of deployments, FR fuel cooling time, oxide vs. metal fuel

- Performs sensitivity analyses to better understand how the system performs

- Informs DOE's decision on a path forward, and helps DOE to communicate to stakeholders 


\section{VISION Analyses: Assumptions for Nominal Cases are Based on Technical Feasibility}

\begin{tabular}{|l|l|}
\hline \multicolumn{1}{|c|}{ 1-tier } & \multicolumn{1}{|c|}{ 2-tier } \\
\hline $\begin{array}{l}\text { Centralized UOX separation starting in 2020 at 0.1\% } \\
\text { loss/recycle }\end{array}$ \\
\hline Recover TRU, Cs/Sr, etc. & $\begin{array}{l}\text { Recover U-Pu, MA, } \\
\text { Cs/Sr, etc. }\end{array}$ \\
\hline $1^{\text {st fast reactor (CR=0.50) in 2022 }}$ \\
\hline & MOX-U-Pu \\
\cline { 2 - 2 } & $\begin{array}{l}\text { Centralized MOX } \\
\text { separation starting in } \\
\text { 2035 at 0.1\% } \\
\text { loss/recycle; recover } \\
\text { TRU, Cs/Sr, etc. }\end{array}$ \\
\hline $\begin{array}{l}\text { Fast reactor (CR=0.50) } \\
\text { learning period } \\
\text { 2032-2041 }\end{array}$ & $\begin{array}{l}\text { Fast reactor (CR=0.50) } \\
\text { learning period } \\
2047-2056\end{array}$ \\
\hline $\begin{array}{l}\text { Onsite fast reactor used fuel separation to recover } \\
\text { TRU, Cs/Sr, etc. at 0.1\% loss/recycle }\end{array}$ \\
\hline
\end{tabular}

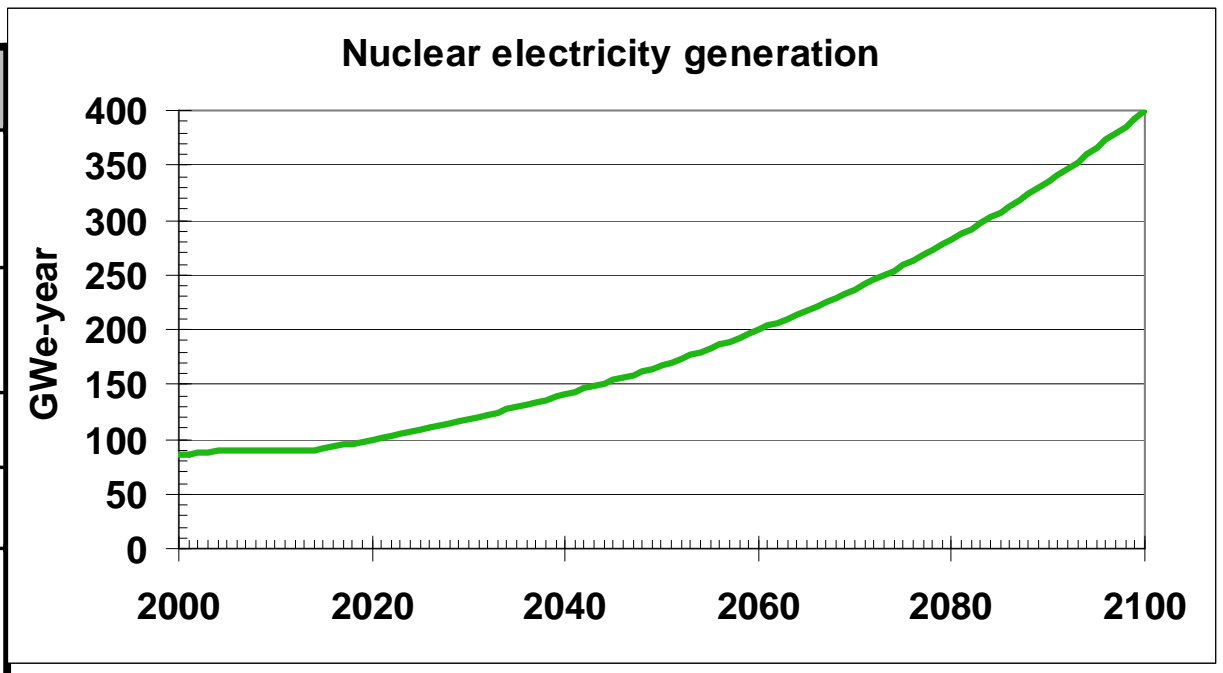

- $1^{\text {st }}$ UOX separation plant 800 tonnes/yr

- Later UOX separation plants $\mathbf{1 6 0 0}$ tonnes/yr, deployed to eliminate used fuel backlog by 2100

- MOX separation deployment lags UOX by 15 years, at $\sim 9 x$ lower capacity

- FR used fuel separation capacity built as FRs are built (co-location) 


\section{Scenario Studies Summary Findings}

- It is feasible to eliminate excess used fuel storage before 2100 while recycling all separated TRU

- Total TRU reduction via recycle must consider both TRU consumed and TRU avoided

- Adding a MOX cycle significantly delays and reduces the number of fast reactors

- If fast reactor used fuel processing is centralized, more TRU is tied up in cooling used fuel and fewer fast reactors can be supported.

- Closed fuel cycles appear to cost 5-6 mils more than once-through, but the uncertainty bounds are large

- Examination of cost drivers help show which improvements contribute most to closing the cost gap 


\section{Material Transportation, Storage, \& Disposal - Recent Accomplishments}

- Continued repository benefit analyses (Alternative disposal pathways, response to questions)

- Material transportation requirements (Assess packaging availability for material shipment, storage)

- Technical evaluation of "Institutional Infrastructure" issues (policy, law, regulation, standards, practice, ...)

- Support for GNEP facilities: (M-TSD strategy consistency, waste stream analyses, disposal alternatives) 


\section{Integrated Waste Management Strategy (IWMS) - Status}

IWMS identifies all waste streams

- Builds on a fuel-cycle using advanced separations

- Describes potential benefits of a NWPA modification to allow risk-based waste management similar to provisions of 10 CFR 61

- Could be applied to DOE, NRC, space, defense, medical, and imaging wastes

- Emphasizes recycle and reuse, but based on economic recovery evaluation factoring in value of material and cost avoidance of disposal

- Considers need for industry to have a reliable system to disposition all byproducts/wastes during a phased transition PUREX, UREX+, Echem...

Independent of 1 or 2 tier recycling concepts

- Integrates current EM GTCC EIS effort

- Anticipates combined oxide and metal waste forms, potential for alternative repository concepts

- Suggests a collaborative approach among DOE-NE/EM/RW, NRC/EPA 


\section{Waste Form Campaign}

- The mission is to develop and demonstrate durable waste and storage forms for management and disposal

- Fundamental understanding of longterm waste and storage form behavior can only come about through closely coupled theory, modeling, and experimentation

Waste treatment and disposition must have acceptable cost impacts. The waste form campaign develops and demonstrates cost effective waste processes and durable forms.
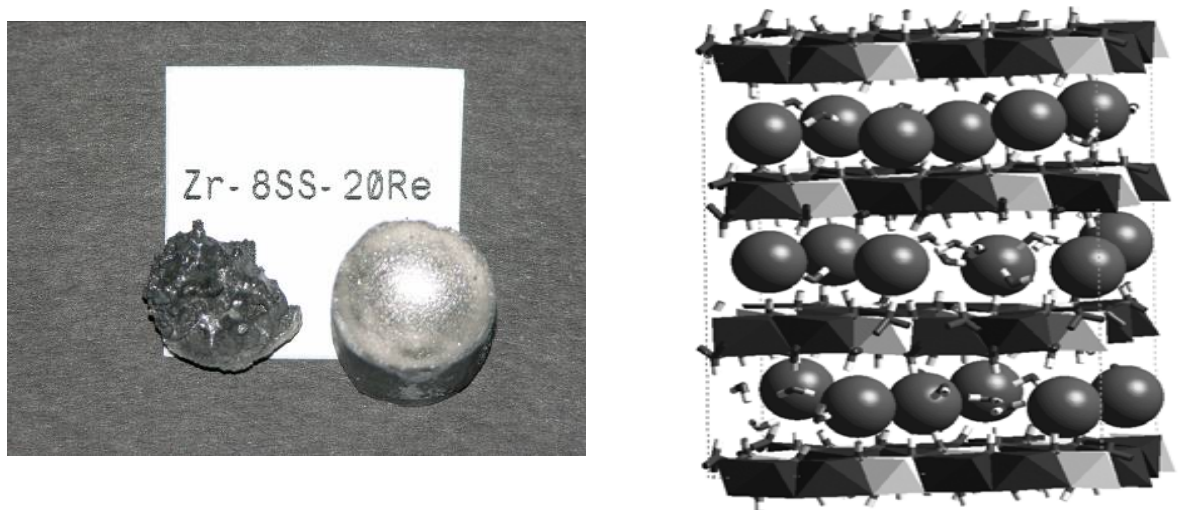


\section{Requirements for Waste Forms}

- Performance (durability, heat transfer, radiation stability)

- Cost effective (low disposal volumes, low cost processes)

- Flexibility (waste composition, loading, process ranges, etc.)

- Predictable performance (natural analogues, release models)

- Match the waste stream to waste form and disposal environment (e.g., keep noble elements in metal waste form) 


\section{Designing Nuclear Waste Forms}

Waste chemistry, radionuclide(s) to immobilize, and disposal environment guide the selection of waste form

Let nature guide, particularly when long-term performance is important

- Use intelligent materials design

- Systematic approach rather than "cook and look" approach

Design material in combination with process

- Process influences form and vice-versa 
- Support development of IWMS and waste management systems analyses

- Preliminary technology readiness level assessment and evaluate waste and storage form durability testing approaches

- Analyses of waste form performance and development of performance requirements in a range of geologic settings

- Continued work on production and performance of candidate baseline waste and storage forms

- Cs/Sr, I, Tc, TM, and LN for aqueous and electrochemical processes 


\section{Accomplishments to Date (cont.) Modeling and Simulation and Long-Term S\&T}

- Conducted workshop and developed Roadmap for M\&S and Long-Term S\&T

- Future Directions

- Development and qualification of advanced, more durable, tailored waste and storage forms

- Development of advanced geologic disposal concepts in a range of geologic settings and geochemical environments

- Enhanced understanding of geologic repository performance

- Systems-level optimization of closed fuel cycle and geologic repository designs

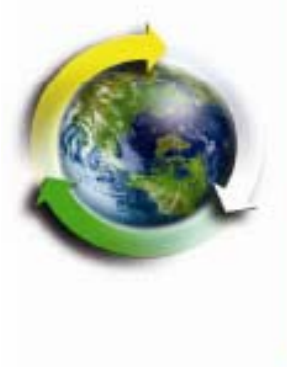

GNEP Waste Form Campaign Science \& Technology and Modeling \& Simulation Program: Roadmap With Rationale \& Recommendations

Global Nuclear Energy Partnership

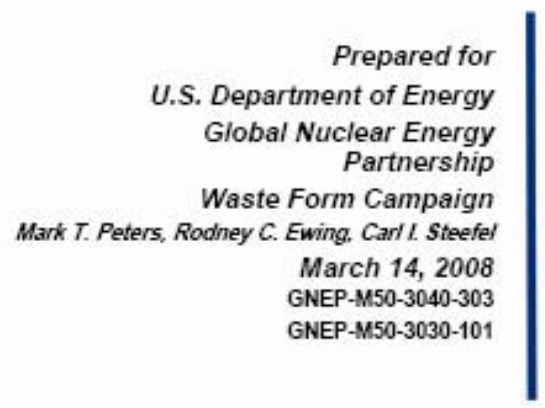




\section{Waste Form S\&T of Specific Materials}

- Structure and chemistry

- Phase transitions as a function of temperature and radiation field

- Chemical durability over a range of conditions (thermodynamic and kinetic studies)

- Corrosion mechanisms and rates

- Mechanical properties

- Response to radiation
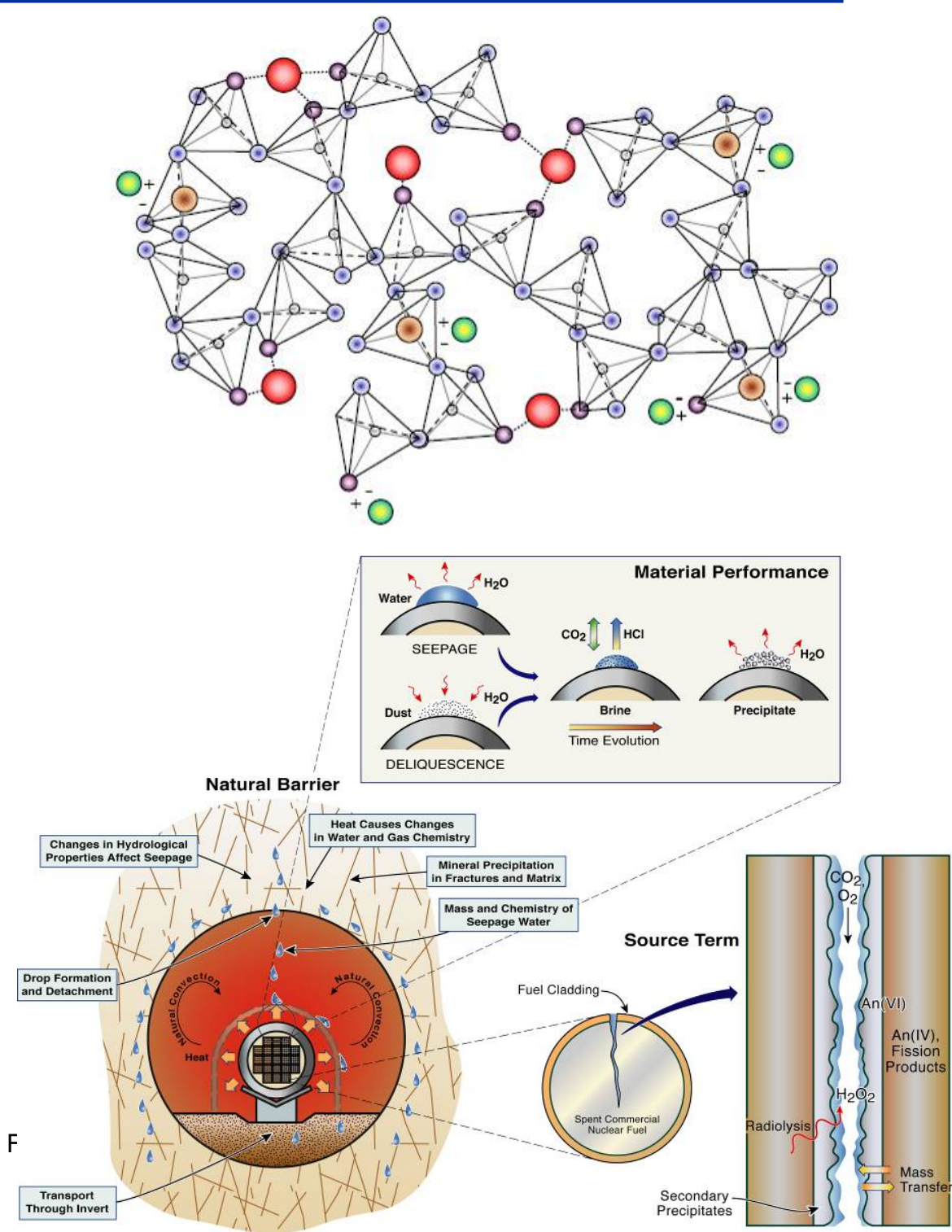


\section{"Integration by Simulation"}

\section{Waste Form Properties \& Performance}

- Computational simulation of:

- Multi-scale simulations of waste form properties (molecular-scale)

- Modeling/simulation of waste form behavior in the near-field environment (meter-scale)

- Reference environments (fractured/monolithic, oxidized/reduced, salt/crystalline/clay)

- Reference waste forms (glass/metal/ceramic phases containing radionuclides)

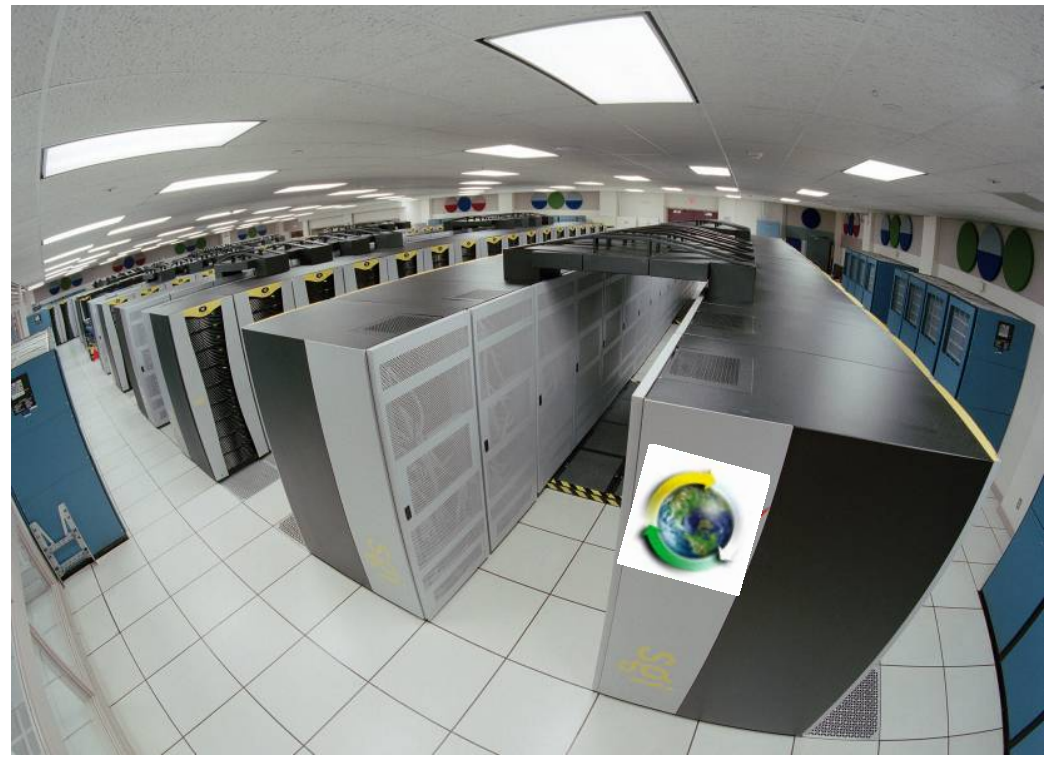

Goal: The modeling and simulation effort will identify the controlling mechanisms and processes for different waste form materials in a range of geochemical environments at different spatial and temporal scales

- Applied in a general manner to provide a scientifically-defensible basis for waste form development, qualification, and future repository system analysis 


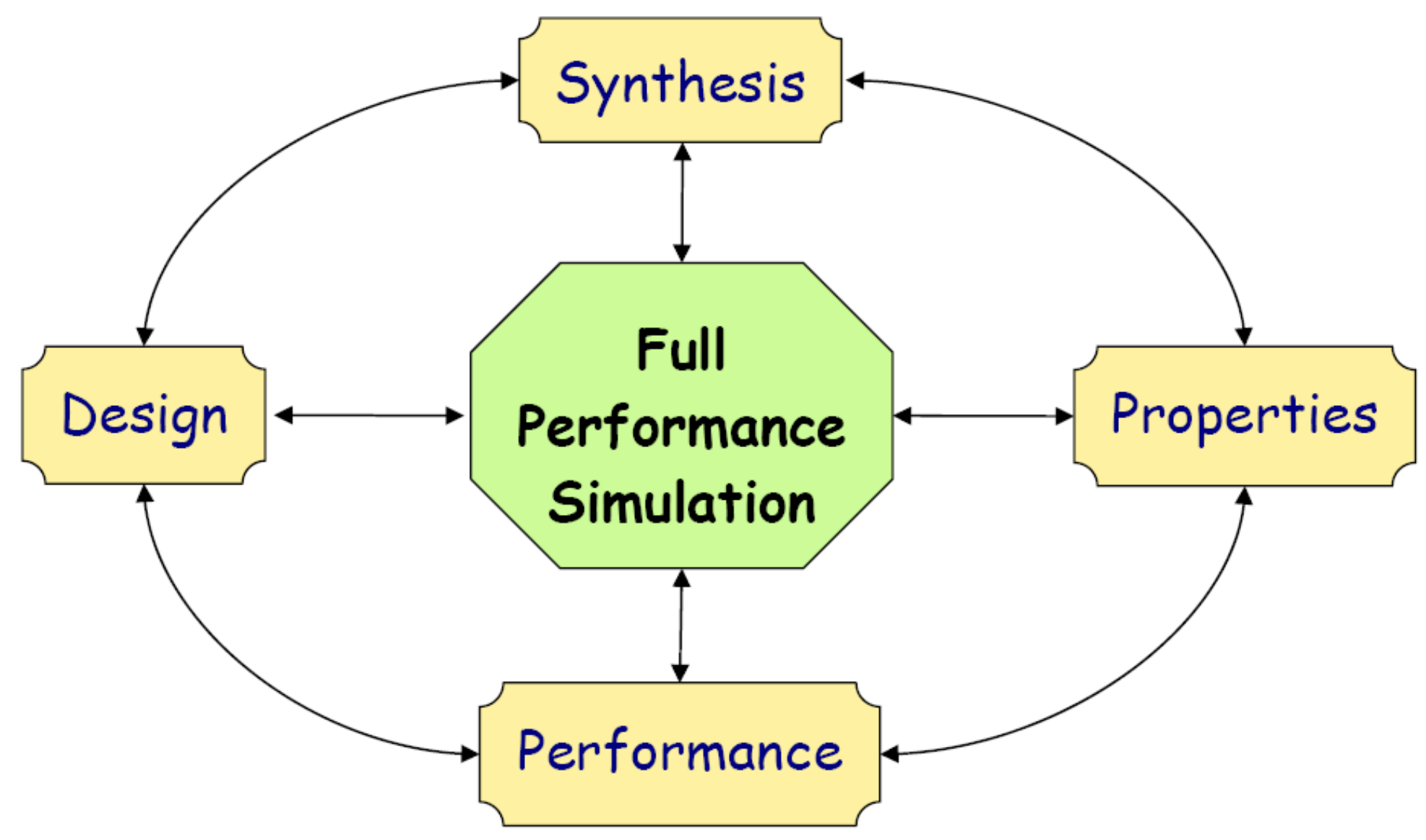

after Tomas de la Rubia (2007) Basic Research Needs for Materials in Extreme Environments 


\section{University Involvement and International Collaborations}

Universities

- Key to the success of GNEP waste form campaign

- Goal is to establish integrated program

- International Collaborations

- France

- Potential collaborative tasks on waste management and advanced waste form S\&T being formulated

- Japan

- Action Plan in place

- Potential collaborative tasks on waste management and advanced waste form S\&T being formulated as Part of Phase 1

- Draft Phase 1 report complete

- Australia

- Action Plan in Place

- Russia

- Action Plan in place

- China

- Action Plan in place 


\section{Yucca Mountain Repository Program}

- Removal of uranium and transuranics and disposition of fission product storage and waste forms as part of a closed fuel cycle would impact the potential technical capacity of Yucca Mountain (assuming statutory limit is adjusted)

- Many factors potentially control the technical capacity of a repository including:

- Postclosure repository performance as measured by radiation dose to the public over 10,000+ years

- Physical area available with suitable geologic and hydrologic characteristics

- Waste form volume

- Waste thermal output

- All of these factors require further analysis before the potential benefits can be clearly understood

- The technical capacity of Yucca Mountain will be capable of accommodating several generations of waste should the technologies being pursued under the GNEP prove successful 


\section{Environmental Management Engineering and Technology}

- DOE Environmental Management E\&T program is evolving and planning additional investment in processing and waste management technology development

U.S. Department of Energy Office of Environmental Management (DOE-EM)

\section{Engineering \& Technology Roadmap}

Reducing Technical Risk and Uncertainty in the EM Program

March 2008 success of GNEP in S\&T and development of integrated waste management strategy 


\section{Questions and Discussion}




\section{BES Workshop - "Basic Research Needs for Advanced Nuclear Energy Systems"}

Advanced Waste Forms

- Basic Science Challenges, Opportunities, and Research Needs

- Novel materials for advanced waste forms

- Long-term predictions of advanced-waste-form performance in the natural environment

- Thermodynamics for complex systems

- Radiation and radiolysis effects

- Interfaces and nano-scale dynamic behavior
Basic Research Needs for Advanced Nuclear Energy Systems

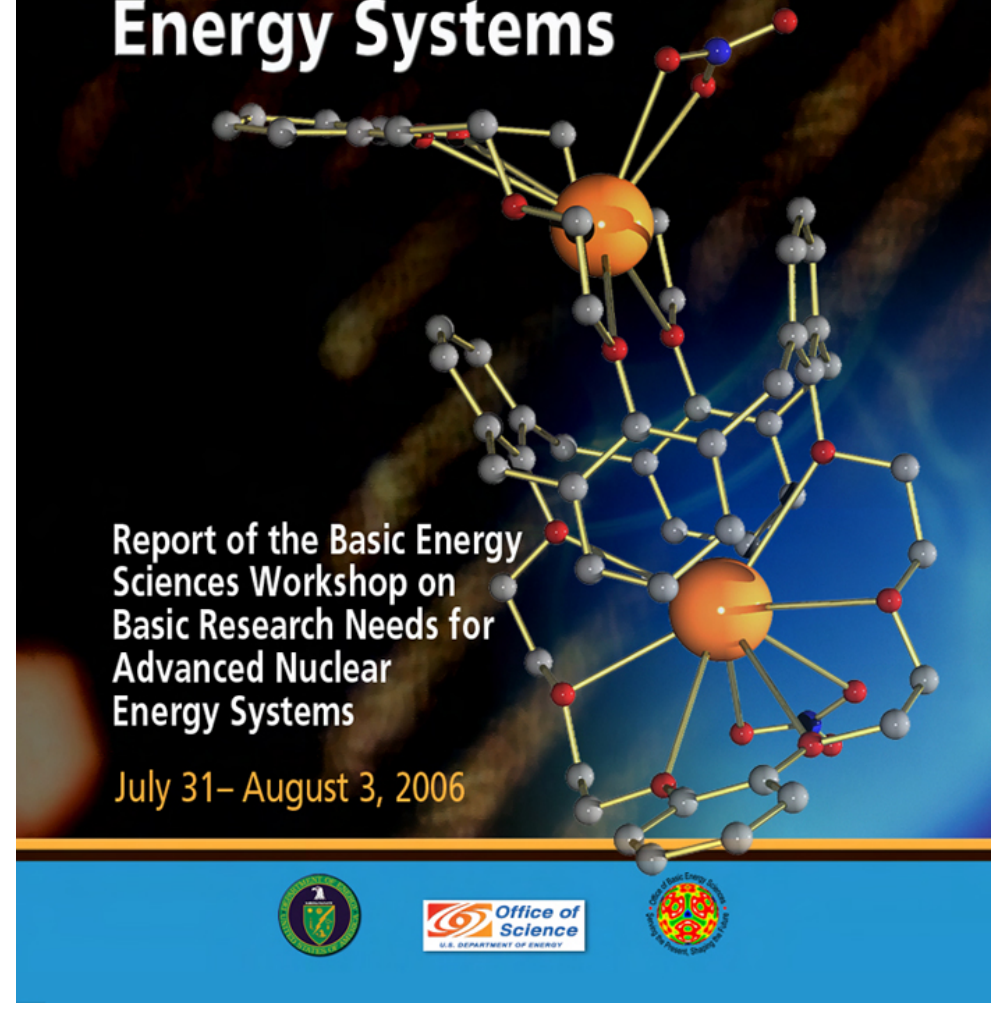




\section{ASCR/NE Workshop - "Simulation and Modeling for Advanced Nuclear Energy Systems"}

Repository Modeling

- Waste Form and Material Degradation

- High Fidelity Assessment of the Geochemical Environment

- Software Infrastructure for Coupled System Performance Assessment

- Uncertainty Propagation

- Visualization

- Modernizing and Parallelizing Existing Legacy Codes

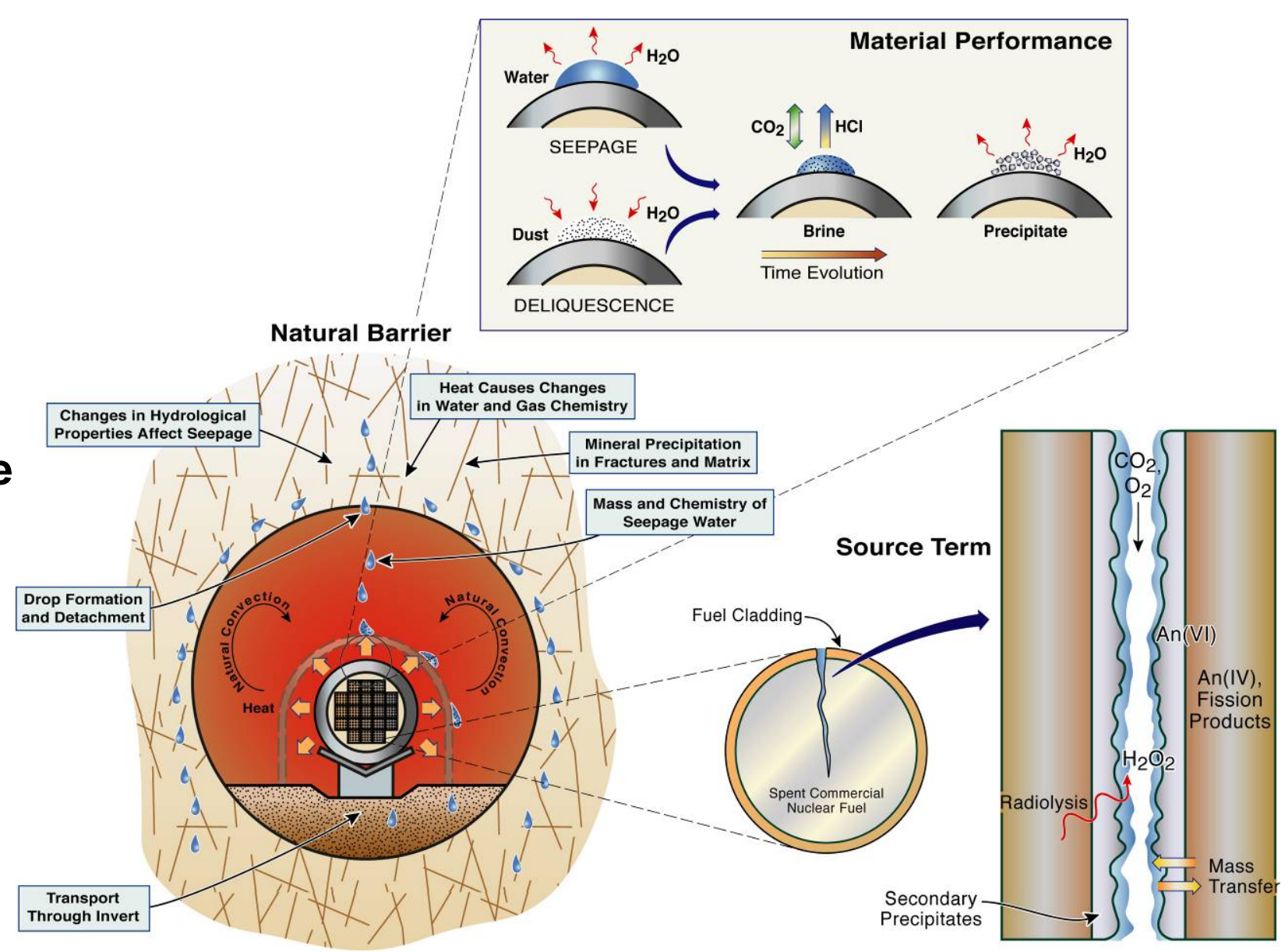


- Priority Research Directions

- Chemistry of mineral surfaces, nanophases, and solutions

- Subsurface monitoring, imaging, and characterization

- Physics and chemistry of multiscale systems

- Biogeochemistry
BASIC RESEARCH NEEDS FOR GEOSCIENCES:

FACILITATING $21^{\text {ST }}$ CENTURY ENERGY SYSTEMS

From the workshop sponsored by the

U.S. Department of Energy, Office of Basic Energy Sciences

Bethesda MD • February 21-23, 2007
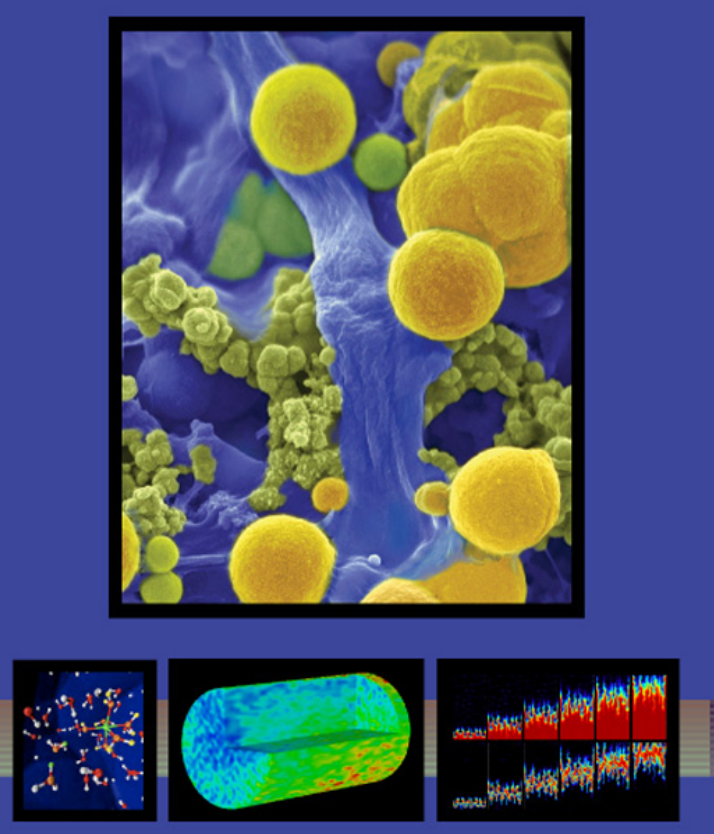


\title{
Advanced Fuel Cycle Safeguards
}

\author{
Michael Miller \\ GNEP Safeguards Campaign Director \\ Los Alamos National Laboratory \\ U.S. Nuclear Regulatory Commission \\ Rockville, MD \\ June 10, 2008
}




\section{Outline}

- Introduction and Current Technical Basis

- Reprocessing

Fuel Fabrication

- Fast Reactor 


\section{Introduction and Current Technical Basis}

- Comparison of NRC, DOE, IAEA Definitions and Requirements

- Fundamentals of NDA

- Gamma-ray Based Instruments

- Neutron Based Instruments

- Calorimetry 


\section{Comparison of NRC, DOE, IAEA Definitions and Requirements}




\section{Safeguard Regimes}

Three Safeguard Regimes

- NRC: Regulates commercial nuclear facilities

- DOE: Regulates defense nuclear facilities

- IAEA: Applies safeguards to Nonproliferation Treaty signatories

- Purpose of Safeguard Regimes

- Domestic (NRC and DOE)

- Protect against sabotage, theft and other threats of direct concern to the government and operators of the facility

- International (IAEA)

- Goal is to detect diversion of significant amounts of fissile nuclear materials by the State/facility operator through verification of the State's declaration 


\section{Types of Safeguards Measures}

- Nuclear Material Accounting

- Establishing the quantities of nuclear material present within defined areas and the changes in those quantities within defined periods.

- Containment and Surveillance

- Ensures previously measured material in containers remains in place and unaltered or moves along declared and authorized paths

- Examples: video and seals

- Process Monitoring

- The use of process data (flow rate, temperature, pressure, density, etc.) to draw frequent conclusions on plant configurations, operations and material flows/inventories

- Necessary for In-process, interim inventories 


\section{Safeguards Goal of Material Balance Areas (MBAs)}

- Fully measured material balance

- All materials accounted for

- All materials have measured values 


\section{DOE Definition of MBA}

Subsidiary account of facility

Geographical area with defined boundaries

Identify location and quantity of nuclear materials 


\section{NRC Definition of MBA}

- Identifiable physical area

Quantify nuclear material with measured values 


\section{IAEA Definition of MBA}

Quantity of nuclear material in transfers can be determined

Physical inventory can be determined

Establish a material balance 


\section{Views of the MBA - Accountant}

- Start with a "known" listing of material

- Record receipts and shipments

- The result is the ending, or "book" inventory:

$\mathrm{BI}+\mathrm{TI}-\mathrm{TO}=$ Book Inventory

- Verify that book inventory = physical inventory

$$
\text { MB = Book inventory }- \text { Physical Inventory }
$$




\section{Views of the MBA - Scientist}

- MBA is the "closed system" for which mass is conserved

Determine the inventory through measurement at end of period

- Measure all the terms and determine the difference

$$
\text { Mass Balance }=\mathrm{BI}-\mathrm{EI}+\mathrm{TI}-\mathrm{TO}
$$




\section{Views of the MBA - Physical Protection}

What is the target?

Where is the target located?

An area containing nuclear material that:

Must have controls

Must be protected 


\section{Summary of MBA definitions}

Accounting unit of facility

Physical location

- Measure materials

Establish a material balance; loss detection 


\section{Material Accountancy}

- Inventory Types

- Long-term, Shut down Inventory

- Every 6-12 months the facility must cease processing and determine the amount of material contained within the facility

- Interim Inventory, Shut down not required

- Every 1-2 months the facility must determine the amount of material within the facility, but shut-down is not required

- In-process inventory is normally performed

- More difficult than shut down inventory

- Larger errors due to estimates of material quantities 


\section{Material Accountancy}

- Detection requirements

- Inventory Difference (Material Balance, Material Unaccounted For) must be determined within certain error limits

- Those error limits determine how well the material must be measured

- Each regime has different error limits 


\section{Inventory Difference}

- Inventory Difference (ID) $=$

Beginning physical inventory

+ Sum of increases to inventory (receipts)

- Sum of decreases from inventory (shipments)

- Ending physical inventory

- Sigma ID

- The uncertainty in the ID

- A statistical combination of the uncertainty of each measurement that makes up the ID

- Determines what losses you can detect 


\begin{tabular}{|l|l|l|l|l|}
\hline Agency & $\begin{array}{l}\text { Goal/ } \\
\text { Requirement } \\
\text { Terms }\end{array}$ & Sigma ID & $\begin{array}{l}\text { Frequency of } \\
\text { Long-Term, } \\
\text { Shutdown } \\
\text { Inventory }\end{array}$ & $\begin{array}{l}\text { Frequency of } \\
\text { Interim Inventory, } \\
\text { Shutdown Not } \\
\text { Required }\end{array}$ \\
\hline IAEA & $\begin{array}{l}\text { Material Unaccounted For } \\
\text { (MUF): } \\
\text { 8kgs Pu abrupt in one } \\
\text { month and 8kgs protracted } \\
\text { in one year }\end{array}$ & $\begin{array}{l}\text { Sigma ID }<=2.42 \\
\text { kg of Pu }\end{array}$ & Annual & Monthly \\
\hline NRC & $\begin{array}{l}\text { Standard Error of Inventory } \\
\text { Difference (SEID) }\end{array}$ & $\begin{array}{l}\text { Sigma ID <=0.1\% } \\
\text { of active inventory }\end{array}$ & Semi-Annual & Monthly \\
\hline DOE & $\begin{array}{l}\text { Limit of Error (LOE) } \\
\text { Sigma ID <= 1\% } \\
\text { of active inventory } \\
\text { or Category II of } \\
\text { material }\end{array}$ & $\begin{array}{l}\text { At least } \\
\text { Annually }\end{array}$ & Bi-monthly \\
\hline
\end{tabular}




\section{Rough Estimate of Sigma ID for a Commercial Reprocessing Facility}

- IAEA goal for Sigma ID

- Absolute number

- Independent of the facility's throughput

- More challenging for high throughput facilities.

- NRC and DOE requirements for Sigma ID

- Percentages of the active inventory

- Change with the throughput

- Current NRC requirement is the most challenging of the three, even for this high throughput facility.

\begin{tabular}{|l|l|}
\hline $\begin{array}{l}\text { LWR Spent Fuel Processed per } \\
\text { year }\end{array}$ & $800 \mathrm{MTHM}$ \\
\hline $\begin{array}{l}\text { Pu processed/yr } \\
\text { (1\% of spent fuel) }\end{array}$ & $8,000 \mathrm{~kg}$ \\
\hline $\begin{array}{l}\text { Pu processed per month } \\
\text { (assumed to be active } \\
\text { inventory at time of shut down } \\
\text { inventory) }\end{array}$ & $667 \mathrm{~kg}$ \\
\hline $\begin{array}{l}\text { NRC's Sigma ID is } 0.1 \% \text { of } \\
\text { active inventory }\end{array}$ & $667 \mathrm{~g}$ \\
\hline $\begin{array}{l}\text { DOE's Sigma ID is 1\% of active } \\
\text { inventory }\end{array}$ & $6.67 \mathrm{~kg}$ \\
\hline IAEA's goal for Sigma ID & $2.42 \mathrm{~kg} \mathrm{Pu}$ \\
\hline
\end{tabular}




\section{Improving Safeguards Effectiveness}

- Reduce sigma ID

- Better measurements

- Less material

- Smaller material balance areas

- More frequent inventories

- Additional Measures

- C/S

- Processing Monitoring

- Access

- Inspector Presence

- But, quantification needed 


\section{Fundamentals of NDA}

EST. 1943 


\section{The Fully Measured Material Balance}

- Strive for highest possible accuracy

- Minimize uncertainty in Material Unaccounted For (MUF)

- Preferred measurement techniques

- weighing, combined with

- destructive analysis of samples
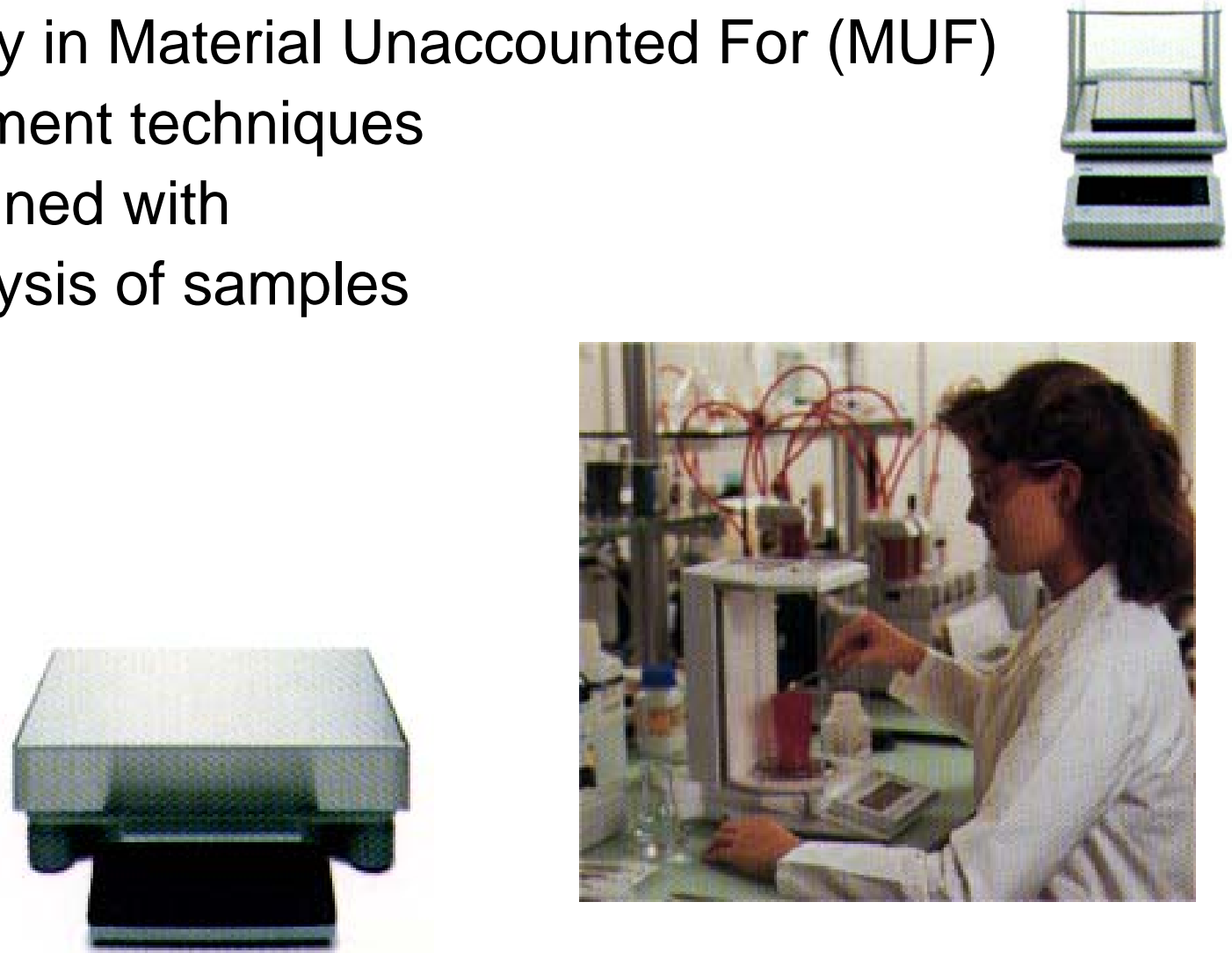
Some SNM items cannot, in practice, be measured by DA

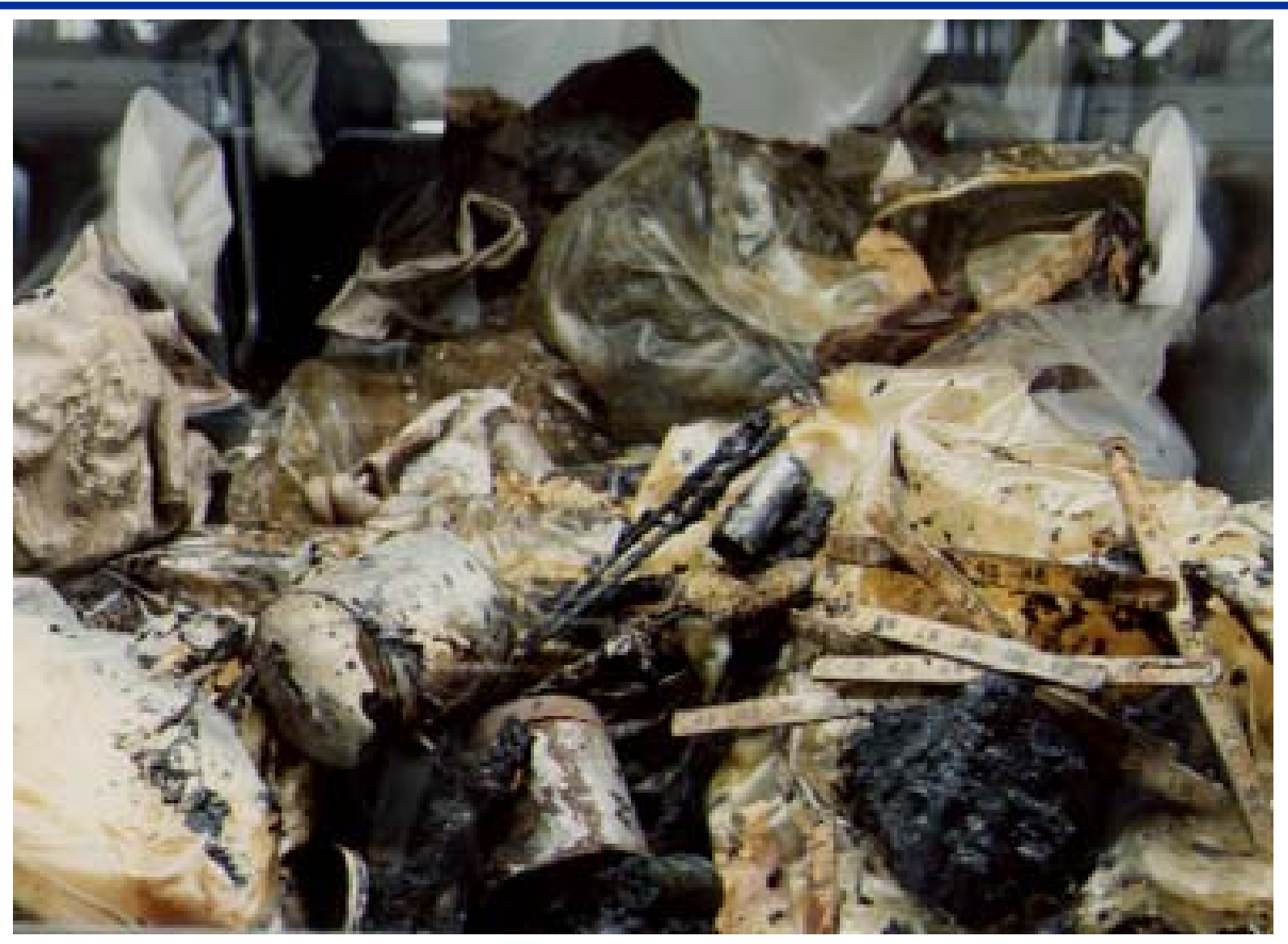

waste, scrap, sealed product, unknown items, etc. 


\section{SNM Sample Containers}

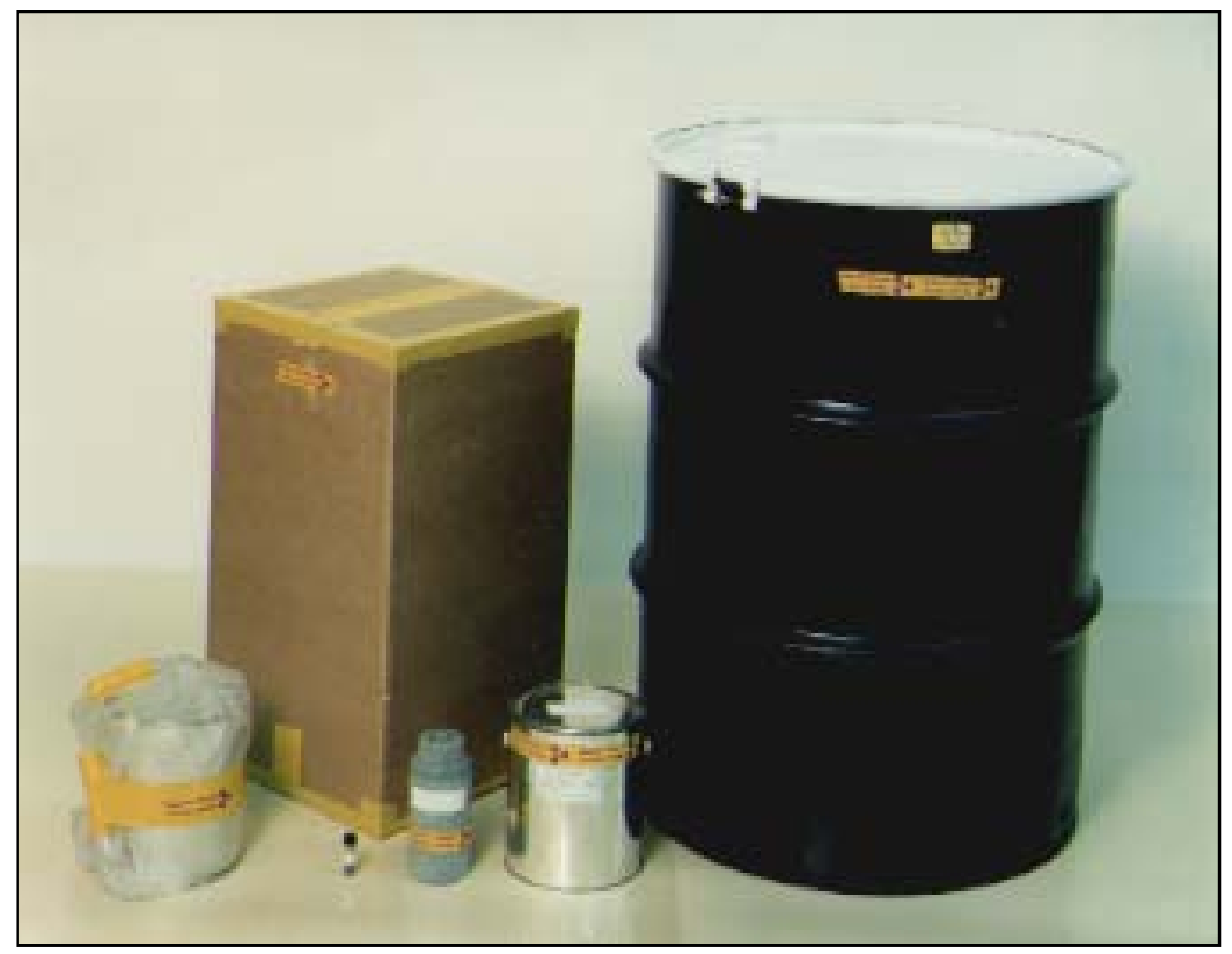

SNM comes not only in a variety of physical and chemical forms, but also in a variety of containers. Each container has an effect on the absorption of the emitted radiation and the measurement result. 


\section{Nondestructive Assay (NDA)}

The quantitative or qualitative determination of the kind and/or amount of nuclear material in a sample without alteration or invasion of the sample. 


\section{Basic Measurement Principle}

Since each gram of a given isotope decays at a specified rate, the amount of radiation per second is proportional to the number of grams of the SNM in question.

The measured radiation is proportional to the amount of SNM in the sample IF...

- all of the radiation produced in the sample is emitted, and - all of the emitted radiation is detected

These assumptions are hardly ever met, so data analysis must correct for the "missing" radiation. This is the main challenge in developing SNM measurement techniques and instruments. 


\section{Role of NDA}

- Rapid verification

- Measurements of poorly-characterized items

- Assay or verification of sealed items

- items in storage

- temporarily sealed items (from cleanout, scrap, ...)

- fuel rods and assemblies

- Measurement of holdup (ducts, pipes, gloveboxes)

- Support of audits \& inspections

- by outside agencies (IAEA, Euratom, ABBACC, GAN,...)

- by in-plant inspectors for internal assessments 


\section{Uses for NDA}

- Ore location

- Process Control

- Quality control

- Health \& safety

- Criticality control

- Material control

- Materials Accounting

- Waste characterization/verification/screening

- Nuclear Inspections (nonproliferation, arms control, regulation) 


\section{SNM Attributes}

Emits alpha \& beta radiation

- Emits gamma $(\gamma)$ radiation

Emits infra-red (heat) radiation

- [from $\alpha$ emissions into the matrix]

Emits singles neutrons

- [from $(\alpha, n)$ matrix interactions, delayed neutrons]

Emits coincidence neutron radiation

- [from spontaneous and induced fissions in the sample]

- Is fissionable - can be induced to fission with neutrons. 


\section{Passive vs. Active NDA}

Passive NDA: Measure the radiation emitted spontaneously by the sample.

Active NDA: Irradiate the sample and measure its response to the radiation. 


\section{Examples of Confirmatory Measurements}

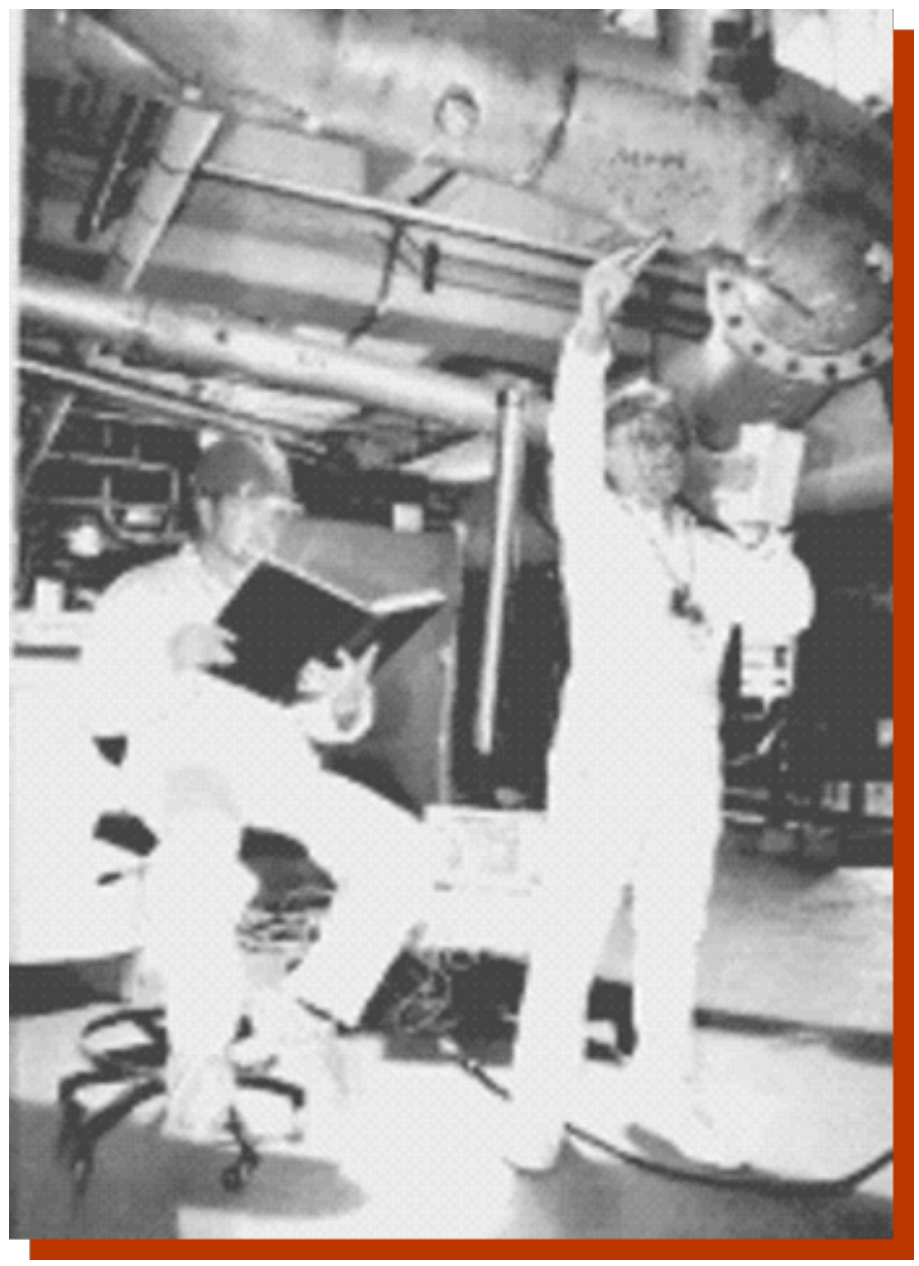

A Geiger counter is used to survey ductwork in a reprocessing plant to locate radioactive deposits.

Quantitative holdup measurements then focus on these locations to determine the in-plant holdup. 


\section{Examples of Verification Measurements}

Quantitative measurements - not used to replace accountability values.

- Sampling of SNM inventory during inspection

- Mass measurements during some emergency inventories 


\section{Gamma-ray Based Instruments}

EST. 1943 


\section{Basic Gamma-Ray Assay}

- Specific gamma rays (identified by energy) indicate the isotopic composition of the sample.

- Intensity of the gamma rays indicate the amount of the isotope. 


\section{Generic $\gamma$-Ray Assay Equation}

\section{$\mathbf{M}_{\mathrm{SNM}}=\frac{\mathbf{R}_{\mathrm{Rad}} \cdot \mathbf{C F}}{\mathbf{K}}$}

$M_{\text {SNM }}=$ Mass of Special Nuclear Material (SNM)

$R_{\text {Rad }}=$ measured radiation rate (counts per second) from SNM sample

CF = correction for losses due to:

- Sample self-absorption

- Container absorption

- Measurement system electronics

$\mathrm{K}=$ Calibration constant (corrected response/gram SNM) 


\section{Gamma-Ray Signature}

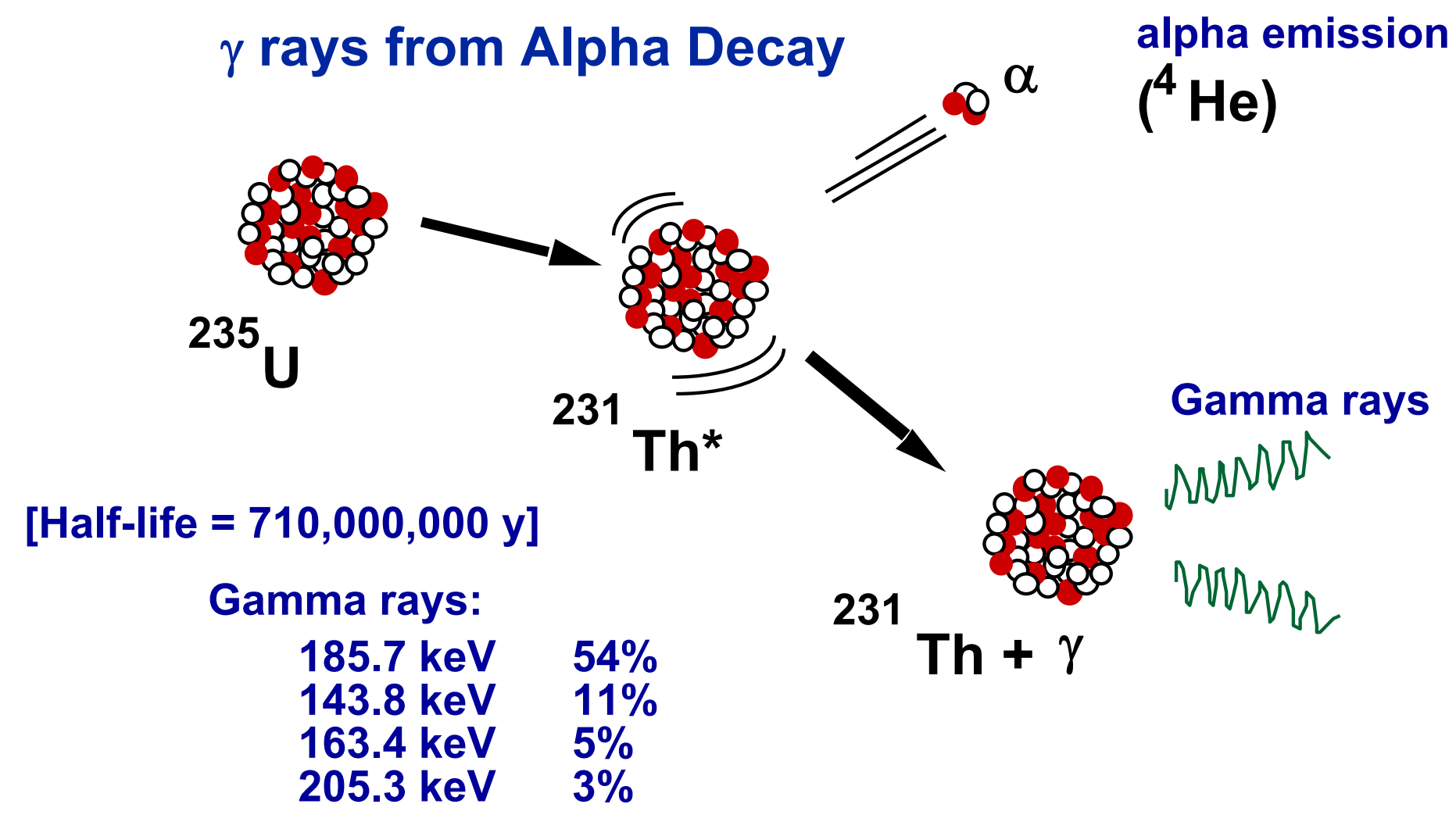




\section{Major $\gamma$-Ray Signatures}

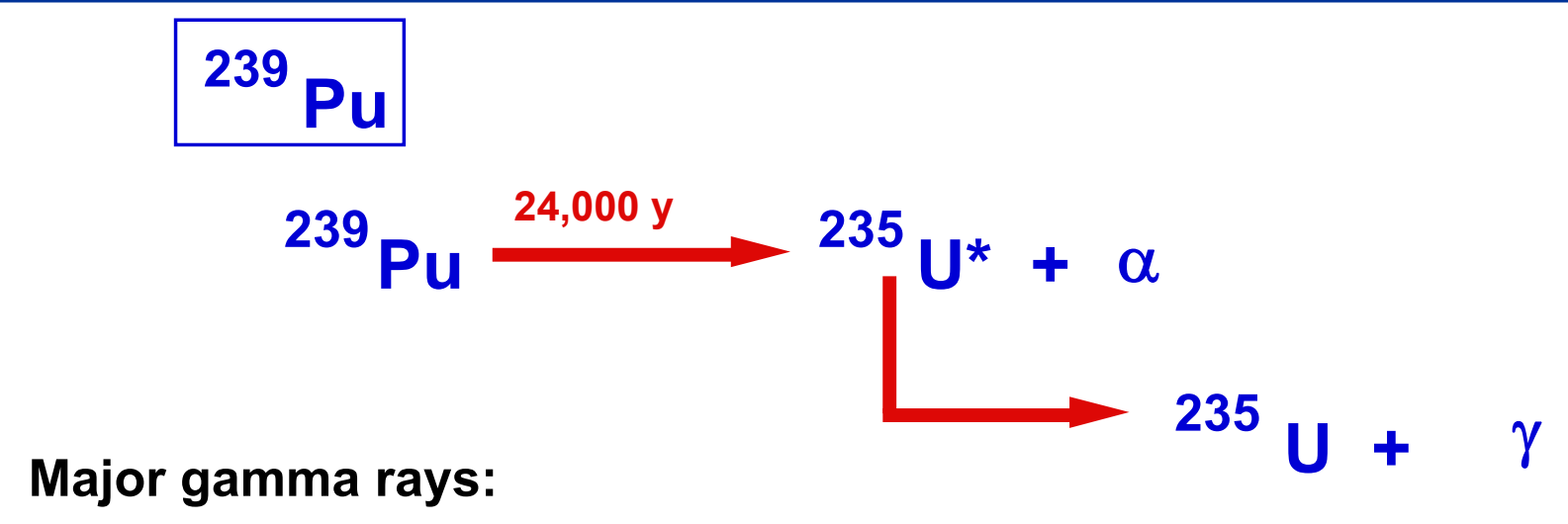

$129.28 \mathrm{keV}$ Intensity 140,000 gammas/(g-sec)

$413.69 \mathrm{keV}$ Intensity 34,000 gammas/(g-sec)

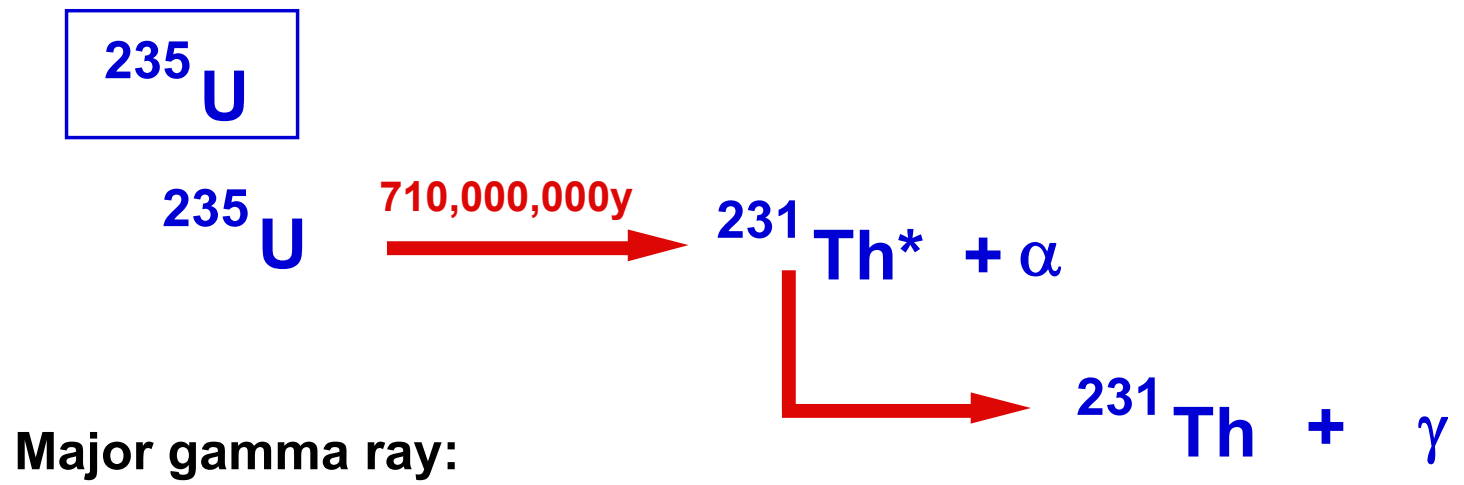

$185.72 \mathrm{keV}$ Intensity $\mathbf{4 3 , 0 0 0}$ gammas/(g-sec) 


\section{Interaction of Gamma Rays with Matter}

\section{PHOTOELECTRIC Effect}

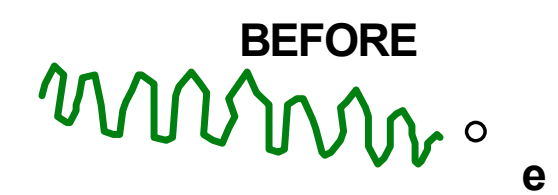

AFTER

e

Gamma ray (or x ray) "collides" with atomic electron, and

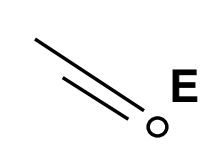

imparts ALL of its energy
to that electron

\section{COMPTON Effect}
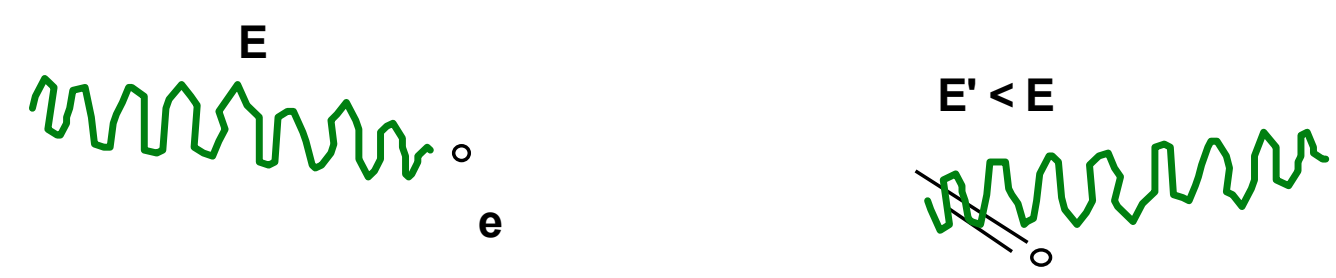

Gamma ray (or x ray) "scatters" off an atomic electron, and

imparts PART of its energy to that electron 


\section{Absorption of $\gamma$-Rays}

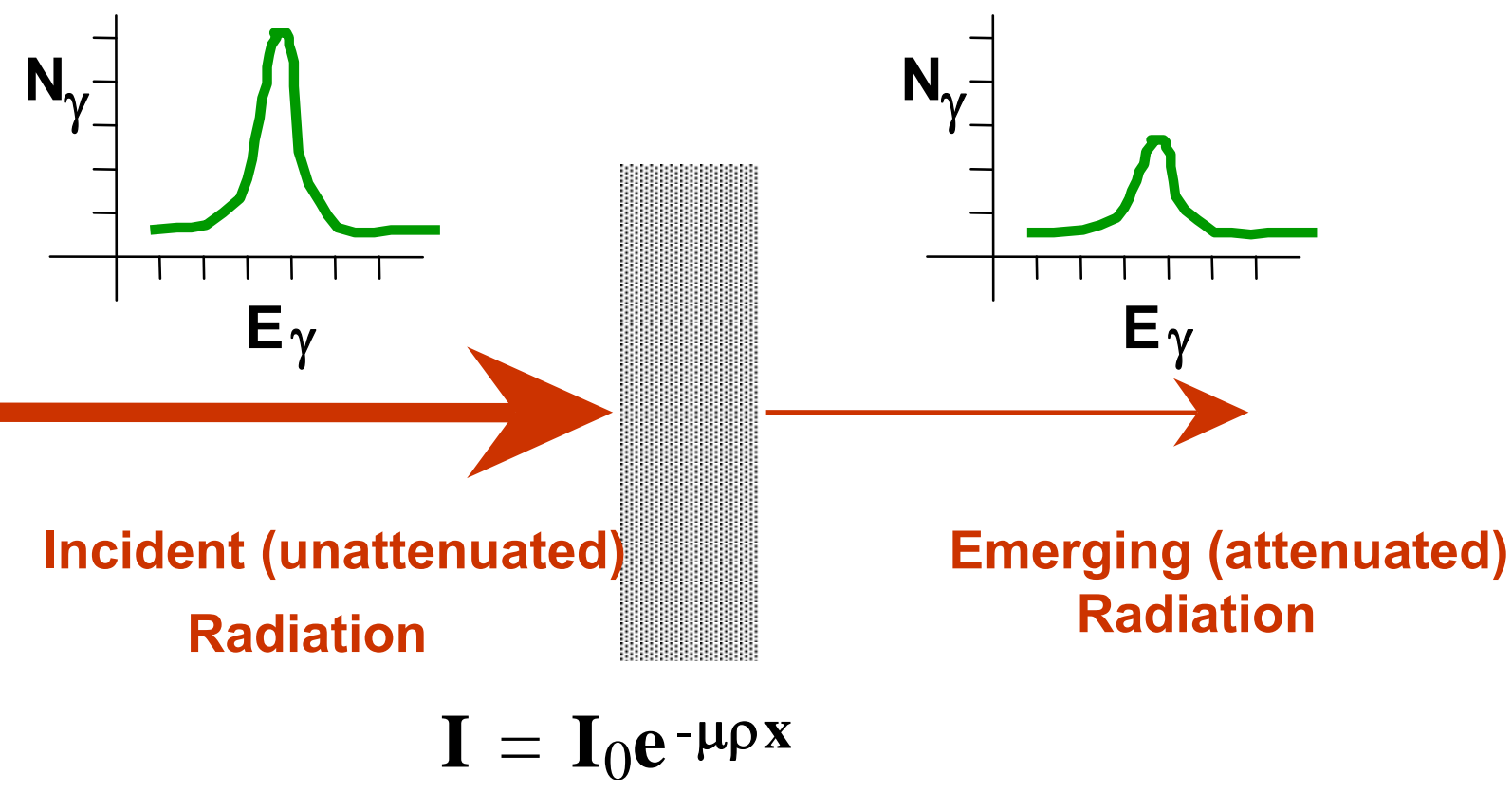

Transmission, $\mathbf{T}=\mathbf{I} / \mathbf{I}_{0}=\mathbf{e}^{-\mu \rho \mathbf{x}}$

$\rho=$ density $\left(\mathrm{g} / \mathrm{cm}^{3}\right)$

$\mu=$ mass absorption coefficient $\left(\mathrm{cm}^{2} / \mathrm{g}\right)$

$x=$ thickness $(\mathrm{cm})$ 


\section{Mass Absorption Coefficient}

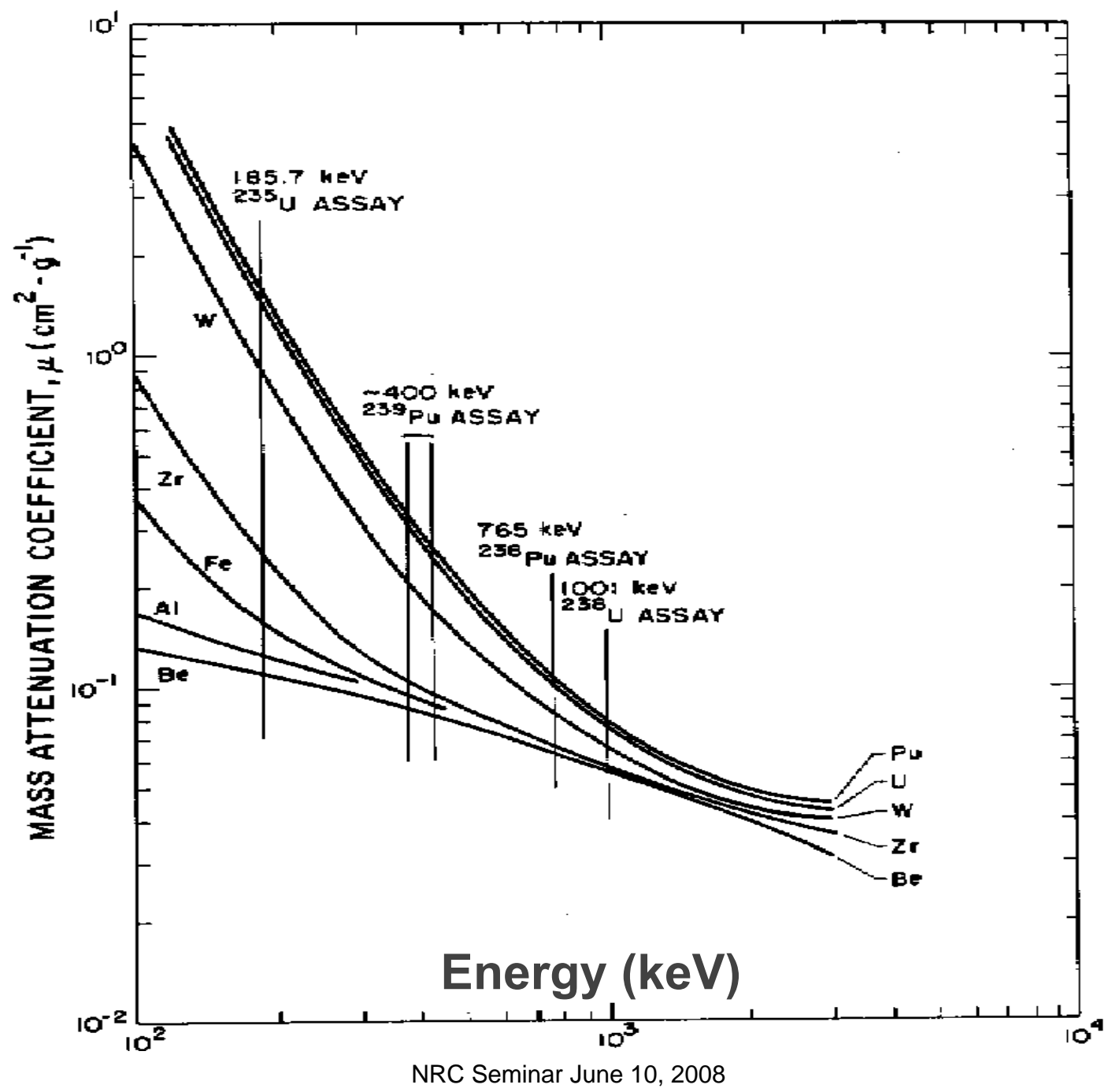




\section{Nal Scintillation Detector}
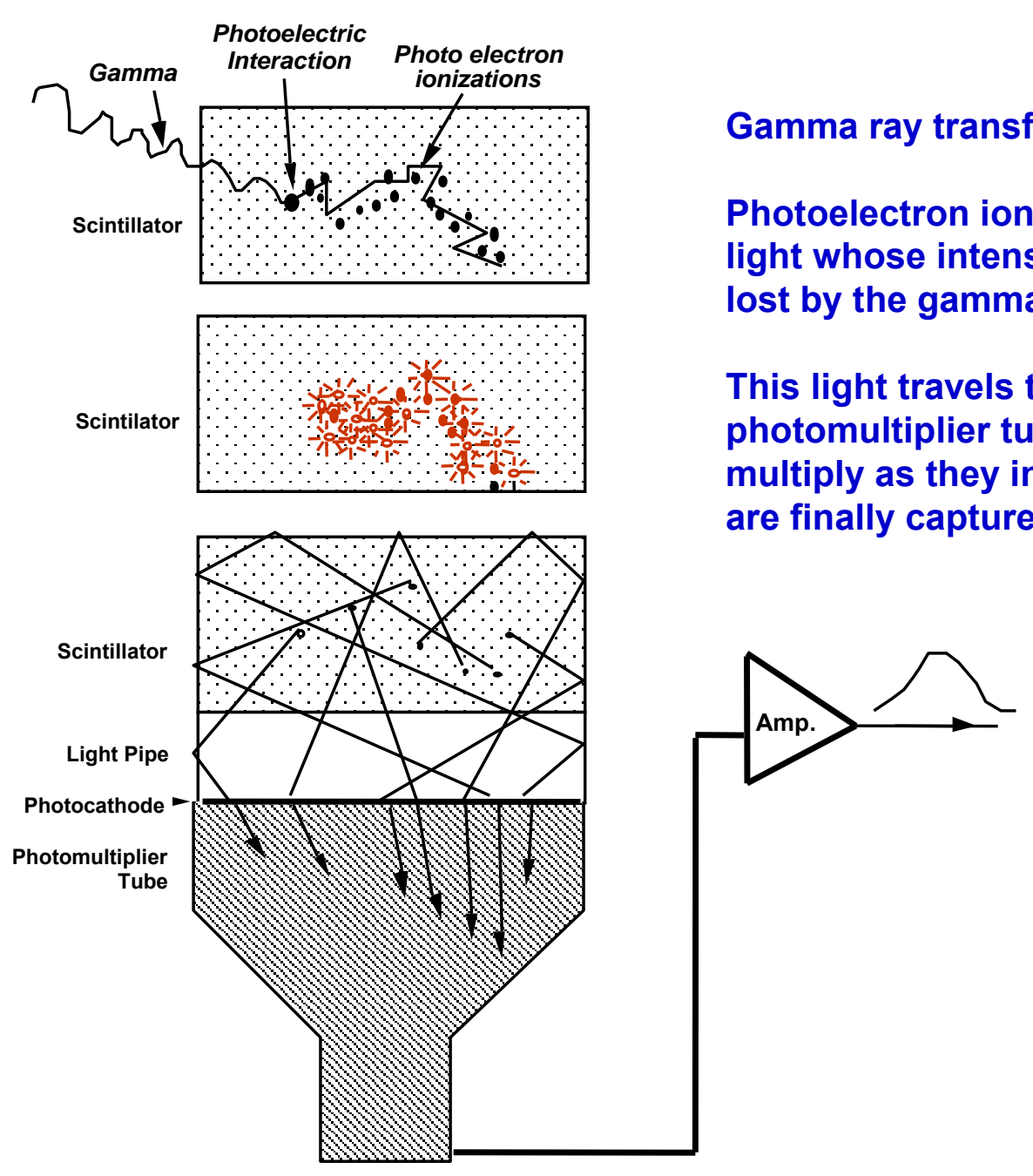

NRC Seminar June 10, 2008
Gamma ray transfers all of its energy to an electron.

Photoelectron ionizes atoms which relax by emitting light whose intensity is proportional to the energy lost by the gamma ray.

This light travels to the photocathode of a photomultiplier tube, which emits electrons that multiply as they interact with the dynode string and are finally captured by the anode. 


\section{HPGe Solid-State Detector}

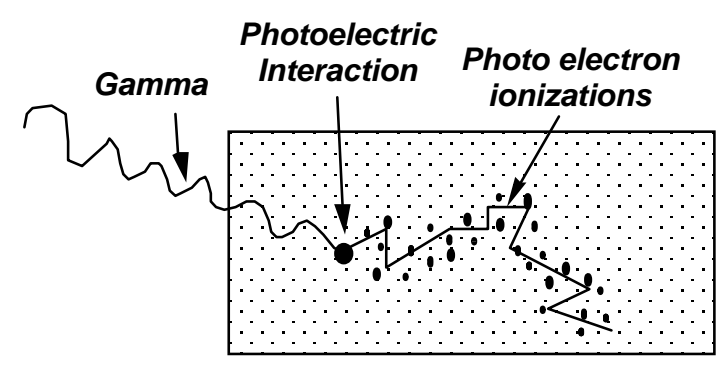

Photoelectron ionizes $\mathrm{Ge}$ atoms

liberating charge that is proportional

to the energy lost by the $\gamma$ ray

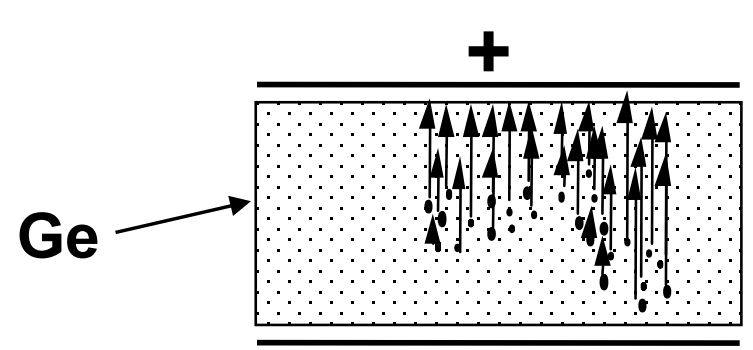

Electrons move toward the positive electrode and "holes" toward the negative one causing a charge pulse

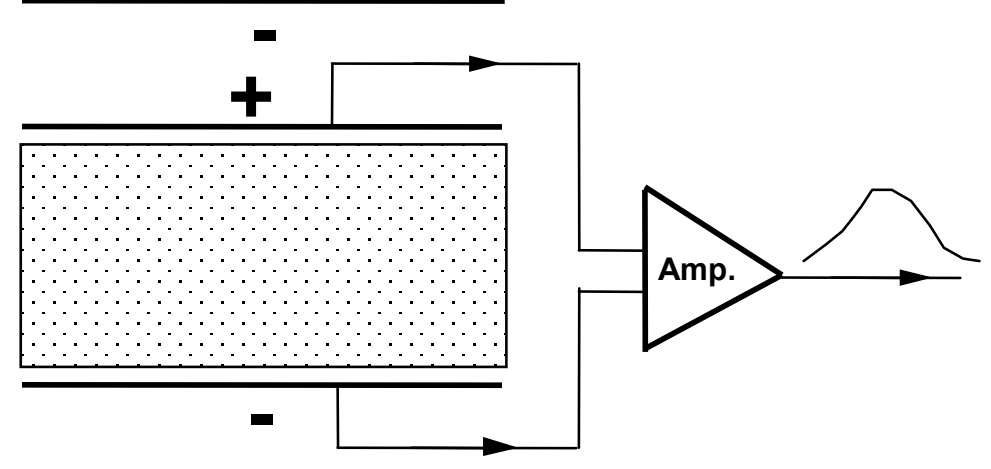

The preamplifier converts the charge pulse to a voltage pulse that is proportional to the energy of the $\gamma$ ray 


\section{Uranium Spectral Features}

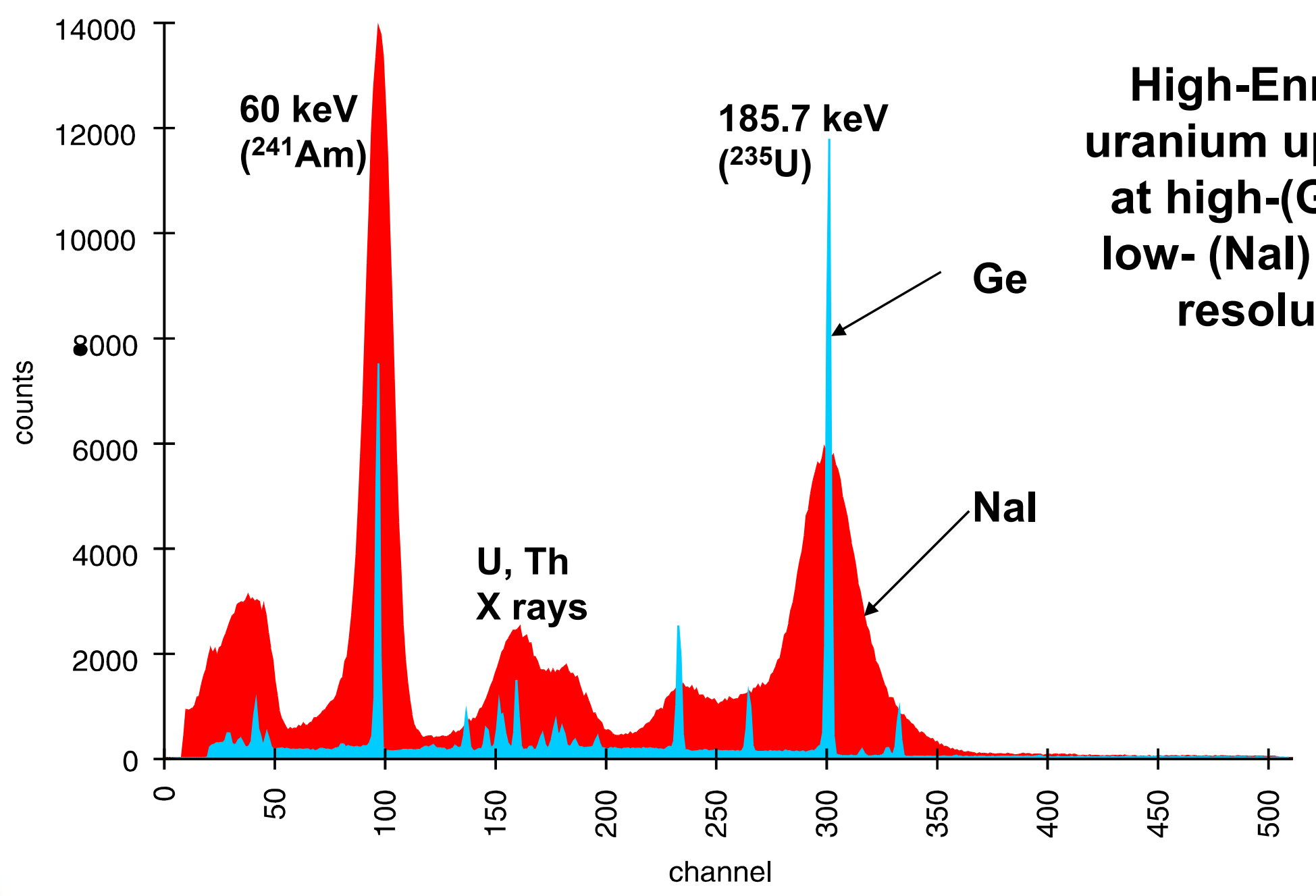




\section{Plutonium Spectra}

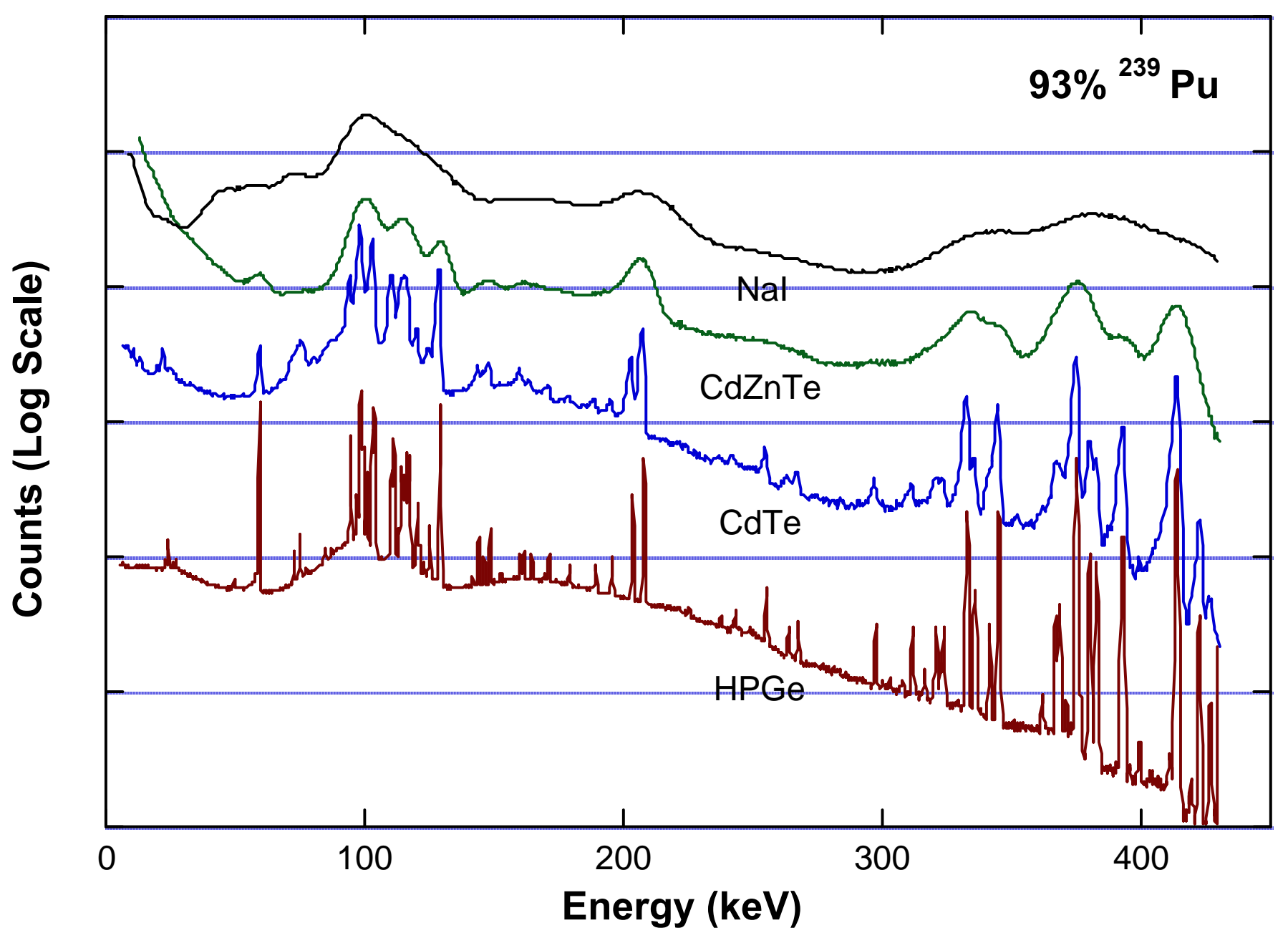




\section{The Isotopic "Fingerprint"}

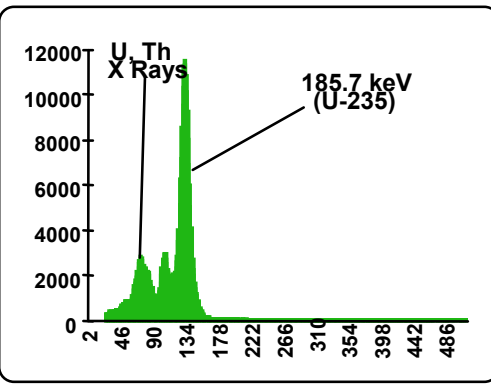

\section{High-Enriched Uranium:}

- $93 \%{ }^{235} \mathrm{U}$, very little ${ }^{238} \mathrm{U}$

- 186-keV gamma-ray peak is strong compared to other radiation, such as $x$-rays

- little background above $186 \mathrm{keV}$ from ${ }^{238 \mathrm{U}}$

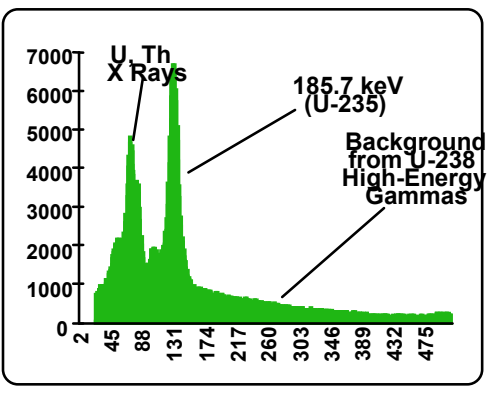

\section{Low-Enriched Uranium}

- $3 \% 235 \mathrm{U}$, mostly $238 \mathrm{U}$

- 186-keV gamma-ray peak is weak compared to other radiation

- significant background above $186 \mathrm{keV}$ from ${ }^{238 \mathrm{U}}$

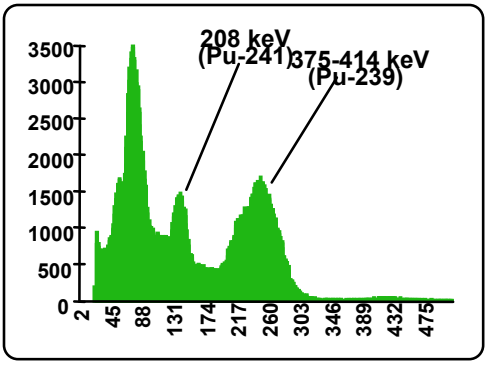

\section{Plutonium:}

- $93 \%{ }^{239} \mathrm{Pu}$, some ${ }^{241} \mathrm{Pu}$

- 414-keV gamma-ray peak from ${ }^{239} \mathrm{Pu}$ evident, as is 208-keV from ${ }^{241} \mathrm{Pu}$ 


\section{Energy Calibration}

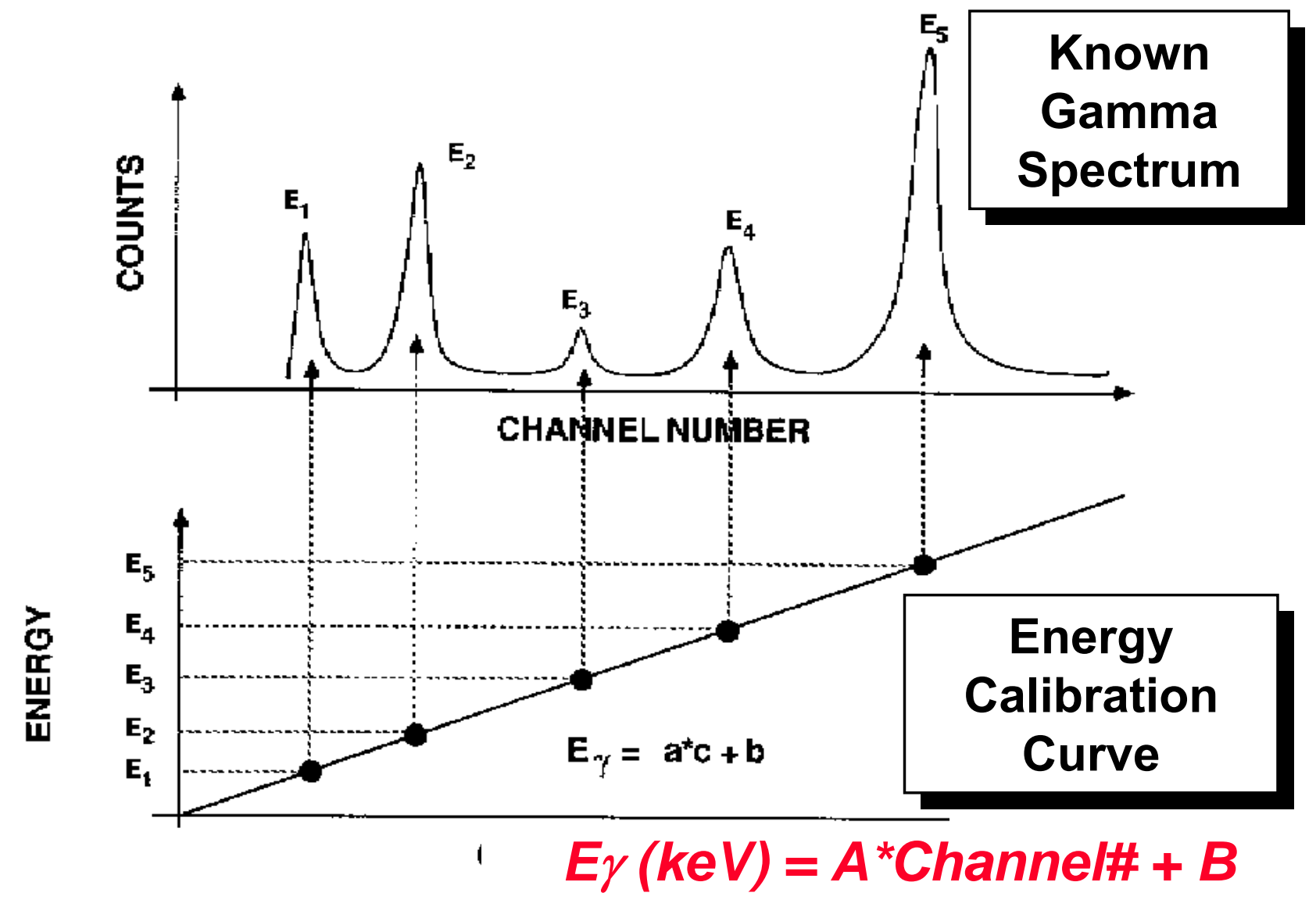

Energy accurate to about $0.1 \mathrm{keV}$ 


\section{Energy Resolution}

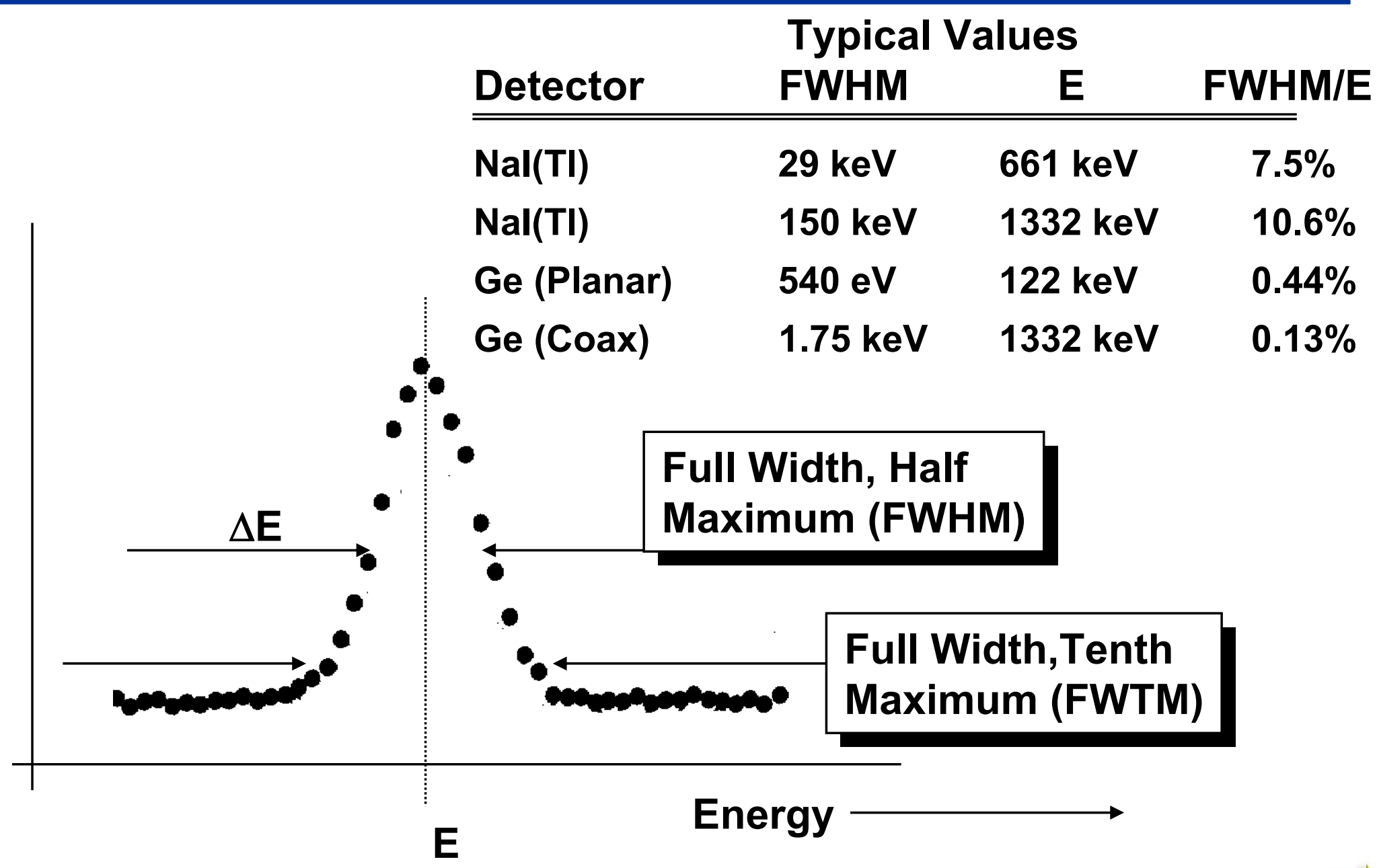


$\gamma$-Ray Photopeak Area Analysis

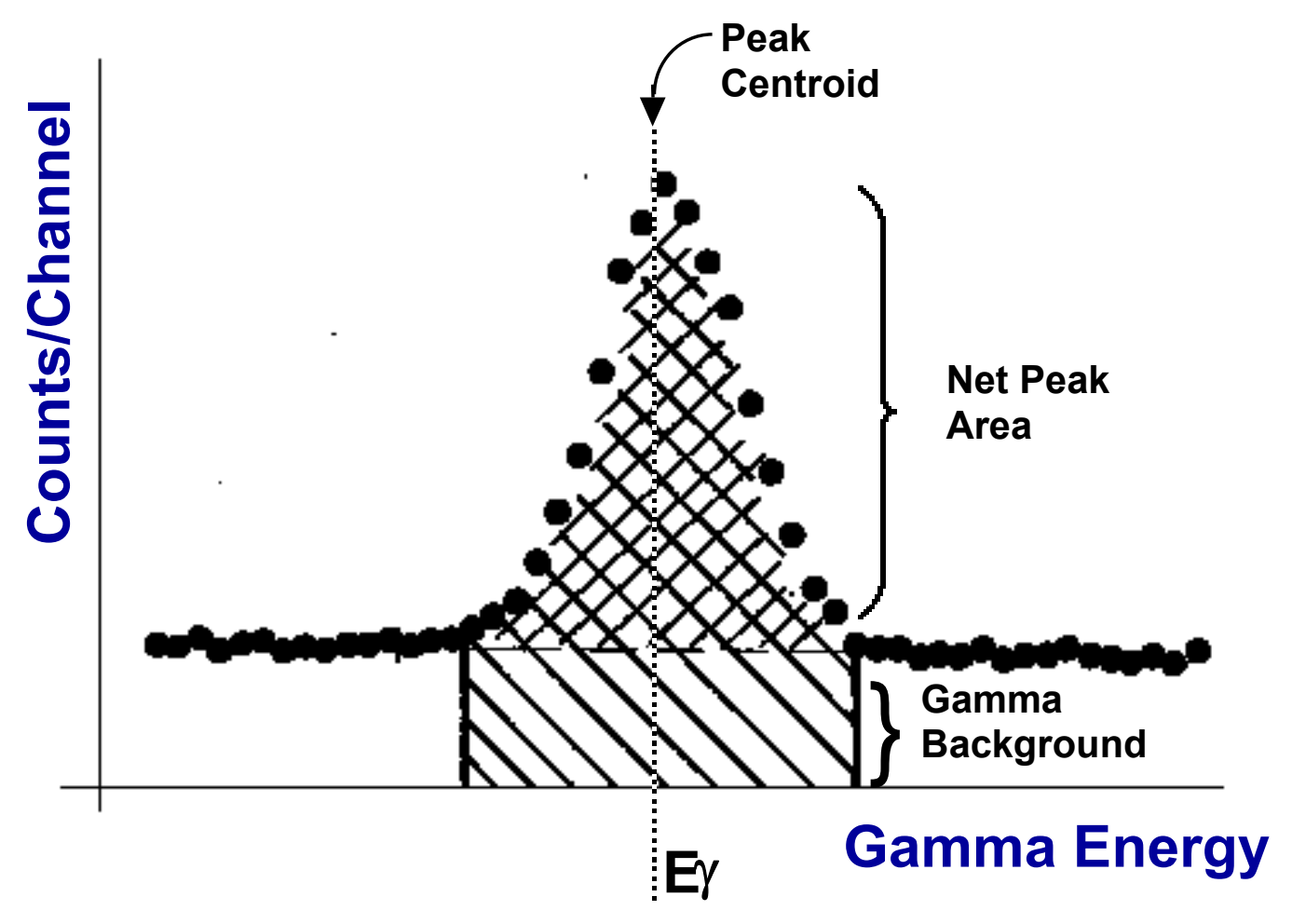

$\gamma$ ray background is evaluated from the Compton continuum on either side of the peak 


\section{Basic Gamma-Ray NDA Setup}

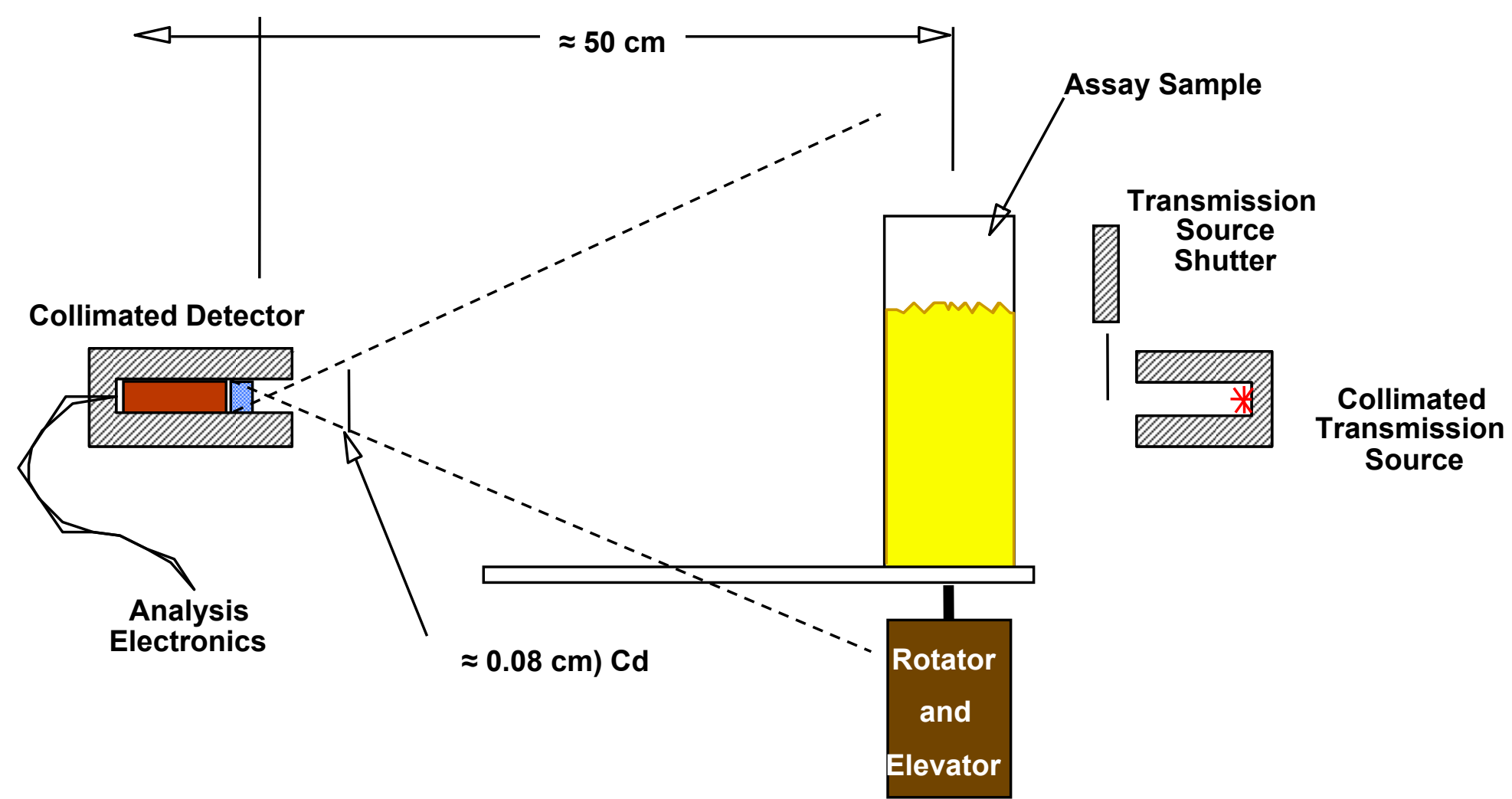

- Transmission source placed on far side of sample from detector.

- Sample mounted on rotating platform, at a distance from the detector.

- Detector views entire sample at one time. 


\section{Gamma Spectroscopy Instrumentation}
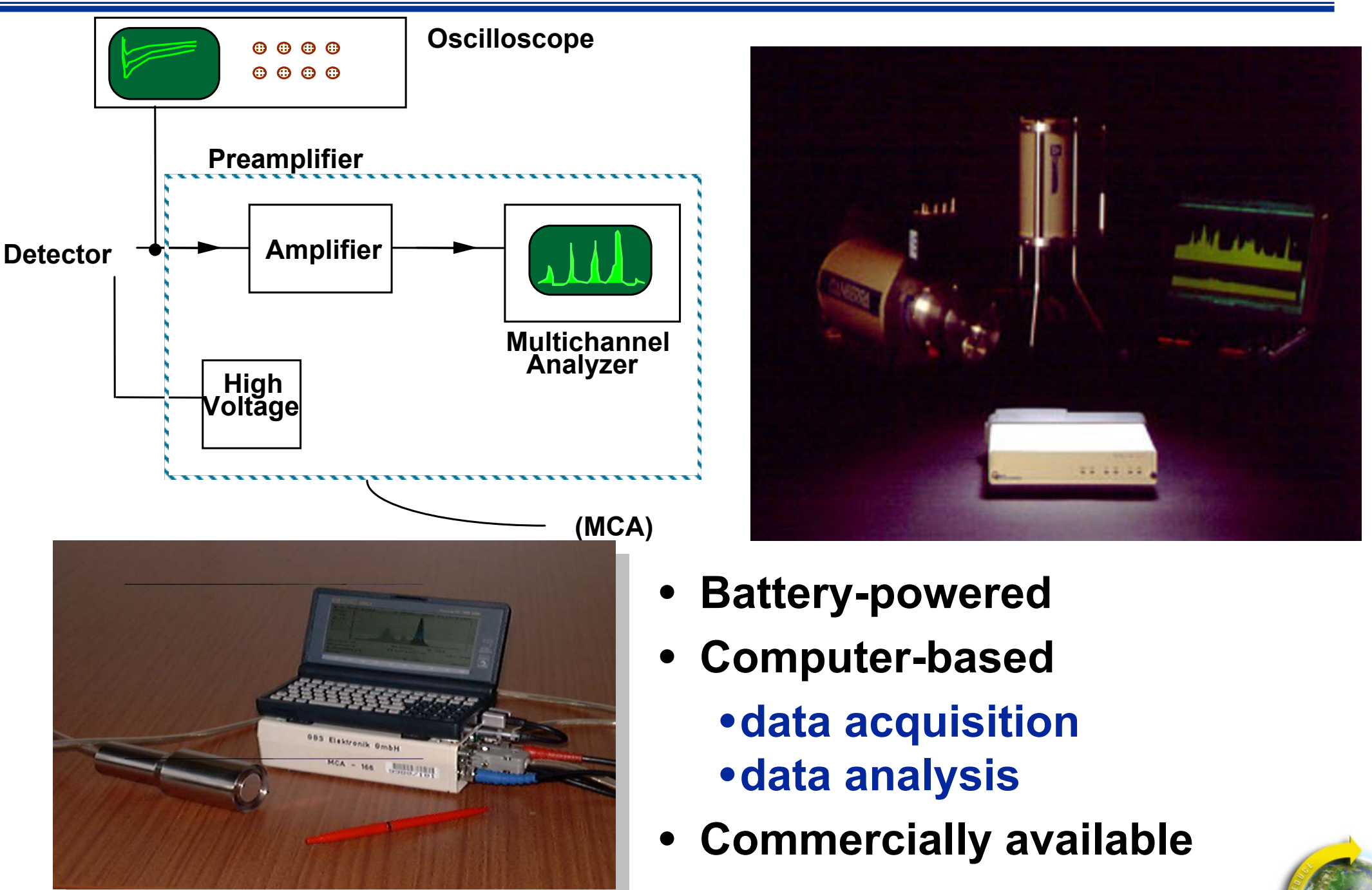

- Battery-powered

- Computer-based

- data acquisition

- data analysis

- Commercially available 


\section{Sample Characteristics for Successful Gamma-Ray Assay}

- Medium to low density

- Medium to small size

- Homogeneous (uniform) material distribution

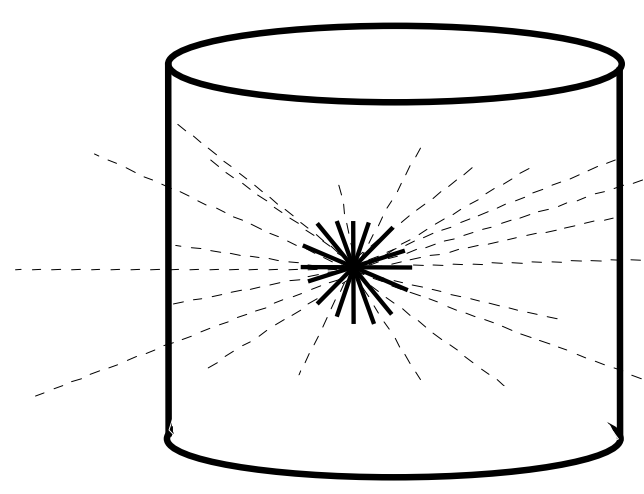

Dense, heterogeneous materials are inappropriate for gamma-ray assay, because they have too much absorption. Such samples are better suited for neutron assay techniques. 


\section{Basic Calibration Procedure}

Purpose: to establish the relationship between the response of the detector system and the amount of SNM in the sample.

- Set up measurement apparatus for assay campaign.

- Establish data acquisition \& analysis procedures.

- Measure known samples (calibration standards) using these procedures and this setup.... 


\section{Example Gamma Assay Calibration Curve}

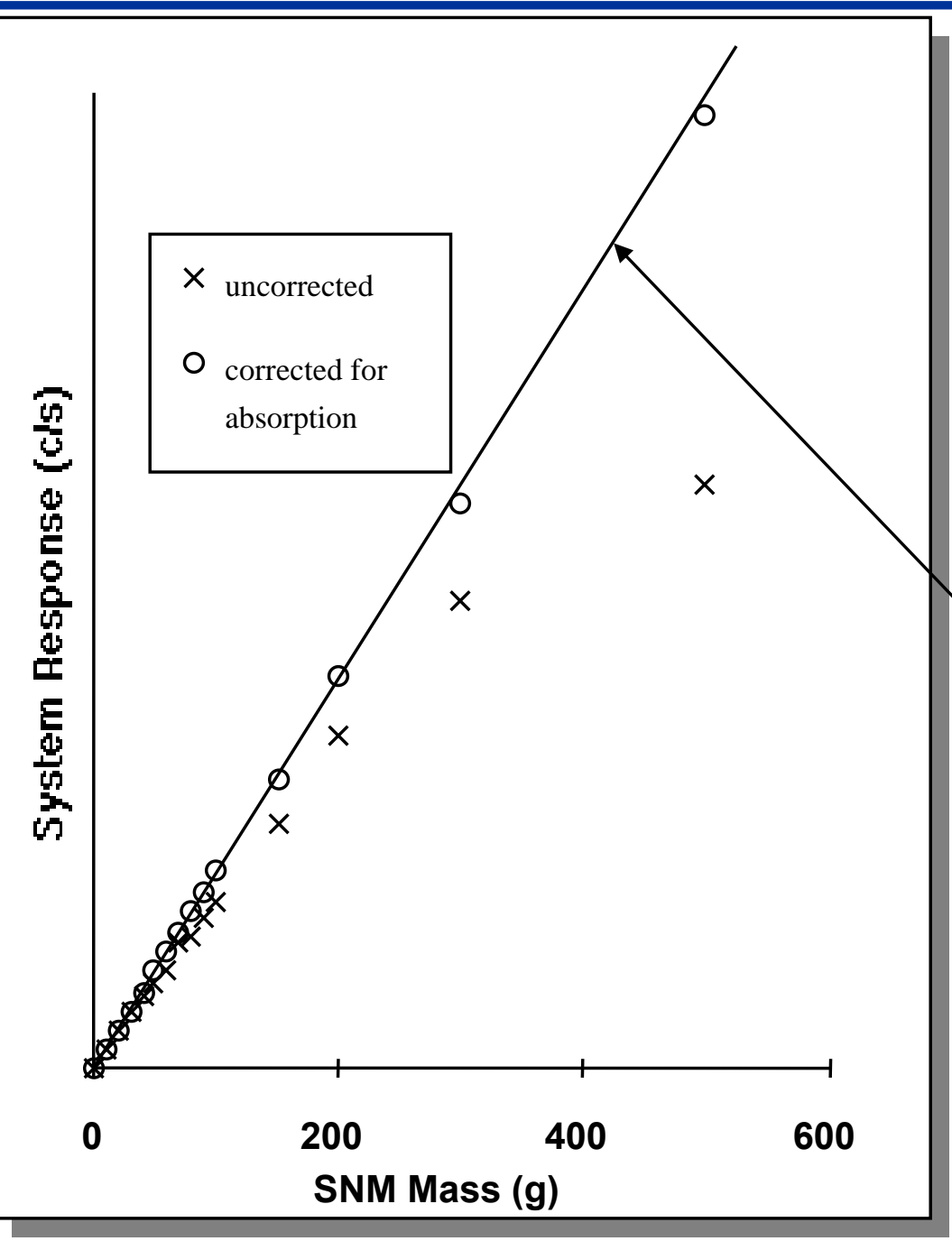

Note that absorption by the sample is increasingly important at higher SNM masses.

Application of the selfabsorption correction (using the external source) removes the effect of this absorption. 


\section{Normal (Gaussian) Distribution}

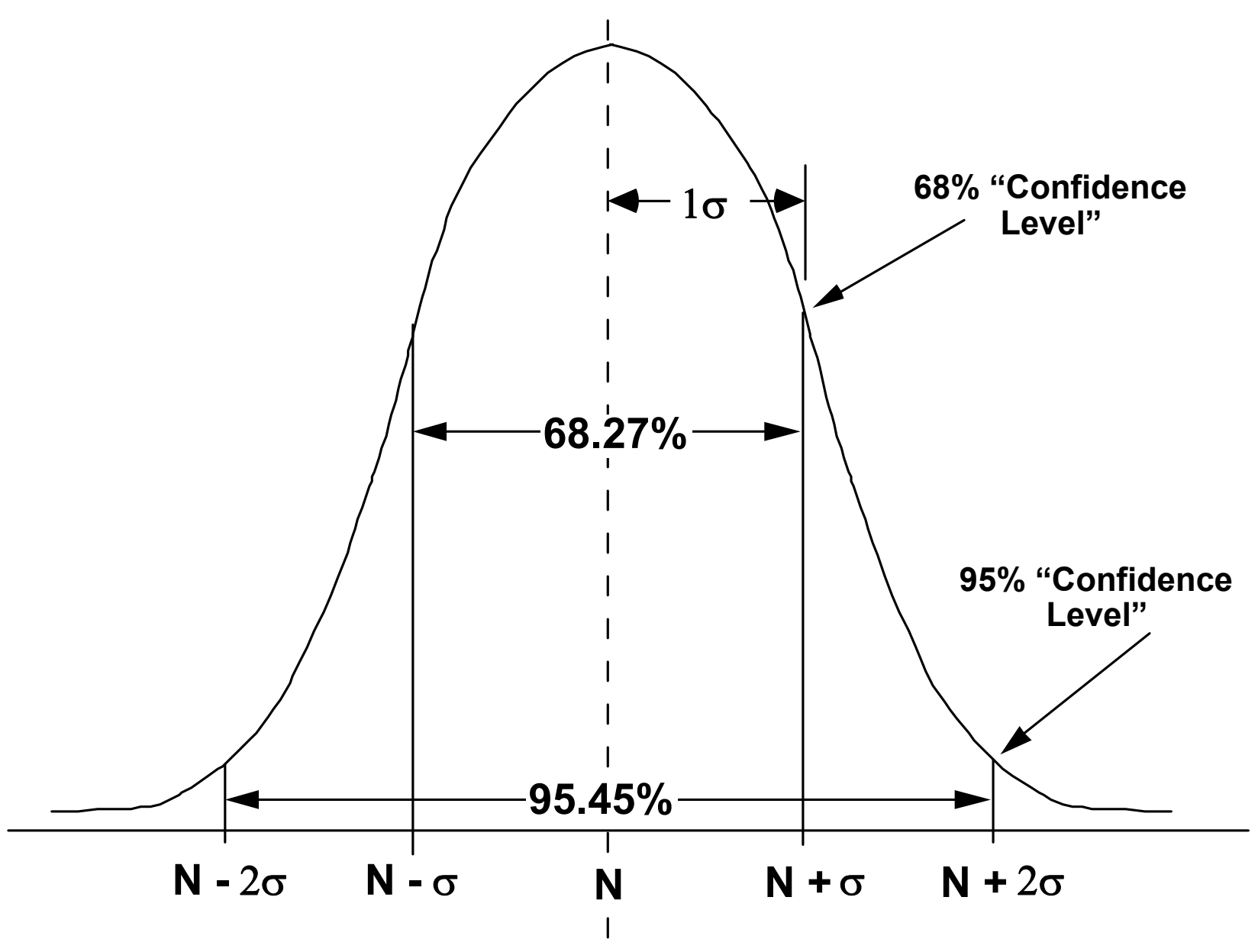




\section{Uncertainty in a Nuclear Count}

For a measured number of counts, $\mathbf{N}$, from a nuclear counting process, the standard deviation in $\mathbf{N}$ is:

$$
\sigma(\mathbf{N})=\sqrt{\mathbf{N}}
$$

The RELATIVE STANDARD DEVIATION (RSD or $\sigma_{R}$ ) of the measurement is:

$$
\sigma_{\mathbf{R}}(\mathbf{N})=\frac{\sigma(\mathbf{N})}{\mathbf{N}}=\frac{1}{\sqrt{\mathbf{N}}}
$$

To improve the RSD, increase N (i.e., "take more data"):

- Count longer or repeat measurement (equivalent)

- Use "hotter" source

- Move sample and detector closer to one another 


\section{Measurement Control}

- Goals:

- To control the quality of the measurement process

- To verify the continued stability of the measurement system since the last calibration

- Procedures

- Assay measurement control standards periodically

- Measure room radiation background periodically

- Measure data quality (appearance of spectrum, etc.)

- electronics gain

- detector resolution

- Note visual appearance of instrument 


\section{Measurement Precision and Bias}

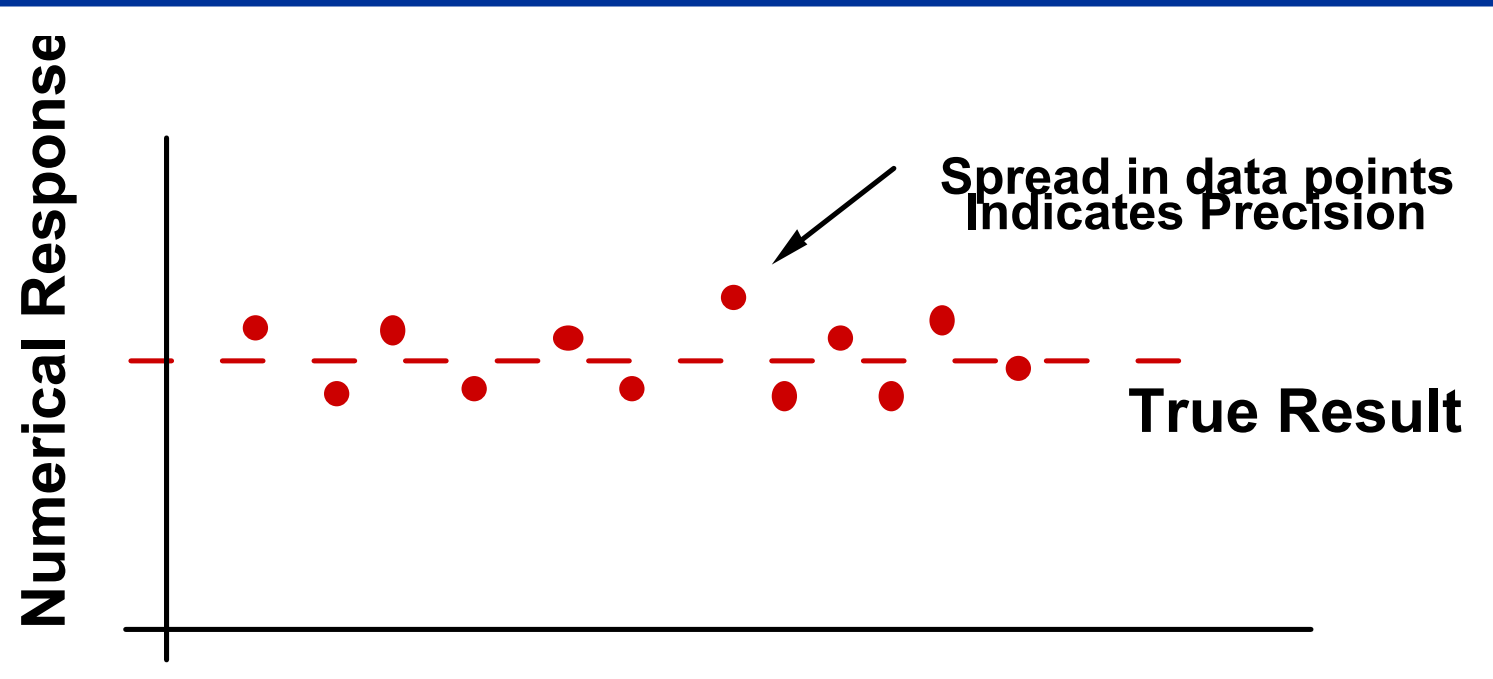

Measurement Precision: The degree to which repeated measurements of the same sample give the same results.

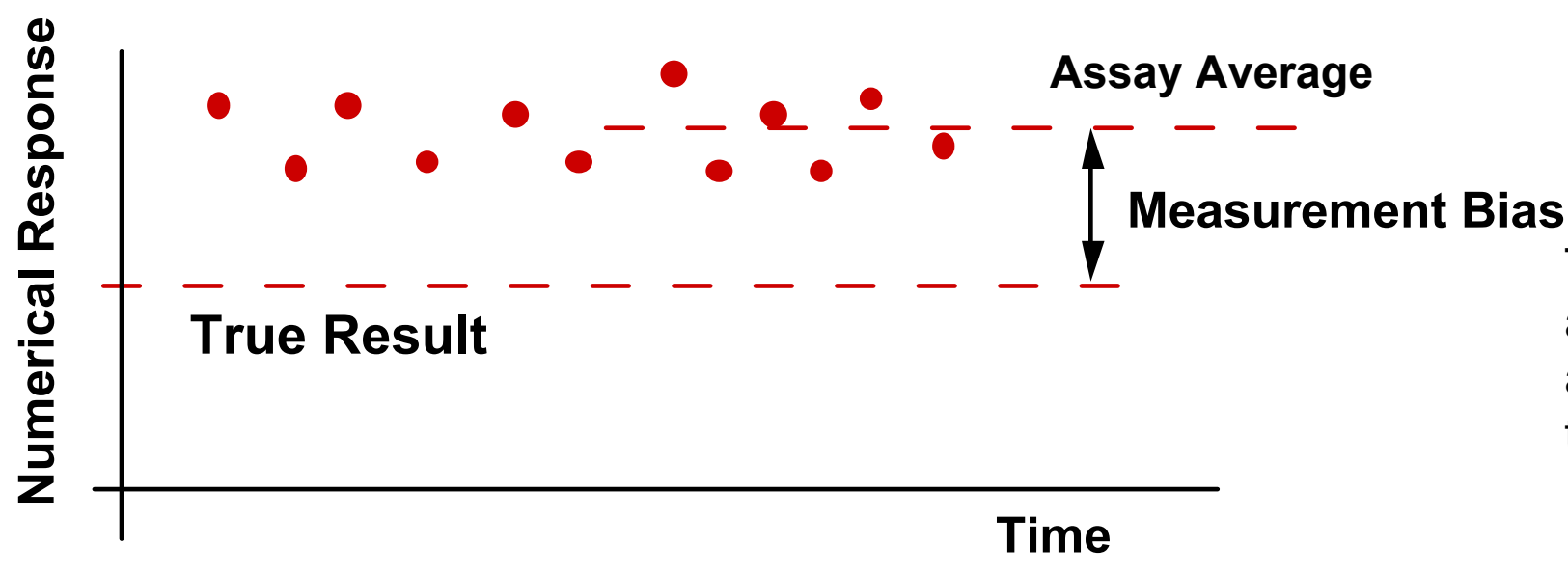

Measurement Bias:

The amount by which the average of many results on a standard differs from the true value. 


\section{Methods to Improve Measurement Precision}

Count for longer time

- Operator Errors

- Provide explicit assay procedures

- Provide careful training for assay procedures

- use checklists to verify execution of procedures

Background Variations

- Shield detector from extraneous signals

- administratively control source traffic in counting area

- perform regular background measurements, diagnostics 


\section{Dealing with Measurement Bias}

- Sources of Measurement Bias

- Statistical errors in calibration

- Shifts in shielding, absorbers, collimators

- Changes in geometry of setup (detector, sample stand,...)

- Differences between sample container and container for calibration standards (diameter, height, wall thickness, ...)

- Lumps in sample (error in absorption correction)

- Strategies to Reduce Measurement Bias

- Calibrate often and make calibration measurement precise

- Anchor shielding and collimators to measurement system

- Anchor detector and sample stations

- Calibrate for several container sizes; develop geometry corrections to calibration; control sample containers to match standard containers.

- Assure uniform samples; apply lump corrections, if possible. 


\section{Control Charts}

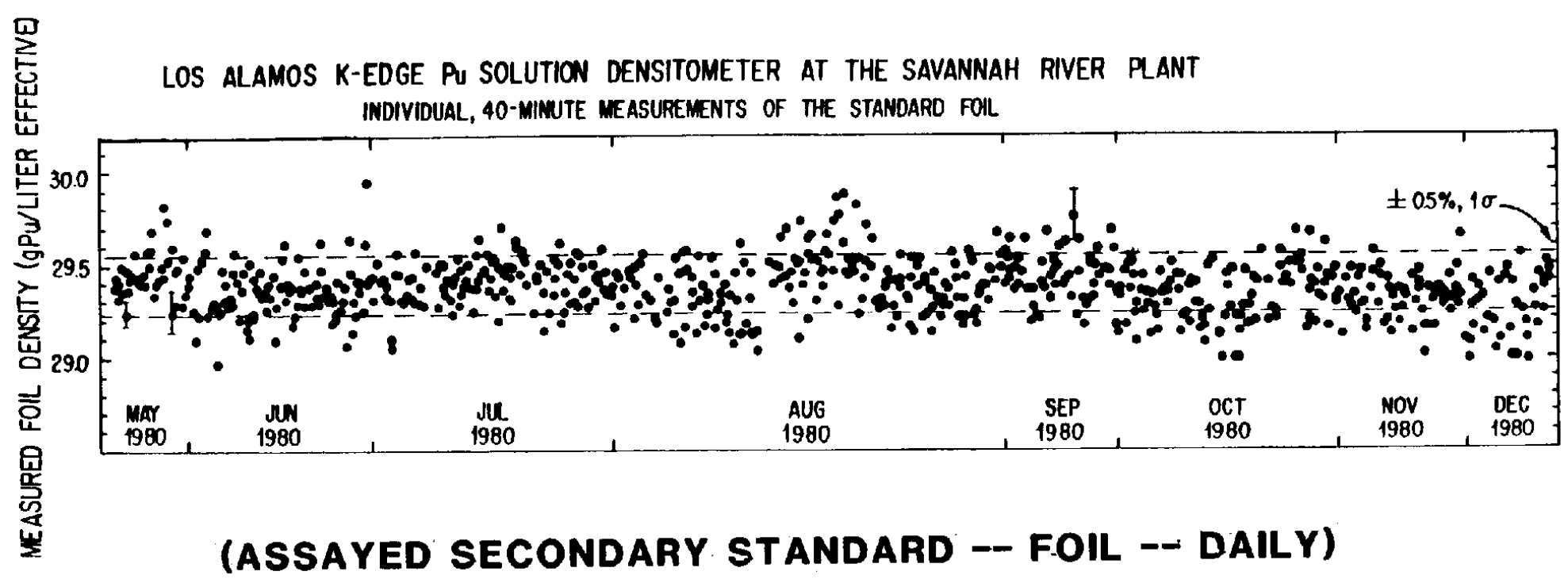

Features

- Assayed standard Pu foil, built into instrument.

- Generally normal, quite stable performance

- Some excursions, in May, August, 1980 [Temperature problems when air conditioning fails]

- Slight downward drift in winter, 1980 


\section{Infinite-Thickness Enrichment Assay}

Schematic of

Enrichment Measurement

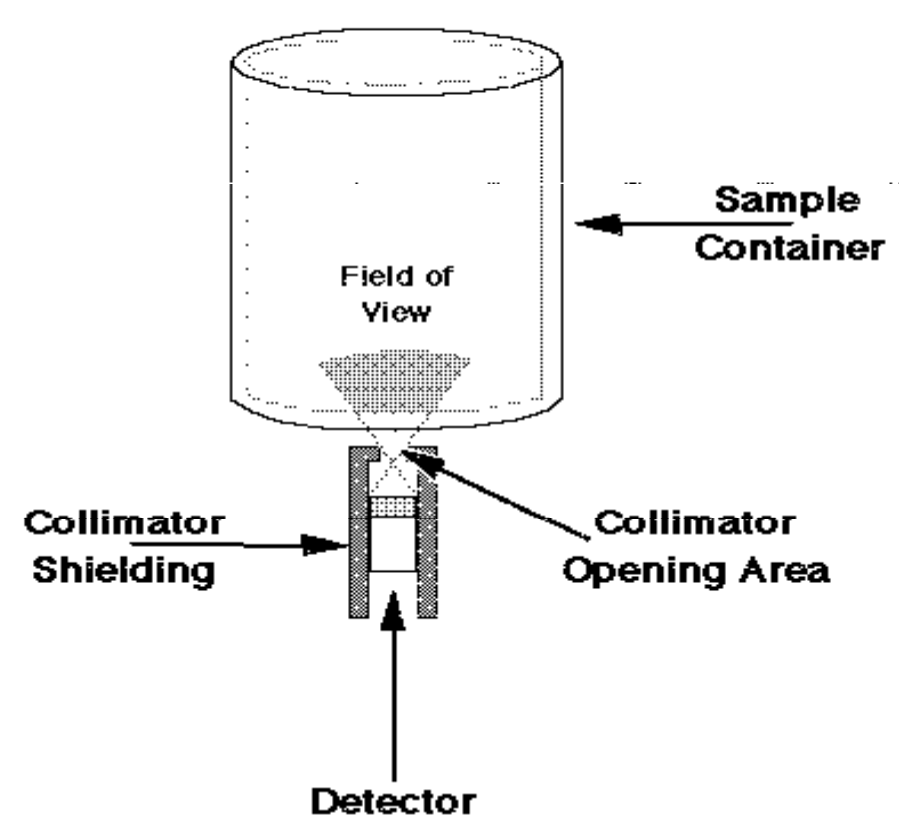

Detector views the sample through a collimator.

Visible volume determined by collimator and the absorption coefficient of $U$.

The 186-keV $\gamma$-ray intensity is proportional to the ${ }^{235} \mathrm{U}$ in the visible volume. 


\section{Infinite Thickness for 186-keV $\gamma$ Rays in Uranium Materials}

\section{Density ( $\rho)$}

Material

$\left(\mathrm{g} / \mathrm{cm}^{3}\right)$

18.7

4.7

10.9

2.0

7.3

2.8
Mean Free Path

(cm)

0.04

0.20

0.07

0.39

0.11

0.43
"Infinite" Thickness

(cm)

0.26

1.43

0.49

2.75

0.74

3.01 


\section{SLAB CORRECTION FACTOR (Far-Field) $\mathrm{CF}_{\text {atten }}$}

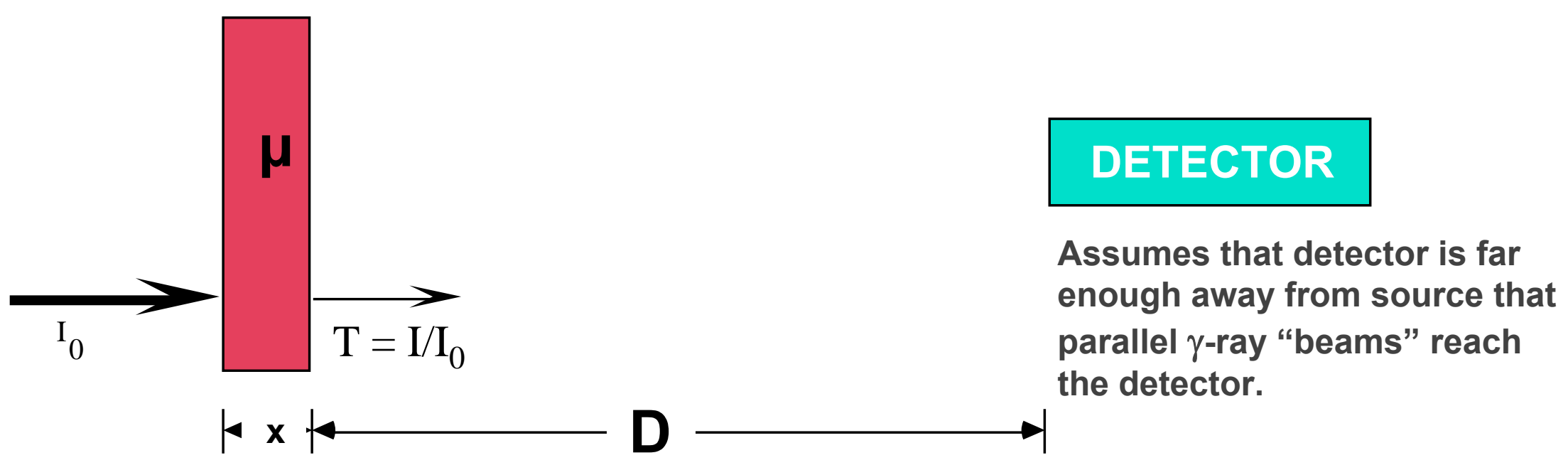

FOR D $\gg x$ :

$$
C F_{\text {atten. }}=\frac{\mu \rho x}{1-e^{-\mu \rho x}}=\frac{-\ln (T)}{1-T}
$$




\section{Solution Assays by Gamma-Ray Spectroscopy}
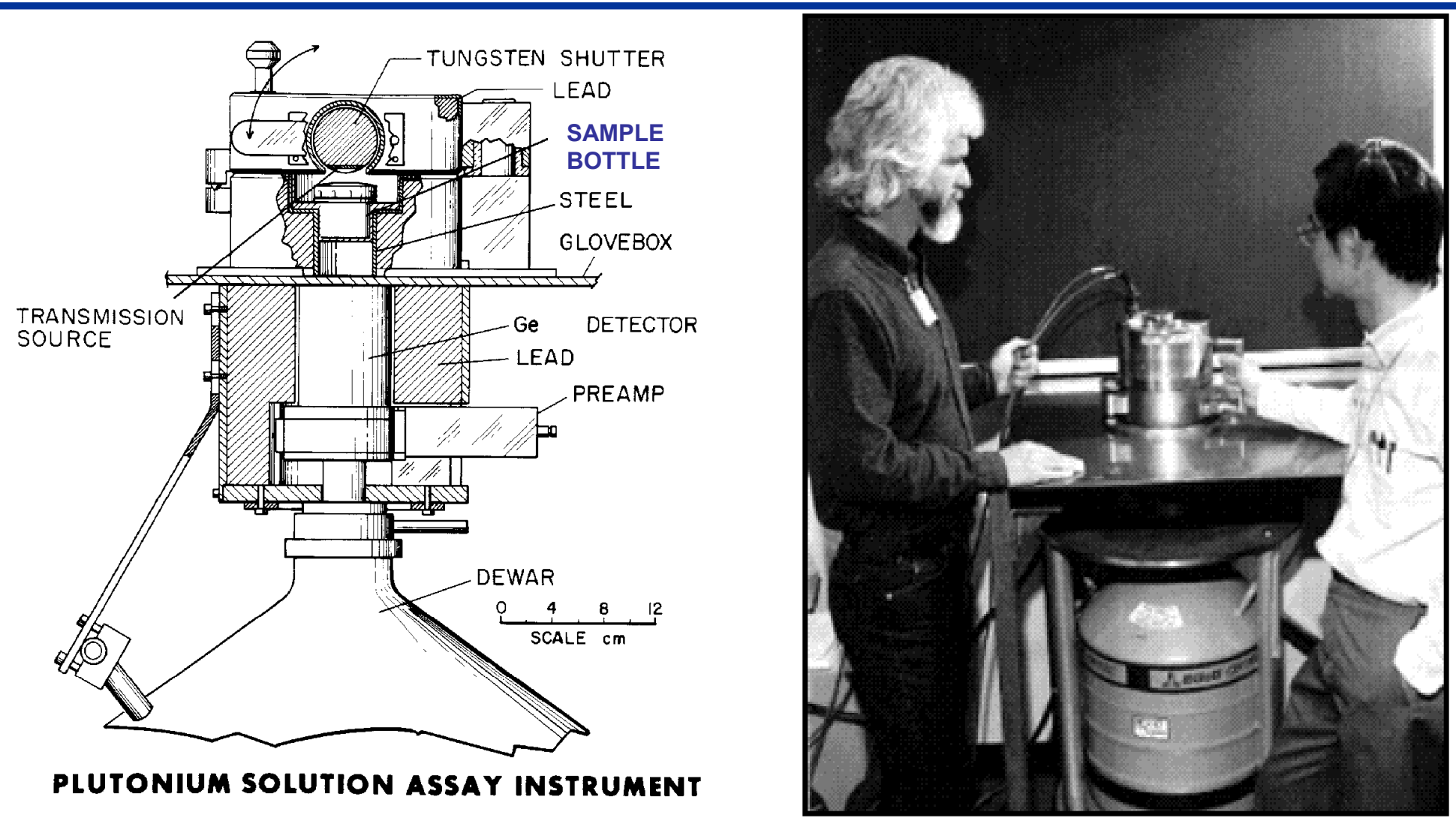

- Absorption-corrected passive gamma-ray assay

- High-resolution $\gamma$ detector measures spectrum through floor of glovebox.

- Gives grams isotope in a 0.001 to 400 gram SNM/liter sample, with $0.2 \%$ to $1 \%$ accuracy in $1000 \mathrm{sec}$. 


\section{Absorption edge densitometry, $x$-ray fluorescence}

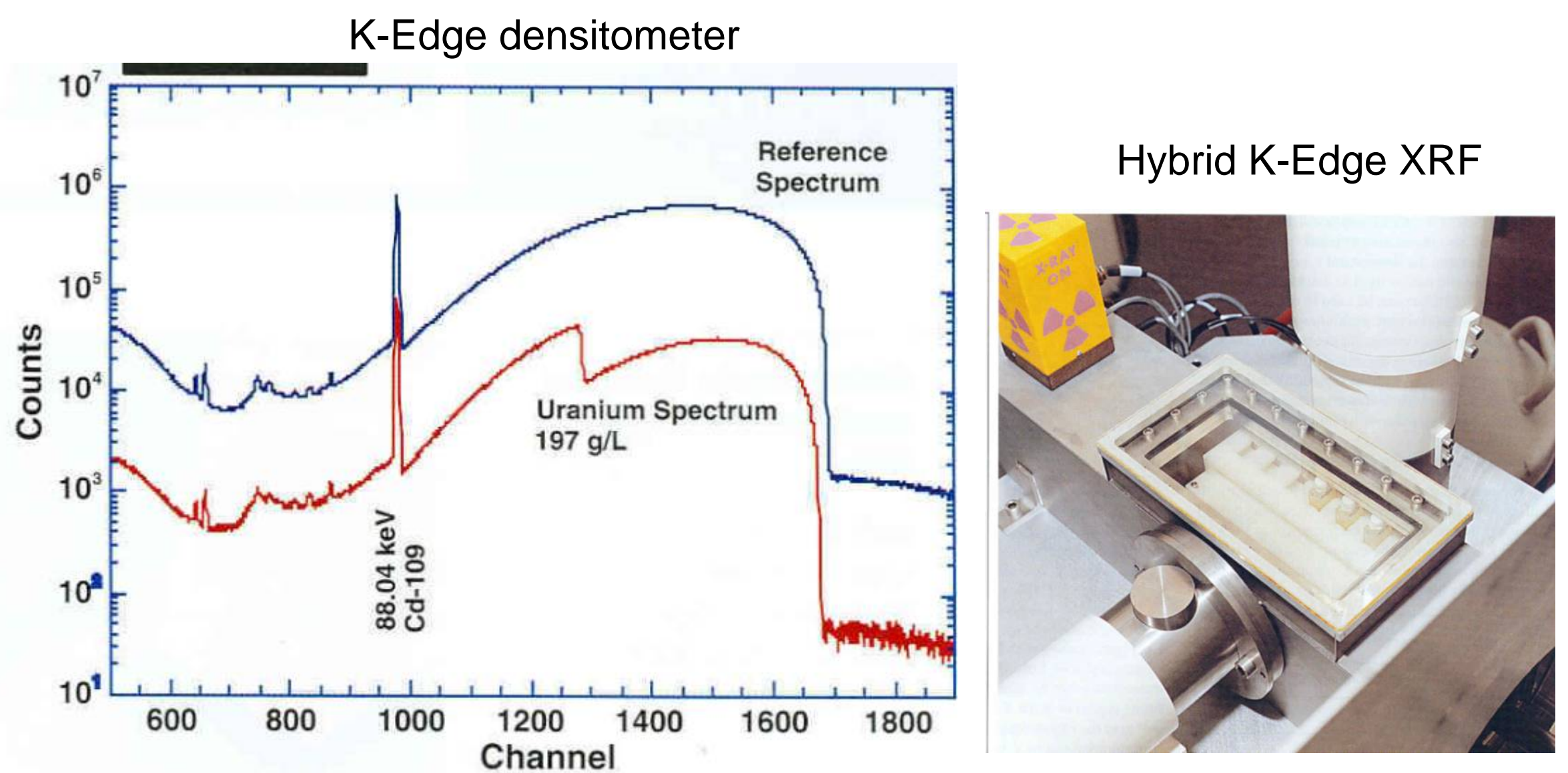

- LosAlamos 


\section{Other Transmission-Corrected Gamma Assay Systems \\ Segmented Gamma Scanner (SGS)}

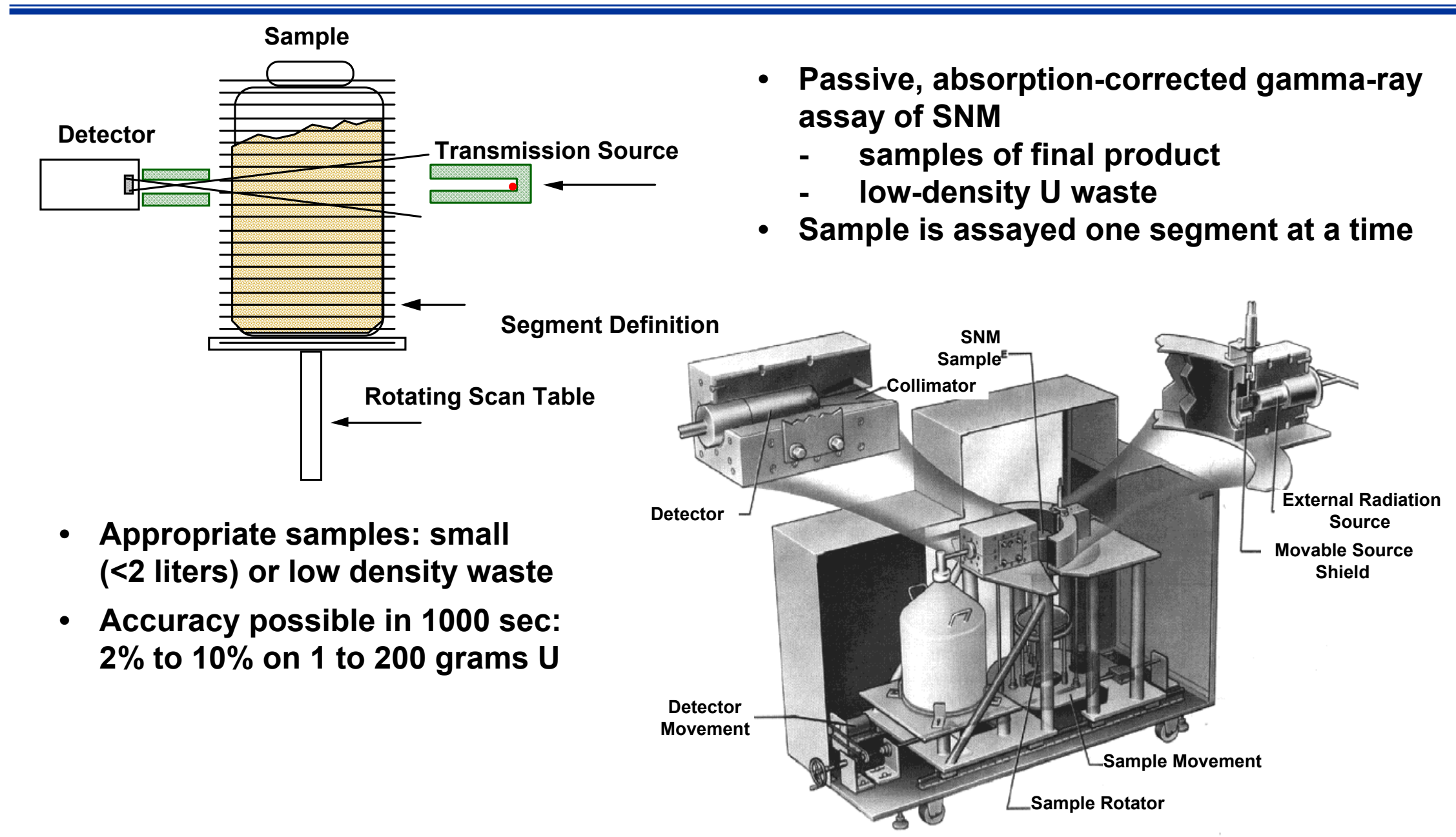




\section{Gamma-Ray Tomography}

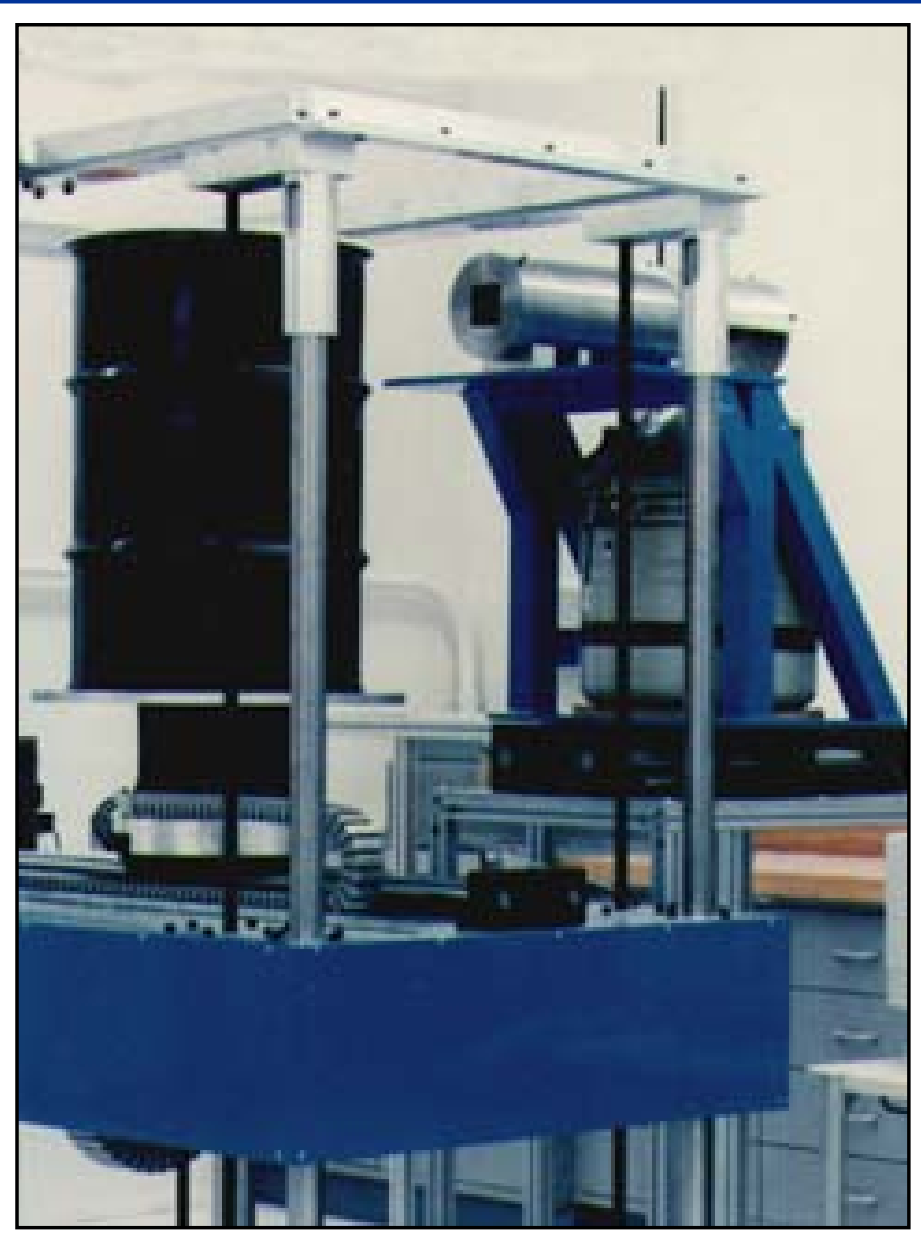

- Segmentation is replaced by collimation that divides the sample into "voxels."

- Measuring the transmission, in each voxel, gives a 3-D "density map" of the sample.

- The measured density and $\gamma$-ray rate from each voxel provide a 3-D image of the SNM content. 


\section{Passive Gamma-Ray NDA Applications:}

\section{Plutonium Isotopic Composition}

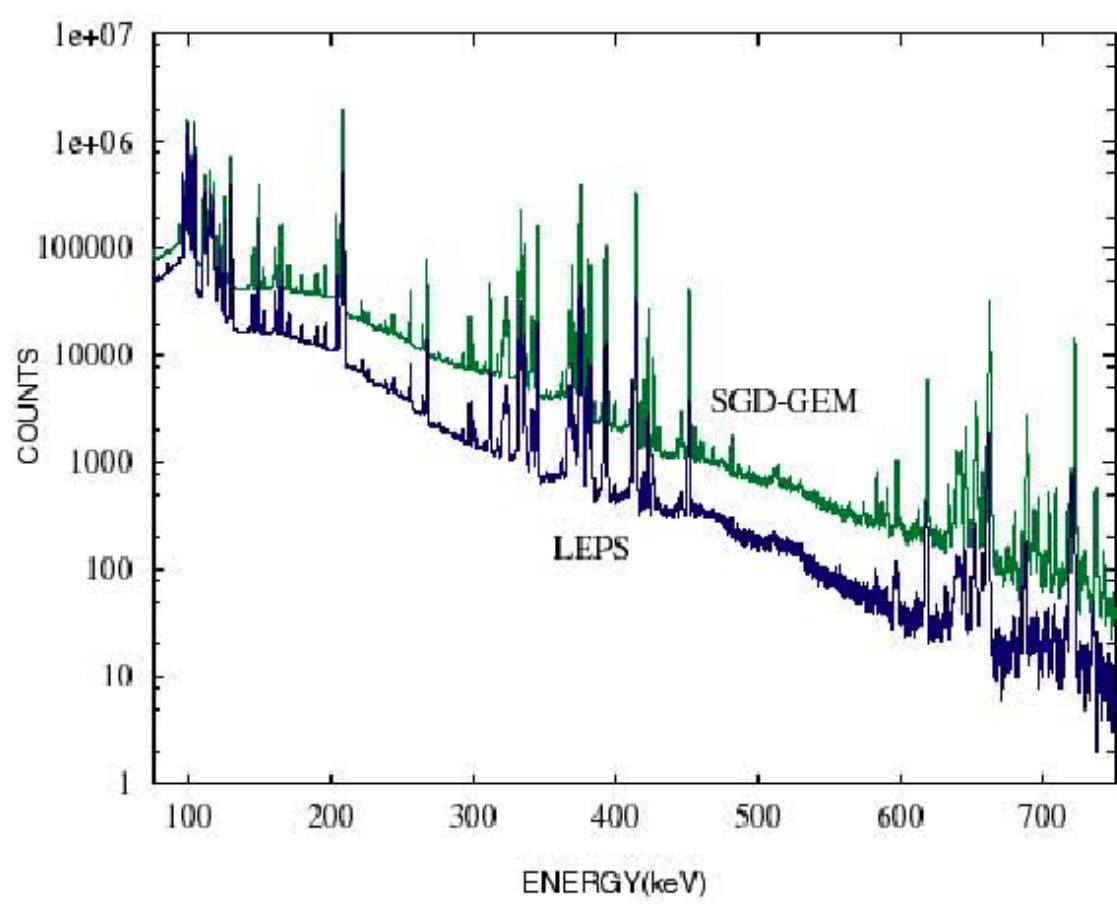

A high-resolution spectrum provides gamma-ray intensities from the isotopes in the sample. Isotope ratios are computed from peak ratios. Since a relative measurement is performed, standards are not needed, and measurement geometry does not need to be controlled. Relative detector efficiency, as a function of gamma-ray energy, is obtained from the spectrum.

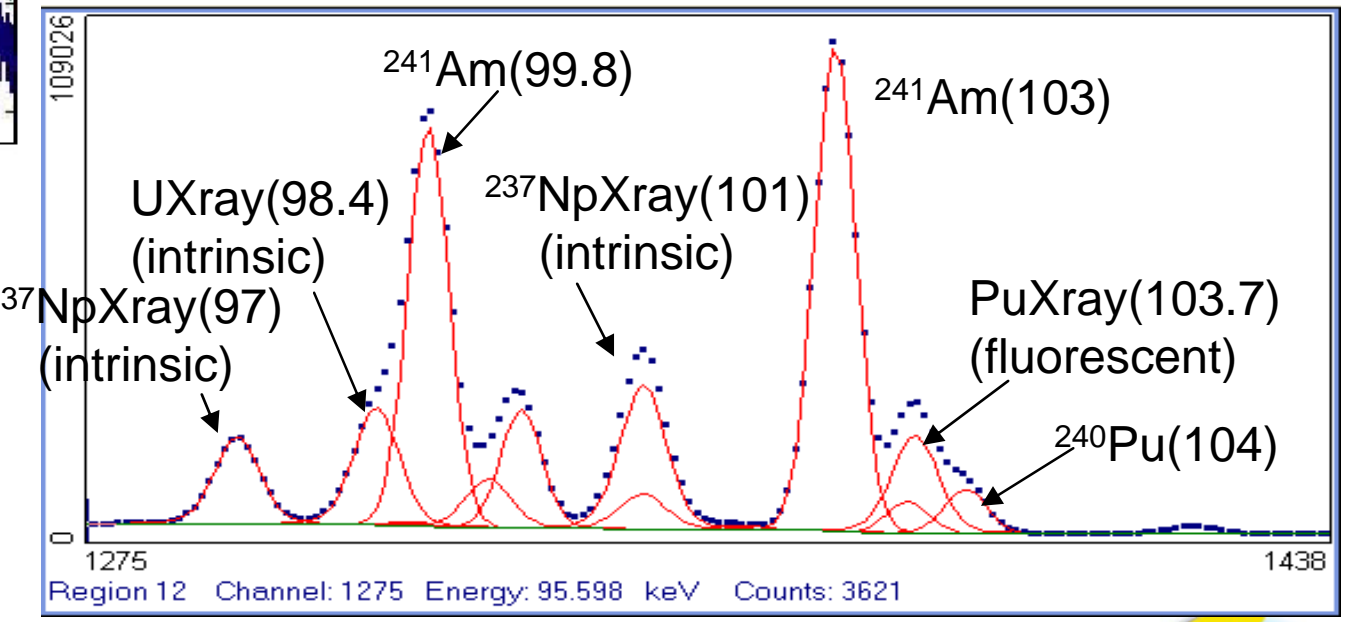



Ray Spectroscopy

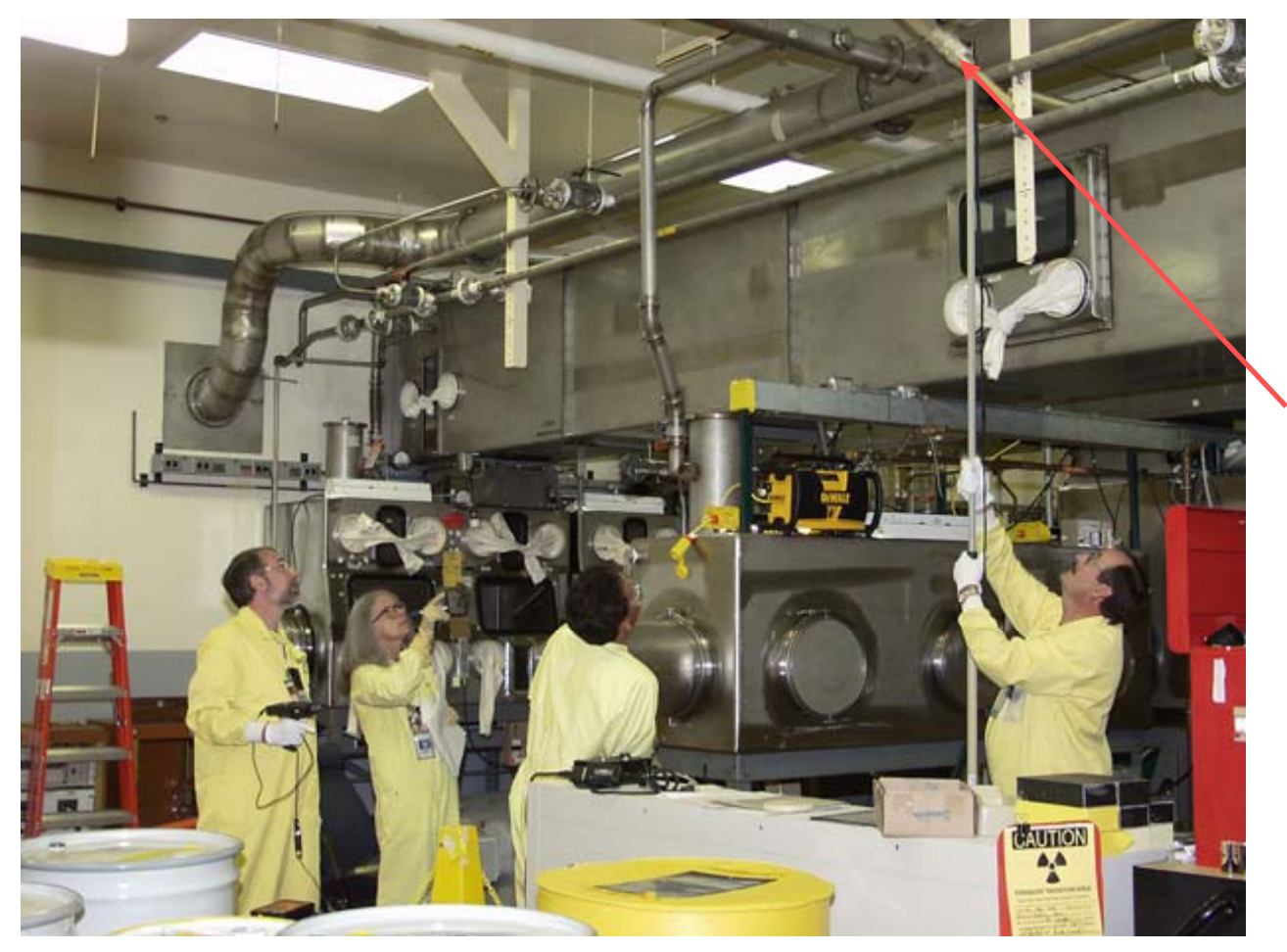

- Portable multichannel analyzer with gamma detector and data analysis electronics.

- Operator can position a shielded detector in a variety of locations to meet variety of measurement requirements.

- Holdup measured at $5 \%$ to $50 \%$ accuracy on 0.1 to 10 grams SNM; accuracy very dependent on measurement geometry. 


\section{Gamma NDA Summary}

- Gamma NDA Technique:

- Count gamma rays from sample

- Gamma-ray absorption correction very important

- Appropriate samples: small to medium density/size, uniform

- Accuracies Possible:

$-0.2 \%$ to $50 \%$, depending on sample uniformity and technique

- Best performance on solutions

- Improved performance for high-resolution over lowresolution detectors.

- Worst cases: Large, dense, heterogeneous samples [often assayable by neutron techniques] 


\title{
Advanced Fuel Cycle Safeguards
}

\author{
Michael Miller \\ GNEP Safeguards Campaign Director \\ Los Alamos National Laboratory \\ U.S. Nuclear Regulatory Commission \\ Rockville, MD \\ June 10, 2008
}




\section{Outline}

- Introduction and Current Technical Basis

- Reprocessing

Fuel Fabrication

- Fast Reactor 


\section{Introduction and Current Technical Basis}

- Comparison of NRC, DOE, IAEA Definitions and Requirements

- Fundamentals of NDA

- Gamma-ray Based Instruments

- Neutron Based Instruments

- Calorimetry 


\section{Neutron Based Instruments}

- LOS Alamos 


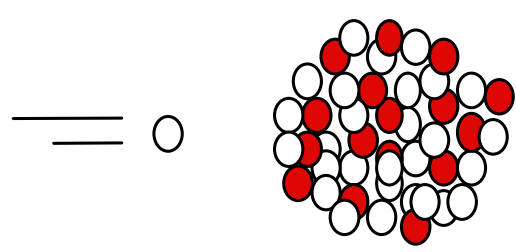

Initiator ("Trigger")

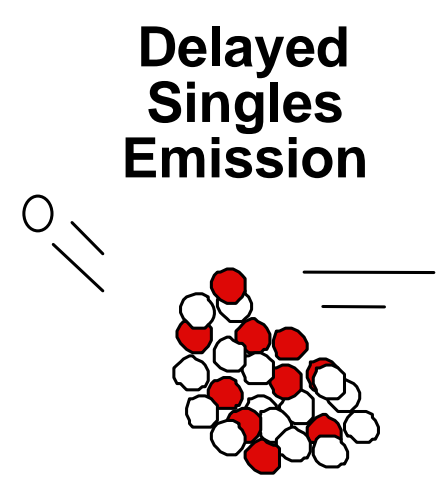

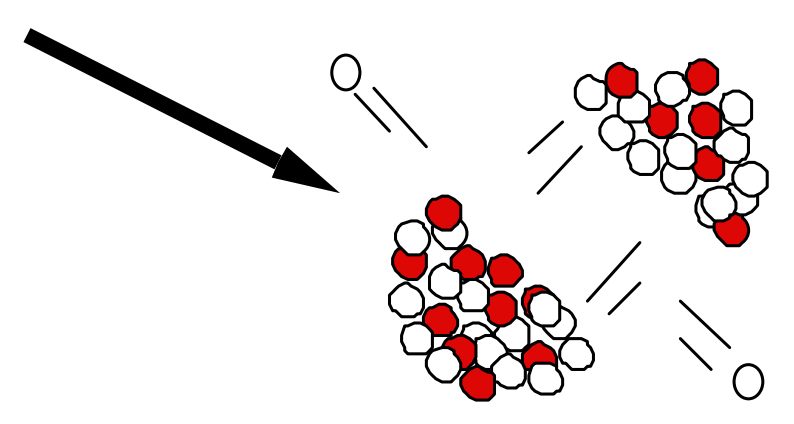

Prompt Coincidence Emission 


\section{Introduction: Why Neutron Counting?}

Neutrons have great penetrability. Thus neutron signatures are sometimes the only way to rapidly assay large, dense samples.

Neutron Count Data can be obtained rapidly. (But isotopic information is needed to interpret the data correctly and this adds more time to the assay.)

- Spontaneous Neutron Emission is a primary signature of the even isotopes of plutonium.

Induced Fission Neutrons are a signature for both fissile plutonium and uranium. 


\section{History of Neutron Counting}

The first neutron assay instruments attempted to use the total neutron rate to deduce assay information -- however, accurate assays can be obtained only for a very few types of SNM.

The next development was neutron coincidence counting. This technique has had wide application for international safeguards. It has had more limited application to US domestic safeguards because large errors can occur if the technique is not applied correctly to impure materials.

Neutron Multiplicity Counting is an extension of neutron coincidence counting. It improves neutron assay accuracy dramatically by adding more measured information. 


\section{Multiplicity Counting Vs. Coincidence Counting}

-In standard neutron coincidence counting, a priori information must be used to obtain an assay. Does not work well for materials that contain variable, low- $Z$ impurities.

- In neutron multiplicity counting, the distribution of coincident multiplets in the neutron pulse stream is used to obtain a third measured quantity: the rate of coincident "triples".

-With careful detector design to reduce the variables to three, neutron multiplicity assays are possible without sample dependent calibrations. 


\section{Neutron Detection - "Well Counter"}

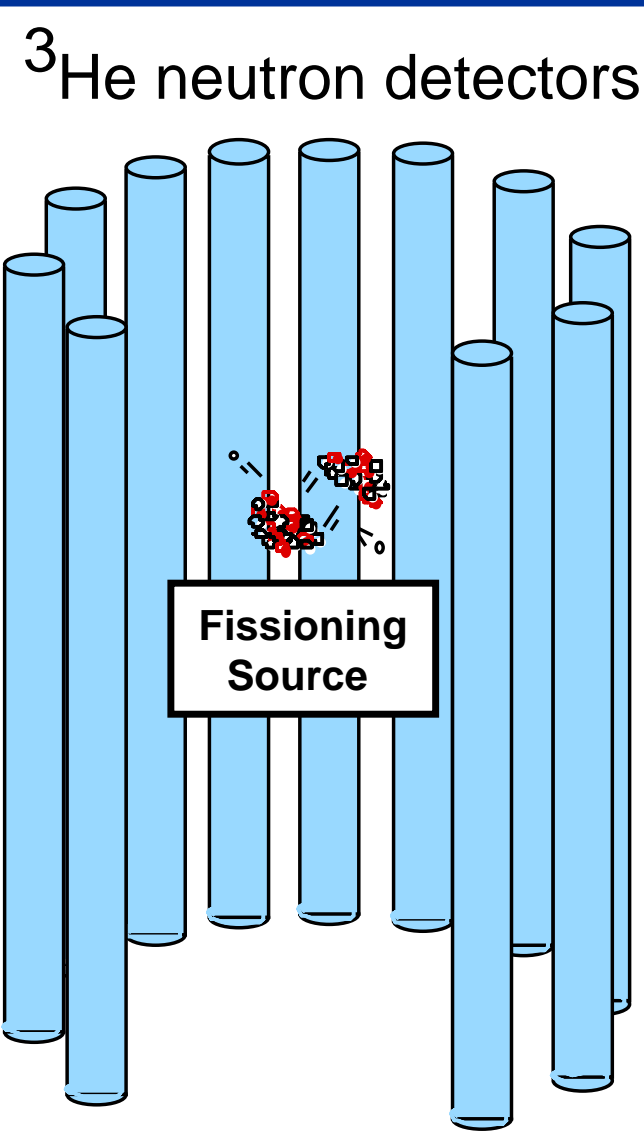

Detector electronics registers the coincidence and total count rates polyethylene moderator

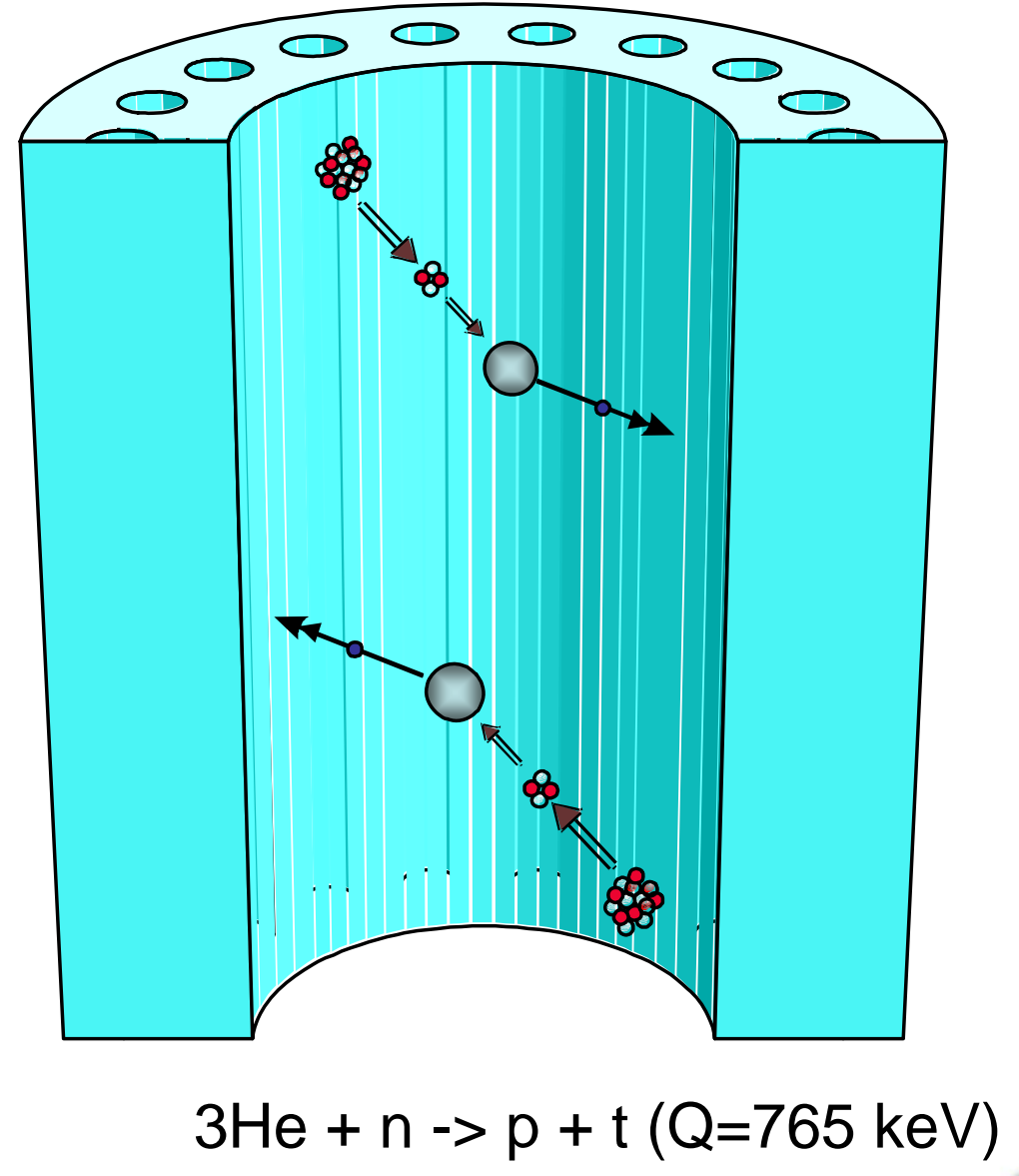




\section{Moderation}

Moderation is the process by which a neutron collides with matter and loses energy.

- i.e. $2 \mathrm{MeV}$ to $0.025 \mathrm{eV}$.

The probability of neutron detection in ${ }^{3} \mathrm{He}$ is largest when the neutrons have energies near thermal.

Most energy lost (best moderation) when neutron collides with nuclei of similar mass. \{i.e. hydrogen (protons)\}.

- Water

- Polyethylene

Moderation usually takes many collisions ( $\sim 27$ for a $2 \mathrm{MeV}$ neutron in polyethylene). 


\section{Neutron Detector Die-Away}

- After moderation, neutrons are lost in the detector by several processes:

- Diffusing out of detector.

- Diffusing to a ${ }^{3} \mathrm{He}$ detector tube and being absorbed.

- Absorption by hydrogen or cadmium.

- Hydrogen both moderates and absorbs the neutrons.

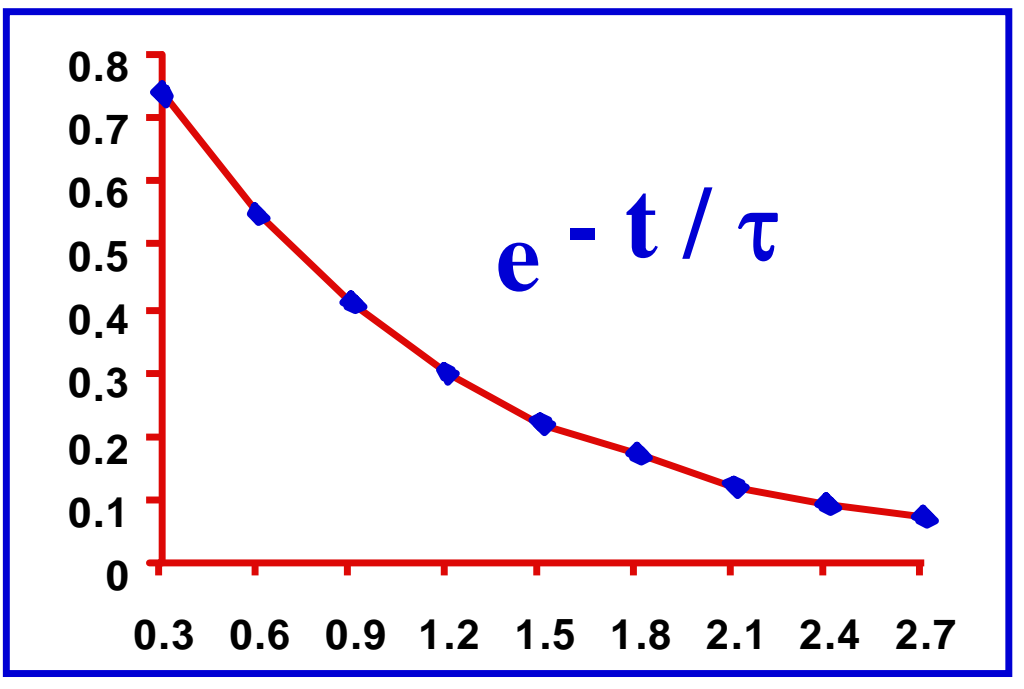

In most thermal detectors the neutron population decreases nearly exponentially in time. The time constant is called the die-away time. 


\section{The Shift Register - An Example}
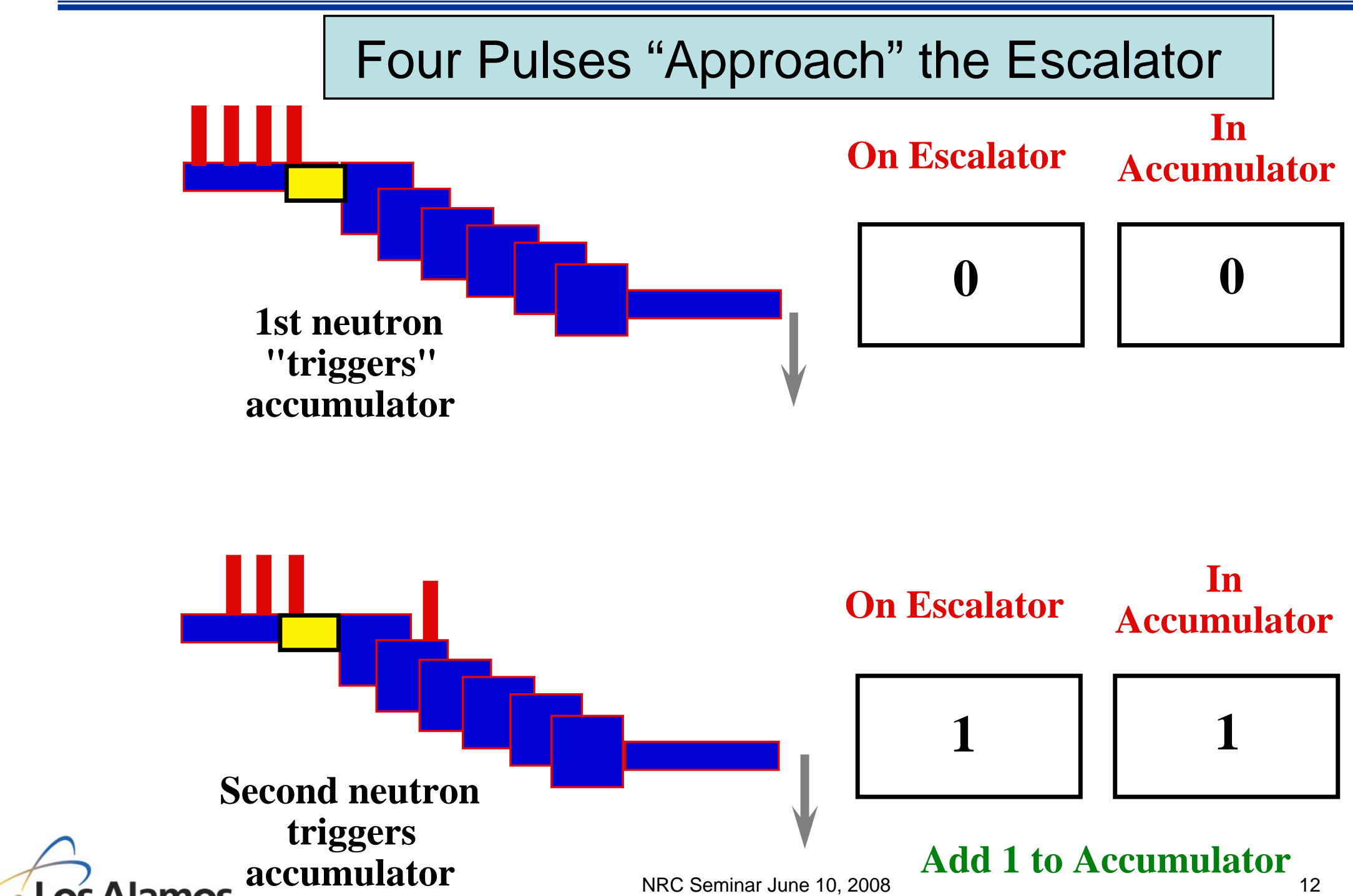

accumulator 


\section{The Shift Register Example Continued}

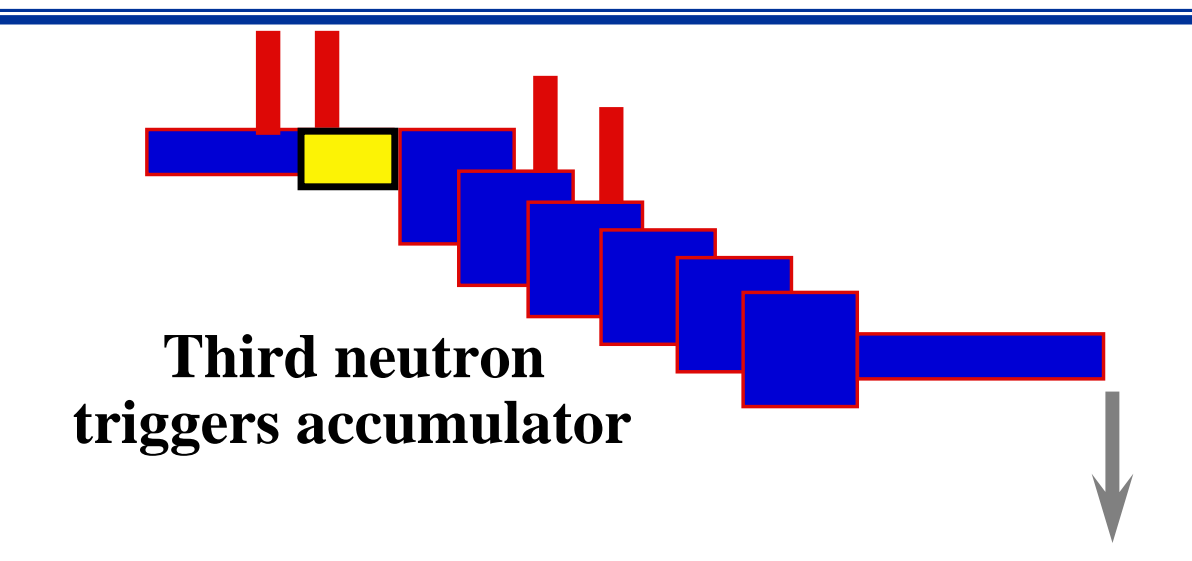

On Escalator

Add 2 to Accumulator

In

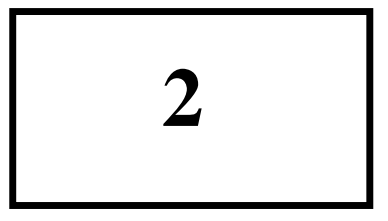

Accumulator

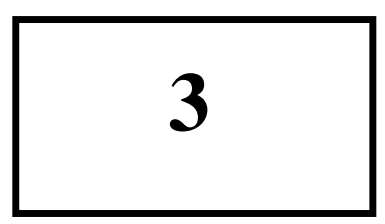

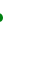

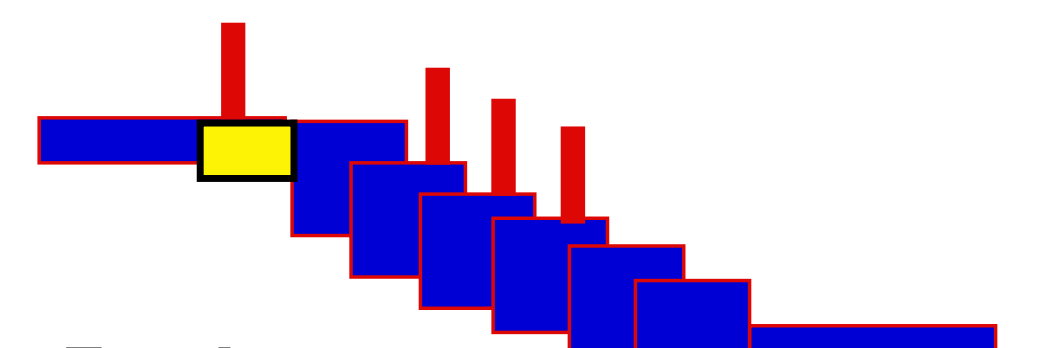

Fourth neutron triggers accumulator

Four Pulses Yield $\underline{6}$ Coincidences

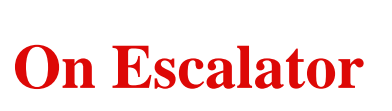

In Accumulator

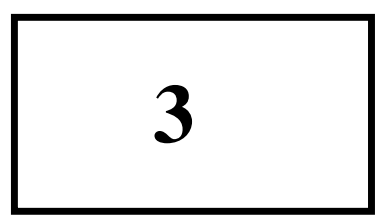

6

Add 3 to Accumulator 


\section{What Do We Really Count?}

- The Shift Register really counts coincidences.

-The Rossi-Alpha distribution is based on counting all possible coincidences.

-The formula for all possible coincidences is:

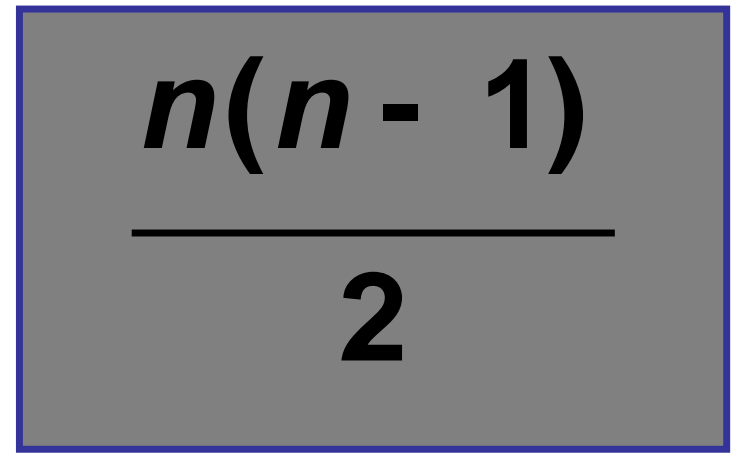

-Where $\mathrm{n}$ is the number of pulses. 


\section{The Shift Register Circuit}

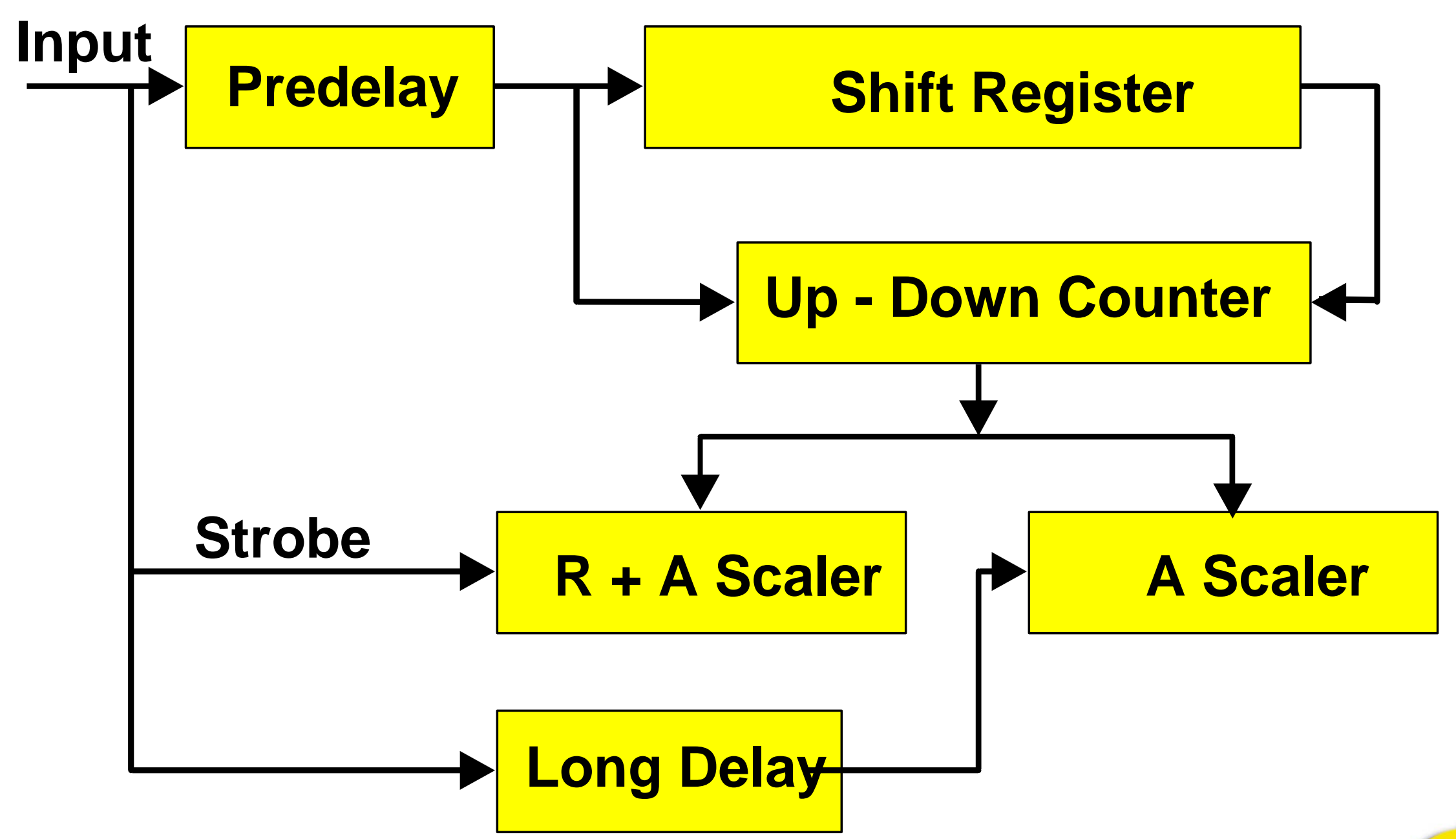




\section{Multiplicity Shift Register}

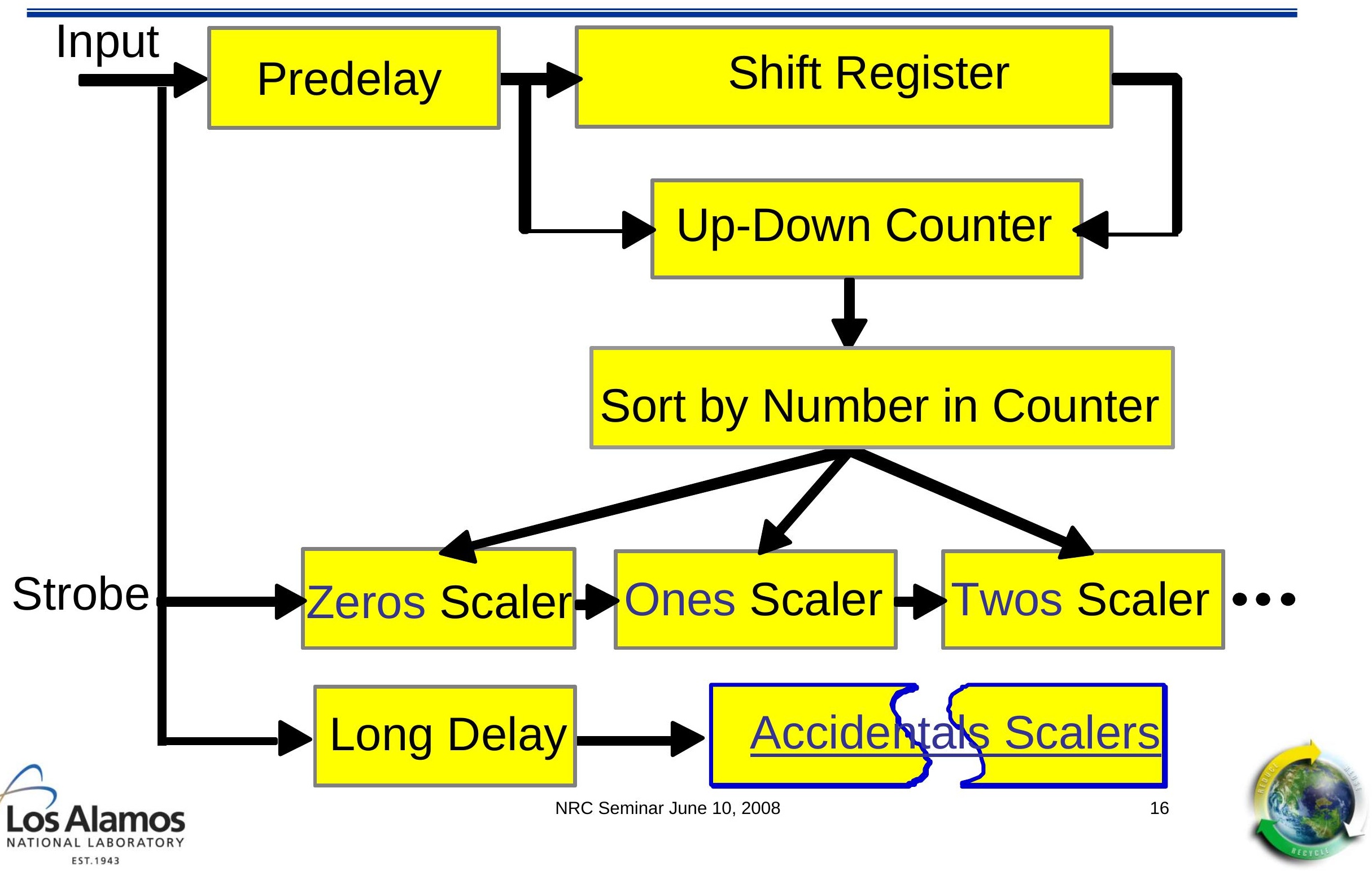




\section{Multiplicity Distribution - 3.8 kg Pu metal}

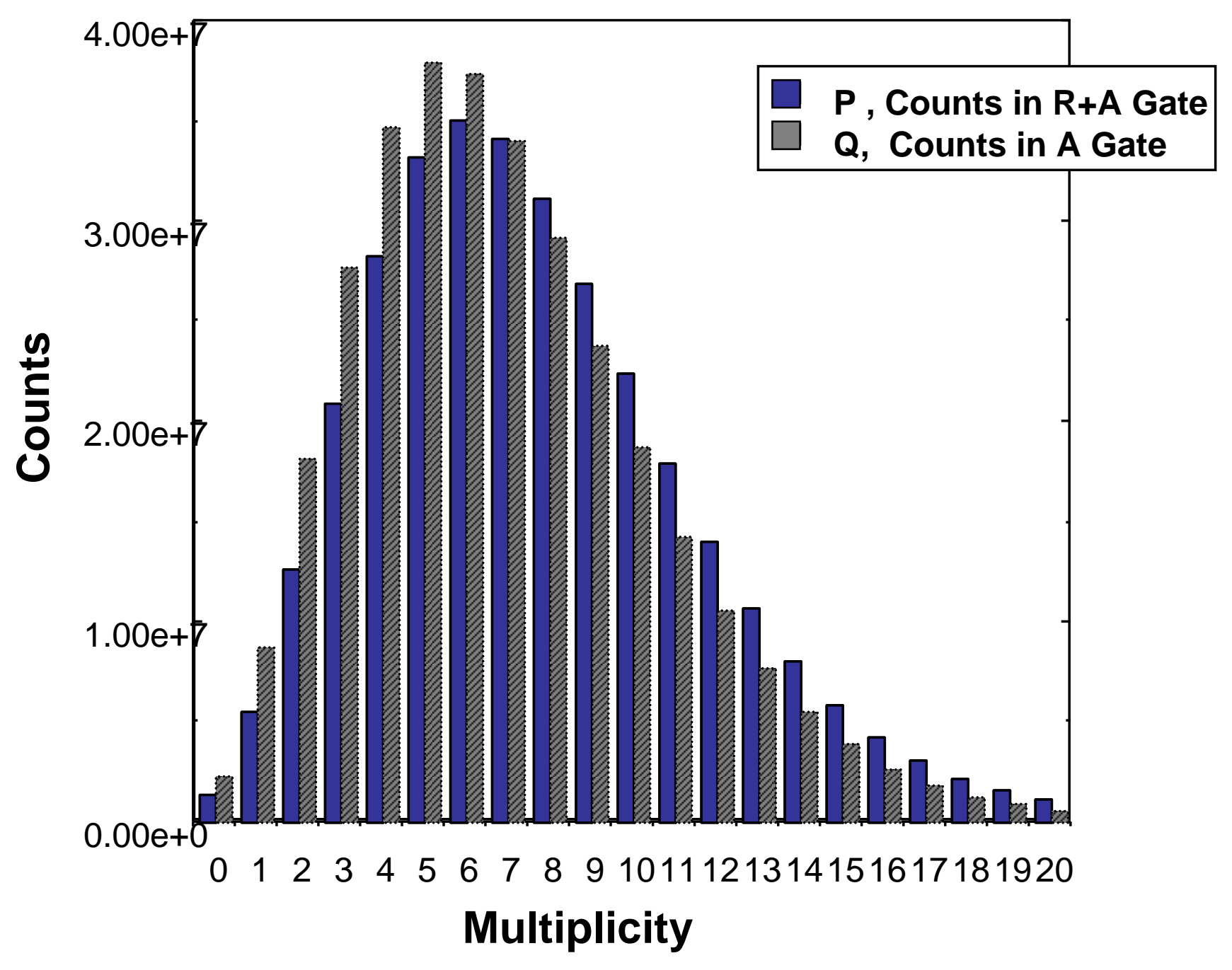




\section{Calibration Curve Method}

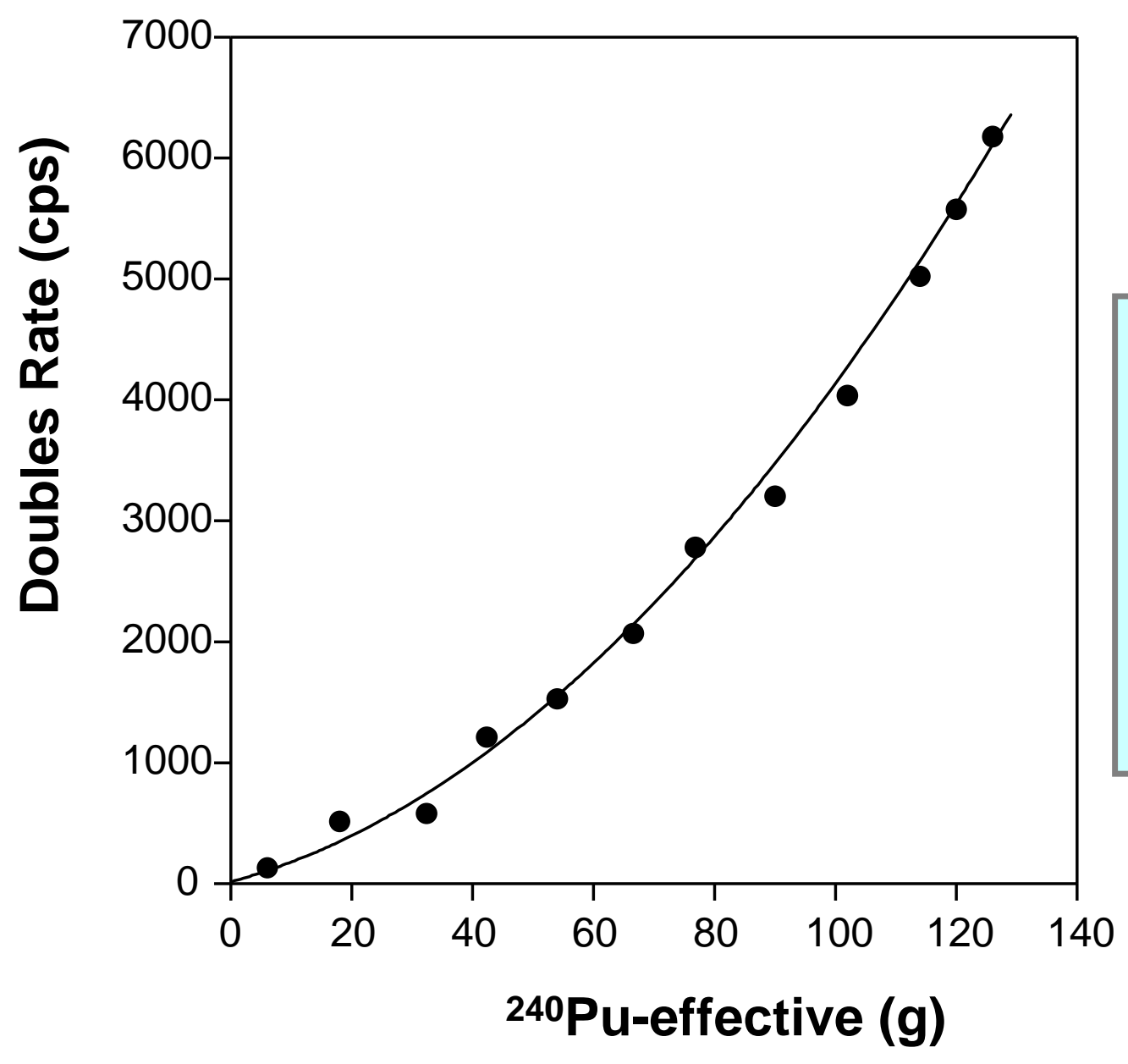

Need representative standards for each sample type and careful calibration measurements. 


\section{Known Alpha}

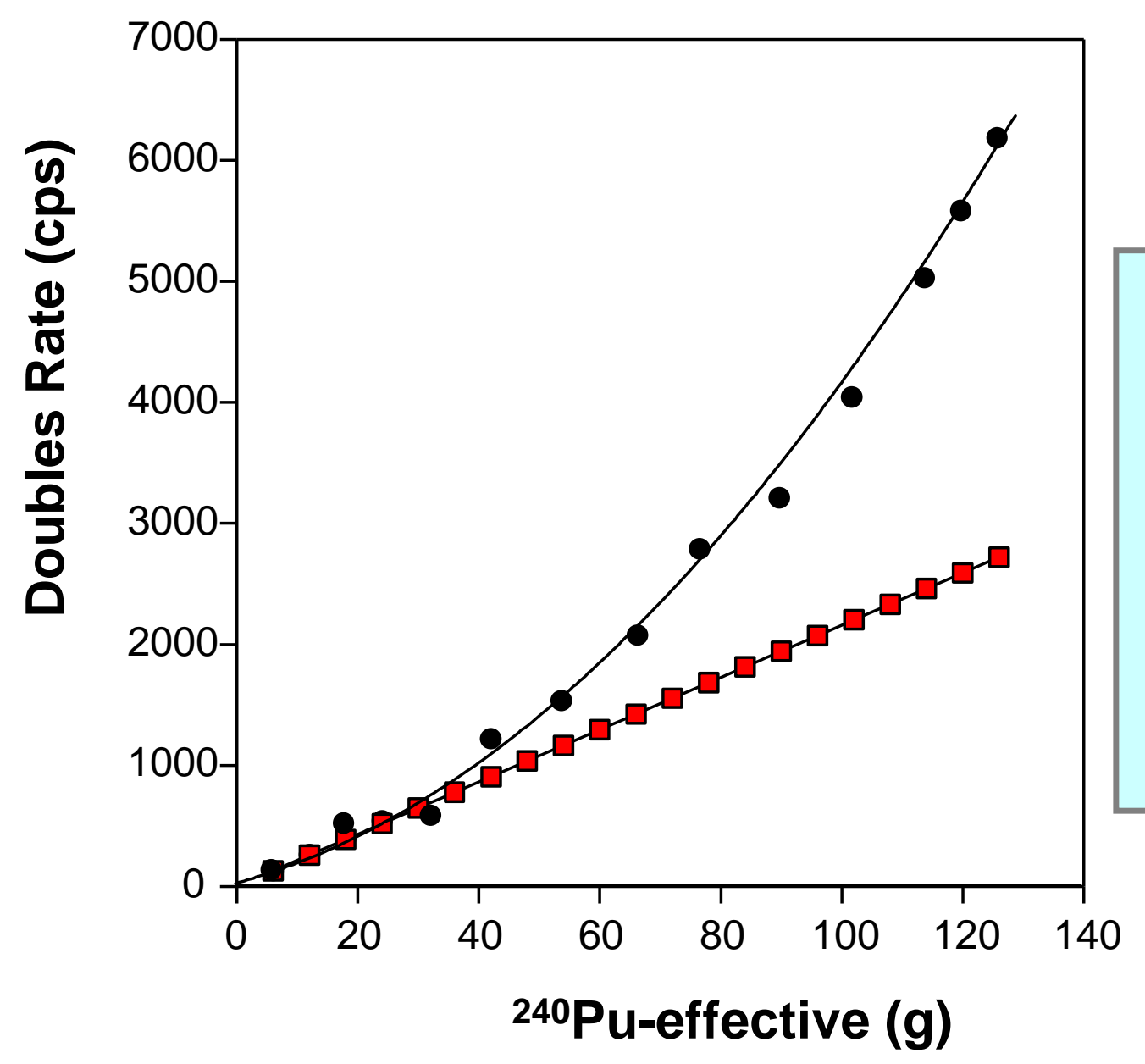

Use singles and doubles to deduce a "multiplication" correction that linearizes the calibration. Works well for pure oxides, metals, and fluorides. Still need standards. 


\section{The Problem with Standard Coincidence Counting}

There are 3 principal unknowns in neutron counting:

${ }^{240} \mathrm{Pu}$-effective mass, $\mathrm{a}$, and $\mathrm{M}$.

Standard Coincidence Counting provides only 2 pieces of measured information, singles and doubles (or totals and coincidences) To obtain an accurate assay, one must know a lot about the sample.

If the assumed information is incorrect, large errors can occur.

In Neutron Multiplicity Counting, 3 pieces of measured information are used with a mathematical model to deduce an assay that is far superior for most impure materials. 


\section{The Point Model Equations}

$$
\begin{aligned}
\mathrm{S}= & \mathrm{F} \varepsilon \mathrm{M} v_{\mathrm{s} 1}(1+\alpha) \\
\mathrm{D}= & \mathrm{F}\left(\mathrm{f}_{\mathrm{d}} / 2\right)(\varepsilon \mathrm{M})^{2}\left\{\mathrm{v}_{\mathrm{s} 2}+\left[(\mathrm{M}-1) /\left(v_{\mathrm{i} 1}-1\right)\right] v_{\mathrm{s} 1}(1+\alpha) v_{\mathrm{i} 2}\right\} \\
\mathrm{T}= & \mathrm{F}\left(\mathrm{f}_{\mathrm{t}} / 6\right)(\varepsilon \mathrm{M})^{3}\left\{\mathrm{v}_{\mathrm{s} 3}+\left[(\mathrm{M}-1) /\left(v_{\mathrm{i} 1}-1\right)\right]\left[\begin{array}{ll}
3 v_{\mathrm{s} 2} v_{\mathrm{i} 2}+ \\
\\
\left.\quad v_{\mathrm{s} 1}(1+\alpha) v_{\mathrm{i} 3}\right]+3\left[(\mathrm{M}-1) /\left(v_{\mathrm{i} 1}-1\right)\right]^{2} v_{\mathrm{s} 1}(1+\alpha) v_{\mathrm{i} 2}^{2}
\end{array}\right.\right.
\end{aligned}
$$

where: $\quad \varepsilon=$ detection efficiency

$f_{d}=$ fraction of doubles in the coincidence gate

$\mathrm{ft}=$ fraction of triples in the coincidence gate

$\mathrm{F}=$ spontaneous fission rate $=473.5 \mathrm{n} / \mathrm{s} / \mathrm{g}$ * effective PU-240 mass

$v_{n 1}=$ average number of neutrons produced per fission event

$\mathrm{n} 1 \quad(\mathrm{n}=\mathrm{s}$-- spontaneous fission, $\mathrm{n}=\mathrm{i}$-- induced fission)

$v_{n 2}=$ average number of neutron pairs produced per fission event

$v_{n 3}=$ average number of neutron "triplets" produced per fission event

$\alpha=$ ratio of (alpha, $\mathrm{n}$ ) neutron rate to the spontaneous fission rate

$\mathrm{M}$ = fission multiplication 


\section{Neutron NDA Techniques}

- Passive coincidence counting

- Active interrogation with coincidence counting

- Active interrogation with counting of delayed neutrons 


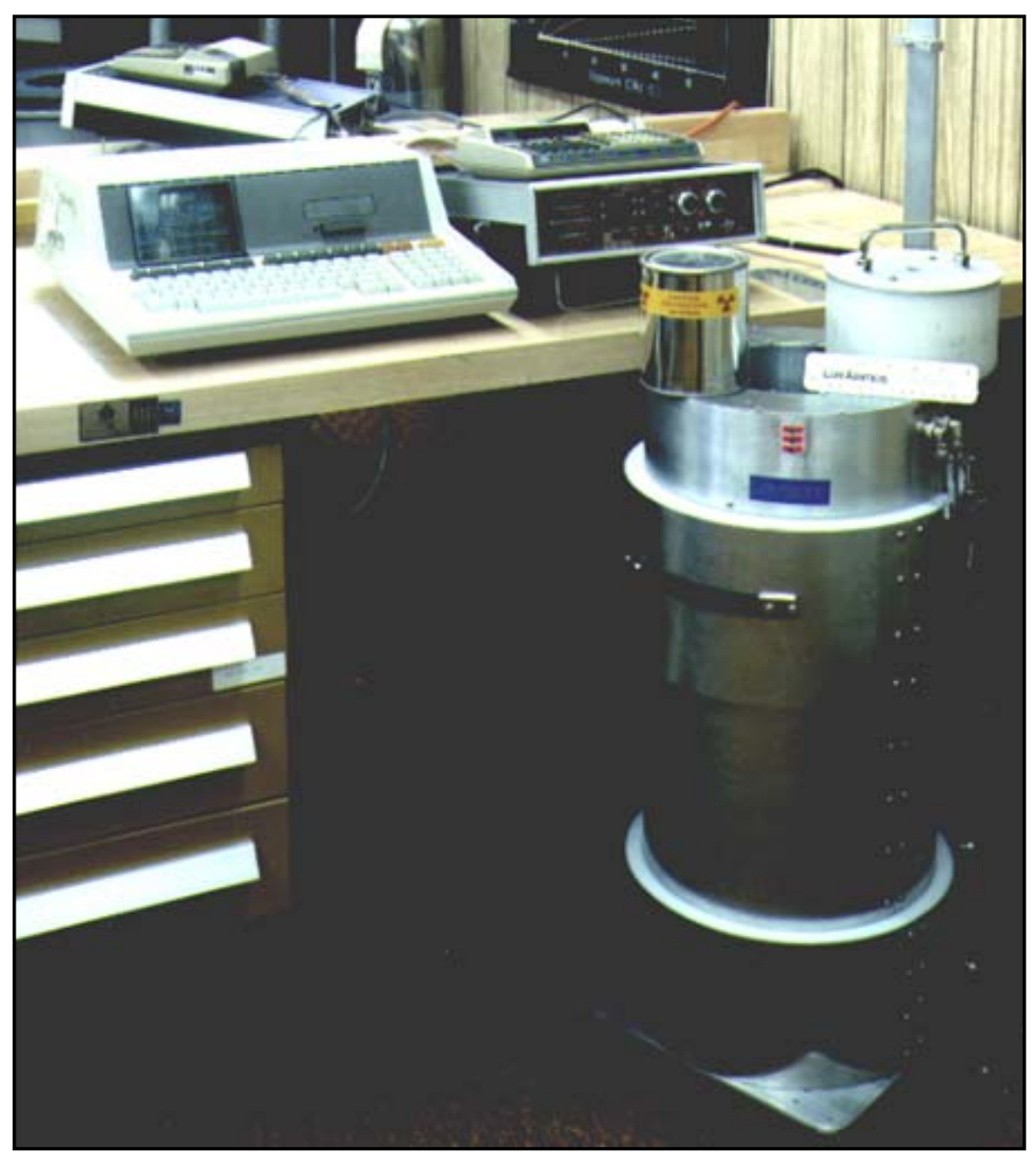

The cylindrical counter (HLNC) surrounds the sample with ${ }^{3} \mathrm{He}$ detectors. The data acquisition and analysis electronics are on the bench. This counter is commercially available. 


\section{Active Neutron Coincidence Counting}

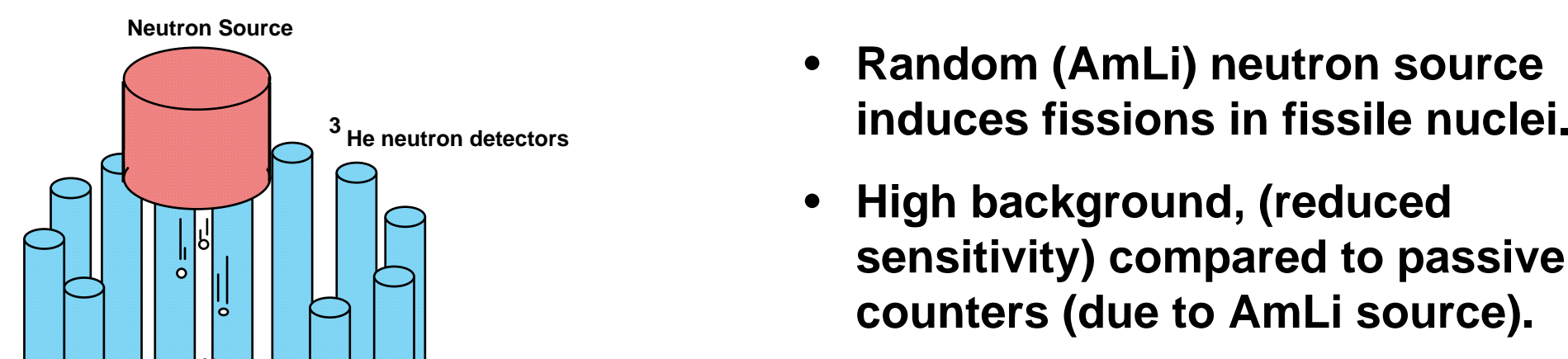

- Fissioning source surrounded by neutron detectors.

- Prompt multiple neutron emission from induced fission detected as coincidence neutron events.

- Designed primarily for ${ }^{235} \mathrm{U}$ assay.

Coincidence electronics registers the coincidence count rate which is proportional to the mass of fissile isotopes

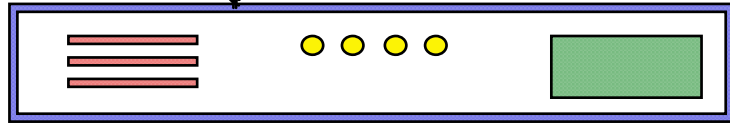

Pulse-processing Electronics 


\section{Active Neutron Coincidence Counter (AWCC)}
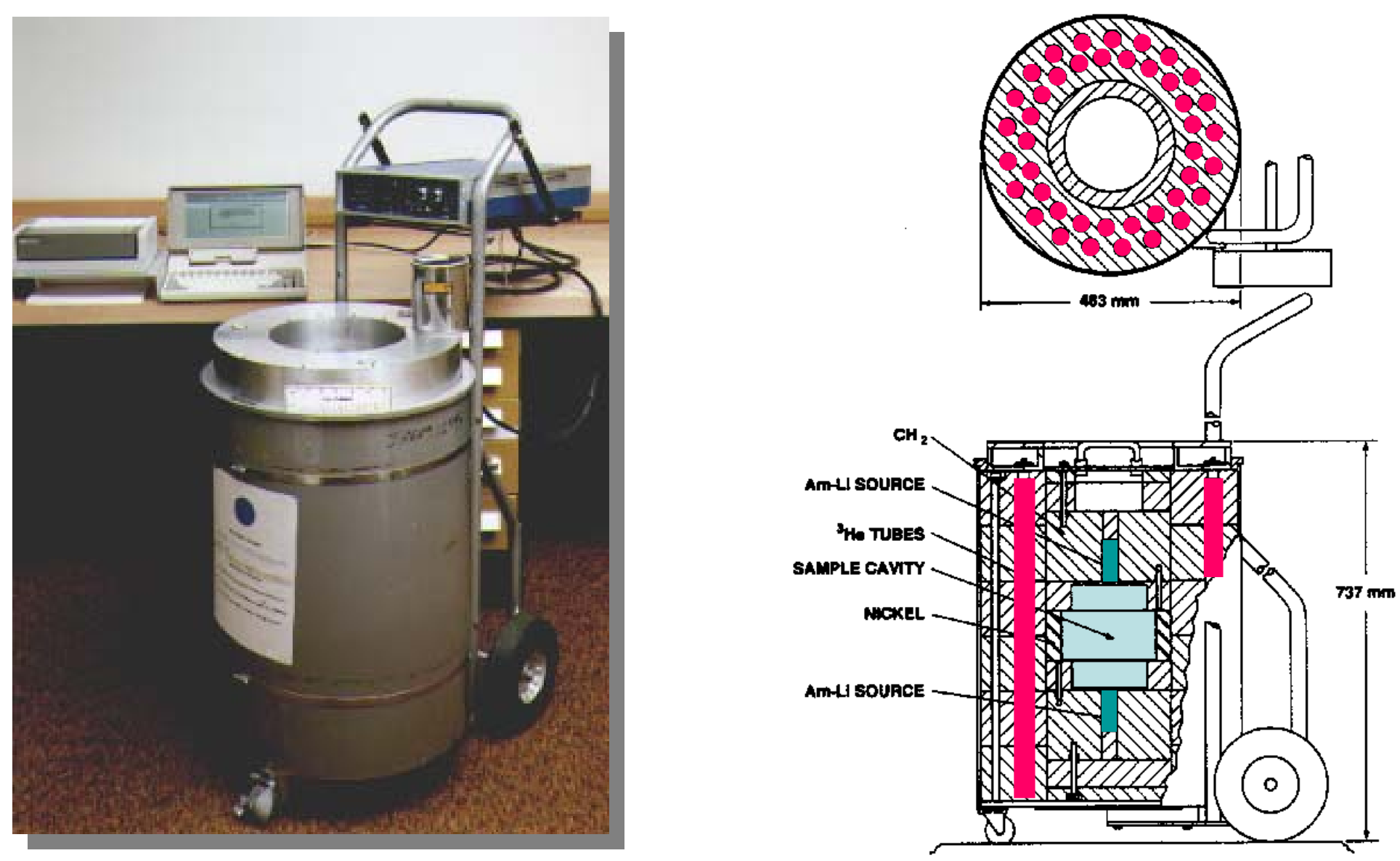

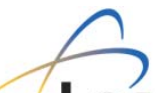




\section{Plutonium Scrap NMC}

Polyethylene

Graphite

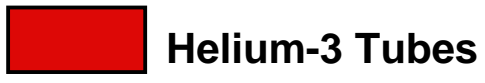

Air

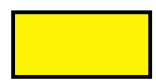

Junction Box

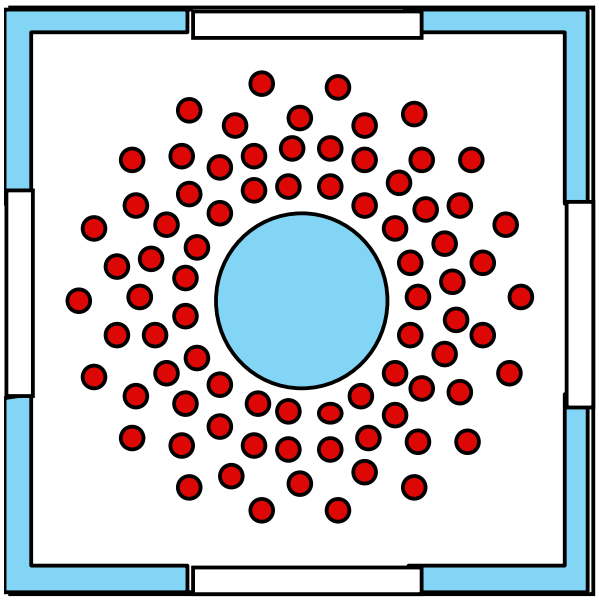

80 Tubes

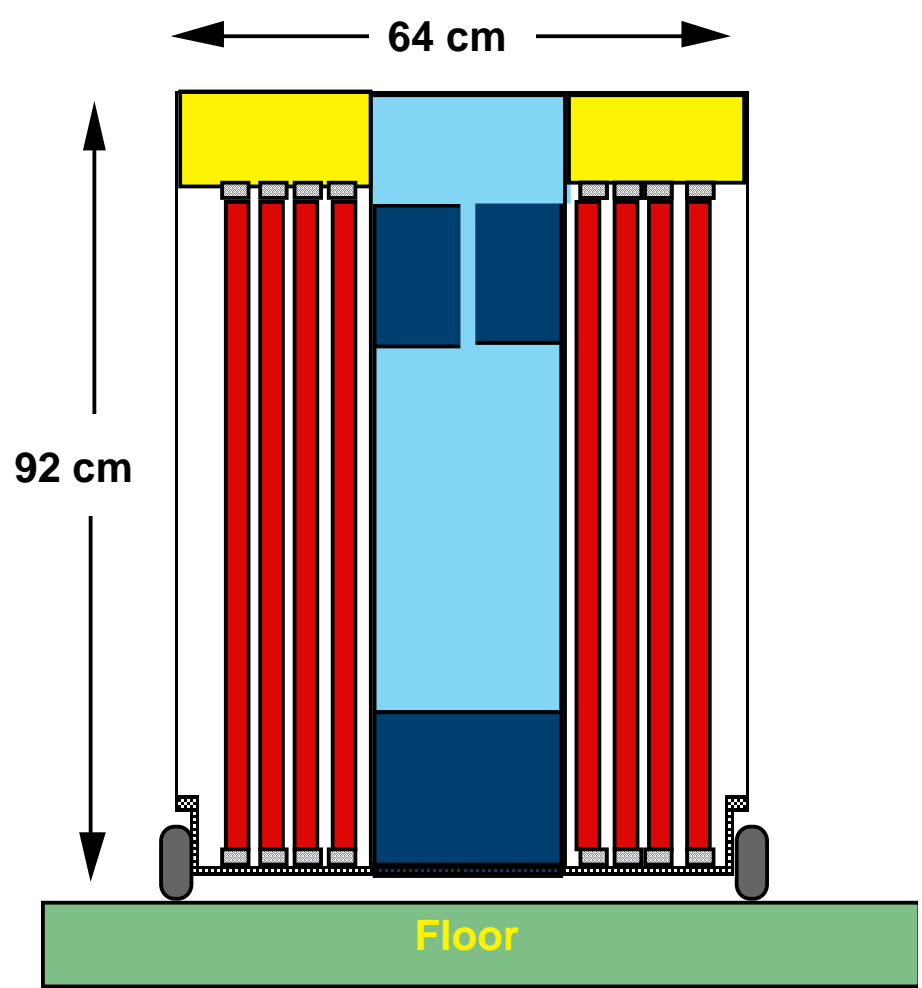

Sample Cavity is $20 \mathrm{~cm} \times 41 \mathrm{~cm}$ and is Cadmium Lined 


\section{The Shuffler Assay Principle}

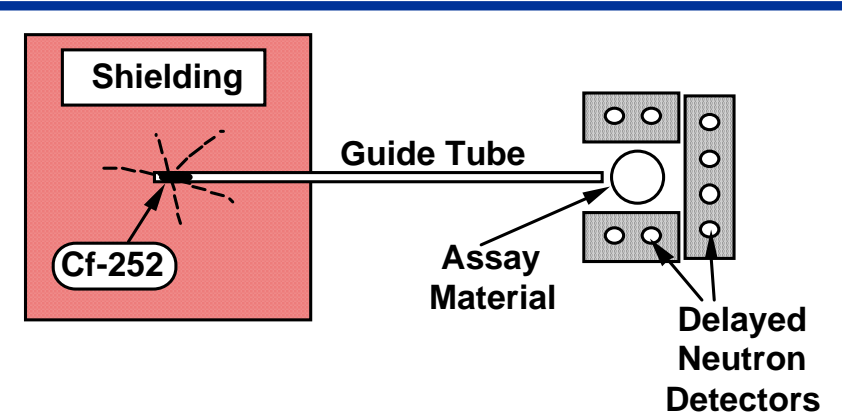

(a)

The interrogating source is stored in heavy shielding.

The interrogating source quickly

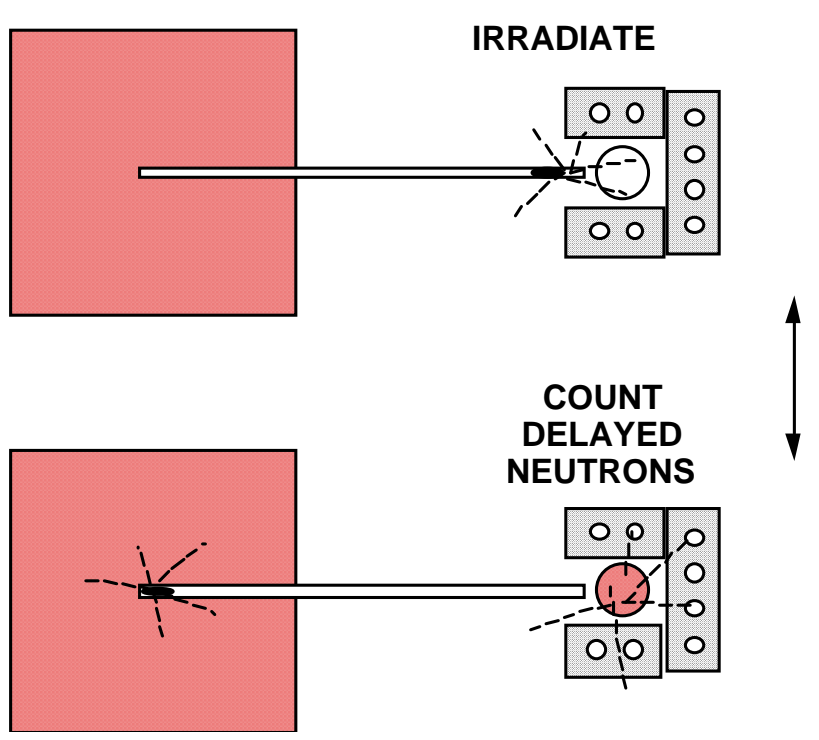
moves to a position near the SNM. The source remains near the sample

(b) for a few seconds, inducing fissions.

The interrogating source is quickly moved back to its shielded position;

(c) the detectors then count delayed neutrons.

The "irradiation-count" cycle is repeated many times to acquire adequate statistical precision. The periodic motion of the interrogating source, shuffling in and out of its shielded storage, gives the "Shuffler" its name. 


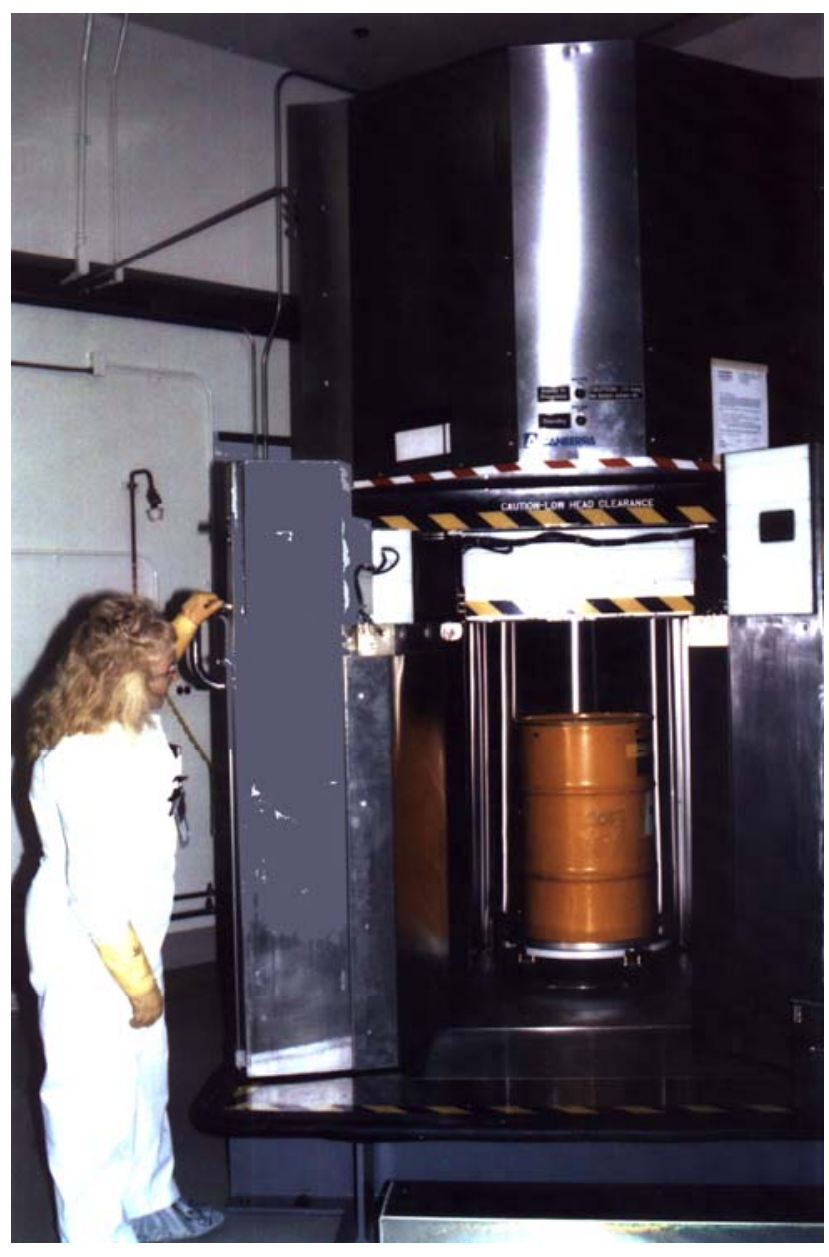

- LOS Alamos EST. 1943 
Sample Characteristics for Neutron Assays

- Uniformity still important, but not always critical

- High-density

- Large size

- Heterogeneous

In addition, most samples assayable with gamma rays are also assayable with neutrons

\section{Special Cases for Neutrons}

- Low or high-density waste (small amount of SNM)

- High-gamma-yield material (e.g., spent fuel) 


\section{Problems for Neutron Assays}

- Hydrogenous materials (Protons!) [increased system response]

- plastics

- moisture

- any other moderator

- Absorption by high-density SNM (fissile)

- $\boldsymbol{n}$ capture to induce fissions (absorption)

- induced fissions (multiplication)

- Absorption by neutron poisons [good neutron absorbers] 

and Delayed Neutron Counting

- All U samples [assays mass of ${ }^{235} \mathrm{U}$ ]

- Pu samples [assays mass of ${ }^{239,241} \mathrm{Pu}$, passive signal may complicate]

- Mixed U/Pu samples (MOX) [need passive and active measurement to sort out components]

- Low-mass or high-gamma samples (waste, spent fuel) [delayed neutron counting (Shufflers)] 


\section{Neutron NDA Calibration}

- Philosophy the same as for gamma NDA

- Measure standards

- Apply all relevant corrections

Best to calibrate over a range of expected sample characteristics 


\section{Neutron Calibration Standards}

- Standards' characteristics:

- Range of SNM masses

- Range of matrices

- Range of material types

- Establishes response variations from:

- Moderation

- Multiplication

- Absorption 


\section{Measurement Precision in Neutron NDA}

Origins

- Random decay processes (counting statistics)

- Fluctuating neutron backgrounds

- Strategies to improve precision

- Longer count times (improve statistics)

- Background/source control

- [Active] Longer count times for interrogation source

- [Shuffler] Careful mechanical design and many count cycles minimize source placement problems. 


\section{Measurement Bias in Neutron NDA}

- Origins

- Calibration uncertainty

- Chronic sample mis-placement in measurement well

- Altered neutron backgrounds (singles and coincidence)

- Strategies to minimize bias

- Calibrate often and with high precision.

- Background/source control 


\section{Measurement Control for Neutron NDA}

- Philosophy - still the same as for $\gamma$-ray measurements

- Periodically check quality of data and instrument.

- Periodically measure measurement control standard.

- Check precision by repeated measurements of standard.

- Check bias by verification of average standard value against declared value.

- Measurement Control standards for neutron NDA:

- Stable SNM (encapsulated metal, sealed oxide, ...)

- ${ }^{252} \mathrm{Cf}$ source (fission neutrons, decay rate known)

- [AWCC] AmLi source built in + SNM sample

- [Shuffler] Calibrated standard 


\section{Active Neutron Coincidence Collar}

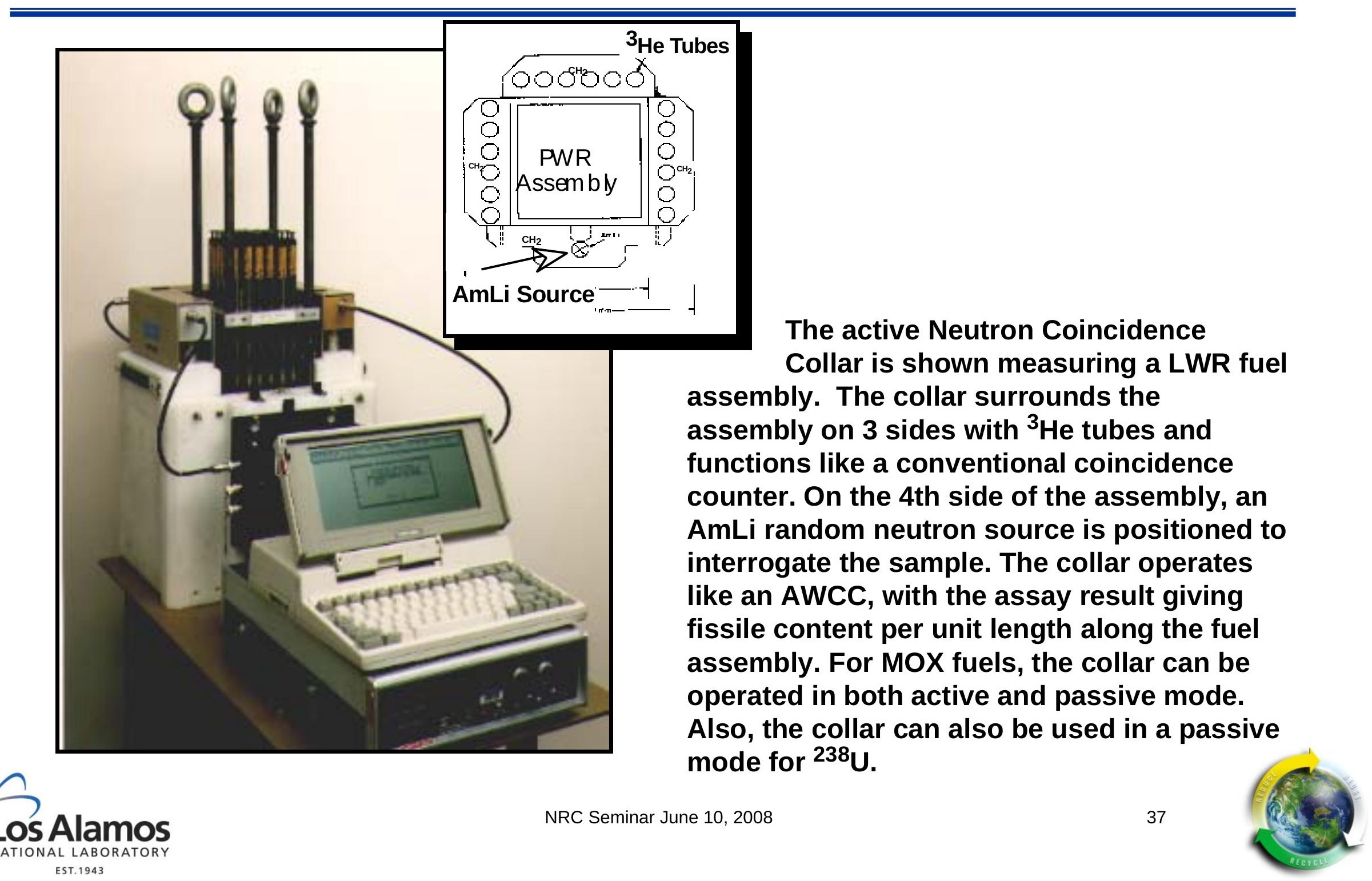




\section{Neutron NDA Summary}

- Neutron NDA Techniques:

- Passive coincidence, active coincidence, delayed $\mathbf{n}$

- Absorption, multiplication, moderation corrections can be important

- $(\alpha, n)$ interactions can affect results strongly (background, bias)

- Appropriate samples: minimum hydrogen (moderator); passive - Pu, active - U; high-sensitivity (waste) - passive or delayed $\mathbf{n}$.

- Calibration curves of families of sample types recommended

- Accuracies Possible:

- $1 \%$ to $50 \%$, depending on sample composition and technique

- Best performance on dry, dilute samples (no moderation, multiplication)

- Worst cases: samples with varying moisture, moderation, matrix. 


\section{Calorimetry}

- Los Alamos 


\section{Calorimetry}

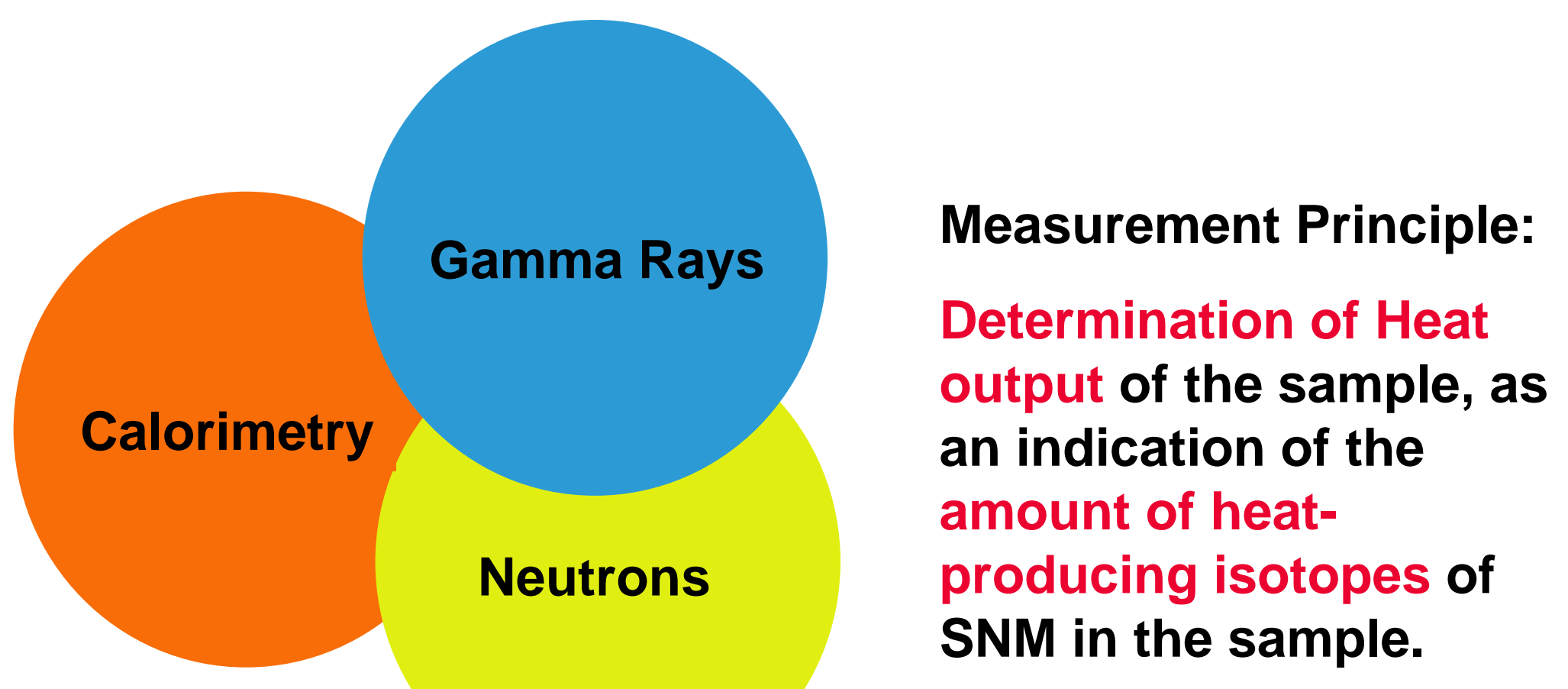




\section{Why Calorimetry?}

- The most accurate NDA measurement ( $<1 \%$ uncertainty) of nuclear material

- You can't hide the heat of the material

- No absorption, moderation, multiplication,...

- Inherently matrix independent

- Assay result independent of material, matrix or container type

- matrix can only affect duration of analysis

- No physical SNM standards needed!

- NIST-traceable technique

- Most DOE facilities are using calorimetry

- Hanford, PNL, RF, LANL, SRS, LLNL, ANL-W... 
- Accountability Measurements

- Verification measurements

- Shipper receiver measurements

- Calibration of NDA working standards

- Measurement of biases and precisions of other NDA techniques

- Resolution of assay "outliers" and problem samples

- Benchmarking NDA measurement campaigns

- Process control measurements

- Product acceptance measurements

Considered the "gold standard" of NDA measurements throughout the complex 


\section{Relative Thermal Powers}

$$
\begin{aligned}
& { }^{238} \mathrm{Pu}(0.568 \mathrm{~W} / \mathrm{g}) \\
& \text { tritium }(0.324 \mathrm{~W} / \mathrm{g})
\end{aligned}
$$

plutonium(0.002 $-0.014 \mathrm{~W} / \mathrm{g})$

human(0.001 $-0.002 \mathrm{~W} / \mathrm{g})$

${ }^{233} \mathrm{U}(0.00028 \mathrm{~W} / \mathrm{g})$

Current calorimeter capability@1\% accuracy

${ }^{235} \mathrm{U}\left(93 \%{ }^{235} \mathrm{U}-235,1 \%{ }^{234} \mathrm{U}, 2 \times 10 * *-6 \mathrm{~W} / \mathrm{g}\right)$

TRU limit(100 nCi/gram, 3 x 10**_9 W/g) 


\section{Fundamental Measurement Characteristics}

- Precise NDA measurements based on heat output of sample

- measurement accuracy of $0.1 \%$ to $0.5 \%$ for most cases

- best suited for plutonium samples

- Sealed containers

- Assay results independent of matrix material

- Requires isotopics to convert power to grams

- isotopics from: Gamma ray (NDA) or Chemistry (DA)

- Integrates over total sample volume

- Faster than DA, slower than NDA ( $\gamma$ or $n$ ) 


\section{Half-lives and Specific Powers}

$\begin{array}{lll}\text { Isotope } & \begin{array}{l}\text { Half-life } \\ \text { (years) }\end{array} & \begin{array}{l}\text { Specific Power } \\ \text { (Watts/gram) }\end{array} \\ \text { Pu-238 } & 87.74_{04} & 0.56757_{26} \\ \text { Pu-239 } & 24119_{26} & 0.0019288_{03} \\ \text { Pu-240 } & 6564_{11} & 0.0070824_{20} \\ \text { Pu-241 } & 14.348_{22} & 0.003412_{02} \\ \text { Pu-242 } & 376300_{900} & 0.0001159_{03} \\ \text { Am-241 } & 433.6_{14} & 0.1142_{05} \\ \text { H-3 } & 12.3232_{43} & 0.3240_{09}\end{array}$




\section{Calorimeters measure the flux through heat sensors of thermal energy generated by radioactive decay}

$\mathrm{dQ} / \mathrm{dt}=\left(\mathrm{T}_{\text {cal }}-\mathrm{T}_{\text {env }}\right) / \mathrm{R}_{\mathrm{Th}}$
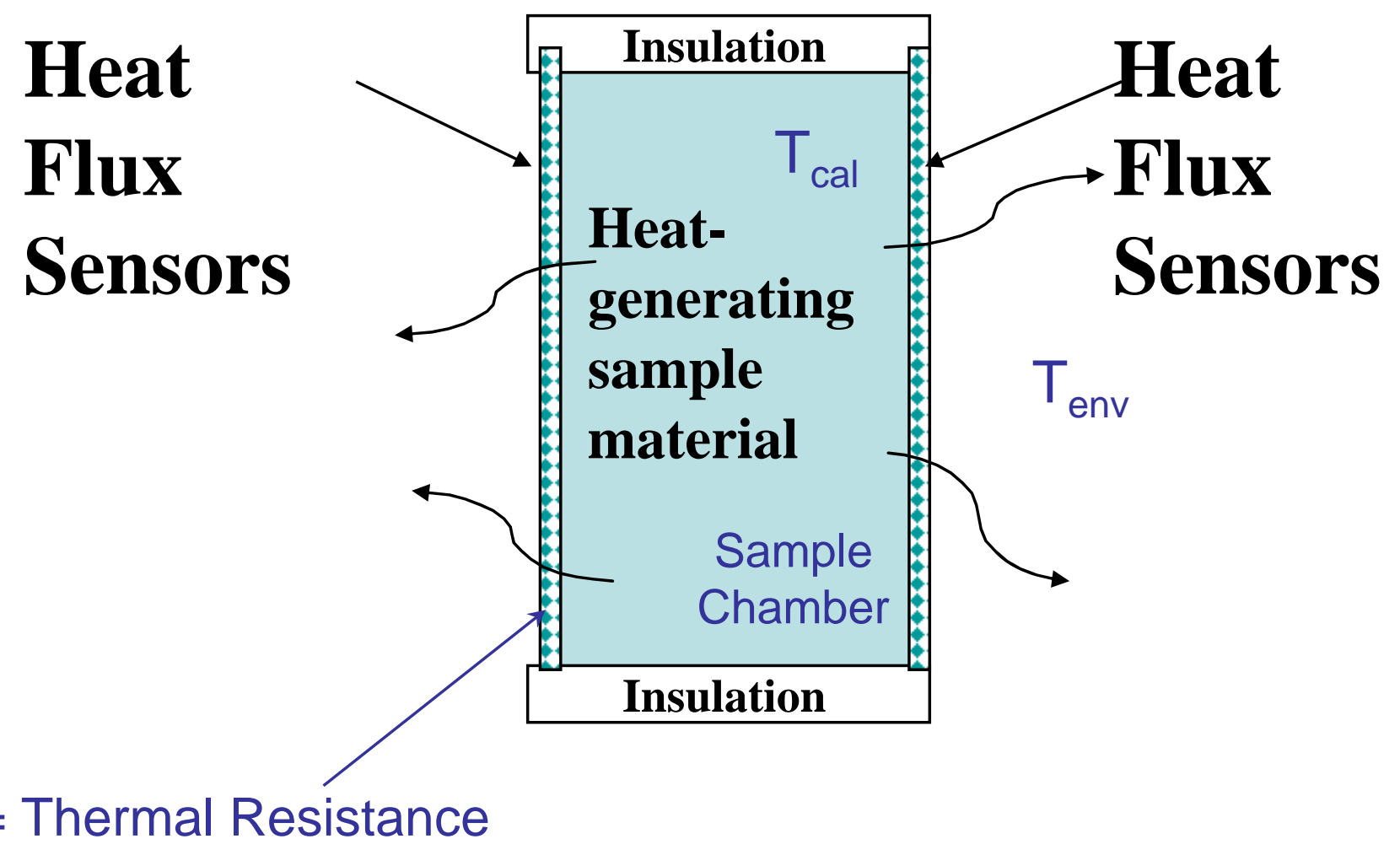

$\mathrm{R}_{\mathrm{Th}}=$ Thermal Resistance 


\section{Twin Bridge Schematic}

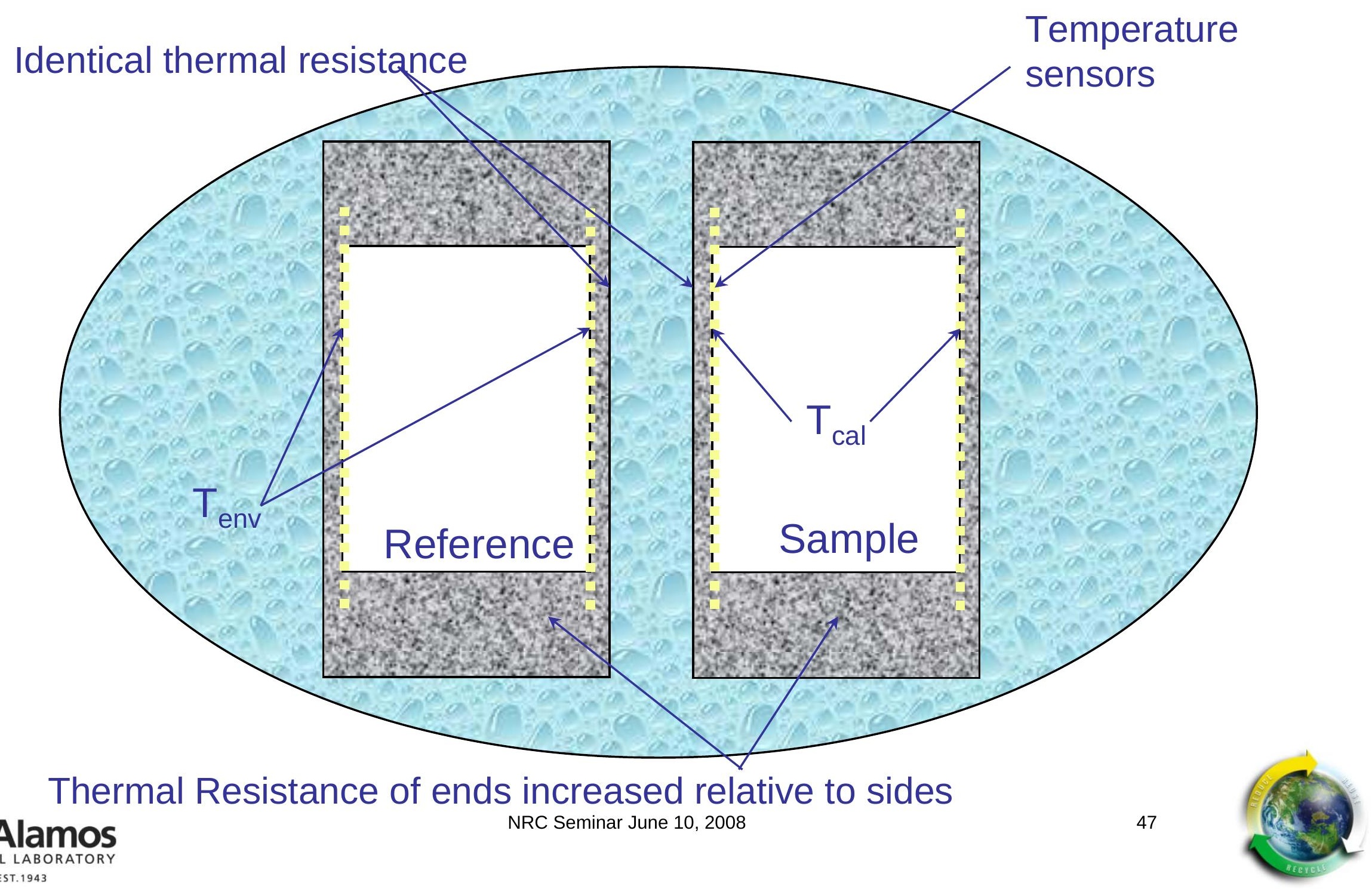




\section{Why Twin Design?}

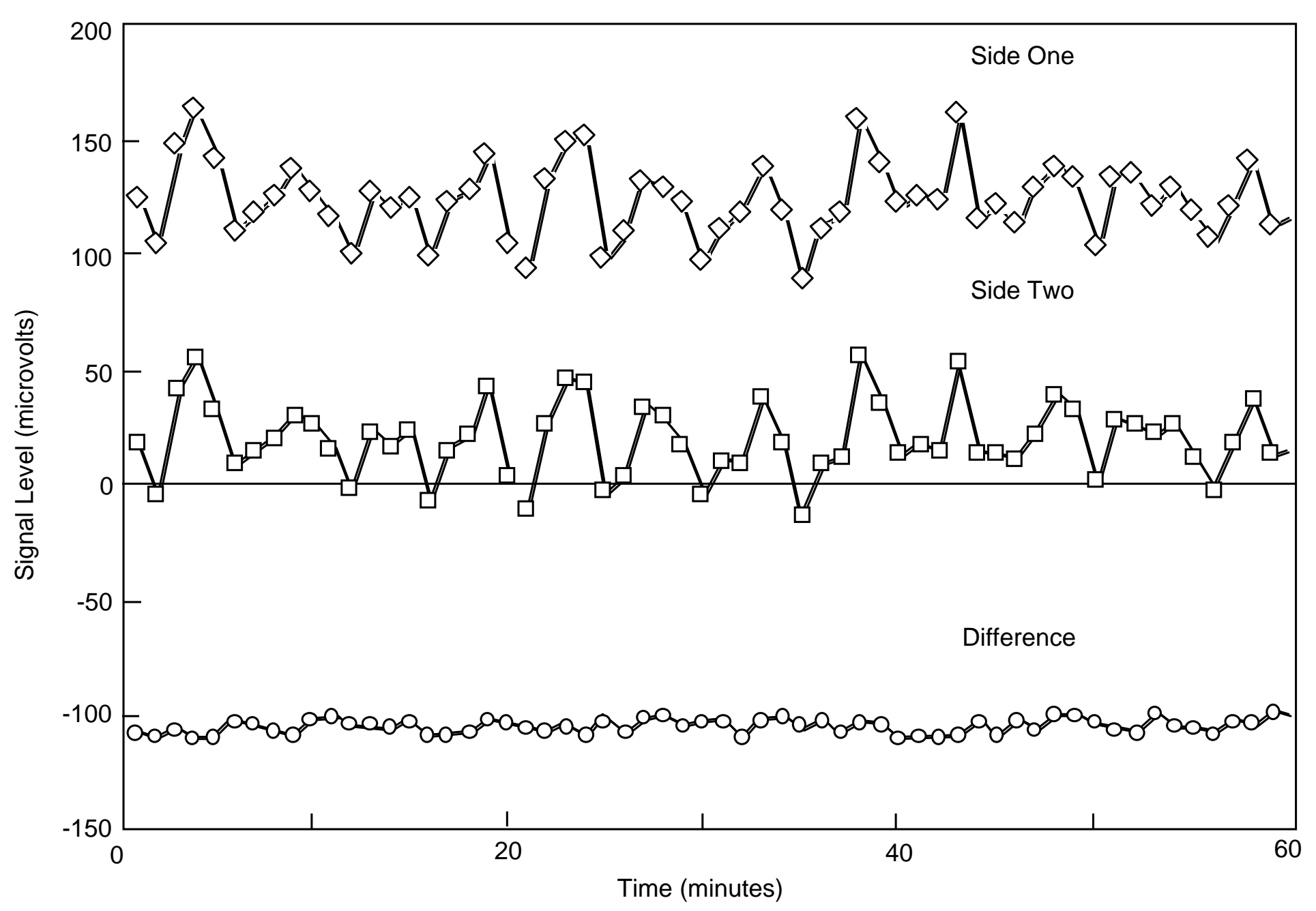




\section{Resistance change measured by Wheatstone}

Bridge

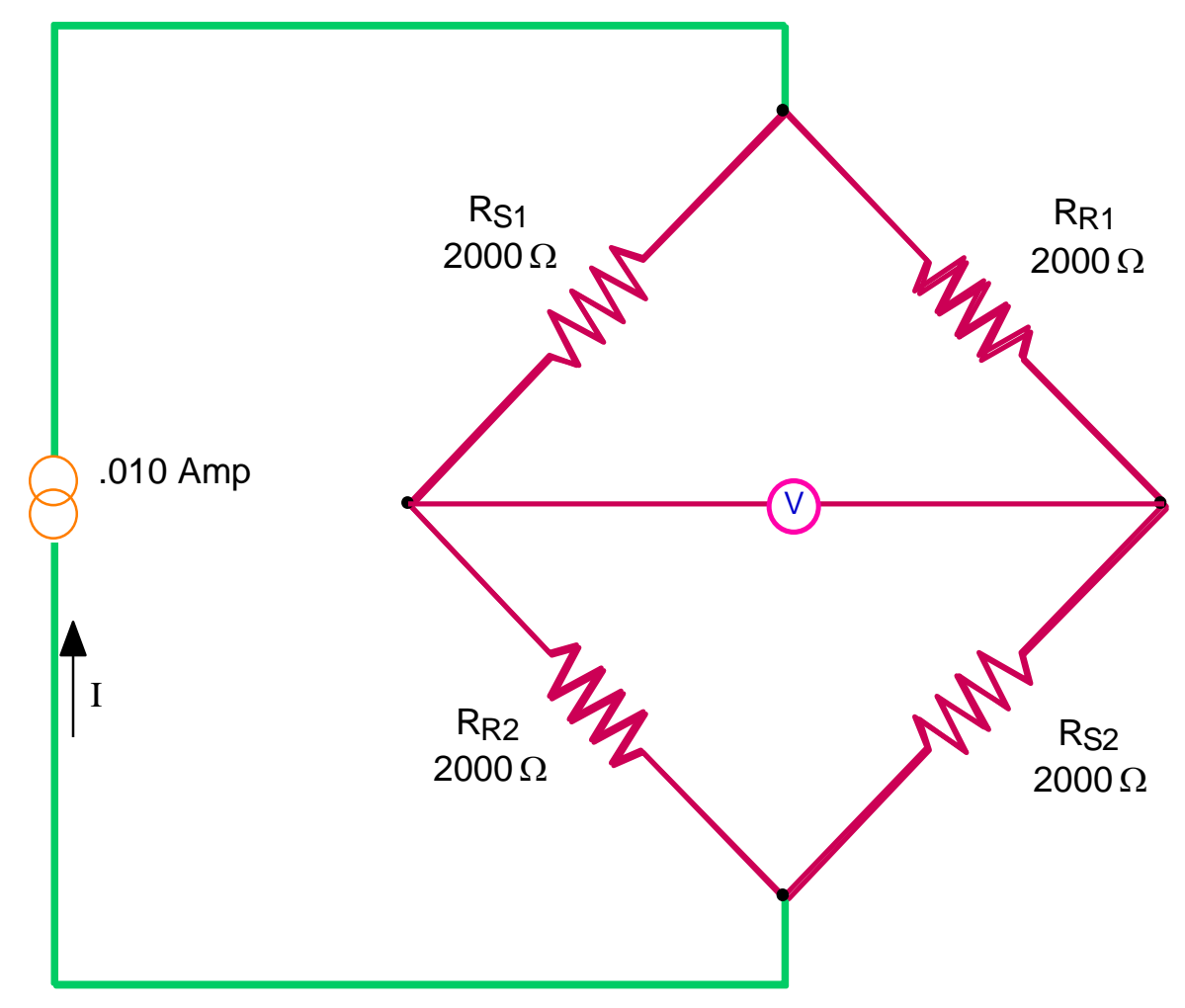




\section{Wheatstone Bridge Calorimeter}

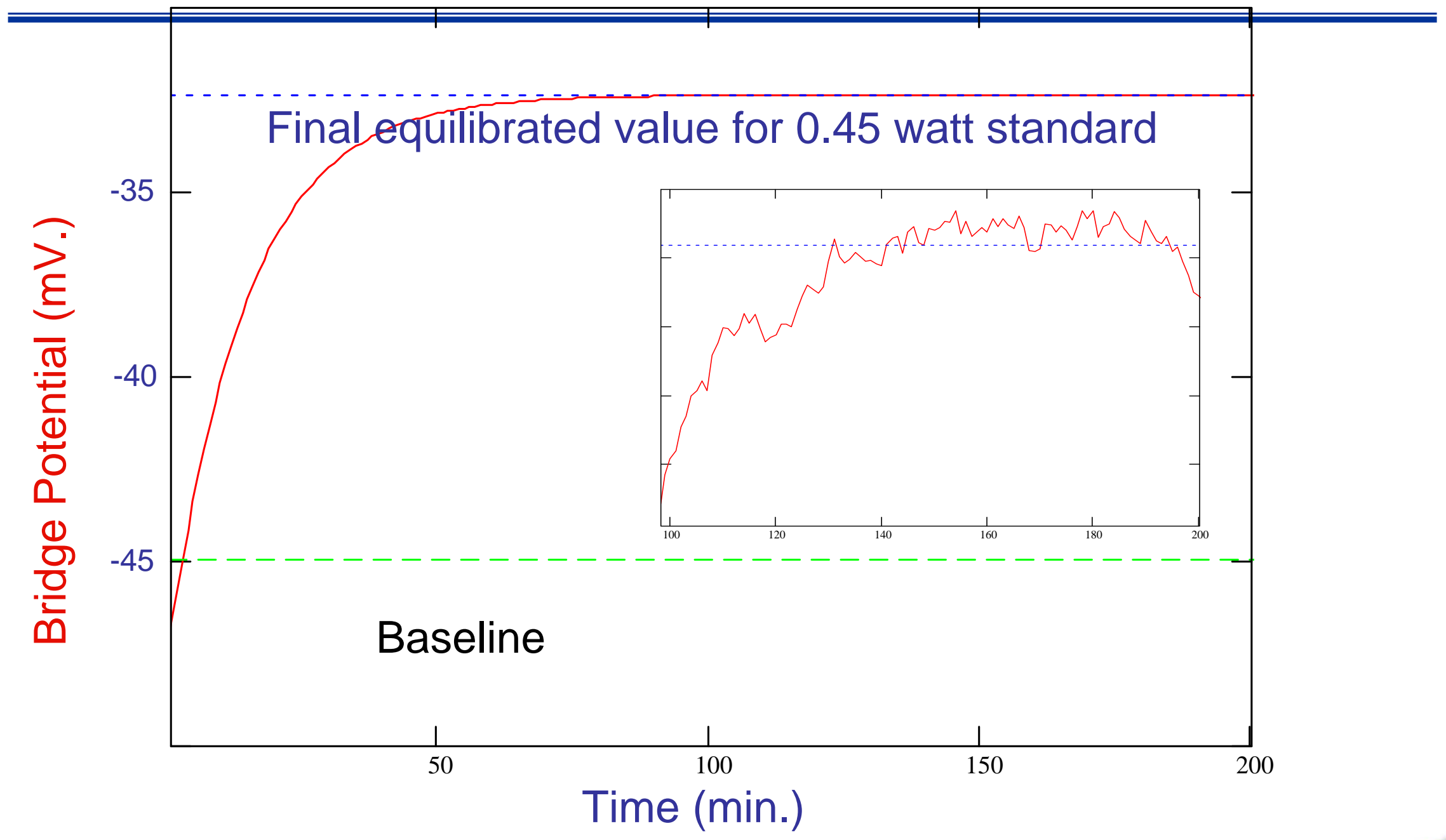




\section{Calorimeter sensor output independent of matrix}

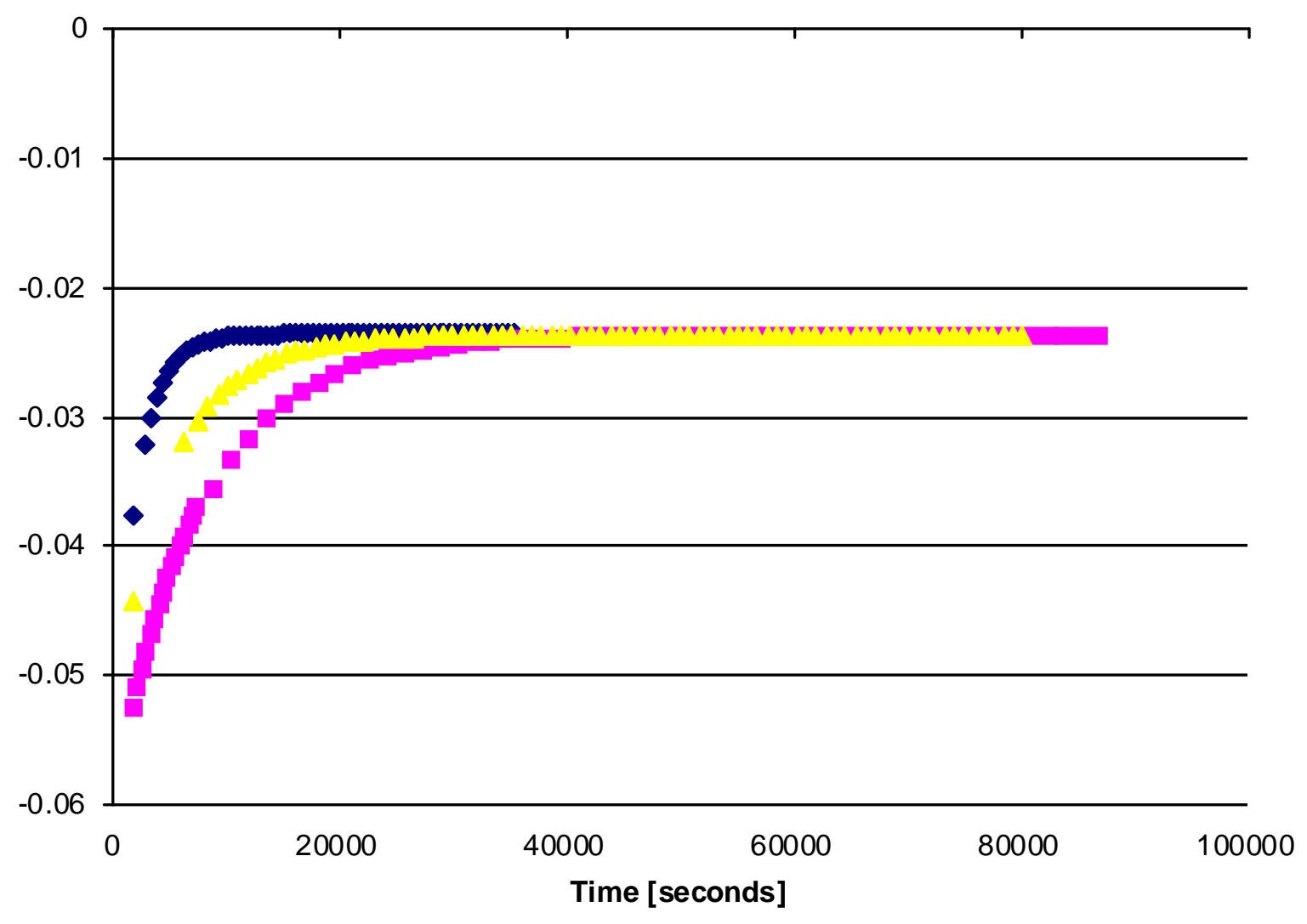

- 27Jun Al foil2 1.0wj 4Jul Cu shot \& 1.0wj

8Jul salt \&1.0wj 


\section{Calorimetric Assay of SNM (mass)}

Equation for total SNM mass

$$
\text { Mass }(\text { grams })=\frac{\text { Thermal Power }(\text { Watts })}{\text { Peff }_{(\text {Watts } / \mathrm{g})}}
$$

- Measure isotopic composition of item (high resolution gamma spectroscopy or mass spectroscopy) and compute Effective Specific Power, $P_{\text {eff }}$

$$
P_{\text {eff }}(\text { Watts } / g)=\sum P_{i} * f_{i}
$$

$\mathrm{P}_{\mathrm{i}}=$ Isotope specific power (Watts/g)

$\mathrm{f}_{\mathrm{i}}=$ Isotopic fraction in sample, relative to plutonium

$\mathrm{i}=$ all isotopes present (i.e. ${ }^{238} \mathrm{Pu},{ }^{239} \mathrm{Pu}, \ldots,{ }^{242} \mathrm{Pu},{ }^{241} \mathrm{Am}$ ) 


\section{Effective Specific Power:}

\section{The rate of energy emission per unit mass of plutonium at the time of measurement.}

$$
\mathrm{P}_{\text {eff }}=\sum_{\mathrm{i}=1}^{\mathrm{n}} \mathrm{R}_{\mathrm{i}} \mathrm{P}_{\mathrm{i}}
$$

Where:

- there are $n$ isotopes in the sample

- $\mathrm{R}_{\mathrm{i}}$ is the mass ratio of each isotope present

- $\mathrm{P}_{\mathrm{i}}$ is the specific power of each isotope

-Isotopic information not required for monoisotopic items (e.g. ${ }^{3} \mathrm{H}$ or ${ }^{241} \mathrm{Am}$ )

${ }^{238} \mathrm{Pu}$ and ${ }^{241} \mathrm{Am}$ can be important because of their very high specific heat values. ${ }^{239} \mathrm{Pu}$ can be important because of it's high abundance in most samples. 


\section{Calibration and Standards}

- No SNM standards representative of material type are needed

- Electrical standards

- Heat standards

- HEAT output is measured, and heat is not absorbed or otherwise lost, unlike neutron or gamma NDA methods. 
Situations that degrade Cal/Iso measurement performance

- Distortions to gamma-ray isotopic assay

- Separated Am-241 and Pu, each in different matrices

- Gamma-ray interferences

- Pu-241/ U-237 equilibrium

- Inhomogeneous isotopic distribution

- Distortions to calorimetry

- Chemical reactions

- Power emitting isotopes with no gamma-ray [e.g., ${ }^{90} \mathrm{Sr}$, $\left.{ }^{3} \mathrm{H}\right]$ 


\section{Calorimeter Performance}

- Plutonium:

- $0.2 \%$ to $0.5 \%$ on power measurements

- $0.5 \%$ to $1.0 \%$ on specific power

- Bulk HEU (multi-Kg):

- 1 to $3 \%$ on power measurements

- 0.5 to $1.0 \%$ on specific power

- Measurement time:

- 20 min. preconditioned high conductivity sample

- 2-4 hours typical samples

- 8-12 hours insulated samples (e.g., salts) 


\section{Appropriate Samples For Calorimetry}

- Measurable heat outputs

- Pu samples

- High-mass U samples

- Tritium

- Good heat-transfer characteristics

- Time to thermal equilibrium

- Throughput considerations 


\section{Calorimetry equipment}

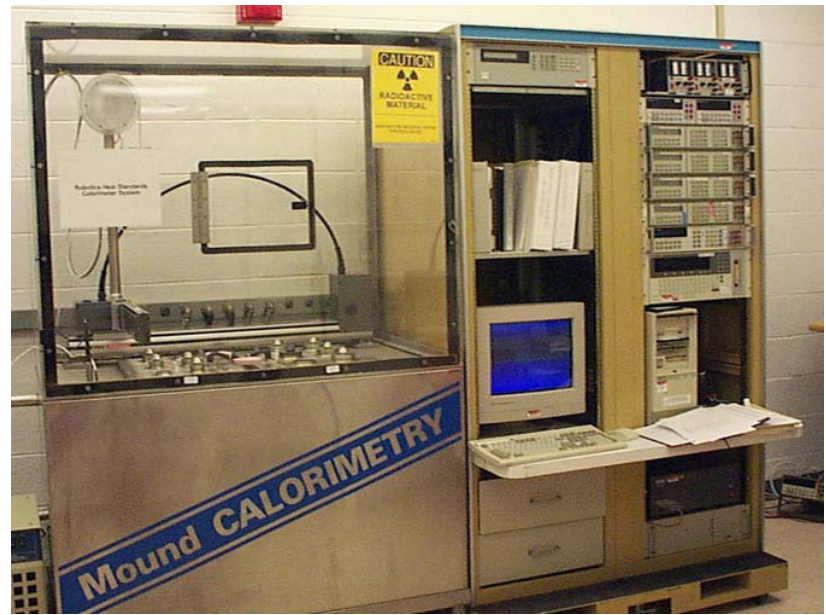

Calorimeter used for standards verification
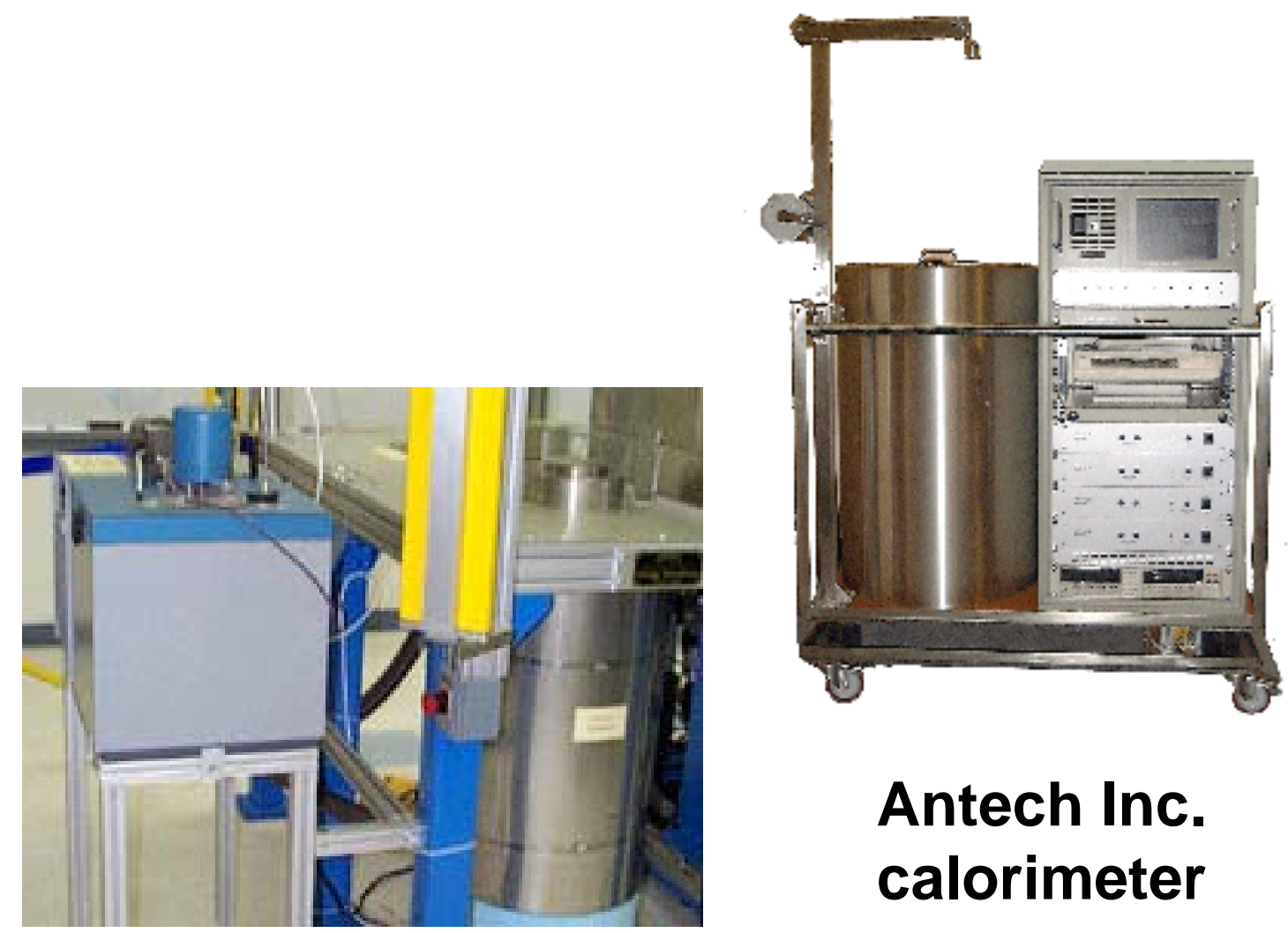

Antech Inc. calorimeter

LANL-customized calorimeter 


\section{Calorimetry NDA Summary}

- Calorimetry NDA Technique

- Measure heat output from the sample

- Measure specific power of the sample

- Appropriate samples: heat-emitting (Pu, large $\mathrm{U}, \mathrm{T})$

- Accuracies Possible [rivals chemistry]

- Power: $0.1 \%$ to $0.5 \%$ (1-8 $\mathrm{hr}$ assay times)

- Specific power (0.5\% to $1 \%)$

- Best performance on isotopically homogeneous samples

- Most useful on heterogeneous NM samples 


\title{
Advanced Fuel Cycle Safeguards
}

\author{
Michael Miller \\ GNEP Safeguards Campaign Director \\ Los Alamos National Laboratory \\ U.S. Nuclear Regulatory Commission \\ Rockville, MD \\ June 10, 2008
}




\section{Outline}

- Introduction and Current Technical Basis

- Reprocessing

Fuel Fabrication

- Fast Reactor 


\section{Safeguards for Advanced Fuel Cycle Facilities}




\section{Safeguards Applications in Advanced Facilities}
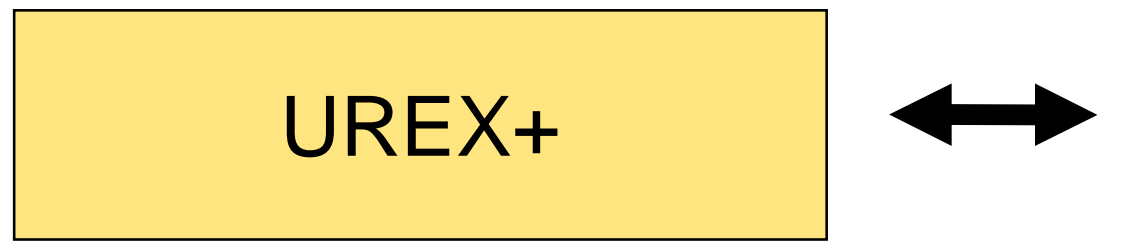

Rokkasho Reprocessing

Plant (RRP)
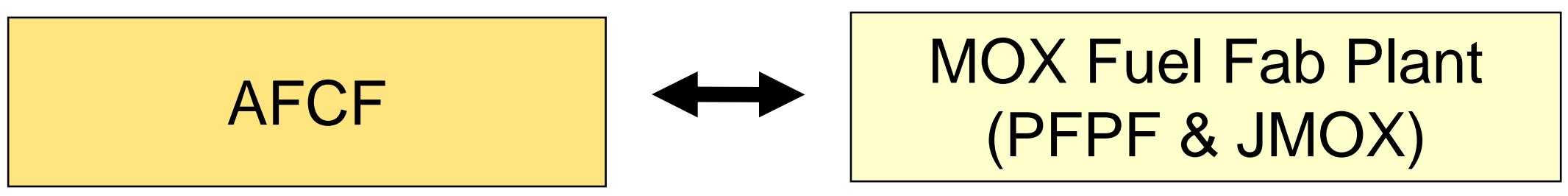

ABR/ABTR

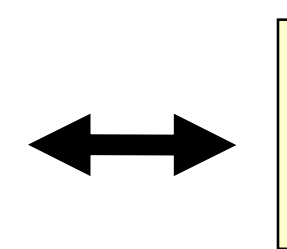

Fast Breeder Reactors

(Joyo \& Monju)

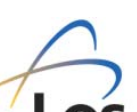




\section{Reprocessing}




\section{Rokkasho Reprocessing Plant (RRP)}

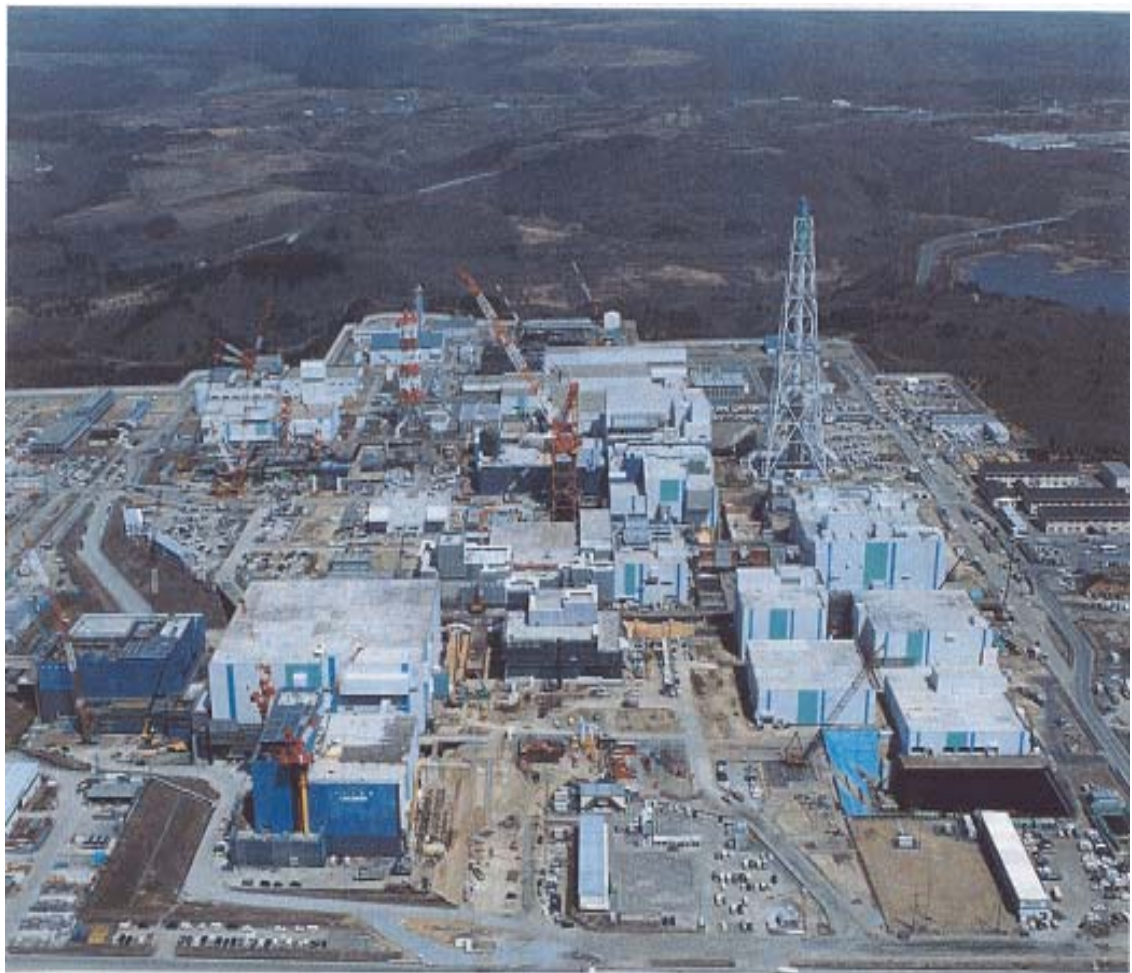

South Side
Features common to UREX

- Spent fuel storage pool

- Head-end shear and dissolver

-Input accountability tank (IAT)

-Mixture with Pu in product

- High level liquid waste (vitrification)

-Solid wastes

Safequards Features

-Remote, unattended monitoring

- Near real-time accounting (NRTA)

- Process monitoring

-Data authentication

-Containment and surveillance

- On-site inspector presence

-Approx. 20 different SG systems 
-ISVS - Integrated Spent fuel Verification System

-IHVS - Integrated Head end Verification

System

nHMS - Rokkasho Hulls Measurement

System

VCAS - Vitrified waste Canister Assay

System

-HKED - Hybrid K-Edge Densitometer

TCVS - Temporary Canister Verification System

iPCAS - improved Plutonium Canister Assay System

wCAS A/B - Waste Crate Assay System

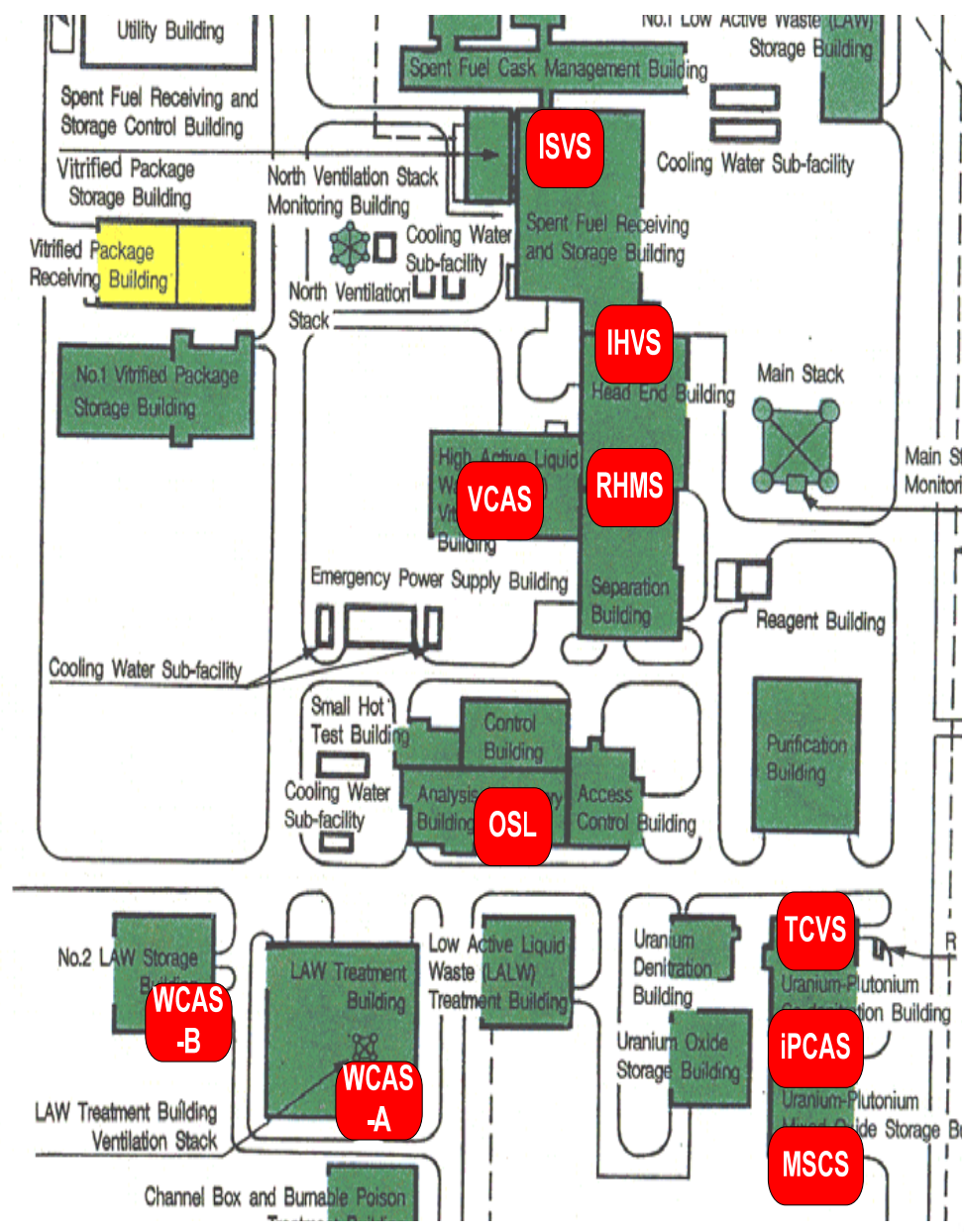

NRC Seminar June 10, 2008 


\section{Head-End Fuel Assembly Verification Camera \& Radiation Detector (CRD)}

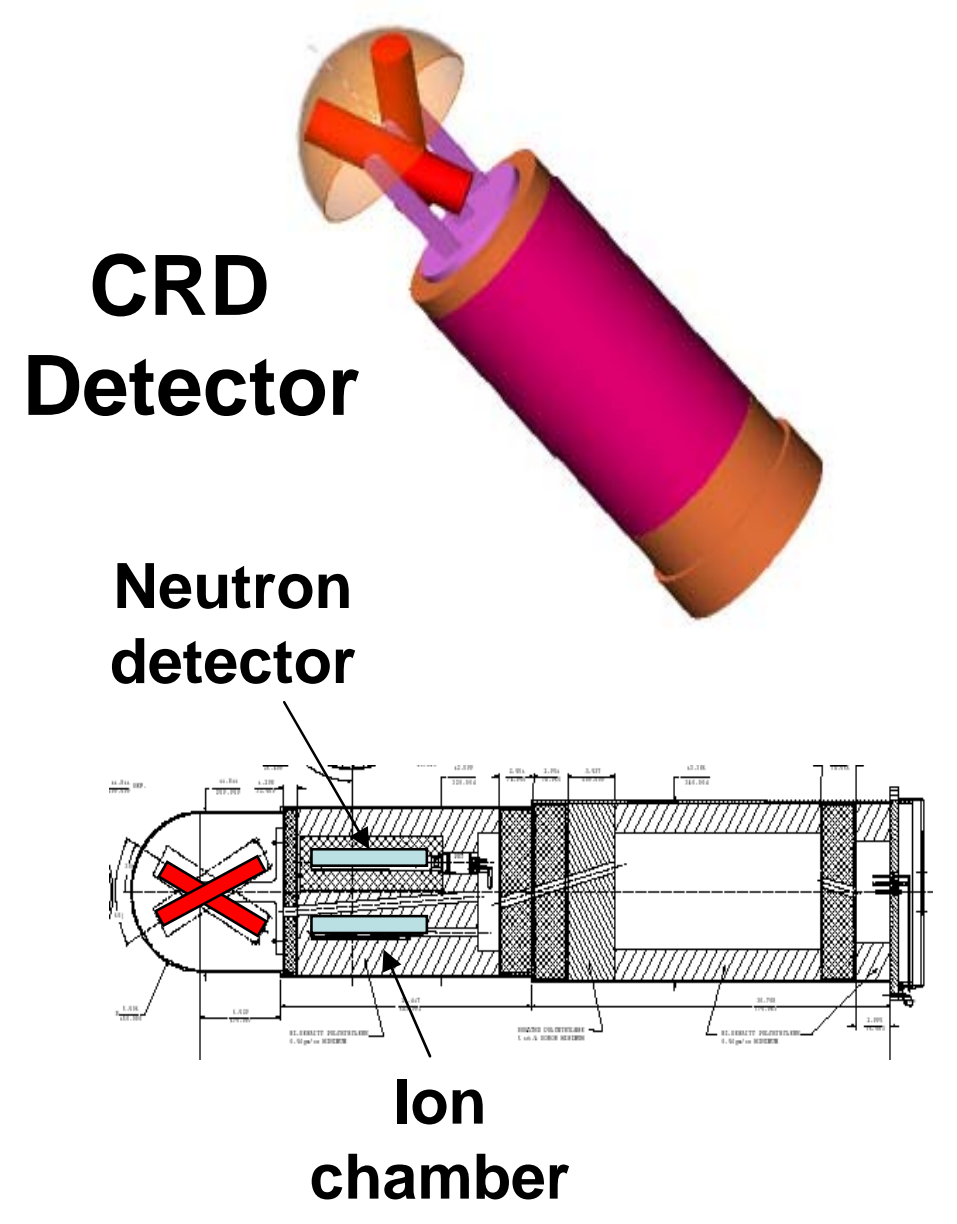

-Verification of LWR fuel assemblies inside shearing cell

-Penetrates the 2-meter thick concrete shielding wall

- Shielded detector head includes cameras, neutron and gamma sensors

-Provides ID, type fuel, and shearing history

-Continuous operation by IAEA and Operator

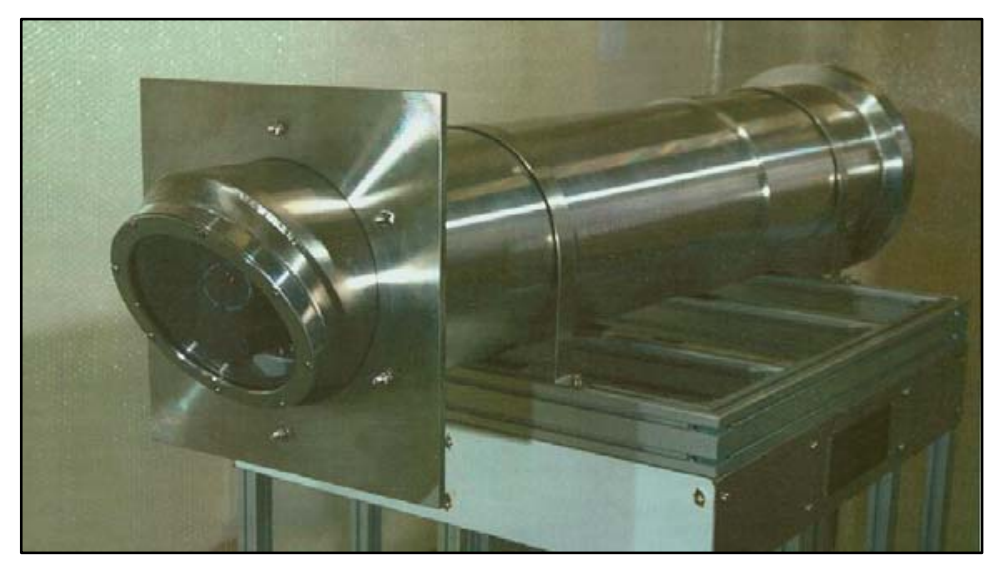




\section{Verify Quantity of Pu in Waste Streams}

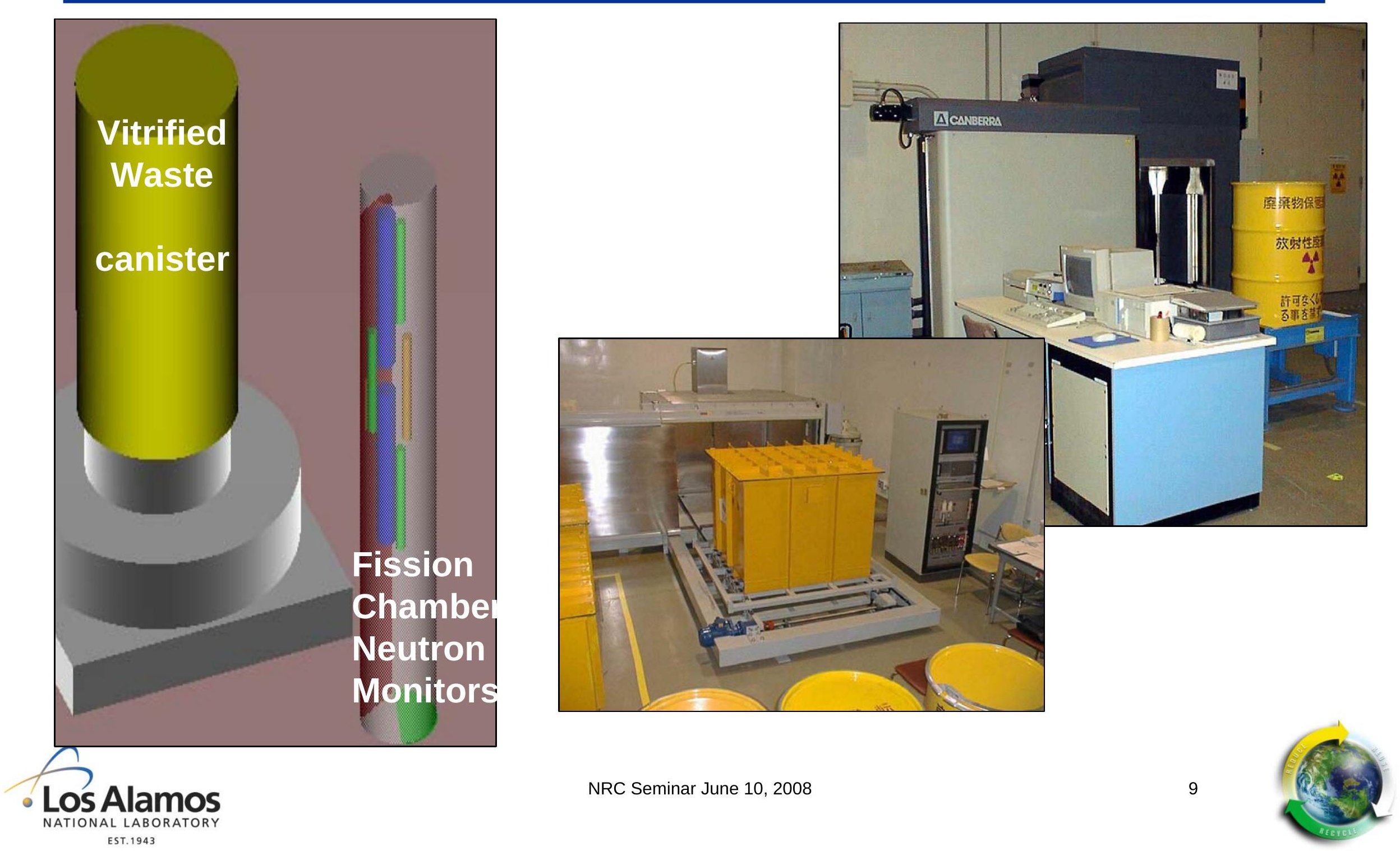


Example of impact of new safeguards measurement technologies: improved Plutonium Canister Assay System (iPCAS)

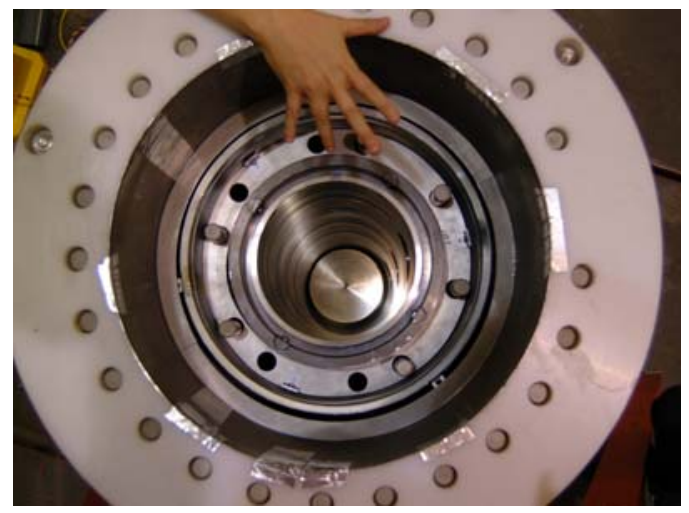

Installed in RRP March 2004: decreased the uncertainty of each measurement $(36 \mathrm{~kg}$ containers of MOX) by $\sim 200 \mathrm{~g} \mathrm{Pu}$

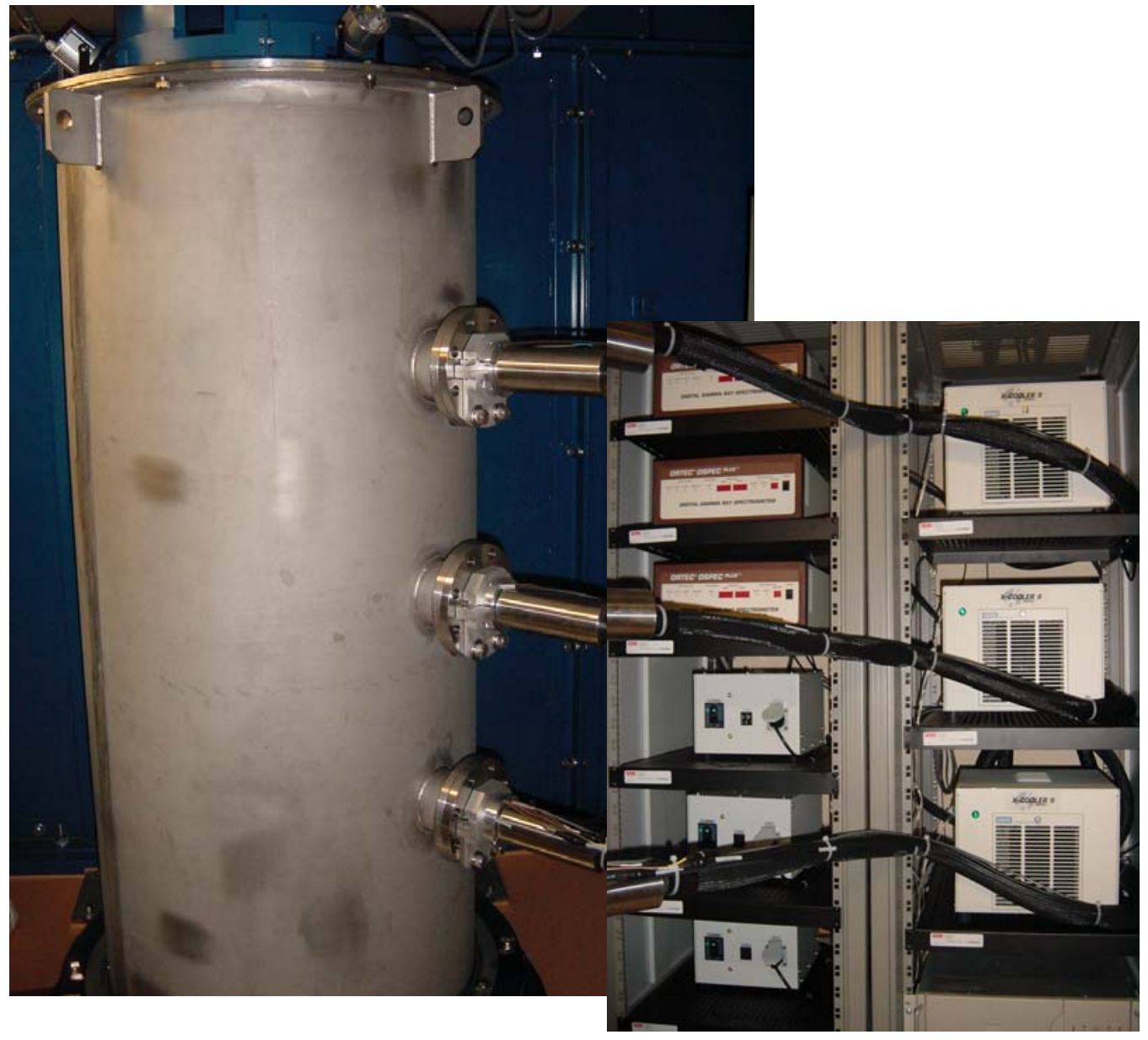




\section{Fuel Fabrication}




\section{Plutonium Fuel Production Facility (PFPF)}

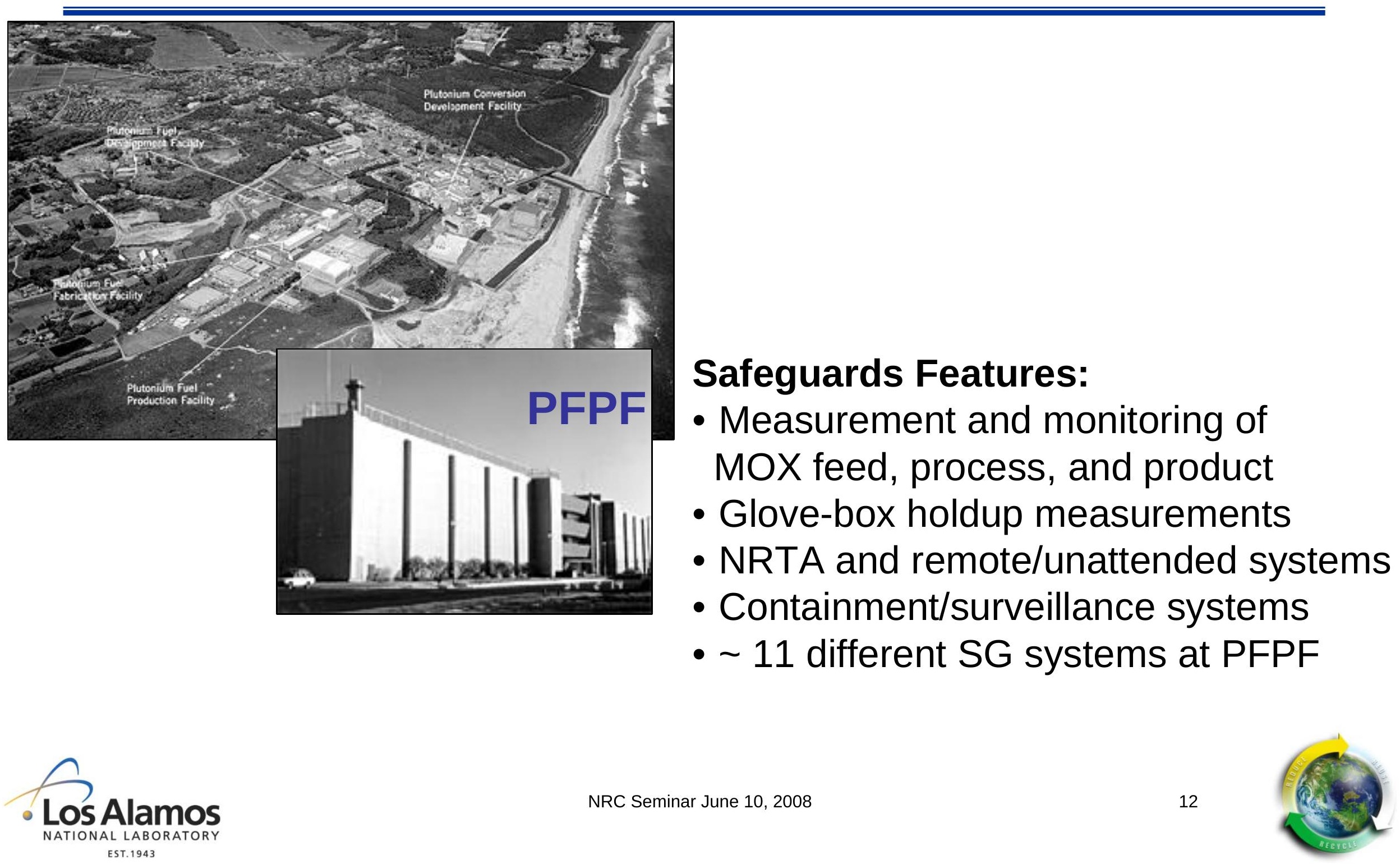




\section{Input MOX verification (PCAS), Process Holdup (GBAS)}

Measure $\mathrm{PuO}_{2}$ \& MOX into facility

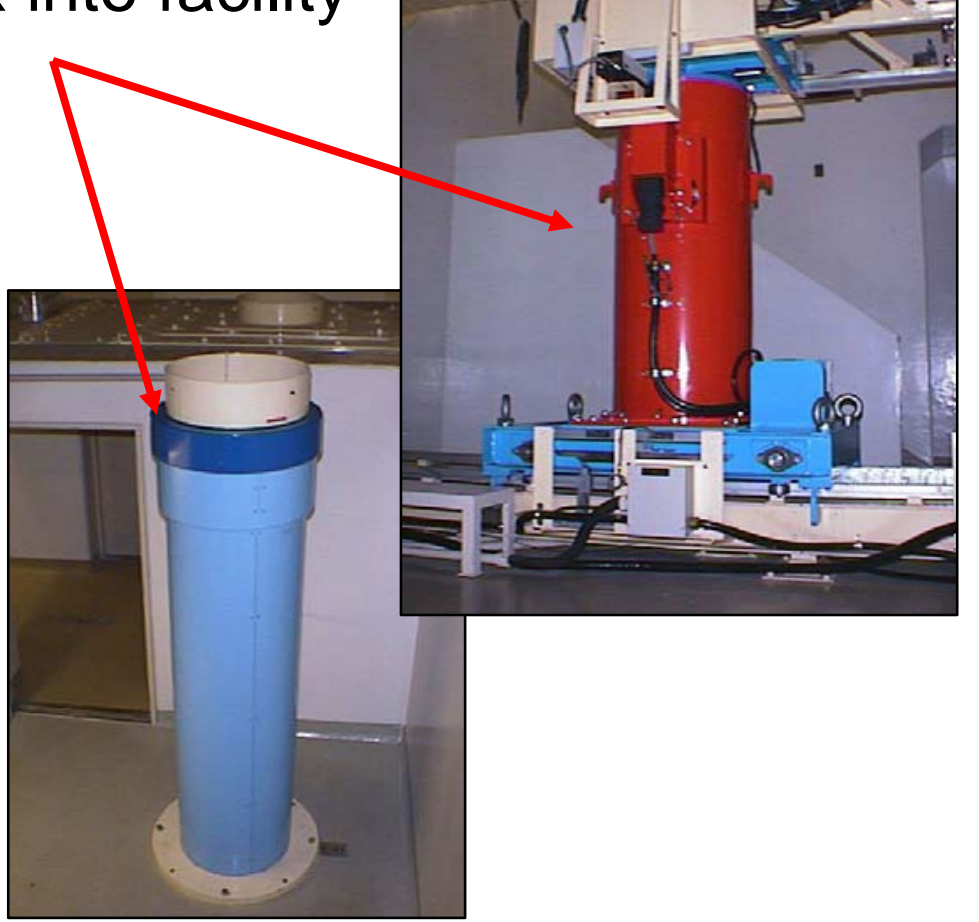

Process Line Holdup Detectors

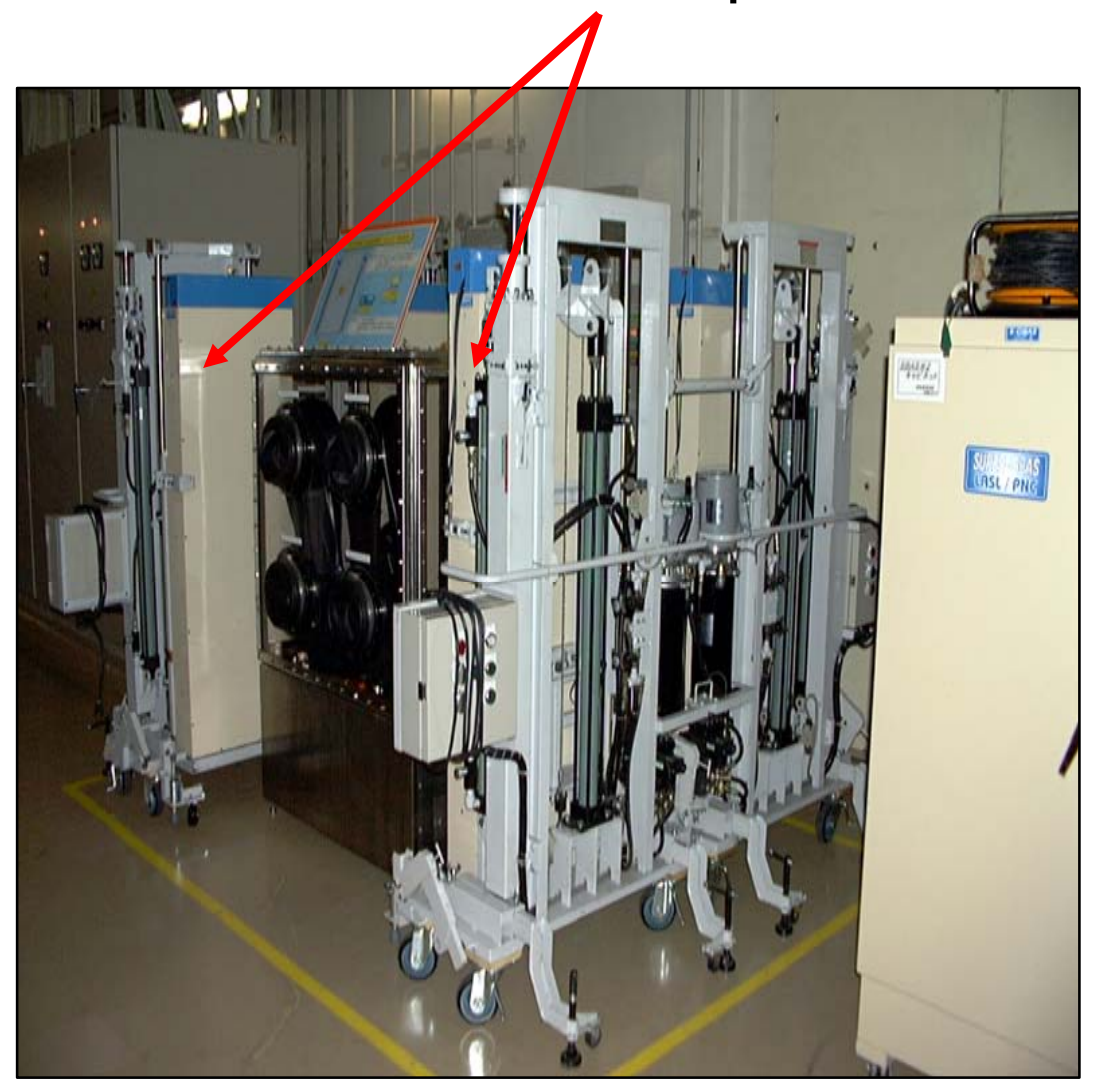

Features * Installed as part of facility robotics transfer system

* Continuous and unattended mode operation 
Fuel Pin Measurement (FPAS), Fuel Assembly (FAAS)

Measure MOX fuel pins during fabrication

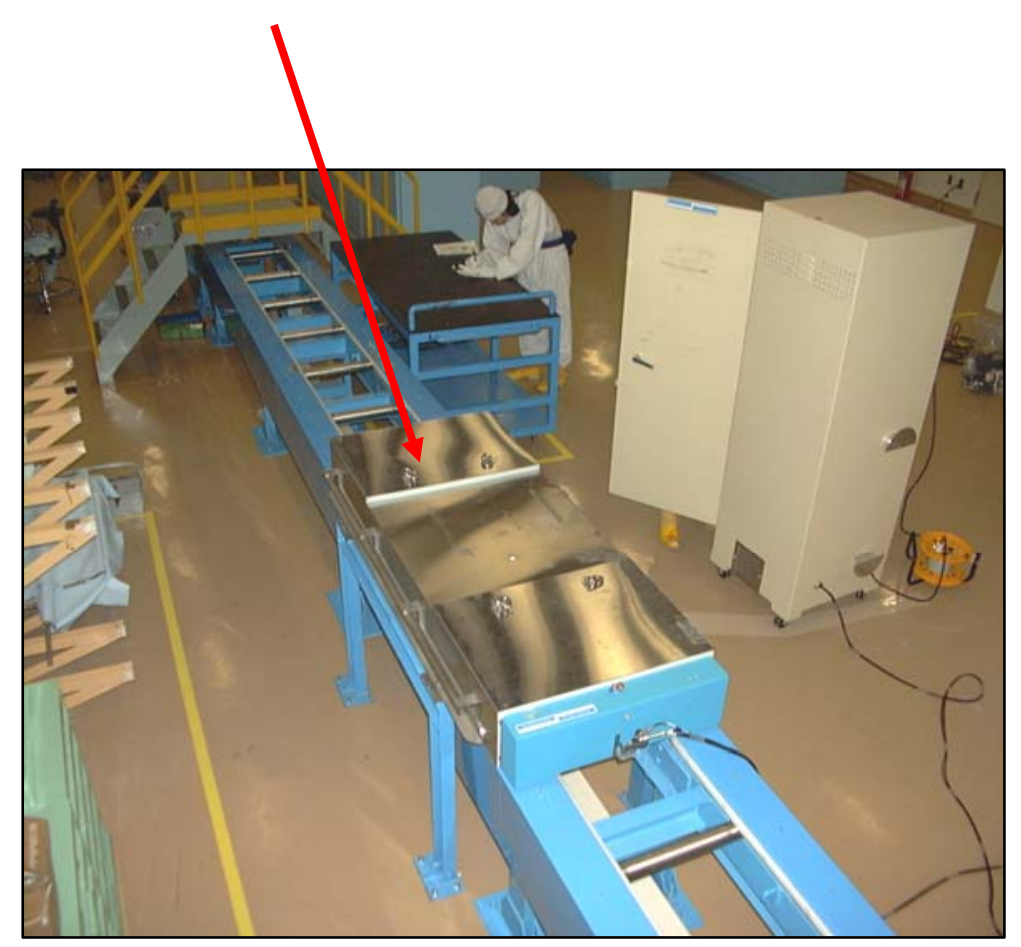

Measure MOX product assemblies leaving facility

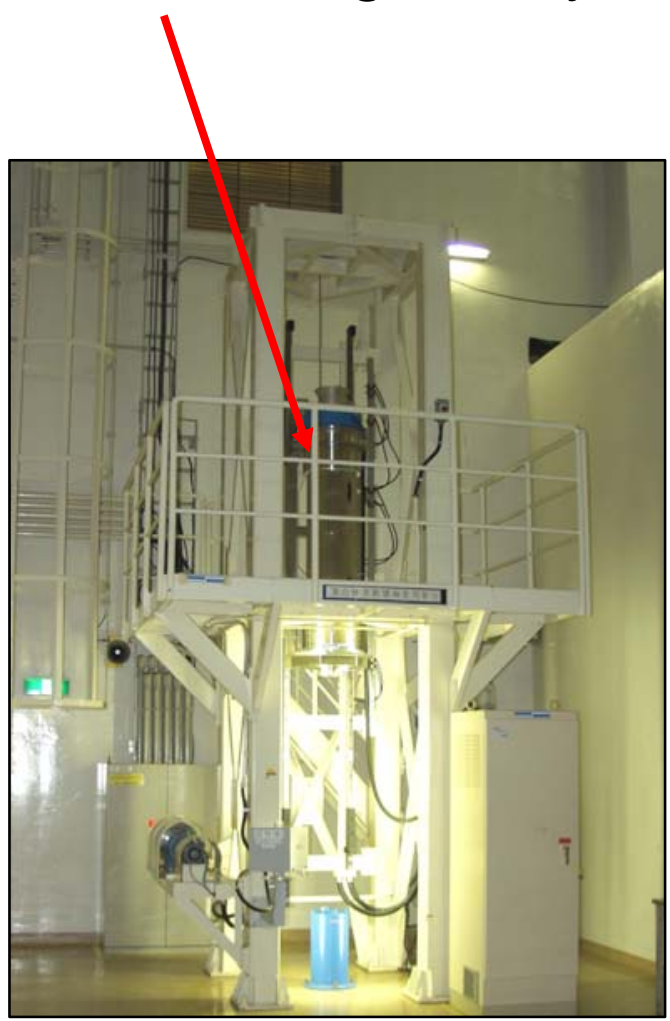




\section{Fast Reactor}

EST. 1943 


\section{Fast breeder reactors in Japan under full-scope IAEA safeguards}

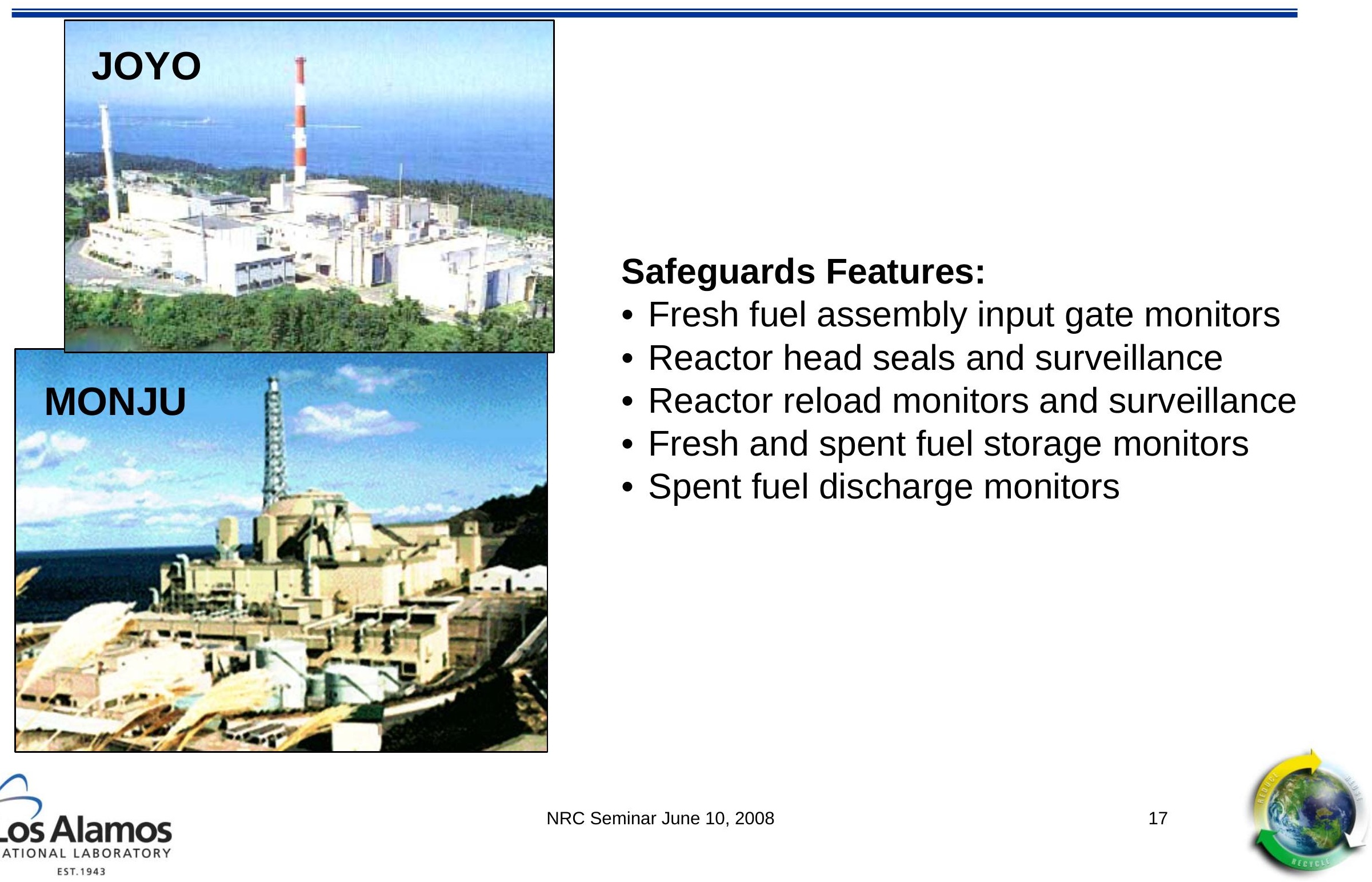




\section{Safeguards at Monju}

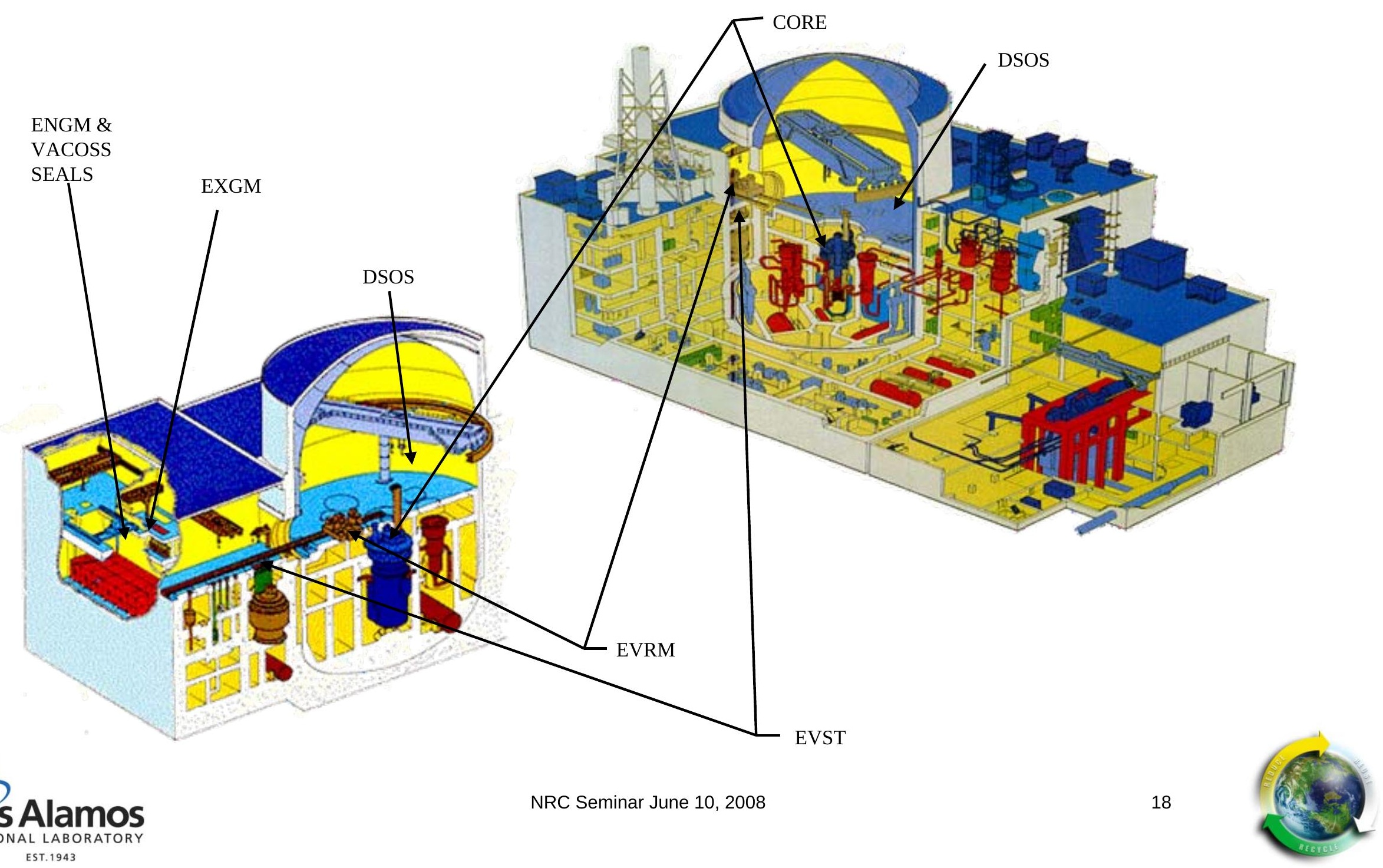




\section{Core Monitoring}

Two detectors monitoring top of CORE

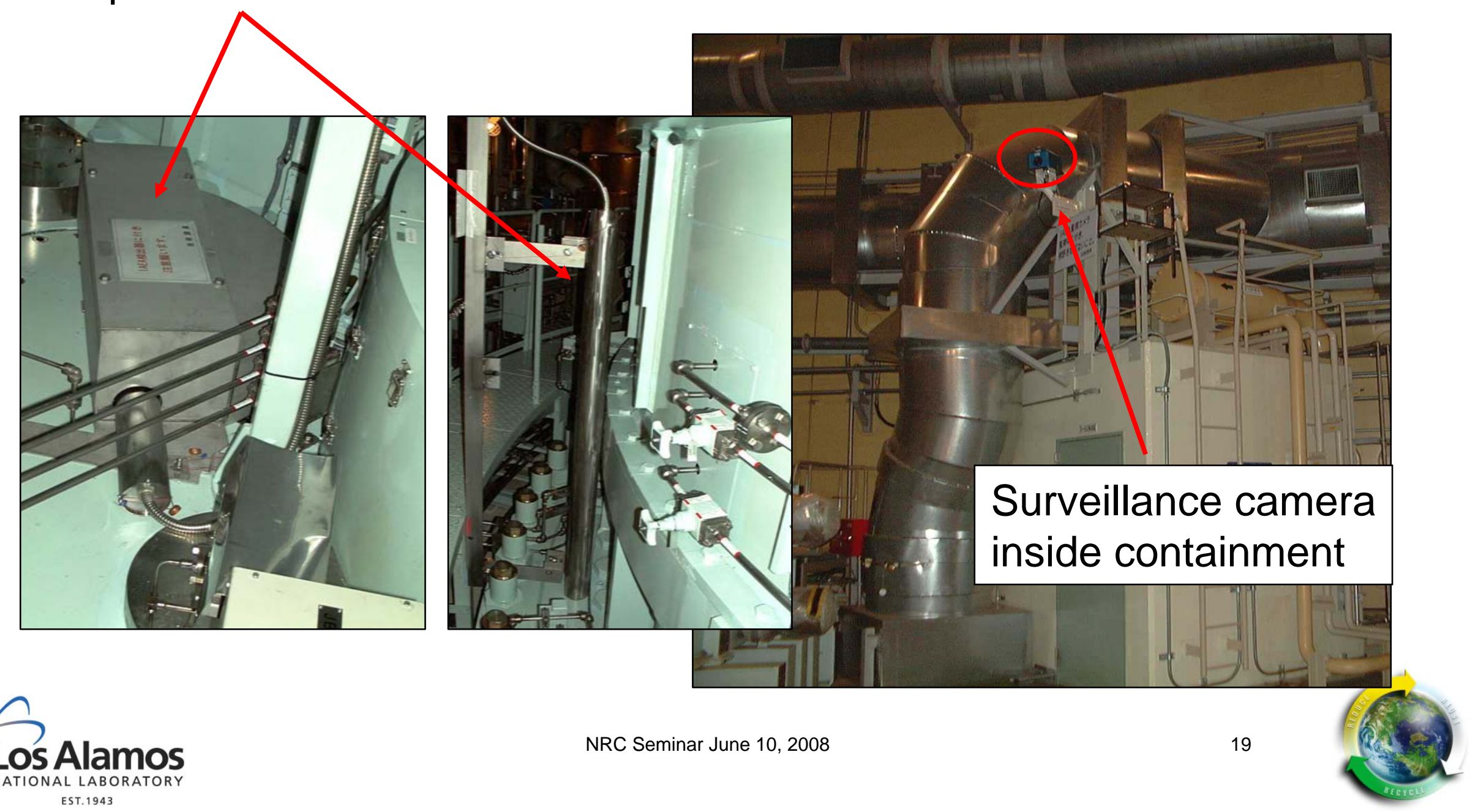




\section{Refueling and Transfer Monitoring}

\section{Two detectors monitoring} refueling machine

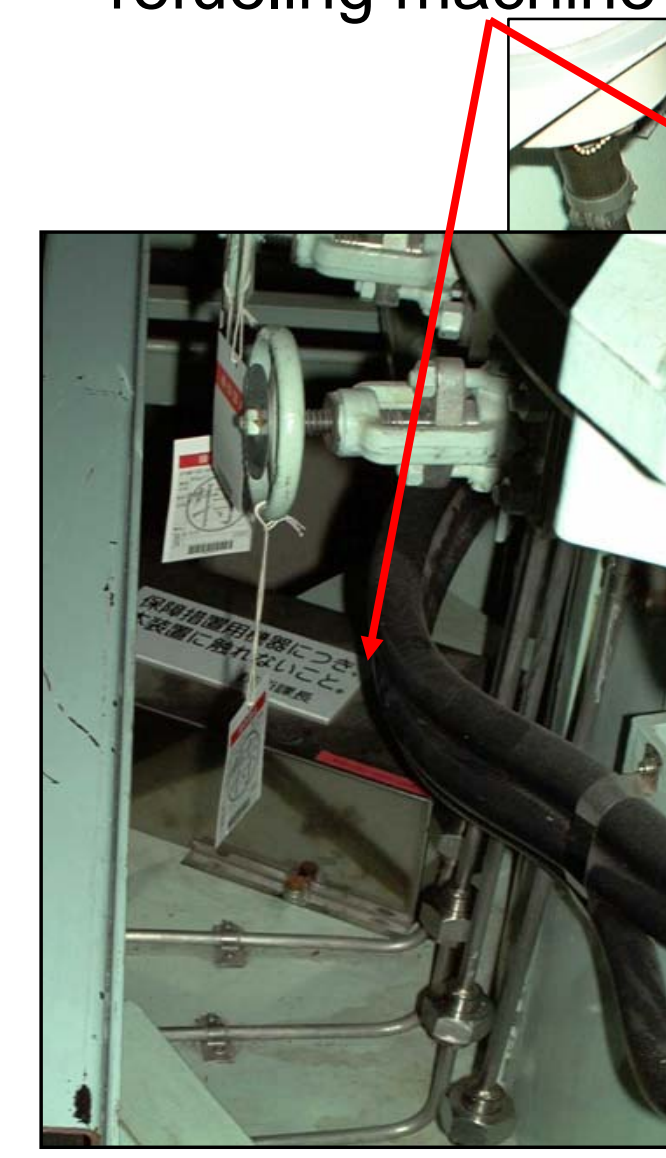

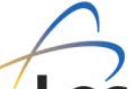

Los Alamos

NATIONAL LABORATORY
One detector monitors transfers between storage and refueling machine
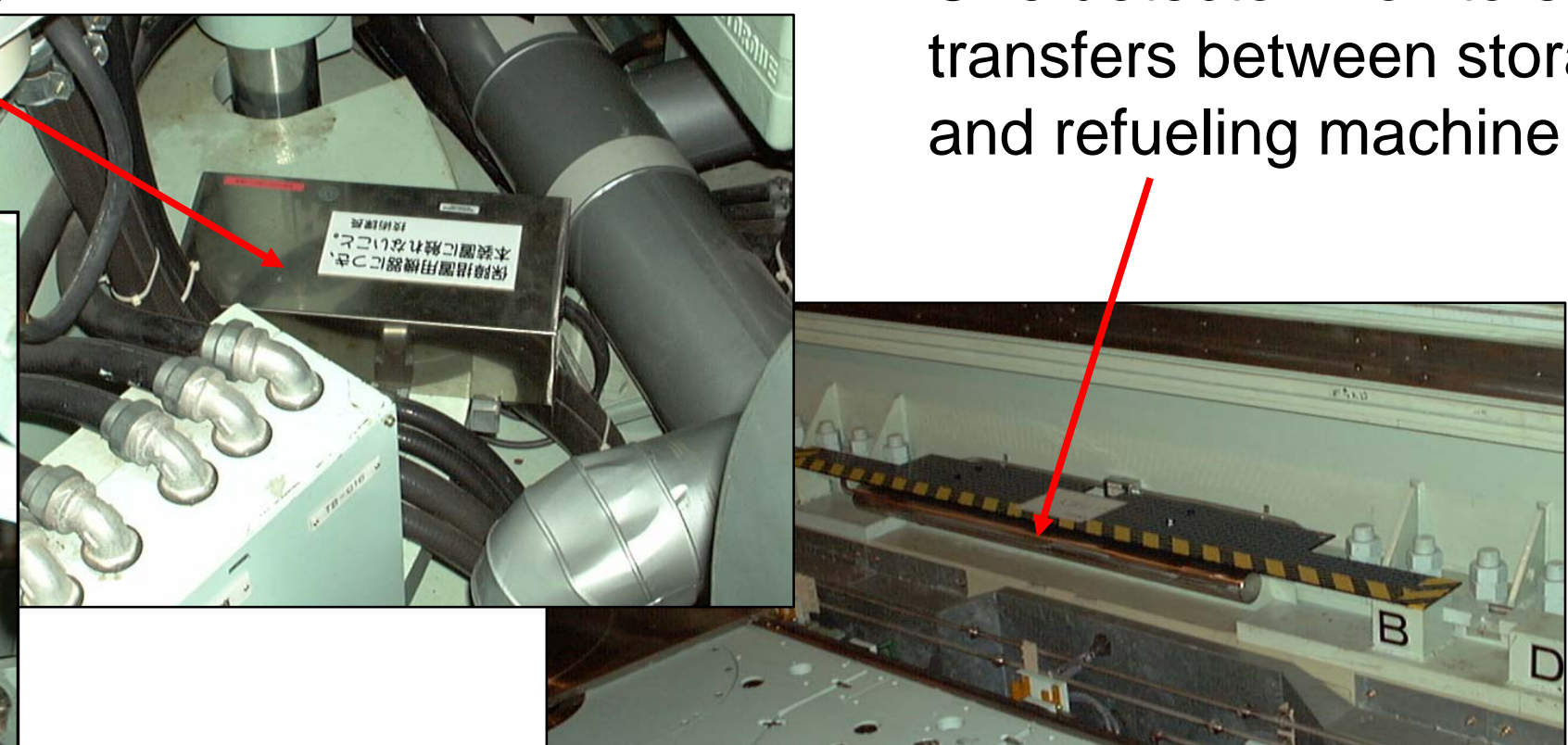


\section{Entrance Gate Monitor, Seals}

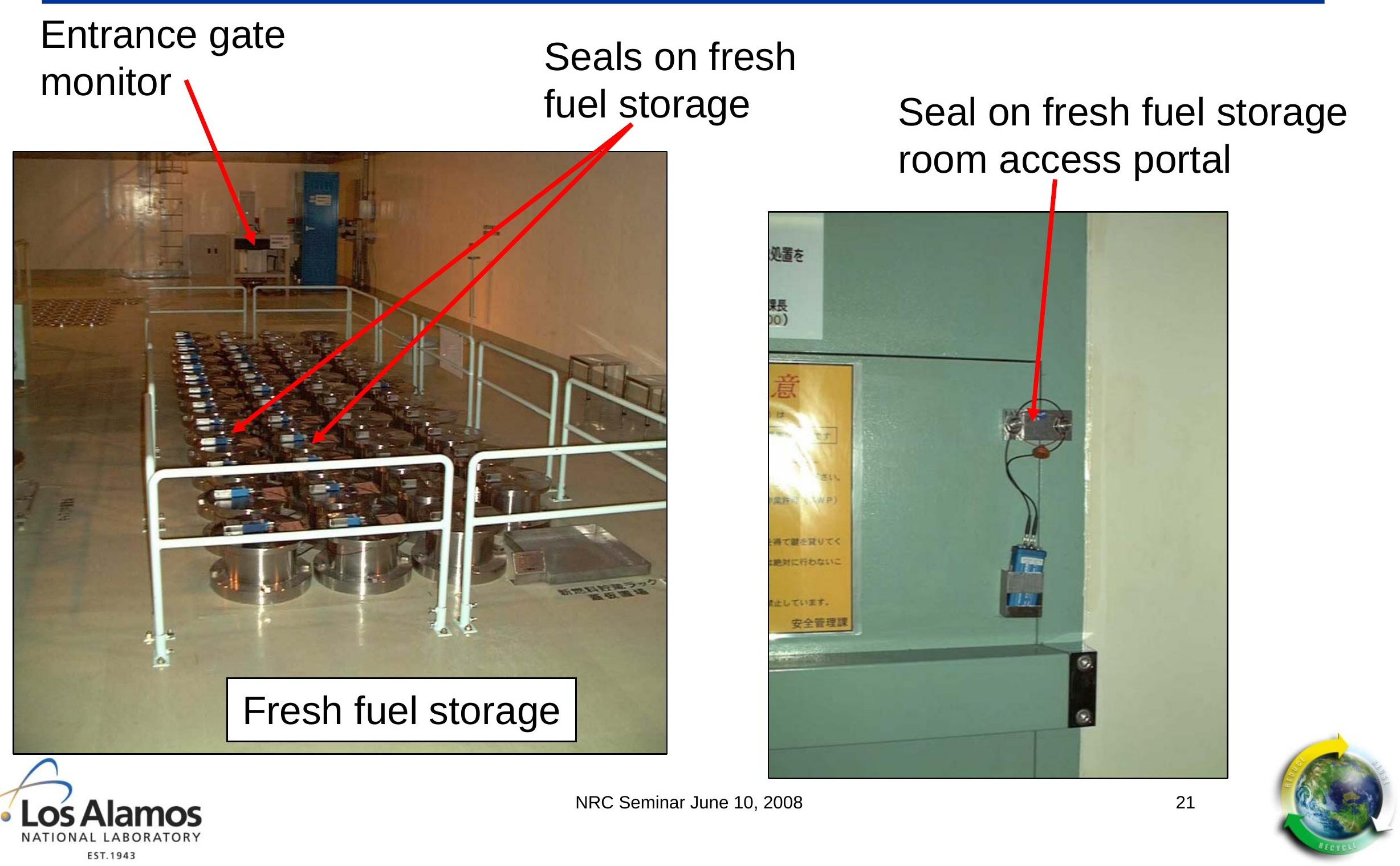




\section{Argonne}

Nuclear Engineering Division

Argonne National Laboratory

9700 South Cass Avenue, Bldg. 208

Argonne, IL 60439

www.anl.gov 